\title{
Study of Horizontally Curved Slab-on-Steel I-Girder Bridges with Integral Abutments Under Thermal Loading
}

\author{
By \\ Ahmed Abdrabbo \\ B.Sc., Arab Academy for Science\& Technology, 2005 \\ M.Eng., University of Western Ontario, 2017
}

\author{
A Thesis \\ presented to Ryerson University \\ in Partial fulfillment of the \\ requirement for the degree of \\ Master of Applied Science \\ in the program of \\ Civil Engineering
}

Toronto, Ontario, Canada, 2019

C)Ahmed Abdrabbo, 2019 


\section{AUTHOR'S DECLARATION}

I hereby declare that I am the sole author of this thesis. This is a true copy of the thesis, including any required final revisions, as accepted by my examiners.

I authorize Ryerson University to lend this thesis to other institutions or individuals for the purpose of scholarly research

I further authorize Ryerson University to reproduce this thesis by photocopying or by other means, in total or in part, at the request of other institutions or individuals for the purpose of scholarly research.

I understand that my thesis may be made electronically available to the public. 


\title{
Study of Horizontally Curved Slab-on-Steel I-Girder Bridges with Integral Abutments under Thermal Loading
}

Ahmed Abdrabbo, Master of Applied Science, 2019

Department of Civil Engineering, Ryerson University

\begin{abstract}
Integral abutment bridges have started to become part of the construction industry worldwide. However, they present challenges arising from the monolithic connection between bridge deck and the abutment. Thermal loading induced by daily cycles superimposed on seasonal cycles result in complex soil-structure interaction. Due to uncertainties in integral abutment bridge performance, there is no consensus among different codes on the bridge maximum length limit. A parametric study was carried out, using SAP2000 software, to examine the behavior of horizontal curved concrete slap-on-steel Igirders, under the effect of thermal loading conditions $\left( \pm 65^{\circ} \mathrm{c}\right)$. The self-weight of the bridge was considered. Spatial variables, including abutment height, radius of curvature, bridge span length, stiffness of backfill and types of foundation soil, were considered. The numerical analysis results were used to drive equation relating abutment height and bridge span with the maximum bridge length limit, which produces $40 \mathrm{~mm}$ horizontal displacement on pile head.
\end{abstract}




\section{ACKNOWLEDGEMENTS}

I would like to express my deep gratitude to Dr. Khaled Sennah whom under his supervision this study was performed. His technical and advice proved to be superior. The department financial support is acknowledged. 


\section{Table of Contents}

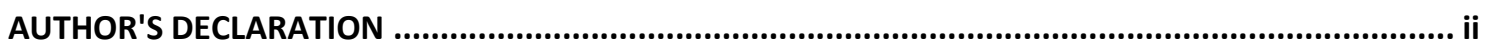

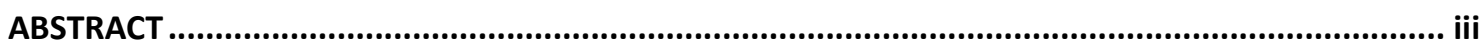

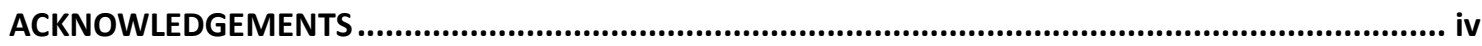

List of Tables ..........................................................................................................................................ii

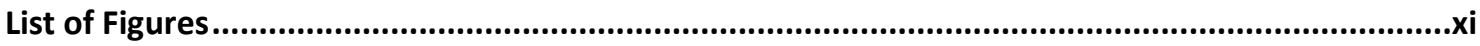

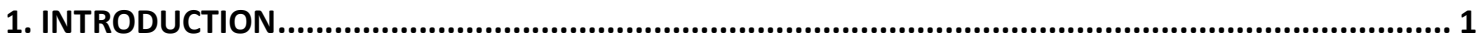

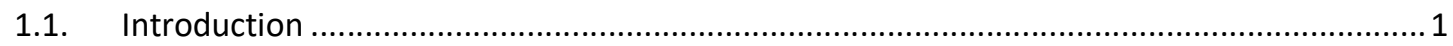

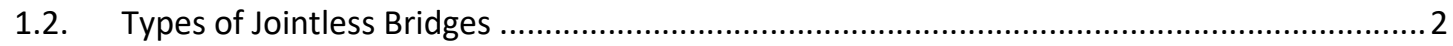

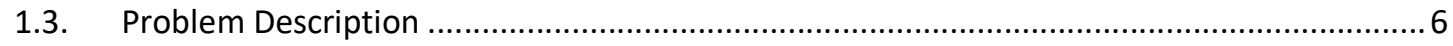

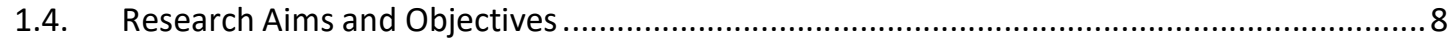

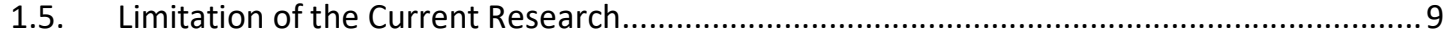

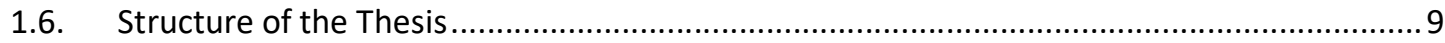

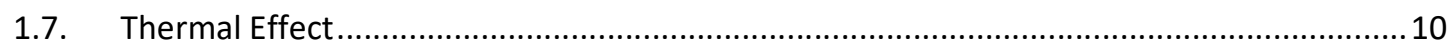

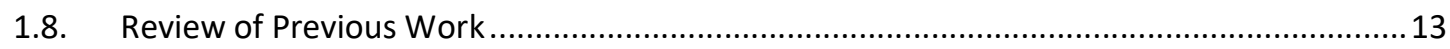

1.8.1. Straight and Skew Integral Abutment Bridge................................................................... 13

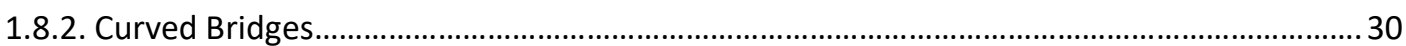

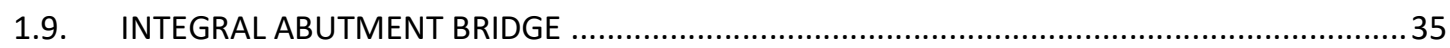

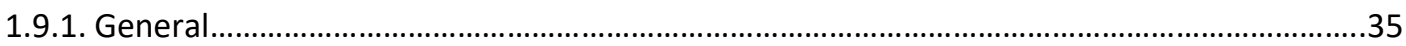

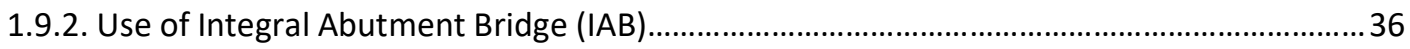

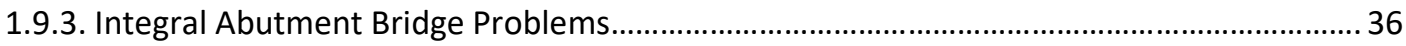

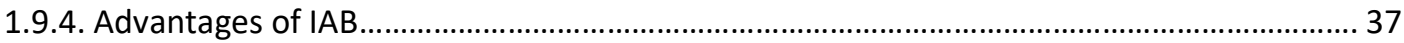

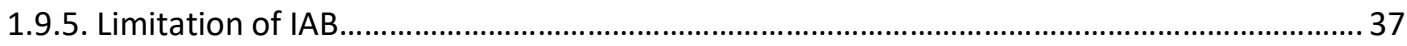

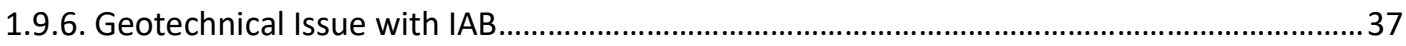

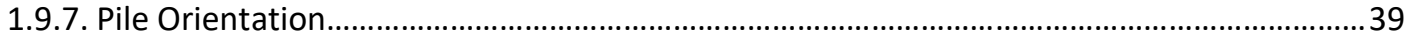

1.9.8. Maximum Length Limit.............................................................................................................. 39

1.9.9. Displacement Capacity of H-Piles................................................................................................ 42

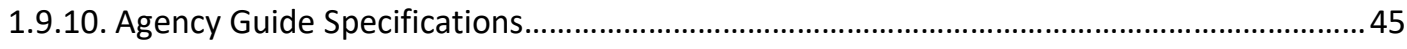

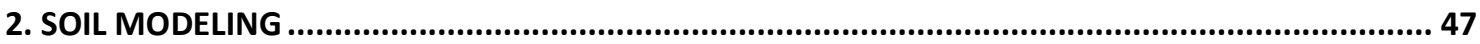

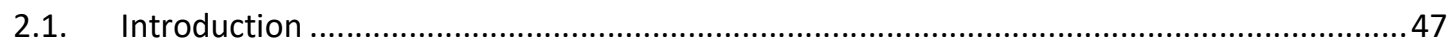

2.2. Behavior of Laterally Loaded Piles According to The API Manual ........................................ 48

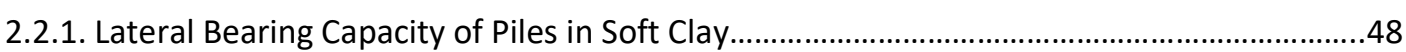

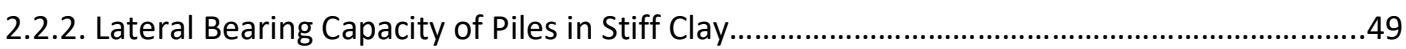

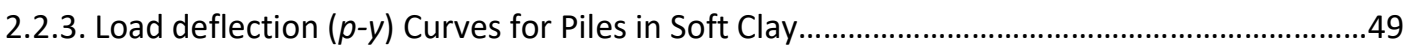

2.2.4. Lateral Bearing Capacity for Piles in Sand............................................................................ 50 
2.2.5. Load Deflection ( $p-y)$ Curves for Piles in Sand.

2.3. Behavior of Laterally Loaded Piles According to the Modified Ramberg-Osgood Model ....52

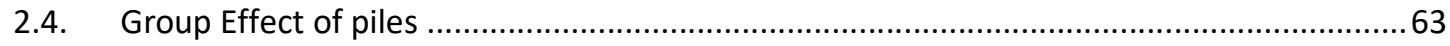

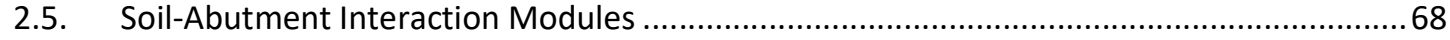

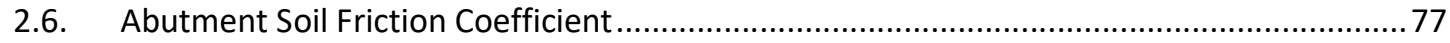

3. FINITE ELEMENT MODEL DESCRIPTION AND VALIDATION .................................................. 79

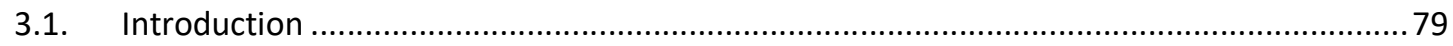

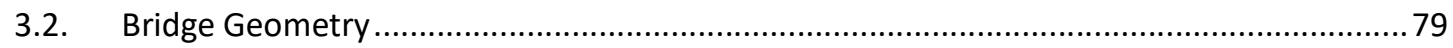

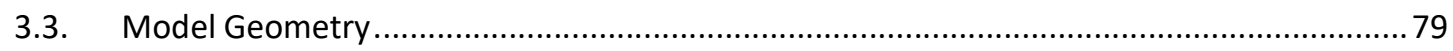

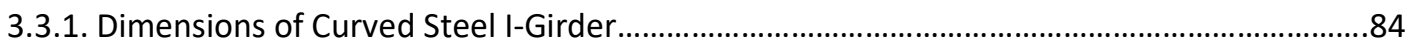

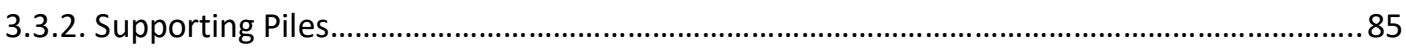

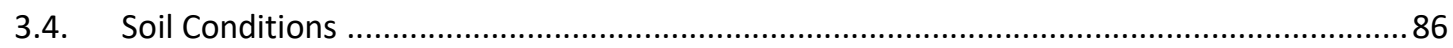

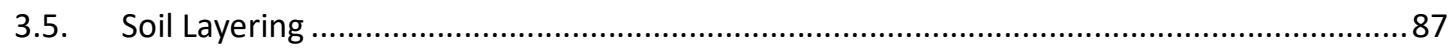

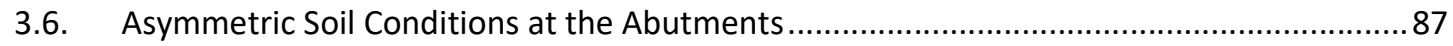

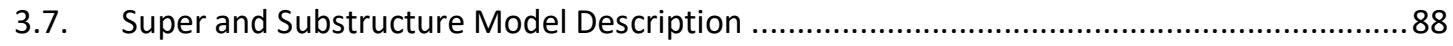

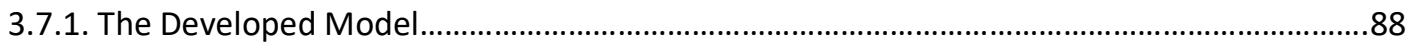

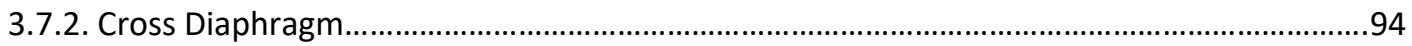

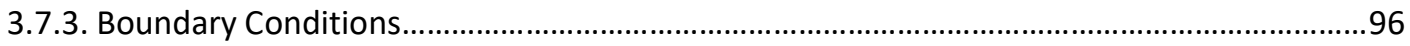

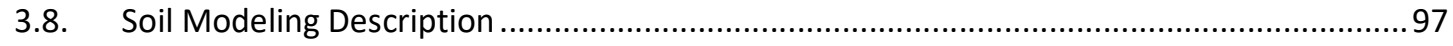

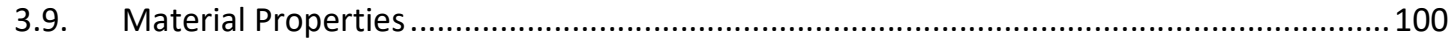

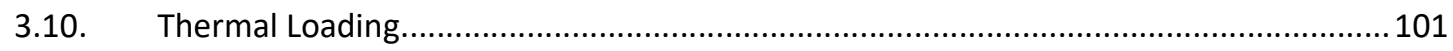

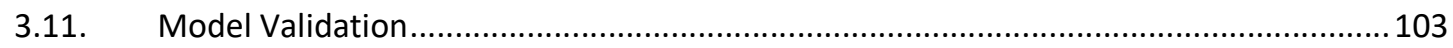

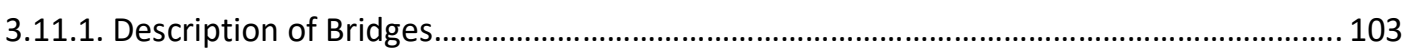

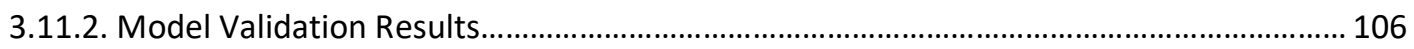

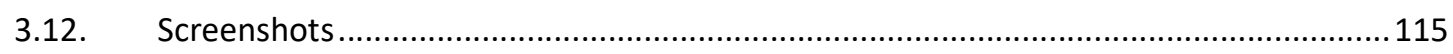

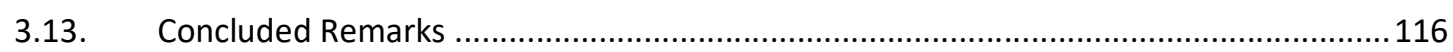

4. SENSITIVITY AND PARAMETRIC STUDY ......................................................................... 129

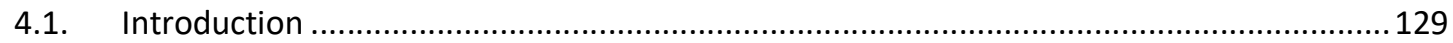

4.2. Effect of the Node Spacing Along the Pile ............................................................ 130

4.3. Effect of Vertical Shear Stress along the Pile ......................................................... 131

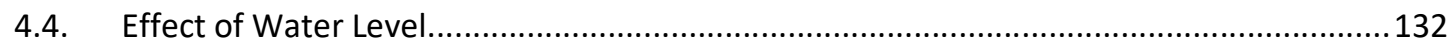

4.5. Effect of the Spacing of the Solid Steel Diaphragms on Pile Displacement..................... 134

4.6. Effect of the Characteristic $(p-y)$ relationship on Pile Displacement.............................136

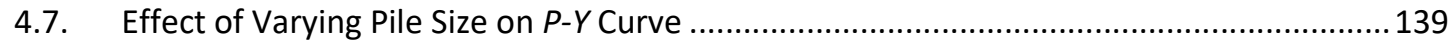

4.8. Effect of Bridge Span Under Positive Thermal Loading Condition............................... 141 
4.9. Effect of Bridge Span at Different Abutment Heights Under the Effect of Positive and

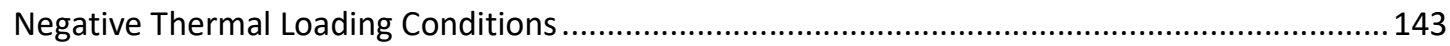

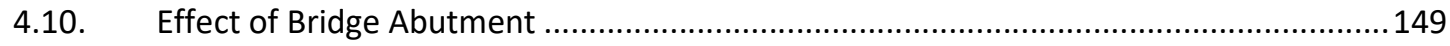

4.10.1. Substructure Piles Embedded in Stiff Clay......................................................................149

4.10.2. Substructure Piles Embedded in Medium Dense Sand.................................................... 159

4.11. Integral Abutment Bridges Under Thermal Contraction ................................................. 168

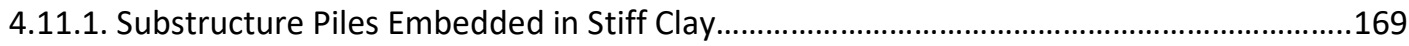

4.11.2. Substructure Piles Embedded in Medium Dense Sand.......................................................178

4.12. Ratio of Pile Tangential Displacement to Pile Resultant Displacement.............................186

4.13. Pile Average Maximum Resultant Displacement Relative to Top Abutment Maximum

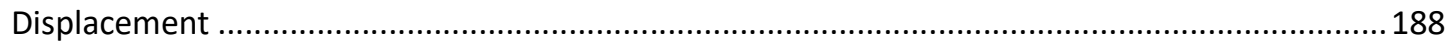

4.14. Effect of Abutment Height on the Reduction of the Pile Maximum Bending Moment 192

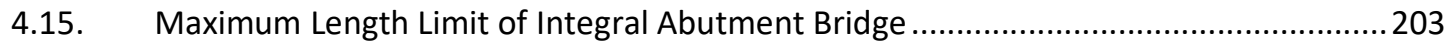

4.15.1. Equations Relating Bridge Maximum Length Limit to Abutment Height where Piles are Embedded in Clay.

4.15.2. Equations Relating Bridge Maximum Length Limit to Abutment Height where Piles are Embedded in Medium Dense Sand.

4.16. Effect of Radius of Curvature on Bridge Maximum Length Limit Abutment Piles in Stiff

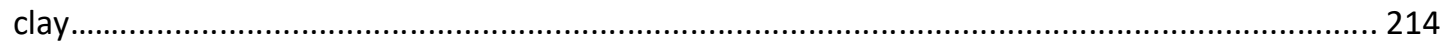

4.17. Effect of Bridge Span Length on Bridge Maximum Length Limit ..................................2217

4.18. General Closed Form Solution of Bridge Maximum Length Limit....................................228

4.19. Effect of Predrilled Holes on Bridge Performance ..........................................................2 230

4.19.1. Pile Maximum Resultant Displacement.................................................................................. 230

4.19.2. Bending Moment............................................................................................................... 243

4.20. Proposed Procedure for Assessing Bridge Maximum Length Limit for Piles without

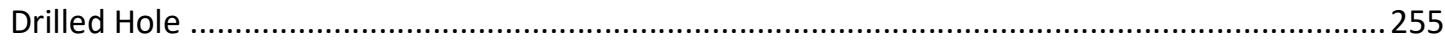

5. SUMMARY, CONCLUSIONS AND RECOMMENDATIONS FOR FURTHER STUDY ......................... 262

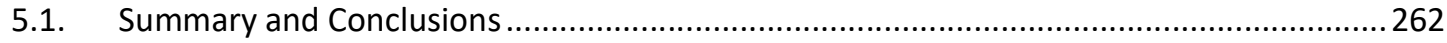

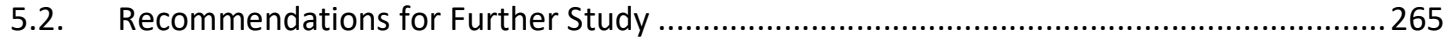

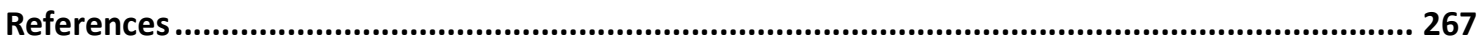




\section{List of Tables}

Table 1.1 Maximum Length Limit in Moderate and Cold Climates (Dicleli and Albhaisia, 2004).........40

Table 1.2 Maximum Length Limit for IAB (Dicleli and Albhaisi, 2004) ............................................... 40

Table 1.3 Integral Abutment Bridge Length Limit for Small Skew Angle (Nikravan, 2013) ..................41

Table 1.4 Integral Abutment Bridge Length Limit for Large Skew Angle (Nikravan, 2013) ...................41

Table 1.5 Allowable Length and Skew Combinations for Steel Integral Abutment Bridges (Nikravan,

2013)

Table 1.6 Allowable Length and Skew Combinations for Concrete Integral Abutment Bridges

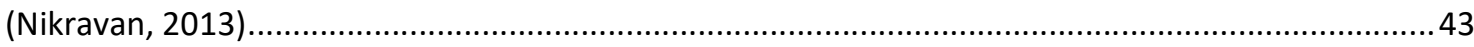

Table 1.7 Summary of Behavior of Piles Supporting Full Integral Abutment Bridges (Arsoy et al., 2002)

Table 2.1 Load-Deflection Relationship for Soft Clay, API (2003) ...................................................50

Table 2.2 Analytical Forms of $p$-y Relationships (Greimann et al., 1984 and 1986; Greimann \& Wolde-

Tinsae, 1988)

Table 2.3 Analytical Forms of $f$-z Relationships (Greimann et al., 1984 and 1986; Greimann \& Wolde-

Tinsae, 1988)

55

Table 2.4 Analytical Forms of $q$-z Relationships (Greimann et al., 1984 and 1986; Greimann \& Wolde-

Tinsae, 1988)

Table 2.5 Parameters Used in the Modified Ramberg-Osgood Models for Clay and Sand (Greimann et

al., 1984 and 1986; Greimann \& Wolde-Tinsae, 1988; Haj-Najib, 2002)...........................................59

Table 2.6 Methods of Static Analysis for Piles in Cohesionless Soil (Hannigan et al., 2016) ................60

Table 2.7 Methods of Static Analysis for Piles in Cohesive Soil (Hannigan et al., 2016) .....................61

Table 2.8 Summary of Static Analysis Methods (Hannigan et al., 2016) ............................................62

Table 2.9 Summary of P-Multiplier Studies (Hannigan et al., 2016) ....................................................67

Table 2.10 Displacement Thresshold to Reach Full Active and Passive Conditions in Cohesionless Soil

as a Function of the Relative Abutment Displacement to Abutment Height, $\Delta \mathrm{H}$ (Clough \& Duncan,

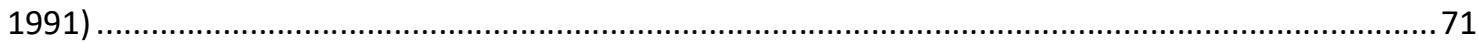

Table 2.11 Passive Earth Pressure Coefficient Versus Soil Friction Angle (Caquot \& Kérisel, 1948) .... 76

Table 2.12 Static Friction Coefficients for Different Materials (Gorst et al., 2003) ............................. 77

Table 2.13 Minimum Value of Coefficient of Static Friction (Gorst et al., 2003).................................78

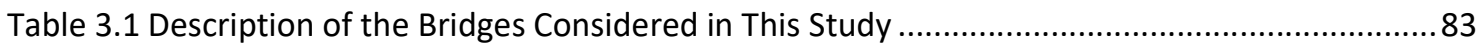

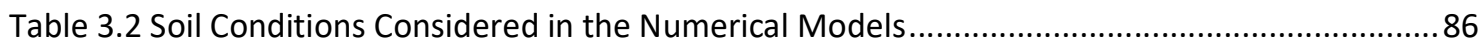

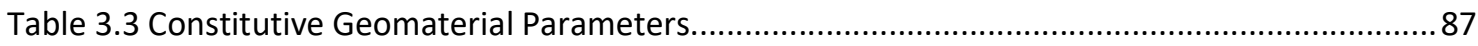

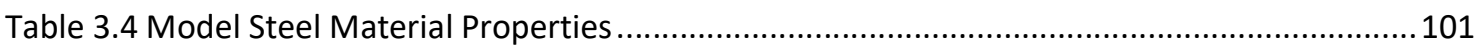

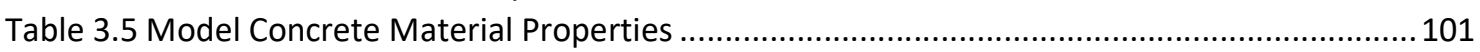

Table 3.6 Maximum and Minimum Effective Temperature of Steel Bridges for Big Cities in Canada

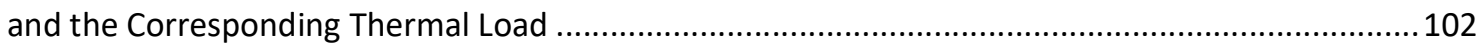

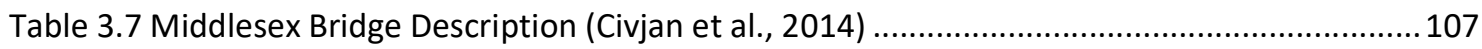

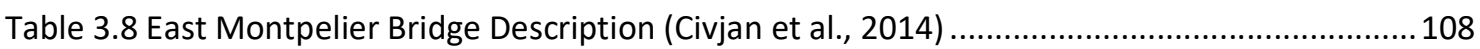

Table 3.9 Stockbridge Bridge Description (Civjan et al., 2014) ...................................................... 109

Table 3.10 Material Properties Used in the Finite Element Models (Civjan et al., 2014)...................109

Table 3.11 Skewed Bridge Characteristics (Quinn and Civjan, 2017) .............................................110

Table 3.12 Bottom-of-Abutment Displacement of Middlesex Bridge .............................................110

Table 3.13 Top-of-Abutment Displacement of Middlesex Bridge .................................................110

Table 3.14 Bottom-of-Abutment Displacement of East Montpelier Bridge ......................................110

Table 3.15 Top-of-Abutment Displacement of East Montpelier Bridge ............................................111 
Table 3.16 Bottom-of-Abutment Displacement of Stockbridge Bridge ...........................................111

Table 3.17 Bottom-of-Abutment Displacement of Stockbridge Bridge ..........................................111

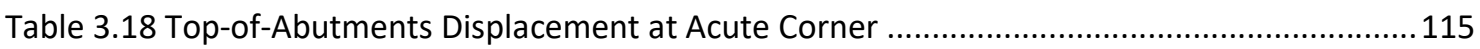

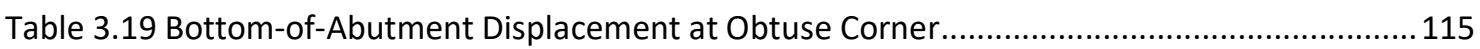

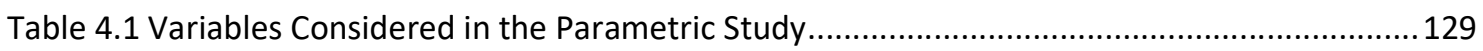

Table 4.2 Bridge Longitudinal Displacement Versus Pile Spring Spacing ......................................... 131

Table 4.3 Effect of Water Level on Bottom-of-Abutment Displacement .........................................134

Table 4.4 Effect of Diaphragm Spacing on Pile Maximum Resultant Displacement (PMRD) .............136

Table 4.5 Effect of Bridge Span Length on Pile Maximum Resultant Displacement Under Positive

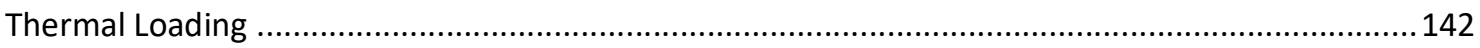

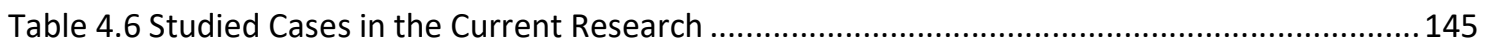

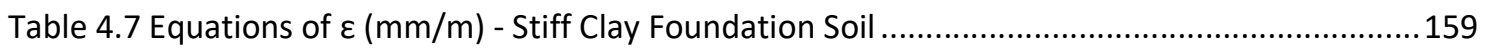

Table 4.8 Equations of $\varepsilon(\mathrm{mm} / \mathrm{m})$ - Medium Dense Sand Foundation Soil ......................................168

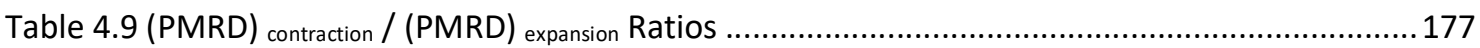

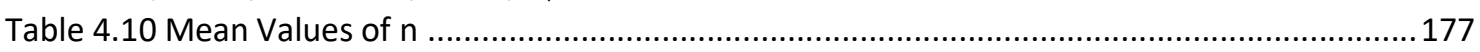

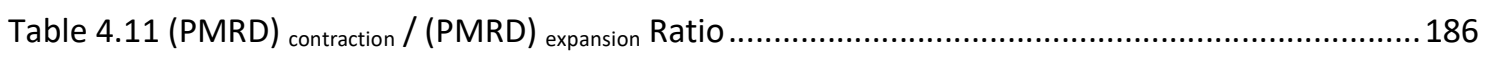

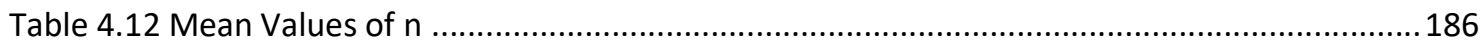

Table 4.13 Pile Average Maximum Displacement to Maximum top Abutment Displacement Ratio for

Piles Embedded in Medium Dense Sand - Contraction Case ........................................................190

Table 4.14 Pile Average Maximum Displacement to Maximum top Abutment Displacement Ratio for

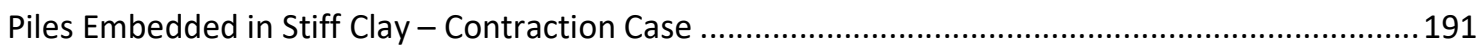

Table 4.15 Pile Average Maximum Displacement to Maximum top Abutment Displacement Ratio for

Piles Embedded in Medium Dense Sand - Expansion Case ...........................................................191

Table 4.16 Pile Average Maximum Displacement to Maximum top Abutment Displacement Ratio for

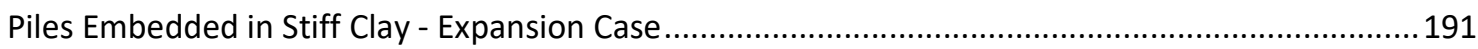

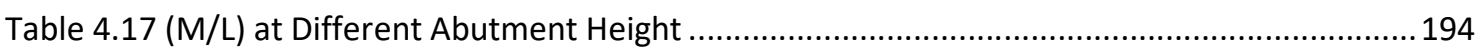

Table 4.18 Equations Correlating Abutment Height with Bridge Maximum Length Limit Where Piles

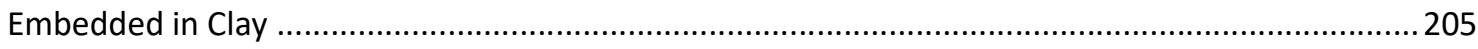

Table 4.19 Equations Correlating Abutment Height with Bridge Maximum Length Limit Where Piles

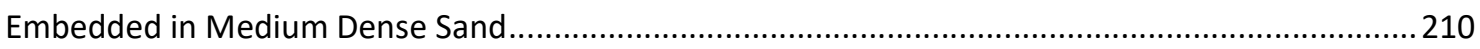

Table 4.20 Pile Maximum Resultant Displacement for Different Bridge Spans ...............................219

Table 4.20 Pile Maximum Resultant Displacement for Different Bridge Spans - Continued..............220

Table 4.20 Pile Maximum Resultant Displacement for Different Bridge Spans - Continued..............221

Table 4.20 Pile Maximum Resultant Displacement for Different Bridge Spans - Continued..............222

Table 4.20 Pile Maximum Resultant Displacement for Different Bridge Spans - Continued..............223

Table 4.21 Bridge Maximum Length Limit of Span $\mathrm{S}_{2}$ / Bridge Maximum Length Limit of Span $\mathrm{S}_{1}$, at

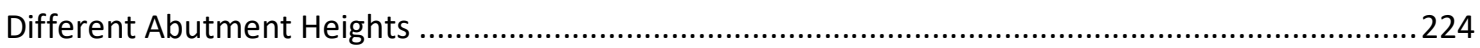

Table 4.22 Actual vs Estimated Abutment Height from Developed Equation (4.29) .........................229

Table 4.23 (a) Pile Maximum Resultant Displacement in Predrilled Holes for Abutment of Height 4.00

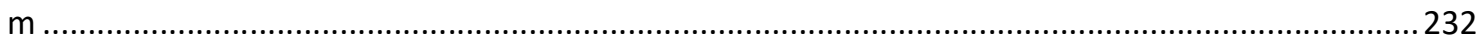

Table 4.23 (b) Continue Pile Maximum Resultant Displacement in Predrilled Holes for Abutment of

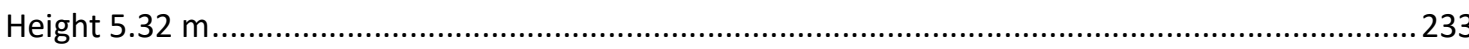

Table 4.23 (c) Continue Pile Maximum Resultant Displacement in Predrilled Holes for Abutment of

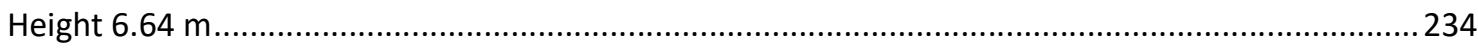

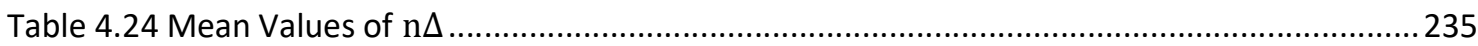

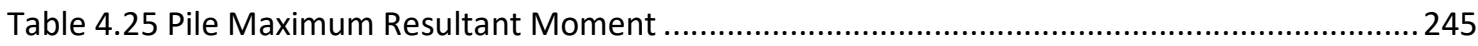

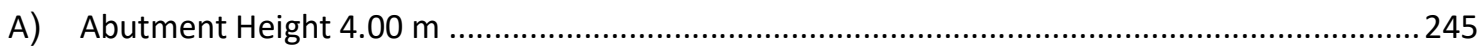

Table 4.25 Continue - Pile Maximum Resultant Moment ................................................................246 
B) Abutment Height $5.32 \mathrm{~m}$

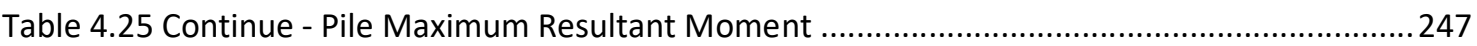

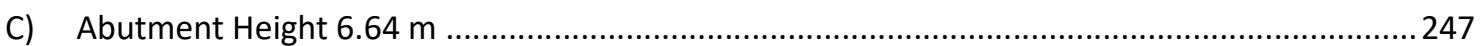

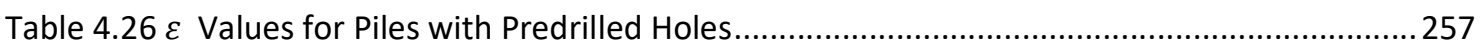

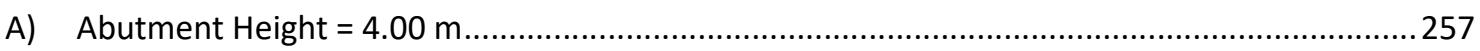

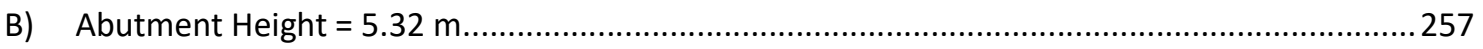

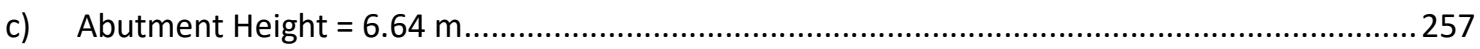

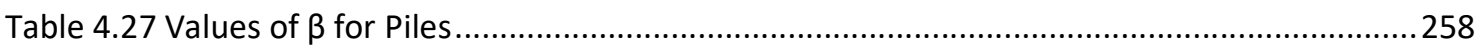

Table 4.28 Bridge Maximum Length Limits for Piles Without Predrilled Hole ..................................258 


\section{List of Figures}

Figure 1.1 Conventional Bridge Diagram (Frosch \& Lovell, 2011) ................................................... 3

Figure 1.2 Sketch of Jointless Integral Abutment Bridge (Frosch \& Lovell, 2011) ................................ 3

Figure 1.3 Jointless Integral Abutment Bridge and Approach Slab (MTO, 1996) ................................. 3

Figure 1.4 Semi Integral Abutment Details (MTO, 1996).................................................................. 4

Figure 1.5 Cross Section of Semi Integral Abutment (New York State Department of Transportation,

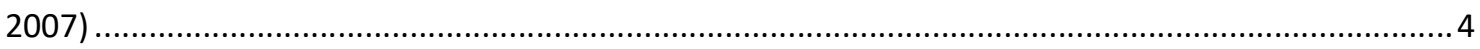

Figure 1.6 Integral Abutment Details-Fixed Connection (MTO, 1996) ..................................................5

Figure 1.7 Cross Section of Integral Abutment with Fixed Connection to the Piles (Durbin, 2011)....... 5

Figure 1.8 Schematic Diagram of Abutment-Pile Hinged Connection (Arsoy et al., 2002) .................. 6

Figure 1.9 Positive Vertical Temperature Gradient in Concrete and Steel Superstructures (AASHTO,

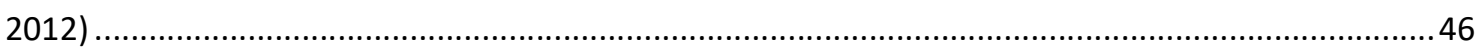

Figure 2.1 Coefficients as Function of $\phi^{\prime}$ (American Petroleum Institute, 2003) ................................... 51

Figure 2.2 Initial Modulus of Subgrade Reaction Versus Angle of Internal Friction (American

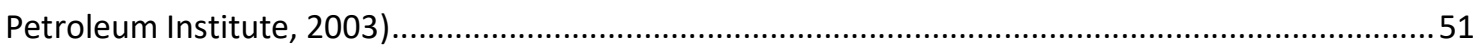

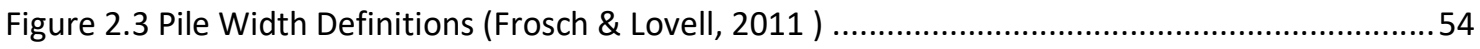

Figure 2.4 Adhesion Versus Undrained Shear Strength (Poulos \& Davis, 1980) ..................................56

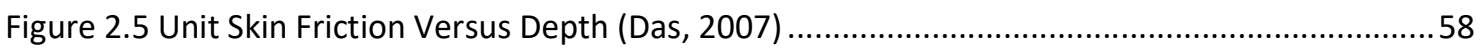

Figure 2.6 $\delta$ / $\phi$ Versus Soil Displacement, V, for Different Pile Types (Nordlund, 1963) ....................62

Figure 2.7 Limiting Unit Tip (Toe) Resistance Versus Friction Angle For Cohesionless Soils (Hannigan

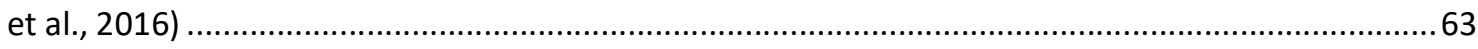

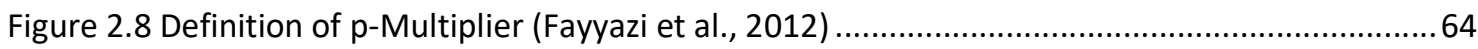

Figure 2.9 Pile Group Configurations (Fayyazi et al., 2012) ............................................................64

Figure 2.10 Pile Head Force of Different Pile Configurations for Displacement of $20 \mathrm{~mm}$ (Fayyazi et

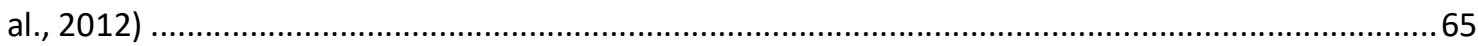

Figure 2.11 Effect of P-Multiplier on Pile Group Load-Displacement Curves (Hannigan et al., 2016) .66

Figure 2.12 Abutment Force-Displacement Relationships Established by the Hyperbolic Model

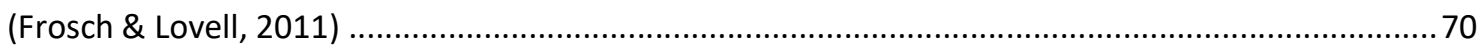

Figure 2.13 Log Spiral Versus Planar Failure Surfaces (Frosch \& Lovell, 2011).................................. 71

Figure 2.14 Lateral Earth Pressure Coefficient Versus Relative Wall Movement................................. 72

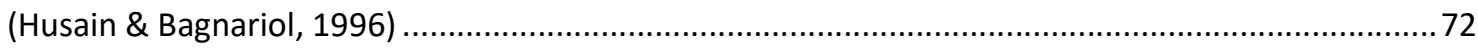

Figure 2.15 Lateral Earth Pressure Coefficients Versus Relative Wall Movement ...............................72

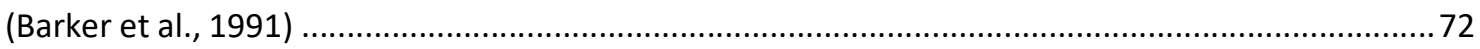

Figure 2.16 Lateral Earth Pressure Coefficients Versus Relative Wall Movement (Clough \& Duncan,

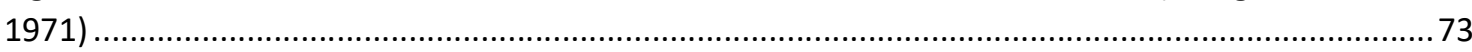

Figure 2.17 Lateral Earth Pressure Coefficient Based on Log Spiral Failure Surface Including Friction between Wall and the Soil (Caquot \& Kerisel, 1948)................................................................. 73

Figure 2.18 Lateral Earth Pressure Coefficients Ignoring Wall Friction and Considering Pure Rotation and Plan Failure Surface (Canadian Foundation Engineering Manual, 1992) .................................... 74 Figure 2.19 Recommended Earth Pressure Coefficients Based on Abutment Displacement (Kerokoski,

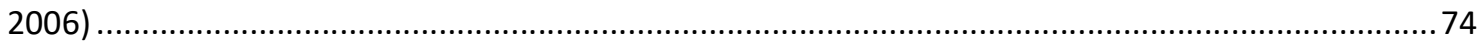

Figure 2.20 Passive Earth Pressure Versus Wall Movement (U.S.Department of the Navy, 1982)......75 Figure 2.21 Passive Earth Pressure Coefficients Versus Soil Friction Angle (Caquot \& Kérisel, 1948) 75 Figure 3.1 Schematic Diagram Showing Typical Cross Section used in the Finite Element Models.....82 Figure 3.2 (a) Schematic Diagram Showing the outer Radius (R), Theta $(\theta)$, Span $(S)$ and Bridge Width (W) 
Figure 3.2 (b) Schematic Diagram Showing the Orientation of the Piles in Regards to the Abutment Adopted in this Study.

Figure 3.3 Complete View of One of the FEM from SAP2000 Software with the Presence of Soil

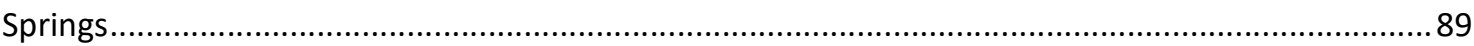

Figure 3.4 View of One of the FEM from SAP2000 Software without Showing Soil Springs ..............89

Figure 3.5 Nodes Spacing Along the Piles from SAP2000 Software.................................................90

Figure 3.6 View of the Meshing of the Bridge Concrete Deck in the Finite Element Model from SAP2000 Software.

Figure 3.7 View from SAP2000 Model Showing Diaphragm Spacing

Figure 3.8 View of Joints of the Deck Slab and the Steel Top Flange Linked by Fixed Link Members

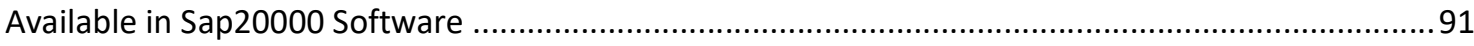

Figure 3.9 View of Abutment Mesh from SAP2000 Software...................................................92

Figure 3.10 View of Common Joints Between Abutment and Girders from SAP2000 .....................92

Figure 3.11 Schematic Diagram of Pile Head Connection with the Abutment.................................93

Figure 3.12 Pile Section Properties inserted in SAP2000 Software for HP $310 \times 125$ Shape...............93

Figure 3.13 Pile Selection Chart (Illinois Department of Transportation, 2012) ...............................94

Figure 3.14 Forces Acting on the Flange and Diaphragm (Doust, 2011) .......................................95

Figure 3.15 Force Equilibrium of the Diaphragm (Doust, 2011) ..................................................95

Figure 3.16 View of Multi Span Curved IAB of one of the Numerical Models with the Support Conditions at the Piers Preventing both the Radial (Lateral) and the Vertical Displacement .............96

Figure 3.17 Laterally Loaded and Unloaded Piles for Soil Modeled as Disconnected Springs (Bowles,

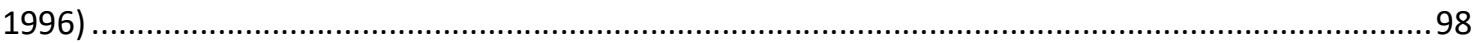

Figure 3.18 Laterally Loaded Pile Where Soil is modeled as Disconnected Springs (Reese, 1984) ......98

Figure 3.19 Force-Displacement Curve for Dense Sand Supporting the Abutment at Depth $2.78 \mathrm{~m}$ from Ground Surfaces

Figure 3.20 Force-Displacement Curve for Loose Sand Supporting the Abutment at Depth $2.78 \mathrm{~m}$ from Ground Surfaces.....

Figure 3.21 Force-Displacement Curve for Piles Embedded in Dense Sand at Depth $7.25 \mathrm{~m}$ from Ground Surfaces. 100 Figure 3.22 Force-Displacement Curve for Piles Embedded in Stiff Clay at Depth 5.27 m from Ground Surfaces 100

Figure 3.23 Bridge Temperature Selection Chart Based on Ambient Air Temperature (EN 1991-1-5,

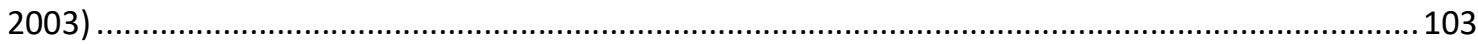

Figure 3.24 a) Middlesex Bridge (Civjan et al., 2014) ................................................................ 116

Figure 3.24 b) Middlesex Bridge (Civjan et al., 2014) ............................................................... 117

Figure 3.25 Elevation View of Middlesex Bridge (Civjan et al., 2014) ............................................117

Figure 3.26 Plan and Elevation View of Abutment-1 at Middlesex Bridge (Civjan et al., 2014) .........118

Figure 3.27 Middlesex Bridge Deck Section (Civjan et al., 2014) ................................................ 118

Figure 3.28 East Montpelier Bridge (Civjan et al., 2014) ........................................................... 119

Figure 3.29 (a) Plan View of East Montpelier Bridge (Civjan et al., 2014) .......................................119

Figure 3.29 (b) Elevation View of East Montpelier Bridge (Civjan et al., 2014) ............................... 119

Figure 3.30 Plan and Elevation View of East Montpelier Bridge Abutment (Civjan et al., 2014) .......120

Figure 3.31 East Montpelier Bridge Deck Section (Civjan et al., 2014)......................................... 120

Figure 3.32 Stockbridge Bridge (Civjan et al., 2014) ............................................................. 121

Figure 3.33 Plan View of Stockbridge Bridge (Civjan et al., 2014) .............................................. 121

Figure 3.34 Elevation View of Stockbridge Bridge (Civjan et al., 2014) ........................................121

Figure 3.35 Plan and Elevation Views of Abutment-1 at Stockbridge Bridge (Civjan et al., 2014) ..... 122

Figure 3.36 Stockbridge Framing Layout (Civjan et al., 2014) .................................................... 122 


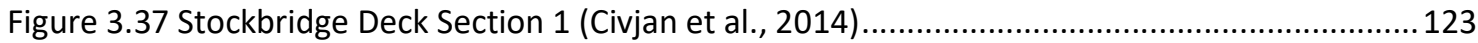

Figure 3.38 Stockbridge Deck Section (Civjan et al., 2014) .........................................................123

Figure 3.39 Finite Element Modeling of the Middlesex Bridge Showing Links and Soil Springs ........123

Figure 3.40 Finite Element Modeling of the Middlesex Bridge without Links and Soil Springs .........124

Figure 3.41 Finite Element Modeling of the Middlesex Bridge from SAP2000 Software Showing Shell

Elements, Mesh Size and Beam Elements Node Distribution.......................................................124

Figure 3.42 Finite Element Modeling of the Middlesex Bridge from SAP2000 Software Showing Shell Elements, Mesh Size, Beam Element Node Distribution, Link Members and Abutment and Piles Soil

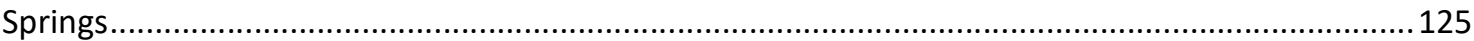

Figure 3.43 Side View of the Finite Element Modeling of the Middlesex Bridge ............................125

Figure 3.44 Plan View of the Finite Element Modeling of the East Montpelier Bridge......................126

Figure 3.45 Elevation View of the Finite Element Modeling of the East Montpelier Bridge..............126

Figure 3.46 Elevation View of the Finite Element Modeling of the East Montpelier Bridge Showing

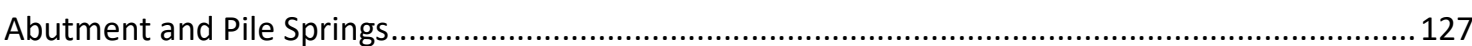

Figure 3.47 Plan View of the Finite Element Modeling of Stockbridge Bridge .................................127

Figure 3.48 Elevation View of the Finite Element Modeling of Stockbridge Bridge ...........................128

Figure 3.49 Elevation View of the Finite Element Modeling of the Modeled Bridge .........................128

Figure 4.1 Pile Soil Force-Displacement Relationship at depth of $10.2 \mathrm{~m}$ Calculated Using the API

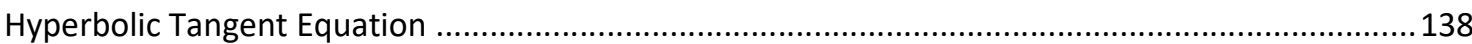

Figure 4.2 Comparison between Pile Soil Force-Displacement Relationship at depth of $10.20 \mathrm{~m}$

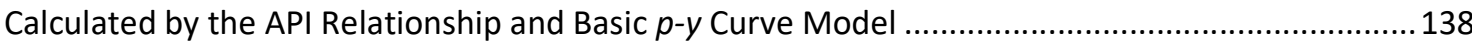

Figure 4.3 Comparison between Pile Soil Force-Displacement Relationships at Depth of $11.17 \mathrm{~m}$

Computed by the Basic $p-y$ Curve Curve and the Modified Ramberg-Osgood Model .......................139

Figure 4.4 Comparison between Properties of Two Steel H-Pile Dimensions ................................... 140

Figure 4.5 Comparison between P-Y Curves for HP 457X460 and HP 310X125 Piles........................141

Figure 4.6 Pile Maximum Resultant Displacement for 200 m Radius Integral Bridge Under Expansion

in Case of Dense Sand Supporting the Abutment and pile Embedded in Medium Dense Sand .........145

Figure 4.7 Pile Maximum Resultant Displacement for 200 m Radius Integral Bridge Under Contraction

in Case of Dense Sand Supporting the Abutment and Pile Embedded in Medium Dense Sand ........146

Figure 4.8 Pile Maximum Resultant Displacement for 200 m Radius Integral Bridge Under Expansion

in Case of Loose Sand Supporting the Abutment and Pile Embedded in Stiff Clay ...........................146

Figure 4.9 Pile Maximum Resultant Displacement for 200 m Radius Integral Bridge Under Contraction in Case of Loose Sand Supporting the Abutment and Pile Embedded in Stiff Clay...

Figure 4.10 Pile Maximum Resultant Displacement for 200 m Radius Integral Bridge Under Expansion

in Case of Dense Sand Supporting the Abutment and Pile Embedded in Stiff Clay 147

Figure 4.11 Pile Maximum Resultant Displacement for 200 m Radius Integral Bridge Under

Contraction in Case of Dense Sand Supporting the Abutment and Pile Embedded in Stiff Clay .......148

Figure 4.12 Pile Maximum Resultant Displacement for 200 m Radius Integral Bridge Under Expansion

in Case of Loose Sand Supporting the Abutment and Pile Embedded in Medium Dense Sand......... 148

Figure 4.13 Pile Maximum Resultant Displacement for 200 m Radius Integral Bridge Under

Contraction in Case of Loose Sand Supporting the Abutment and Pile Embedded in Medium Dense

Sand.

Figure 4.14 Pile Maximum Resultant Displacement Under Thermal Expansion for $60 \mathrm{~m}$ Radius

Integral Bridge in Case of Loose Sand Behind the Abutment and Piles Embedded in Stiff Clay ........ 152

Figure 4.15 Pile Maximum Resultant Displacement Under Thermal Expansion for $60 \mathrm{~m}$ Radius Integral Bridge in Case of Dense Sand Behind the Abutment and Piles Embedded in Stiff Clay........152 Figure 4.16 Pile Maximum Resultant Displacement Under Thermal Expansion for $100 \mathrm{~m}$ Radius Integral Bridge in Case of Dense Sand Behind the Abutment and Piles Embedded in Stiff Clay........153 
Figure 4.17 Pile Maximum Resultant Displacement Under Thermal Expansion for $100 \mathrm{~m}$ Radius Integral Bridge in Case of Loose Sand Behind the Abutment and Piles Embedded in Stiff Clay ........153 Figure 4.18 Pile Maximum Resultant Displacement Under Thermal Expansion for $150 \mathrm{~m}$ Radius Integral Bridge in Case of Loose Sand Behind the Abutment and Piles Embedded in Stiff Clay .........154 Figure 4.19 Pile Maximum Resultant Displacement Under Thermal Expansion for $150 \mathrm{~m}$ Radius Integral Bridge in Case of Dense Sand Behind the Abutment and Piles Embedded in Stiff Clay........154 Figure 4.20 Pile Maximum Resultant Displacement Under Thermal Expansion for $200 \mathrm{~m}$ Radius Integral Bridge in Case of Loose Sand Behind the Abutment and Piles Embedded in Stiff Clay ........155 Figure 4.21 Pile Maximum Resultant Displacement Under Thermal Expansion for $200 \mathrm{~m}$ Radius Integral Bridge in Case of Dense Sand Behind the Abutment and Piles Embedded in Stiff Clay........ 155 Figure 4.22 Pile Maximum Resultant Displacement Under Thermal Expansion for $250 \mathrm{~m}$ Radius Integral Bridge in Case of Loose Sand Behind the Abutment and Piles Embedded in Stiff Clay ........ 156 Figure 4.23 Pile Maximum Resultant Displacement Under Thermal Expansion for $250 \mathrm{~m}$ Radius Integral Bridge in Case of Dense Sand Behind the Abutment and Piles Embedded in Stiff Clay........156 Figure 4.24 Pile Maximum Resultant Displacement Under Thermal Expansion for $300 \mathrm{~m}$ Radius Integral Bridge in Case of Dense Sand Behind the Abutment and Piles Embedded in Stiff Clay.........157 Figure 4.25 Pile Maximum Resultant Displacement Under Thermal Expansion for $300 \mathrm{~m}$ Radius Integral Bridge in Case of Loose Sand Behind the Abutment and Piles Embedded in Stiff Clay ........ 157 Figure 4.26 Unit Change in Bridge Total Length, $\varepsilon$, Versus Radius of Curvature Under Thermal Expansion in Case of Loose Sand Behind the Abutment and Piles Embedded in Stiff Clay................158 Figure 4.27 Unit Change in Bridge Total Length, $\varepsilon$, Versus Radius of Curvature Under Thermal Expansion in Case of Dense Sand Behind the Abutment and Piles Embedded in Stiff Clay 158 Figure 4.28 Pile Maximum Resultant Displacement Under Thermal Expansion for $60 \mathrm{~m}$ Radius Integral Bridge in Case of Dense Sand Behind the Abutment and Piles Embedded in Medium Dense Sand.

Figure 4.29 Pile Maximum Resultant Displacement Under Thermal Expansion for $60 \mathrm{~m}$ Radius Integral Bridge in Case of Loose Sand Behind the Abutment and Piles Embedded in Medium Dense Sand.

Figure 4.30 Pile Maximum Resultant Displacement Under Thermal Expansion for 100 m Radius Integral Bridge in Case of Dense Sand Behind the Abutment and Piles Embedded in Medium Dense Sand.

Figure 4.31 Pile Maximum Resultant Displacement Under Thermal Expansion for $100 \mathrm{~m}$ Radius Integral Bridge in Case of Loose Sand Behind the Abutment and Piles Embedded in Medium Dense Sand.

Figure 4.32 Pile Maximum Resultant Displacement Under Thermal Expansion for $150 \mathrm{~m}$ Radius Integral Bridge in Case of Loose Sand Behind the Abutment and Piles Embedded in Medium Dense Sand.

Figure 4.33 Pile Maximum Resultant Displacement Under Thermal Expansion for $150 \mathrm{~m}$ Radius Integral Bridge in Case of Dense Sand Behind the Abutment and Piles Embedded in Medium Dense Sand.

Figure 4.34 Pile Maximum Resultant Displacement Under Thermal Expansion for 200 m Radius Integral Bridge in Case of Dense Sand Behind the Abutment and Piles Embedded in Medium Dense Sand.

Figure 4.35 Pile Maximum Resultant Displacement Under Thermal Expansion for 200 m Radius Integral Bridge in Case of Loose Sand Behind the Abutment and Piles Embedded in Medium Dense Sand.. 
Figure 4.36 Pile Maximum Resultant Displacement Under Thermal Expansion for $250 \mathrm{~m}$ Radius Integral Bridge in Case of Loose Sand Behind the Abutment and Piles Embedded in Medium Dense Sand......

Figure 4.37 Pile Maximum Resultant Displacement Under Thermal Expansion for $250 \mathrm{~m}$ Radius Integral Bridge in Case of Dense Sand Behind the Abutment and Piles Embedded in Medium Dense

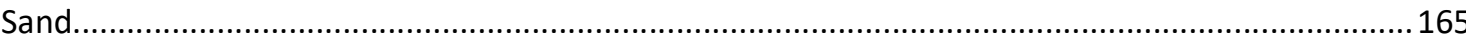

Figure 4.38 Pile Maximum Resultant Displacement Under Thermal Expansion for 300 m Radius Integral Bridge in Case of Loose Sand Behind the Abutment and Piles Embedded in Medium Dense Sand. 166

Figure 4.39 Pile Maximum Resultant Displacement Under Thermal Expansion for 300 m Radius Integral Bridge in Case of Dense Sand Behind the Abutment and Piles Embedded in Medium Dense

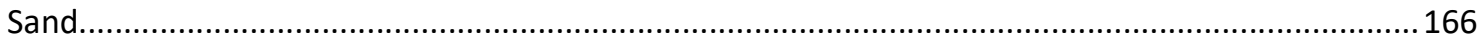

Figure 4.40 Unit Change in Bridge Length, $\varepsilon$, Versus Radius of Curvature Under Thermal Expansion in Case of Loose Sand Behind the Abutment and Piles Embedded in Medium Dense Sand. 167 Figure 4.41 Unit Change in Bridge Length, $\varepsilon$, Versus Radius of Curvature Under Thermal Expansion in Case of Dense Sand Behind the Abutment and Piles Embedded in Medium Dense Sand 167 Figure 4.42 Abutment-Soil Force-Displacement Relationship Using Rankine Theory (Frosch \& Lovell, 2011) 169

Figure 4.43 Pile Maximum Resultant Displacement for $60 \mathrm{~m}$ Radius Integral Bridge in Case of Dense Sand Behind the Abutment and Piles Embedded in Stiff Clay 170 Figure 4.44 Pile Maximum Resultant Displacement for $60 \mathrm{~m}$ Radius Integral Bridge in Case of Loose Sand Behind the Abutment and Piles Embedded in Stiff Clay 171 Figure 4.45 Pile Maximum Resultant Displacement for 100 m Radius Integral Bridge in Case of Dense Sand Behind the Abutment and Piles Embedded in Stiff Clay 171 Figure 4.46 Pile Maximum Resultant Displacement for 100 m Radius Integral Bridge in Case of Loose Sand Behind the Abutment and Piles Embedded in Stiff Clay Figure 4.47 Pile Maximum Resultant Displacement for 150 m Radius Integral Bridge in Case of Dense Sand Behind the Abutment and Piles Embedded in Stiff Clay 172 Figure 4.48 Pile Maximum Resultant Displacement for $150 \mathrm{~m}$ Radius Integral Bridge in Case of Loose Sand Behind the Abutment and Piles Embedded in Stiff Clay 173 Figure 4.49 Pile Maximum Resultant Displacement for 200 m Radius Integral Bridge in Case of Dense Sand Behind the Abutment and Piles Embedded in Stiff Clay 173 Figure 4.50 Pile Maximum Resultant Displacement for 200 m Radius Integral Bridge in Case of Loose Sand Behind the Abutment and Piles Embedded in Stiff Clay 174 Figure 4.51 Pile Maximum Resultant Displacement for 250 m Radius Integral Bridge in Case of Dense Sand Behind the Abutment and Piles Embedded in Stiff Clay 174 Figure 4.52 Pile Maximum Resultant Displacement for 250 m Radius Integral Bridge in Case of Loose Sand Behind the Abutment and Piles Embedded in Stiff Clay 175 Figure 4.53 Pile Maximum Resultant Displacement for 300 m Radius Integral Bridge in Case of Dense Sand Behind the Abutment and Piles Embedded in Stiff Clay 175 Figure 4.54 Pile Maximum Resultant Displacement for 300 m Radius Integral Bridge in case of Loose Sand Behind the Abutment and Piles Embedded in Stiff Clay 176 Figure 4.55 Pile Maximum Resultant Displacement for $60 \mathrm{~m}$ Radius Integral Bridge in Case of Dense Sand behind the Abutment and Piles Embedded in Medium Dense Sand...... 179 Figure 4.56 Pile Maximum Resultant Displacement for $60 \mathrm{~m}$ Radius Integral Bridge in Case of Loose Sand Behind the Abutment and Piles Embedded in Medium Dense Sand......................................180 Figure 4.57 Pile Maximum Resultant Displacement for 100 m Radius Integral Bridge in Case of Dense Sand Behind the Abutment and Piles Embedded in Medium Dense Sand 180 
Figure 4.58 Pile Maximum Resultant Displacement for 100 m Radius Integral Bridge in Case of Loose Sand Behind the Abutment and Piles Embedded in Medium Dense Sand...................................... 181 Figure 4.59 Pile Maximum Resultant Displacement for 200 m Radius Integral Bridge in Case of Dense Sand Behind the Abutment and Piles Embedded in Medium Dense Sand 181

Figure 4.60 Pile Maximum Resultant Displacement for 200 m Radius Integral Bridge in Case of Loose Sand Behind the Abutment and Piles Embedded in Medium Dense Sand..... 182

Figure 4.61 Pile Maximum Resultant Displacement for $150 \mathrm{~m}$ Radius Integral Bridge in case of Dense Sand Behind the Abutment and Piles Embedded in Medium Dense Sand..... 182 Figure 4.62 Pile Maximum Resultant Displacement for 150 m Radius Integral Bridge in Case of Loose Sand Behind the Abutment and Piles Embedded in Medium Dense Sand. 183

Figure 4.63 Pile Maximum Resultant Displacement for 250 m Radius Integral Bridge in Case of Dense Sand Behind the Abutment and Piles Embedded in Medium Dense Sand..... 183 Figure 4.64 Pile Maximum Resultant Displacement for 250 m Radius Integral Bridge in Case of Loose Sand Behind the Abutment and Piles Embedded in Medium Dense Sand.....

Figure 4.65 Pile Maximum Resultant Displacement for 300 m Radius Integral Bridge in case of dense sand Behind the abutment and Piles Embedded in Medium Dense Sand ...... 184 Figure 4.66 Pile Maximum Resultant Displacement for 300 m Radius Integral Bridge in Case of Loose Sand Behind the Abutment and Piles Embedded in Medium Dense Sand..... 185 Figure 4.67 Comparison between Pile Maximum Tangential and Pile Maximum Resultant Displacement in the Case of Thermal Expansion for 60 m Radius Integral Bridge with Dense Sand Supporting the Abutment and Piles Embedded in Stiff Clay

Figure 4.68 View of a Numerical Model for Abutment pile Bending Moment Under Thermal Contraction and Own Weight Loading.....

Figure 4.69 Pile Maximum Moment in Case of Dense Sand Supporting the Abutment and Piles Embedded in Stiff Clay for Bridge at Radius of $300 \mathrm{~m}$.

Figure 4.70 Pile Maximum Moment in Case of Loose Sand Supporting the Abutment and Piles Embedded in Stiff Clay for Bridge at Radius of $300 \mathrm{~m}$.

Figure 4.71 Pile Maximum Moment in Case of Dense Sand Supporting the Abutment and Piles Embedded in Dense Sand for Bridge at Radius of $300 \mathrm{~m}$ 196 Figure 4.72 Pile Maximum Moment in Case of Loose Sand Supporting the Abutment and Piles Embedded in Dense Sand for Bridge at Radius of $300 \mathrm{~m}$

Figure 4.73 Pile Maximum Moment in Case of Dense Sand Supporting the Abutment and Piles Embedded in Stiff Clay for Bridge at Radius of $250 \mathrm{~m}$

Figure 4.74 Pile Maximum Moment in Case of Loose Sand Supporting the Abutment and Piles Embedded in Stiff Clay for Bridge at Radius of $250 \mathrm{~m}$

Figure 4.75 Pile Maximum Moment in Case of Dense Sand Supporting the Abutment and Piles Embedded in Medium Dense Sand for Bridge at Radius of $250 \mathrm{~m}$

Figure 4.76 Pile Maximum Moment in Case of Loose Sand Supporting the Abutment and Piles Embedded in Medium Dense Sand for Bridge at Radius of $250 \mathrm{~m}$

Figure 4.77 Pile Maximum Moment in Case of Dense Sand Supporting the Abutment and Piles Embedded in Stiff Clay for Bridge at Radius of $150 \mathrm{~m}$

Figure 4.78 Pile Maximum Moment in Case of Loose Sand Supporting the Abutment and Piles Embedded in Stiff Clay for Bridge at Radius of $150 \mathrm{~m}$

Figure 4.79 Pile Maximum Moment in Case of Loose Sand Supporting the Abutment and Piles Embedded in Medium Dense for Bridge at Radius of $150 \mathrm{~m}$. 200 Figure 4.80 Pile Maximum Moment in Case of Dense Sand Supporting the Abutment and Piles Embedded in Medium Dense for Bridge at Radius of $150 \mathrm{~m}$. 
Figure 4.81 Pile Maximum Moment in Case of Dense Sand Supporting the Abutment and Piles Embedded in Stiff Clay for Bridge at Radius of $200 \mathrm{~m}$

Figure 4.82 Pile Maximum Moment in Case of Loose Sand Supporting the Abutment and Piles Embedded in Stiff Clay for Bridge at Radius of $200 \mathrm{~m}$

Figure 4.83 Pile Maximum Moment in Case of Loose Sand Supporting the Abutment and piles Embedded in Medium Dense Sand for Bridge at Radius of $200 \mathrm{~m}$

Figure 4.84 Pile Maximum Moment in Case of Dense Sand Supporting the Abutment and Piles Embedded in Medium Dense Sand for Bridge at Radius of $200 \mathrm{~m}$ 202

Figure 4.85 Equation Correlating Abutment Height and Bridge Maximum Length Limit Derived for 60 $\mathrm{m}$ Radius Integral Bridge in Case of Dense Sand Behind the Abutment and Piles Embedded in Clay205 Figure 4.86 Equation Correlating Abutment Height and Bridge Maximum Length Limit Derived for 60 $\mathrm{m}$ Radius Integral Bridge in Case of Loose Sand Behind the Abutment and Piles Embedded in Clay 206 Figure 4.87 Equation Correlating Abutment Height and Bridge Maximum Length Limit Derived for $100 \mathrm{~m}$ Radius Integral Bridge in Case of Dense Sand Behind the Abutment and Piles Embedded in Clay

Figure 4.88 Equation Correlating Abutment Height and Bridge Maximum Length Limit Derived for $100 \mathrm{~m}$ Radius Integral Bridge in Case of Loose Sand Behind the Abutment and Piles Embedded in Clay

Figure 4.89 Equation Correlating Abutment Height and Bridge Maximum Length Limit Derived for $150 \mathrm{~m}$ Radius Integral Bridge in Case of Dense Sand Behind the Abutment and Piles Embedded in Clay.

Figure 4.90 Equation Correlating Abutment Height and Bridge Maximum Length Limit Derived for $150 \mathrm{~m}$ Radius Integral Bridge in Case of Loose Sand Behind the Abutment and Piles Embedded in Clay

Figure 4.91 Equation Correlating Abutment Height and Bridge Maximum Length Limit Derived for $200 \mathrm{~m}$ Radius Integral Bridge in Case of Dense Sand Behind the Abutment and Piles Embedded in Clay.

Figure 4.92 Equation Correlating Abutment Height and Bridge Maximum Length Limit Derived for 250 m Radius Integral Bridge in Case of Loose Sand Behind the Abutment and Piles Embedded in Clay

Figure 4.93 Equation Correlating Abutment Height and Bridge Maximum Length Limit Derived for $300 \mathrm{~m}$ Radius Integral Bridge in Case of Dense Sand Behind the Abutment and Piles Embedded in Clay.

Figure 4.94 Equation Correlating Abutment Height and Bridge Maximum Length Limit Derived for 60 $\mathrm{m}$ Radius Integral Bridge in Case of Dense Sand Behind the Abutment and Piles Embedded in Medium Dense Sand.

Figure 4.95 Equation Correlating Abutment Height and Bridge Maximum Length Limit Derived for $100 \mathrm{~m}$ Radius Integral Bridge in Case of Dense Sand Behind the Abutment and Piles Embedded in Medium Dense Sand

Figure 4.96 Equation Correlating Abutment Height and Bridge Maximum Length Limit Derived for $150 \mathrm{~m}$ Radius Integral Bridge in Case of Dense Sand Behind the Abutment and Piles Embedded in Medium Dense Sand

Figure 4.97 Equation Correlating Abutment Height and Bridge Maximum Length Limit Derived for $200 \mathrm{~m}$ Radius Integral Bridge in Case of Dense Sand Behind the Abutment and Piles Embedded in Medium Dense Sand

Figure 4.98 Equation Correlating Abutment Height and Bridge Maximum Length Limit Derived for $250 \mathrm{~m}$ Radius Integral Bridge in Case of Dense Sand Behind the Abutment and Piles Embedded in Medium Dense Sand 
Figure 4.99 Equation Correlating Abutment Height and Bridge Maximum Length Limit Derived for $300 \mathrm{~m}$ Radius Integral Bridge in Case of Dense Sand Behind the Abutment and Piles Embedded in Medium Dense Sand

Figure 4.100 Bridge Maximum Length Limit Versus Bridge Abutment Height in Case of Piles Embedded in Stiff Clay and Bridge Span Length of 26.17 m.........................................................215

Figure 4.101 Bridge Maximum Length Limit Versus Bridge Abutment Height in Case of Piles Embedded in Stiff Clay and Bridge Span Length of $17.45 \mathrm{~m}$ 215

Figure 4.102 Bridge Maximum Length Limit Versus Bridge Abutment Height in Case of Piles Embedded in Stiff Clay and Bridge Span Length of $21.80 \mathrm{~m}$ and $20.94 \mathrm{~m}$ 216

Figure 4.103 Bridge Maximum Length Limit Versus Bridge Abutment Height in Case of Piles Embedded in Medium Dense Sand and Bridge Span Length of $17.40 \mathrm{~m}$ 216

Figure 4.104 Bridge Maximum Length Limit Versus Bridge Abutment Height in Case of Piles Embedded in Medium Dense Sand and Bridge Span Length of $21.80 \mathrm{~m}$ and $20.94 \mathrm{~m}$

Figure 4.105 Bridge Maximum Length Limit Versus Bridge Abutment Height in Case of Piles

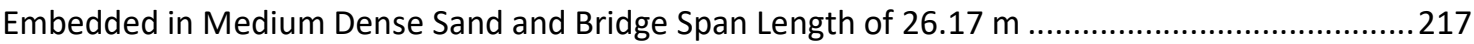

Figure 4.106 Pile Maximum Resultant Displacement Versus Bridge Length .....................................224

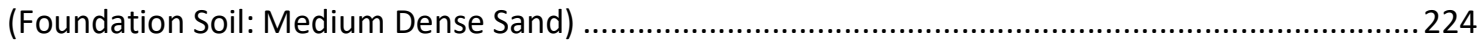

Figure 4.107 Pile Maximum Resultant Displacement Versus Bridge Length ....................................225

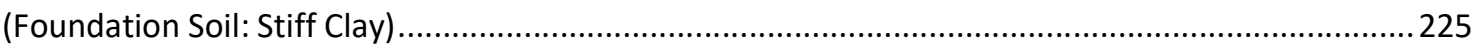

Figure 4.108 Pile Maximum Resultant Displacement Versus Bridge Length ...................................225

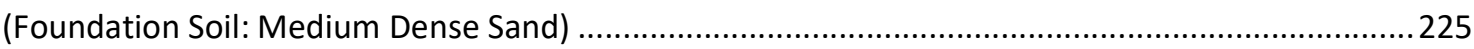

Figure 4.109 Pile Maximum Resultant Displacement Versus Bridge Length ...................................226

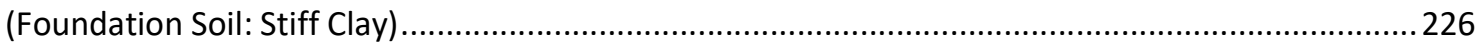

Figure 4.110 Pile Maximum Resultant Displacement Versus Bridge Length ..................................226

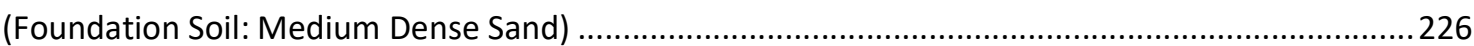

Figure 4.111 Pile Maximum Resultant Displacement Versus Bridge Length .....................................227

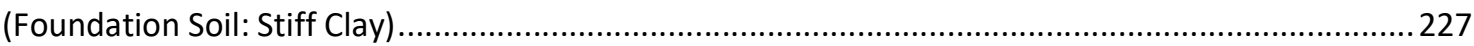

Figure $4.112 \mathrm{n}_{\Delta}$ Versus Bridge Length at Different Abutment Heights............................................236

Figure $4.113 \mathrm{n}_{\Delta}$ Versus Bridge Length at Different Abutment Heights.............................................2. 236

Figure $4.114 n_{\Delta}$ Versus Bridge Length at Different Abutment Heights............................................237

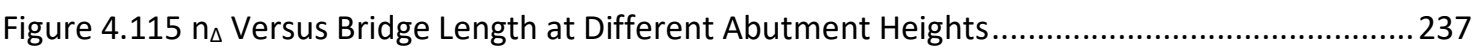

Figure $4.116 \mathrm{n}_{\Delta}$ Versus Bridge Length at Different Abutment Heights.............................................. 238

Figure $4.117 \mathrm{n}_{\Delta}$ Versus Bridge Length at Different Abutment Heights.............................................238

Figure 4.118 Pile Maximum Resultant Displacement Versus Bridge Length ....................................239

Figure 4.119 Pile Maximum Resultant Displacement Versus Bridge Length ....................................239

Figure 4.120 Pile Maximum Resultant Displacement Versus Bridge Length ......................................240

Figure 4.121 Pile Maximum Resultant Displacement Versus Bridge Length ......................................240

Figure 4.122 Pile Maximum Resultant Displacement Versus Bridge Length .....................................241

Figure 4.123 Pile Maximum Resultant Displacement Versus Bridge Length .....................................241

Figure 4.124 Pile Maximum Resultant Displacement Versus Bridge Length ....................................242

Figure 4.125 Pile Maximum Resultant Displacement Versus Bridge Length ......................................242

Figure 4.126 Pile Maximum Resultant Displacement Versus Bridge Length .....................................243

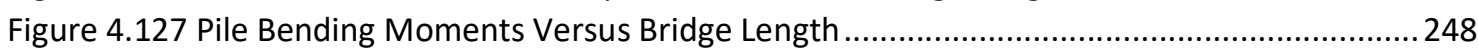

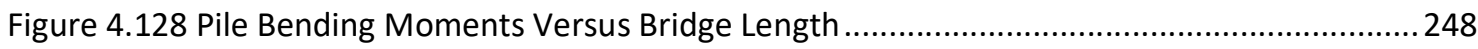

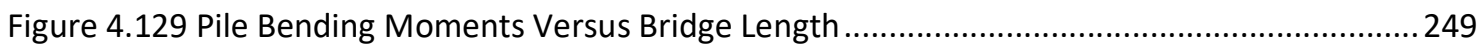

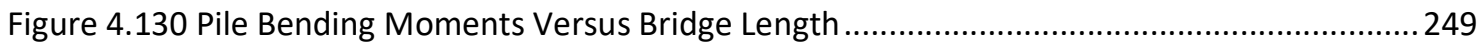

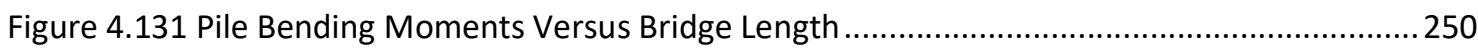

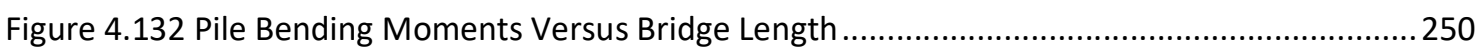

xviii 
Figure 4.133 Pile Bending Moments Versus Bridge Length ....................................................251

Figure 4.134 Pile Bending Moments Versus Bridge Length ...................................................... 251

Figure 4.135 Pile Bending Moments Versus Bridge Length ......................................................252

Figure 4.136 Percentage of Reduction in Pile Moment Versus Bridge Length $(\mathrm{R}=60 \mathrm{~m})$................252

Figure 4.137 Percentage of Reduction in Pile Moment Versus Bridge Length $(\mathrm{R}=100 \mathrm{~m})$.............253

Figure 4.138 Percentage of Reduction in Pile Moment Versus Bridge Length $(\mathrm{R}=150 \mathrm{~m})$.............253

Figure 4.139 Percentage of Reduction in Pile Moment Versus Bridge Length $(\mathrm{R}=200 \mathrm{~m})$.............254

Figure 4.140 Percentage of Reduction in Pile Moment Versus Bridge Length $(R=250 \mathrm{~m})$.............254

Figure 4.141 Percentage of Reduction in Pile Moment Versus Bridge Length $(\mathrm{R}=300 \mathrm{~m})$............. 255

Figure 4.142 Pile Maximum Resultant Displacement Versus Bridge Length for Piles with Predrilled

Holes

Figure 4.143 Pile Maximum Resultant Displacement Versus Bridge Length for Piles with Predrilled

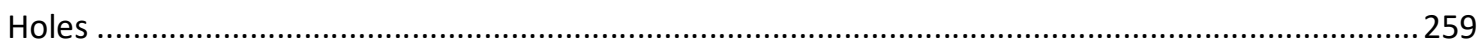

Figure 4.144 Pile Maximum Resultant Displacement Versus Bridge Length for Piles with Predrilled

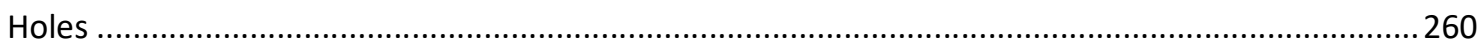

Figure 4.145 Pile Maximum Resultant Displacement Versus Bridge Length for Piles with Predrilled

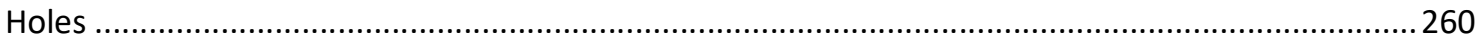

Figure 4.146 Pile Maximum Resultant Displacement Versus Bridge Length for Piles with Predrilled

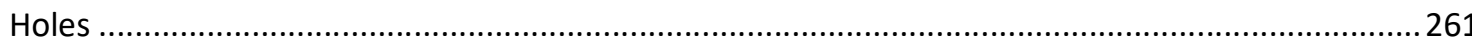

Figure 4.147 Pile Maximum Resultant Displacement Versus Bridge Length for Piles with Predrilled

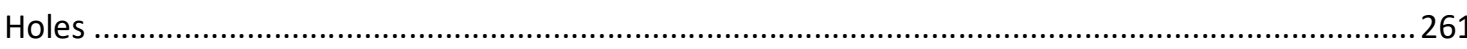




\section{CHAPTER 1 \\ INTRODUCTION}

\subsection{Introduction}

Bridges have employed expansion joints as shown in Figure 1.1 to accommodate thermal movement generated from thermal loading which results in either expansion or contraction of the bridge deck. Not only bridges but even structures such as rigid pavement utilize expansion joints to accommodate such movements. Although these expansion joints provide much needed relief to the structure in question by facilitating the expansion and contraction of the structure, but they create other issues which can impact the serviceability, the durability and the longevity of the structure.

For bridges which utilizes expansion joints, these expansion joints are required to have a seal which is water tight, gives smooth ride, acoustically friendly with as low noise as possible and resistant to cyclic and repeated loading, among others. But in reality these expansion joints can be highly susceptible to fail in respect to the water tightness criterion. Failure can be manifested in disbanding of the sealant from one side of the expansion joint, weathering, embrittlement, cracking, disbanding, loss of adhesion and leaking (French \& McKeel, 2003).

Even if the expansion joint performed outstandingly in the first couple of months, there is no guarantee that it will not deteriorate with continuous usage and exposure to the weathering conditions through its expected life time. In addition, in cold climate countries where deicing salt is used extensively for facilitating traffic movement on roads in winter time, this deicing salt provides additional hazard to bridge integrity by leaking through construction and expansion joints causing irreversible corrosion to bridge components such as bearings, piers,

girders and deck. In order to avoid the almost inevitable corrosion-generating chemicals leaking through expansion joints and the high cost of maintenance associated with such, the concept of jointless bridge started to evolve as shown in Figure 1.2. 


\subsection{Types of Jointless Bridges}

The ideal integral abutment bridge is the bridge without joints and bearings from the end to the end of approach slab. But based on the needs, some structural systems have been developed. However, jointless bridges can be classified into several types as follows:

Integral Bridge with Flexible Piers: These are bridges that are constructed without expansion joints and without bearings either on the abutments or on the piers, which is the ideal type.

Integral Bridge with Rigid Piers: these are bridges that are constructed without expansion joints and without bearings on the abutment but have guided and/or fixed bearings on the piers.

Semi-Integral with Flexible Piers: These are bridges that are constructed without expansion joints but with bearings on the abutments and none on the piers (integral pier). In these bridges, the piers are flexible to be able to accommodate the bridge deck movements and the abutments are rigid and isolated from bridge deck.

Semi-Integral with Rigid Piers: These are bridges that are constructed without expansion joints but have bearings on both the piers and the abutments.

Although there is several types of jointless bridges with different configurations in regard to the types of supports on abutments and piers, the common among them is that they all require an approach slab as shown in Figure 1.3, since the state of the soil behind the abutment can be in the loose or dense state arising from the cyclic movement of the bridge. Semi integral abutment bridges details are shown in Figures 1.4 and 1.5, while cross section details of integral abutment with supporting piles are shown in Figures 1.6 through 1.8.

Abutment-piles connection can be fixed as shown in Figures 1.6 and 1.7. Different opinions between researchers and codes are about the fixed length of piles inside the abutment. Alternatively, the connection between piles and abutment can be hinged. This connection can be constructed using pin connection between the pile and the abutment or by placing $50 \mathrm{~mm}$ expanded polystyrene around the pile butt as shown in Figure 1.8. 
It is noteworthy that, construction details of integral abutment bridge are varying as shown elsewhere (Soltani and Kukreti, 1992; Kunin and Alampalli, 2000; Maruri and Petro, 2005; Conboy, 2005; Civjan et al., 2014).

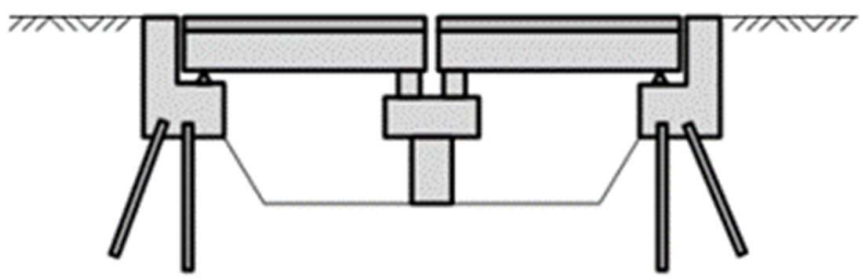

Figure 1.1 Conventional Bridge Diagram (Frosch \& Lovell, 2011)

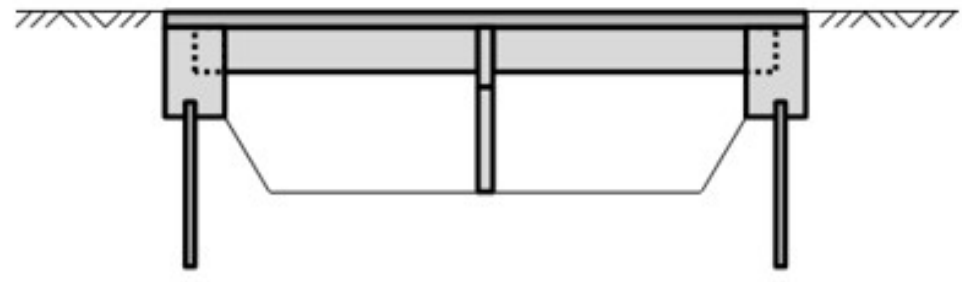

Figure 1.2 Sketch of Jointless Integral Abutment Bridge (Frosch \& Lovell, 2011)

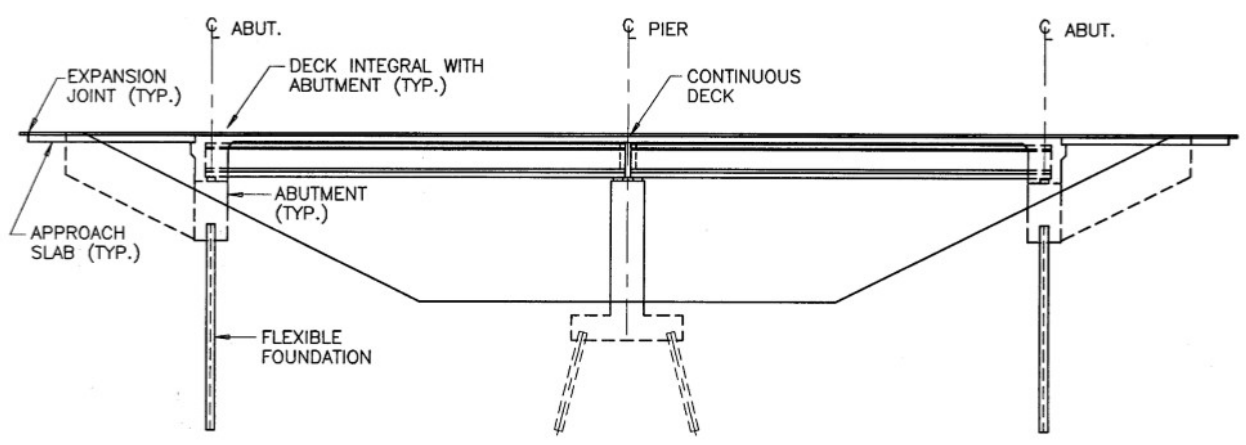

Figure 1.3 Jointless Integral Abutment Bridge and Approach Slab (MTO, 1996) 


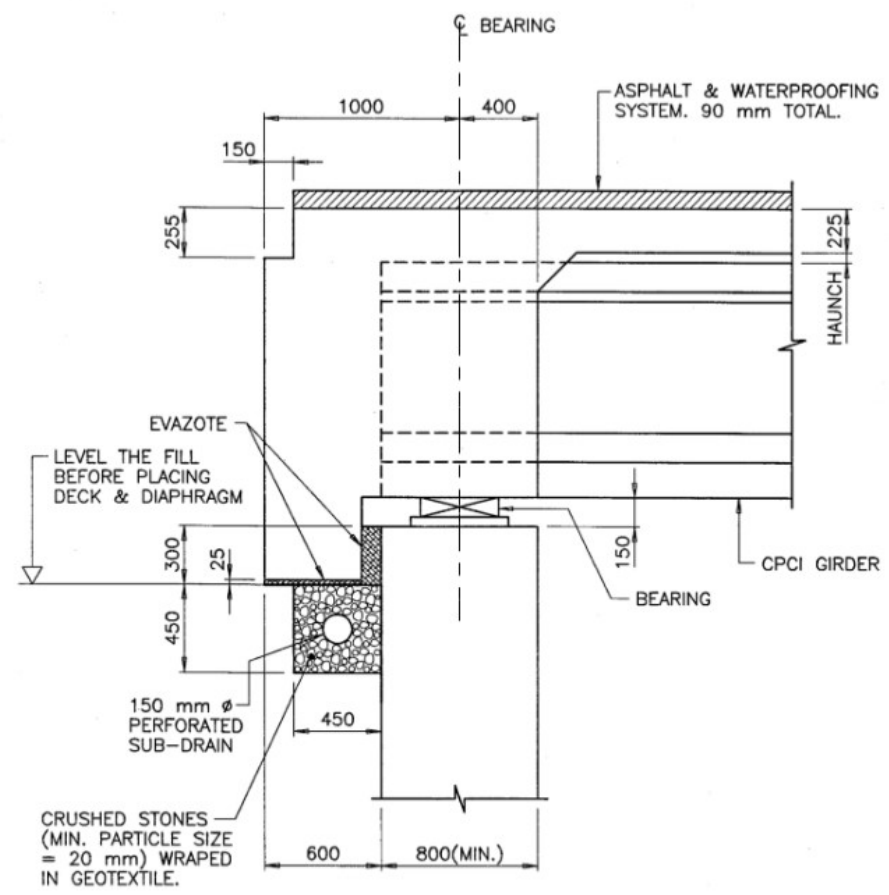

Figure 1.4 Semi Integral Abutment Details (MTO, 1996)

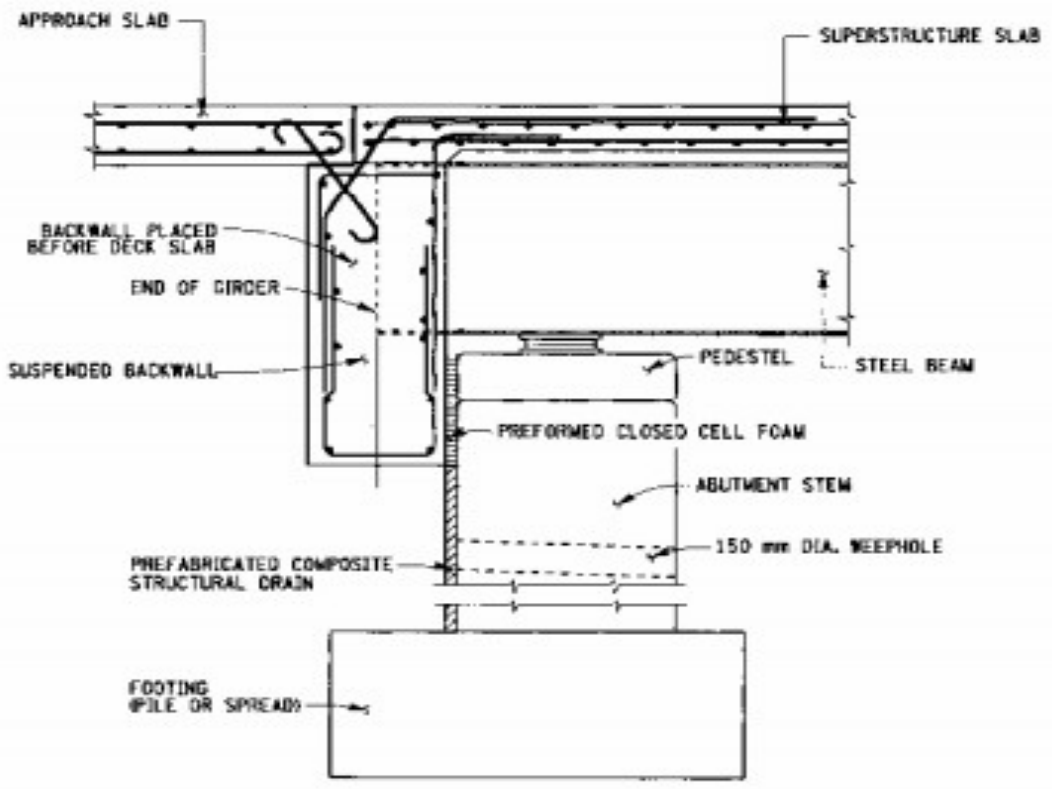

Figure 1.5 Cross Section of Semi Integral Abutment (New York State Department of Transportation, 2007) 


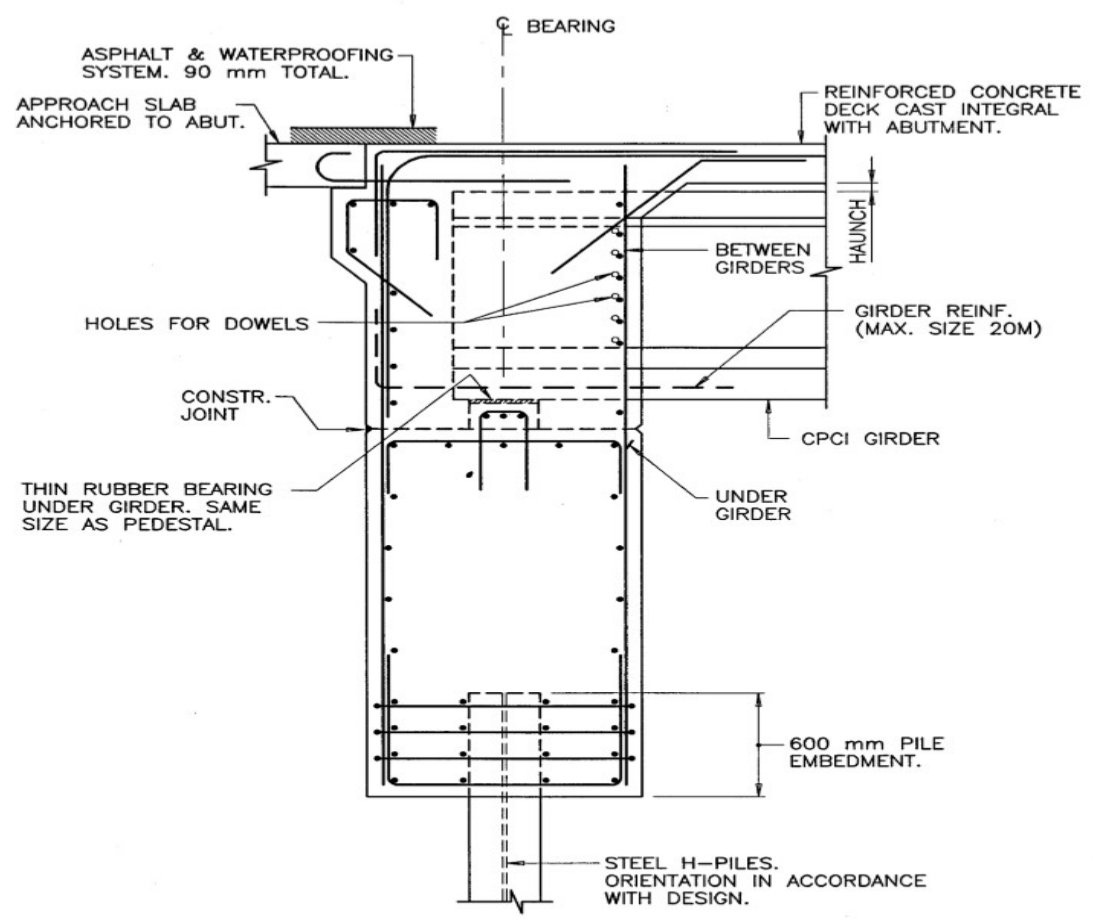

Figure 1.6 Integral Abutment Details-Fixed Connection (MTO, 1996)

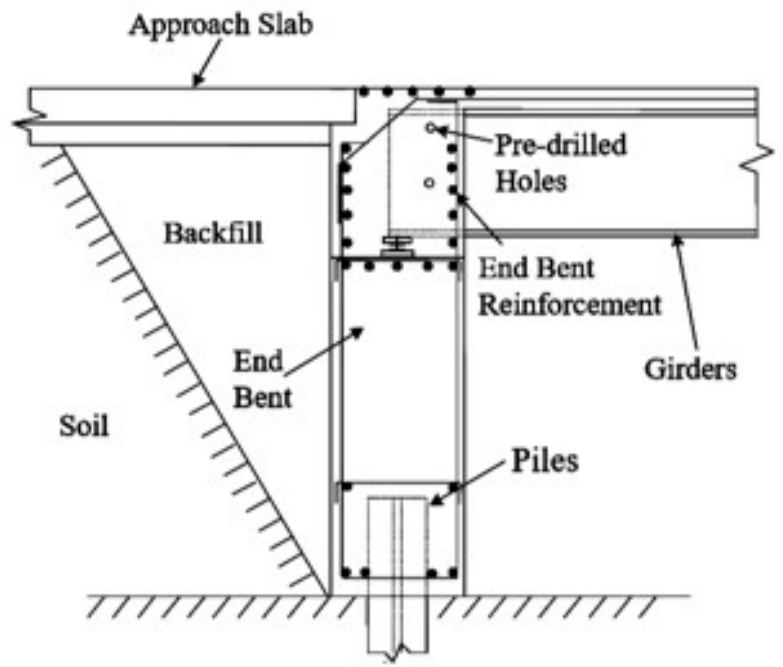

Figure 1.7 Cross Section of Integral Abutment with Fixed Connection to the Piles (Durbin, 2011) 

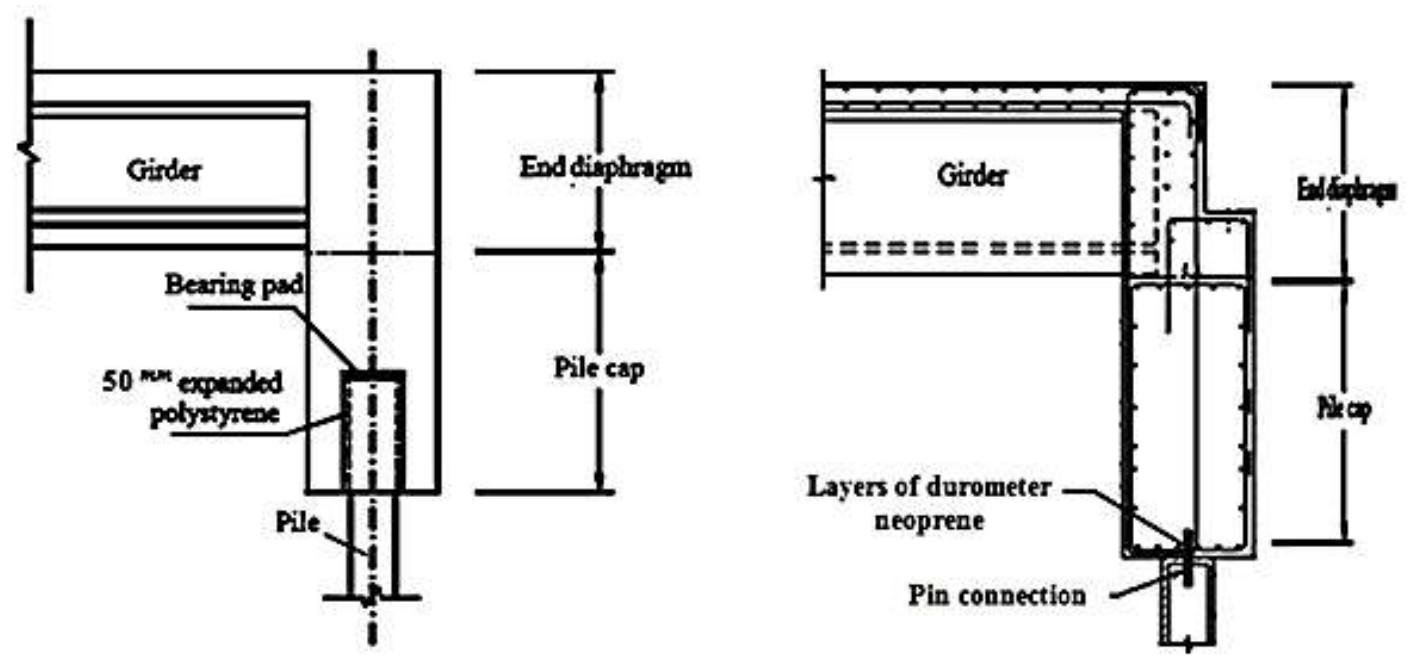

(a)

(b)

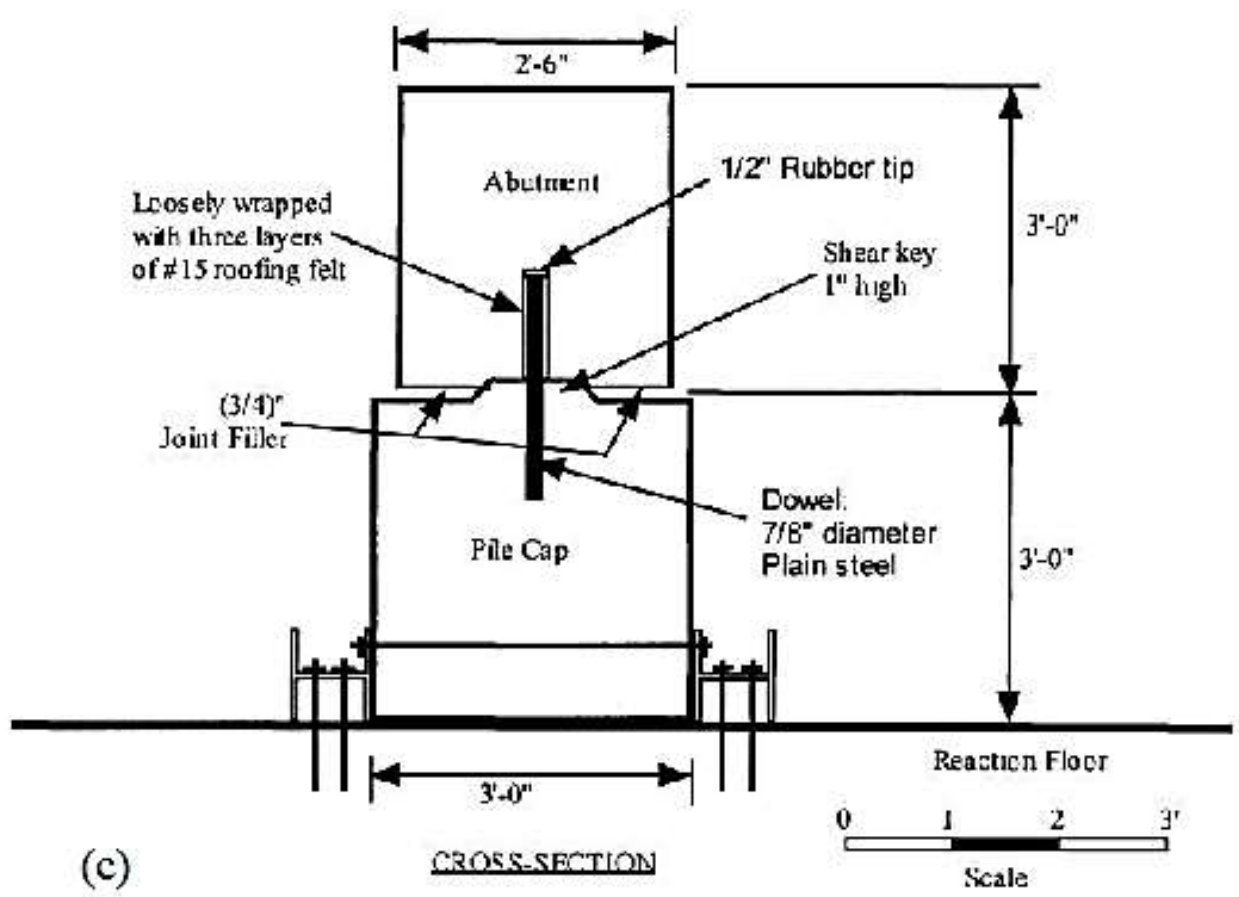

Figure 1.8 Schematic Diagram of Abutment-Pile Hinged Connection (Arsoy et al., 2002)

\subsection{Problem Description}

Due to thermal changes of the bridge deck, the backfill soil supporting bridge abutment is subjected to cyclic loading, which can result in an increase or decrease of earth pressure imposed on the abutment. Increase in earth pressure may lead to failure in backfill or in bridge 
deck. While decrease in earth pressure leads to excessive settlement in the backfill associated with subsidence of backfill surface.

Meanwhile, the abutment and the supporting piles are subjected to vertical and lateral loads in addition to rotational moments which produce complex deformations and displacements within the bridge substructure and soil. Therefore, the design of integral abutment bridge required extensive scrutiny of soil-structure interaction, as the length of the bridge increased. This has formed the basis for the researchers and authorities to recommend limiting length of the bridge and heights of the abutment (BD 57/01, 2001; Arsoy et al., 2002; BA 42/96, 2003; Dicleli and Albhaisi, 2004b).

Other researchers have recommended changes in the geometric configuration of the bridge or to reduce the earth pressure by using granular backfill and synthetic geomaterial (Horvath, 2000; BA 42/96, 2003; White et al., 2010).

Due to lack of knowledge of the behavior of integral abutment bridge (IAB), a comprehensive and standardized design and construction guideline, accepted to authorities worldwide, has not been yet developed (Efretuei, 2013). Furthermore, the design of IAB has been based on judgment and empirical rules rather than on scientific and engineering understanding (Griton et al., 1991; Oesterle et al., 2002). Notably, horizontally curved integral abutment bridges add more complexity to straight or skew integral abutment bridge.

Therefore, the current research is dealing with horizontally curved IAB. The superstructure and substructure were modeled using 3D finite element. The impact of thermal loading conditions on the backfill and foundation soil was modeled by induced-abutment displacement. Abutment displacement-pressure relationship documented in literature was used for assessing earth pressure, while $p$ - $y$ curves were implemented for predicting forces developed along the supporting pile.

The superstructure of the bridge consisted of reinforced concrete slab deck resting on steel Igirders. The steel I-girders were integrated with bridge abutment, while the girders were restraint laterally at supporting piers.

The research work dealing with the behavior of curved integral abutment bridge is scarce (Thanasattayawibul, 2006; Doust, 2011; David, 2012; Kalayci et al., 2012; McBride, 2013; 
Greimann et al., 2014). Therefore, due to uncertainities inheretnt in curved integral abutment bridge design and construction, transportation agencies have limited their application (Doust, 2011).

Inadequate past research and lack of knowledge concerning the response of horizontally curved integral abutment bridge led the designers to follow conservative design approach. Also, bridge design codes provide conservative design, due to the complication inherent in the response of the bridge and lack of knowledge. For example, Burke (2009) limited the curvature of the bridge to $5^{\circ}$, while Maruri and Petro (2005) set the limit to $10^{\circ}$, these limits were quoted by Doust (2011). On the other hand, Doust (2011) quoted that Arockiasamy and Sivakumar (2005) limited the radius of horizontally curved bridge by more than $330 \mathrm{~m}$.

\subsection{Research Aims and Objectives}

The goal of this research was to try to figure out a length limit for curved integral abutment steel I-girders bridges constructed on H-piles under thermal loading. Numerous 3D finite element models were built using SAP2000 Software (SAP2000, 2019). Several bridge configurations supported on H-piles, wished-in-foundation soil having different characteristics with two different densities of backfill soil supporting the abutment were investigated through a parametric study. The length limit of curved integral abutment bridge was based on the displacement capacity of $\mathrm{H}$-piles. The maximum pile displacement limit was set equal to $40 \mathrm{~mm}$. The displacement capacity was adopted from field test results conducted by Knoxville University, which is slightly less than 2 in. set by Frosch and Lovell (2011). Additionally, the effects of bridge abutment height, the radius of curvature and the span length on the performance of the horizontal curved integral abutment bridge were studied.

It is well known that, in contrary to straight bridges, the inner piles of curved bridges exhibit less displacement than the outer piles. Hence, the aim of this research was to find the maximum bridge length for a two-lane curved integral abutment bridge that causes no more than $40 \mathrm{~mm}$ displacement at the head of the outer H-Pile. The piles supporting curved integral abutment bridge exhibit displacement out of planes, contrary to piles supporting straight integral abutment bridge which exhibit displacement in the plane of the bridge deck. Therefore, the maximum resultant displacements of the piles were considered. 


\subsection{Limitation of the Current Research}

The work presented in thesis is limited to selected bridge configuration and conditions as follows:

The supporting piles were $\mathrm{H}$-piles, arranged in strong axis. The piles supporting the two abutments were similar in number and characteristics. The bearing soil at the two abutments is of similar properties. Therefore, the abutment piles were installed in bearing soil having the same properties. The superstructure and substructure of the bridge were symmetrical about vertical centerline of the bridge. The bearing stratum was homogeneous, isotropic and semiinfinite. A uniform thermal loading along the cross section of the bridge was considered. The abutment in contact with the supporting backfill was without gap and there was no bump at the bridge end's due to cyclic displacement and deformation of substructure. The properties of backfill soil was kept constant. The backfill subjected to cyclic strain due to thermal variation and ratcheting phenomenon were out of the scope of the current research. The initial conditions of bridge expansion considered the earth pressure of backfill soil supporting the abutment being at rest state, in addition to straining in superstructure due to self-weight of the bridge. Cyclic loading of soil supporting the abutment is out of the scope of the current research.

The piles supporting the bridge were arranged in a raw with the weak axis perpendicular to the centerline of the abutment. The spacing between piles was taken $1.5 \mathrm{~m}$. The pier was considered rigid. The lateral movements of the bridge's deck at the supporting piers were restraint, while the movements of the deck in the tangential directions of the bridge were allowed. The concrete deck of the bridge was modeled as uncracked section. The piles were fixed in the abutment.

\subsection{Structure of the Thesis}

The thesis was organized as follows:

Chapter 1 provides introduction to the topic of integral abutment bridge and definition of integral abutment bridge. Then, the chapter elaborates on the types of jointless bridges and introduces the concept of thermal influence on integral abutment bridge's length limit. Research aims and objectives and structure of the thesis are incorporated in chapter 1 . 
Additionally, in-depth literature review of several topics related to integral abutment bridges is summarized.

Chapter 2 provides review of several topics related to soil-structure interaction such as the lateral bearing capacity of vertical piles embedded in different types of soils, namely: soft and stiff clay and sand. The chapter then discusses the load-deflection curves $(p-y)$ of laterally loaded pile recommended by the API (2003) as well as in the available literature. The pile-soilpile interaction expressed as group effect is described and abutment displacement-earth pressure relationships are introduced and discussed.

Chapter 3 provides description and validation of the finite element model. The chapter introduces the bridge geometry for all the models, the constitutive parameters that affect the response of the bridge were assessed. Then, soil cases and properties adopted in the study are mentioned as well as their limitations and assumptions. The superstructure and substructure model is described including the soil model. The chapter ended with introducing the thermal loading adopted in the study and how it was determined and a description of the validation models and validation results concluded the chapter.

Chapter 4 contains the sensitivity and parametric study that was carried out. Then, the behavior of the modeled integral abutment bridges under both thermal expansion and contraction loads is addressed in the form of maximum pile bending moment and maximum pile displacement versus bridge length and abutment height through a series of graphs. Ratio of tangential to resultant displacement of the pile exhibiting maximum resultant displacement is addressed. Then, the concept of bridge length limit is introduced. The chapter ends with derived equations relating bridge length limit with abutment height and span length in several soil conditions.

Chapter 5 provides concluding remarks as well as recommendations for future research based on the limitations of the current research.

\subsection{Thermal Effect}

There is consensus that construction of jointless bridges has started in the USA at the end of 1938 and spread to Australia and New Zealand. Since codes and guidelines for such structures were not available, the length of these bridges was limited generally to no more than $30 \mathrm{~m}$ 
(Thanasattayawibul, 2006). And from then onward, the length limit has developed by the years. For instance, Tennessee Department of Transportation set the limit for integral abutment bridge by setting the limit of expansion and contraction to 1 inch. This limit (i.e. 1 inch) was developed empirically over a period of several years. Tennessee used the average AASHTO temperature change of $35^{\circ} \mathrm{F}$ for concrete structures and $60^{\circ} \mathrm{F}$ for steel and then the maximum bridge length was calculated according to the following equations:

$$
\begin{aligned}
& \mathrm{L}_{\text {concrete }}=\frac{\Delta}{\alpha_{\mathrm{c}}(\Delta \mathrm{T})_{\mathrm{c}}}=\frac{1 / 12}{.0000060(35)}=396 \mathrm{ft}(120.7 \mathrm{~m}) \\
& L_{\text {Steel }}=\frac{\Delta}{\alpha_{s}(\Delta T)_{s}}=\frac{1 / 12}{.0000065(60)}=214 \mathrm{ft}(65.22 \mathrm{~m})
\end{aligned}
$$

Where;

$\Delta:$ Temperature induced change in bridge length $(f t)$,

$\alpha_{c}, \alpha_{s}$ : Coefficients of thermal expansion of concrete and steel, respectively $\left(1 /{ }^{\circ} \mathrm{F}\right)$,

$\Delta T$ : Change in temperature $\left({ }^{\circ} \mathrm{F}\right)$,

$L$ : Total length of structure $(f t)$.

These equations ignored the effect of the restraint of substructure on the bridge deck.

North Dakota Department of Transportation used equation 1.3, to determine the temperature change of the bridge, $\Delta T$. The equation is a function of air temperature at dawn on the hottest day, $T_{1}$, air temperature at dawn at the coldest day, $T_{2}$, and the maximum air temperature at the hottest day, $T_{3}$.

$\Delta \mathrm{T}=\mathrm{T}_{1}-\mathrm{T}_{2}+\frac{\mathrm{T}_{3}-\mathrm{T}_{1}}{3}$

On the other hand, the AASHTO LRFD Bridge Design Specifications (AASHTO, 2017) specifies in cold climate, temperature range for concrete structures of $80^{\circ} \mathrm{F}$ and a thermal coefficient of $0.00000601 /{ }^{\circ} \mathrm{F}$ as well as temperature range for steel superstructure of $150{ }^{\circ} \mathrm{F}$ and a thermal coefficient of $0.00000651 /{ }^{\circ} \mathrm{F}$.

In practice, the temperature range is the difference between the construction temperature and the maximum and minimum bridge temperature. Bridge temperature can be calculated as the weighted average of the bridge temperature over the bridge cross-section according to the following equation: 
$T_{a v g}=\frac{\sum A_{i} E_{i} \alpha_{i} T_{i}}{\sum A_{i} E_{i} \alpha_{i}}$

Where;

$i$ : Segment of the bridge cross section,

$A_{i}$ : Cross sectional area of the ith segment,

$E_{i}$ : Elastic modulus of the ith segment,

$\alpha_{i}$ : Coefficient of thermal expansion of the ith segment,

$T_{i}$ : Temperature of the $i t h$ segment.

Likewise, the equivalent coefficient of thermal expansion can be calculated as the weighted average of the coefficients of thermal expansion of both the concrete deck and the steel girders as per equation 1.5:

$\alpha_{\text {equivalent }}=\frac{(E A \alpha)_{\text {deck }}+(E A \alpha)_{\text {girder }}}{(E A)_{\text {deck }}+(E A)_{\text {girder }}}$

Where;

$E$ : The modulus of elasticity,

$A$ : The cross sectional area,

$\alpha$ : Coefficient of thermal expansion.

As it can be seen, the bridge temperature is a major factor that causes the change in the length of a bridge and induces abutment displacements. This temperature is a function of the air temperature, solar radiation, wind velocity, shading, and type of bridge structure among others. Oesterle et al. (1998) provided empirical equations for the average minimum and average maximum bridge temperatures for concrete superstructures. These equations are function of the air temperature measured in the shade and solar radiation as follows:

$T_{\text {min ave }}=1.0 T_{\text {min shade }}+9^{\circ} \mathrm{F}$

$T_{\text {max ave }}=0.97 T_{\text {max shade }}-3^{\circ} \mathrm{F}+\Delta T_{\text {solar }}$

For solar radiation, refer to (Thanasattayawibul, 2006 ). 


\subsection{Review of Previous Work}

\subsubsection{Straight and Skew Integral Abutment Bridge}

\subsubsection{General}

Several researchers tackled the issue of integral abutment bridges under thermal loading either by applying numerical modeling using commercial software or by field monitoring of integral abutment bridges.

In the work done by Dicleli \& Albhaisi (2003) using the finite element SAP2000 Software, a 2D numerical Frame model was built for concrete and steel integral abutment bridges. Static pushover analyses were conducted to estimate the displacement capacity of steel H-Piles under thermal loading. The piles were modeled as beam elements with frame hinges to simulate the inelastic deformation of steel $\mathrm{H}$-piles, and horizontal truss elements with plastic axial hinges at their ends attached at each node along the pile to model the force-deformation behavior of the soil. From the results of the numerical analyses, the following conclusions were drawn by the researchers:

a) Maximum length limit for concrete integral abutment bridges ranges between 150 and $265 \mathrm{~m}$ in cold climates and 180 and $320 \mathrm{~m}$ in moderate climates. For steel integral abutment bridges the range is between 80 and $145 \mathrm{~m}$ in cold climates and 125 and $220 \mathrm{~m}$ in moderate climates.

b) Concrete bridges are more suited for integral abutment construction than steel since they are less sensitive to temperature variations.

c) Pinned abutment-pile connection increases the displacement capacity of integral bridges with stub abutments.

d) The effect of the orientation of steel H-piles on the displacement capacity of integral bridges having stub abutments is negligible.

In another work carried by Dicleli \& Albhaisi (2003), the maximum length of integral bridges supported on steel H-piles driven in sand was assessed. The assessment was based on the abutment flexure capacity and the H-piles' displacement capacity. A total of 150 static pushover analyses were conducted to estimate the displacement capacity of integral bridges based on H-piles low-cycle fatigue performance. The authors used the finite element SAP2000 
Software and modeled the bridge as a 2D frame model. The following conclusions were drawn by the researchers:

a) As the size of the pile increases, the displacement capacity of the bridge increases proportional to the flexural capacity of the pile.

b) The stiffness of the foundation soil has a profound effect on the displacement capacity of the bridge. As the sand stiffness increases, the displacement capacity of the bridge decreases.

c) Maximum length of concrete integral bridges is to be limited to $190 \mathrm{~m}$ in cold climates and $240 \mathrm{~m}$ in moderate climates. For steel integral bridges, maximum length is to be limited to $100 \mathrm{~m}$ in cold climates and $160 \mathrm{~m}$ in moderate climates. These limits are valid only for steel $\mathrm{H}$-piles driven in sand.

Dicleli \& Albhaisi (2004) modeled an integral abutment bridge using SAP2000 software. The bridge was modeled using a 2D frame element considering a single interior girder and only half of the bridge was modeled due to the symmetrical configuration of the bridge. Piles were modeled using frame elements. The abutment was modeled using elastic beam elements, and bearings were modeled as simple roller supports neglecting the lateral stiffness of the elastomeric bearings over the piers.

The effective length of the $\mathrm{H}$-pile in responding to the lateral displacement was taken as 30 times the pile width. Below this depth, there is no significant lateral pile displacement and hence negligible soil pile interaction. A roller support was introduced at the end of the pile to provide vertical stability.

Horizontal truss elements with plastic axial hinges at their ends were attached at each node along the pile to model the force deformation behavior of the foundation soil. Horizontal truss elements with nonlinear axial hinges at their ends were attached at each node along the abutment to model the force deformation behavior of the backfill (Dicleli \& Albhaisi, 2004).

From their study, the following conclusions were drawn:

a) The size and orientation of the steel $\mathrm{H}$-piles have negligible effect on the distribution and intensity of the backfill pressure.

b) Variation in abutment thickness within the range of 1 to $1.5 \mathrm{~m}$ has negligible effect on the distribution and intensity of the backfill pressure. 
c) The abutment height is found to have notable effect on the abutment backfill pressure distribution and magnitude of the shear force and bending moment in the abutment.

d) The backfill pressure intensity and the internal forces in the abutment are a function of the abutment displacement due to thermal loading.

Parametric study was carried by Arockiasamy et al. (2004) using SAP2000 software, LPILE software and FB-PIER Software to study the effect of a predrilled holes to facilitate piles installation, type of backfill placed in the predrilled holes, elevation of the water table, soil type and pile orientation on the horizontal displacement, moment and shear along the depth of the piles. Three different degrees of compaction of sand in the predrilled holes were used, namely: loose, medium and dense sand. Three cases of predrilled hole depth were chosen to be investigated by the researchers namely: 0, 2.44 and $4.88 \mathrm{~m}$. Orientation of the pile along the weak and strong axes was part of the parametric study. Three types of foundation soil, namely: stiff clay, very stiff clay and dense sand, were considered in the parametric study. The pile length was calculated based on the pile skin friction capacity using the $\alpha$ method. The researchers drew the following conclusions and recommendations:

a) Elevation of the water table has very little effect on pile deformation.

b) Pile displacement is inversely proportional to the density of sand in the predrilled hole. As the density increases, the pile displacement decreases.

c) Pile displacement increases with the increase of the depth of the predrilled hole.

d) Orienting the pile along the weak axes allows the pile to undergo larger stresses and larger horizontal displacement.

e) Pile displacement varies with the variation of the type of soil in which the pile is embedded.

f) Properly drained approach slabs are required to combat embankment settlement and prevent damage arising from saturated backfill.

g) It is imperative to provide proper drainage system for the backfill such as using porous granular backfill to avoid freeze/thaw damage arising from backfill saturation. 
h) As the pile length is assessed based on the pile axial capacity derived from the pile skin friction, then replacing the top part of the pile with less dense sand requires longer piles for the same loading condition. While the required pile length will be less in a stiffer soil.

i) Piles in predrilled holes are more flexible, however the required pile length to support the bridge dead and live load is more when predrilled holes are adopted.

Dicleli \& Albhaisi (2005) conducted static pushover analyses to estimate the displacement capacity of integral bridges at the deck level, based on low-cycle fatigue performance of $\mathrm{H}$-piles imbedded in cohesive soils. The following conclusions were drawn by the researchers;

a) Clay stiffness is observed to have big effect on the maximum temperature-induced displacement that an integral bridge can accommodate. As the clay stiffness increases the displacement capacity of the bridge decreases.

b) Bridges with larger pile size have larger displacement capacity, and bridges with piles oriented to bend about their strong axes can accommodate larger displacement than those bridges with piles oriented to bend about their weak axes.

c) The height of the abutment has profound effect on the displacement capacity, based on low-cyclic fatigue performance of the piles, taller abutments have larger displacement capacity.

d) Variation in abutment thickness has no effect on the displacement capacity of the integral abutment bridge.

e) Increasing the overall size or stiffness of integral abutment bridge deck has a negative effect on its displacement capacity under thermal loading based on low-cyclic fatigue performance of the piles. The stiffer it gets, the smaller its displacement capacity.

f) The displacement capacity of integral abutment bridge is a function of the properties of the bridge, piles, foundation soil and backfill.

g) The maximum length limit of integral abutment bridges is a function of the properties of the bridge, piles, foundation soil and backfill.

h) The flexure capacity of the abutment may control the displacement capacity of the integral abutment bridge. 
i) The shear capacity of the thick abutment does not control the displacement capacity of the integral abutment bridge.

j) The displacement capacity of the bridge decreases considerably when the foundation soil becomes stiffer.

k) When the flexural capacity of the abutment controls the bridge displacement capacity, the orientation of the pile for bending about the week axes is recommended otherwise the piles should be oriented about their strong axes of bending.

I) Maximum length limit for concrete integral abutment bridges ranges from 130 to 290 $\mathrm{m}$ and the range for steel integral bridge is from 95 to $210 \mathrm{~m}$ based on climate condition at the bridge site and pile size.

Fennema et al. (2005) observed that abutments contraction is higher due to long-term creep and shrinkage of the concrete deck. This shrinkage is augmented when using PPCI (Pre-cast, Pre-stressed Concrete I-beam) for girders. Due to the monolithic nature of integral abutment bridges, this shrinkage behavior of concrete components can induce large axial compressive force in the bridge girders and deck.

Fennema et al. (2005) conducted a series of field data measurement on a Pennsylvania bridge in USA, which was used afterwards to adjust finite element numerical models. According to the authors, the adjusted finite element models were used to predict the behavior of similar integral abutment bridges in Pennsylvania. The finite element models included laterally loaded piles. Two-dimensional, 2D single bent models and 3D finite element models were implemented. Field measurements were compared to the results of the finite element models. For instance, the author claimed that laterally loaded pile models confirmed that inclusion of multi-linear soil springs created from $p-y$ curves is a valid approach for modeling soil-pile interaction within a finite element program. This statement must have originated by comparing the $p-y$ curves to the measured data from monitoring pile strains, soil pressure behind abutments, abutment displacement, abutment rotation, girder rotation, and girder strains. In addition, a weather station was constructed within the vicinity of the monitored bridge to capture environmental information including ambient air temperature, solar radiation, wind speed and direction, humidity, rainfall, and barometric pressure. According to the authors, the $2 \mathrm{D}$ and $3 \mathrm{D}$ numerical models were verified with the field data indicating that primary accommodation of superstructure expansion and contraction is through rotation 
of the abutment about its base rather than longitudinal translation. Also, the girder axial compressive forces developed during bridge expansion are influenced by both the stiffness of the backfill and by the girder location within the bridge. Normally for straight integral abutment bridge, there is no much difference between the displacement of the inner pile in comparison with the displacement of the outer pile, or the displacement of the inner edge of the abutment in comparison to the outer edge of the abutment. However, this is not the case in curved integral abutment bridges where there exists a difference between the displacement of the inner and the outer pile and the inner and outer edge of the abutment. Also, the author concluded that the connection between the girder and the abutment is not rigid and is best described as hinged. This conclusion came after observations from field measurements which shows that girder rotations are opposite of abutment rotations during bridge expansion and contraction.

In the work done by Breña et al. (2007), field monitoring of a straight integral abutment bridge constructed in Massachusetts, namely: Orange-Wendell Bridge, was carried on for a period of three years. The bridge construction temperature was taken as $19^{\circ} \mathrm{C}$ and the ambient temperature at the bridge site was recorded for three years starting 2002 and ending December 2004. The average measured ambient temperatures ranged between $-23^{\circ} \mathrm{C}$ and $35^{\circ} \mathrm{C}$ which correspond to maximum temperature decrease of $42^{\circ} \mathrm{C}$ and a maximum temperature increase of $16^{\circ} \mathrm{C}$ from the average reference construction temperature. This is in comparison to the Massachusetts Highway Department (MHD) Bridge Manual (1999) for the OW Bridge, which gave design temperature rise and fall to $+40^{\circ} \mathrm{C}$ and $-55^{\circ} \mathrm{C}$, respectively (Breña et al., 2007). This difference can be attributed to the design philosophy of the MHD which can consider the maximum and minimum anticipated design temperature for the bridge site for a long period of time such as 50 years return period and apply a statistical and probabilistic approach for such design temperature. For example, a 50-year return period value corresponds to 0.02 or $2 \%$ chance of this value being exceeded in any one year. Although the bridge is symmetric, differences have been observed in the displacement between the north and south abutment. The authors attributed this difference to the differences in construction conditions and to change in backfill properties and soil conditions. Additionally, the difference is more likely attributed to the difference in the in-situ soil 
conditions and or change in the soil properties such as the soil density with time as the bridge undergoes cycles of thermally induced displacements.

Albhaisi et al. (2012) investigated the effect of substructure stiffness on the performance of short and medium length steel integral abutment bridges built on clay under thermal loading effects. Detailed 3D finite element models were developed using LUSAS software and a parametric study was carried out. The girders, stiffeners, deck slab and the abutments were modeled as thick shell element, while the piles and the transverse diaphragms were modeled as thick 3D beam elements. Uncracked concrete properties were used to model all concrete members including prestressed concrete piles. From the study, the following conclusions were drawn by the researchers:

a) Clay stiffness was found to have a minor effect on the displacement of the top of the abutment.

b) Clay stiffness has significant role on the displacement of the pile. As the clay stiffness increases, the pile displacement decreases.

c) The displacement of the exterior portion of the abutment was greater than displacement of the interior portion of the abutment.

d) The exterior piles experienced bigger displacements, rotations and moments than the interior piles.

e) Pile orientation has a minor effect on the displacement at the top and bottom of the abutment.

f) Enclosure of the top part of the pile in a sleeve filled with loose sand or crushed stone reduces the stresses in the substructure and superstructure.

g) For short integral abutment bridges, prestressed concrete piles present a viable alternative to steel $\mathrm{H}$-piles, especially in harsh corrosive conditions.

Zhu et al. (2015) investigated the effect of superstructure temperature changes on stresses imposed on intermediate pier foundation in integral abutment bridges. In this study, a 4-span integral abutment bridge, namely New Trammel Creek Bridge located within the southcentral region of Kentucky in the southeast United States, was instrumented with temperature and bridge response remote-monitoring devices. The aim of this study was to measure superstructure temperature, pier deformations and foundation pressures to assess the suitability of AASHTO Procedure for Uniform Temperature Loading of the superstructure 
for an in-service integral abutment bridge (Zhu et al., 2015). In response to thermally-induced motions in the integral bridge, the bridge flexible piers undergo rotation. The pier rotations led to changes in bearing pressures beneath the footings under the intermediate bridge piers. The field measurements were done in parallel with developing a finite element model for the bridge. The field data results were used to calibrate the finite element model. According to the researchers, the following findings were established based on the bridge response values in the field and those that were generated by subjecting the bridge finite element model to combined gravity-temperature loading (Zhu et al., 2015):

a) The pier footings have been designed so that pressure is limited to approximately onehalf of the allowable soil bearing capacity.

b) AASHTO Procedure for Uniform Temperature Loading of the superstructure leads to conservative estimates of foundation design pressures for the New Trammel Creek Bridge.

c) The foundation bearing pressures attributed to temperature change can be significant relative to the pressure that is attributed to gravity loading.

Based on literature review, field inspections and a finite element analysis, Comisu \& Gheorghita (2010) drew the following conclusions:

a) The magnitude of the passive earth pressure developed by the movement of the abutment into the approach fill is displacement-dependent.

b) Using full passive pressure regardless of displacement is not conservative since it gives exaggerated values of the passive earth pressure which will not be developed in actual field conditions.

c) There exist several types of abutments such as stub and counterfort. The most desirable type of abutments, according to the author's point of view, is the stub type since it provides greater flexibility and offers least resistance to cyclic thermal movements.

d) Approach slabs are required for integral abutment jointless bridges. The length of the approach slab can vary from $3 \mathrm{~m}$ minimum to a maximum that is based on the intercept of a 1 on 1.5 lines from the bottom of the abutment excavation to the top of the highway pavement. 
Civjan et al. (2007) conducted finite element model on a three-span bridge in OrangeWendell, Massachusetts, USA, using GTSTRUDL software (Georgia Tech Research Corporation, 2002), followed by field observations. The researchers noted that abutment stiffness were not symmetric in the field. Abutment backfill degree of compaction varied between the north and south abutment. So, by varying the soil unit weight and angle of internal friction for the abutment backfill in the finite element model, two conditions of backfill materials were created, namely: loose and dense backfill. From the field observations and finite element models, the researchers drew the following conclusions:

a) In the expansion case, the abutment displacement is greatly affected by backfill degree of compaction and unit weight.

b) In the contraction case, the abutment displacement is greatly affected by the soil conditions and construction practices at the pile.

c) During bridge expansion, denser backfill results in greater abutment rotation and soil pressure behind the abutments.

d) Soil pressure behind the abutment is directly proportional to backfill unit weight. As the unit weight increase, the soil pressure behind the abutment increases.

e) Due to cyclic seasonal thermal loads, backfill and foundation soil undergo change in their properties.

In the work done by Civjan et al. (2016), a parametric study using SAP2000 Software was carried out to study the effect of pile orientation on the performance of straight and skewed single-span steel girder integral abutment bridges. The top and the bottom abutment displacements as well as bending moment were compared once when the H-piles were oriented about the weak or strong axes. From the model results, the researchers concluded that for the specific modeled bridge geometry, the optimal pile orientation is dependent on the expected thermal range and construction temperatures.

Rollins and Stenlund (2010) investigated pile-head fixity in the pile-abutment connection through the variation of embedment depth and steel reinforcement in concrete-filled shell piles. The aim of their research was to determine the relationship between connection details and lateral load capacity. Through numerical analysis and full-scale tests, the researchers found that embedment depth with cage reinforcement as shallow as 6 in., which is widely considered pinned in design, could develop around $50 \%$ of the pile moment capacity. Even 
without any reinforcement along the embedment length, Rollins and Stenlund (2010) showed that only with adequate embedment length such as 24 in., a concrete-filled shell pile connection can develop full moment capacity.

Frosch et al. (2006) instrumented and monitored two Indiana State integral abutment bridges, constructed using pre-cast pre-stressed concrete I-beam girders for several years. It was noticed that the abutment ratchet inward away from the fill. This resulted in higher contraction displacements of the foundation piles from their original position each year. The ratcheting appeared to slow down with time strongly indicating that shrinkage, primarily of the cast-in-place deck, was driving the observed contraction (Olson et al., 2013).

Frosch and Lovell (2011) investigated abutment-pile connections in the laboratory. It was concluded that increasing the embedment length of pile into the abutment wall from 15 in. to 24 in. improves the load-deformation performance. Additionally, Frosch and Lovell (2011) tested an $\mathrm{H}$-pile with spiral confining reinforcement surrounding the embedded portion and found that this configuration improved the lateral load capacity of the pile. The laboratory tests conducted by Frosch and Lovell (2011), in addition to experimental investigation carried by Talbott (2008) and Chovichien (2004), showed that pile-head displacements in the order of 2 in. could be accepted in integral abutment bridges. Beyond 2 in. and up to 4 in. of displacement at the pile head was possible on the grounds that this amount of displacement still maintain the pile within the acceptable damage range.

Frosch and Lovell (2011) also set the skew limit for skewed integral bridges to no more than $30^{\circ}$ on the argument that skew beyond $30^{\circ}$ causes undesirable and excessive pile's longitudinal and transverse displacements. Additionally skew can introduce biaxial bending in the piles. On the other hand, they stated that pile section, orientation and soil spring resistance were insignificant contributors to pile displacement. And as expected, the maximum displacement occurred at the acute corners of the skewed bridge for both the expansion and contraction cases.

Time-dependent behavior has been shown to be imperative in the design and construction of integral abutment bridges (Olson et al., 2013). Mainly, backfill soil and foundation soil properties are prone to change with cyclic loading as well as creep and shrinkage associated with concrete components in integral abutment bridges. 
The backfill pressure behind the abutment changes with thermal cycles. The backfill pressure may increase or decrease with thermal cyclic loading. Hassiotis and Xiong (2007) noted that during a 4-year field study of integral abutment bridge in New Jersey, USA, the backfill pressure behind an abutment increased with yearly thermal cycles. The researchers attributed this increase to densification of the backfill due to abutment displacement induced by thermal loading through the years.

Albaisi (2012) carried out a comprehensive research work through analyzing two real life integral abutment bridges using numerical models. Parametric study was carried out to investigate the effect of substructure stiffness on the behavior of integral bridges. The author concluded that the stiffness of foundation soil has a negligible effect on the top-abutmentdisplacement, but it has effect on the rotation along the abutment and the displacement of the piles. The top-pile-displacement is bigger under bridge contraction compared by pile displacement under expansion. Enclosure of the pile is reducing the stresses at the top of the pile, increasing the top-pile-displacement, reducing the rotation at the top of the pile, reducing stresses in the girders of short bridges build on stiff soils. Orientation of piles has a negligible effect on superstructure and substructure performance during bridge expansion, but has a notable effect during bridge contraction. Abutment height has negligible effect on the top-abutment-displacement, but it has significant effect on the abutment rotation. The top-pile-displacement is reduced by increasing abutment height.

In the report by Olson et al. (2013), it was stated that lowa State design approach for integral abutment bridge is completely different from that of Illinois State. Illinois State seeks to avoid yielding in integral abutment bridge piles while lowa State assumes that plastic hinge will form at the fixed connection to the pile cap. The primary objective of permitting pile plastic hinging is that once it occurs, the only additional moments induced in the piles from thermal loading are the second-order P- $\Delta$ effects of the axial loads (Olson et al., 2013). lowa integral abutment bridges utilized predrilled hole of no less than $3 \mathrm{~m}$ filled with bentonite slurry. This renders the pile unconfined in this $3 \mathrm{~m}$ length where the bentonite is assumed to provide no resistance to lateral pile movement (Olson et al., 2013).

Orienting the piles about their weak axes, in addition to the encasement of the top $3 \mathrm{~m}$ of the pile in bentonite slurry, provides sufficient flexibility in the substructure to greatly increase the allowable bridge length compared with design based on elastic pile behavior (Olson et al., 
2013). But this approach necessitates that other failure mechanism should be assessed, such as pile fatigue and flange local buckling. lowa State research indicated that pile fatigue could decrease flange local buckling capacity, causing flange local buckling to occur unexpectedly.

Tennessee State, on the other hand, has no explicit limits on integral abutment bridge length or skew. Each bridge design is unique owing to the specific site, road, and other conditions (Olson et al., 2013). Tennessee has similar approach to Illinois state approach to predrilled holes. Both states do not adopt predrilled holes approach, instead the soil confines the pile through its entire length up to the pile cap. But unlike lowa which orients the H-pile around the weak axis, Tennessee orients the piles about their strongest axes such that the web is parallel to the longitudinal axes of the road. The philosophy behind Tennessee inclination for orienting the piles around their strongest axes is to minimize the potential for concrete crushing within the abutment at the pile head. Another incentive for adopting the strong axes is that it alleviates to a great degree the potential for fatigue damage as indicated by the exhumation of several integral abutment bridge foundations in Tennessee, which showed no sign of fatigue damage.

The University of Tennessee at Knoxville conducted numerous full-scale tests of both $\mathrm{H}$-piles and concrete friction piles (Olson et al., 2013). From these tests, the following results were established:

a) Beam-column equation such as those in AASHTO is not accurate description of the state of the stresses within H-Pile and does not apply when the H-Pile is confined in soil. The axial load carrying capacity of the H-piles was virtually unchanged under extreme lateral loadings.

b) The piles in the study were able to develop plastic bending moments under large axial load. Normally in unconfined columns, the axial load carrying capacity for such a column decreases with the increase in the moment applied to the column or with the increase in the column slenderness.

c) The surrounding soil provided enough confinement which supported the column overall stability, preventing substantial reduction in its axial load carrying capacity.

Tests with 1-ft pile embedment into the abutment showed adequate performance of the connection for the anticipated displacement by Tennessee Department of Transportation. A test on a pile with 2-ft embedment into the abutment demonstrated significantly enhanced 
capacity for lateral deflection under axial load without loss of structural integrity (Olson et al., 2013). As such, a 2-ft pile embedment length is a common practice in Tennessee State Department of Transportation for integral abutment bridges. This embedment length would maintain integrity and stability for $\mathrm{H}$-piles under lateral loading. A 3-ft concrete encasement of $\mathrm{H}$-pile below the top of the pile cap is adopted for some integral abutment bridges in Tennessee. This is to enhance the stability and confinement in the region of the pile expected of having the maximum pile bending moment.

Adding to the ambiguity of the topic of the integral abutment bridges, LaFave et al. (2016) stated that Illinois Department of Transportation in 2012 has changed its design philosophy regarding integral abutment bridges in which longer lengths and larger skews were allowed. Also, changing the pile orientation from strong axes orientation to weak axes orientation which allow pile yielding and formation of plastic hinge at the pile head. The maximum length was previously $310 \mathrm{ft}$ for steel girders and $410 \mathrm{ft}$ for concrete girders. This was increased to $550 \mathrm{ft}$ for both bridge types. Also, the maximum abutment skew was $30^{\circ}$ which was later amended to $45^{\circ}$. Moreover, an Integral Abutment Pile Selection Chart was developed to facilitate pile design. The maximum pile size in the chart was considered HP14×117.

LaFave et al. (2016) carried out numerical simulations evaluating the behavior of steel Igirders integral abutment bridge, subjected to temperature changes. Bridge superstructure and substructure were modeled to determine various structure demands imposed by temperature changes. Non-linear bridge model was adopted. The analysis revealed that the bridge effective expansion length has a primary influence on bridge longitudinal movement under thermal loads regardless of bridge components. The results indicated that bridge superstructure response is elastic, while the bridge substructure response is inelastic. The superstructure and substructure response are influenced by effective expansion length, pile size, skew angle and the rotational restraint that the superstructure imposed on the substructure.

Quinn and Civjan (2017) carried out parametric study using 3D finite element model to explore the effects of thermal load on single-span straight IAB having different skewed angles and with various lengths. Three different thermal loads were considered. The authors concluded that the abutment piles orientation have little effect on longitudinal and transverse bridge displacements. However, resulting pile moment was dependent on pile orientation. 
Top-of-abutment displacement could be estimated using free expansion equation, while backfill soil and abutment piles affect abutment rotation and displacement at the abutment bottom. When introducing skew angle, the resulting critical moments were about the weak axis of abutment piles, irrespective of the orientation. Additionally, significant transverse moments in the pile were introduced. The construction temperature was a crucial factor affecting the moment introduced in abutment piles.

Literature review shows contradictory opinions about the location of the critical pile. Sherafati (2013) stated that it is the acute corner pile, while Quinn and Civjan (2017) reported that it is the obtuse corner pile, under contraction response of the bridge. Notable, the response was different in case of expansion. Under thermal expansion, the acute and obtuse corners displayed similar behavior. While under contraction, the two corners exhibit dissimilar behavior. Transverse pile moment from skew effect have to be considered when bridge skew angle is bigger than $15^{\circ}$. Similar conclusion was drawn by Civjan et al. (2014).

Civjan et al. (2013) studied the results collected from instrumenting and monitoring two straight bridges of length $40 \mathrm{~m}$. The bridges were single span I-girders and concrete deck, supported on piles. One of the bridges was skewed $15^{\circ}$. The authors highlighted that the maximum bottom-abutment displacement was about $1 / 3$ to $1 / 2$ of the values of topabutment displacement. Pile deformation response was predominantly elastic under bridge contraction, but highly non-linear under bridge expansion. The deformations are timedependent. No indication of either soil ratcheting or pile yielding were observed. Through the monitoring period of four years, a permanent offset of bridge abutment towards the backfill for straight IAB and straight bridge with skewed angle $15^{\circ}$ was reported. The movement of piles toward backfill during bridge expansion is not immediately recovered when bridge contracts. Therefore, subsequent thermal contraction result in concentration in curvature at the pile-abutment interface, associated with a higher bending moment under maximum bridge expansion. Under bridge contraction, the piles did not exhibit concentrated curvature of pile-abutment interface. Maximum backfill pressure, including construction pressure, was less than $40 \%$ of full passive earth pressure. Daily and seasonal performances of the bridge were similar.

Zhu et al. (2015) investigated the robustness of existing design provisions to quantify the effect of thermal stresses induced in a selected bridge case, on the bridge piers of IAB. The 
scope of research was achieved by instrumenting and monitoring 2-lane, multi-span, IAB, with bridge spans ranging from $24.4 \mathrm{~m}$ to $36.6 \mathrm{~m}$ in length. The bridge abutments were supported on H-piles, while the piers were supported on spread footings. All bridge foundations were resting on good-quality to high-quality limestone bed rock. Monitoring was carried out under gravity and thermal loads. Furthermore, the authors carried out numerical study through finite element analysis under induced thermal loading. The bridge deck was resting on precast/prestressed concrete beams. Due to the nature of IAB, the temperature-induced axial deformations in bridge deck generate stresses in superstructure elements. In the response to the span stress and temperature induced motion, the underlying bridge piers undergo rotations which lead to significant change in bearing pressure beneath spread footings of intermediate bridge piers. The study revealed that the available design provisions such as AASHTO temperature-loading provisions (2012) lead to conservative bridge foundation design.

La Fag et al. (2017) carried out field study on two steel I-girder IABs. The bridges were instrumented and monitored to validate assumptions of numerical models associated with the project and to provide further insight into IAB performance. The authors pointed out that the measured bridge expansion and contraction are less than the theoretical free expansion or contraction. The acute corner of the abutment demonstrated large-magnitude displacement due to thermal loading. The abutment pile at acute corner exhibited the highermagnitude strains.

La Fag et al. (2016) carried out parametric study on a steel I-girder IAB. The abutments were supported on $\mathrm{H}$-piles oriented with web perpendicular to the bridge longitudinal axis. Abutment skew ranged from $0^{\circ}$ to $45^{\circ}$. The authors revealed the following key results. Smaller end spans increased the superstructure rotational stiffness of the bridge. Pile strains and girder stresses increased by the increase of rotational restraint. The bridge deck width has small effect on the performance of straight $I A B$, but has significance as the skew angle increased in such a way that strain induced in piles increased. Stiffer backfill reliefs pile head loads, at the meantime increases superstructure load. Stiffer foundation soil increases pile strains due to restraining of pile deformation. Encasing of the top several meters of the pile in loose fill acts similar to pile in stratified soil with top softer layer. Arranging the abutment pile in such a way of placing pile both underneath each girder and in between produces an 
increase in the foundation stiffness. Pipe piles and strong axis-oriented $\mathrm{H}$-piles provide more lateral stiffness and produce more moment capacity. Deeper abutment results in reduced pile strain, at the meantime increases girder stress.

OLson et al. (2013) carried out a comprehensive parametric study using the finite element modeling (FEM) to investigate the performance of a 2-span, steel I-girder, IAB. The bridge abutments were supported on H-piles. The girders pass on rolling intermediate supports. The bridge is skewed $40^{\circ}$. The study included instrumentation and analysis of two IABs to investigate long-term response of the bridges and to validate the numerical model. The response of the bridge captured under thermal loading while the bridge in service. The research was primary focused on the performance of substructure resulted from thermal expansion and contraction. The authors offer the following conclusions. The performance of abutment pile disproportions with abutment skew angle. The authors recommend orienting the abutment $\mathrm{H}$-piles with webs parallel to the longitudinal axis of the bridge (strong-axis orientation). Furthermore, using compacted granular backfill behind abutments increases passive pressure induced on the abutment. Passive pressure is beneficial to passive resisting thermal expansion, except bridges with skews beyond $45^{\circ}$. Live loads imposed on IABs change the rotation of the bridge abutment and consequently affect thermally induced pile stresses. Concrete shrinkage may significantly affect maximum pile stresses in certain IAB configurations.

Arenas et al. (2013) carried out a research work focused on the performance of IAB with foundation piling in the backfill of Mechanically stabilized earth (MSE) walls that have U-back configuration. The authors used excel spreadsheet that quantifies the impact of thermal displacement in longitudinal direction and also in the transverse direction, when the abutment wall has a skew angle. The spreadsheet accommodates various parameters affecting the performance of the bridge. Both concrete and steel girders were considered. The authors emphasized that the spreadsheet calculates the increments of displacement, forces, moments and pressures on bridge components due to thermal displacements of IABs. Arsoy et al. (2002) investigated, through experimental large scale cyclic load tests and analytical studies, the complex soil-structure interaction that takes place between the structural components of an IAB and the adjoining Soil. The authors concluded that H-piles are most suitable for supporting abutment bridge. Concrete piles and pipe piles were too stiff 
in response to repeated lateral load, resulting tension cracks at pile-abutment connection. Additionally, a hinge at pile-abutment connection effectively reduces pile stresses by absorbing some of the rotational movement.

\subsubsection{Concluded Remarks}

Different conclusions were drawn concerning the maximum length limit of straight and skew integral abutment bridges due to interrelated parameters affecting this length. The maximum length limit is a function of the properties of bridge superstructure, bridge substructure, foundation soil, backfill soil supporting bridge abutment and geographic area.

The coefficient of thermal expansion of concrete is less than that of the steel. Therefore, concrete bridges are more suitable to be integrated with the abutment compared with steel bridges. But many other factors, such as construction time, available construction site, costeffective of the project and availability of construction material, may affect the suitability of the bridge type.

Most research work indicated that the effect of the orientation of steel H-piles on the displacement capacity of the bridge is negligible. However, piles oriented along the weak axis allow the pile to undergo higher stress and bigger horizontal displacement. The displacement capacity of the bridge is affected by stiffness of backfill soil, foundation soil, and flexural capacity of the piles. Variation of abutment thickness within the range of 1 to $1.5 \mathrm{~m}$ has negligible effect on the distribution and intensity of backfill soil pressure, while the height of the abutment has notable effect on backfill soil pressure distribution and intensity.

The lateral displacement of the pile is affected by the density of backfill soil placed around the pile in predrilled hole. The pile displacement is also affected by the depth of the hole and by the stiffness of foundation soil. However, enclosure of the top part of the pile in sleeve filled with loose sand reduces stresses imposed on substructure and superstructure. The recommended range of maximum length limit by agencies and researchers is 130 to $320 \mathrm{~m}$ for concrete bridges and 80 to $220 \mathrm{~m}$ for steel bridges according to the climate conditions. Foundation soil stiffness and backfill soil stiffness have appreciable effect on the thermalinduced displacement of the bridge. 
Bridge displacement capacity due to thermal loading increases with the increase of soil stiffness, backfill soil stiffness, pile size, with piles oriented in their strong axes and with the increase of abutment height. Abutment thickness has no effect on bridge displacement capacity. However, flexural capacity may control the displacement capacity of the bridge. Increase of bridge deck stiffness has negative effect on bridge displacement capacity.

The magnitude of backfill soil pressure developed due to thermal-induced displacement is abutment-displacement dependent and time dependent. Due to cyclic seasonal thermal loads, backfill soil and foundation soil undergo change in their properties.

Concrete-filled shell pile with 24 in. embedment into the abutment is adequate to develop full moment capacity. But if the embedment depth is only 6 in., the connection of pile with the abutment develops $50 \%$ of the pile moment capacity. Tennessee Transportation Department recommended 24 in. embedded depth of the pile into the abutment. The agency recommended 3-ft concrete encasement of $\mathrm{H}$-piles below the bottom of the abutment to enhance the stability and confinement in the region of the pile having the maximum bending moment. Skew angle of skewed bridges is limited to $30^{\circ}$ amended to $45^{\circ}$ by Tennessee agency. Transverse moment induced in the abutment piles have to be considered when abutment's skew angle is bigger than $15^{\circ}$.

\subsubsection{Curved Bridges}

\subsubsection{General}

Roeder and Moorty (1990) reported from field observations that thermal movement of a curved bridge is neither on the tangent nor on the chord direction. Juhl (1970) demonstrated that the interior bearing conditions of the bridge affect the displacement of boundary points. Theoretically, the movement at free support of the bridge will be in the chord direction from the fixed point. But this is not prevailing due to flexibility of the support point which may have thermal deflection and complicates the movement. Roeder and Moorty (1990) emphasized that directionally guiding devices at movable bearing are certain to be in a less than optimal direction. The researchers emphasized that for curved bridge, guiding devices must be strong on the supporting piers and the supporting elements must be relatively flexible. 
Thanasattayawibul (2006) carried out numerical analysis on a simulated single-span curved integral abutment bridge and concluded that curved bridges of smaller radius exhibited larger lateral displacement compared with bridges of larger radius. Lateral displacements of the curved bridge with $15.0 \mathrm{~m}$ span supported on abutment piles in predrilled hole are greater than that of a curved integral abutment bridge with piles without predrilled holes. The opposite takes place for $30 \mathrm{~m}$ bridge span. Lateral displacement of curved integral abutment bridge with $15.0 \mathrm{~m}$ span is greater than that of curved bridge with $30.0 \mathrm{~m}$ span due to the effect of self-weight of the bridge. A temperature increase of $30^{\circ} \mathrm{F}$ resulted in an increase of both the stresses in the piles and lateral displacement of the bridge superstructure. The increase in stress in piles of the curved bridge with $15.0 \mathrm{~m}$ span is greater than that of a similar bridge but with $30.0 \mathrm{~m}$ span. Also, the stress increase in piles for $15.0 \mathrm{~m}$ span bridge and smaller radius is greater than that for a similar bridge of larger radius.

Thanasattayawibul et al. (2014) reported that the radius of curvature of integral abutment bridge have significant role in their design and construction. The concentration of stresses in piles increases with the decrease of the radius of curvature for bridge lengths up to $91 \mathrm{~m}$. The same observation was noted for pile, in drilled hole for bridge length up to $122 \mathrm{~m}$. Beyond those bridge lengths, the maximum stress intensity in the piles increased with the increase of the radius of curvature. Pile stress intensity reduction due to the increase in number of spans with a smaller radius integral abutment bridge is greater than that of curved integral abutment bridge with larger radius. The author considered single span bridge in his study and the obtained results are comparative in nature.

Kalayci et al. (2012) investigated the thermal behavior of a horizontally curved integral abutment bridge using the finite element method. The self-weight of the two-span bridge was considered. The abutments were U-shape type. The authors found that, as the curvature of the bridge $(1 / R)$ increased, longitudinal displacement, earth pressure acting on bridge abutment and weak axis bending moment of abutment piles decreased. Meanwhile, the lateral displacement of the bridge increased. Under positive temperature, loose sand backfill resulted in decrease in backfill pressure and relieved abutment pile-head movements.

Horizontal curvature of the bridge includes large amount of complexity in the response of curved integral abutment bridge, in addition to the inherent uncertainties in design and construction. Due to this complicated issues, bridge designer adopt conservative approach in 
their design (Doust, 2011). Due to this complexity in curved integral abutment bridge design, Burke (2009) set a limitation of the curvature of the bridge to $5^{\circ}$ as a sort of conservatism. But Maruri and Petro (2005) set a limitation of $10^{\circ}$ for the curvature of steel and concrete bridges. Arockiasamy and Sivakumar (2005) set a limitation for the radius of curvature to be more than $374 \mathrm{~m}$.

Doust (2011) emphasized the problems associated with bridge displacement. These problems are explained as follows. The end displacements are not in the same direction and resultant values should be used. The change in bridge length occurs in a curved line. The end displacement is not resulted from changes in bridge length only, but also from rotation of the bridge ends. The authors emphasized not only temperature change, shrinkage and creep but also all loads participate in displacing the bridge ends. The bridge width also affects the total bridge displacement.

Doust (2011) concluded that the bridge end displacement is not just a function of seasonal temperature changes but also due to earth pressure imposed on the abutment. The magnitude and direction of the bridge end displacement are unknown. Furthermore, rotation of the abutment due to all loads acting on the bridge should be considered as a source of displacement at the pavement level. Doust (2011) developed a relation between the bridge displacements and the shortening due to contraction and shrinkage. Doust concluded that the bridge width affects the direction of bridge end displacement. Doust developed closedform solutions for the effect of bridge width on the direction of displacement due to contraction and shrinkage. He stated that abutment piles should be oriented so that the strong axis of the piles is perpendicular to the direction of maximum displacement. Doust (2011) emphasized that for a horizontally curved integral abutment bridge longer than a specified length, the internal forces, which are a measure of bridge expansion, are smaller than those included in straight integral abutment bridge of similar length. The specified length is dependent on bridge curvature. Doust (2011) stated that there is no apparent direct relationship between abutment pile movements and the bridge radius or length under the effect of live loads.

Greimann et al. (2014) provided a comprehensive report dealing with horizontally curved integral abutment bridges. The authors reported the method of analysis of horizontally curved integral abutment bridges and the common design methods. The authors stated that 
upon personnel interview from six USA State Agencies, none of them have any evidence of bridge performance associated with thermal expansion.

The authors inspected two bridges in USA, and monitored the behavior of six integral and semi-integral bridges under the effects of live load (truck load) and thermal load. In addition, one of the monitored bridges was selected for detailing analysis using the finite element method, following AASHTO LRFD Specifications (2010).

The authors reported that there was no appreciable difference in the behavior of horizontally curved integral abutment bridges and straight integral abutment bridges of similar length. The same conclusion was drawn by Doust (2011), but with little difference. Thermal strain in integral abutment bridges and semi-integral abutment bridges were not noticeable. The simulation of abutment piles as cantilevers fell short of accuracy. Backfill pressure was below approximate passive soil pressure. The stress in the girders varied with changes in skew angle and the curvature of the bridge.

McBride (2013) studied the effect of thermal loading in curved I-girder bridges. In his study a curved semi-integral bridge, namely: Buffalo Creek Bridge, was modeled using ADINA software. Since the bridge was curved, the constraints on the girder bottom flanges act in a different direction for each individual bearing at each individual location. Therefore, McBride used individual skewed coordinate systems, which were applied to the appropriate nodes. This was done so that the boundary conditions were applied in the correct direction locally at the bearings and not just in the global coordinate systems. This would ensure that the longitudinal direction is along the centerline of the bottom flange and the transverse direction is perpendicular to this centerline. A similar approach was adopted in modeling the finite element models of this study.

Deng et al. (2015) investigated the behavior of curved and skewed steel girder bridge with integral abutment through numerical analysis and field monitoring. One lane, three-span, horizontally-curved IAB was instrumented and monitored to capture the bridge performance under thermal loading. Parametric study was carried out to investigate the influence of curvature and skew on the performance of the bridge. It was found that stresses in girders were affected by changes in curvature and skew angle. The authors also pointed out that curved and skewed bridges with $10^{\circ}$ skew angle and with radial arc span length-to-radius 
ratio, $L / R$, of 0.06 can be designed as straight bridges if a $10 \%$ increase is applied to the total induced stress.

\subsubsection{Concluded remarks}

Thermal movement of a curved bridge is neither on the tangent direction nor in the cord. The interior bearing conditions of the bridge affect the displacement of boundary points in magnitude and direction. Directional guiding devices at movable bearings are certain. The guiding devices must be strong or the supporting piers and the supporting elements must be relatively flexible.

The lateral displacement of single-span horizontally integral abutment bridge is inversely proportional with the radius of the bridge and with the bridge span length. While longitudinal displacements, backfill earth pressure, weak axis bending moments are proportional with the radius of the bridge. Predrilled abutment piles increased the lateral displacement of curved integral abutment bridge. The researchers attempted to correlate the response of horizontally curved integral abutment bridge with the response of straight integral abutment bridge. These attempts were carried out through the correlation of bridge length of the curved bridge with the limit of the skew angle and with the limit ratio between radian arc span length to radius of the bridge.

Stresses induced in the abutment pile of single-span horizontally curved integral abutment bridge are inversely proportional with bridge radius, for bridges having bridge span less than $15 \mathrm{~m}$. For bridges of span length $30 \mathrm{~m}$, stresses induced in piles are in proportion with the bridge radius.

The radius of curvature of single-span horizontally curved integral abutment bridge has significant role in their design and construction. Concentration of stresses in abutment piles increases with the decrease of the radius of curvature for bridge lengths up to $91.0 \mathrm{~m}$. The same trend is observed for piles in drilling hole up to length $122.0 \mathrm{~m}$. Beyond these bridge lengths, the maximum stress intensity increases with the increase of the radius of curvature. Abutment pile stress's intensity reduction is due to the increase in number of spans with smaller radius of horizontally curved integral abutment bridge. 
Horizontally curved bridge induces large amount of complexity in their performance in addition to inherent uncertainties in design and construction. As a result, different agencies and designers set a limitation for bridge length and skew angle (FHW, 1980; Burke, 1993; BD 57/01, 2001; Arockiasamy and Sivakumar, 2005). The problems observed with the end displacements are:

- The bridge displacements are not in the same direction to be added.

- Change in bridge length occurs in a curved line.

- The end displacements of the bridge result from temperature variation, rotation due to all loads acting on the bridge, creep, shrinkage, and earth pressure imposed on the abutment.

- The bridge width affects the magnitude and direction of bridge displacement.

- Different opinions between researchers were observed about the orientation of abutment piles. There is doubt about the comparison condition by researchers between the response of curved and straight integral abutment bridge of the same length.

The above review revealed that the concept of thermal loading on horizontally curved integral abutment I-girder bridge has received very little attention from researchers (McBride, 2013), even though the bridges inherent major uncertainties. Therefore, the research work presented in this thesis is devoted to an attempt to assess the bridge length limit which produces a maximum displacement of $40.0 \mathrm{~mm}$ at pile heads, which is the displacement capacity of the piles to maintain their elastic response.

\subsection{INTEGRAL ABUTMENT BRIDGE}

\subsubsection{General}

Integral bridges are generally single-span or multi-span bridges with a deck and without expansion joints. The bridge deck is supported on abutments in case of single-span bridge, and on abutments and piers in case of multi-span bridges. The abutments and piers may be supported on piles or on competent soil. The components of the bridge, which are the deck, the abutments, the piers, the supporting piles and the approach slab, interact with each other and with the tangible and non-tangible components of the host environment. Tangible 
components are the foundation, soil, backfill and road base. Non tangible component is the thermal effect on the structure, which is responsible for soil-structure interaction.

\subsubsection{Use of Integral Abutment Bridge (IAB)}

As a result of lower construction and maintenance cost, the concept of $I A B$ is increasingly being used. The acceptable limiting lengths of IAB vary between countries and regions. In UK, the acceptable bridge span is up to $60 \mathrm{~m}$ (BD 57/01, 2001). IAB were in use in 41 American States, based on survey carried by Paraschos and Amde (2011). IABs are becoming more popular in Europe (White, 2007). The proportion of IAB in UK is about 64\% in 2004 (ILES, 2006).

\subsubsection{Integral Abutment Bridge Problems}

The stresses and strains within the components of the IAB result from self-weight of the bridge, live load, wind load, secondary loads, such as: concrete creep and shrinkage. Such loads generate cyclic stresses and strains in the backfill and foundation soil and the superstructure. The effects of thermal loads on IABs components are comparable to those caused by live loads (Lawver et al., 2000; Paul et al., 2005). Expansion and contraction of IABs have been the primary cause of soil-structure interaction problems between the abutment and the backfill soil.

Movement of the abutment due to thermal induced expansion of the deck is resisted by the abutment stiffness, mobilized earth pressure in the backfill, friction between abutment wall and backfill, friction between abutment and foundation soil, stiffness of supporting piles (Lawver et al., 2000; Knickerbocker et al., 2003). Accordingly, thermal movement of IAB is of primary consideration in IAB design.

Furthermore, changes in backfill properties with time impact the performance of bridge components. The calculation of earth pressure imposed on bridge abutment inherents uncertainties. Thermal daily cyclic induced movements, superimposed on seasonal cyclic movements on the bridge abutment, produce time-dependent performance of the bridge. 


\subsubsection{Advantages of IAB}

The advantages of IAB include lowering construction and maintenance costs, improving seismic performance, reducing number of piles required for foundation support, improving riding quality, and improving construction procedure with shorter construction time (Darley et al., 1998; Carder and Hayes, 2000; Mistry, 2005; Arockiasamy and Sivakumar, 2005; Burkem, 2009; Davids et al., 2010).

\subsubsection{Limitation of IAB}

Temperature-induced cyclic movement of the abutment can cause settlement or heave of the backfill behind the abutment resulting in either a gap or bump near the abutment and the approach slab. Due to daily cyclic movement imposed on seasonal cyclic movement of the abutment, a complex soil-structure interaction is formed. Therefore, the backfill actual characteristics in the bridge analysis and design inherent uncertainties (Xu, 2006; Zordan et al., 2011; Faraji et al., 2001).

The supporting piles can be subjected to a considerable flexural stress, since the piles resist the thermal induced displacement (Lawver et al., 2000; Arsoy et al., 2002). There is no rational guideline to calculate the distribution and intensity of lateral earth pressure imposed on the abutment due to thermal induced displacement and the effect of the pile-soil system (Dicleli and Albhaisi, 2004c; Dicleli and Erhan, 2010; Kim and Lamon, 2010). Integral abutment bridges with skewed or curved geometry tend to rotate under the effect of cyclic earth pressure acting on the abutment (Hoppe and Gomez, 1966; Arsoy et al., 1999).

\subsubsection{Geotechnical Issue with IAB}

Integral abutment bridge (IAB) is a favorable selection for construction, even though it encounters geotechnical problems which have to be considered in the design. The cyclic earth pressure of soil supporting the abutment, due to daily changes in temperature and the magnitude of lateral earth pressure, can approach or exceed the passive value in summer time, when the bridge expansion is in the high range. The bridge abutment should be designed to withstand this lateral earth pressure. Choudhary et al. (2002) pointed out that failure in the $I A B$ happened due to the ratcheting of soil behind the abutment. Soil ratcheting was confirmed by Hassiotis et al. (2006) and Xu et al. (2007). Horvath (2000) proposed the use of geofoam to 
overcome partly the settlement of pavement surface behind the abutment and the tending toward ratcheting behavior. Furthermore, Burke (2009) set a limitation and reported a guidelines to avoid passive earth pressure and limit pile stresses.

Xu et al. (2007) carried out an experimental work on stiff clay backfill behind IAB. The results show that daily and annual temperature changes can cause significant horizontal stress variations behind the abutment. The results also show no build-up in lateral earth pressure due to temperature-induced cyclic loading. Additionally, stress-strain and stiffness behavior were not influenced by continued cycles of thermal loading.

During the deck expansion of $I A B$, the imposed displacement makes the abutment move towards the supporting soil. This movement is a mixed one with rotational and translational components. The mode of abutment movement depends on the flexural stiffness ratio of superstructure and substructure. During the movement of abutment towards the supporting soil due to expansion of bridge deck, lateral earth pressure increases. While during movement of abutment in opposite direction due to contraction of bridge deck, active lateral earth pressure develops and active soil wedge may be formed. In the subsequent summer, the bridge deck expands and the abutment moves towards the supporting soil, but the soil displacement is not fully recovered due to the inelastic nature of soil. Subsequently, the abutment position will not be recovered. This is the main reason for long-term inwards abutment position.

Razmi et al. (2014) pointed out that the displacement of the piles supporting the bridge depends upon the temperature difference, during expansion or contraction, length of the bridge, type of the bridge deck, and restraints provided and the substructure. Piles exhibit either cyclic elastic or cyclic plastic deformation. Cyclic elastic deformation results in highcyclic fatigue, whereas plastic deformation results in low-cyclic fatigue. Therefore, lateral displacement of the piles is a crucial aspect in IAB design.

Griton et al. (1991), Jorgensen (1983), Lawver et al. (2000), and Razmi et al. (2014) concluded that a linear relationship has been found between the length of the bridge and the lateral displacement of piles oriented in a way that the bending occurs about their strong axis, due to seasonal and daily temperature variation. Bloodworth et al. (2012) provided a method of calculating the effect of thermal cycling on lateral earth pressure imposed on IAB using the 
resulting cyclic triaxial test in a numerical model. The authors reported that wall friction have no significant effects on predicted lateral pressure.

\subsubsection{Pile Orientation}

Razmi et al. (2014) quoted that a survey conducted by Maruri and Petro (2005) revealed that $33 \%$ of U.S. States orient the piles with the strong axis parallel to the centerline of the bearing, $46 \%$ of the States oriented the piles with the weak axis parallel to the centerline of the bearing, $8 \%$ of the States leave the issue to the decision of the engineer and $13 \%$ of the States do not provide a comment. Dicleli and Albhaisi (2003) reported that fatigue life is longer in piles oriented with strong axis parallel to the centerline of bearing. Dicleli and Albhaisi (2004) reported that the cyclic displacement of the pile decreases considerably as the foundation soil becomes stiffer and consequently the maximum length limit for IAB decreases. The effect of pile orientation on the displacement capacity of IAB is negligible.

\subsubsection{Maximum Length Limit}

The maximum length limit (MLL) of the IAB given by research agencies inherent uncertainties. From theoretical approach, Dicleli and Albhaisi (2004) obtained the MLL. But the approach treated the pile as cantilever with critical length defined as: $L_{c}=4 \sqrt[4]{\frac{E_{p} I_{p}}{K_{h}}}$

where $E_{p}$ is the Young's modulus of pile material, $N / \mathrm{m}^{2}, I_{p}$ is the moment of inertia of the pile, $\mathrm{m}^{4}, \mathrm{~K}_{\mathrm{h}}$ is the coefficient of subgrade reaction, $\mathrm{N} / \mathrm{m}^{2} / \mathrm{m}$. The authors considered linear distribution of bending moment $(\mathrm{M})$ along the pile with $\mathrm{M}$ equals to maximum cyclic moment at the pile head which equals to fatigue failure moment. The displacement capacity of the

pile was obtained and hence, the maximum length limit of the bridge was assessed. The procedure inherits lots of uncertainties.

Diceli and Albhaisia (2004) and Nikravan (2013) reported maximum length limit for IAB used by different agencies as shown in Tables 1.1 through 1.4. Notably, the MLLs are not rational and are limited in regions with specified temperature. Nevertheless, these lengths lack the type of backfill behind abutment, foundation soil, the characteristic of supporting pile and the height of the abutment. 
Nikravan (2013) conducted a parametric study, using the three-dimensional finite element modeling, to determine the limiting span of integral abutment bridges in straight and skew alignments under temperature variations in the Canadian environment. His study resulted in empirical expressions of the limiting span lengths listed in Table 1.5 for steel I-girder bridges and Table 1.6 for concrete I-girder bridges, as a function of abutment height, skew angle and H-pile size.

Table 1.1 Maximum Length Limit in Moderate and Cold Climates (Dicleli and Albhaisia, 2004)

\begin{tabular}{|c|c|c|c|c|}
\hline \multirow{2}{*}{$\begin{array}{c}\text { Pile } \\
\text { Size }\end{array}$} & \multicolumn{2}{|c|}{ Steel Bridge } & \multicolumn{2}{c|}{ Concrete Bridge } \\
\cline { 2 - 5 } & Moderate Climate & $\begin{array}{c}\text { Cold Climate } \\
\text { L (m) }\end{array}$ & $\begin{array}{c}\text { Moderate } \\
\text { Climate } \\
\text { L (m) }\end{array}$ & $\begin{array}{c}\text { Cold Climate } \\
\text { L (m) }\end{array}$ \\
\hline HP $310 \times 125$ & 220 & 145 & 320 & 265 \\
\hline HP $310 \times 110$ & 205 & 135 & 300 & 250 \\
\hline HP $250 \times 85$ & 160 & 110 & 240 & 195 \\
\hline HP $200 \times 63$ & 125 & 80 & 180 & 150 \\
\hline
\end{tabular}

Table 1.2 Maximum Length Limit for IAB (Dicleli and Albhaisi, 2004)

\begin{tabular}{|c|c|c|}
\hline Department & Steel Bridge $\mathbf{L}(\mathbf{m})$ & Concrete Bridge $\mathbf{L}(\mathbf{m})$ \\
\hline Colorado & 195 & 240 \\
\hline Illinois & 95 & 125 \\
\hline New jersey & 140 & 100 \\
\hline Ontario, Canada & 100 & 244 \\
\hline Tennessee & 152 & 107 \\
\hline Washington & 91 & \\
\hline
\end{tabular}


Table 1.3 Integral Abutment Bridge Length Limit for Small Skew Angle (Nikravan, 2013)

\begin{tabular}{|c|c|c|c|}
\hline $\begin{array}{c}\text { State } \mathbf{P} \\
\text { Province }\end{array}$ & Steel Bridge $\mathbf{L}(\mathbf{m})$ & Concrete Bridge $\mathbf{L}(\mathbf{m})$ & Skew Angle $\mathbf{~}^{\circ}$ ) \\
\hline Alberta & 90 & 120 & 20 \\
\hline Colorado & 195 & 240 & 30 \\
\hline lowa & 122 & 175 & 30 \\
\hline Missouri & 130 & 183 & 30 \\
\hline New York & 200 & 200 & 20 \\
\hline Ontario & 150 & 150 & 30 \\
\hline South Dakota & 107 & 214 & 30 \\
\hline Tennessee & 152 & 358 & 20 \\
\hline Vermont & 119 & 210 & 30 \\
\hline
\end{tabular}

Table 1.4 Integral Abutment Bridge Length Limit for Large Skew Angle (Nikravan, 2013)

\begin{tabular}{|c|c|c|c|}
\hline $\begin{array}{c}\text { State / } \\
\text { Province }\end{array}$ & Steel Bridge $\mathbf{L}(\mathbf{m})$ & Concrete Bridge $\mathbf{L}(\mathbf{m})$ & Skew Angle $\left.\mathbf{(}^{\circ}\right)$ \\
\hline Georgia & 79 & 79 & $30-40$ \\
\hline Missouri & 130 & 183 & $30-45$ \\
\hline New York & 200 & 200 & $30-45$ \\
\hline Ontario & Not allowed & Not allowed & $30-45$ \\
\hline South Dakota & 107 & 214 & $30-35$ \\
\hline Tennessee & 152 & 358 & $30-45$ \\
\hline
\end{tabular}

FHW technical advisory (1980) issued the following recommendations for integral-no-joint structure.

Length limit: $\quad 91.4 \mathrm{~m} \quad$ (for steel)

$152.4 \mathrm{~m}$ (for poured-in- place concrete)

$182.4 \mathrm{~m} \quad$ (for prestressed concrete)

Burke (1993) recommended the following primary limitations to minimize the secondary effects: 
Bridge length less than $91 \mathrm{~m}$;

Bridge span less than $24 \mathrm{~m}$;

Skew less than $30^{\circ}$;

Curvature less than $30^{\circ}$; and

Settlement of supports less than $1 / 1000$ of the span length.

BD 57/01 (2001) state that bridge with length not exceeding $60 \mathrm{~m}$ and skews not exceeding $30^{\circ}$ can be designed as integral with abutments.

CHBDC S6-14 (2014) stated that the jointless superstructure of limited back wall height using integral pile-supported end diaphragm or semi-integral abutment may be designed longer than the $60 \mathrm{~m}$ limit specified in BD 57/01.

\subsubsection{Displacement Capacity of H-Piles}

Dicleli and Albhaisi (2004) reported that the stiffness of the foundation soil has a remarkable effect on the maximum temperature-induced displacement, $\Delta \mathrm{P}$, that steel $\mathrm{H}$ - pile can accommodate. The displacement capacity of the piles decreased as the stiffness of foundation soil increased. The ratio of the displacement capacities of the same pile driven in loose and dense sand ranged between 2.3 to 2.7 depending on pile size and orientation.

The pile displacement capacity depends upon the pile-abutment connection. Pinned connection increases the cyclic displacement capacity of the piles. The pile displacement capacity of pinned case is about three times that for the fixed case, for loose sand. The ratio becomes about six times for soft clay. 
Table 1.5 Allowable Length and Skew Combinations for Steel Integral Abutment Bridges (Nikravan, 2013)

\begin{tabular}{|c|c|c|c|c|}
\hline \multirow{2}{*}{$\begin{array}{l}\text { Abutment } \\
\text { Pile } \\
\text { Connection }\end{array}$} & \multirow{2}{*}{$\begin{array}{l}\text { Skew } \\
\text { Angle, } \theta \text {, } \\
\text { (Degrees) }\end{array}$} & \multicolumn{3}{|c|}{ Maximum Length, L, (m) } \\
\hline & & HP200X 53 & HP $250 \times 85$ & HP $310 \times 110$ \\
\hline \multirow[t]{2}{*}{ Fixed } & $0 \leq \theta \leq 20$ & $\mathrm{~L}=-0.4 \mathrm{H}^{2}+11 \mathrm{H}+85$ & $\mathrm{~L}=-0.4 \mathrm{H}^{2}+11 \mathrm{H}+105$ & $L=-0.4 \mathrm{H}^{2}+11 \mathrm{H}+145$ \\
\hline & $\begin{array}{c}20 \leq \\
\theta \leq 60\end{array}$ & $\begin{array}{l}\mathrm{L}=\left[\left(-0.01 \Theta^{2}-1.675 \theta\right)\right. \\
\left.+\left(-0.4 \mathrm{H}^{2}+11 \mathrm{H}+123\right)\right] \\
{[1-0.03(\mathrm{n}-2)]}\end{array}$ & $\begin{array}{l}\mathrm{L}=\left[\left(-0.01 \theta^{2}-1.675 \theta\right)\right. \\
\left.+\left(-0.4 \mathrm{H}^{2}+11 \mathrm{H}+138\right)\right] \\
{[1-0.03(\mathrm{n}-2)]}\end{array}$ & $\begin{array}{l}\mathrm{L}=\left[\left(-0.01 \Theta^{2}-1.675 \theta\right)\right. \\
\left.+\left(-0.4 \mathrm{H}^{2}+11 \mathrm{H}+178\right)\right] \\
{[1-0.03(\mathrm{n}-2)]}\end{array}$ \\
\hline \multirow[t]{2}{*}{ Hinged } & $0 \leq \theta \leq 20$ & $\mathrm{~L}=-0.4 \mathrm{H}^{2}+11 \mathrm{H}+125$ & $\mathrm{~L}=-0.4 \mathrm{H}^{2}+11 \mathrm{H}+145$ & $\mathrm{~L}=-0.4 \mathrm{H}^{2}+11 \mathrm{H}+185$ \\
\hline & $\begin{array}{c}20 \leq \\
\theta \leq 60\end{array}$ & $\begin{array}{l}\mathrm{L}=\left[\left(-0.037 \Theta^{2}+0.008 \theta\right)\right. \\
\left.+\left(-0.4 \mathrm{H}^{2}+11 \mathrm{H}+139.5\right)\right] \\
{[1-0.03(\mathrm{n}-2)]}\end{array}$ & $\begin{array}{l}\mathrm{L}=\left[\left(-0.037 \Theta^{2}+0.008 \Theta\right)\right. \\
\left.+\left(-0.4 \mathrm{H}^{2}+11 \mathrm{H}+159.5\right)\right] \\
{[1-0.03(\mathrm{n}-2)]}\end{array}$ & $\begin{array}{l}\mathrm{L}=\left[\left(-0.037 \Theta^{2}+0.008 \Theta\right)\right. \\
\left.+\left(-0.4 \mathrm{H}^{2}+11 \mathrm{H}+199.5\right)\right] \\
{[1-0.03(\mathrm{n}-2)]}\end{array}$ \\
\hline
\end{tabular}

Note: $\mathrm{n}=$ number of design lanes, $\mathrm{H}=$ abutment height in meter $(1 \mathrm{~m} \leq \mathrm{H} \leq 6 \mathrm{~m})$.

Table 1.6 Allowable Length and Skew Combinations for Concrete Integral Abutment Bridges (Nikravan, 2013)

\begin{tabular}{|c|c|c|c|c|}
\hline \multirow{2}{*}{$\begin{array}{l}\text { Abutment } \\
\text { Pile } \\
\text { Connection }\end{array}$} & \multirow{2}{*}{$\begin{array}{c}\text { Skew } \\
\text { Angle, } \theta \text {, } \\
\text { (Degrees) }\end{array}$} & \multicolumn{3}{|c|}{ Maximum Length, L, (m) } \\
\hline & & HP200 X 53 & HP $250 \times 85$ & HP $310 \times 110$ \\
\hline \multirow[t]{2}{*}{ Fixed } & $0 \leq \theta \leq 20$ & $\mathrm{~L}=-0.4 \mathrm{H}^{2}+11 \mathrm{H}+145$ & $\mathrm{~L}=-0.4 \mathrm{H}^{2}+11 \mathrm{H}+165$ & $\mathrm{~L}=-0.4 \mathrm{H}^{2}+11 \mathrm{H}+205$ \\
\hline & $20 \leq \theta \leq 60$ & $\begin{array}{l}\mathrm{L}=\left[\left(-0.037 \Theta^{2}+0.008 \theta\right)\right. \\
\left.+\left(-0.4 \mathrm{H}^{2}+11 \mathrm{H}+159.5\right)\right] \\
{[1-0.03(\mathrm{n}-2)]}\end{array}$ & $\begin{array}{l}\mathrm{L}=\left[\left(-0.037 \Theta^{2}+0.008 \theta\right)\right. \\
\left.+\left(-0.4 \mathrm{H}^{2}+11 \mathrm{H}+179.5\right)\right] \\
{[1-0.03(n-2)]}\end{array}$ & $\begin{array}{l}\mathrm{L}=\left[\left(-0.037 \Theta^{2}+0.008 \theta\right)\right. \\
\left.+\left(-0.4 \mathrm{H}^{2}+11 \mathrm{H}+219.5\right)\right] \\
{[1-0.03(\mathrm{n}-2)]}\end{array}$ \\
\hline \multirow[t]{2}{*}{ Hinged } & $0 \leq \theta \leq 20$ & $\mathrm{~L}=-0.4 \mathrm{H}^{2}+11 \mathrm{H}+165$ & $\mathrm{~L}=-0.4 \mathrm{H}^{2}+11 \mathrm{H}+205$ & $\mathrm{~L}=-0.4 \mathrm{H}^{2}+11 \mathrm{H}+245$ \\
\hline & $20 \leq \theta \leq 60$ & $\begin{array}{l}\mathrm{L}=\left[\left(-0.031 \Theta^{2}-1.029 \Theta\right)\right. \\
\left.+\left(-0.4 \mathrm{H}^{2}+11 \mathrm{H}+199.3\right)\right] \\
{[1-0.03(\mathrm{n}-2)]}\end{array}$ & $\begin{array}{l}L=\left[-0.031 \Theta^{2}-1.029 \theta+(-\right. \\
\left.\left.0.4 H^{2}+11 H+239.3\right)\right][1- \\
0.03(n-2)]\end{array}$ & $\begin{array}{l}\mathrm{L}=\left[-0.031 \Theta^{2}-1.029 \theta\right. \\
\left.+\left(-0.4 \mathrm{H}^{2}+11 \mathrm{H}+289.3\right)\right] \\
{[1-0.03(\mathrm{n}-2)]}\end{array}$ \\
\hline
\end{tabular}

Note: $\mathrm{n}=$ number of design lanes, $\mathrm{H}=$ abutment height in meter $(1 \mathrm{~m} \leq \mathrm{H} \leq 6 \mathrm{~m})$. 
Table 1.7 Summary of Behavior of Piles Supporting Full Integral Abutment Bridges (Arsoy et al., 2002)

\begin{tabular}{|c|c|c|c|}
\hline Bridge & Reference & $\begin{array}{l}\text { Maximum } \\
\text { Pile Stress } \\
\text { (\% of } \\
\text { Nominal } \\
\text { Yield) }\end{array}$ & Remarks \\
\hline $\begin{array}{c}\text { The Cass County } \\
\text { Bridge }\end{array}$ & $\begin{array}{l}\text { Jorgensen } \\
\text { (1983) }\end{array}$ & 100 & $\begin{array}{l}\text { Strain gages failed. Author estimated } \\
\text { stresses based on analytical methods and } \\
\text { concluded that maximum pile stresses were } \\
\text { around the yield stress, and that plastic } \\
\text { hinge formation in piles was not possible. } \\
\text { Piles were able to tolerate } 2 \text { inches of bridge } \\
\text { contraction and about } 3 \text { inches of total } \\
\text { displacement without damage. }\end{array}$ \\
\hline $\begin{array}{c}\text { The Boone River } \\
\text { Bridge }\end{array}$ & \multirow{2}{*}{$\begin{array}{l}\text { Griton et al. } \\
\text { (1991) }\end{array}$} & $60+$ & $\begin{array}{l}\text { Piles were able to tolerate } 1.2 \text { inches of } \\
\text { bridge contraction and about } 2 \text { inches of } \\
\text { total displacement without damage. }\end{array}$ \\
\hline $\begin{array}{c}\text { The Maple River } \\
\text { Bridge }\end{array}$ & & $75+$ & $\begin{array}{l}\text { Piles were able to tolerate } 1.6 \text { inches of } \\
\text { bridge contraction and about } 2.5 \text { inches of } \\
\text { total displacement without damage. }\end{array}$ \\
\hline $\begin{array}{c}\text { Rochester } \\
\text { Minnesota Bridge }\end{array}$ & $\begin{array}{l}\text { Lawver et al. } \\
(2000)\end{array}$ & 100 & $\begin{array}{l}\text { Piles were able to tolerate } 0.65 \text { inches of } \\
\text { bridge contraction and } 1.06 \text { inches of total } \\
\text { displacement without damage. }\end{array}$ \\
\hline
\end{tabular}

Pile orientation with stub abutment has little effects on the pile displacement capacity, within $15 \%$ in case of piles in clay and $20 \%$ in case of piles in sand. The displacement capacity of the pile increases with the increase of the pile size. Also, the displacement capacity of the pile is affected by the height of abutment.

Table 1.7 (Arsoy et al., 2002) presents the maximum pile stress and the pile displacement capacity. From the table, the Cass County Bridge abutment piles tolerated up to 2" (50 mm) of bridge contraction while the Boone River Bridge tolerated 1.6" (40 mm) of bridge contraction. Rochester Minnesota Bridge tolerated 0.65" (15 mm) of bridge contraction. Both abutment piles in the Cass County Bridge and Rochester Minnesota Bridge exhibited maximum stresses equal to $100 \%$ of nominal yield stress. Therefore, the maximum stresses 
developed in abutment piles were dependent on tolerated displacement and pile section dimensions.

\subsubsection{Agency Guide Specifications}

AASHTO Guide Specifications for Steel I-Girder Bridge Design Procedure (2003) specify a uniform temperature change as specified by AASHTO (2002), which state that for metal structures, a range of temperatures from $-17.8^{\circ} \mathrm{C}$ to $48.9^{\circ} \mathrm{C}$ should be considered. This range of temperature was adopted by LRFD specifications (2004, 2007 and 2010). In addition, AASHTO Guide Specifications (2003) state that the load effects due to a temperature differential of $-3.9^{\circ} \mathrm{C}$ between the deck and the girders shall be added to uniform temperature effect, when the width of deck is less than one-fifth the span length. AASHTO Guide Specifications (2003) acknowledge the design of bridges for assumed uniform temperature change. The bearing orientation on a curved bridge is often made in such a way that as thermal expansion and contraction occur, the bridge is allowed to move freely along rays emanating from a fixed point, causing the thermal force to be minimal.

AASHTO (2012) sets a vertical temperature gradient as shown in Figure 1.9. In this Figure, $T_{1}$ and $T_{2}$ depend on geographic location of the bridge, while $T$ and $A$ depend on the characteristics of the bridge. $\mathrm{T}_{3}$ equals to $0^{\circ} \mathrm{F}$ unless a site specific study is made. For negative gradient, the values of $T_{1}$ and $T_{2}$ are multiplied by -0.3 .

The above literature review revealed that the issues in the design of integral abutment bridges is pertinent to lack of standard design guideline (Arsoy et al., 1999; Dicleli, 2000; Huang et al., 2004; Dicleli and Erhan, 2010; Kim and Lamon, 2010). Also no clear understanding was reached for the complex soil-structure interaction behavior of bridge substructure due to thermal-induced movement of bridge deck (Lawver et al., 2000; Huang et al., 2004; Dicleli and Albhaisi, 2004c; Comisu and Gheorghita, 2010).

Moreover there is no available comprehensive computational model to analyze the response of integral abutment bridges due to thermal loading conditions (Dicleli, 2000; Jaafar et al., 2003; Arockiasamy and Sivakumar, 2005; Kim and Lamon, 2010). Finally, contradictory conclusions due to different restraint of bridge deck at piers were observed. Therefore, the integral abutment bridges require more research effort. 


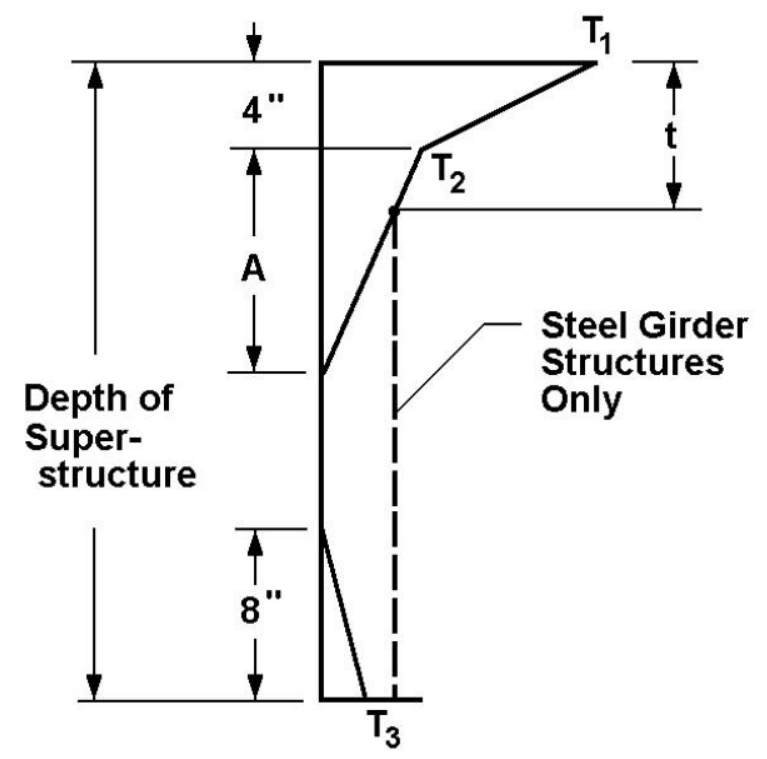

Figure 1.9 Positive Vertical Temperature Gradient in Concrete and Steel Superstructures (AASHTO, 2012) 


\section{CHAPTER 2 \\ SOIL MODELING}

\subsection{Introduction}

Soil can be classified into three general types, namely: clay, sand and silt as a result of the breakdown and weathering of rock by chemical and physical process. Peat, on the other hand, is a type of organic soil which results mainly from the decay of organic matter and hence considered not suitable for engineering purposes.

In conventional bridges, the bridge is subjected in its life span to temperatures, which can be higher or lower than the installation or erection temperature. Hence, the bridge expands if it is subjected to higher temperature than the installation temperature, while it contracts if it is subjected to a smaller temperature than the installation temperature. Bridge temperature is a function of several variables which includes the ambient temperature, the shade, solar radiation and the relative humidity. The presence of expansion joints in the bridge allows the bridge to expand and contract freely.

The absence of expansion joints as in the case of integral abutment (jointless) bridges creates horizontal force, which will be transferred to the abutments and the piles, generating additional soil reaction against both. So, the need to study the behavior of bridge substructure due to thermal-induced displacement becomes a necessity.

From previous study, it was concluded that there is a lot of soil models in the literature. These models describe the response of soil behind a man-made structure such as an abutment or a pile, to a lateral excitation or movement. To model the soil within a numerical model, a study had to be carried out to find the most agreed upon approach for tackling this complex behavior of soil-structure interaction.

Among the various equations and procedures found in the literature to describe the behavior of laterally loaded piles, two-sets of equations were chosen for comparison, namely: one set from the API (American Petroleum Institute, 2003) and the other from the papers by Greimann et al. (1988). 
The API model describes the behavior of soil surrounding a laterally loaded pile. The procedure relates pile-soil lateral deformation $(y)$ to lateral soil stress $(p)$, and hence, lateral soil stress deflection $(p-y)$ relationship has to be constructed. This procedure for soft clay was based on the work of Matlock (1970), and for stiff clay on the work of Reese et al. (1975), Also, the procedure for sand is based on the work done by O'Neill and Murchison (1983).

$\mathrm{H}$-piles are considered small displacement piles, so using small displacement soil properties such as soil shear modulus $G_{\max }$ or $G_{0}$ is advisable. However, due to bridge thermal loading and the subsequent expansion and contraction of the bridge superstructure, large lateral displacement of the soil occurs and residual soil properties should be adopted instead. It is worth mentioning that in laterally loaded piles if the pile is short, the soil will probably yield before the pile material. On the other hand, if the pile is long, the pile material, at the developed maximum bending moment, will probably attained to yield condition before failure takes place in soil.

\subsection{Behavior of Laterally Loaded Piles According to The API Manual}

The API Recommended Practice for Planning, Designing and Constructing of Fixed Offshore Platforms (American Petroleum Institute, 2003) presents the equations in the following subsections for calculating soil lateral response.

\subsubsection{Lateral Bearing Capacity of Piles in Soft Clay}

The ultimate unit lateral bearing capacity is considered the smaller of:

$P_{u}=3 c+\gamma X+J \frac{c X}{D}$

And $P_{u}=9 c$ for $X>$

$X_{r}$

Where;

$P_{u}$ : Ultimate soil resistance, $\mathrm{kPa}$ (psi),

$c:$ Undrained shear strength of undisturbed clay soil, $\mathrm{kPa}(\mathrm{psi})$,

$\gamma:$ Effective unit weight of soil, $\mathrm{MN} / \mathrm{m}^{3}\left(\mathrm{Ib} / \mathrm{in}^{2}\right)$,

$J$ : Dimensionless empirical constant with values ranging from 0.25 to 0.5 , having been determined by field testing, 
$X$ : Depth below soil surface, $\mathrm{mm}$ (in.),

$X_{r}$ : Depth below soil surface to bottom of reduced resistance zone, $\mathrm{mm}$ (in.),

$D$ : Pile diameter, $\mathrm{m}$ (in.).

Equations (2.1) and (2.2) can be solved simultaneously to give:

$$
X_{r}=\frac{6 D}{\frac{\gamma D}{c}+J}
$$

The ultimate unit lateral bearing capacity of soft clay, $P_{\mathrm{u}}$, was found to vary from $3 c$ to $9 c$ as $X$ increases from 0 to $X_{r}$, however, cyclic loadings and large deflections can cause reduction in ultimate resistance.

\subsubsection{Lateral Bearing Capacity of Piles in Stiff Clay}

For statically loaded stiff clay $(c>96 \mathrm{kPa})$, the ultimate unit bearing capacity $\left(p_{u}\right)$ would vary between $8 c$ and $12 c$. However, as mentioned cyclic loadings and large deflections reduce the ultimate lateral bearing capacity.

\subsubsection{Load deflection $(p-y)$ Curves for Piles in Soft Clay}

The $p-y$ curve represents the relationship between lateral pile deformation and the corresponding lateral soil pressure (force per unit length of pile) mobilized due to pile lateral displacement into the soil. The load deflection curve $(p-y)$ for soft clay can be taken as shown in Table 2.1 using the following definitions:

$p$ : Lateral resistance, $\mathrm{kPa}(\mathrm{psi})$,

$y$ : Lateral deflection, $\mathrm{mm}$ (in.),

$p_{u}$ : Ultimate unit lateral bearing capacity, $\mathrm{kPa}(\mathrm{psi})$,

$y_{c}:=2.5 \varepsilon_{c} D_{c}$,

$\varepsilon_{c}$ : Strain which occurs at one half the maximum deviator stresses in laboratory undrained triaxial compression tests on undisturbed soil samples. 
Table 2.1 Load-Deflection Relationship for Soft Clay, API (2003)

\begin{tabular}{|c|c|}
\hline$\frac{\boldsymbol{p}}{\boldsymbol{p}_{\boldsymbol{u}}}$ & $\frac{\boldsymbol{y}}{\boldsymbol{y}_{\boldsymbol{c}}}$ \\
\hline 0 & 0 \\
\hline 0.5 & 1 \\
\hline 0.72 & 3 \\
\hline 1 & 8 \\
\hline 1 & $\infty$ \\
\hline
\end{tabular}

\subsubsection{Lateral Bearing Capacity for Piles in Sand}

The ultimate lateral bearing capacity for sand is the smaller of the following two equations:

$p_{u}=\left(c_{1} \times H+c_{2} \times D\right) \times \gamma \times H$

$p_{u}=c_{3} \times D \times \gamma \times H$

Where;

$p_{u}$ : Ultimate resistance (force/unit length), $\mathrm{kN} / \mathrm{m}$ (Ibs/in.),

$\gamma$ : Effective soil weight, $\mathrm{kN} / \mathrm{m}^{3}$ (lb/in. $\left.{ }^{3}\right)$,

$H$ : Depth, m (in.),

$D$ : Pile diameter, $\mathrm{m}$ (in.),

$c_{1}, c_{2}, c_{3}$ :Coefficients determined from Figure 2.1 as a function of soil angle of internal friction $\phi$. 


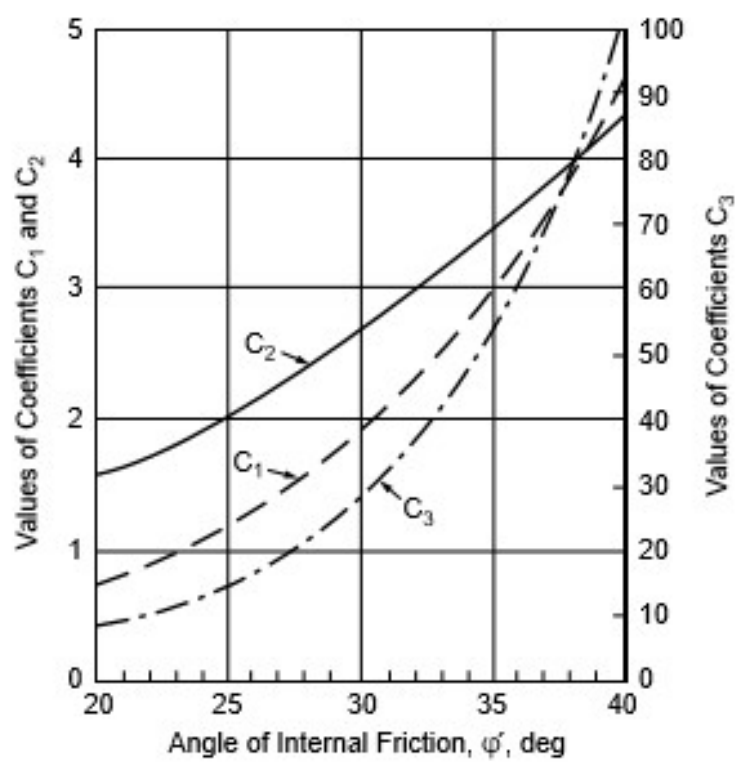

Figure 2.1 Coefficients as Function of $\phi^{\prime}$ (American Petroleum Institute, 2003)

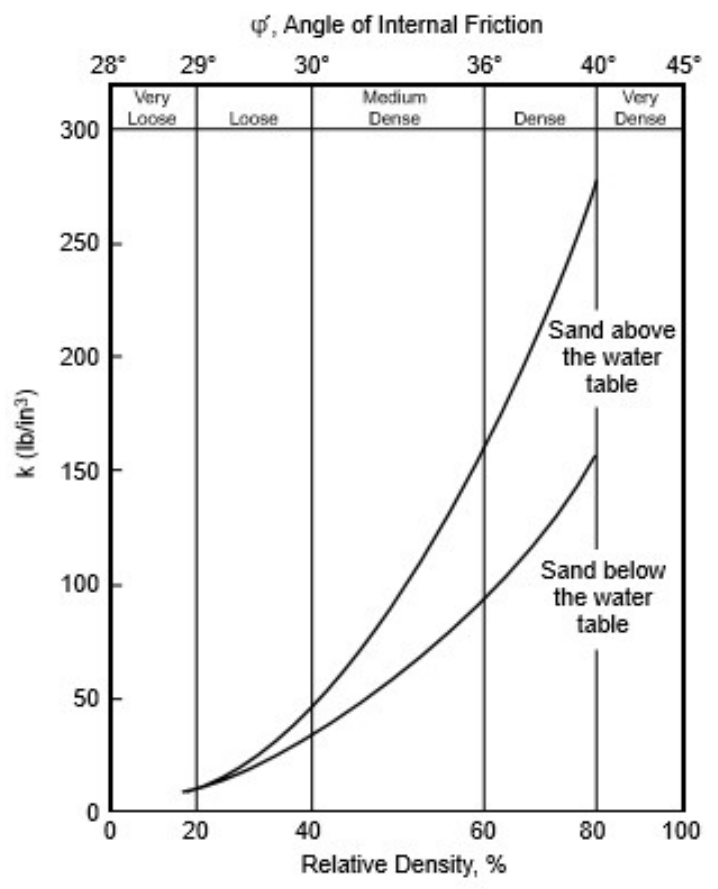

Figure 2.2 Initial Modulus of Subgrade Reaction Versus Angle of Internal Friction (American Petroleum Institute, 2003)

\subsubsection{Load Deflection ( $p-y)$ Curves for Piles in Sand}

The lateral soil pressure-deflection relationship for sand can be taken as follows: 
$p=A \times p_{u} \times \tanh \left[\frac{k \times H}{A \times p_{u}} \times y\right]$

Where;

A: Factor account for cyclic or static loading condition evaluated by

$A=0.9$ for cyclic loading,

$A=3-0.8 \frac{H}{D} \geq 0.9$ for static loading,

$k$ : Initial modulus of subgrade reaction, $\mathrm{kN} / \mathrm{m}^{3}$ (lb/in. $\left.{ }^{3}\right)$, Figure 2.2,

$y$ : Lateral deflection, $\mathrm{m}$ (in.),

$H$ : Depth, m (in.),

$p_{u}$ : Ultimate resistance (force/unit length), $\mathrm{kN} / \mathrm{m}$ ( lbs/in.).

\subsection{Behavior of Laterally Loaded Piles According to the Modified Ramberg- Osgood Model}

To approximate the $p-y, f-z$ and $q-z$ relationships of laterally loaded piles embedded in different soil types, Modified Ramberg-Osgood model can be used, which expressed as; (Greimann et al., 1984 and 1986),

$p=\frac{k_{h} y}{\sqrt[n]{1+\left|\frac{y}{y_{u}}\right|^{n}}}$

In which,

$y_{u}=\frac{p_{u}}{k_{h}}$

Where;

$k_{h}$ : Initial lateral stiffness $\mathrm{E}_{\mathrm{si}}$ (Gerimann et al., 1984; Greimann \& Wolde-Tinsae, 1988; HajNajib, 2002),

$p, p_{u}$ : Generalized and ultimate soil resistance, respectively, n: Shapes parameter (Greimann et al., 1984 and 1986; Greimann \& Wolde-Tinsae, 1988; Haj-Najib, 2002),

$y, y_{u}$ : Generalized and ultimate pile displacement, respectively. 
Greimann et al. (1984 and 1988) developed set of equations for different types of soil, based on Modified Ramberg-Osgood model, Table 2.2, which is specifically for $p-y$ relationship.

Table 2.2 Analytical Forms of $p-y$ Relationships (Greimann et al., 1984 and 1986; Greimann \& Wolde-Tinsae, 1988)

\begin{tabular}{|c|c|c|c|c|}
\hline Case & Basic $p-y$ Curve Equations & $\begin{array}{c}P_{u} \text { (Use Lesser Values of the Following } \\
\text { Equations) }\end{array}$ & $E_{s i}$ & $n$ \\
\hline Soft Clay & $p / p_{u}=0.5\left({ }^{y} / y_{50}\right)^{1 / 3}$ & $\begin{array}{c}p_{u}=9 c_{u} B \\
p_{u}=\left(3+\frac{\gamma}{c_{u}} x+\frac{0.5}{B} x\right) c_{u} B\end{array}$ & $\frac{p_{u}}{y_{50}}$ & 1 \\
\hline Stiff Clay & $p / p_{u}=0.5\left({ }^{y} / y_{50}\right)^{1 / 4}$ & $\begin{array}{c}p_{u}=9 c_{u} B \\
p_{u}=\left(3+\frac{\gamma}{c_{u}} x+\frac{0.5}{B} x\right) c_{u} B\end{array}$ & $\frac{p_{u}}{y_{50}}$ & 1 \\
\hline $\begin{array}{l}\text { Very Stiff } \\
\text { clay }\end{array}$ & $p / p_{u}=0.5\left({ }^{y} / y_{50}\right)^{1 / 2}$ & $\begin{array}{c}p_{u}=9 c_{u} B \\
p_{u}=\left(3+\frac{\gamma}{c_{u}} x+\frac{2}{B} x\right) c_{u} B\end{array}$ & $\frac{p_{u}}{2 y_{50}}$ & 2 \\
\hline Sand & $p / p_{u}=\tanh \left(E_{s i}^{y} / p_{u}\right)$ & $\begin{array}{c}p_{u}=\gamma x\left\{B\left(k_{p}-K_{a}\right)+\eta+\mu\right\} \\
p_{u}=\gamma x\left(k_{p}^{3}+2 k_{p}^{2} k_{o} \tan \phi-k_{a}\right) B \\
\eta=x k_{p} \tan \alpha \tan \beta \\
\mu=x k_{o} \tan \beta(\tan \phi-\tan \alpha)\end{array}$ & $\frac{J \gamma x}{1.35}$ & 3 \\
\hline
\end{tabular}

The following notations are used in Table 2.2:

$c_{u} \quad$ Undrained cohesion measured from unconsolidated, undrained triaxial laboratory test, taken as undrained (average) shear strength at depth $z$,

$B \quad$ Pile width, or according to Figure 2.3,

$\gamma \quad$ Effective soil unit weight, taken as average unit weight from ground surface to $p$ - $y$ curve point,

$x$ Depth from soil surface,

$\phi \quad$ Angle of soil internal friction,

$k_{p} \quad$ Rankine passive earth pressure coefficient, $\left(=\frac{1+\sin \phi}{1-\sin \phi}\right)$, 


$$
\begin{aligned}
& k_{a} \quad \text { Rankine active earth pressure coefficient, }\left(=\frac{1-\sin \phi}{1+\sin \phi}\right), \\
& k_{0} \quad=1-\sin \phi, \\
& \quad=\frac{\phi}{2} \text { for medium to dense sand } \\
& \quad=\frac{\phi}{3} \text { for loose sand, } \\
& \quad 200 \text { for loose sand; } 600 \text { for medium dense sand; } 1500 \text { for dense sand, } \\
& \quad \text { Displacement at one half the ultimate soil reaction, } \\
& \quad=2.5 B \varepsilon_{50} \text { for soft and stiff clay, } \\
& \quad=2.0 B \varepsilon_{50} \text { for very stiff clay, } \\
& \quad \text { Strain at } 50 \% \text { peak deviation stress, or use } 0.02 \text { for soft clay, } 0.01 \text { for stiff } \\
& \quad \text { clay and } 0.005 \text { for very stiff clay. }
\end{aligned}
$$

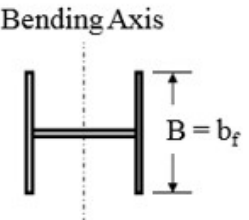

(a) Strong Axis Bending

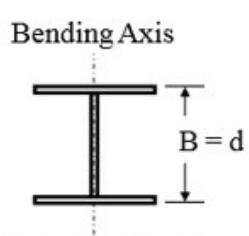

(b) WeakAxis Bending

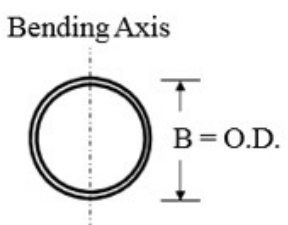

(c) Symmetric Axis

Figure 2.3 Pile Width Definitions (Frosch \& Lovell, 2011)

The $f-z$ relationships was obtained using Equation 2.7, by substituting the initial vertical stiffness $k_{\mathrm{v}}$, vertical displacement $\mathrm{z}$, and shear stress $f$ instead of $k_{\mathrm{h}}, y$ and $p$, respectively (Greimann et al., 1984 and 1988). The $f$-z relationships describe the relationship between skin friction (force per unit length of the pile) and the relative vertical displacement between the pile and the soil, Table 2.3 .

Equation 2.7 with the aid of Table 2.5 was used to obtain $q-z$ relationships. The $q-z$ relationships describe the relationship between the bearing stress at the pile tip and the pile tip settlement, Table 2.4. Pile tip force is $q$ times the effective pile tip area. In regards to the tip area for the HP pile, the pile was reasonably assumed to be fully plugged. In researching 
the literature, it was found that plugging of an open ended pipe pile or HP pile is an uncertain phenomenon. Plugging may occur under static conditions when the penetration depth of the pile-to-pile diameter ratio exceeds 20 in dense sand and clay or 20 to 30 in medium dense sand. Scholars argue that the toe resistance for $\mathrm{H}$-piles driven to rock is calculated based on the steel cross sectional area, and should not include the area of a plug. In HP piles, the distance between the $\mathrm{H}$-pile flanges are small compared to the inside diameter of most openended pipe piles. Therefore, an H-pile is more likely to be plugged under static conditions, where the cross section area $\left(b_{f} x d\right)$ is to be used when calculating the pile tip resistance. In the numerical models, the HP piles were assumed to be plugged, hence the cross section area was used in calculating the pile tip load versus vertical displacement curves, and the perimeter $2 \times\left(b_{f}+d\right)$ was used when calculating the $f-z$ relationships.

Table 2.3 Analytical Forms of $f$-z Relationships (Greimann et al., 1984 and 1986; Greimann \& Wolde-Tinsae, 1988)

\begin{tabular}{|l|c|c|c|c|}
\hline \multirow{2}{*}{ Case } & \multirow{2}{*}{ Basic $f-z$ Curve Equations } & \multicolumn{2}{|c|}{$f_{\max }$} & \multirow{2}{*}{$\boldsymbol{n}$} \\
\cline { 3 - 5 } & $\frac{f}{f_{\max }}=2 \sqrt{\frac{z}{z_{c}}}-\frac{z}{z_{c}}$ & H Piles & Others & \\
\hline Clay & $2\left(d+2 b_{f}\right) c_{a}$ & $l_{g} c_{a}$ & \\
& & $2\left(d+b_{f}\right) c_{u}$ & $l_{g} c_{u}$ & \\
& & $2\left(d c_{u}+b_{f} c_{a}\right)$ & & \\
& & & & \\
\hline Sand & $\frac{f}{f_{\max }}=2 \sqrt{\frac{z}{z_{c}}}-\frac{z}{z_{c}}$ & $0.04 N\left(d+2 b_{f}\right)$ & $0.04 N l_{g}$ & \\
& & & & \\
\end{tabular}

The notation in Table 2.3 are as follows:

$B \quad$ Pile width, $\mathrm{m}(\mathrm{ft})$,

$b_{f} \quad$ Flange width of H-pile, $\mathrm{m}(\mathrm{ft})$,

$c_{a} \quad$ Adhesion between soil and pile, $\mathrm{kN} / \mathrm{m}^{2}$ (psf),

$c_{u} \quad$ Undrained cohesion of the clay soil, $\mathrm{kN} / \mathrm{m}^{2}$ (psf), which may be estimated as; 
$c_{u}=97 N+114$

$l_{g} \quad$ Gross perimeter of the pile, $\mathrm{m}(\mathrm{ft})$,

$N \quad$ Average standard penetration blow count,

$d \quad$ Section depth of $\mathrm{H}$-pile or diameter of pipe pile, $\mathrm{m}(\mathrm{ft})$.

$z_{c} \quad$ Limiting relative displacement between pile and soil required to develop maximum friction stress $f_{\max }$, which can estimated as;

$z_{c}=0.4^{\prime \prime}(10 \mathrm{~mm})$ for piles in sand

$z_{c}=0.2^{\prime \prime}(5 \mathrm{~mm})$ for piles in clay

$\alpha \quad$ Shear strength reduction factor, depending upon the undrained shear strength of soil, Figure 2.4,

It can be seen from the unit skin friction equations listed in Table 2.3 that these equations are based on the assumptions that the failure will be either in the soil-to-soil cohesion or in the soil-to-metal adhesion or a combination of both. The adhesion between soil and pile can be estimated from Figure 2.4 while Table 2.4 lists the equations for $q-z$ curves, which relate the bearing stress at the pile tip to pile tip displacement.

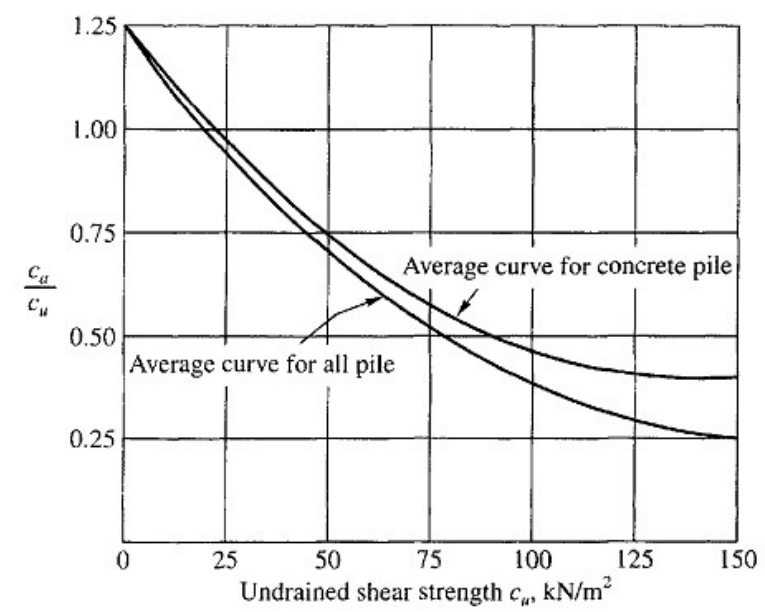

Figure 2.4 Adhesion Versus Undrained Shear Strength (Poulos \& Davis, 1980) 
Table 2.4 Analytical Forms of $q-z$ Relationships (Greimann et al., 1984 and 1986; Greimann \& Wolde-Tinsae, 1988)

\begin{tabular}{|c|c|c|c|}
\hline Case & Basic $\boldsymbol{q - z}$ Curve Equations & $\boldsymbol{q}_{\max }$ & $\boldsymbol{n}$ \\
\hline Clay & $\frac{q}{q_{\max }}=\left(\frac{z}{z_{c}}\right)^{1 / 3}$ & $9 c_{u}$ & 1 \\
\hline Sand & $\frac{q}{q_{\max }}=\left(\frac{z}{z_{c}}\right)^{1 / 3}$ & $8 N_{\text {corr }}$ & 1 \\
\hline
\end{tabular}

The notation in Table 2.4 are as follows:

$N_{\text {corr }}$ Corrected standard penetration test (SPT) blow count at depth of pile tip,

$Z_{C} \quad$ Relative displacement required to develop $f_{\max }$ or $q_{\text {max }}$

$=0.4$ in. $(0.033 \mathrm{~mm})$ for sand,

$=0.2 \mathrm{in} .(0.021 \mathrm{~mm})$ for clay,

$f_{\max }$ and $q_{\max }$, which are the pile unit skin friction and the pile unit tip resistance respectively, can be calculated using other methods and equations. Some of these methods are presented in Tables 2.6 to 2.8. Table 2.6 is for piles in cohesionless soil while Table 2.7 is for piles in cohesive soil. Table 2.8 presents summary of these methods. It should be noted that unit skin friction in sand is hard to estimate since it depends to a great extent on the method of pile installation as it changes soil properties. For example, driven piles in sand have higher unit skin friction than that of bored or jetted piles since the vibrations caused by the driving process lead to densification of loose sand around the pile in a zone as much as 2.5 times the pile diameter. Driven piles can be classified further into high displacement piles such as closed ended pipe piles and low displacement piles such as H-piles. Unit skin friction is much higher in high displacement piles than in low displacement piles. As such, the effective earth pressure coefficient $(k)$ that is used in calculating the unit skin friction is a function of the pile installation method. For bored and jetted piles, $k$ equal $k_{o}$. For low-displacement driven piles, $k$ varies from $k_{o}$ to $1.4 k_{o}$. For high-displacement driven piles, $k$ varies from $k_{o}$ to $1.8 k_{o}$, where $k_{o}$ is equal to $\left(1-\sin \phi^{\prime}\right)$ and $\phi^{\prime}$ is the critical state friction angle. The Nordlund Method (Nordlund, 1963) produced several charts to calculate the unit skin friction in cohesionless soil based on several parameters including the volume of soil displaced by the 
pile. Also, some theories argue that the unit skin friction increases with depth until a certain depth is reached and remains constant afterwards. This depth is postulated to be in the range of 15 to 20 times the pile diameters, afterwards the unit skin friction is assumed to stay constant as depicted in Figure 2.5.

The friction angle between the pile and the soil, $\delta$, which is needed for calculating the unit skin friction in sand, can be assumed to be $0.8 \phi$, where $\phi$ is the sand friction angle. The Nordlund method presented a graph to calculate the friction angle between the pile and the soil, $\delta$, was based on the volume of soil the pile displaces as shown in Figure 2.6.
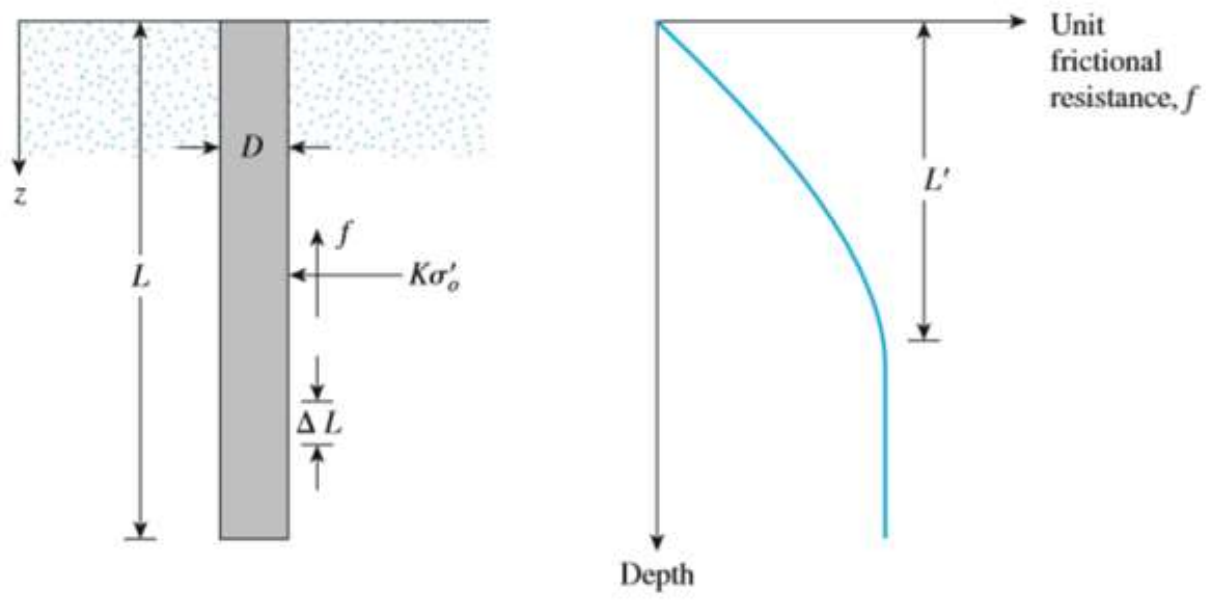

Figure 2.5 Unit Skin Friction Versus Depth (Das, 2007) 
Table 2.5 Parameters Used in the Modified Ramberg-Osgood Models for Clay and Sand (Greimann et al., 1984 and 1986; Greimann \& Wolde-Tinsae, 1988; Haj-Najib, 2002)

\begin{tabular}{|c|c|c|c|c|c|}
\hline \multirow{2}{*}{ Curve Type } & \multirow{2}{*}{ Soil Type } & \multicolumn{2}{|c|}{ Calculated } & \multicolumn{2}{|c|}{ Used } \\
\hline & & $\boldsymbol{k}_{(\boldsymbol{h} . v \cdot \boldsymbol{q})}$ & $\mathbf{n}$ & $\boldsymbol{k}_{(\boldsymbol{h} . v \cdot \boldsymbol{q})}$ & $n$ \\
\hline \multirow{4}{*}{$p-y$} & Soft Clay & $0.669 \frac{p_{u}}{\mathrm{y}_{50}}$ & 1.5 & $\frac{p_{u}}{y_{50}}$ & 1.0 \\
\hline & Stiff Clay & $0.915 \frac{p_{u}}{\mathrm{y}_{50}}$ & 1.07 & $\frac{p_{u}}{\mathrm{y}_{50}}$ & 1.0 \\
\hline & Very Stiff Clay & $0.539 \frac{p_{u}}{\mathrm{y}_{50}}$ & 2.56 & $\frac{p_{u}}{2 \mathrm{y}_{50}}$ & 2.0 \\
\hline & Sand & - & - & $\frac{J_{y x}}{1.35}$ & 3.0 \\
\hline$f-z$ & All Soils & $7.32 \frac{f_{\max }}{z_{c}}$ & 1.33 & $10 \frac{f_{\max }}{z_{c}}$ & 1.0 \\
\hline$q-z$ & All Soils & $7.32 \frac{q_{\max }}{z_{c}}$ & 1.33 & $10 \frac{q_{\max }}{z_{c}}$ & 1.0 \\
\hline
\end{tabular}


Table 2.6 Methods of Static Analysis for Piles in Cohesionless Soil (Hannigan et al., 2016)

\begin{tabular}{|c|c|c|c|c|c|}
\hline Method & Approach & $\begin{array}{l}\text { Method of } \\
\text { Obtaining } \\
\text { Design } \\
\text { Parameters }\end{array}$ & Advantages & Disadvantages & Remarks \\
\hline $\begin{array}{l}\text { Nordlund } \\
\text { Method. }\end{array}$ & $\begin{array}{l}\text { Semi- } \\
\text { Empirical. }\end{array}$ & $\begin{array}{l}\text { Charts } \\
\text { provided by } \\
\text { Nordlund. } \\
\text { Estimate of } \\
\text { soil friction } \\
\text { angle is } \\
\text { needed. }\end{array}$ & $\begin{array}{l}\text { Allows for } \\
\text { increased shaft } \\
\text { resistance of } \\
\text { tapered piles } \\
\text { and includes } \\
\text { effects of pile- } \\
\text { soil friction } \\
\text { coefficient for } \\
\text { different pile } \\
\text { materials. }\end{array}$ & $\begin{array}{l}\text { No limiting } \\
\text { value on unit } \\
\text { shaft } \\
\text { resistance is } \\
\text { recommended. } \\
\text { Soil friction } \\
\text { angle often } \\
\text { estimated from } \\
\text { SPT data. } \\
\text { Limit on pile } \\
\text { sizes. }\end{array}$ & $\begin{array}{l}\text { Good approach } \\
\text { to design that is } \\
\text { widely used. } \\
\text { Method is } \\
\text { based on field } \\
\text { observations. } \\
\text { Details } \\
\text { provided in } \\
\text { Section } \\
7.2 .1 .3 .1 \text {. }\end{array}$ \\
\hline API RP2A. & $\begin{array}{l}\text { Empirical, } \\
\text { effective } \\
\text { stress } \\
\text { analysis. }\end{array}$ & $\begin{array}{l}\mathrm{N}_{\mathrm{q}} \text { selected } \\
\text { from Table 7-8 } \\
\text { based on soil } \\
\text { type. }\end{array}$ & $\begin{array}{l}\text { Developed } \\
\text { specifically for } \\
\text { large diameter } \\
\text { open end pipe. }\end{array}$ & $\begin{array}{l}\text { Application to } \\
\text { non-LDOEPs } \\
\text { is limited. }\end{array}$ & $\begin{array}{l}\text { Used almost } \\
\text { exclusively for } \\
\text { offshore pile } \\
\text { design. }\end{array}$ \\
\hline $\begin{array}{l}\text { Effective } \\
\text { Stress } \\
\text { Method. }\end{array}$ & $\begin{array}{l}\text { Semi- } \\
\text { empirical. }\end{array}$ & $\begin{array}{l}\beta \text { and } \mathrm{N}_{\mathrm{t}} \\
\text { selected } \\
\text { based on soil } \\
\text { classification } \\
\text { and estimated } \\
\text { friction angle. }\end{array}$ & $\begin{array}{l}\beta \text { value } \\
\text { considers pile- } \\
\text { soil friction } \\
\text { coefficient for } \\
\text { different pile } \\
\text { materials. Soil } \\
\text { resistance } \\
\text { related to } \\
\text { effective vertical } \\
\text { stress. }\end{array}$ & $\begin{array}{l}\text { Results } \\
\text { affected by } \\
\text { range in } \beta \\
\text { values and in } \\
\text { particular by } \\
\text { range in } N_{t} \\
\text { chosen. }\end{array}$ & $\begin{array}{l}\text { Good approach } \\
\text { for design. } \\
\text { Details } \\
\text { provided in } \\
\text { Section } \\
7.2 .1 .3 .3 .\end{array}$ \\
\hline $\begin{array}{l}\text { Brown } \\
\text { Method. }\end{array}$ & Empirical. & $\begin{array}{l}\text { Results of SPT } \\
\text { tests based of } \\
N_{60} \text { values. }\end{array}$ & $\begin{array}{l}\text { Widespread use } \\
\text { of SPT test and } \\
\text { input data } \\
\text { availability. } \\
\text { Simple method } \\
\text { to use. }\end{array}$ & $\begin{array}{l}\text { Relies solely } \\
\text { on } N_{60} \text { values, } \\
\text { which may not } \\
\text { always be } \\
\text { available. }\end{array}$ & $\begin{array}{l}\text { Simple method } \\
\text { based on } \\
\text { correlations } \\
\text { with } 71 \text { static } \\
\text { load test } \\
\text { results. Details } \\
\text { provided in } \\
\text { Section } \\
7.2 .1 .3 .5 \text {. }\end{array}$ \\
\hline $\begin{array}{l}\text { Methods } \\
\text { based on } \\
\text { Cone } \\
\text { Penetration } \\
\text { Test (CPT) } \\
\text { data. }\end{array}$ & Empirical. & $\begin{array}{l}\text { Results of } \\
\text { CPT tests. }\end{array}$ & $\begin{array}{l}\text { Testing analogy } \\
\text { between CPT } \\
\text { and pile. } \\
\text { Reliable } \\
\text { correlations and } \\
\text { reproducible } \\
\text { test data. }\end{array}$ & $\begin{array}{l}\text { Limitations on } \\
\text { pushing cone } \\
\text { into dense } \\
\text { strata. }\end{array}$ & $\begin{array}{l}\text { Good approach } \\
\text { for design. } \\
\text { Details } \\
\text { provided in } \\
\text { Sections } \\
7.2 .1 .3 .6 \text { and } \\
7.2 .1 .3 .7 \text {. }\end{array}$ \\
\hline
\end{tabular}


Table 2.7 Methods of Static Analysis for Piles in Cohesive Soil (Hannigan et al., 2016)

\begin{tabular}{|c|c|c|c|c|c|}
\hline Method & Approach & $\begin{array}{l}\text { Method of } \\
\text { Obtaining } \\
\text { Design } \\
\text { Parameters }\end{array}$ & Advantages & Disadvantages & Remarks \\
\hline $\begin{array}{l}\text { a-Method } \\
\text { (Tomlinson } \\
\text { Method). }\end{array}$ & $\begin{array}{l}\text { Empirical, } \\
\text { total stress } \\
\text { analysis. }\end{array}$ & $\begin{array}{l}\text { Undrained } \\
\text { shear strength } \\
\text { estimate of } \\
\text { soil is needed. } \\
\text { Adhesion } \\
\text { calculated } \\
\text { from Figures } \\
7-17 \text { and } 7-18 .\end{array}$ & \begin{tabular}{|l|} 
Simple \\
calculation \\
from \\
laboratory \\
undrained \\
shear strength \\
values to \\
adhesion.
\end{tabular} & $\begin{array}{l}\text { Wide scatter in } \\
\text { adhesion } \\
\text { versus } \\
\text { undrained } \\
\text { shear strengths } \\
\text { in literature. } \\
\text { Limits on s. } \\
\text { strengths in soft } \\
\text { and medium } \\
\text { cohesive soils. }\end{array}$ & $\begin{array}{l}\text { Widely used } \\
\text { method } \\
\text { described in } \\
\text { Section } \\
7.2 .1 .3 .2\end{array}$ \\
\hline AP1 RP2A & $\begin{array}{l}\text { Empirical, } \\
\text { effective } \\
\text { stress } \\
\text { analysis. }\end{array}$ & $\begin{array}{l}\text { Undrained } \\
\text { shear strength } \\
\text { estimate of } \\
\text { soil is needed. }\end{array}$ & $\begin{array}{l}\text { Developed } \\
\text { specifically for } \\
\text { large diameter } \\
\text { open end pipe } \\
\text { piles. }\end{array}$ & $\begin{array}{l}\text { Application to } \\
\text { non-LDOEPs is } \\
\text { limited. }\end{array}$ & $\begin{array}{l}\text { Used almost } \\
\text { exclusively for } \\
\text { offshore pile } \\
\text { design. }\end{array}$ \\
\hline $\begin{array}{l}\text { Effective } \\
\text { Stress } \\
\text { Method. }\end{array}$ & $\begin{array}{l}\text { Semi- } \\
\text { Empirical, } \\
\text { based on } \\
\text { effective } \\
\text { stress at } \\
\text { failure. }\end{array}$ & $\begin{array}{l}\beta \text { and } \mathrm{N}_{\mathrm{t}} \\
\text { values are } \\
\text { selected from } \\
\text { Table 7-9 } \\
\text { based on } \\
\text { drained soil } \\
\text { strength } \\
\text { estimates. }\end{array}$ & $\begin{array}{l}\text { Ranges in } \beta \\
\text { and } N_{t} \text { values } \\
\text { for most } \\
\text { cohesive soils } \\
\text { are relatively } \\
\text { small. }\end{array}$ & $\begin{array}{l}\text { Range in } \mathrm{N}_{\mathrm{t}} \\
\text { values for hard } \\
\text { cohesive soils } \\
\text { such as glacial } \\
\text { tills can be } \\
\text { large. }\end{array}$ & $\begin{array}{l}\text { Good design } \\
\text { approach } \\
\text { theoretically } \\
\text { better than } \\
\text { undrained } \\
\text { analysis. } \\
\text { Details in } \\
\text { Section } \\
7.2 .1 .3 .3 .\end{array}$ \\
\hline $\begin{array}{l}\text { Methods } \\
\text { based on } \\
\text { Cone } \\
\text { Penetration } \\
\text { Test data. }\end{array}$ & Empirical. & $\begin{array}{l}\text { Results of } \\
\text { CPT tests. }\end{array}$ & $\begin{array}{l}\text { Testing } \\
\text { analogy } \\
\text { between CPT } \\
\text { and pile. } \\
\text { Reproducible } \\
\text { test data. }\end{array}$ & $\begin{array}{l}\text { Cone can be } \\
\text { difficult to } \\
\text { advance in very } \\
\text { hard cohesive } \\
\text { soils such as } \\
\text { glacial tills. }\end{array}$ & $\begin{array}{l}\text { Good } \\
\text { approach for } \\
\text { design. } \\
\text { Details in } \\
\text { Section } \\
7.2 .1 .3 .6 \text { and } \\
\text { Section } \\
7.2 .1 .3 .7\end{array}$ \\
\hline
\end{tabular}


Table 2.8 Summary of Static Analysis Methods (Hannigan et al., 2016)

\begin{tabular}{|c|c|c|c|c|c|}
\hline Analysis Method & $\begin{array}{c}\text { Soil } \\
\text { Type }\end{array}$ & $\begin{array}{c}\text { Soil } \\
\text { Information } \\
\text { Required }\end{array}$ & $\begin{array}{c}\text { Presented } \\
\text { in } \\
\text { GEC-12 }\end{array}$ & $\begin{array}{c}\text { Presented } \\
\text { in 2014 } \\
\text { AASHTO } \\
\text { Code }\end{array}$ & $\begin{array}{c}\text { AASHTO } \\
\phi_{\text {stat }}\end{array}$ \\
\hline Meyerhof (1976) & Cohesionless & SPT N & No & Yes & 0.30 \\
\hline Nordlund (1963) & Cohesionless & $\phi^{\prime}$ & Yes & Yes & 0.45 \\
\hline$\alpha$-method (1980) & Cohesive & su $_{u}$ & Yes & Yes & 0.35 \\
\hline$\beta$-method (1951)(1979)* & Cohesive & Su $^{*}$ & No & Yes & 0.25 \\
\hline$\lambda$-method (1972) & Cohesive & su $_{u}$ & No & Yes & 0.40 \\
\hline API RP2A (1993) & Mixed & Su, $^{\prime}$ & Yes & No & $\ldots$ \\
\hline$\beta$-method (1991)** & Mixed & $\phi^{\prime}$ & Yes & No & Differs ${ }^{\prime}$ \\
\hline Brown (2001) & Mixed & SPT N & Yes & No & $\ldots$ \\
\hline Elsami \& Fellenius (1997) & Mixed & CPTu & Yes & No & $\ldots$ \\
\hline Schmertmann (1975) & Mixed & CPT & Yes & Yes & 0.50 \\
\hline
\end{tabular}

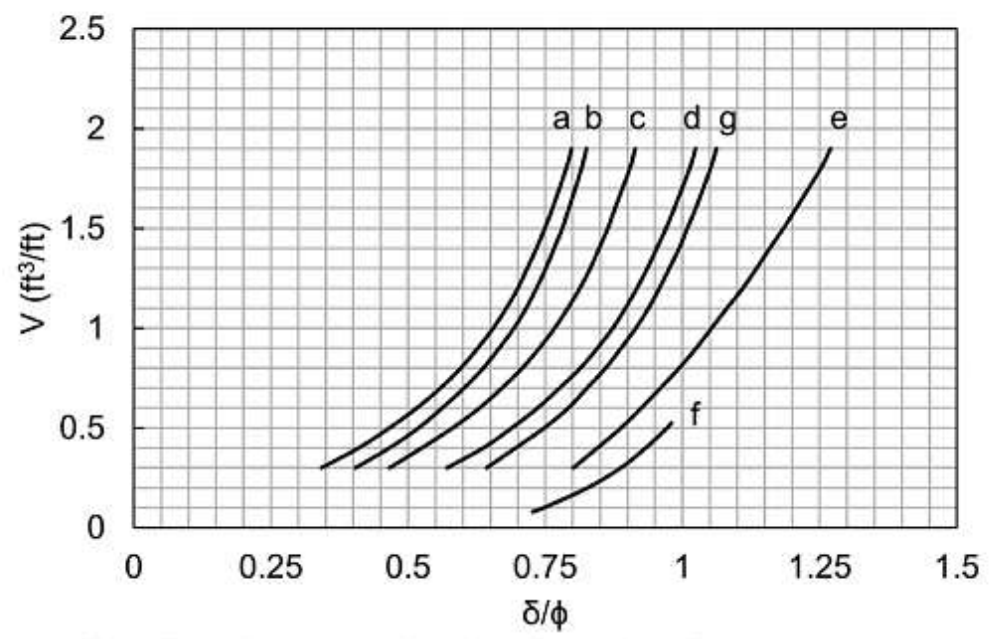

a. Pipe piles and non-tapered portion of monotube piles

b. Timber piles

e. Raymond uniform taper piles

c. Precast concrete piles

f. H-piles and augercast piles

d. Raymond step-taper piles

g. Tapered portion of monotube piles

Figure $2.6 \delta$ / $\phi$ Versus Soil Displacement, V, for Different Pile Types (Nordlund, 1963) 
Similar to the pile unit skin friction resistance, the pile unit tip resistance for sand can be estimated by several methods, most of which set limit to the unit tip resistance as a function of the sand angle of internal friction as it can be seen from Figure 2.7.

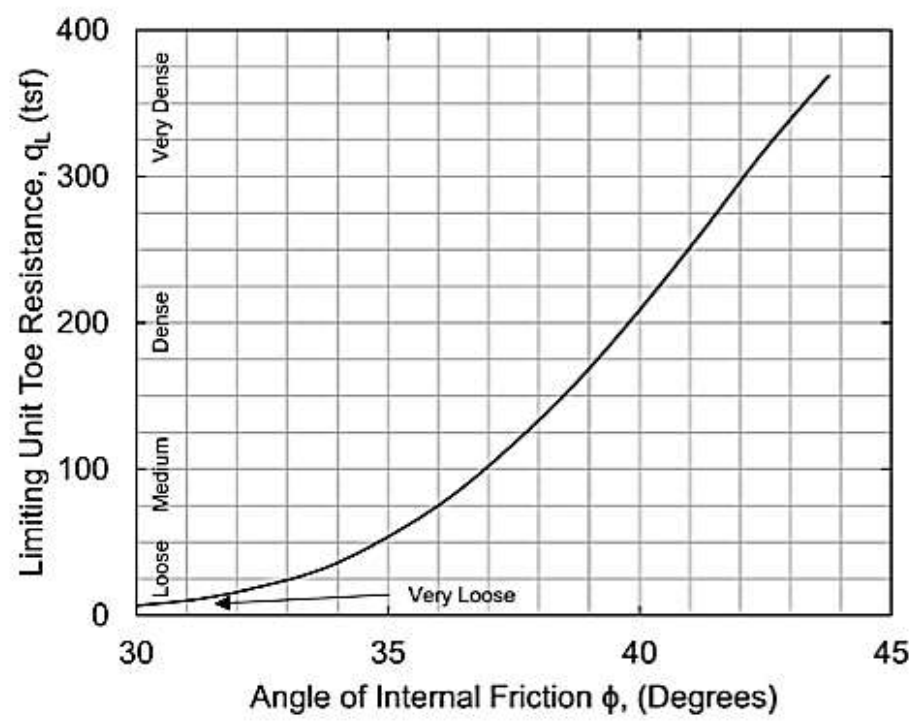

Figure 2.7 Limiting Unit Tip (Toe) Resistance Versus Friction Angle For Cohesionless Soils (Hannigan et al., 2016)

\subsection{Group Effect of piles}

In regards to the group effect of piles, the piles in integral abutment bridges are installed in a single row, which negates any effect of shedding. So there are no leading, middle or rear piles. The spacing between the piles is typically taken as $1.5 \mathrm{~m}$, which is less than 4 times the equivalent pile diameter. Among different methods that exist for the analysis of laterally loaded pile groups, the P-multiplier method shown in Figure 2.8 is widely used in practice. The influence of pile spacing in the same row, normal to the loading direction on pile-soil-pile interaction, is usually ignored, Figure 2.9 (Fayyazi et al. 2012). Nevertheless, a literature review was conducted to examine the effect of pile group on the deformation of HP piles for integral abutment bridges as shown in Figure 2.11. Reduction in pile resistance occurs in the second and third rows (middle and rear piles) and subsequent rows, while the first row (the leading pile-row) exhibit comparatively small reduction due to group effect. In the study conducted by Fayyazi et al. (2012) on the evaluation of p-multiplier method for performancebased design of pile groups, two pile group configurations, namely: pile group configuration I and pile group configuration II shown in Figure 2.9, were modeled in a continuum model. The 
two groups of piles were embedded in sand, and a displacement of $0.02 \mathrm{~m}$ is applied equally on all pile heads and forces at the pile heads were measured. The same displacements of 0.02 $m$ was applied on a single pile to compare the results with the piles in these two pile group configurations, Fayyazi et al. (2012).

Single row piles in integral abutment bridges resemble pile group configuration II. It can be seen from Figure 2.10 that at spacing of 3 times the pile diameter, the difference between the force mobilized by a single pile, and the force mobilized by a pile in a single row pile group under the same lateral displacement is around $14 \%$. So, the P-multiplier in this case will be around 0.86 . When the spacing between the piles increased to 7 times the pile diameter, the difference between force mobilized by single pile and force mobilized by a pile in a pile group under the same lateral displacement is almost not existng. Table 2.9 shows a summary of Pmultiplier studies. As such, the group effect of piles was resenobaly ignored in the numerical models.

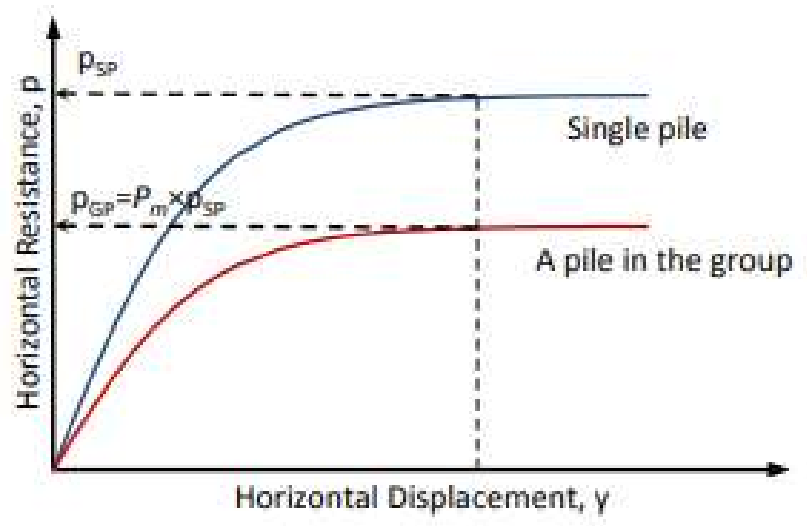

Figure 2.8 Definition of p-Multiplier (Fayyazi et al., 2012)

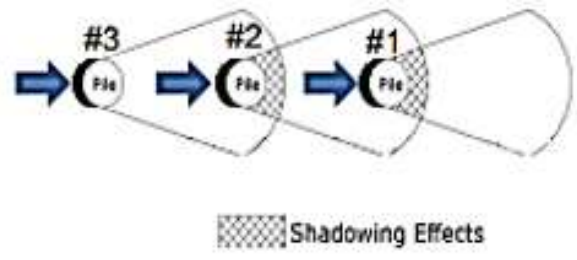

(a) Pile Group Configuration I

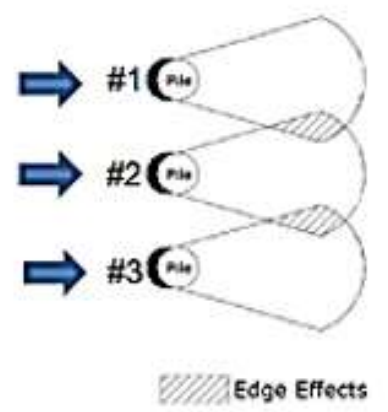

(b) Pile Group Configuration II

Figure 2.9 Pile Group Configurations (Fayyazi et al., 2012) 


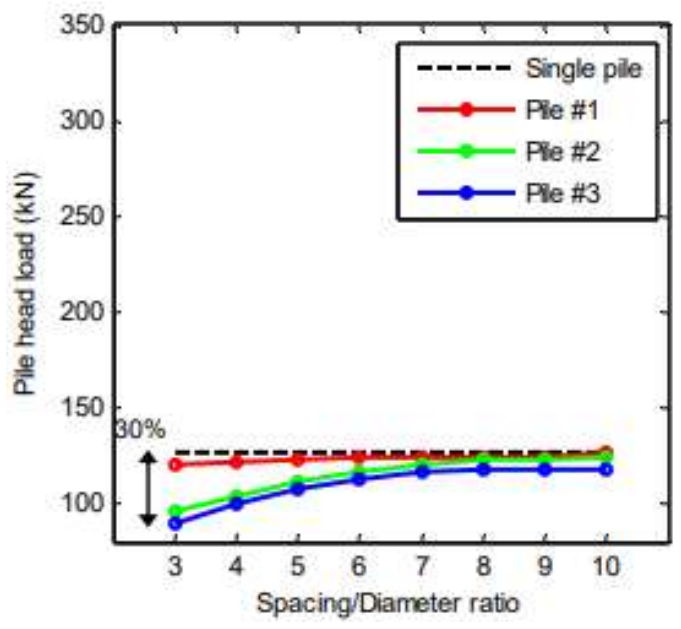

(a) Pile Group Configuration I

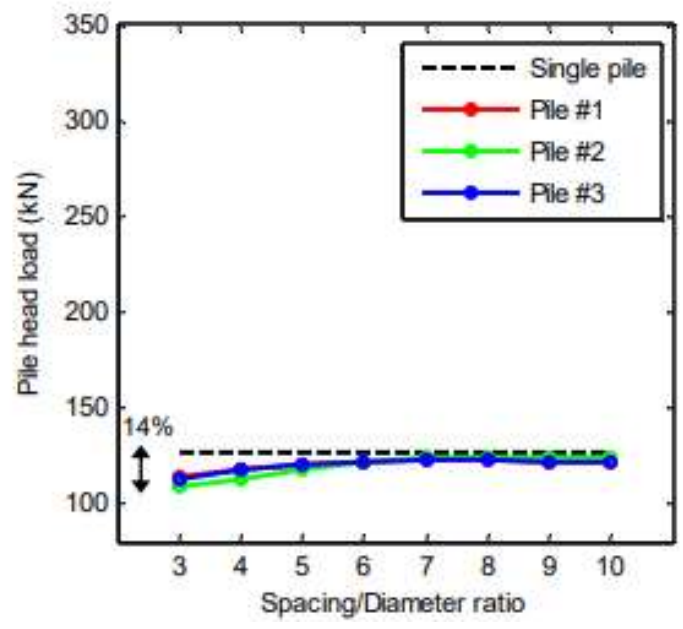

(b) Pile Group Configuration II

Figure 2.10 Pile Head Force of Different Pile Configurations for Displacement of $\mathbf{2 0 ~} \mathbf{m m}$ (Fayyazi et al., 2012) 


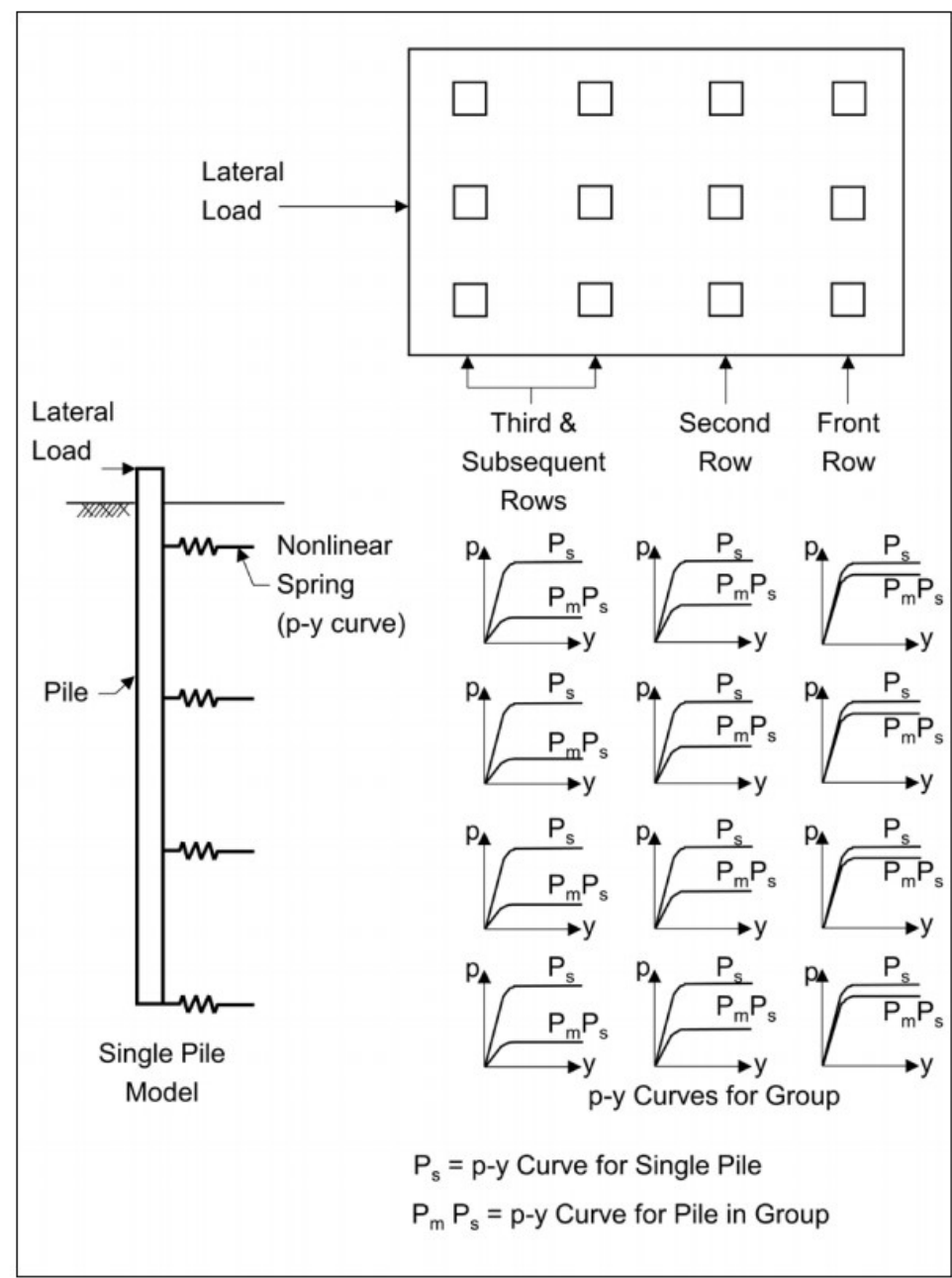

Figure 2.11 Effect of P-Multiplier on Pile Group Load-Displacement Curves (Hannigan et al., 2016) 
Table 2.9 Summary of P-Multiplier Studies (Hannigan et al., 2016)

\begin{tabular}{|c|c|c|c|c|c|}
\hline $\begin{array}{l}\text { Soil } \\
\text { Type }\end{array}$ & $\begin{array}{l}\text { Test } \\
\text { Type }\end{array}$ & $\begin{array}{l}\text { Center to } \\
\text { Center } \\
\text { Pile } \\
\text { Spacing }\end{array}$ & $\begin{array}{c}\text { Calculated } \\
\text { p-Multipliers, Pm } \\
\text { For Rows } \\
1,2, \& 3+\end{array}$ & $\begin{array}{c}\text { Deflection, } \\
\text { inches }\end{array}$ & Reference \\
\hline Stiff Clay & Field Study & $3 b$ & $0.70,0.50,0.40$ & 2 & $\begin{array}{c}\text { Brown et al. } \\
\text { (1987) }\end{array}$ \\
\hline Stiff Clay & Field Study & $3 b$ & $0.70,0.60,0.50$ & 1.2 & $\begin{array}{c}\text { Brown et al. } \\
\text { (1987) }\end{array}$ \\
\hline Stiff Clay & Field Study & $3.3 \mathrm{~b}$ & $0.82,0.61,0.45$ & 3.5 & $\begin{array}{l}\text { Rollins et al. } \\
\text { (2006) }\end{array}$ \\
\hline Stiff Clay & Field Study & $4.4 \mathrm{~b}$ & $0.90,0.80,0.69$ & 1.6 & $\begin{array}{l}\text { Rollins et al. } \\
(2006)\end{array}$ \\
\hline Stiff Clay & Field Study & $5.65 b$ & $0.95,0.88,0.77$ & 2.6 & $\begin{array}{l}\text { Rollins et al. } \\
\quad(2006)\end{array}$ \\
\hline $\begin{array}{l}\text { Medium } \\
\text { Clay }\end{array}$ & $\begin{array}{l}\text { Scale Model- } \\
\text { Cyclic Load }\end{array}$ & $3 b$ & $0.60,0.45,0.40$ & $\begin{array}{c}2.4 \text { at } \\
50 \text { cycles }\end{array}$ & $\begin{array}{l}\text { Moss } \\
\text { (1997) }\end{array}$ \\
\hline Clayey Silt & Field Study & $3 b$ & $0.60,0.40,0.40$ & $1.0-2.4$ & $\begin{array}{l}\text { Rollins et al. } \\
\text { (1998) }\end{array}$ \\
\hline $\begin{array}{l}\text { V. Dense } \\
\text { Sand }\end{array}$ & Field Study & $3 \mathrm{~b}$ & $0.80,0.40,0.30$ & 1 & $\begin{array}{c}\text { Brown et al. } \\
\text { (1988) }\end{array}$ \\
\hline $\begin{array}{l}\text { M. Dense } \\
\text { Sand }\end{array}$ & $\begin{array}{l}\text { Centrifuge } \\
\text { Model }\end{array}$ & $3 b$ & $0.80,0.40,0.30$ & 3 & $\begin{array}{c}\text { McVay et al. } \\
\text { (1995) }\end{array}$ \\
\hline $\begin{array}{l}\text { M. Dense } \\
\text { Sand }\end{array}$ & $\begin{array}{c}\text { Centrifuge } \\
\text { Model }\end{array}$ & $5 b$ & $1.0,0.85,0.70$ & 3 & $\begin{array}{l}\text { McVay et al. } \\
\text { (1995) }\end{array}$ \\
\hline $\begin{array}{l}\text { Loose } \\
\text { M. Sand }\end{array}$ & $\begin{array}{c}\text { Centrifuge } \\
\text { Model }\end{array}$ & $3 b$ & $0.65,0.45,0.35$ & 3 & $\begin{array}{c}\text { McVay et al. } \\
\text { (1995) }\end{array}$ \\
\hline $\begin{array}{l}\text { Loose } \\
\text { M. Sand }\end{array}$ & $\begin{array}{c}\text { Centrifuge } \\
\text { Model }\end{array}$ & $5 b$ & $1.0,0.85,0.70$ & 3 & $\begin{array}{c}\text { McVay et al. } \\
\text { (1995) }\end{array}$ \\
\hline $\begin{array}{l}\text { Loose } \\
\text { F. Sand }\end{array}$ & Field Study & $3 b$ & $0.80,0.70,0.30$ & $1-3$ & $\begin{array}{l}\text { Ruesta et al. } \\
\text { (1997) }\end{array}$ \\
\hline
\end{tabular}




\subsection{Soil-Abutment Interaction Modules}

The earth pressure behind a retaining structure such as an abutment can vary as active, passive or at rest depending on the retaining structure magnitude of movement and direction of movement either towards the backfill soil or away from the backfill soil. This means that the earth pressure behind the abutment is displacement-dependent.

When an integral abutment bridge exhibits induced-thermal movement due to thermal positive loading, the abutment will move towards the backfill generating passive earth pressure. The magnitude of the passive earth pressure is not a constant value but it depends on the amount of displacement relative to the abutment height. The magnitude of the passive earth pressure ranges from a minimum value which is equal to earth pressure at rest to a maximum value which creates shear failure in soil depending on the ratio of abutment lateral displacement relative to the abutment height, Figure 2.12 . To fully mobilize passive earth pressure, a certain abutment displacement threshold must be met. This threshold displacement depends on the soil model and the state of the fill behind the abutment, whether it is dense, medium dense or loose sand as shown in Table 2.10.

The lateral earth pressure coefficient is the ratio between geostatic vertical effective stress and lateral earth pressure. Several theories do exist for calculating the lateral earth pressure coefficient. Some theories assume the failure surface behind the retaining structure a plane surface such as Rankine and Coulomb. Another method considers the failure surface to be hyperbolic log spiral as shown in Figure 2.13. Some theories assume the retaining-structure surface to be smooth and frictionless such as Rankine theory. Other theories consider the friction between the retaining structure and the backfill soil in calculating the lateral earth pressure coefficient such as the Coulomb theory.

Similar to laterally loaded piles and the numerous soil models describing their behavior, numerous models do exist to describe the response of laterally loaded abutments. These models are used to predict the active and passive lateral earth pressure coefficient based on the relative retaining structure movement. These include the model proposed by Husain \& Bagnariol (1996) shown in Figure 2.14 and the model proposed by Barker et al. (1991) shown in Figure 2.15. Also, Clough \& Duncan (1971) proposed another model, shown in Figure 2.16, to calculate the lateral earth pressure coefficient which is similar to the one by Husain and 
Bagnariol. Caquot and Kerisel (1948) proposed a model based on log spiral technique and both soil friction angle and soil-retaining structure friction angle as depicted in Figure 2.17. Caquot and Kerisel (1948) proposed an earth pressure model that is independent of wall movement. The model can only be used for the calculation of the earth pressure corresponding to passive and active states of soil. The Canadian Foundation Engineering Manual (1992) proposed a model to calculate lateral earth pressure coefficient based on wall rotation and state of the soil whether it is loose or dense as shown in Figure 2.18.

Kerokoski (2006) assumed that one-third passive earth pressure would develop at zero abutment movement as shown in Figure 2.19. The US Department of the Navy (1982) developed a chart for calculating earth pressure coefficient based on retaining wall rotation as shown in Figure 2.20. Figure 2.21 and Table 2.11 list values of lateral earth pressure coefficients proposed by Caquot and Kérisel (1948). Figure 2.21 revealed that Caquot and Kérisel method overestimates the earth pressure coefficients, with the best value obtained using $\varnothing / 2$ to $\varnothing / 3$. All these theories and models consider either pure translation or pure rotation movement, which is neither the case in actual field conditions, since the abutment translate and rotate at the same time.

The active and passive earth pressure coefficient, $K$, computed from any of the models can then be used to compute the force behind the retaining wall according to the following equation:

$F=K \gamma A Z$

Where $\gamma$ is the effective soil unit weight, $Z$ is the depth below soil surface and $A$ is the area. Notably $K$ varies with depth according to abutment displacement at that depth.

Since the 1970s, hyperbolic models have been used to describe load-deflection and stressstrain relationship in geotechnical problems (Stewart et al., 2007). A model proposed by Duncan and Mokwa (2001) based on the hyperbolic models was introduced to solve loaddisplacement modeling of retaining structures. The load-displacement equation is as follows:

$$
p=\frac{y}{\frac{1}{k_{\max }}+R_{f} \frac{y}{p_{u l t}}}
$$

Where; 
$p$ : Passive resistance mobilized by lateral displacement $y$ (unit of force),

$p_{\text {ult }}$ : Ultimate passive resistance (unit of force),

$y$ : Deflection (unit of displacement),

$R_{f}$ : Failure ratio, defined as the ratio of the ultimate passive pressure load divided by the hyperbolic asymptotic value of passive resistance, which can be taken as 0.85 (Duncan \& Mokwa, 2001). While the value of $R_{f}$ can be calculated from Equation 2.10, by substituting $p_{u l t}$ and $y_{\max }$ instead of $p$ and $y$,

$$
R_{f}=1-\frac{P_{u l t}}{y_{\max } k_{\max }}
$$

$k_{\max }$ Initial stiffness of backfill material (Force/Length).

The procedure of assessing $k_{\max }$ was explained by Mokwa (1999). The procedure is based on the calculation of elastic settlement of embedded loaded area in semi-infinite elastic halfspace. The load is applied horizontally on finite area $(\mathrm{bxH})$ and the displacements at the four corners of the loaded area were calculated. The initial stiffness $K$ was calculated as the load divided by the average displacement of the loaded area, or simply the inverse of the average displacement, since the displacement is function of the load.

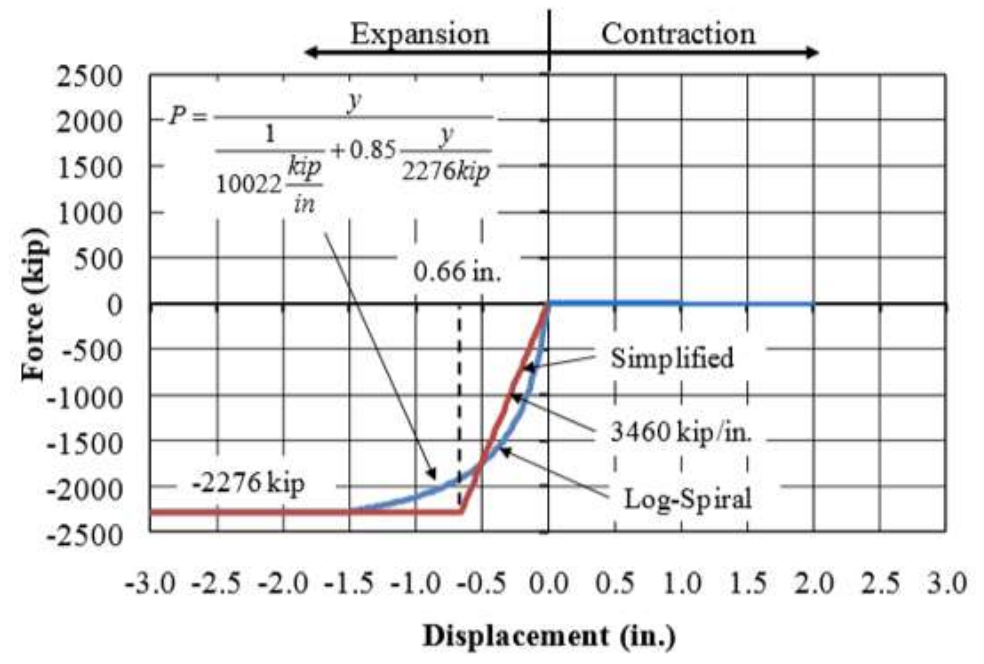

Figure 2.12 Abutment Force-Displacement Relationships Established by the Hyperbolic Model (Frosch \& Lovell, 2011)

The basic form of the hyperbolic model can be re-written as follows (Stewart et al., 2007): 
$p=\frac{y}{A+B y}$

So:

$\begin{aligned} A & =\frac{1}{k_{\max }} \\ B & =\frac{R_{f}}{p_{u l t}}\end{aligned}$
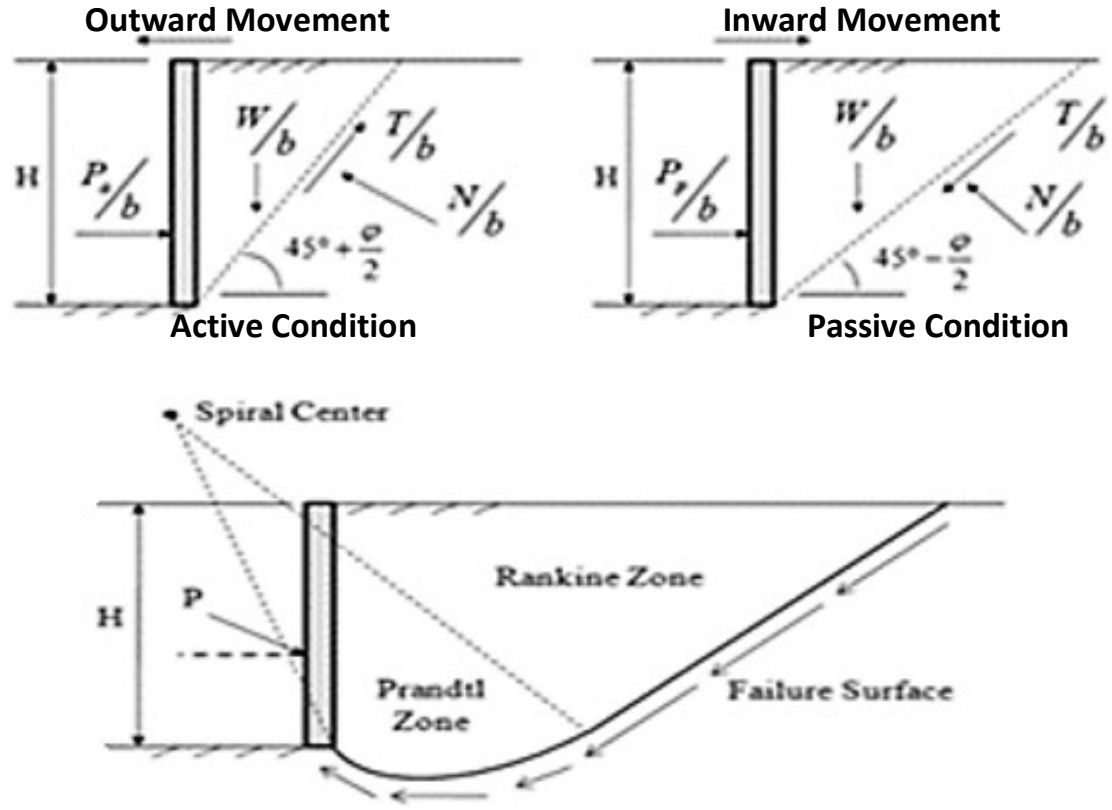

Assumed Failure Mechanism of Log-spiral Theory

Figure 2.13 Log Spiral Versus Planar Failure Surfaces (Frosch \& Lovell, 2011)

Table 2.10 Displacement Thresshold to Reach Full Active and Passive Conditions in Cohesionless Soil as a Function of the Relative Abutment Displacement to Abutment Height, $\Delta / H$ (Clough \& Duncan, 1991)

\begin{tabular}{|c|c|c|}
\hline \multirow{2}{*}{ Backfill } & \multicolumn{2}{|c|}{$\frac{\Delta}{\boldsymbol{H}}$} \\
\cline { 2 - 3 } & Active & Passive \\
\hline Dense Sand & 0.001 & 0.01 \\
\hline Medium Dense Sand & 0.002 & 0.02 \\
\hline Loose Sand & 0.004 & 0.04 \\
\hline
\end{tabular}




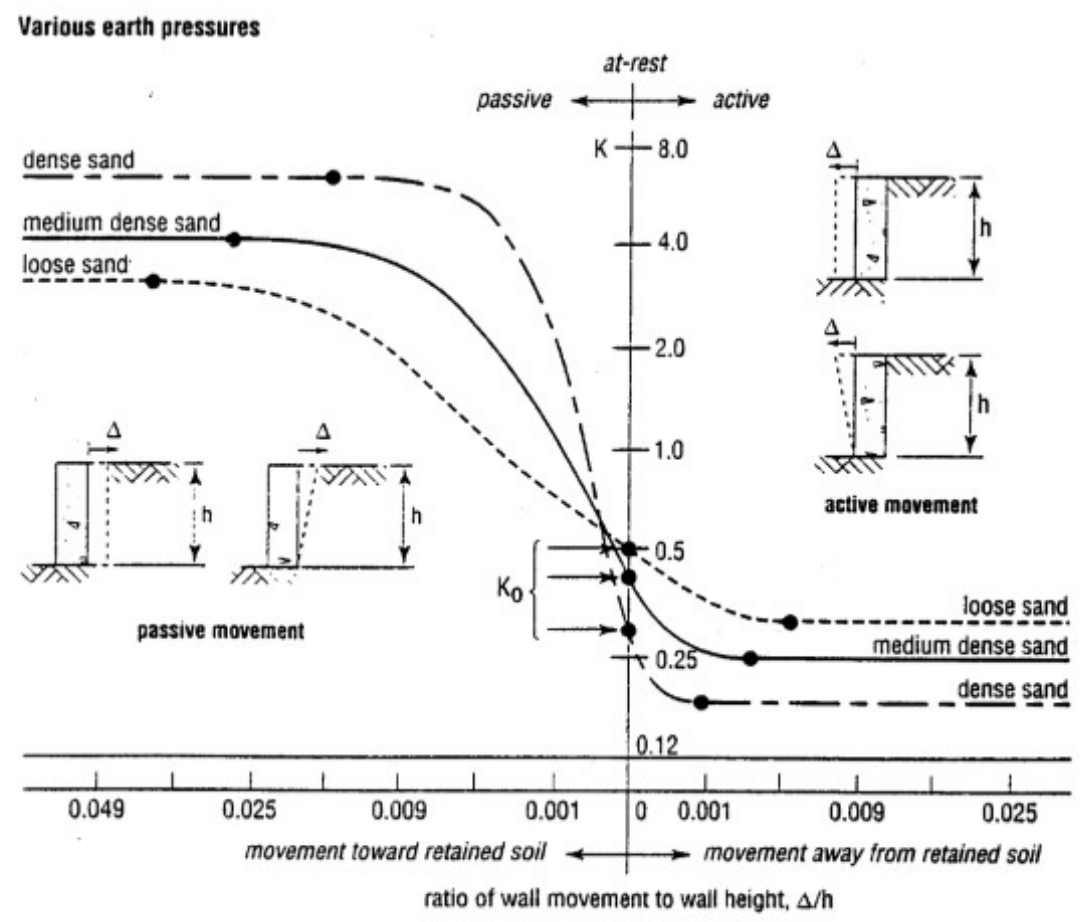

Figure 2.14 Lateral Earth Pressure Coefficient Versus Relative Wall Movement

(Husain \& Bagnariol, 1996)

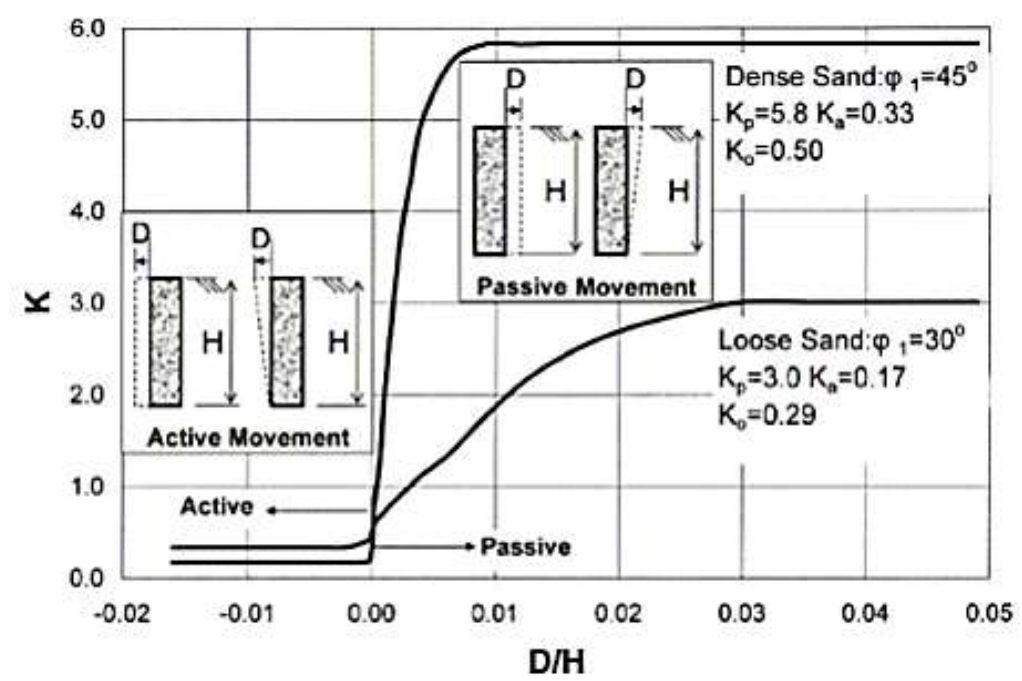

Figure 2.15 Lateral Earth Pressure Coefficients Versus Relative Wall Movement

(Barker et al., 1991) 


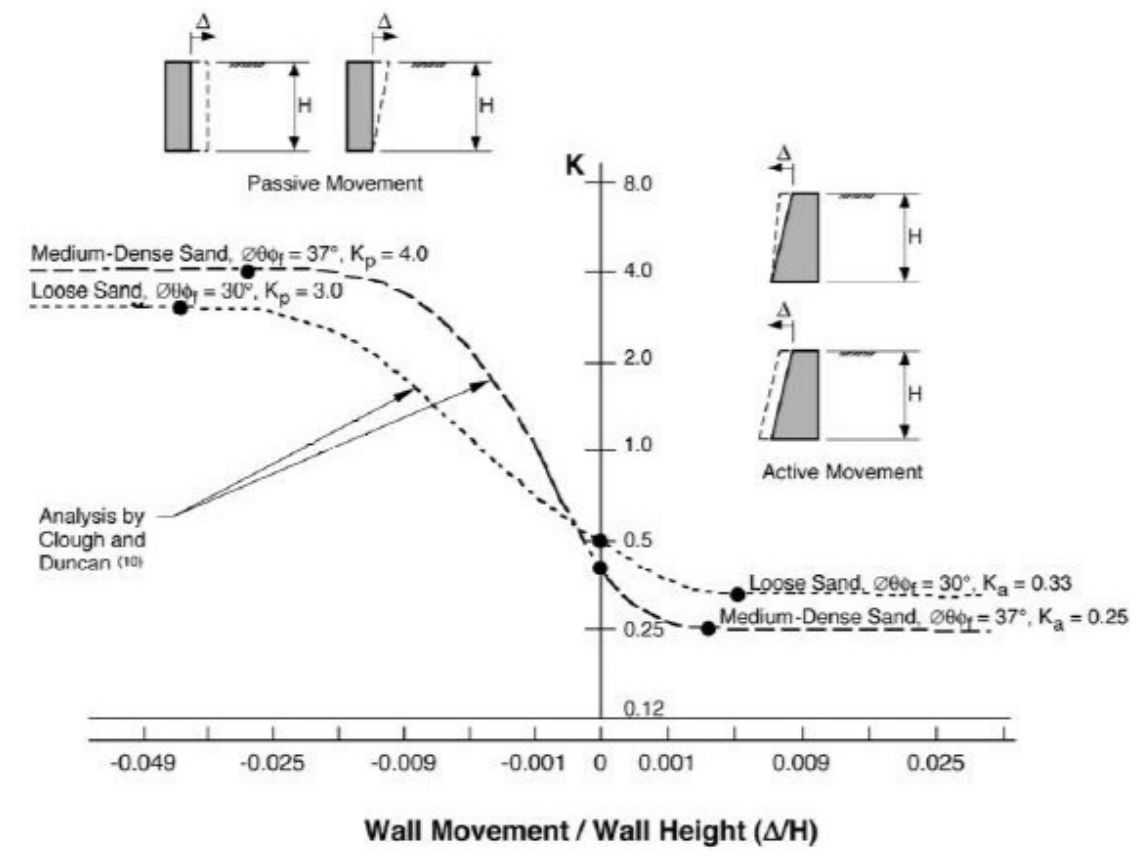

Figure 2.16 Lateral Earth Pressure Coefficients Versus Relative Wall Movement (Clough \& Duncan, 1971)

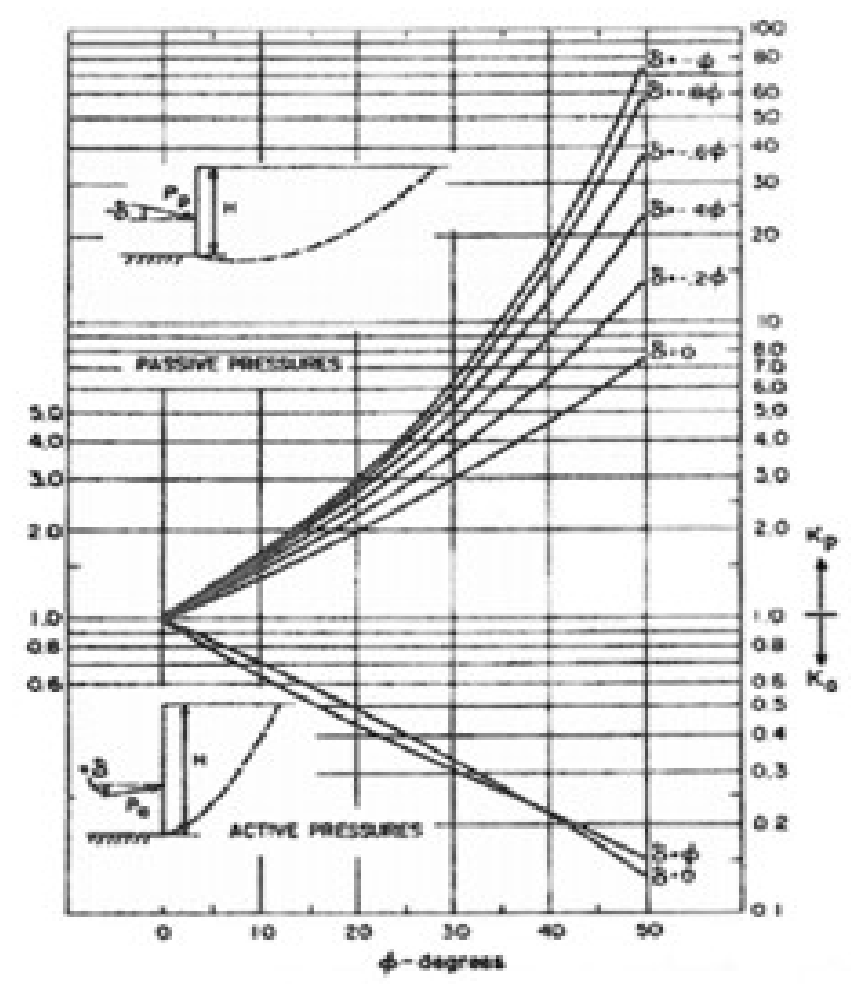

Figure 2.17 Lateral Earth Pressure Coefficient Based on Log Spiral Failure Surface Including Friction between Wall and the Soil (Caquot \& Kerisel, 1948) 


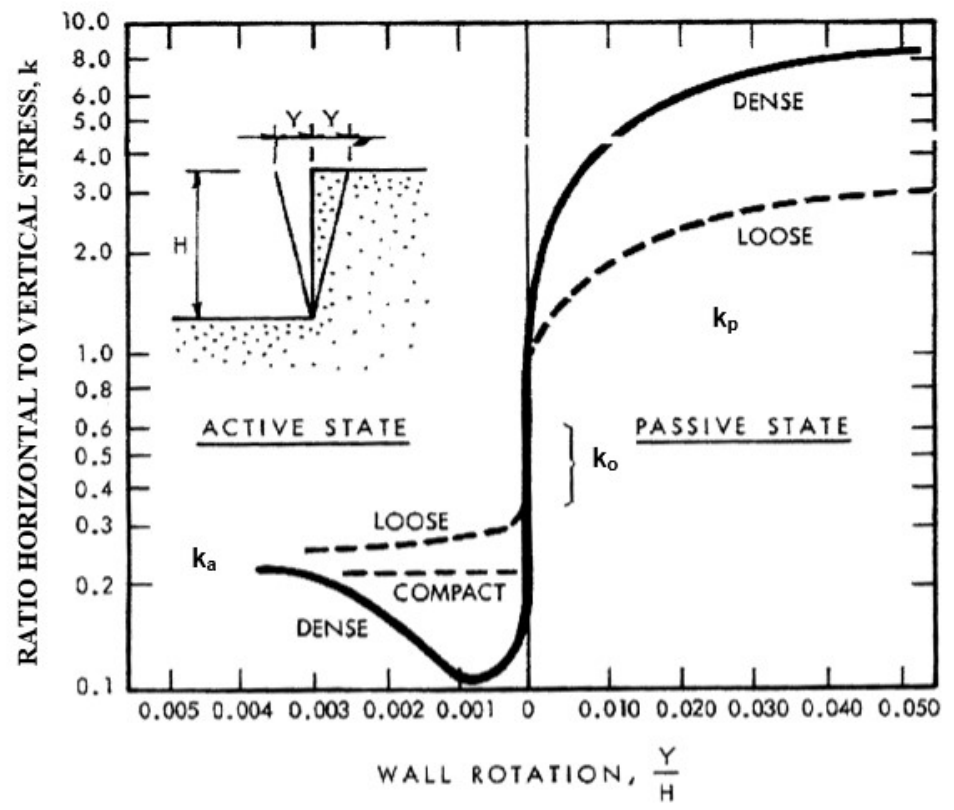

Figure 2.18 Lateral Earth Pressure Coefficients Ignoring Wall Friction and Considering Pure Rotation and Plan Failure Surface (Canadian Foundation Engineering Manual, 1992)

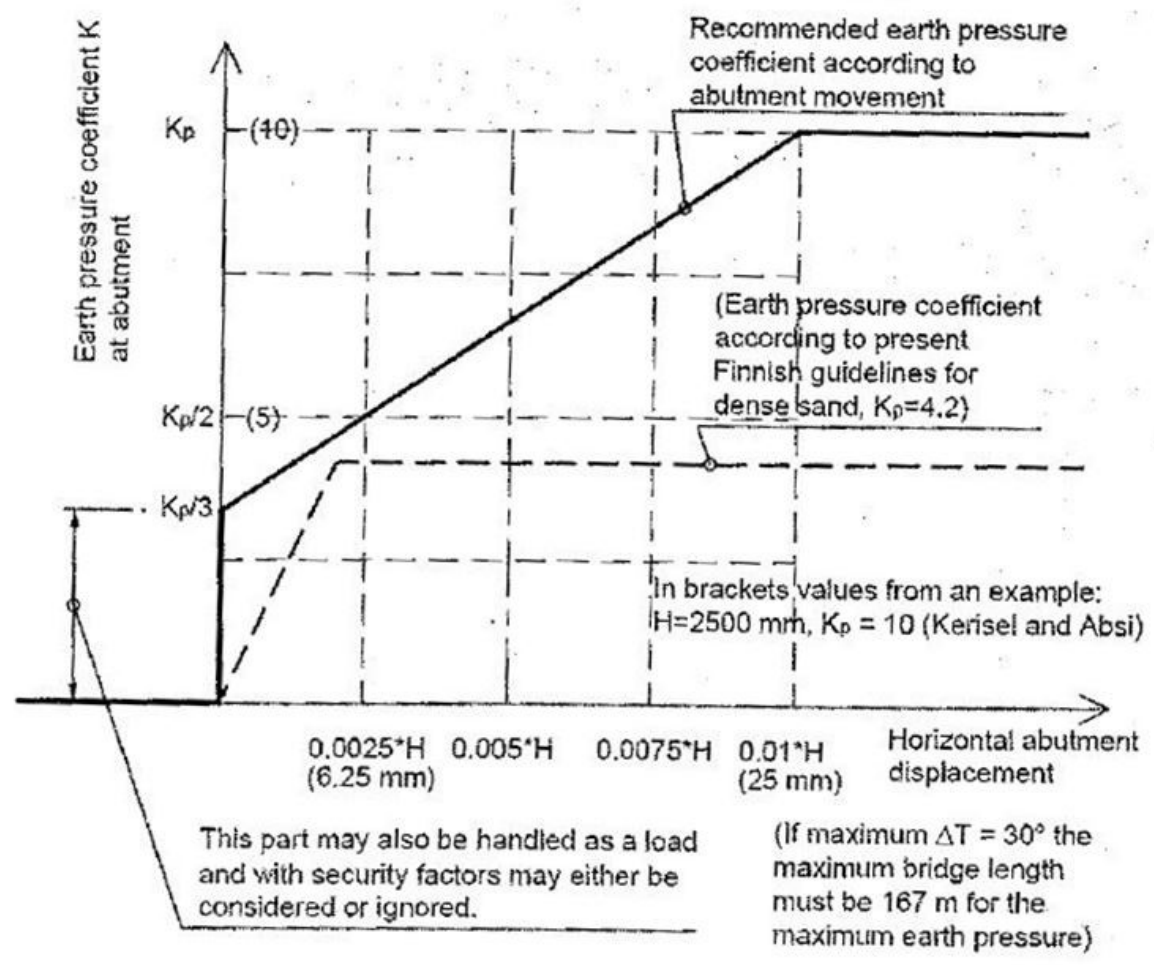

Figure 2.19 Recommended Earth Pressure Coefficients Based on Abutment Displacement (Kerokoski, 2006) 

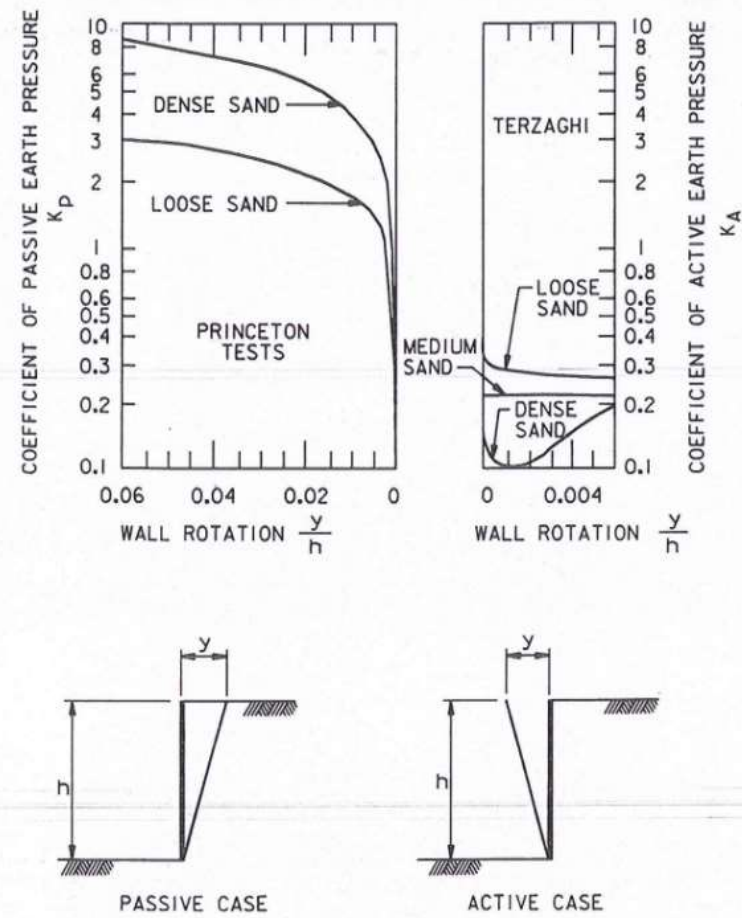

Figure 2.20 Passive Earth Pressure Versus Wall Movement (U.S.Department of the Navy, 1982)
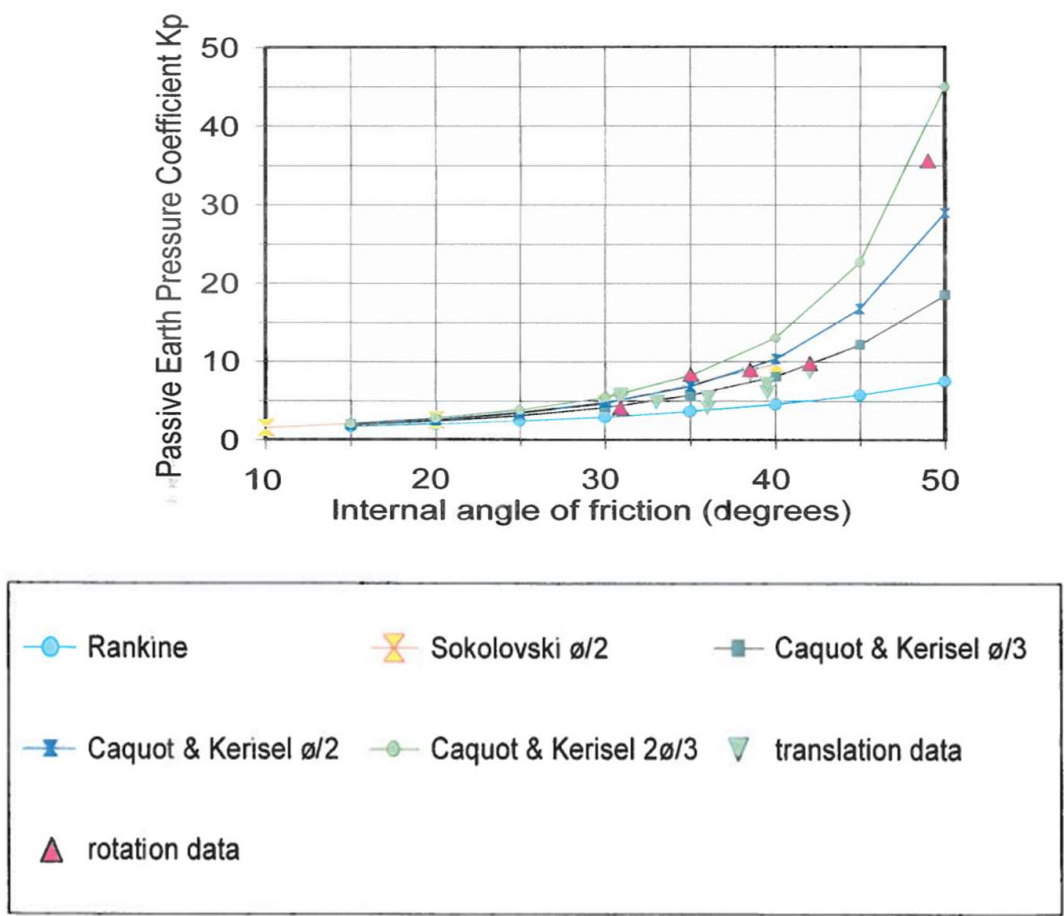

Figure 2.21 Passive Earth Pressure Coefficients Versus Soil Friction Angle (Caquot \& Kérisel, 1948) 
Table 2.11 Passive Earth Pressure Coefficient Versus Soil Friction Angle (Caquot \& Kérisel, 1948)

\begin{tabular}{|c|c|c|c|c|c|}
\hline$\phi$ & $\delta=0$ & $\delta=\phi / 3$ & $\delta=\phi / 2$ & $\delta=2 \phi / 3$ & $\delta=\phi$ \\
\hline $15^{\circ}$ & 1.70 & 1.89 & 1.99 & 2.08 & 2.19 \\
\hline $20^{\circ}$ & 2.04 & 2.41 & 2.59 & 2.79 & 3.01 \\
\hline $25^{\circ}$ & 2.46 & 3.12 & 3.47 & 3.84 & 4.29 \\
\hline $30^{\circ}$ & 3.00 & 4.15 & 4.79 & 5.49 & 6.42 \\
\hline $35^{\circ}$ & 3.69 & 5.70 & 6.87 & 8.24 & 10.20 \\
\hline $40^{\circ}$ & 4.60 & 8.13 & 10.40 & 13.10 & 17.50 \\
\hline $45^{\circ}$ & 5.83 & 12.20 & 16.80 & 22.70 & 33.50 \\
\hline
\end{tabular}




\subsection{Abutment Soil Friction Coefficient}

The static friction coefficient between the abutment and the soil is dependent on the materials in contact, which is in this case the concrete abutment and the granular soil and independent of the contact area between the two materials (Gorst et al., 2003). The properties of the contact surface has an effect in determining the value of the coefficient of static friction as shown in Table 2.12 for the numerical models. The coefficient of the static friction depends on the degree of roughness and texture of the concrete surface, the kind of formwork used, and the soil properties supporting the abutment. The coefficient of static friction between the abutment and the soil was taken as 0.4 , which is agreeable with the values found in the literature and listed in Table 2.13.

Table 2.12 Static Friction Coefficients for Different Materials (Gorst et al., 2003)

\begin{tabular}{|c|c|c|c|c|c|c|c|c|c|c|c|c|c|c|c|c|c|}
\hline & & & SURFACF & & & & & & & & & & & & & & \\
\hline & & & & St & & & Alum. & & & Timber & & & & $\mathrm{Ply} v$ & rood & & Concrete \\
\hline SIRFACE? & & & Plain & Plain & Galv. & Prop. & Prop. & Soft w & & Hard n & & Proprietary & Good & Combi & Film & Film & Cast \\
\hline SUNATE & & & Unrusted & rusted & & painted & waling & Parallel & Perp & Parallel & Perp & beam & one side & ply faced & Fimnish & quality & face \\
\hline & Plain unrust & & 0.3 & 0.4 & 0.3 & 0.3 & 0.2 & 0.3 & 0.4 & 0.4 & 0.5 & 0.5 & 0.3 & - & - & 0.1 & 0.1 \\
\hline & Plain rusted & & 0.4 & 0.4 & 0.3 & 0.6 & 0.3 & - & - & 0.6 & -. & 0.4 & 0.3 & 0.2 & 0.2 & 0.2 & - \\
\hline & Galvanised & & 0.3 & 0.3 & 0.2 & 0.4 & 0.2 & 0.4 & 0.5 & 0.5 & 0.5 & 0.4 & 0.2 & -. & - & 0.1 & -. \\
\hline & Proprietary & ainted & 0.3 & 0.6 & 0.4 & 0.7 & 0.4 & 0.4 & 0.4 & 0.4 & 0.5 & 0.5 & 0.4 & 0.2 & 0.2 & 0.1 & 0.0 \\
\hline Aluminium & Proprietary & aling & 0.2 & 0.3 & 0.2 & 0.4 & 0.2 & 0.4 & 0.4 & 0.4 & 0.3 & 0.2 & 0.2 & 0.2 & 0.2 & 0.1 & - \\
\hline & Con & Parallel & 0.3 & - & 0.4 & 0.4 & 0.4 & 0.6 & 0.5 & 0.4 & 0.4 & 0.4 & 0.2 & 0.2 & 0.3 & 0.2 & 0.8 \\
\hline & Sortwood & Perpendicular & 0.4 & - & 0.5 & 0.4 & 0.4 & 0.5 & - & 0.4 & -. & 0.3 & 0.3 & 0.2 & 0.2 & 0.1 & 0.7 \\
\hline Timber & H & Parallel & 0.4 & 0.6 & 0.5 & 0.4 & 0.4 & 0.4 & 0.4 & 0.4 & 0.5 & 0.4 & 0.3 & - & - & 0.2 & 0.5 \\
\hline & hararitiod & Perpendicular & 0.5 & - & 0.5 & 0.5 & 0.3 & 0.4 & - & 0.5 & - & 0.4 & 0.3 & - & - & 0.2 & 0.7 \\
\hline & & Proprietary beam & 0.5 & 0.4 & 0.4 & 0.5 & 0.2 & 0.4 & 0.3 & 0.4 & 0.4 & 0.5 & 0.3 & - & - & 0.1 & - \\
\hline & Good one sic & & 0.3 & 0.3 & 0.2 & 0.4 & 0.2 & 0.2 & 0.3 & 0.3 & 0.3 & 0.3 & 0.3 & 0.2 & 0.2 & 0.2 & 0.3 \\
\hline & Combi ply $f$ & & - & 0.2 & - & 0.2 & 0.2 & 0.2 & 0.2 & -. & -. & - & 0.2 & -. & - & - & 0.3 \\
\hline & Film faced $\mathrm{F}$ & unish & - & 0.2 & - & 0.2 & 0.2 & 0.3 & 0.2 & -. & -. & - & 0.2 & - & - & - & 0.3 \\
\hline & Film faced $\mathrm{Q}$ & & 0.1 & 0.2 & 0.1 & 0.1 & 0.1 & 0.2 & 0.1 & 0.2 & 0.2 & 0.1 & 0.2 & -. & - & 0.2 & 0.2 \\
\hline Hardened & Cast face & & 0.1 & - & - & 0.0 & - & 0.8 & 0.7 & 0.5 & 0.7 & -- & 0.3 & 0.3 & 0.3 & 0.2 & 0.4 \\
\hline Concrete & Trowelled fa & & 0.5 & 0.7 & 0.2 & 0.6 & 0.4 & 1.1 & 0.7 & 0.7 & 0.6 & 0.6 & 0.3 & - & - & - & 0.4 \\
\hline Soil & Granular & & 0.3 & -. & - & 0.3 & - & 0.3 & 0.3 & 0.3 & 0.3 & -. & - & -. & - & - & 0.4 \\
\hline
\end{tabular}


Table 2.13 Minimum Value of Coefficient of Static Friction (Gorst et al., 2003)

\begin{tabular}{|c|c|c|c|c|c|}
\hline $\begin{array}{c}\text { Lower Load } \\
\text {-Accepting } \\
\text { Member }\end{array}$ & \multicolumn{5}{|c|}{ Upper Load-Accepting Member } \\
\cline { 2 - 6 } & Plain Steel & Painted Steel & Concrete & Softwood & Hardwood \\
\hline Plain Steel & 0.15 & 0.10 & 0.10 & 0.20 & 0.10 \\
\hline $\begin{array}{c}\text { Painted } \\
\text { Steel }\end{array}$ & 0.10 & 0 & 0 & 0.20 & 0 \\
\hline Concrete & 0.10 & 0 & 0.40 & 0.40 & 0.30 \\
\hline $\begin{array}{c}\text { Softwood } \\
\text { Granular } \\
\text { Soil }\end{array}$ & 0.20 & 0.20 & 0.40 & 0.40 & 0.30 \\
\hline \begin{tabular}{c} 
Hardwood \\
\hline
\end{tabular} & 0.10 & 0.30 & 0.40 & 0.30 & 0.30 \\
\hline
\end{tabular}




\section{CHAPTER 3}

\section{FINITE ELEMENT MODEL DESCRIPTION AND VALIDATION}

\subsection{Introduction}

A three-dimensional finite element model using the commercial software CSI Bridge/SAP2000 (SAP2000, 2019) was used to model the integral abutment bridges. The three-dimensional numerical model comprised of the superstructure (slab, girders, and solid steel diaphragms) and the substructure (abutment and piles supporting the abutment as well as the foundation soil and the backfill behind the abutments). The bridges were numerically analyzed under the effect of self-weight and thermal loading of \pm 65 degrees. This chapter addresses the types of elements and the technique implemented to achieve the numerical results.

\subsection{Bridge Geometry}

The bridge considered in this study consisted of five built-up main girders. The web of the girder was manufactured from steel plates of $20 \mathrm{~mm}$ thickness, while the flanges were manufactured from steel plates of $40 \mathrm{~mm}$ thickness. The height of the web was taken 1200 $\mathrm{mm}$ and the width of the flanges was taken $500 \mathrm{~mm}$. Diaphragms of $1200 \mathrm{~mm}$ height and 20 $\mathrm{mm}$ thickness were used to brace the main girders in the radial direction. The diaphragms were attached to the main girders via rigid connections. The diaphragms were placed in radial direction as shown in Figures 3.1 and 3.2. Diaphragms were also placed on top of the piers.

\subsection{Model Geometry}

The finite element models were generated in this study based on varying the bridge length at constant radius. Table 3.1 illustrates the different parameters used in this study, where $L_{i}(i=1$ to 6) stands for the length of the bridge along the outer girder curved centerline in meters. The table includes the radius of curvature $R$, average diaphragm spacing along bridge curved centerline, $\mathrm{S}_{\mathrm{D}}$, and pier spacing along the outer girder curved centerline, $\mathrm{S}$, all in meters. The total bridge length was computed according to the equation " $\mathrm{L}=\mathrm{R} \theta$," where $\mathrm{R}$ was taken as the outer radius of curvature as depicted in Figure 3.2 and $\theta$ in radians, while the width of the bridge, $\mathrm{W}$, in all models was taken equal to $12.5 \mathrm{~m}$, representing a two-lane bridge crosssection showing in Figure 3.1. The bridge cross-section was made of $200 \mathrm{~mm}$ thick slab fully 
connected on top of 5 steel I-girders. The girders were spaced at $3 \mathrm{~m}$ and connected together using steel solid diaphragms of $20 \mathrm{~mm}$ thickness and 1200 depth. The girder had $500 \times 40 \mathrm{~mm}$ top and bottom flange and $1200 \times 20 \mathrm{~mm}$ web. The baseline was the outer periphery of the bridge. The bridge length $(L)$ was measured along the baseline as well the pier spacing's $(S)$. While the spacing between the diaphragms $\left(S_{D}\right)$ was measured along the curved centerline of the bridge's deck. The abutment of $1.0 \mathrm{~m}$ thickness having three different heights, $\mathrm{H}$, namely: $4 \mathrm{~m}, 5.32 \mathrm{~m}$ and $6.64 \mathrm{~m}$. The piers were of rigid type. Rigidity of the piers can be achieved by installing a pile group to support loads transmitted to the pier. The pier extended in radial direction to support the five main girders. Piles arranged in one row were installed to support the abutment loads and to accommodate the bridge end-displacement resulting from all loads acting on the bridge deck in addition to thermal loading. Each abutment was supported on 9 piles arranged in one row and oriented in strong axis as shown in Figure 3.2 (b). Strong axis was parallel to the centerline of abutment. The piles were installed such as one pile underneath the end of each girder, and one is under the mid-distance between two subsequent girders.

The steel girders were integrated with abutment of thickness $1.0 \mathrm{~m}$ considering rigid joints between them. Figure 3.3 presents complete view of one of the finite element models of a bridge having 5-bridge spans. The concrete slab was modeled using shell elements with nodes placed along the centerline and edges of each main girder in the tangential direction of the bridge. Additional nodes were placed on lines half-way between girders leading to shell element aspect ratio 2.23 .

Shell elements were used to model the steel I-girders with nodes at each end of the flange and three nodes along the web. These nodes were spaced $3.35 \mathrm{~m}$ in longitudinal direction. Lydzinski and Baber (2008) emphasized that the number of elements per girder cross section has little influence on results. But the results were more sensitive to the two nodes located at the edge of the top flange of the steel I-girders In addition to the nodes located on top of the web and connected to slab nodes with rigid links. Each abutment was modeled using shell elements, with each element having 4 nodes. The nodes were along the same line of superstructure as shown in Figure 3.4 and 3.5. The vertical distance between the nodes in the abutment was $0.66 \mathrm{~m}$, except the top two lines of nodes, whereas the spacing was $0.12 \mathrm{~m}$. 
Piles were modeled using frame elements. At each layer of nodes, three nonlinear springs simulating the soil were placed. The springs were in three orthogonal directions. One spring was in the vertical direction and the other two were oriented in lateral directions were perpendicular to each other. The top three orthogonal springs were at $0.3 \mathrm{~m}$ below the abutment height, while the spacing between others were $0.97 \mathrm{~m}$. Since the piles of $12.0 \mathrm{~m}$ were supposed to be embedded $0.40 \mathrm{~m}$ to $0.66 \mathrm{~m}$ into the abutment, the connection between the abutment and top of pile were considered rigid.

Finally the radial diaphragms were modeled by four-node shell elements. Two-nodes located along the centerline of steel I-girders were shared with the diaphragm shell elements. The top shared node was located at point of intersection of the top flange of the girder and the diaphragm. The bottom shared node was attached at point of intersection of the bottom flange of the girder and diaphragm. Figure 3.6 presents meshing of bridge concrete deck, where the width of the bridge was discretized into eighteen elements. While Figures 3.7 and 3.8 present simulation of the diaphragms and the I-girder beams.

Figures 3.9 and 3.10 show the common nodes between the abutment and steel I-girders to ensure complete integration between the abutment and the bridge deck. At each abutment, there were seven common nodes for each girder. Noteworthy, each node of the shell and frame elements had six degrees of freedom, three translations and three rotations.

Each element had local coordinate systems 1, 2 and 3, which are different from the global coordinate system $x, y$ and $z$. Both systems are right-handed coordinate systems. The element's local coordinate system used to define force-deformation properties and output. Axis (1) is directed along the length of the element and corresponding to expansion/contraction deformation, the other two axes corresponding to shear deformation. McBride, (2013) has elaborated on the transformation from global to local coordinate system when building the finite element model for curved integral bridge. As mentioned earlier, a similar approach has been tackled in the current study.

Table 3.1 shows total bridge length ranging from $L_{1}$ to $L_{6}$ with pier spacing listed in the last column of the table. So, the number of bridge spans for each bridge configuration is calculated as the bridge length of $L_{1}$ through $L_{6}$ values divided by the pier spacing. As an example, Figure 3.2 (a) shows schematic diagram of a curved integral abutment bridge considering 2 spans 
with total length at the outer side, far away from the center of curvature, equal $2 S$ that represent the case of total bridge length of $L_{2}$ listed in Table 3.1. While Figure 3.2 (b) shows the orientation of the piles adopted in this study with strong axis of the pile oriented in the tangential direction.

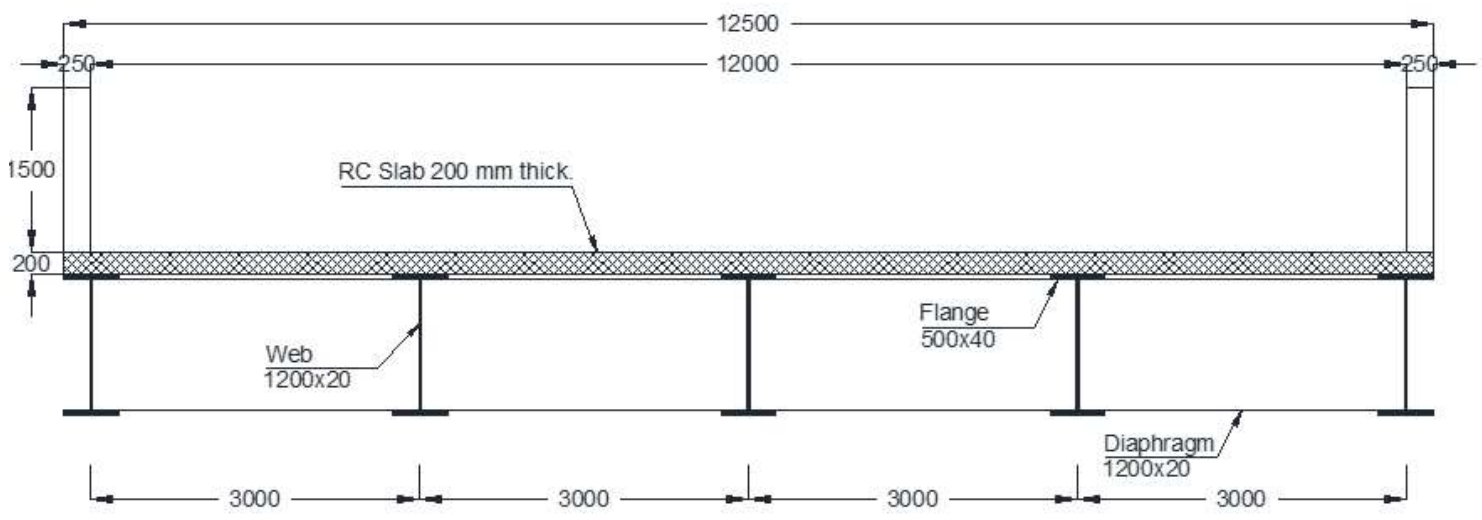

Figure 3.1 Schematic Diagram Showing Typical Cross Section used in the Finite Element Models

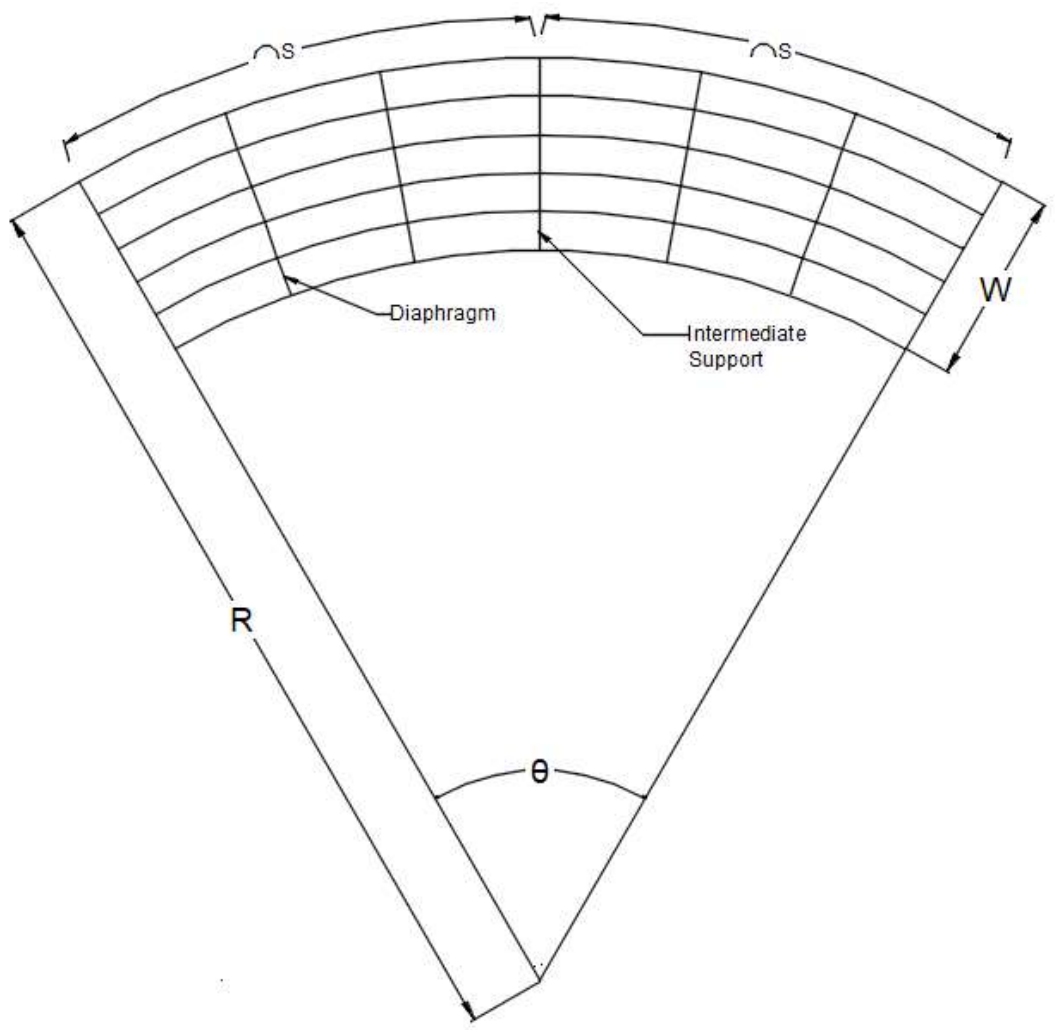

Figure 3.2 (a) Schematic Diagram Showing the outer Radius (R), Theta $(\theta)$, Span (S) and Bridge Width (W) 


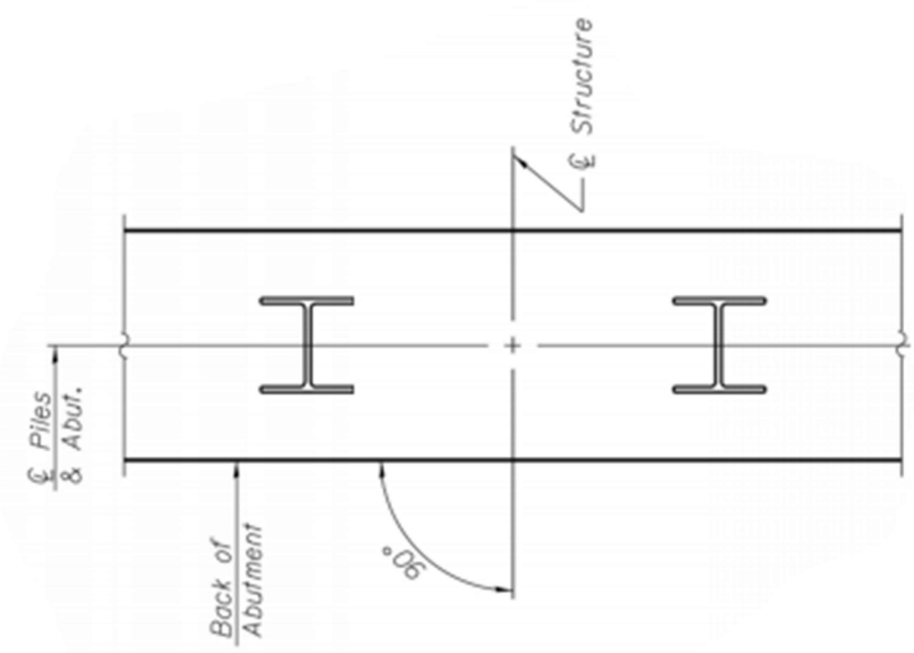

Figure 3.2 (b) Schematic Diagram Showing the Orientation of the Piles in Regards to the Abutment Adopted in this Study

Table 3.1 Description of the Bridges Considered in This Study

\begin{tabular}{|c|c|c|c|c|c|c|c|c|}
\hline $\begin{array}{c}\text { Radius } \\
(\mathbf{R}) \\
(\mathbf{m})\end{array}$ & $\mathrm{L}_{1}$ & $\mathrm{~L}_{2}$ & $\mathrm{~L}_{3}$ & $\mathrm{~L}_{4}$ & $\mathrm{~L}_{5}$ & $\mathrm{~L}_{6}$ & $\begin{array}{c}\text { Average } \\
\text { Diaphragm }\end{array}$ & $\begin{array}{c}\text { Pier } \\
\text { Spacing } \\
\text { at outer } \\
\text { Edge (S) } \\
(\mathbf{m})\end{array}$ \\
\hline 60 & 20.94 & 41.88 & 62.83 & 83.77 & 104.71 & 125.66 & 4.69 & 20.94 \\
\hline 100 & 34.90 & 69.81 & 104.71 & 139.62 & 174.52 & 209.43 & 3.27 & 17.45 \\
\hline 150 & 52.35 & 104.71 & 157.07 & 209.43 & 261.79 & 314.15 & 5.02 & 26.17 \\
\hline 200 & 69.81 & 139.62 & 209.43 & 279.24 & 349.05 & 418.86 & 6.76 & 17.45 \\
\hline 250 & 87.26 & 174.52 & 261.79 & 349.05 & 436.31 & 523.58 & 8.51 & 21.8 \\
\hline 300 & 104.70 & 209.40 & 314.10 & 418.80 & 523.50 & 628.30 & 10.25 & 26.17 \\
\hline
\end{tabular}

In the finite element modeling, material and section properties were defined as follows: the concrete unit weight for the slab and abutments was taken as $23.5 \mathrm{kN} / \mathrm{m}^{3}$, while the steel unit weight for piles, girders and diaphragms was taken as $76.97 \mathrm{kN} / \mathrm{m}^{3}$. The section properties were reasonably derived from actual and similar integral abutment bridges in the field. 
For the abutment thickness, it was taken as $1 \mathrm{~m}$ and kept constant for all the finite element models generated in this study. The $1 \mathrm{~m}$ thickness of the abutment is a reasonable assumption based on actual abutment thicknesses for integral abutment bridges in the field. Nevertheless, a sensitivity study was made on the effect of varying abutment thickness on thermal-induced pile displacement and it was found that the abutment thickness has no effect on the displacement of laterally loaded abutment piles.

The concrete slab thickness was taken as $0.2 \mathrm{~m}$. In considering the girder dimensions, care was addressed towards the stability of the girder as a whole and the stability of the girder components such as the flange and the web to general and local buckling. As such, the girder dimensions were adopted from actual girder dimensions for an integral abutment bridge in the field with a span length little bit greater than that assumed in the models.

\subsubsection{Dimensions of Curved Steel I-Girder}

The dimensions of steel I-girders were justified according to the AASHTO LRFD Bridge Design Specifications (AASHTO 2017). The depth-to-thickness ratio which satisfies compact section requirements for the web is:

$\frac{D}{t_{w}} \leq \frac{19230}{\sqrt{f_{y}}}$

$D=$ Clear distance between the flanges (in.),

$t_{w}=$ Web thickness (in.),

$f_{y}=$ Specific yield stress for steel (psi).

Applying the above equation for a web thickness of $20 \mathrm{~mm}$ (0.78 in.) and web height of 1200 $\mathrm{mm}$ (47.24 in.) and taken $f_{y}$ as $380 \mathrm{~N} / \mathrm{mm}^{2}$ (55,000 psi), yields depth-to-thickness ratio equal to 60 which is less than the maximum allowable value of 82 . To satisfy compact requirements of the flange, the width to thickness ratio must satisfy the following formula:

$$
\begin{aligned}
\frac{b}{t} & \leq \frac{4110}{\sqrt{f_{y}}} \\
b & =\text { Flange width (in.), } \\
t & =\text { Flange thickness (in.), } \\
f_{y} & =\text { Specific yield stress for steel (psi). }
\end{aligned}
$$


Applying the above equation for a flange width of $500 \mathrm{~mm}$ and thickness of $40 \mathrm{~mm}$ gives width-to-thickness ratio of 12.5 which is the less than the maximum allowable thickness ratio of 17.5.

\subsubsection{Supporting Piles}

The piles were chosen as an HP section which is the most common type of piles used in integral abutment bridges. The spacing between the piles was taken as $1.5 \mathrm{~m}$ and a total number of 9 piles at each abutment was used. The length of the pile was taken as $12 \mathrm{~m}$ below bottom-of-abutment and the piles were oriented as such the pile strongest axis is parallel to the direction of abutment as depicted in Figure 3.2. Along HP piles, concrete filled steel pipes (CFT) are used for integral abutment foundations such as the ones used in Southbound I-65 over SR-25 bridge. This bridge is an integral abutment bridge in Tippecanoe County, USA, which used combination of both HP piles, namely HP $12 \times 53$, and concrete filled steel pipes CFT 14.5x0.25 (Frosch \& Lovell, 2011). It must be noted that pile connection with the abutment in the finite element models was taken as fixed connection as shown in Figure 3.11. So, no moment release was applied at the abutment-pile connection. In the field, the fixed connection is established by providing enough pile embedment length inside the abutment, generally from 1 to $3 \mathrm{ft}$ with cage reinforcement spanning the embedment length (Burke, 1990).

The piles used in the numerical models was chosen to be HP $310 \times 125$ which has been used in several integral abutment bridges in the field such as Middlesex Bridge which is an integral abutment bridge located on VT12 over Martin's Brook in Middlesex, Vermont USA and East Montpelier Bridge which is an integral abutment bridge located on US2 over the Winooski River in East Montpelier, Vermont USA (Civjan et al., 2014). The HP $310 X 125$ pile dimensions in meters are as shown in Figure 3.12.

It is worth mentioning that Illinois Department of Transportation has created a chart for pile selection as depicted in Figure 3.13. The pile selection is based on several restricted criteria and assumptions in regards to pile orientation, type of soil in which the pile is embedded, soil unconfined compressive strength and bridge effective expansion length (Illinois Department of Transportation, 2012). 


\subsection{Soil Conditions}

Usually granular backfill geomaterial is adapted to backfill behind the bridge abutment. The abutment backfill material must have high coefficient of permeability to avoid building up pore water pressure, which may impose hydrostatic water pressure on the bridge abutment. Furthermore, the soil pressure resulted from the backfill has great influence on the bridge performance (Kalayci et al., 2012). Therefore, two conditions of the abutment backfill were considered namely: loose sand backfill and dense sand backfill. Also, the foundation soil can affect performance of the bridge especially during negative thermal loading (Civjan et al., 2007). While Albhaisi et al. (2012) concluded that clay stiffness and the foundation soil have a minor effect on the displacement of the top of the abutment. Upon this contradiction about the role of foundation soil on the bridge performance, two foundation soil, namely: stiff clay and medium dense sand, were adopted to emphasize the role of foundation soil on the performance of horizontally curved IAB. Accordingly, loose sand abutment backfill was simulated within the developed numerical model, while the foundation soil was considered either stiff clay or medium-dense sand. In addition, dense sand abutment backfill was simulated, while the foundation soil was considered either stiff clay or medium dense sand, as shown in Table 3.2. The constitutive geometrical parameters are presented in Table 3.3.

Table 3.2 Soil Conditions Considered in the Numerical Models

\begin{tabular}{|c|c|c|}
\hline Soil Cases & Abutment Backfill & Foundation Soil \\
\hline Case 1 & Loose sand & Stiff clay \\
\hline Case 2 & Dense sand & Stiff clay \\
\hline Case 3 & Loose sand & Medium dense sand \\
\hline Case 4 & Dense sand & \\
\hline
\end{tabular}


Table 3.3 Constitutive Geomaterial Parameters

\begin{tabular}{|c|c|c|c|}
\hline Type of Soil & $\begin{array}{c}\text { Unit Weight } \\
\mathbf{k N} / \mathbf{m}^{\mathbf{3}}\end{array}$ & Friction Angle $\boldsymbol{\Phi}$ & $\begin{array}{c}\text { Undrained Shear } \\
\text { Strength } \mathbf{~ N} / \mathbf{m}^{\mathbf{2}}\end{array}$ \\
\hline Loose Sand & 15 & 30 & - \\
\hline Dense Sand & 20 & 45 & - \\
\hline Medium Dense Sand & 18 & 35 & 100 \\
\hline Stiff Clay & 19 & - & \\
\hline
\end{tabular}

\subsection{Soil Layering}

It is worth mentioning that soil layering is out of the scope of this study. The piles were embedded in either homogeneous isotropic stiff clay formation or homogeneous isotropic medium dense sand formation. Nevertheless, some differences should exist in the lateral capacity of piles in case of layered soil. In reference to the paper by Yang and Jeremic (2005) on which they studied the effects of soil layering on the performance of laterally loaded piles. From their study, the authors concluded that consecutive stratification of sand-clay-sand, layers, the intermediate clay layer has effect on the lateral resistance of the upper sand layer, and also the sand layer has effect on the lateral resistance of the intermediate clay layer. This interaction in soil stiffness, to the best knowledge of the writer, is not yet modeled. Furthermore, the interaction between the stiffness of soil layers depends upon the consecutive stratification of soil layer. The interaction between layer stiffness of soft claysand-clay differs from sand-clay-sand stratification. Furthermore, the $p-y$ relationship was developed from field test on small diameter pile embedded in homogeneous soil either clay or sand. Therefore, $p-y$ relationship cannot be implemented in stratified soil. As a result of that discussion, foundation soil is homogenous isotropic and foundation soil comprises succession of different soil layers that is out of the scope of the current research.

\subsection{Asymmetric Soil Conditions at the Abutments}

In this research, soil conditions were assumed identical at both abutments and piers. If this is not the case, the bridge deck end displacement will not be equal at both abutments. Illinois 
Department of Transportation (2012) defines the effective expansion length (EEL) as a function of the stiffness of the abutment-soil system and pile-soil stiffness. Soil borings at both abutments and piers are used to recover soil samples to be tested in laboratory and assessing the properties of soil which in turn used to define abutment-pile-soil stiffness at each abutment. According to Illinois Department of Transportation, the critical pile depth is taken as the first ten feet of soil beneath the abutment. The critical pile length $\left(L_{c}\right)$ is defined as the length beyond which the pile behaves as if it was infinitely long. The critical pile length dependent upon pile bending stiffness and soil stiffness and type of soil that is either sand or clay. If the difference in the average unconfined compressive strength $\left(q_{u}\right)$ at each abutment within the critical pile length is $\leq 1.5$ tsf and each abutment has the same number of piles, the centroid of stiffness of the structure may be assumed to be at the center of the structure and the controlling expansion length may be assumed to be half the total structure length. In these cases, there are no corrections to be applied to the controlling expansion length. Where the difference in the average $q_{u}$, within the critical pile length, of the foundation soil at the abutments exceeds 1.5 tsf, a pile stiffness modifier (M) shall be used in determining the centroid of stiffness of the structure. The pile stiffness modifier accounts for the differences in soil stiffness and shall be calculated using the following formula:

$$
\mathrm{M}=\frac{1}{1.45-0.3 \mathrm{q}_{\mathrm{u}}}
$$

\subsection{Super and Substructure Model Description}

\subsubsection{The Developed Model}

As mentioned earlier, SAP2000 software was used to model a horizontally curved integral abutment bridges in this study.

Figures 3.3 and 3.4 shows views of one of the finite element models with and without soil springs, respectively. Figure 3.5 shows the node spacing along the piles taken as $0.97 \mathrm{~m}$ as well as the connection between the pile head and the abutment. Figure 3.6 shows the meshing of the bridge concrete deck in the finite element models. Figure 3.7 shows diaphragm spacing for one of the models. In that particular model, a total of 7 diaphragms 
were used, one at the pier support and 3 diaphragms on each side of the pier for a total bridge length of $41.88 \mathrm{~m}$, representing the case of bridge length of $L_{2}$ in Table 3.1.

In all the models, rigid link members were used to join each joint of the girder and the corresponding joint on the slab as shown in Figure 3.8. The abutment was divided along its height with spacing between the generated nodes of no more than $0.66 \mathrm{~m}$ as depicted in Figure 3.9. The girders were integrated in the abutment, generating common nodes between the abutment and the girders as shown in Figure 3.10.

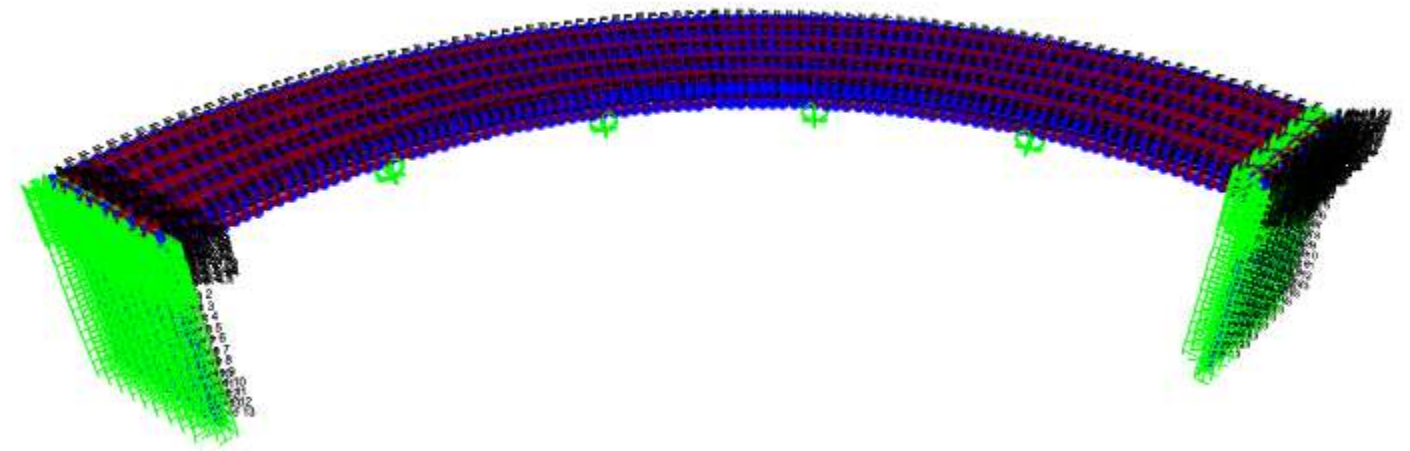

Figure 3.3 Complete View of One of the FEM from SAP2000 Software with the Presence of Soil Springs

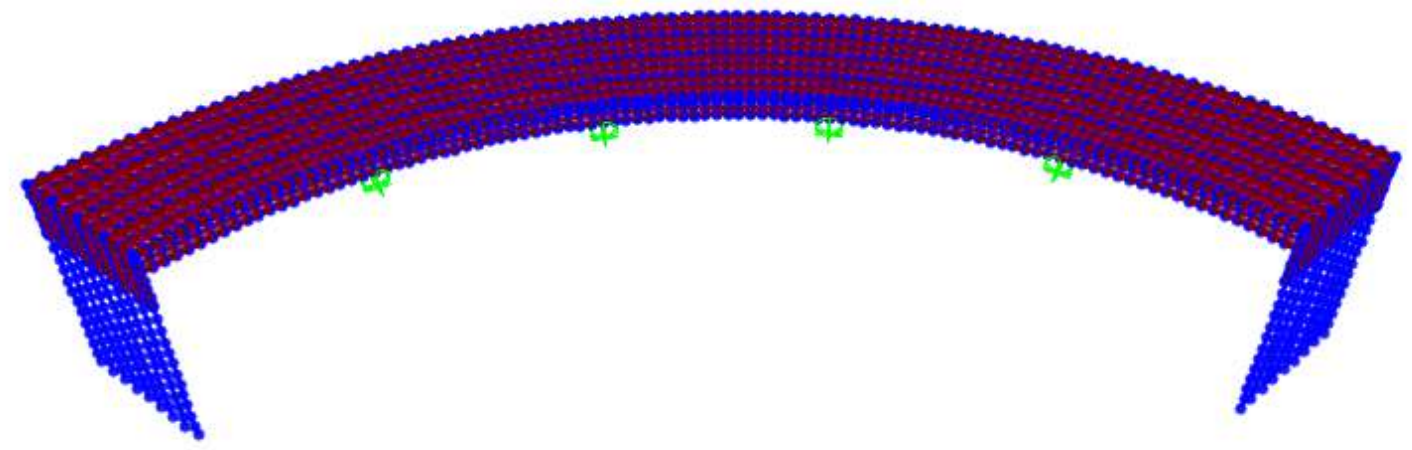

Figure 3.4 View of One of the FEM from SAP2000 Software without Showing Soil Springs 


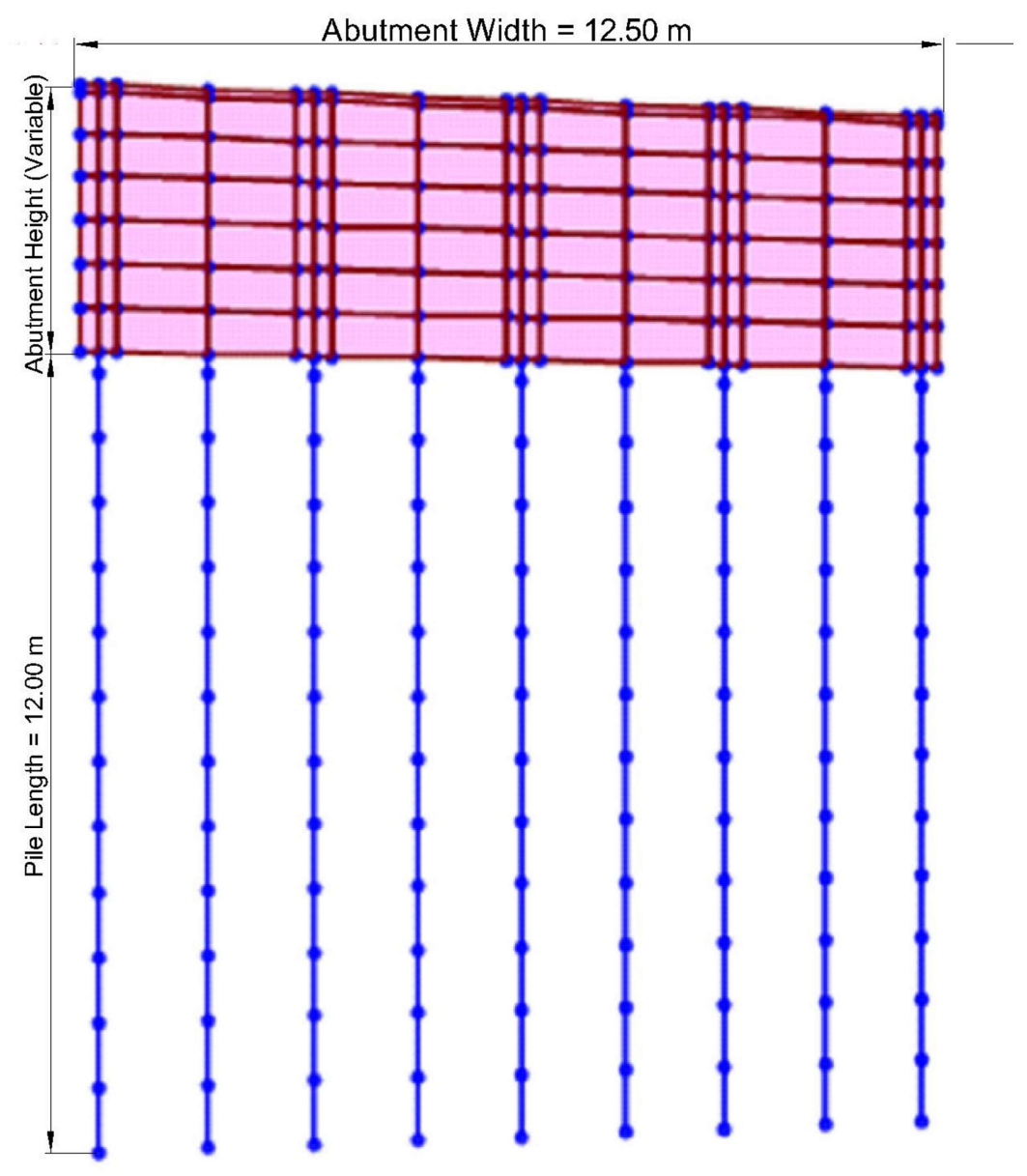

Figure 3.5 Nodes Spacing Along the Piles from SAP2000 Software

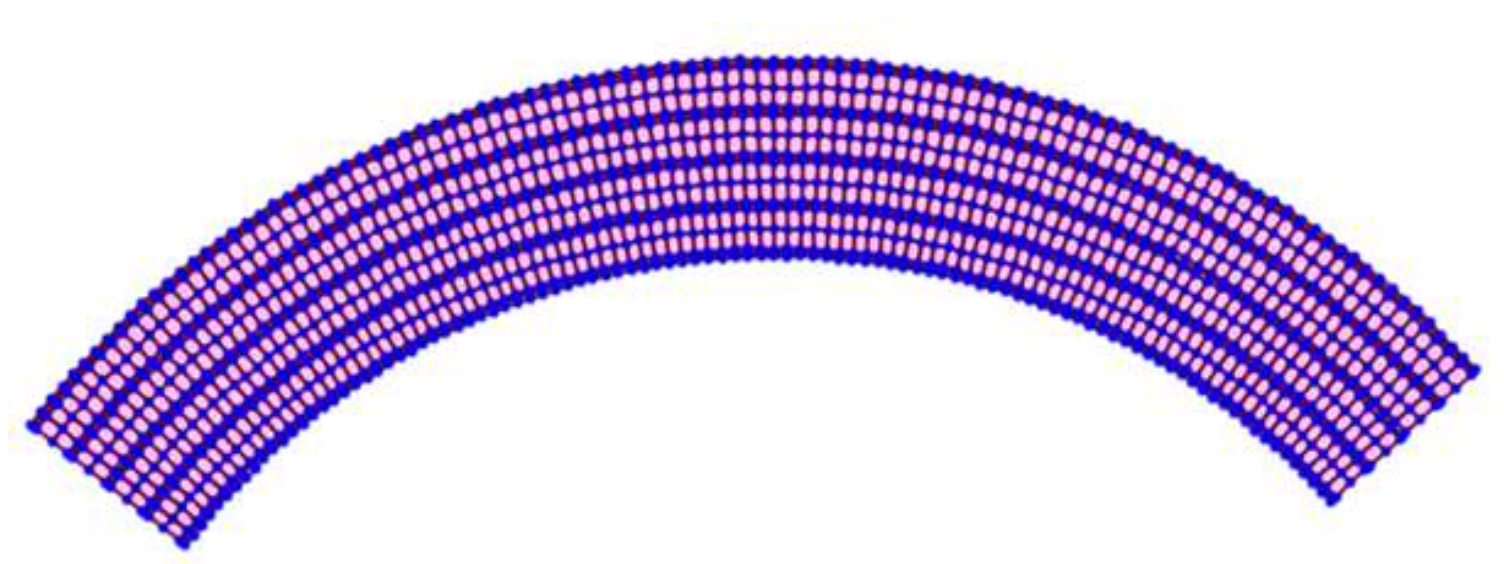

Figure 3.6 View of the Meshing of the Bridge Concrete Deck in the Finite Element Model from SAP2000 Software 


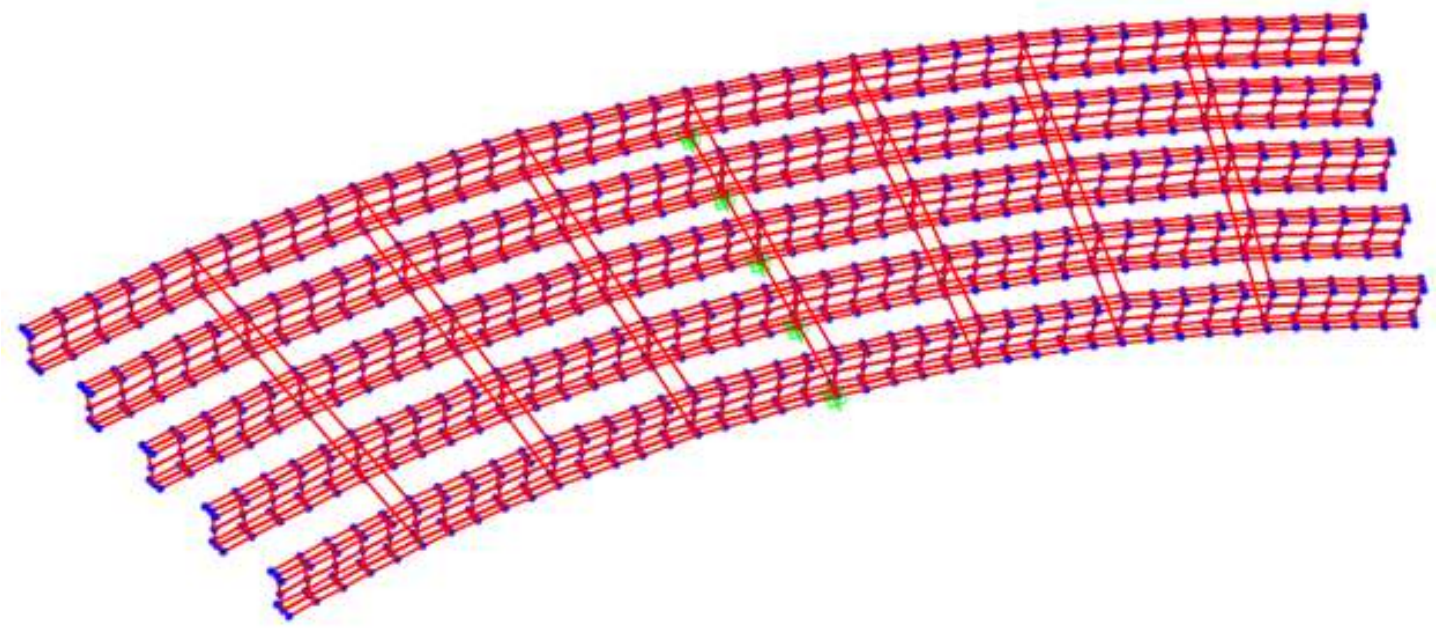

Figure 3.7 View from SAP2000 Model Showing Diaphragm Spacing

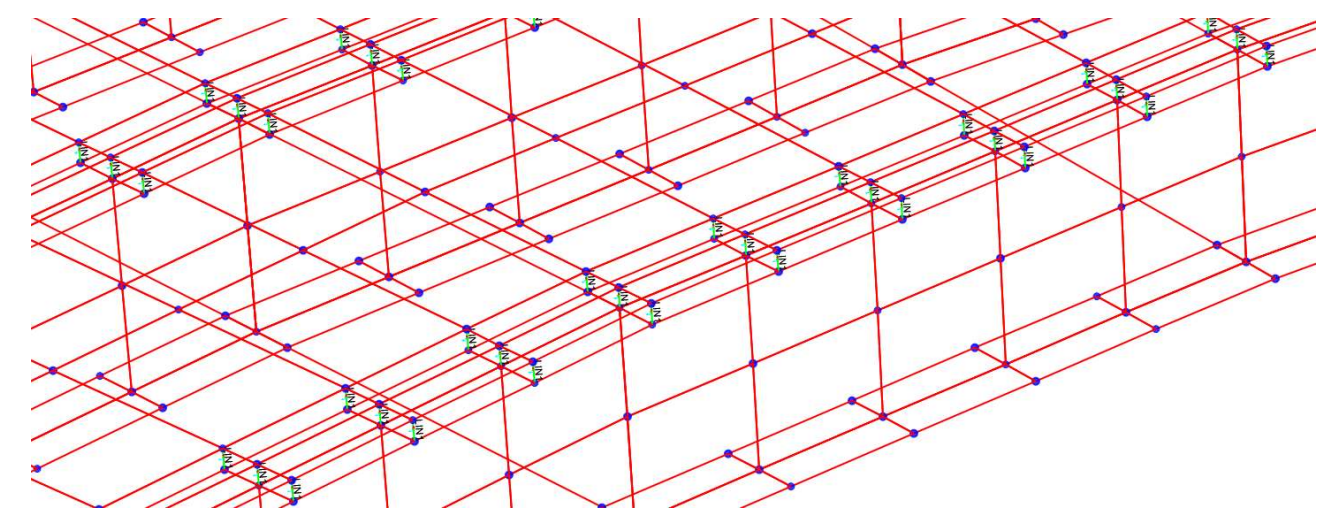

Figure 3.8 View of Joints of the Deck Slab and the Steel Top Flange Linked by Fixed Link Members Available in Sap20000 Software 


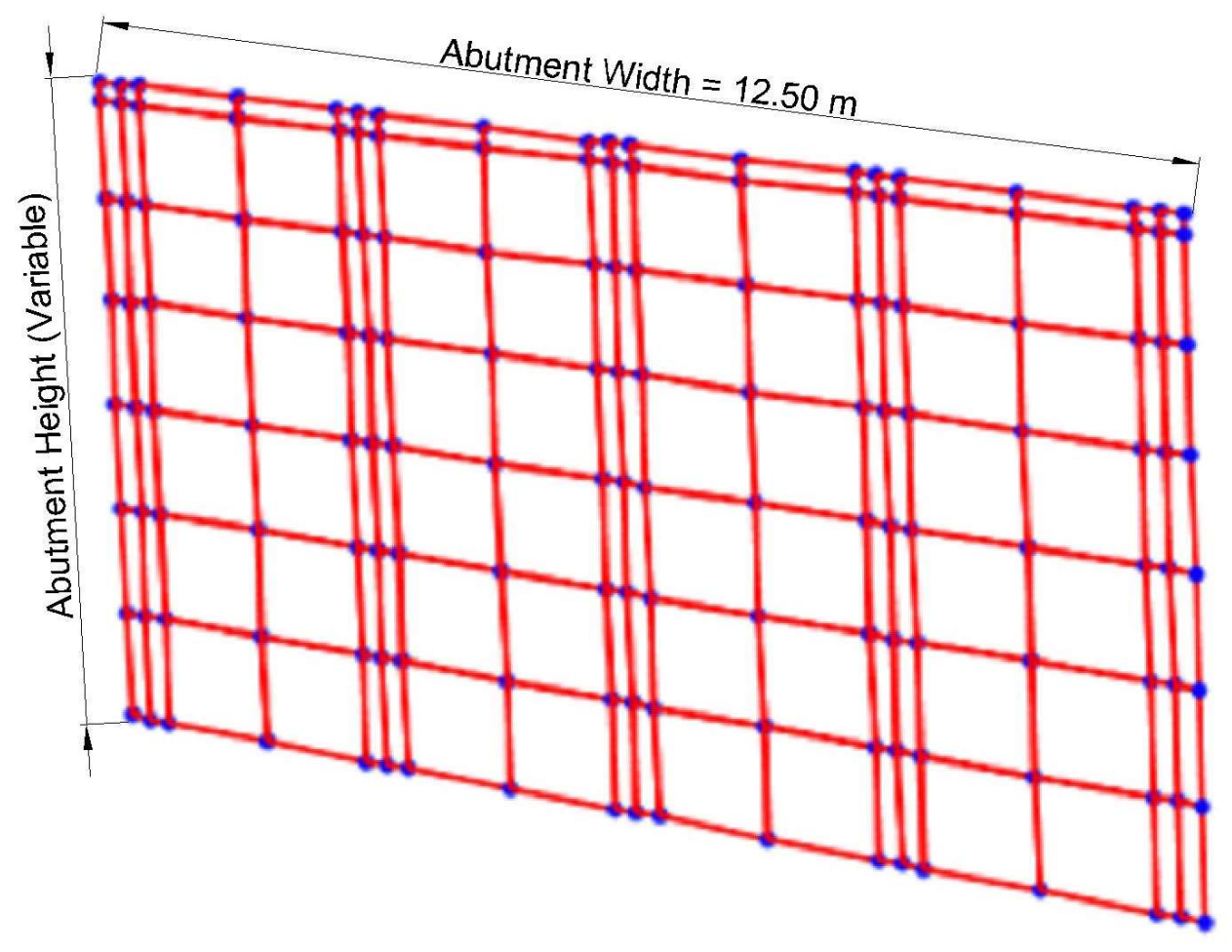

Figure 3.9 View of Abutment Mesh from SAP2000 Software

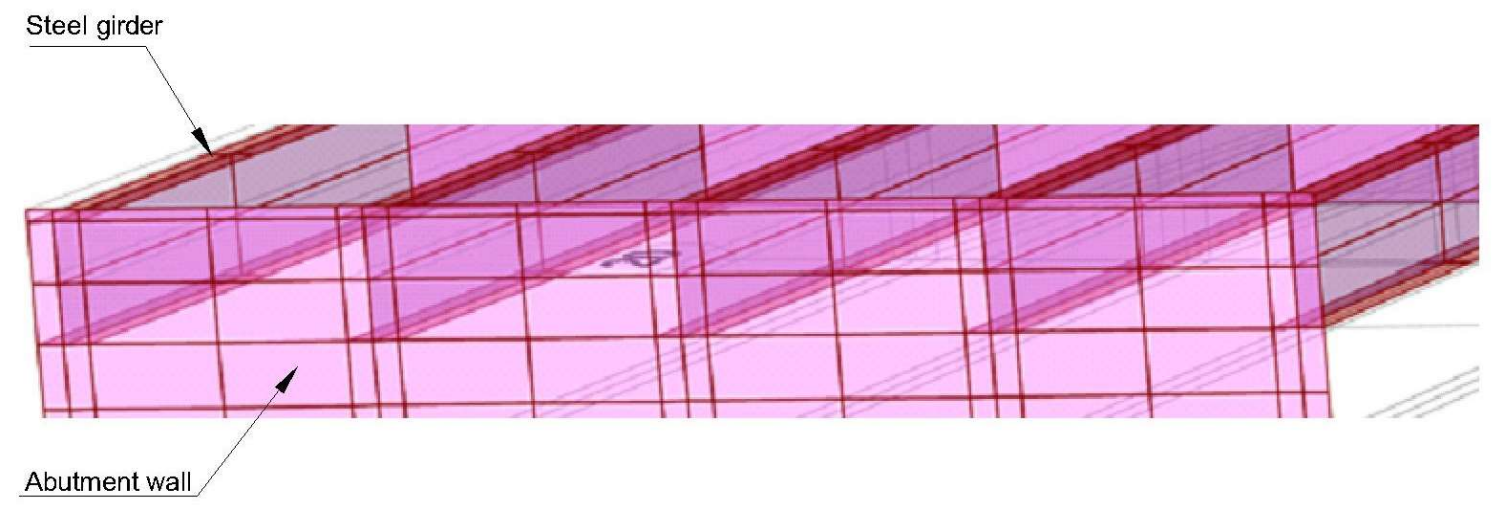

Figure 3.10 View of Common Joints Between Abutment and Girders from SAP2000

The quick bridge tool was assessed in CSI Bridge. It was found that using the quick bridge option in CSI bridge software is helpful in generating straight and skewed bridges. While for curved bridges unless extreme care, prudence and knowledge are practiced, the chance of generating asymmetric curved bridge is high. So, based on this finding, for sake of validation, for straight and skewed bridges modeled, quick bridge tool was used as well as other technique of modeling such as building the model by generating first the grid lines. 
For modeling curved bridges, the quick bridge tool was not used. Instead, the models were built by generating grid lines in both radial and tangential coordinates, and along the $Z$ direction to create the three-dimensional model.

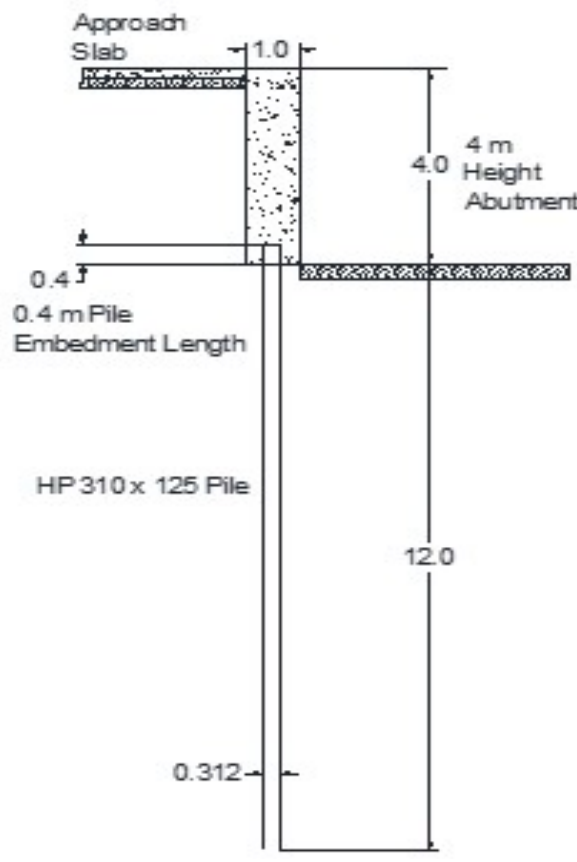

Figure 3.11 Schematic Diagram of Pile Head Connection with the Abutment

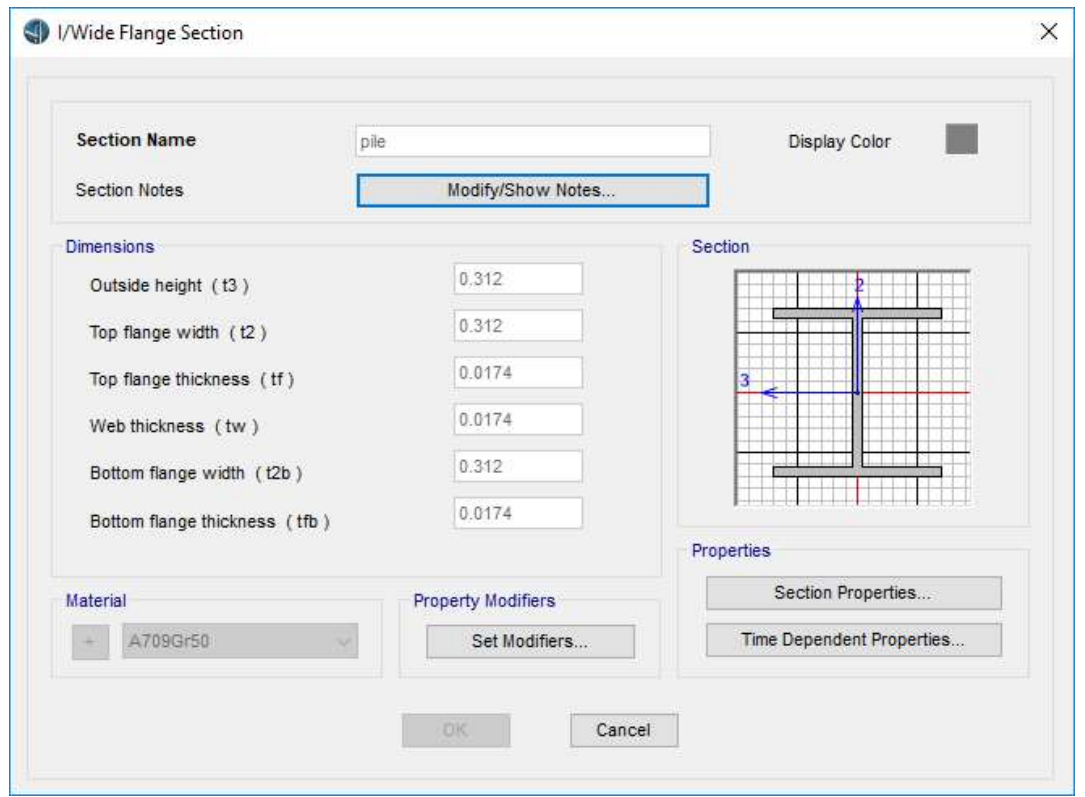

Figure 3.12 Pile Section Properties inserted in SAP2000 Software for HP 310 x 125 Shape 


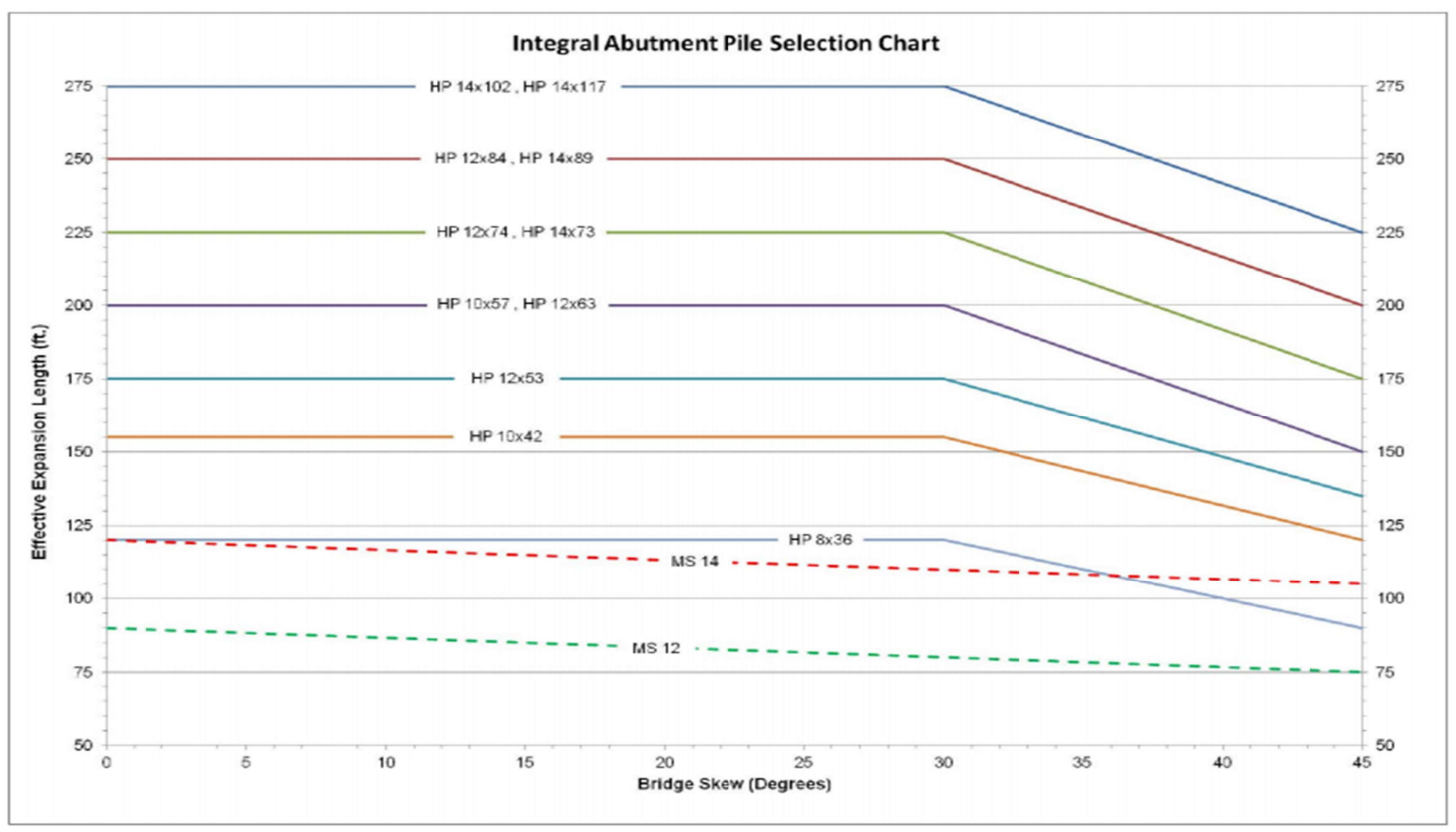

Figure 3.13 Pile Selection Chart (Illinois Department of Transportation, 2012)

\subsubsection{Cross Diaphragm}

In straight bridges, cross frames and solid diaphragms act as secondary members in maintaining structural integrity (Thanasattayawibul, 2006). However, in curved bridges, torsion is resisted by the curved girders and their interaction with the diaphragms (Doust, 2011). The spacing of cross frames was given by Davidson et al. (1996), and reported by Doust (2011). Meanwhile, Doust (2011) derived an equation to calculate the spacing between cross frames, using V-load method. Figures 3.14 and 3.15 show schematic diagrams for forces acting on the steel flanges and diaphragms in curved girders, (Doust, 2011). The forces in the flanges are $M / h_{1}$, where $M$ is the moment and $h_{1}$ is the distance between the compression and tension flanges. Notably, the moment imposed on the outer beam differ from that acting on the inner one. For a two-girder bridge, due to the curvature of the girders, the forces in the flanges are neither equal nor balanced. There exists a component that tends to deflect the girders outward in case of the force in the upper flange and deflect the girder inward in case of the force in the lower flange. This force is resisted by the force $\mathrm{H}_{1}$, shown in Figure 3.15 , which is a force along the plane of the diaphragm. This force is equal and in opposite directions for the top and bottom flanges. The force $\mathrm{H}_{1}$ can be found by resolving the forces in the flanges in the $x$ and $y$ directions and equating the force in the $y$ direction with $\mathrm{H}_{1}$. By 
simple mathematical manipulation, the force $H_{1}$ is equal to $M d_{1} / h_{1} R_{1}$, where $d_{1}$ is the spacing between the diaphragms $\left(S_{D}=d_{1}\right)$ and $R_{1}$ is the radius of curvature taken at the point of consideration.

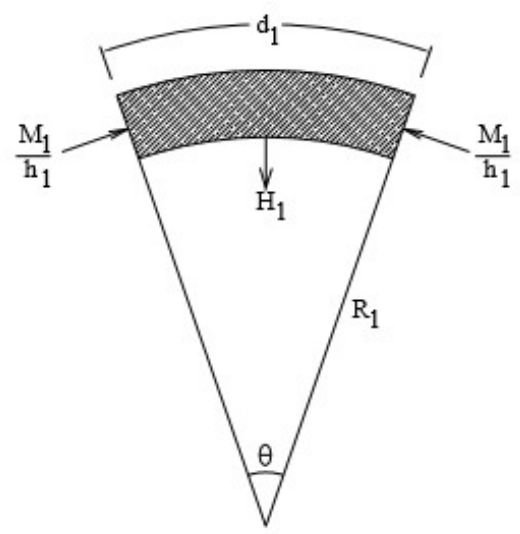

Figure 3.14 Forces Acting on the Flange and Diaphragm (Doust, 2011)
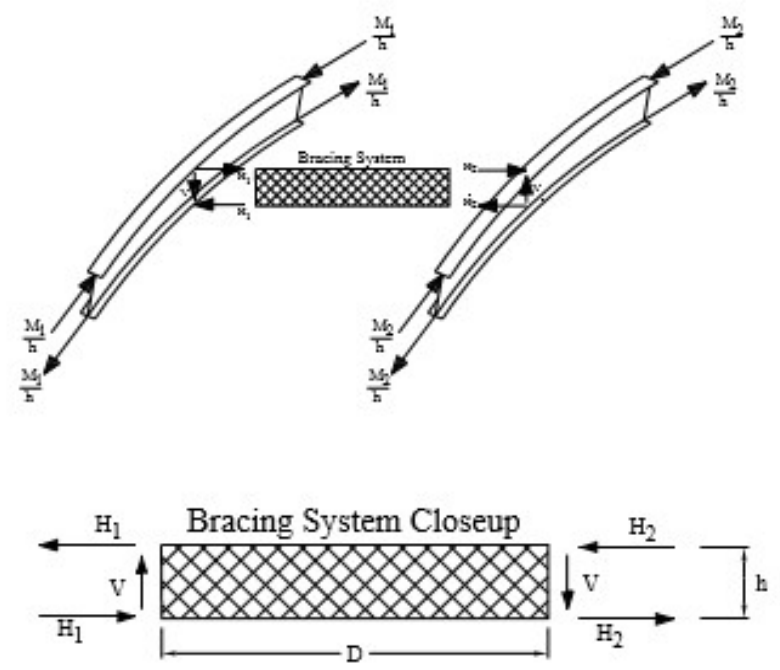

Figure 3.15 Force Equilibrium of the Diaphragm (Doust, 2011)

The moment equilibrium of the diaphragm necessitates the existence of vertical shear force which can be calculated according to the following equation: 
$V=\left(H_{1}+H_{2}\right) \frac{h}{D}$

Where;

$H_{2}=\frac{M_{2} d_{2}}{h_{2} R_{2}}$

Since there is an interaction between the girders and the diaphragms, the diaphragm was chosen to have a thickness equal to that of the web of the girder which is $20 \mathrm{~mm}$ and the diaphragm height was taken equal to the web height.

\subsubsection{Boundary Conditions}

The support conditions at the piers were taken such that they prevent both the vertical and the radial movement of steel I-girders as shown in Figure 3.16. While In field, the support conditions at the pier can be different from the conditions implemented in the model. The support conditions at the pier may differ from one girder to another, such as Stockbridge Bridge which is a two-span integral abutment bridge in Vermont, USA, with different support conditions at the same pier. The bridge slab rests on five curved steel girders, two of which have fixed bearings on the pier, the other three have guided bearings which allows only radial displacement (Kalayci et al., 2012). Greimann et al. (2014) pointed out that the orientation of bearing guides and the freedom of bearing movement are extremely important in studying the performance of horizontally curved bridges.

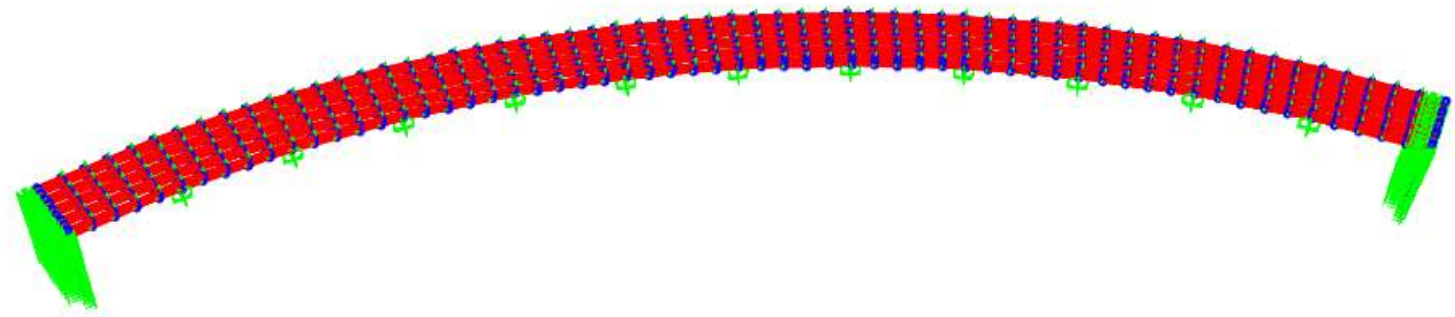

Figure 3.16 View of Multi Span Curved IAB of one of the Numerical Models with the Support Conditions at the Piers Preventing both the Radial (Lateral) and the Vertical Displacement 


\subsection{Soil Modeling Description}

Soil was modeled using Winkler soil model (Matlock, 1970) which assumed that soil reaction at a point depends only on the pile deflection at that point and not on pile deflection above or below that point. Thus, soil was modeled by a series of independent springs as shown in Figures 3.17 and 3.18. The spacing between the springs along the pile in the finite element models was taken as $0.97 \mathrm{~m}$, starting $0.3 \mathrm{~m}$ below the bottom of abutment. At each node, there were three orthogonal springs representing the soil. The vertical springs represent $(\tau-z)$ relationship, while the other two springs represent $(p-y)$ relationship in the two perpendicular directions. At the pile base, the soil is simulated by independent spring representing $(q-z)$ relationship.

The soil behind the abutmen is simulated by three orthogonal springs. The perpendicular spring on the bridge abutment represents $(p-\Delta)$ relationship, while the other two springs simulate the friction developed on the wall in two perpendicular directions. The coefficient of friction was taken equal to 0.4 .

The input values for these springs in SAP2000 commercial software were a set of forcedisplacement relationships generated from the selected abutment and pile soil models. As an example for such curves, Figure 3.19 represents force-displacement relationship $(p-\Delta)$ for dense sand backfill behind the abutment at depth of $2.78 \mathrm{~m}$. While Figure 3.20 represents force-displacement curve for loose sand supporting the abutment at depth of $2.78 \mathrm{~m}$. Figure 3.21 represents force-displacement relationship for piles embedded in dense sand at depth of $7.25 \mathrm{~m}$ from the ground surface. Figure 3.22 represents force-displacement relationship for piles embedded in stiff clay at depth of $5.27 \mathrm{~m}$ from ground surface. 


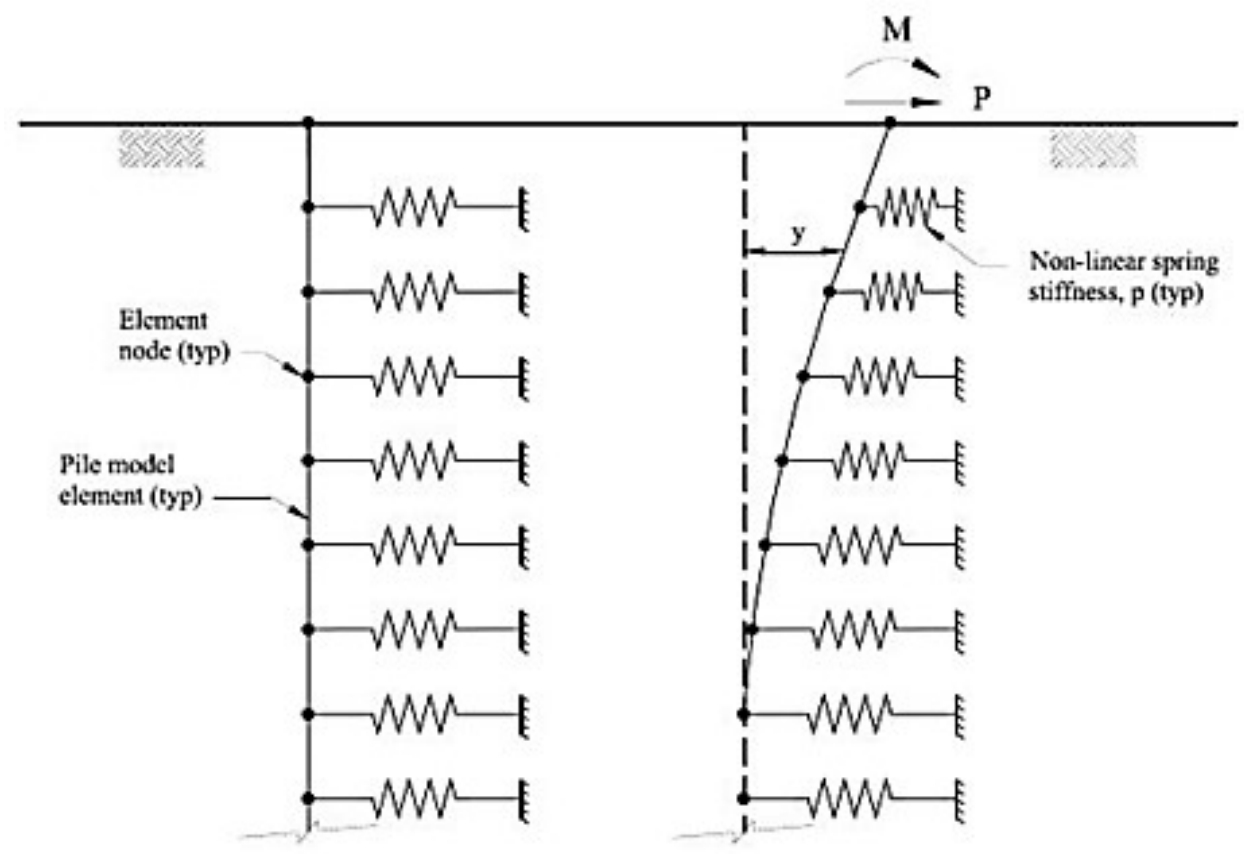

Figure 3.17 Laterally Loaded and Unloaded Piles for Soil Modeled as Disconnected Springs (Bowles, 1996)

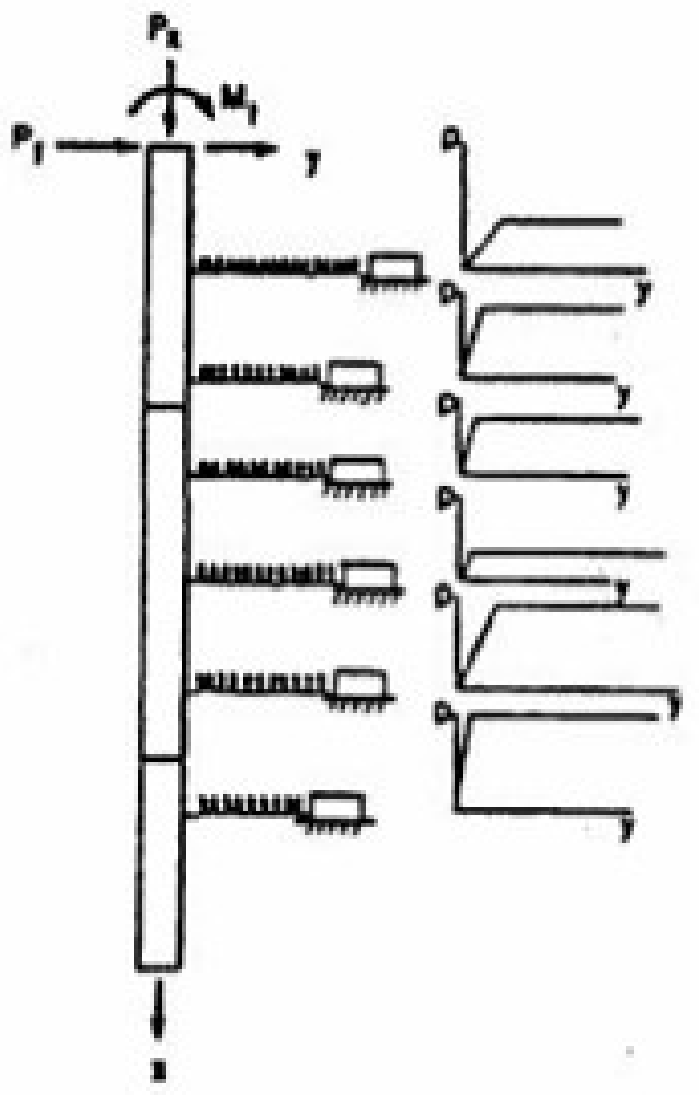

Figure 3.18 Laterally Loaded Pile Where Soil is modeled as Disconnected Springs (Reese, 1984) 


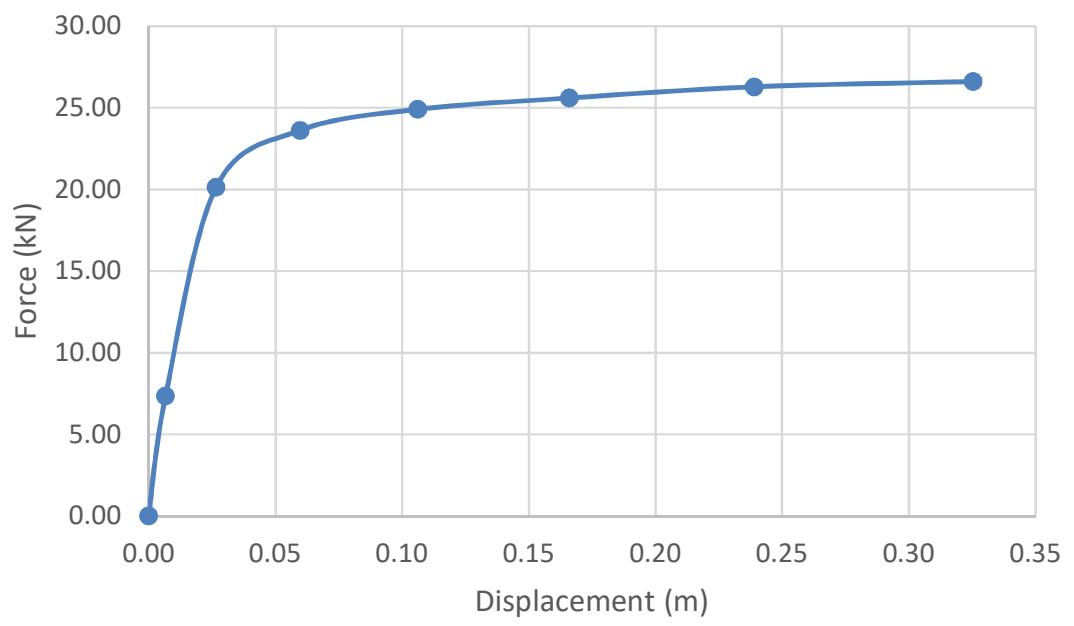

Figure 3.19 Force-Displacement Curve for Dense Sand Supporting the Abutment at Depth $2.78 \mathrm{~m}$ from Ground Surfaces

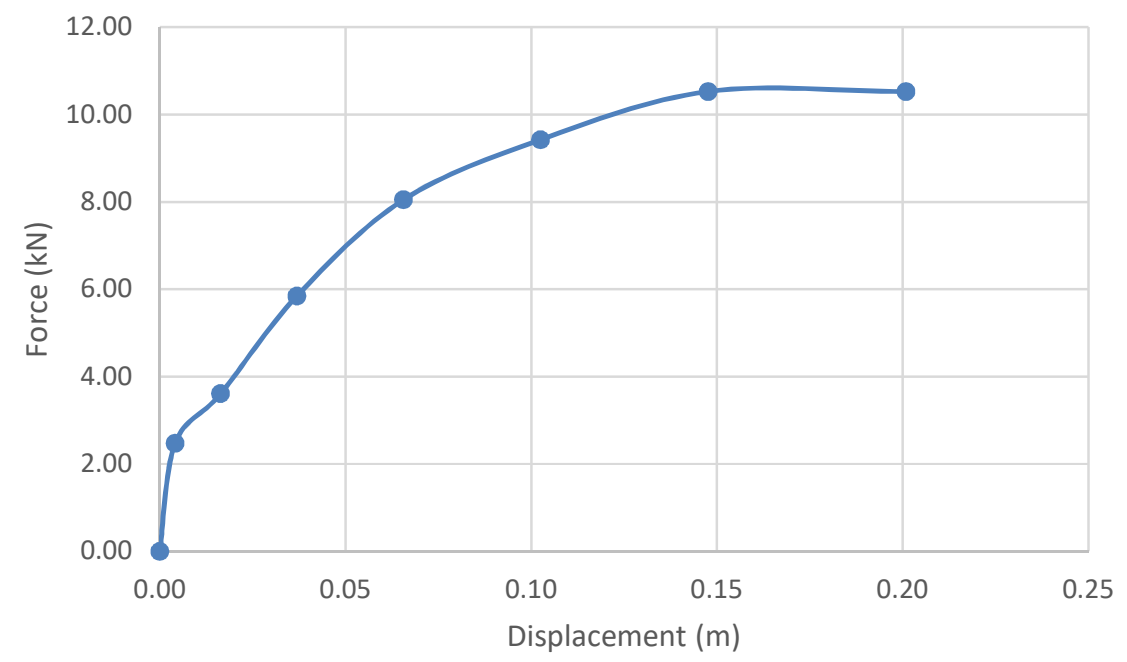

Figure 3.20 Force-Displacement Curve for Loose Sand Supporting the Abutment at Depth $2.78 \mathrm{~m}$ from Ground Surfaces 


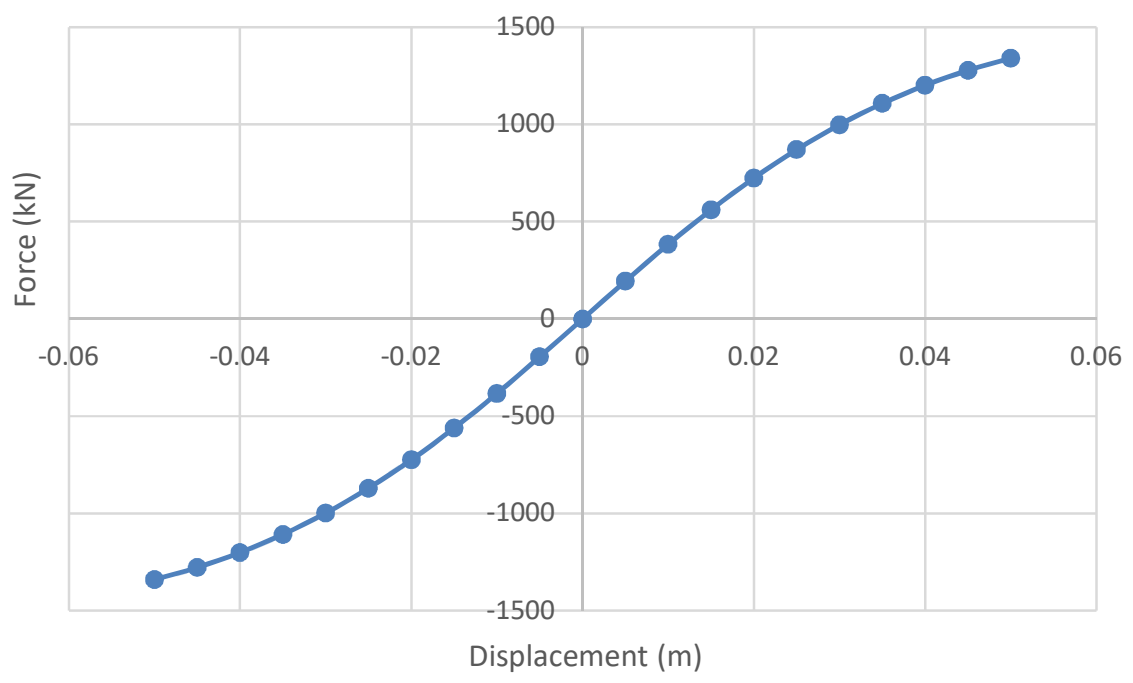

Figure 3.21 Force-Displacement Curve for Piles Embedded in Dense Sand at Depth $7.25 \mathrm{~m}$ from Ground Surfaces

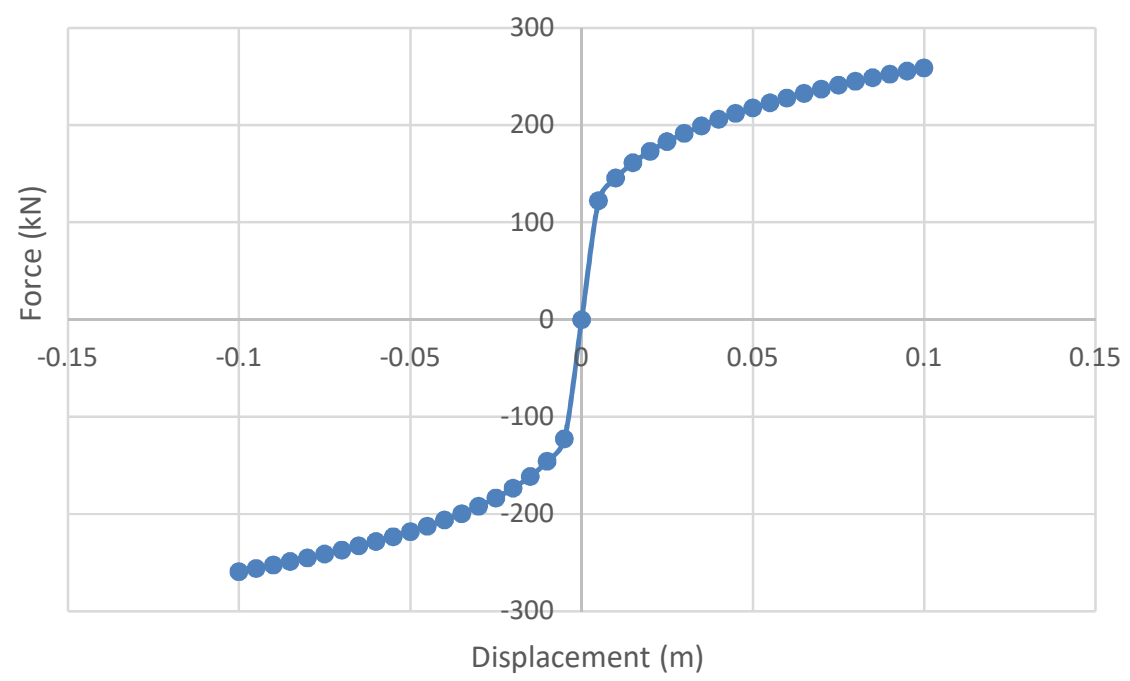

Figure 3.22 Force-Displacement Curve for Piles Embedded in Stiff Clay at Depth $5.27 \mathrm{~m}$ from Ground Surfaces

\subsection{Material Properties}

The material properties used in the finite element model namely: concrete and steel, were obtained from literature. The uncertainties in the modulus of elasticity (E), Poisson's ratio ( $V)$ and unit weight of material $(\mathrm{Y})$ are much less than that inherent in coefficient of linear thermal expansion. Table 3.4 and Table 3.5 present the material properties of steel and concrete 
respectively. Steel material properties were applied to girders, diaphragms and abutment piles as listed in Table 3.4. The concrete modulus of elasticity, Poisson's ratio, density and coefficient of linear thermal expansion were applied to concrete deck and abutment.

Table 3.4 Model Steel Material Properties

\begin{tabular}{|c|c|c|c|}
\hline $\begin{array}{c}\text { Modulus of Elasticity } \\
(\mathrm{MPa})\end{array}$ & Poisson's Ratio & $\begin{array}{c}\text { Unit Weight } \\
\left(\mathbf{k N} / \mathbf{m}^{\mathbf{3}}\right)\end{array}$ & $\begin{array}{c}\text { Coefficient of Linear } \\
\text { Thermal Expansion } \\
\left(\mathbf{m} / \mathbf{m} \cdot{ }^{\circ} \mathbf{C}\right)\end{array}$ \\
\hline $1.999 \mathrm{E}+5$ & 0.3 & 76.97 & $1.17 \mathrm{E}-05$ \\
\hline
\end{tabular}

Table 3.5 Model Concrete Material Properties

\begin{tabular}{|c|c|c|c|}
\hline $\begin{array}{c}\text { Modulus of Elasticity } \\
(\mathrm{MPa})\end{array}$ & Poisson's Ratio & $\begin{array}{c}\text { Unit Weight } \\
\left(\mathbf{k N} / \mathbf{m}^{3}\right)\end{array}$ & $\begin{array}{c}\text { Coefficient of Linear } \\
\text { Thermal Expansion } \\
\left(\mathbf{m} / \mathbf{m} \cdot{ }^{\circ} \mathrm{C}\right)\end{array}$ \\
\hline $24.85 \mathrm{E}+3$ & 0.2 & 23.563 & $9.9 \mathrm{E}-6$ \\
\hline
\end{tabular}

\subsection{Thermal Loading}

The Finite Element Models of the integral abutment bridges were analysed in the parametric study, implementing uniform thermal loading conditions of $\pm 65^{\circ} \mathrm{C}$. The thermal loading condition was taken from Figure 3.23. The Eurocode EN 1991-1-5 (2003) divide bridges into 3 types, namely: type 1 steel deck, type 2 composite deck and type 3 concrete deck. This grouping aims to differentiate between massive bridge decks that take longer times to heat and cool, from lighter bridge decks that are more rapidly heated and cooled. As it can be seen from the figure, the maximum and minimum bridge temperature for type 2 is $5{ }^{\circ} \mathrm{C}$ above the shade air temperature.

The shade temperature used is the temperature where the annual probability of exceeding is 0.002. It is obvious that the difference is much greater for type 1 and much smaller for type 3. In the numerical models, $T_{e} \max$ was taken equal to $36^{\circ} \mathrm{C}$, while $T_{e} \min$ was taken equal to $-29^{\circ} \mathrm{C}$. Therefore, $\Delta T$ becomes equal to $65^{\circ} \mathrm{C}$, where $T_{e \text { max }}$ and $T_{e \text { min }}$ are the maximum and minimum uniform bridge temperature respectively. This value is close to the $55.6{ }^{\circ} \mathrm{C}$ that is used as thermal loading in the paper by Kalayci et al. (2012) in modeling integral abutment bridges under thermal loading. 
If the lock-in temperature (construction temperature) were assumed to range from $-1.1^{\circ} \mathrm{C}$ to $32.2^{\circ} \mathrm{C}$ (Quinn and Civjan, 2017), the thermal loads for different cities in Canada based on maximum and minimum temperature given by Nikravan (2013) are shown in Table 3.6.

Table 3.6 Maximum and Minimum Effective Temperature of Steel Bridges for Big Cities in Canada and the Corresponding Thermal Load

\begin{tabular}{|c|c|c|c|c|c|}
\hline \multirow{3}{*}{ City } & \multicolumn{2}{|c|}{ Nikravan (2013) } & \multirow{2}{*}{\multicolumn{2}{|c|}{$\begin{array}{l}\text { Quinn and Civjan (2017) } \\
\text { Lock-in Temperature }{ }^{\circ} \mathrm{C}\end{array}$}} & \multirow{3}{*}{$\Delta \mathbf{T}$} \\
\hline & \multirow{2}{*}{$\begin{array}{c}\text { Minimum } \\
\text { Temperature } \\
{ }^{\circ} \mathrm{C}\end{array}$} & \multirow{2}{*}{$\begin{array}{c}\text { Maximum } \\
\text { Temperature } \\
{ }^{\circ} \mathrm{C}\end{array}$} & & & \\
\hline & & & Min. & Max. & \\
\hline Toronto & -33 & 50 & -1.1 & +32.2 & $-65.2 /+51.1$ \\
\hline Vancouver & -19 & 44 & -1.1 & +32.2 & $-51.2 /+45.1$ \\
\hline Ottawa & -39 & 51 & -1.1 & +32.2 & $-71.2 /+52.1$ \\
\hline Montreal & -39 & 50 & -1.1 & +32.2 & $-71.2 /+51.1$ \\
\hline
\end{tabular}

Therefore, a thermal load of $65^{\circ} \mathrm{C}$ covers the performance of the presumed bridges having different configurations in Toronto and Vancouver. While, the assumed thermal load underestimates $\Delta \mathrm{T}$ in Ottawa and Montreal. Meanwhile, if the construction temperature is assumed $7.2^{\circ} \mathrm{C}$ (Quinn and Civjan, 2017), which would be typical of construction being completed, a thermal load of $65^{\circ} \mathrm{C}$ shall cover all big cities in Canada.

For sake of comparison, Doust (2011) applied a non-uniform temperature gradient for concrete deck and non-uniform thermal gradient for the steel girder. The temperature through concrete varies from $54^{\circ} \mathrm{F}\left(12.2^{\circ} \mathrm{C}\right)$ to $14^{\circ} \mathrm{F}\left(-10^{\circ} \mathrm{C}\right)$, and through steel girder less than $14^{\circ} \mathrm{F}$.

Thanasattayawibul, (2006) applied two categories of thermal loading as follows:

$\Delta \mathrm{T}$ slab $=90^{\circ} \mathrm{F}\left(32^{\circ} \mathrm{C}\right)$ and $\Delta \mathrm{T}$ the rest $=60^{\circ} \mathrm{F}\left(15^{\circ} \mathrm{C}\right)$

$\Delta \mathrm{T}$ slab $=120^{\circ} \mathrm{F}\left(48^{\circ} \mathrm{C}\right)$ and $\Delta \mathrm{T}$ the rest $=90^{\circ} \mathrm{F}\left(32^{\circ} \mathrm{C}\right)$ 


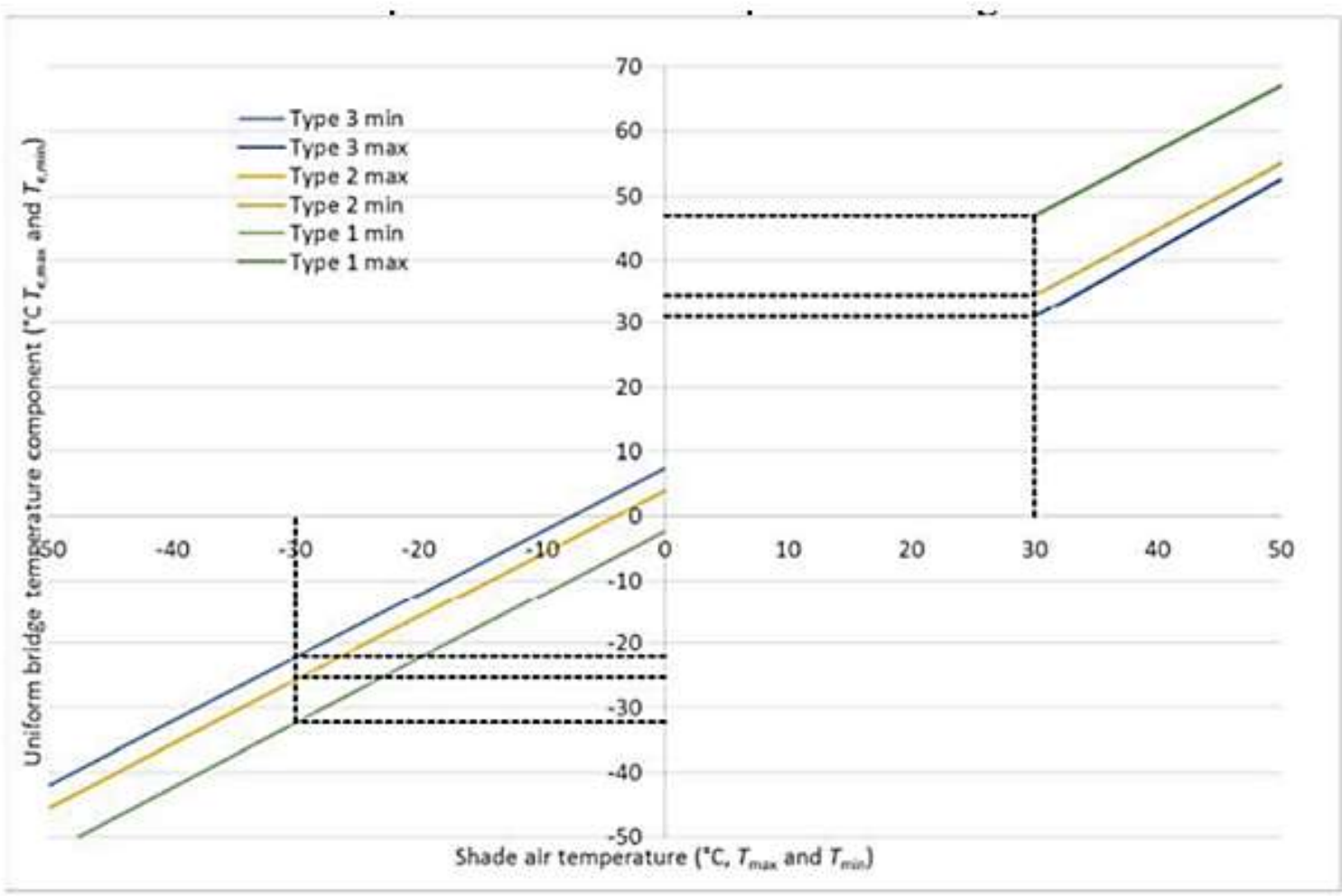

Figure 3.23 Bridge Temperature Selection Chart Based on Ambient Air Temperature (EN 1991-1-5, 2003)

\subsection{Model Validation}

Model validation was achieved by comparing the output results from the finite element analysis with four separate data sets. First, the finite element analysis was compared with field monitored results obtained from field instrumentation of three integral abutment bridges, namely: Middlesex Bridge, East Montpelier Bridge and Stockbridge Bridge. The three bridges included: (1) straight integral abutment bridge with $43 \mathrm{~m}$ span, (2) $15^{\circ}$ skewed integral bridge with $37 \mathrm{~m}$ bridge span and (3) curved two-span continuous bridge deck with $11.25^{\circ}$ of curvature and $68 \mathrm{~m}$ total bridge length. Additionally, the finite element analysis was compared with results provided by Quinn and Civjan (2017).

\subsubsection{Description of Bridges}

\subsubsection{Middlesex Bridge}

The bridge has a single span of $43.0 \mathrm{~m}$ from bearing to bearing. The bridge is straight IAB. The structure of the bridge is as follows: $220 \mathrm{~mm}$ concrete deck supported on five plate steel 
girders evenly spaced at $2.05 \mathrm{~m}$, starting $1.0 \mathrm{~m}$ from each deck fascia. The web of girders is 1170x14 mm with top and bottom flange plates of 510x25 mm and 510x54 mm, respectively. The steel girders are provided by shear studs to achieve composite action between the girders and slab. The bridge is provided with cross frames through the length of the bridge at $5.50 \mathrm{~m}$ spacing. Each abutment of $1.0 \mathrm{~m}$ thickness is supported on 5 HP $310 \times 125$ steel piles, embedded $1.0 \mathrm{~m}$ into the bottom of the abutment and embedded $9.0 \mathrm{~m}$ in the foundation soil. The height of the abutment varies from $4.0 \mathrm{~m}$ to $4.20 \mathrm{~m}$. Wing walls of $0.45 \mathrm{~m}$ thickness are integrated with the abutment and extend $3.0 \mathrm{~m}$ perpendicular to the abutment. Approach slab of thickness $380 \mathrm{~mm}$ is provided at each end of the bridge, as it can be shown in Figures 3.24 through 3.27 and Table 3.7.

\subsubsection{East Montpelier Bridge}

The bridge is a single-span bridge with length $37.0 \mathrm{~m}$, skewed $15^{\circ}$, and Road width of $14.2 \mathrm{~m}$, as shown in Figures 3.28 through 3.31. The bridge structure includes $220 \mathrm{~mm}$ concrete deck, five plate girders with $1346 \times 16 \mathrm{~mm}$ web, 457x22 top flange and $457 \times 41 \mathrm{~mm}$ bottom flange. The steel girders are evenly spaced every $3.0 \mathrm{~m}$, starting $1.10 \mathrm{~m}$ from each deck fascia. Shear studs are provided to accomplish composite action between concrete deck and girders. The steel girders are integrated with abutments at both ends, which are supported on steel reinforced elastomeric pad. The bridge girders are provided by cross frames, at $4.63 \mathrm{~m}$ spacing. Each bridge abutment of $0.9 \mathrm{~m}$ thickness and of height varying from $3.90 \mathrm{~m}$ to 4.05 $\mathrm{m}$, is supported on five HP $310 \times 125 \mathrm{~mm}$ steel piles. The piles are embedded $0.60 \mathrm{~m}$ into the abutment and extend $38.0 \mathrm{~m}$ below the bottom of abutment into foundation soil. The abutment is provided with wing walls of $0.45 \mathrm{~m}$ thickness and extends $2.8 \mathrm{~m}$ from the centerline of the abutment. The wing walls are tapered at $45^{\circ}$. The bridge is provided with an approach slab at each end. Table 3.8 summarizes the main features of the bridge.

\subsubsection{Stockbridge Bridge}

Stockbridge Bridge is a curved two-span steel I-girders bridge, which has a length of $67.6 \mathrm{~m}$ along its curved centerline. The degree of curvature along the bridge alignment is $11.25^{\circ}$. Guided bearings are placed on the top of pier cap to guide the displacement and support the steel girders. The longitudinal displacements of girders 1 to 3 are restrained, while for girder 4 and 5, the displacements in all directions are restrained. At road level, there is a super 
elevation of $6 \%$ and there is vertical elevation difference between the start and the end of the bridge, see Figures 3.32 through 3.38 . The road width is $11.30 \mathrm{~m}$. The concrete deck thickness is $203 \mathrm{~mm}$. The bridge deck rests on five steel l-girders, with variable cross section along the bridge and at spacing of $3105 \mathrm{~mm}$. Web dimensions are $1170 \times 16 \mathrm{~mm}$, while flange dimensions are different among girders and vary along the span, as shown in Figures 3.37 and 3.38. The steel girders are provided by shear stud, to integrate the girders with the deck slab. Cross frames are also provided with spacing varying from $2.6 \mathrm{~m}$ to $5.8 \mathrm{~m}$. The abutments are of $0.9 \mathrm{~m}$ thickness and $6.3 \mathrm{~m}$ average height, each is supported on five HP 360x174 mm steel piles. The piles are embedded $0.6 \mathrm{~m}$ into the bottom of the abutment and extend $23 \mathrm{~m}$ into foundation soil. The abutments are provided by tapered wing walls oriented at $85^{\circ}$ and $110^{\circ}$ from the abutment as shown in Figure 3.33. Table 3.9 summarizes the main components of the bridge.

The Vermont Agency of Transport bridges were adopted for validation for the following reasons;

a) The three bridges were analyzed through numerical models using finite element analysis (Civjan et al., 2014), as well the bridges were monitored in the field. Therefore, two-sets of wealthy data are available namely: field data and numerical analysis data.

b) The field data was collected through long-term monitoring. This represents the longterm behavior of the bridges. The monitoring of Middlesex Bridge began December 04, 2009, through December 31, 2013. While the response of East Montpelier Bridge was monitored from November 24, 2009, up to December 31, 2013. The long-term monitoring of Stockbridge Bridge began November 2, 2009, through December 31, 2013.

c) The monitoring of the response of the bridges started from the construction time.

d) The three bridges represent state of the art, with the set of the bridges containing straight $I A B$, skew IAB, and curved IAB bridge. Furthermore, the bridges are provided with wing walls, and geofoam behind the abutment of one of these bridges. The material properties used in the finite element model are presented in Table 3.10. 


\subsubsection{Quinn and Civjan 2017}

The results obtained from the developed numerical model were compared with those obtained by Quinn and Civjan (2017). Quinn and Civjan (2017) carried out parametric study using a 3D finite element model to study the effect of thermal loading conditions on the performance of straight IAB. The research focused on the effect of thermal loading on the performance of the bridge, with different orientation of abutment piles. The effects of various bridge lengths and abutment skew angles on the performance of the bridge were taken into consideration. Four thermal loads were considered in the analysis. The adopted bridge for validation of the developed numerical model has the characteristics presented in Table 3.11. The bridge width is $11.0 \mathrm{~m}$ and deck slab thickness is $152.44 \mathrm{~mm}$. the piles are embedded in medium-dense sand to a depth of $6.1 \mathrm{~m}$ below bottom of abutment, while backfill supporting the abutment is dense sand.

\subsubsection{Model Validation Results}

The loading conditions for the Middlesex Bridge, East Montpelier Bridge and Stockbridge Bridge were the bridge self-weight in addition to the thermal loading.

Vermont Agency of Transportation researchers did a long-term monitoring as well as a finite element numerical modeling on Middlesex bridge, East Montpelier Bridge and Stockbridge Bridge using SAP2000 commercial software, (Kalayci et al., 2012; Civjan et al., 2014). The elastic and thermal properties used in the finite element model are given in Table 3.10.

Stockbridge Bridge was unique among the three bridges from the fact that geofoam material was placed behind the abutment to relieve soil pressure. As such, in the developed finite element model, the abutment was taken as having zero earth pressure, while maintaining earth pressure on the wing walls.

Tables 3.12 through 3.17 show both the field data results which are the sum of abutments' movements as well as Vermont Agency of Transportation researcher's finite element results, In addition the current numerical model results. Displacements are also included in Tables 3.12 through 3.17. Good agreement between the finite element modeling developed in this study and field data was observed. 
Table 3.7 Middlesex Bridge Description (Civjan et al., 2014)

\begin{tabular}{|c|c|}
\hline Bridge Length & $43 \mathrm{~m}$ \\
\hline Number of Spans & 1 \\
\hline Bridge Width & $10.2 \mathrm{~m}$ \\
\hline Slab Thickness & $0.22 \mathrm{~m}$ \\
\hline Number of Girders & 5 \\
\hline Girder Dimensions & $\begin{array}{c}1.170 \times 0.014 \text { web, } 0.510 \times 0.025 \text { top flange, } 0.510 \times 0.054 \text { bottom } \\
\text { flange }\end{array}$ \\
\hline Girder Spacing & $2.05 \mathrm{~m}$ \\
\hline $\begin{array}{l}\text { Number of Piles Supporting } \\
\text { Each Abutment }\end{array}$ & 5 \\
\hline Pile Section & HP 310x125 \\
\hline Abutment Dimensions & $1 \mathrm{~m}$ thick, $4.1 \mathrm{~m}$ average depth \\
\hline Wing Wall Dimensions & $0.45 \mathrm{~m}$ thick, $3.00 \mathrm{~m}$ perpendicular to the abutment \\
\hline $\begin{array}{l}\text { Soil Strata Behind The } \\
\text { Abutment }\end{array}$ & $\begin{array}{l}\text { Dense sand fill, total unit weight, } \gamma \text {, of } 22.77 \mathrm{kN} / \mathrm{m}^{3} \text {, angle of } \\
\text { Internal Friction, } \phi^{\prime} \text {, of } 45^{\circ}\end{array}$ \\
\hline Foundation Soil & $\begin{array}{c}\text { medium dense sand, total unit weight, } \nu^{\prime} \text { of } 21.2 \mathrm{kN} / \mathrm{m}^{3} \text {, angle } \\
\text { of Internal Friction, } \phi^{\prime} \text {, of } 35^{\circ}\end{array}$ \\
\hline
\end{tabular}


Table 3.8 East Montpelier Bridge Description (Civjan et al., 2014)

\begin{tabular}{|c|c|}
\hline Bridge Length & $37.0 \mathrm{~m}$ \\
\hline Skew Angle & $15^{\circ}$ \\
\hline Number of Spans & 1 \\
\hline Bridge Width & $14.2 \mathrm{~m}$ \\
\hline Slab Thickness & $0.22 \mathrm{~m}$ \\
\hline Number of Girders & 5 \\
\hline Girder Dimensions & $\begin{array}{c}1.346 \times 0.016 \text { web, } 0.457 \times 0.022 \text { top flange, } 0.457 \times 0.041 \text { bottom } \\
\text { flange }\end{array}$ \\
\hline Girder Spacing & $3.00 \mathrm{~m}$ \\
\hline $\begin{array}{l}\text { Number of Piles Supporting } \\
\text { Each Abutment }\end{array}$ & 5 \\
\hline Pile Section & HP $310 \times 125$ \\
\hline Abutment Dimensions & $1 \mathrm{~m}$ thick, $4.1 \mathrm{~m}$ average depth \\
\hline Wing Wall Dimensions & $0.45 \mathrm{~m}$ thick, $2.80 \mathrm{~m}$ length \\
\hline $\begin{array}{l}\text { Soil Strata Behind the } \\
\text { Abutment }\end{array}$ & $\begin{array}{l}\text { dense sand fill, total unit weight, } \gamma \text {, of } 22.77 \mathrm{kN} / \mathrm{m}^{3} \text {, angle of } \\
\text { Internal Friction, } \phi^{\prime} \text {, of } 45^{\circ}\end{array}$ \\
\hline Foundation Soil & $\begin{array}{c}\text { medium dense sand, total unit weight, } \nu \text {, of } 21.2 \mathrm{kN} / \mathrm{m}^{3} \text { angle } \\
\text { of Internal Friction, } \phi^{\prime} \text {, of } 35^{\circ}\end{array}$ \\
\hline
\end{tabular}


Table 3.9 Stockbridge Bridge Description (Civjan et al., 2014)

\begin{tabular}{|c|c|}
\hline Bridge Length & $67.6 \mathrm{~m}$ \\
\hline Number of Spans & 2 \\
\hline Bridge Width & $11.3 \mathrm{~m}$ \\
\hline Slab Thickness & $0.203 \mathrm{~m}$ \\
\hline Number of Girders & 5 \\
\hline Girder Web Dimensions & $1.170 \times 0.016 \mathrm{~m}$ \\
\hline Girder Spacing & $2.36 \mathrm{~m}$ \\
\hline $\begin{array}{c}\text { Number of Piles Supporting } \\
\text { Each Abutment }\end{array}$ & 5 \\
\hline Pile Section & HP 360X174 \\
\hline Pile Length & $23 \mathrm{~m}$ \\
\hline Abutment Dimensions & $0.9 \mathrm{~m}$ thick, $6.3 \mathrm{~m}$ average depth \\
\hline Wing Wall Thickness & $0.45 \mathrm{~m}$ thick \\
\hline $\begin{array}{l}\text { Soil Strata Behind the } \\
\text { Abutment }\end{array}$ & $\begin{array}{c}\text { dense sand fill, total unit weight } \gamma \text { of } 22.77 \mathrm{kN} / \mathrm{m}^{3} \text {, angle of } \\
\text { Internal Friction } \phi^{\prime} \text { of } 45^{\circ}\end{array}$ \\
\hline Foundation Soil & $\begin{array}{c}\text { medium dense sand, total unit weight } \gamma \text { of } 21.2 \mathrm{kN} / \mathrm{m}^{3} \text { angle } \\
\text { of Internal Friction } \phi^{\prime} \text { of } 35^{\circ}\end{array}$ \\
\hline
\end{tabular}

Table 3.10 Material Properties Used in the Finite Element Models (Civjan et al., 2014)

\begin{tabular}{|c|c|c|c|c|c|c|}
\hline $\begin{array}{c}\text { Construction } \\
\text { Material }\end{array}$ & $\begin{array}{c}\text { Strength } \\
\text { (MPa) }\end{array}$ & $\begin{array}{c}\text { Elastic } \\
\text { Modulus } \\
(\mathrm{MPa})\end{array}$ & $\begin{array}{c}\text { Shear Modulus } \\
\mathbf{( M P a})\end{array}$ & $\begin{array}{c}\text { Coefficient of Thermal } \\
\text { Expansion } \mathbf{m} / \mathbf{m} /{ }^{\circ} \mathrm{C}\end{array}$ & $\begin{array}{c}\text { Poisson's } \\
\text { Ratio }\end{array}$ & $\begin{array}{c}\text { Unit } \\
\text { Weight } \\
\left(\mathbf{t} / \mathbf{m}^{3} \mathbf{)}\right.\end{array}$ \\
\hline $\begin{array}{c}\text { Concrete } \\
\text { Class (A) }\end{array}$ & 28.0 & $25.0 \mathrm{E}+3$ & $10.0 \mathrm{E}+3$ & $9.9 \mathrm{E}-6$ & 0.2 & 2.4 \\
\hline $\begin{array}{c}\text { Concrete } \\
\text { Class (B) }\end{array}$ & 24.0 & $23.5 \mathrm{E}+3$ & $10.0 \mathrm{E}+3$ & $9.9 \mathrm{E}-6$ & 0.2 & 2.4 \\
\hline Steel & 345 & $200 \mathrm{E}+3$ & $77.0 \mathrm{E}+3$ & $11.7 \mathrm{E}-6$ & 0.3 & 7.85 \\
\hline
\end{tabular}


Table 3.11 Skewed Bridge Characteristics (Quinn and Civjan, 2017)

\begin{tabular}{|c|c|c|c|c|c|}
\hline \multirow{2}{*}{$\begin{array}{c}\text { Bridge Length } \\
\text { (m) }\end{array}$} & \multirow{2}{*}{ Girder } & \multirow{2}{*}{ Piles } & \multirow{2}{*}{$\begin{array}{c}\text { Skew Angle } \\
\text { (degree) }\end{array}$} & \multicolumn{2}{|c|}{ Abutment } \\
\hline & & & & Thickness (m) & Height (m) \\
\hline 45.7 & W40X593 & HP $12 X 84$ & 45.0 & 0.91 & 3.58 \\
\hline
\end{tabular}

Table 3.12 Bottom-of-Abutment Displacement of Middlesex Bridge

\begin{tabular}{|c|c|c|c|c|c|}
\hline \multirow[b]{2}{*}{ Year } & \multirow[b]{2}{*}{$\begin{array}{c}\text { Thermal Load } \\
\left({ }^{\circ} \mathrm{F}\right)\end{array}$} & \multicolumn{3}{|c|}{ Sum of Abutment Movements (in.) } & \multirow{2}{*}{$\begin{array}{l}\text { Thermal } \\
\text { Expansion } \\
\text { Equation }\end{array}$} \\
\hline & & $\begin{array}{c}\text { Field } \\
\text { Monitoring }\end{array}$ & $\begin{array}{c}\text { Vermont } \\
\text { Agency } \\
\text { Researchers }\end{array}$ & $\begin{array}{c}\text { Current } \\
\text { Study }\end{array}$ & \\
\hline 2013 & 109.5 & 0.47 & 0.32 & 0.46 & 1.2 \\
\hline
\end{tabular}

Table 3.13 Top-of-Abutment Displacement of Middlesex Bridge

\begin{tabular}{|c|c|c|c|c|c|}
\hline \multirow[b]{2}{*}{ Year } & \multirow[b]{2}{*}{$\begin{array}{c}\text { Thermal Load } \\
\left({ }^{\circ} \mathrm{F}\right)\end{array}$} & \multicolumn{3}{|c|}{ Sum of Abutment Movements (in.) } & \multirow{2}{*}{$\begin{array}{l}\text { Thermal } \\
\text { Expansion } \\
\text { Equation }\end{array}$} \\
\hline & & $\begin{array}{c}\text { Field } \\
\text { Monitoring }\end{array}$ & $\begin{array}{c}\text { Vermont } \\
\text { Agency } \\
\text { Researchers }\end{array}$ & $\begin{array}{l}\text { Current } \\
\text { Study }\end{array}$ & \\
\hline 2013 & 109.5 & 1.17 & 1.20 & 1.13 & 1.2 \\
\hline
\end{tabular}

Table 3.14 Bottom-of-Abutment Displacement of East Montpelier Bridge

\begin{tabular}{|c|c|c|c|c|c|}
\hline \multirow[b]{2}{*}{ Year } & \multirow{2}{*}{$\begin{array}{c}\text { Thermal Load } \\
\left({ }^{\circ} \mathrm{F}\right)\end{array}$} & \multicolumn{3}{|c|}{ Sum of Abutment Movements (in.) } & \multirow{2}{*}{$\begin{array}{l}\text { Thermal } \\
\text { Expansion } \\
\text { Equation }\end{array}$} \\
\hline & & $\begin{array}{c}\text { Field } \\
\text { Monitoring }\end{array}$ & $\begin{array}{c}\text { Vermont } \\
\text { Agency } \\
\text { Researchers }\end{array}$ & $\begin{array}{l}\text { Current } \\
\text { Study }\end{array}$ & \\
\hline 2010 & 100.6 & 0.49 & 0.31 & 0.53 & 0.95 \\
\hline
\end{tabular}


Table 3.15 Top-of-Abutment Displacement of East Montpelier Bridge

\begin{tabular}{|c|c|c|c|c|c|}
\hline \multirow[b]{2}{*}{ Year } & \multirow[b]{2}{*}{$\begin{array}{c}\text { Thermal Load } \\
\left({ }^{\circ} \mathrm{F}\right)\end{array}$} & \multicolumn{3}{|c|}{ Sum of Abutment Movements (in.) } & \multirow{2}{*}{$\begin{array}{l}\text { Thermal } \\
\text { Expansion } \\
\text { Equation }\end{array}$} \\
\hline & & $\begin{array}{c}\text { Field } \\
\text { Monitoring }\end{array}$ & $\begin{array}{c}\text { Vermont } \\
\text { Agency } \\
\text { Researchers }\end{array}$ & $\begin{array}{c}\text { Current } \\
\text { Study }\end{array}$ & \\
\hline 2010 & 100.6 & 1.24 & 0.92 & 0.91 & 0.95 \\
\hline
\end{tabular}

Table 3.16 Bottom-of-Abutment Displacement of Stockbridge Bridge

\begin{tabular}{|c|c|c|c|c|c|}
\hline \multirow[b]{2}{*}{ Year } & \multirow[b]{2}{*}{$\begin{array}{c}\text { Thermal Load } \\
\qquad\left(^{\circ} \mathrm{F}\right)\end{array}$} & \multicolumn{3}{|c|}{ Sum of Abutment Movements (in.) } & \multirow{2}{*}{$\begin{array}{l}\text { Thermal } \\
\text { Expansion } \\
\text { Equation }\end{array}$} \\
\hline & & $\begin{array}{c}\text { Field } \\
\text { Monitoring }\end{array}$ & $\begin{array}{c}\text { Vermont } \\
\text { Agency } \\
\text { Researchers }\end{array}$ & $\begin{array}{c}\text { Current } \\
\text { Study }\end{array}$ & \\
\hline- & 45 & 0.118 & 0.078 & 0.114 & - \\
\hline
\end{tabular}

Table 3.17 Bottom-of-Abutment Displacement of Stockbridge Bridge

\begin{tabular}{|c|c|c|c|c|c|}
\hline \multirow[b]{2}{*}{ Year } & \multirow[b]{2}{*}{$\begin{array}{c}\text { Thermal Load } \\
\qquad\left({ }^{\circ} \mathrm{F}\right)\end{array}$} & \multicolumn{3}{|c|}{ Sum of Abutment Movements (in.) } & \multirow{2}{*}{$\begin{array}{l}\text { Thermal } \\
\text { Expansion } \\
\text { Equation }\end{array}$} \\
\hline & & $\begin{array}{c}\text { Field } \\
\text { Monitoring }\end{array}$ & $\begin{array}{c}\text { Vermont } \\
\text { Agency } \\
\text { Researchers }\end{array}$ & $\begin{array}{l}\text { Current } \\
\text { Study }\end{array}$ & \\
\hline 2011 & 102.1 & 1.55 & 1.51 & 1.54 & 1.77 \\
\hline
\end{tabular}

\subsubsection{Middlesex Bridge}

Top-of-abutment displacement refers to the displacement measured at the top flanges of girders. The measured displacement excludes the displacement measured during construction of the bridge. Longitudinal abutment displacements are presented in Tables 3.12 and 3.13. The displacement is the sum of both abutments movements. The total longitudinal displacement due to thermal fluctuation through the four years is compared to FEM results by Vermont Agency researchers and by the current FEM. The current FEM was focused on predicting the longitudinal displacement over year 2013. Tables 3.12 and 3.13 show bottomand top-of-abutment longitudinal displacements of Middlesex Bridge. The monitoring data 
resulted that the top-of-abutment displacement over year 2013 is 1.17 " (29.17 mm), while the bottom displacement is $0.47 "(11.93 \mathrm{~mm})$. Therefore, the abutment deformation is a combination of rigid body displacement and rotation. Notably, the monitoring of the bridge was carried out through four years. Naturally, temperature fluctuates through these years. The bottom displacements of abutment (the sum of the abutments displacements) were 0.52", 0.60", 0.46" and 0.47" over years 2010 up to 2013. While the longitudinal top displacements were 1.14", 1.39", 1.15" and 1.17" over the same period.

Tables 3.12 and 3.13 show good agreement between the values of the sum of abutment displacements obtained from the developed model and that monitored from the field. Thermal expansion equation implementing $\alpha$ equal to $6.5 \mathrm{E}-61 / \mathrm{F}$ was used to calculate the total longitudinal displacement of the bridge deck, considering the bridge length $L$. The free expansion yields 1.2". The free bridge displacement equals to that value of the sum top-ofabutment displacements obtained by researchers and $6 \%$ bigger than that obtained from current numerical model. This is attributed to the restraining action imposed by backfill behind the retaining wall and the abutment pile. While the free bridge displacement is much bigger than that of the sum of the bottom-of-abutment movements. This is attributed to the rotation of abutment-pile system. The top displacements of the two abutments are not similar (Civjan et al., 2014). Nevertheless, the bridge is non-skew and symmetrical. This unsymmetrical performance can be attributed to the variation in soil conditions at the two abutments.

The researcher's numerical finite element model predicted the sum of bottom displacements of the two abutments by $60 \%$, while the current numerical model predicted a value that agrees well with the monitoring value. The sum of monitored abutment displacements, top and bottom, is not consistent through the four years. The largest value of top displacement equals to 1.14 times the mean values, while the smallest value is 0.94 times the mean values. While the largest bottom displacement is 1.17 times the mean value and the smallest value is 1.01 times the mean value. This may be attributed to sudden abrupt in environmental conditions. Meanwhile, the predicted value is less than the Agency researchers' value. Additionally, this may be due to the fact that the researchers matched their finite element model results with the measured value. The matched results prevail that the backfill soil and the foundation soil changed from initial soil state and became loose during bridge expansion 
and looser during contraction. Current study was based on the initial condition properties of backfill supporting the abutment and foundation soil.

\subsubsection{East Montpelier Bridge}

The monitoring of East Montpelier skewed bridge was completed on November 24, 2009. The monitoring started from the construction date through December 31, 2013. Tables 3.14 and 3.15 present the sum of abutment displacements at upstream corner. The obtuse corner of abutment-1 is opposite to the acute corner of abutment-2. Therefore, the displacements of obtuse corner and acute corner were summed. The current finite element model results were compared with those monitored through 2010, the first year of monitoring program. The current study revealed sum of bottom-of-abutment displacements as $0.53 "$, while the monitored value was $0.49 "$, with over prediction of $8.1 \%$. Meanwhile, the Agency researchers underpredict the sum of the bottom-of-abutment displacements by $63 \%$. The free expansion of the bridge ( $\delta=\alpha L \Delta T$ ) was 0.95", as shown in Table 3.14. The sum of top-of-abutment displacements predicted by the current numerical model is $0.91 "$, which underpredict the measured value by $73 \%$. The free expansion of the bridge deck is slightly bigger than those predicted values by current numerical model and Agency researcher's model at the top-ofabutments, but smaller than that of the measured value. The Agency researchers reported that the displacement at the acute and obtuse corner of each abutment exhibit similar displacements. The free expansion of the bridge given by equation ( $\delta=\alpha L \Delta T$ ) is smaller than the sum of the bottom-of-abutment displacements, due to the rotation of the abutment in the vertical direction, resulted from restraining the abutment by the piles and the supporting soil.

The agency researchers reported that predicting substructure response of the bridge to thermal load is quit complex because the response of the bridge is not only dependent on thermal load but also on soil properties, variations with the expansion and contraction of the bridge deck. Additionally, there is lag in pile recovery after bridge expansion, and also after bridge contraction. Meaning the piles deflected shapes never fully recovered. Therefore, to predict the performance of the superstructure of the bridge, a complex finite element model is required. 


\subsubsection{Stockbridge Bridge}

Due to the presence of geofoam behind bridge abutment, the backfill soil pressure was omitted in the Agency researcher numerical model as well in the current research. The Agency researcher's model was calibrated to match field data, while the current model used the initial state properties of foundation soil and supporting fill. The bridge is two-span with interior pier. Kalayci et al. (2012) reported field data concerning Stockbridge Bridge, Table 3.16 presents the average bottom-of-abutment displacement through hot season. The Table also presents the predicted values by the finite element model developed by Agency researchers and by the current research.

The table indicates that the predicted value by the current model agrees reasonably with the measured value, while the predicted value by Agency researchers underpredicts the measured value by $66.10 \%$. The sum of measured top-of-abutment displacement at upstream corner of the abutment- 1 and at the downstream corner was obtained and the mean value was assessed. The same was carried out for abutment-2. The sum of the two average values was obtained and called it "sum of average abutment displacement".

The same was carried out on the results obtained from current numerical model. The measured and the predicted values by Agency researchers and current research were tabulated in Table 3.17. The table indicates that the value obtained by the developed model agrees well with the measured value as well the value predicted by Agency researchers. The free expansion value differs from the measured and the predicted value, because free expansion equation does not take into account the effect of curvature, the effects of foundation soil and the supporting backfill.

\subsubsection{Quinn and Civjan 2017}

Another comparison was carried out on a numerically modeled straight integral abutment bridge by Quinn and Civjan (2017). The modeled bridge was a skewed integral abutment bridge with $45^{\circ}$ skew angle, length of $45.7 \mathrm{~m}$ and abutment height of $3.58 \mathrm{~m}$. That bridge was modeled among others by the researchers and the abutment displacement was presented. Tables 3.18 and 3.19 illustrate the results of both the transverse and longitudinal displacement at the top and the bottom of the abutment. Table 3.18 shows the top displacement of the abutment at the acute corner. While Table 3.19 shows the bottom 
displacement of the abutment at obtuse corner. Good agreement between the developed finite element model results and the published data was observed.

Table 3.18 Top-of-Abutments Displacement at Acute Corner

\begin{tabular}{|c|c|c|c|c|}
\hline \multirow{2}{*}{$\begin{array}{c}\text { Applied } \\
\text { Temperature }\end{array}$} & \multicolumn{2}{|c|}{$\begin{array}{c}\text { Civjan et al. (2014) \& Quinn and Civjan } \\
\text { (2017) }\end{array}$} & $\begin{array}{c}c \\
\text { Current Study }\end{array}$ \\
\cline { 2 - 5 }$\left({ }^{\circ} \mathrm{F}\right)$ & $\begin{array}{c}\text { Transverse } \\
\text { Displacement } \\
\text { (in) }\end{array}$ & $\begin{array}{c}\text { Longitudinal } \\
\text { Displacement (in) }\end{array}$ & $\begin{array}{c}\text { Transverse } \\
\text { Displacement } \\
\text { (in) }\end{array}$ & $\begin{array}{c}\text { Longitudinal } \\
\text { Displacement } \\
\text { (in) }\end{array}$ \\
\hline 75 & 0.02 & 0.53 & 0.03 & 0.51 \\
\hline
\end{tabular}

Table 3.19 Bottom-of-Abutment Displacement at Obtuse Corner

\begin{tabular}{|c|c|c|c|c|}
\hline \multirow{2}{*}{$\begin{array}{c}\text { Applied } \\
\text { Temperature } \\
\left({ }^{\circ} \mathrm{F}\right)\end{array}$} & \multicolumn{2}{|c|}{$\begin{array}{l}\text { Civjan et al. (2014) \& Quinn and Civjan } \\
\text { (2017) }\end{array}$} & \multicolumn{2}{|c|}{ Current Study } \\
\hline & $\begin{array}{c}\text { Transverse } \\
\text { Displacement } \\
\text { (in) }\end{array}$ & $\begin{array}{c}\text { Longitudinal } \\
\text { Displacement (in) }\end{array}$ & $\begin{array}{c}\text { Transverse } \\
\text { Displacement } \\
\text { (in) }\end{array}$ & $\begin{array}{l}\text { Longitudinal } \\
\text { Displacement } \\
\text { (in) }\end{array}$ \\
\hline 75 & 0.26 & 0.22 & 0.22 & 0.26 \\
\hline
\end{tabular}

Tables 3.18 and 3.19 indicate that the results of transverse and longitudinal displacements obtained from the developed model for the skew bridge match very well with those obtained by Quinn and Civjan (2017).

\subsection{Screenshots}

Figures 3.39 through 3.43 are screenshots of the finite element model of the Middlesex Bridge obtained from SAP2000 Software. While Figures 3.44 and 3.45 present screenshots of Montpelier Bridge. Whereas the screenshots of Stockbridge Bridge are shown in Figures 3.47 and 3.48. Finally Figure 3.49 presents a screenshot of a bridge adopted from Quinn and Civjan (2017). 


\subsection{Concluded Remarks}

a) The developed numerical model was adapted to analyze straight IAB, straight IAB with 15 ${ }^{\circ}$ bridge skew, straight $I A B$ with $45^{\circ}$ skew and curved bridge. The obtained results match reasonably with the results obtained from field monitoring and with the results obtained from current numerical models. These reasonable agreements are a source of evidence to implement the developed numerical model in conducting a parametric study.

b) Field monitoring on three bridges sponsored by Vermont Agency of transport shows that (1) the abutment displacements are time-dependent due to the change of backfill properties with time, (2) the abutment displacements are affected by electrical storms and Hurricane, (3) the abutment deformation is a combination of rigid body displacement and rotation, and (4) the behavior of backfill shows that soil ratcheting does not occur in the backfill. The Agency researchers reported that the soil condition around the top $3 \mathrm{~m}$ of the pile is time-dependent in a way that dense sand gets looser with time. The piles never recover from their deflection shape during bridge expansion and contraction.

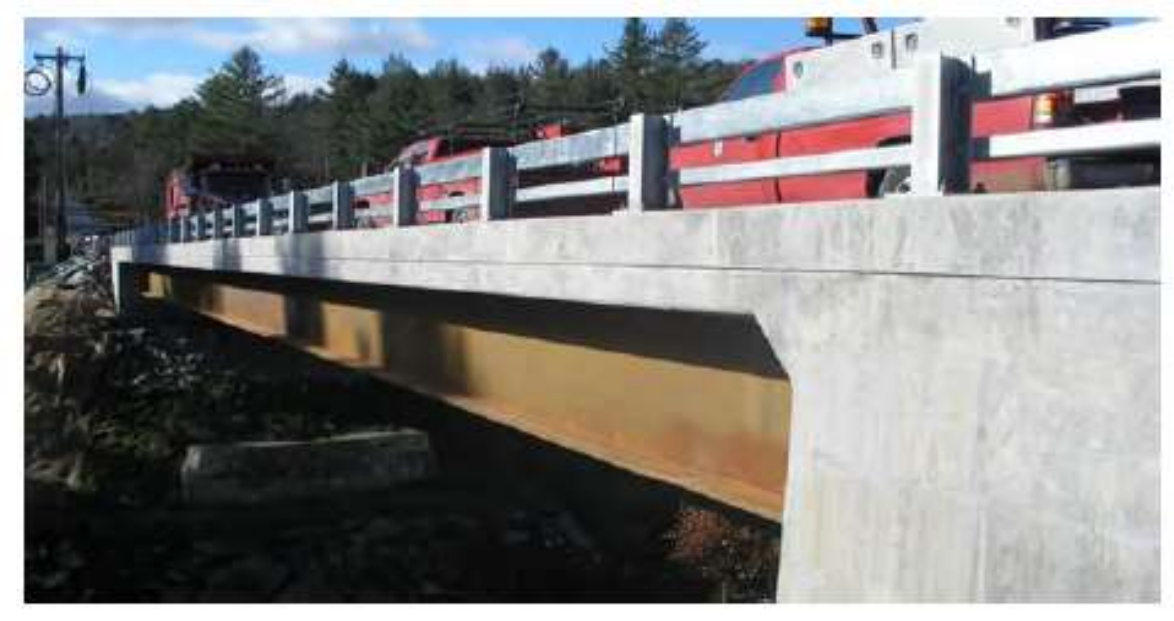

Figure 3.24 a) Middlesex Bridge (Civjan et al., 2014) 


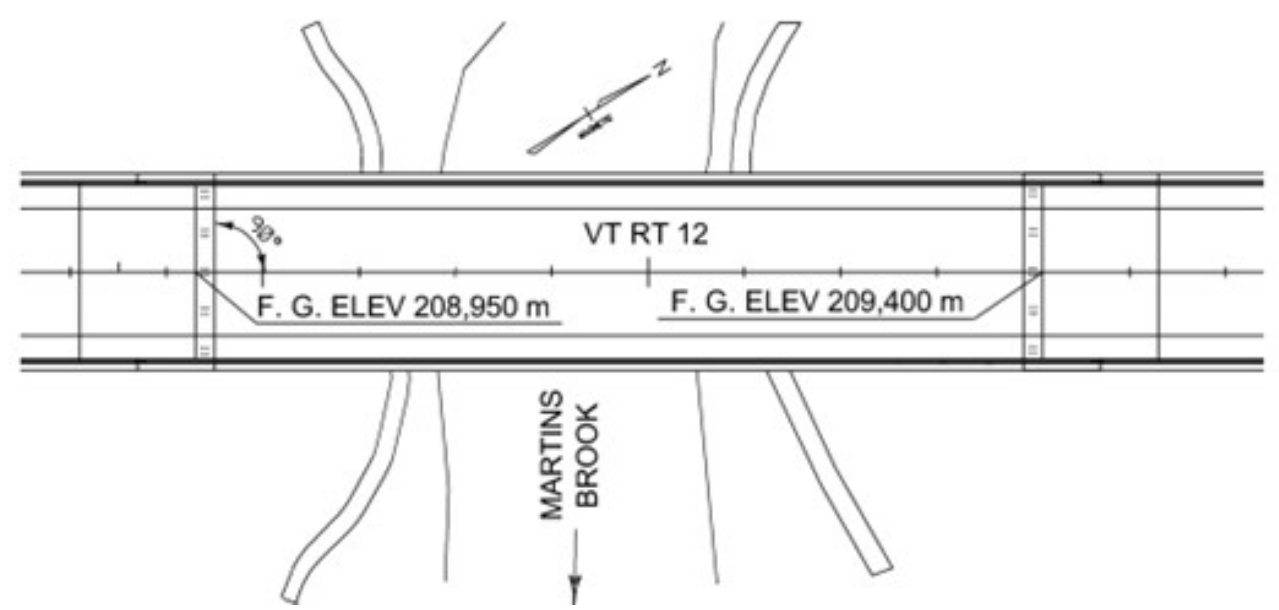

Figure 3.24 b) Middlesex Bridge (Civjan et al., 2014)

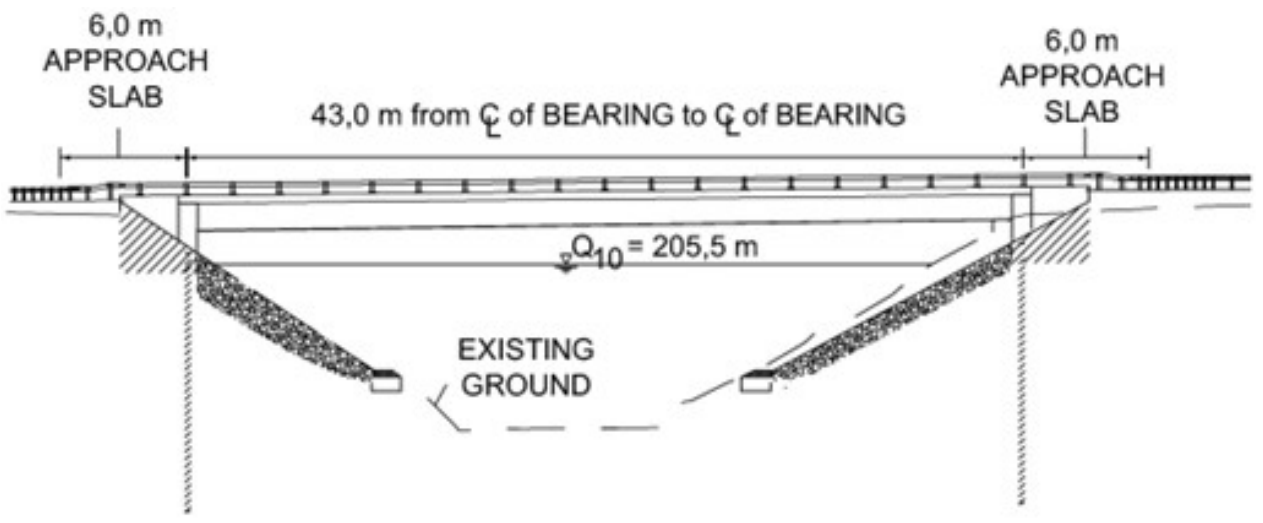

Figure 3.25 Elevation View of Middlesex Bridge (Civjan et al., 2014) 


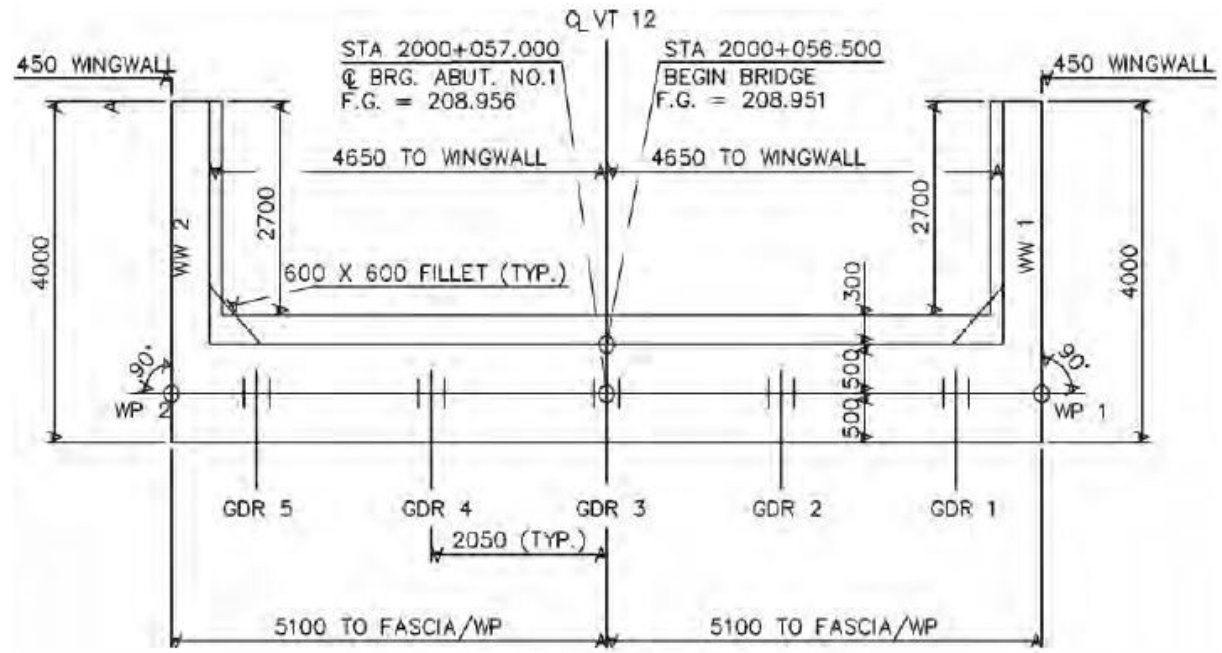

ABUTMENT NO.1 PLAN

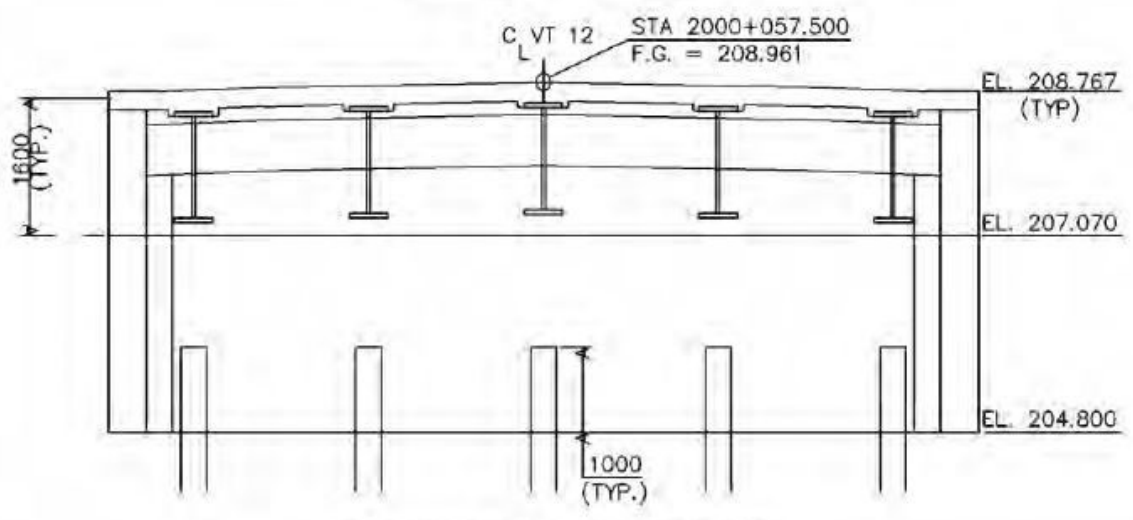

ABUTMENT NO.1 ELEVATION

Figure 3.26 Plan and Elevation View of Abutment-1 at Middlesex Bridge (Civjan et al., 2014)

10200 FASCIA TO FASCIA

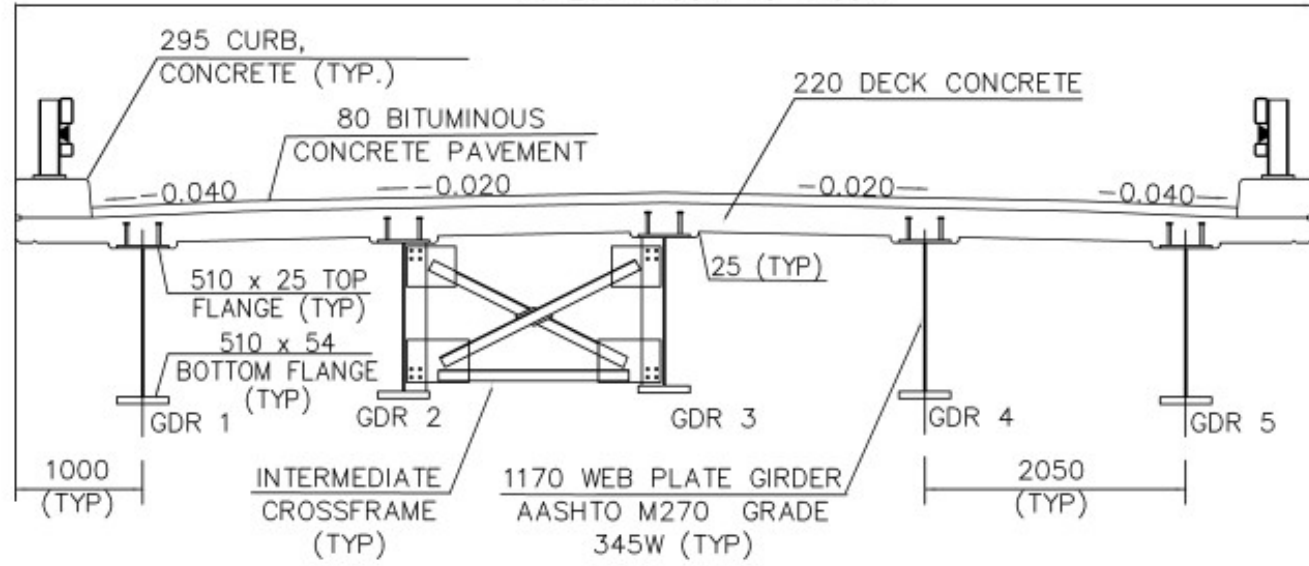

Figure 3.27 Middlesex Bridge Deck Section (Civjan et al., 2014) 


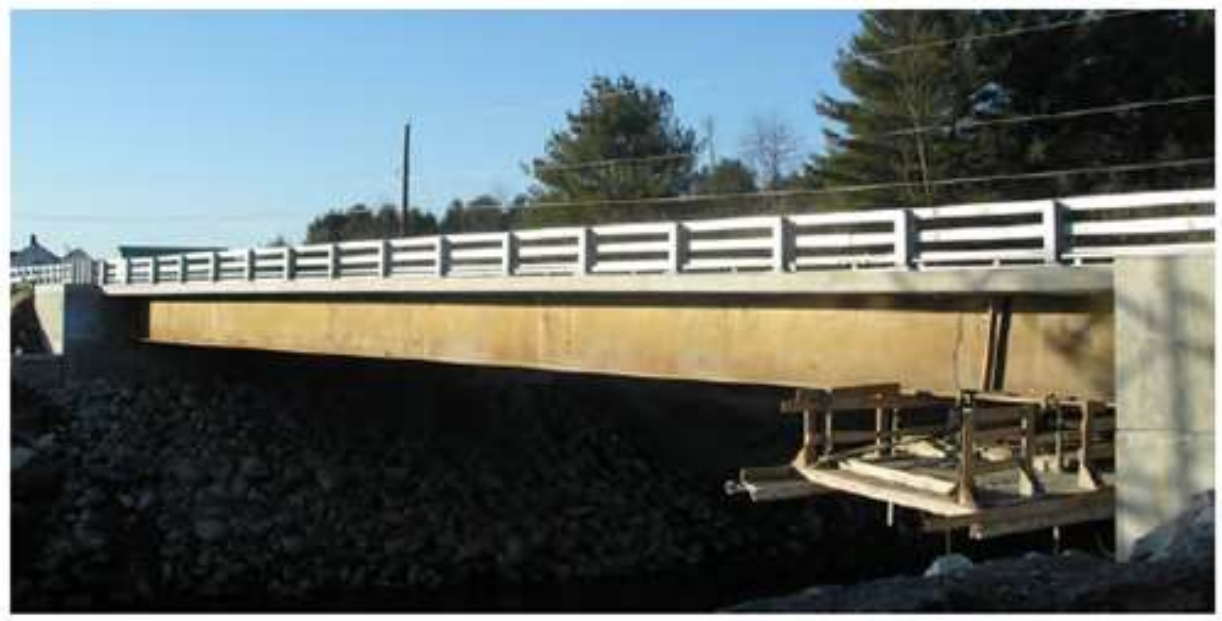

Figure 3.28 East Montpelier Bridge (Civjan et al., 2014)

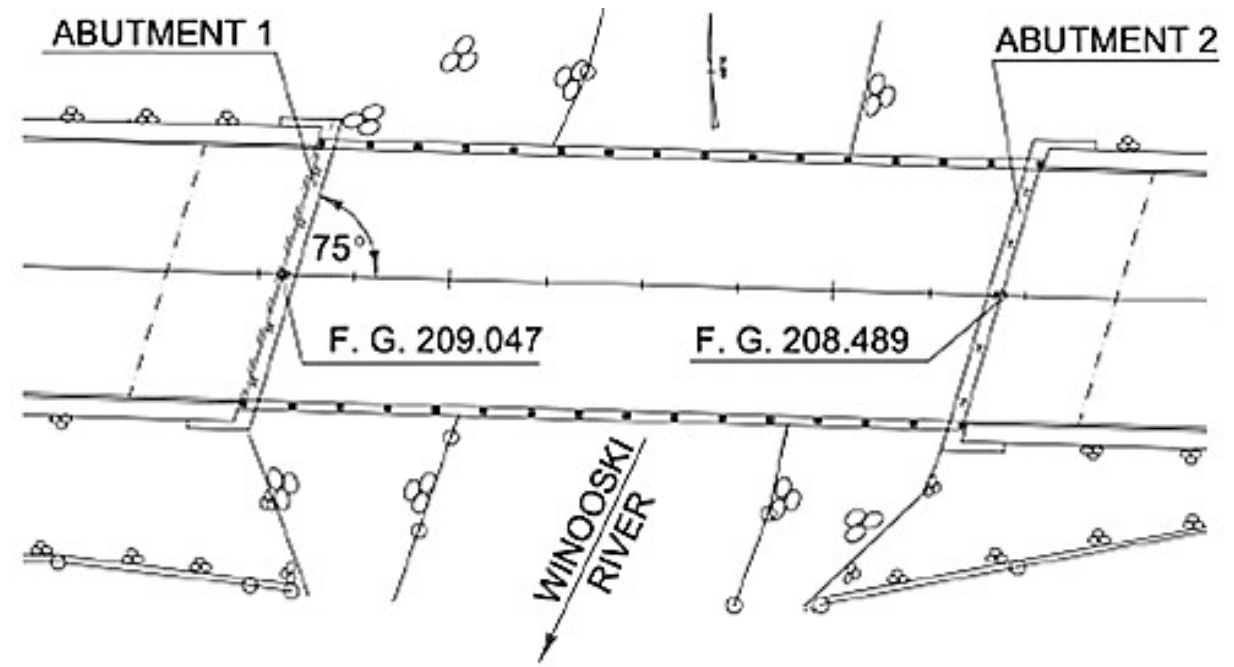

Figure 3.29 (a) Plan View of East Montpelier Bridge (Civjan et al., 2014)

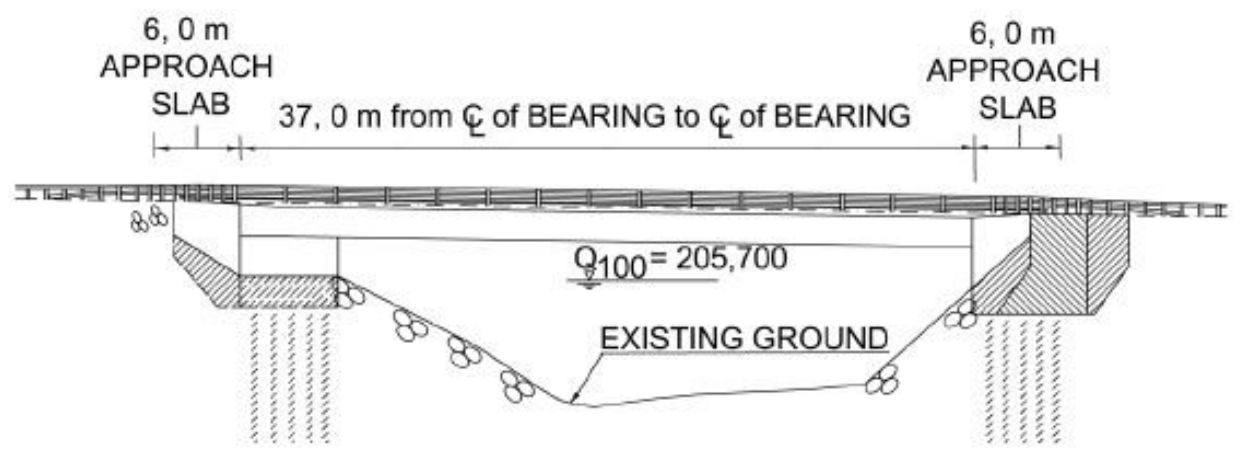

Figure 3.29 (b) Elevation View of East Montpelier Bridge (Civjan et al., 2014) 


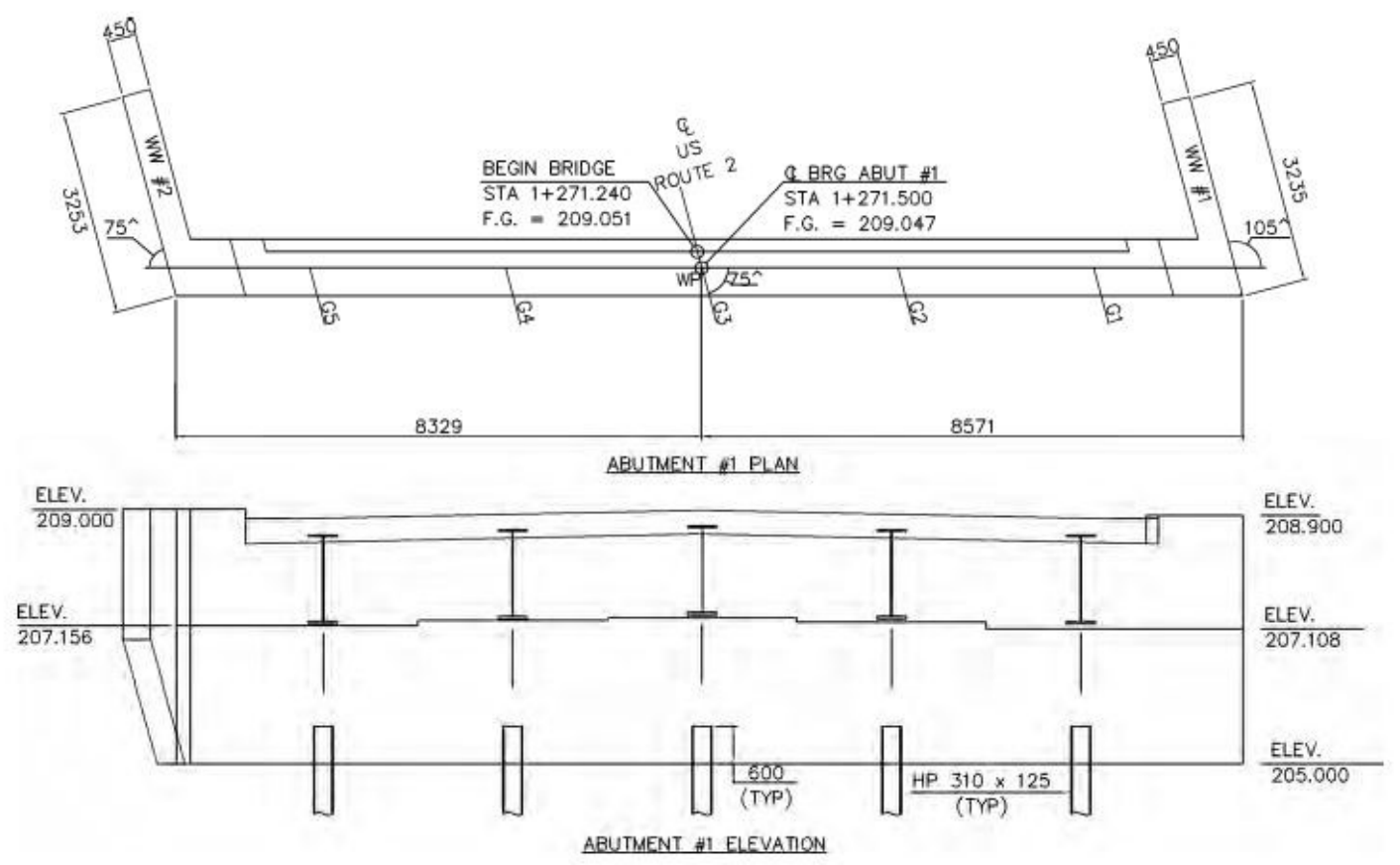

Figure 3.30 Plan and Elevation View of East Montpelier Bridge Abutment (Civjan et al., 2014)

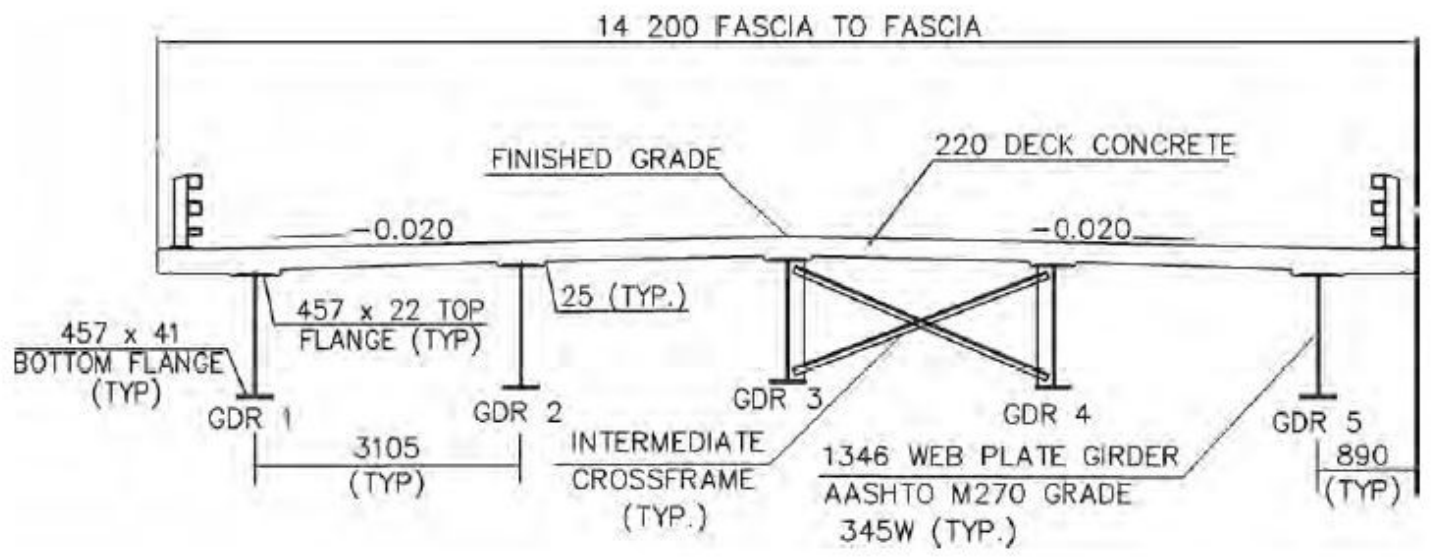

Figure 3.31 East Montpelier Bridge Deck Section (Civjan et al., 2014) 


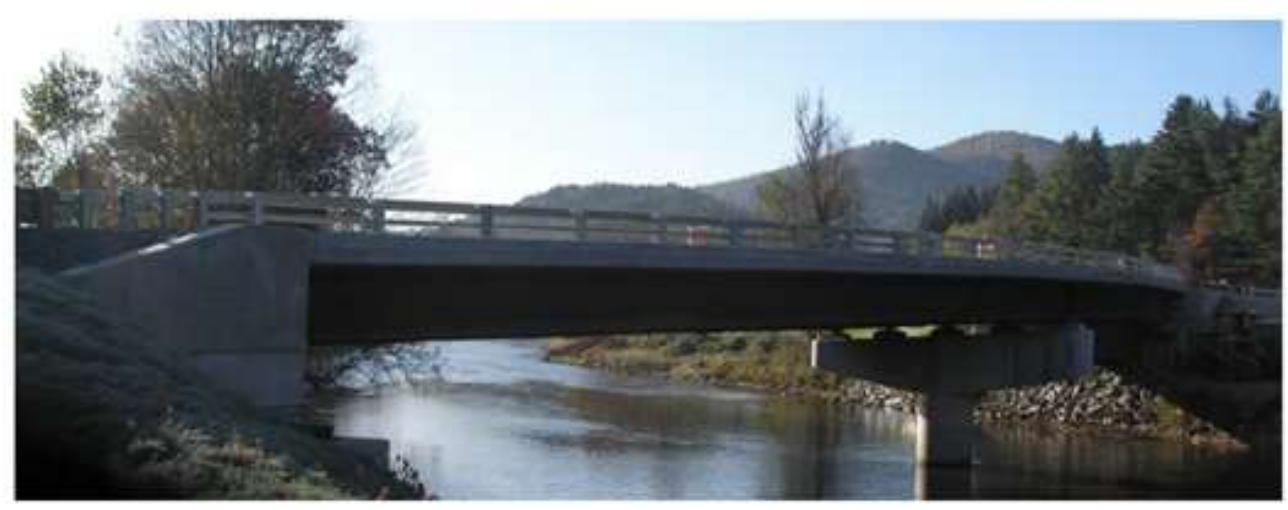

Figure 3.32 Stockbridge Bridge (Civjan et al., 2014)

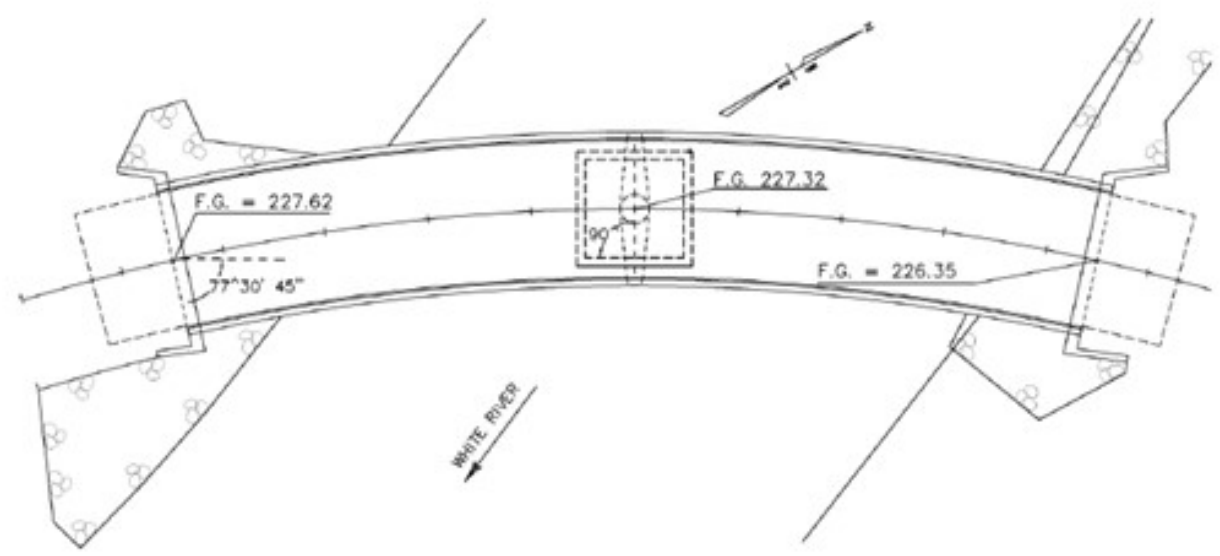

Figure 3.33 Plan View of Stockbridge Bridge (Civjan et al., 2014)

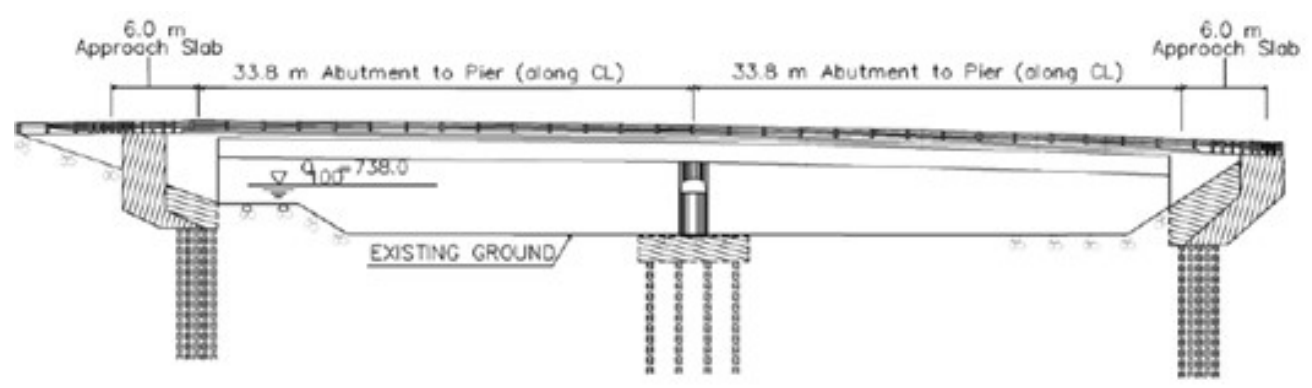

Figure 3.34 Elevation View of Stockbridge Bridge (Civjan et al., 2014) 

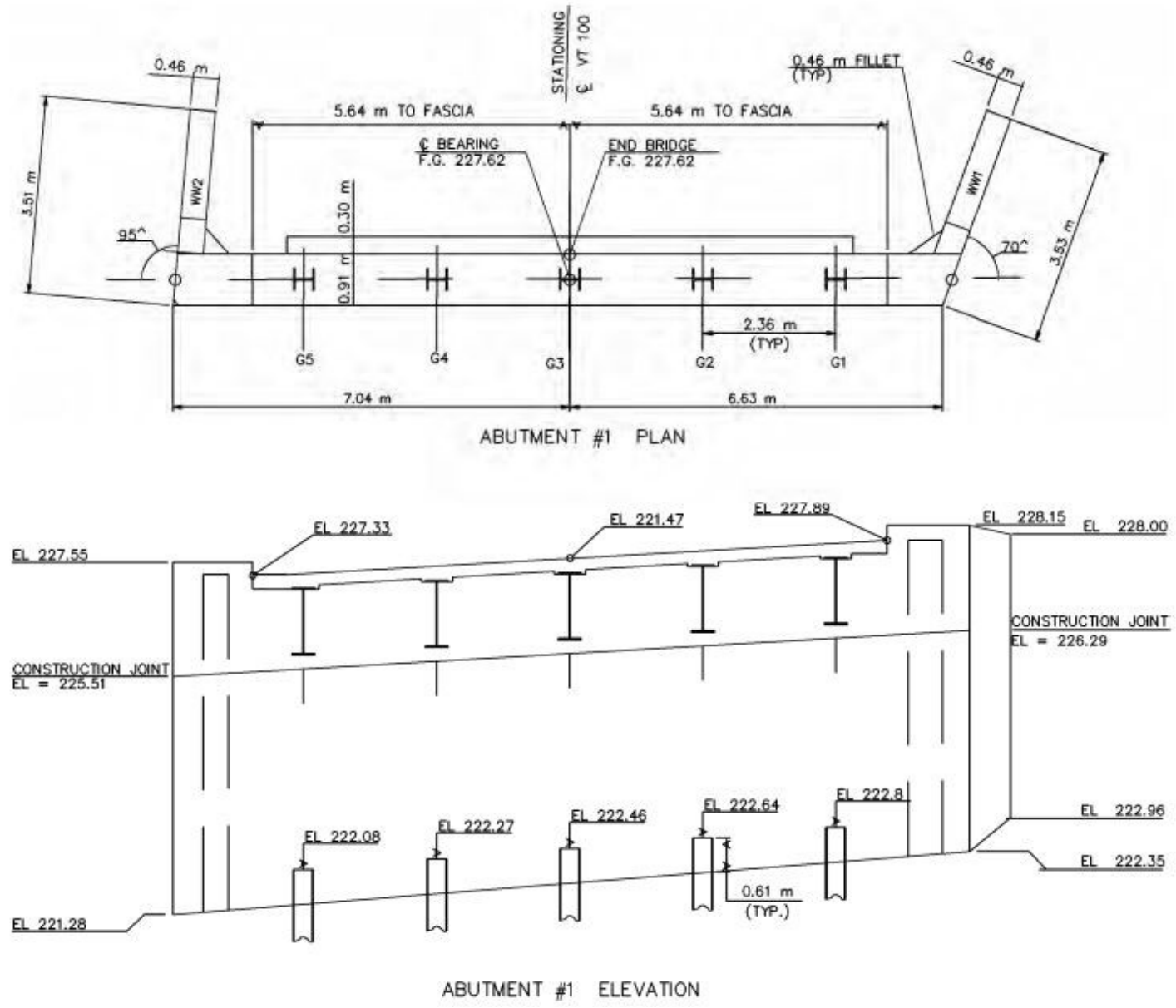

Figure 3.35 Plan and Elevation Views of Abutment-1 at Stockbridge Bridge (Civjan et al., 2014)

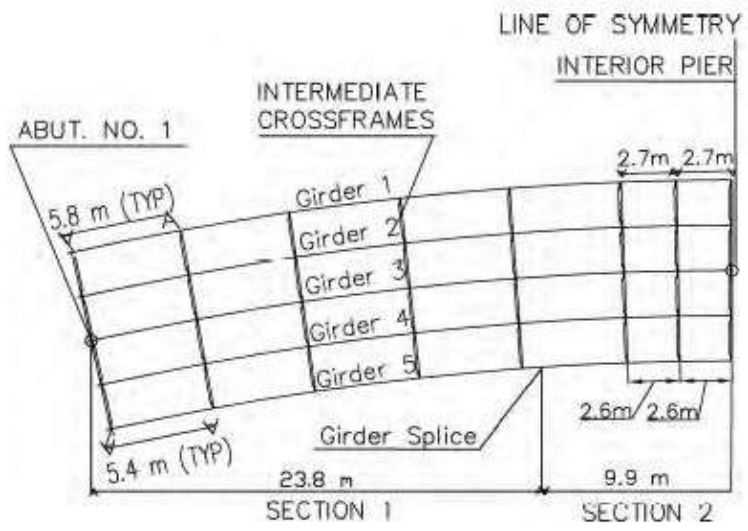

Figure 3.36 Stockbridge Framing Layout (Civjan et al., 2014) 


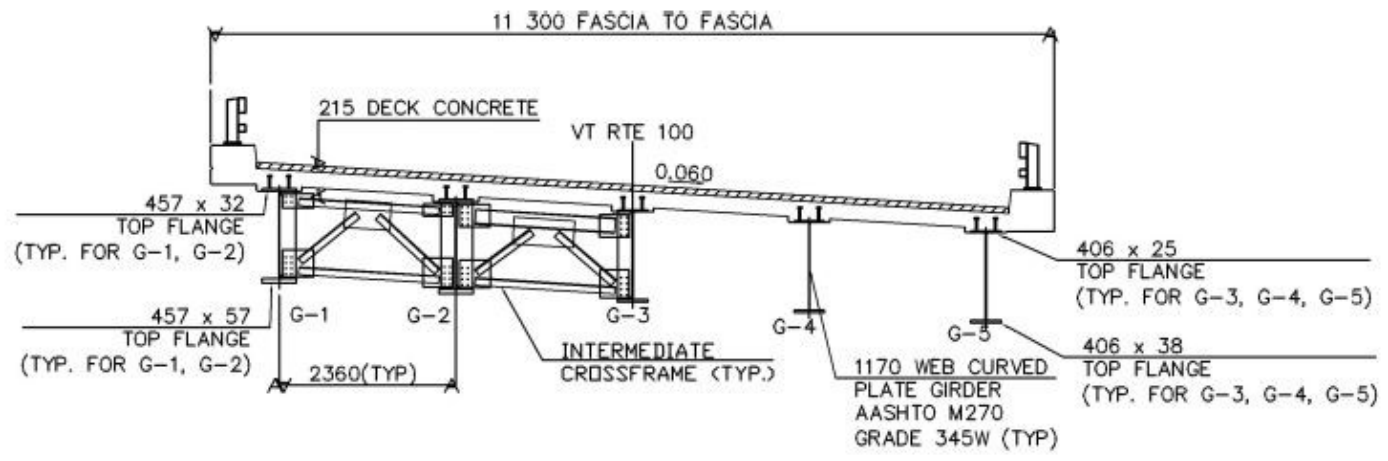

Figure 3.37 Stockbridge Deck Section 1 (Civjan et al., 2014)

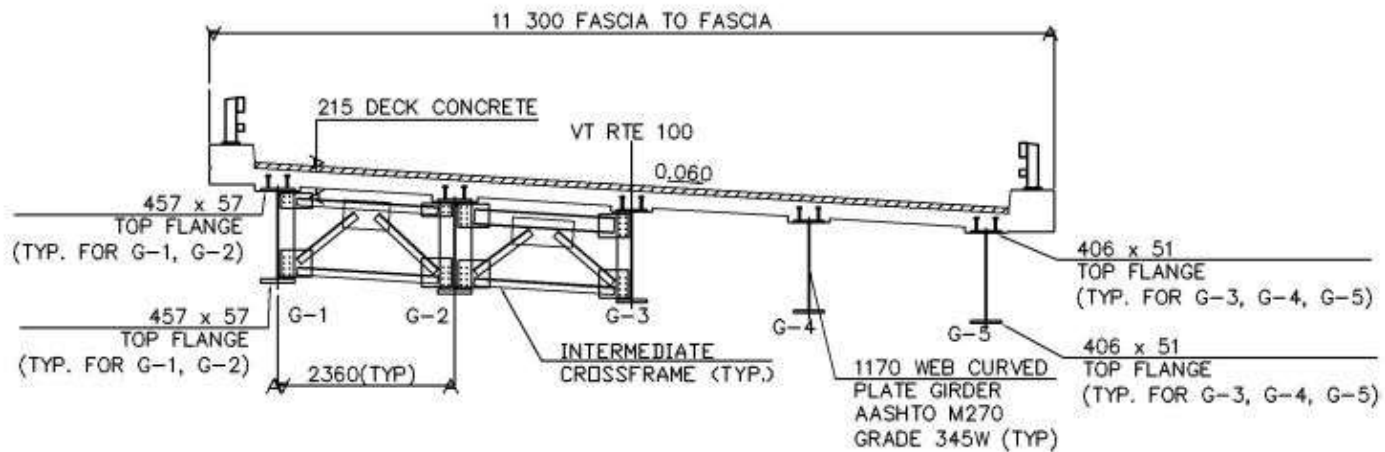

Figure 3.38 Stockbridge Deck Section (Civjan et al., 2014)

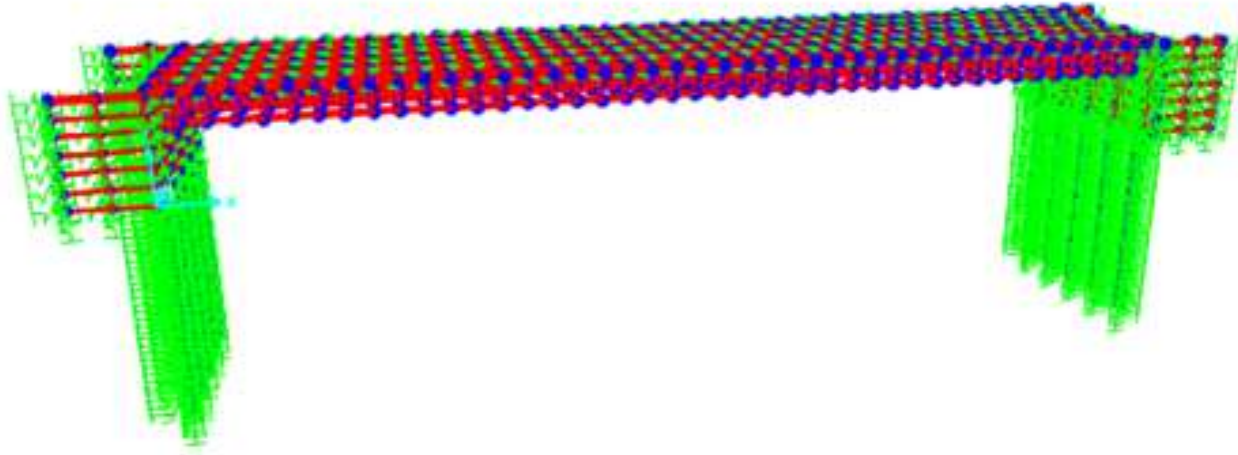

Figure 3.39 Finite Element Modeling of the Middlesex Bridge Showing Links and Soil Springs 


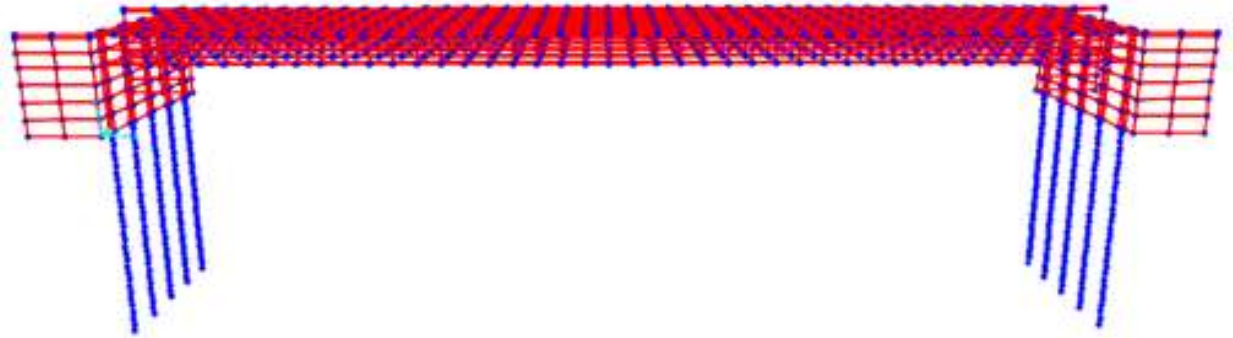

Figure 3.40 Finite Element Modeling of the Middlesex Bridge without Links and Soil Springs

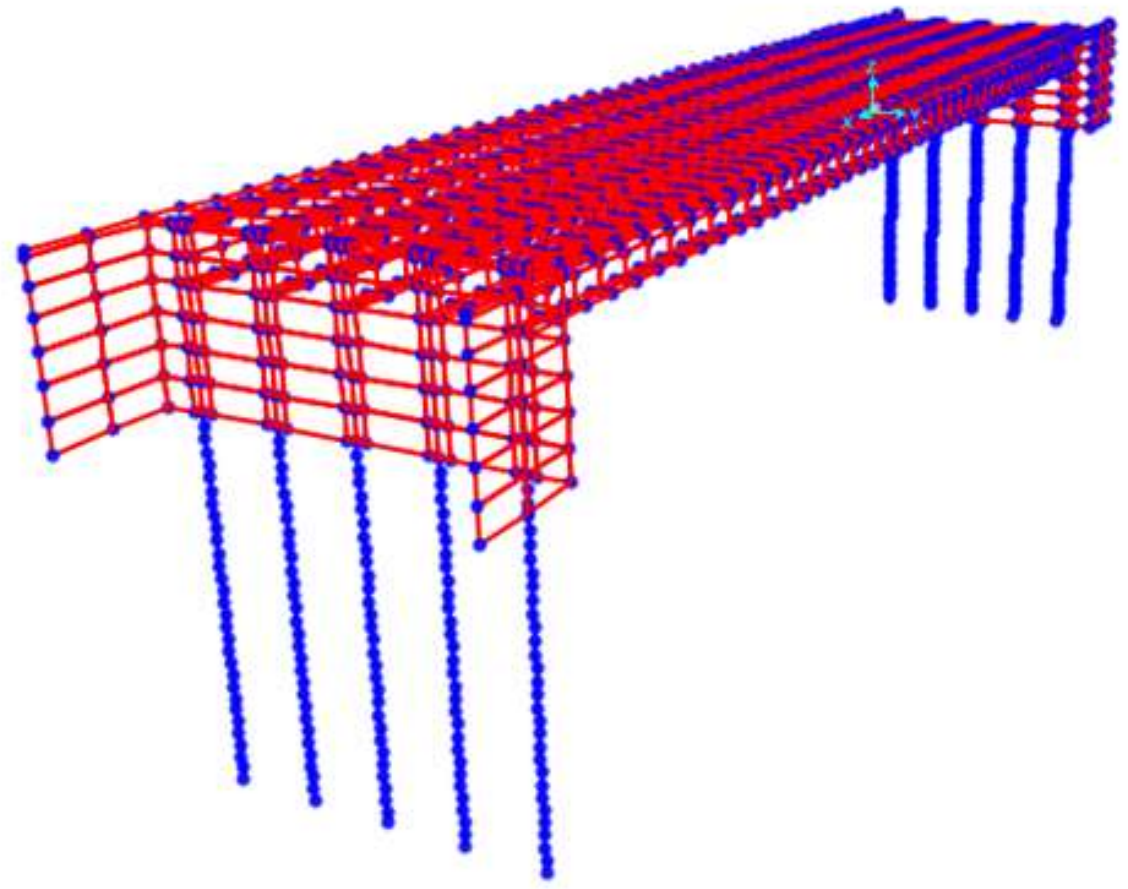

Figure 3.41 Finite Element Modeling of the Middlesex Bridge from SAP2000 Software Showing Shell Elements, Mesh Size and Beam Elements Node Distribution 


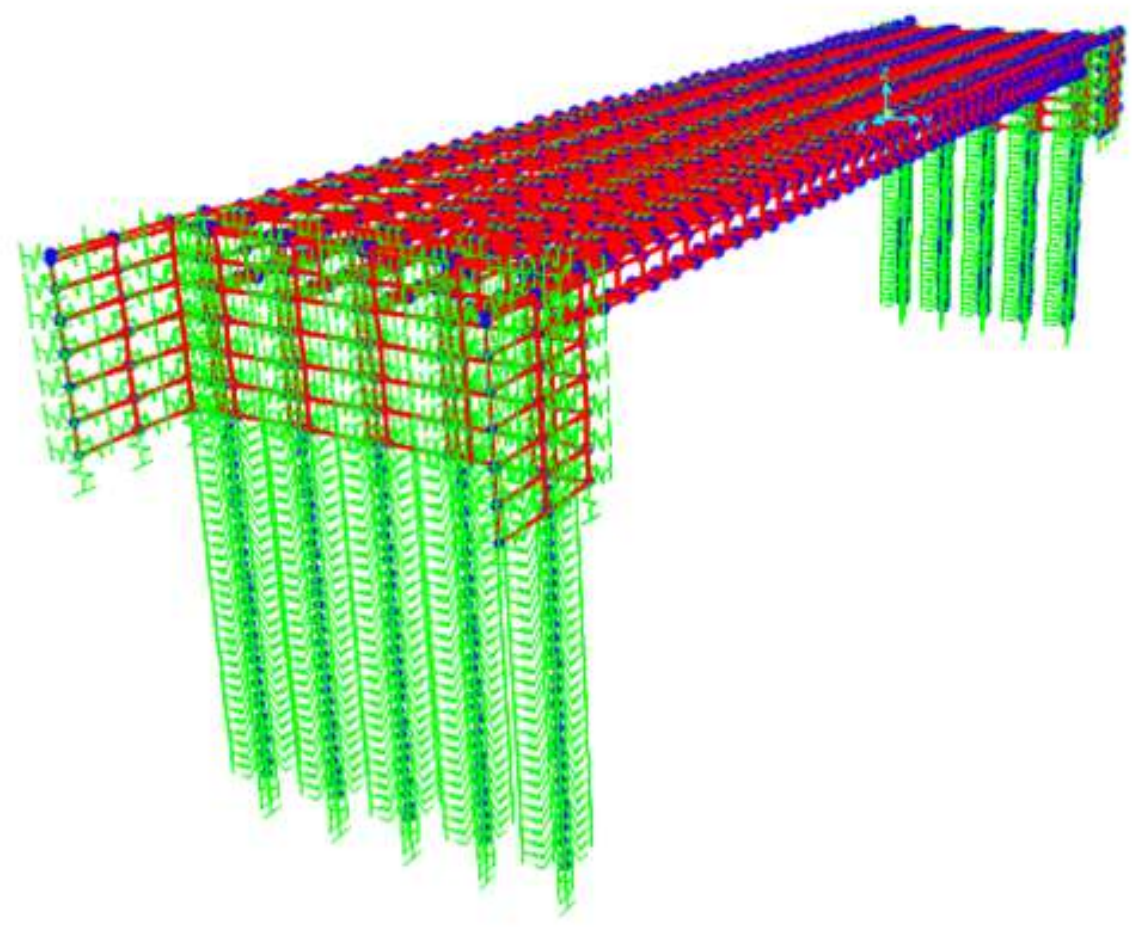

Figure 3.42 Finite Element Modeling of the Middlesex Bridge from SAP2000 Software Showing Shell Elements, Mesh Size, Beam Element Node Distribution, Link Members and Abutment and Piles Soil Springs

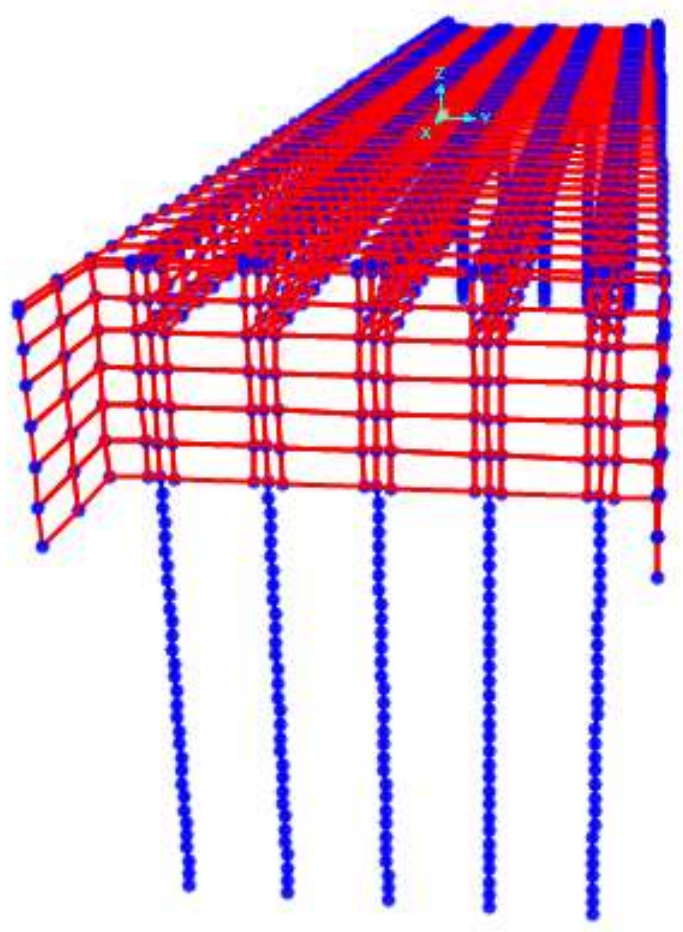

Figure 3.43 Side View of the Finite Element Modeling of the Middlesex Bridge 


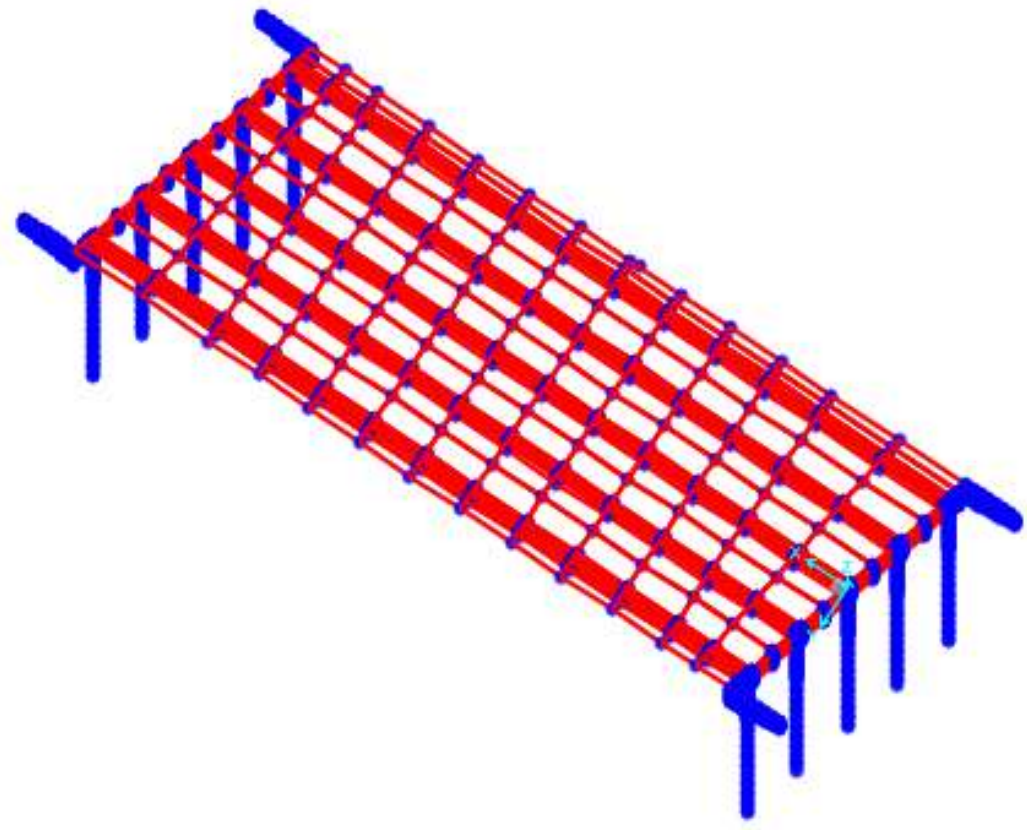

Figure 3.44 Plan View of the Finite Element Modeling of the East Montpelier Bridge

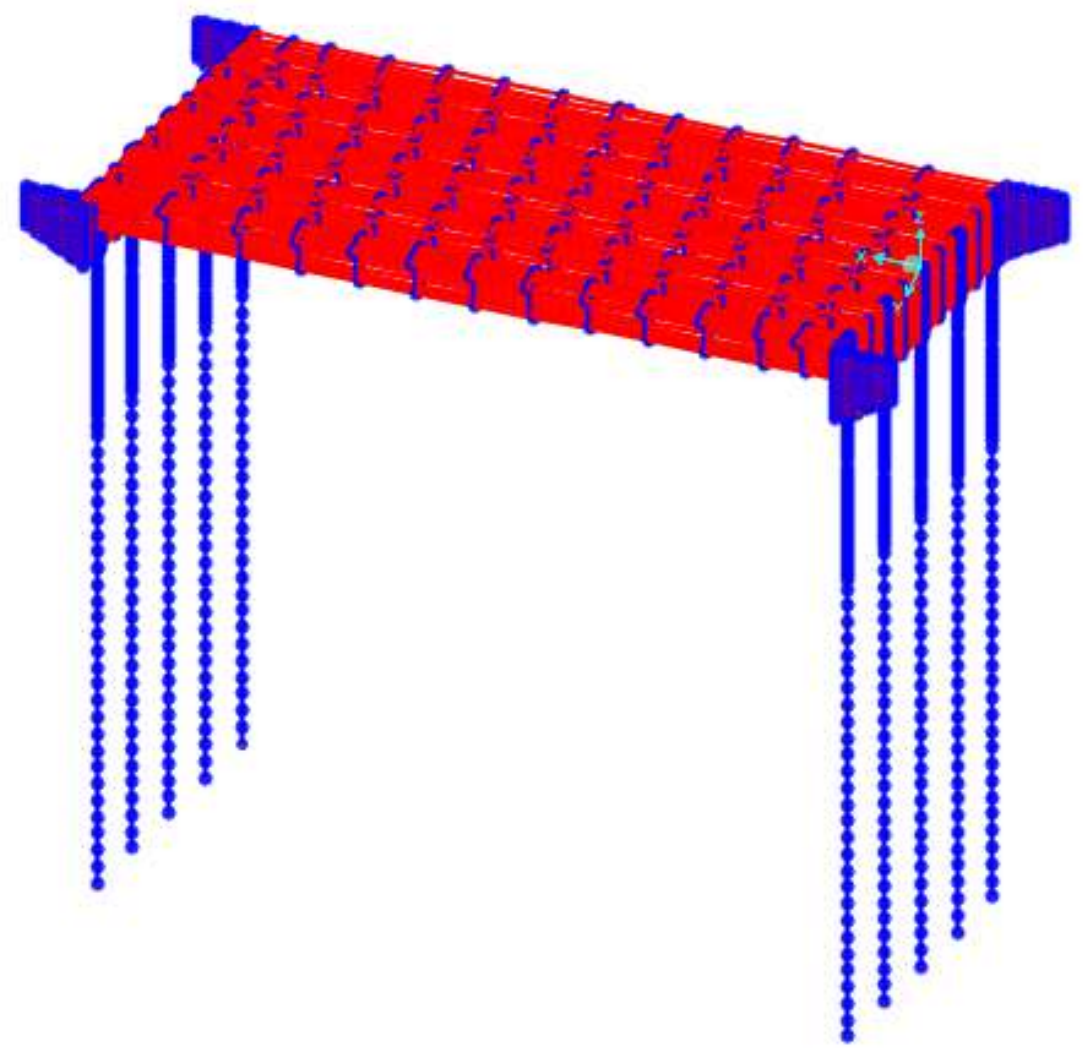

Figure 3.45 Elevation View of the Finite Element Modeling of the East Montpelier Bridge 


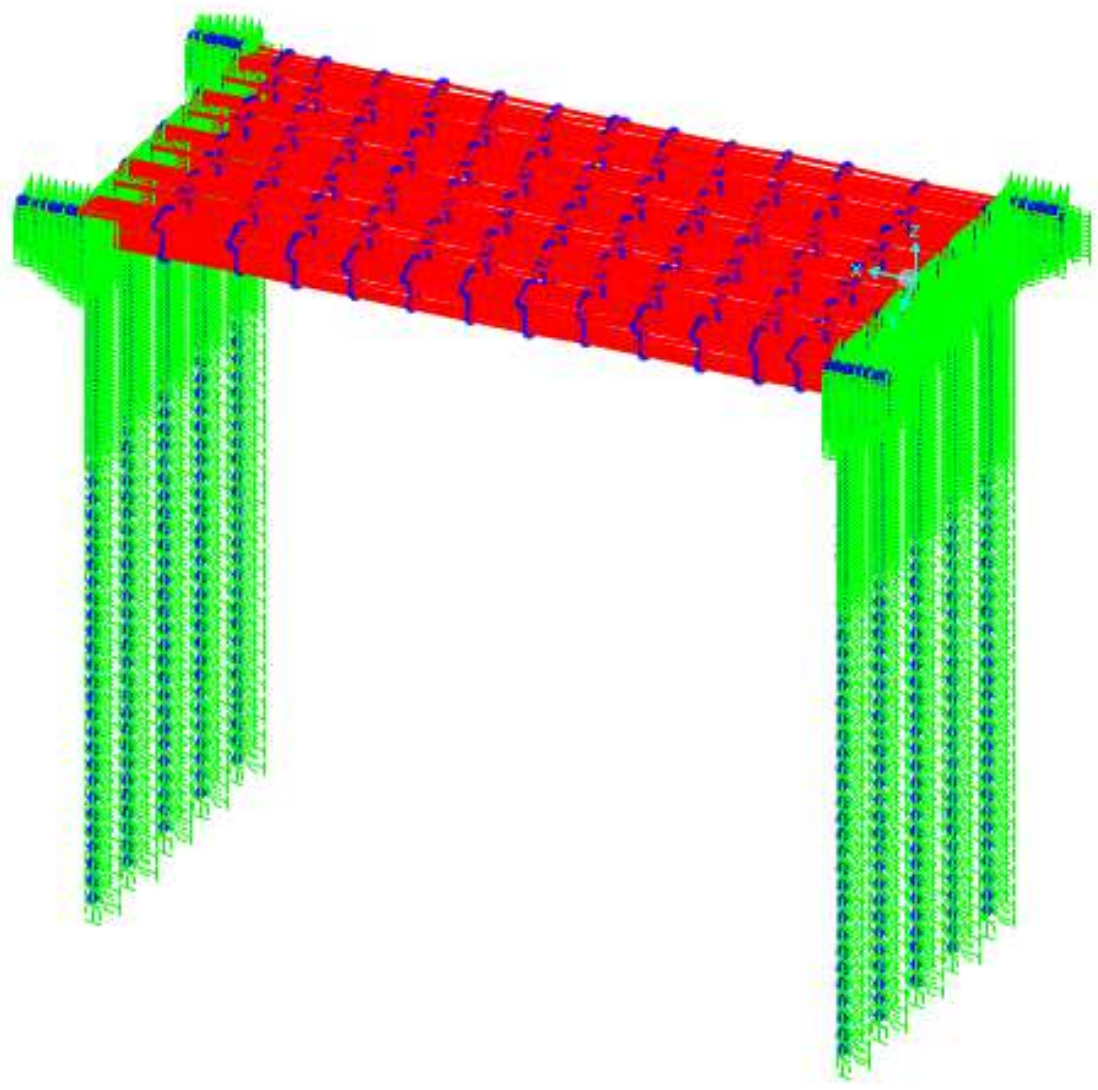

Figure 3.46 Elevation View of the Finite Element Modeling of the East Montpelier Bridge Showing Abutment and Pile Springs

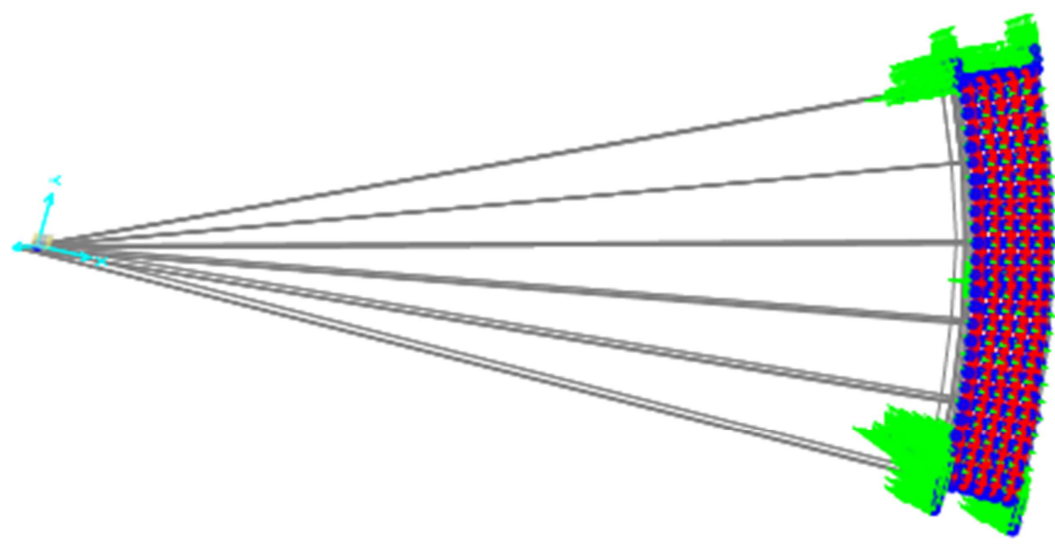

Figure 3.47 Plan View of the Finite Element Modeling of Stockbridge Bridge 


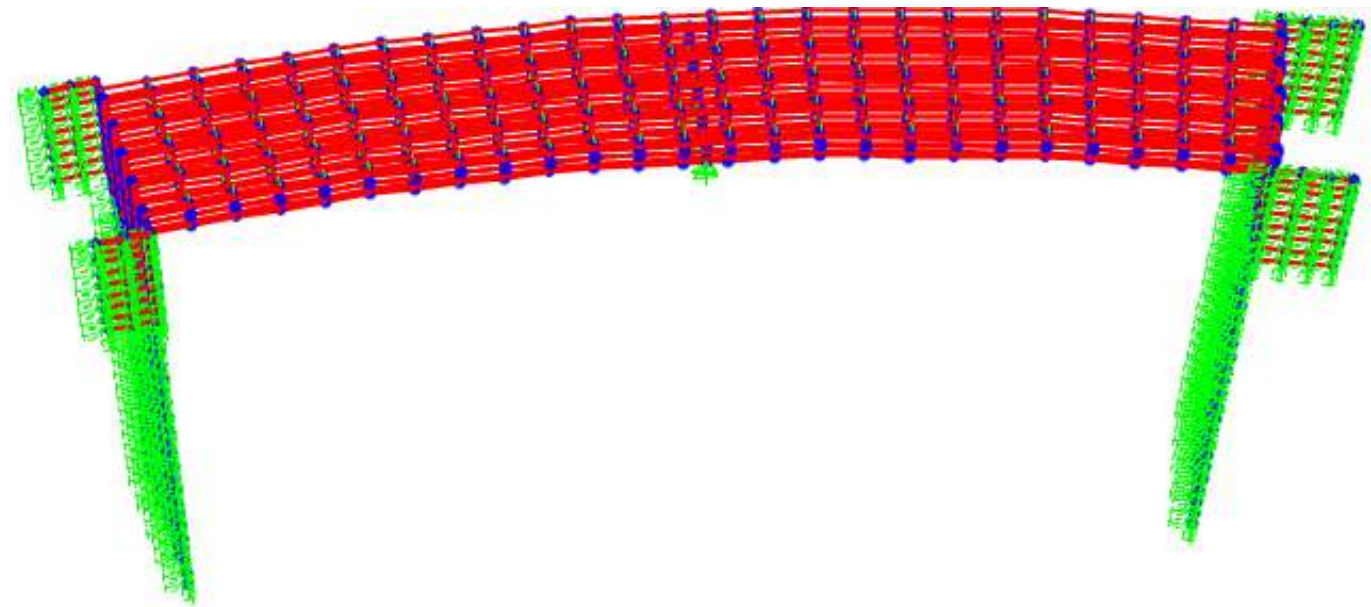

Figure 3.48 Elevation View of the Finite Element Modeling of Stockbridge Bridge

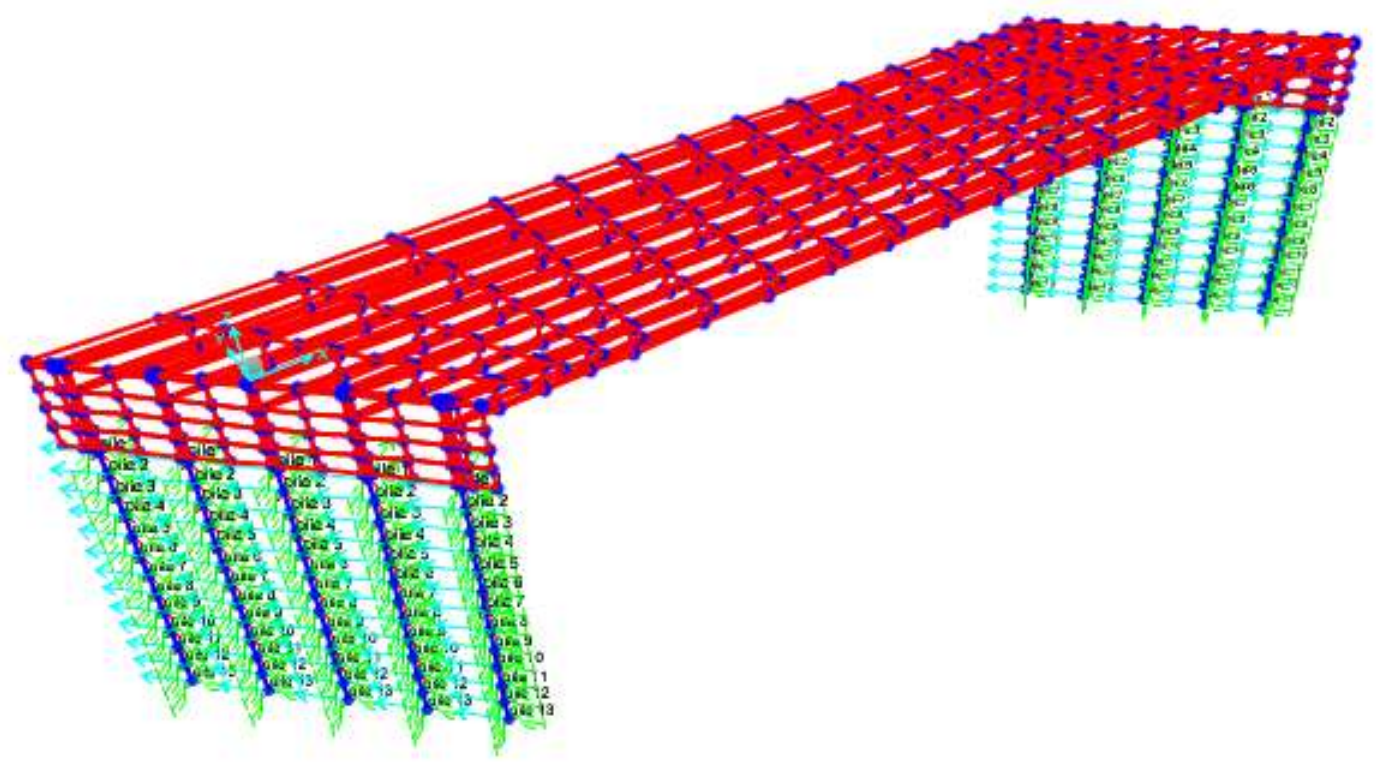

Figure 3.49 Elevation View of the Finite Element Modeling of the Modeled Bridge 


\section{CHAPTER 4}

\section{SENSITIVITY AND PARAMETRIC STUDY}

\subsection{Introduction}

The spatial variables affecting the performance of horizontally curved bridge include the radius of curvature $(R)$, the angle of curvature $(\theta)$, the abutment height $(H)$, the unit weight of granular backfill soil supporting the bridge abutment $(\gamma)$, loose and dense sand, and the type of foundation soil, stiff clay and medium dense sand. To investigate the sensitivity of each variable, a range of this variable was considered as presented in Table 4.1. These variables produce various bridges of different lengths, starting from $20.94 \mathrm{~m}$ up to $628.3 \mathrm{~m}$. The baseline of the curved bridge is the outer edge of the concrete bridge deck. Additionally, the effects of pier spacing $(\mathrm{S})$ and steel I-girders diaphragm spacing were investigated.

Table 4.1 Variables Considered in the Parametric Study

\begin{tabular}{|c|c|}
\hline Variable & Magnitude \\
\hline $\mathbf{R}(\mathbf{m})$ & $60,100,150,200,250$ and 300 \\
\hline $\boldsymbol{\theta}$ (degree) & $20,40,60,80,100$ and 120 \\
\hline $\begin{array}{c}\text { Abutment Height } \\
(\mathbf{m})\end{array}$ & $4.0,5.32$ and 6.64 \\
\hline $\begin{array}{c}\text { Condition of } \\
\text { Abutment Backfill }\end{array}$ & Loose sand and Dense sand \\
\hline $\begin{array}{c}\text { Condition of } \\
\text { Foundation Soil }\end{array}$ & Medium-Dense sand and stiff clay \\
\hline
\end{tabular}

Various finite element models were developed using combinations of variables shown in Table 4.1 to investigate the effect of these parameters on the performance of the bridge. The finite element models were constructed by varying a parameter, while the other parameters were kept constant at specified values. The radius of curvature varies from $60 \mathrm{~m}$ which is slightly above the minimum radius for curved bridge, up to $300 \mathrm{~m}$.

It is worth mentioning that the $6.64 \mathrm{~m}$ abutment height is $10 \%$ greater than the $6 \mathrm{~m}$ height that is currently the limit for integral abutment bridge height set by the Ministry of Transportation of Ontario (MTO, 1996). This MTO abutment height limit is not the consensus 
everywhere. For instance, Stockbridge Bridge which is a two-span curved integral abutment bridge located on VT Route 100 and crosses the White River in Stockbridge, Vermont, United States, has a $6.3 \mathrm{~m}$ height integral abutment (Civjan et al., 2014)

One of the purposes of varying the abutment height is to examine its effect on the pile deformation in different soil conditions. So, the wing walls were discarded in the finite element models. The pier supports were chosen to inhibit both the vertical and radial displacements in all the models and the bridge span between piers was chosen to be within 15 to $43.6 \mathrm{~m}$. The span length was measured along the baseline. Care was taken to limit the bridge span length (S), to avoid overstress of steel I-girders under their own weights.

\subsection{Effect of the Node Spacing Along the Pile}

Soil response to loads is complex and needs to be modeled to enable studying soil-structure interaction. Different soil models were established and published in literature (among them: Chen and Mizuno, 1990). Non-liner discrete Winkler springs were adopted to simulate the backfill soil behind the bridge abutment and the foundation soil. Notably, there is no interaction between these individual springs. Therefore, it is essential to assess the spacing between these spring to ensure accuracy of results without extensive effort in setting the input data and to optimize the computation time.

Sensitivity analysis was carried out to determine the optimum spacing between Winkler soil springs that should be applied along the length of the pile. So, various numerical models were established using SAP2000 Software to examine the effect of soil springs' spacing on the deformation of the substructure. The piles were discretized into elements of length $0.3,0.6$ and $0.9 \mathrm{~m}$. The straight bridge modeled in this sensitivity study was located on VT12 over Martin's Brook in Middlesex, VT, USA (Civjan et al., 2014). The different components of the bridge were described in Chapter 3. The $(p-y)$ relationship chosen for modeling soil resistance was the model descried in the API (2002). For better illustrating the impact of the spring spacing and due to limitations imposed by the small span length of the aforementioned bridge which is equal to $43.0 \mathrm{~m}$, an unrealistic temperature difference of $300^{\circ} \mathrm{C}$ was applied to the bridge superstructure in the finite element analysis. The bottom of abutment longitudinal displacement versus node spacing is listed in Table 4.2. The analysis aimed to assess the node spacing along the piles, which can be used for parametric study. 
Table 4.2 Bridge Longitudinal Displacement Versus Pile Spring Spacing

\begin{tabular}{|c|c|}
\hline Node Spacing $(\mathbf{m})$ & $\begin{array}{c}\text { Bottom Abutment } \\
\text { Displacement }(\mathbf{m})\end{array}$ \\
\hline 0.3 & 0.0142 \\
\hline 0.6 & 0.0146 \\
\hline 0.9 & 0.0146 \\
\hline
\end{tabular}

Results in Table 4.2 show that around $3 \%$ difference between the bottom of abutment longitudinal displacements while varying the spring spacing from 0.3 to $0.9 \mathrm{~m}$. Given the time and effort consumed in setting the required data for $0.3 \mathrm{~m}$ soil spring spacing and the fact that the pile beyond its critical length almost exhibits zero to minimum bending deformation, greater spacing between soil springs can be used. As an alternative, the top part of the pile may have close soil spring spacing around $0.3 \mathrm{~m}$. After the pile critical length is exceeded, the spacing of the soil springs may increase but with no more than $1 \mathrm{~m}$ spacing between soil springs. This, in effect, concurs with some of the published literature which varied the node spacing along the pile length (Quinn and Civjan, 2017).

Definitely, the smaller spacing between pile nodes is considered better accuracy for the model results, but with more effort in preparing enormous $(p-y)$ relationships and setting the data in the numerical model. Wide spacing between nodes, probably, produces less accuracy in model results, but with less effort and less computation time. However, Table 4.2 revealed that changing the spacing between nodes from $0.3 \mathrm{~m}$ to $0.9 \mathrm{~m}$ lacks the accuracy by about $3 \%$. In the current study, the spacing between nodes along the pile was taken $0.90 \mathrm{~m}$, sacrificing by $3 \%$ accuracy.

\subsection{Effect of Vertical Shear Stress along the Pile}

It was noticed in the literature that some researchers ignore the vertical shear stress developed along pile-soil interface, which simulated by $(f-z)$ relationships, when modeling integral abutment bridges subjected to thermal loading. However, they consider only two lateral orthogonal springs representing only the lateral soil resistance of the soil $(p-y)$ relationships at each node on the pile (Quinn and Civjan, 2017). Other researchers simulated the soil by three orthogonal springs (Thanasattayawibul, 2006). In order to assess the impact of ignoring the vertical shear stress along pile-soil interface on the response of integral 
abutment bridge under thermal loading conditions, the Middlesex straight integral Abutment Bridge was modeled including and excluding vertical springs which simulate vertical shear stress in the pile-soil interface displacement relationships $(f-z)$. The displacements of the piles and abutment due to thermal loading were compared in both cases. From the results that are not presented herein, it was concluded that there was no significant effect of vertical shear stress developed along the pile on the thermally-induced longitudinal and radial displacements of the integral abutment bridge. But, the self-weight of the bridge is resisted by vertical shear stresses developed along pile-soil interfaces and bearing stress at pile bases. Therefore, when the integral bridge is subjected to thermally included loading conditions, there are lock-in shear stresses along pile-soil interfaces and lock-in bearing stresses underneath pile bases.

\subsection{Effect of Water Level}

The study of the lateral deformation of substructure of integral abutment bridge due to thermal loading requires accurate knowledge of the soil properties for both the backfill behind the abutment and the foundation soil. However, in most, if not all, of these bridge types, the bridge crosses a water body. This water body is subjected to varying surface water level. The level of the water in the water body is fluctuated since it is dependent on the amount of supplied water, demand and environmental conditions. Additionally, to other man-made or force-majeure circumstances that can alter the water level. All the soil models used to describe the resistance of the soil incorporate the effective unit weight of soil in their formulas. The effective soil unit weight above the water level equals to the bulk unit weight. While below the water table, the effective soil unit weight is equal to the total unit weight minus water unit weight. So, in order to assess the effect of the time varying water level on the deformation of integral abutment bridge substructure under thermally-induced loading, various numerical models were carried out. Middlesex Bridge was modeled using SAP2000 Software (Civjan et al., 2014). The bridge was analyzed, first assuming the water level lies beneath the pile tip, and then the water level was taken at the level of the bottom of the bridge's abutment. The bottom of abutment longitudinal displacement was compared in both cases. From the numerical model results, it was shown that varying the water level from pile tip level to bottom of abutment level, the bottom of abutment displacement changed by less 
than $3 \%$ as shown in Table 4.3. These results agree with those presented by Arockiasamy et al. (2004). This can be attributed to the fact that the unit weight of soil has no appreciable effect on soil stiffness, specially clay soil. The reason behind this is that the soil models used in calculating the lateral soil resistance require average effective unit weight measured from the ground surface to the point of calculating the $p-y$ relationship, in addition to the API (2002) formula itself which is a hyperbolic tangent formula as depicted in Equation 4.1.

$$
P=A \times P u \tanh \left(\frac{K \times H \times Y}{A \times p_{u}}\right)
$$

Where;

$A$ : Factor to account for cyclic or static loading, $A=0.9$, for cyclic loading, $A=\left(3-0.8 \frac{H}{D}\right) \geq 0.9$, for static loading, $p_{u}$ : Ultimate bearing capacity at depth $\mathrm{H}$, $H$ : Depth, $K$ : Initial modulus of subgrade reaction, determined from a figure given by API (2002), as a function of the angle of internal friction, $\varphi$,

$Y$ : Lateral deflection resistance, $p_{u}$ at a given depth $(\mathrm{H})$ is the smallest of;

$p_{u s}=\left(c_{1} H+c_{2} D\right) \gamma H$

$p_{u d}=c_{3} D \gamma H$

Where;

$\gamma$ : Effective soil weight, $c_{1}, c_{2}$ and $c_{3}$ : Coefficients determined from a figure given by API (2002), as a function of angle of internal friction, $\varphi$. 
Table 4.3 Effect of Water Level on Bottom-of-Abutment Displacement

\begin{tabular}{|c|c|c|}
\hline Bridge & $\begin{array}{c}\text { Displacement Considering Water Level at } \\
\text { Pile Head }(\mathbf{m})\end{array}$ & $\begin{array}{c}\text { Displacement Considering } \\
\text { Water Level at Pile Tip }(\mathbf{m})\end{array}$ \\
\hline $\begin{array}{c}\text { Middlesex } \\
\text { Bridge }\end{array}$ & 0.0162 & 0.0157 \\
\hline
\end{tabular}

\subsection{Effect of the Spacing of the Solid Steel Diaphragms on Pile Displacement}

To enhance lateral stiffness of steel-plate girder bridges, several configurations of crossframes and diaphragms can be used such " $X$ " shaped frames, "K" shaped frames and folded plate diaphragms. In the current finite element models, diaphragms were chosen to provide radial stiffness to the steel girders. This choice concurs with what can be found in the field. For Instance, Bridge 309 which is $7.92 \mathrm{~m}$ wide, three span, horizontally-curved integral abutment bridge located in USA utilized bent plate diaphragms which were connected to the welded I-shaped composite steel-plate girders. Other bridges, namely: 209, 2208 and 2308, in Des Moines, lowa, USA, which are curved steel I-girder bridge with semi-integral and integral abutment, utilized bent plate diaphragms for the girder radial support (Greimann et al., 2014; Hoffman and Phares, 2014).

The effect of solid steel diaphragm spacing was examined by using the FEM of a four-span horizontally curved integral abutment bridge of $250 \mathrm{~m}$ radius and a length of $87 \mathrm{~m}$, measured along the baseline. Abutment height was taken as $4 \mathrm{~m}$. The abutment was supported by dense sand and piles were embedded in medium dense sand. Contraction phase of $-65{ }^{\circ} \mathrm{C}$ was considered. Two models were analyzed; the diaphragm average spacing was taken as $8.51 \mathrm{~m}$ in the first model and $4.25 \mathrm{~m}$ in the second model. The pile maximum resultant displacements in both cases were compared. The bridge with $4.25 \mathrm{~m}$ diaphragm spacing gave pile maximum resultant displacement of $24.50 \mathrm{~mm}$, while the much spacious diaphragm spacing gave pile maximum resultant displacement of $23.5 \mathrm{~mm}$, with a difference of $4.2 \%$.

Another FEM was examined for the effect of varying diaphragm spacing. A four-span, $100 \mathrm{~m}$ radius, bridge with a total length of $69.8 \mathrm{~m}$ was modeled and analyzed. Abutment height was taken as $4 \mathrm{~m}$. The abutment was supported by dense sand and piles were embedded in medium dense sand. Contraction case of $-65^{\circ} \mathrm{C}$ was considered. The pile maximum resultant displacement was compared when the diaphragm spacing were $1.64 \mathrm{~m}$ and $3.27 \mathrm{~m}$. The 1.64 
$\mathrm{m}$ diaphragm spacing gave pile maximum resultant displacement of $17.8 \mathrm{~mm}$, while that of $3.27 \mathrm{~m}$ spacing gave pile maximum resultant displacement of $17.25 \mathrm{~mm}$, a difference of 3.1 $\%$. Hence, it was concluded that varying diaphragm spacing has insignificant effect on the pile maximum resultant displacement. Also, it was found in both finite element models that the pile maximum resultant displacement increases slightly with the decrease in diaphragm spacing.

The third FEM examined for the effect of varying diaphragm spacing was of a horizontally curved multi-span integral abutment bridge of $200 \mathrm{~m}$ radius and a total length of $209 \mathrm{~m}$. Abutment height was taken as $5.32 \mathrm{~m}$. Contraction case of $-65^{\circ} \mathrm{C}$ was considered. Abutment was supported by dense sand and piles were embedded in medium dense sand. The diaphragm spacing was taken as $3.38 \mathrm{~m}$ and $6.76 \mathrm{~m}$. The $3.38 \mathrm{~m}$ spacing gave pile maximum resultant displacement of $53.8 \mathrm{~mm}$, while the $6.76 \mathrm{~m}$ diaphragm spacing gave pile maximum resultant displacement of $51.78 \mathrm{~mm}$, a difference of $3.9 \%$.

The fourth FEM model examined for the effect of varying diaphragm spacing was of a horizontally curved multi-span integral abutment bridge of $150 \mathrm{~m}$ radius and a total length of $209.43 \mathrm{~m}$. Abutment height was taken as $6.64 \mathrm{~m}$. Abutment was supported by loose sand and piles were embedded in medium dense sand. Expansion case of $+65^{\circ} \mathrm{C}$ was considered. The pile maximum resultant displacement was $15.9 \mathrm{~mm}$ when the diaphragm spacing was $5.02 \mathrm{~m}$. When the spacing increased to $10 \mathrm{~m}$, the pile maximum resultant displacement was $15.79 \mathrm{~mm}$, with difference of $0.7 \%$.

The achieved results in section 4.5 were tabulated as shown in Table 4.4. The table revealed that the pile maximum resultant displacement (PMRD) increased slightly with the decrease of diaphragm spacing, due the increase of the bridge deck rotation stiffness. Thus, decreasing the spacing between diaphragms improves the performance of bridge deck, meanwhile impairing the performance of substructure.

So, the spacing of the diaphragm for all the studied models in the current research and listed in Table 3.1 was kept under the $9.14 \mathrm{~m}$ to $10.06 \mathrm{~m}$ (30 ft to $33 \mathrm{ft}$ ) limit of maximum radial spacing that was found in the literature (Hall et al., 1999). 
Table 4.4 Effect of Diaphragm Spacing on Pile Maximum Resultant Displacement (PMRD)

\begin{tabular}{|c|c|c|c|c|c|}
\hline Backfill Soil & $\begin{array}{c}\text { Abutment } \\
\text { Height (H) } \\
\text { (m) }\end{array}$ & $\begin{array}{c}\text { Radius of } \\
\text { Curvature (R) } \\
\text { (m) }\end{array}$ & $\begin{array}{l}\text { Length of the } \\
\text { Bridge (L) } \\
\text { (m) }\end{array}$ & $\begin{array}{c}\text { Diaphragm } \\
\text { Spacing (Ds) } \\
\text { (m) }\end{array}$ & $\begin{array}{c}\text { Pile Maximum } \\
\text { Resultant } \\
\text { Displacement }(\Delta) \\
(\mathrm{mm})\end{array}$ \\
\hline \multirow{2}{*}{ Dense Sand } & \multirow{2}{*}{4.0} & \multirow{2}{*}{250} & \multirow{2}{*}{87.0} & 8.5 & 23.5 \\
\hline & & & & 4.25 & 24.5 \\
\hline \multirow{2}{*}{ Dense Sand } & \multirow{2}{*}{4.0} & \multirow{2}{*}{100} & \multirow{2}{*}{69.8} & 3.27 & 17.25 \\
\hline & & & & 1.64 & 17.8 \\
\hline \multirow{2}{*}{ Dense Sand } & \multirow{2}{*}{5.32} & \multirow{2}{*}{200} & \multirow{2}{*}{209.0} & 6.76 & 51.7 \\
\hline & & & & 3.38 & 53.8 \\
\hline \multirow{2}{*}{ Loose Sand } & \multirow{2}{*}{6.64} & \multirow{2}{*}{150} & \multirow{2}{*}{209.0} & 10.0 & 15.79 \\
\hline & & & & 5.02 & 15.9 \\
\hline
\end{tabular}

\subsection{Effect of the Characteristic $(p-y)$ relationship on Pile Displacement}

Soil exhibits reversible elastic and irreversible plastic strain during loading. The soil has combination of these two mechanisms. In the field of soil-structure interaction, there is a need to model the soil. Different methodologies were implemented in simulating the soil around laterally loaded pile, such as Winkler model, elastic model, hyperbolic elastic-plastic model (Cauchy Elastic Model) and viscous model (Chen and Mizuno, 1990).

The approach of $p-y$ relationship method was developed by Matlock (1970), Reese et al. (1975), and O'Neill and Murchinson (1983). The basis of this method is Winkler approach (winkler, 1867). The method was adopted by API (2002), nevertheless, the method inherent disadvantages such as the lack of continuity and not validated neither for large diameter piles nor H-piles. Additionally, pile stiffness was not considered in the development of $p-y$ relationships.

The adopted procedure for developing $p$-y relationships, which was based on Osgood model, was compared with that adopted by API. Figure 4.1. Figure 4.1 shows the lateral forcedisplacement relationship $(p-y)$ computed using the hyperbolic tangent equation in the API 
manual at a depth level of $10.2 \mathrm{~m}$ from the ground level. While Figure 4.2 shows a comparison between the basic $(p-y)$ relationship and that obtained from API. Although the ultimate loads are the same, the initial stiffness of $(p-y)$ relationship obtained from API is bigger than that exhibited by the Basic relationship. Figure 4.3 shows that the initial stiffness of Basic $(p-y)$ relationship is slightly bigger than that exhibited by Ramberg-Osgood model. While the ultimate load of the two approaches are the same. The slight difference in values in the soil force-displacement relationships computed by the modified Ramberg-Osgood model and the basic $(p-y)$ curve equation yields similar performance of abutment piles, if any of these relationships are implemented in the numerical model. While the API equation provides less displacement and bigger initial stiffness compared to the other two models as shown in Figure 4.3.

To confirm the effect of the characteristics of $(p-y)$ relationship, either from API or from Modified Ramberg-Osgood on the performance of bridge substructure, the pile maximum resultant displacement under thermal loading was assessed in a numerical model where the pile soil force-displacement relationship the pile soil force-displacement relationship $(p-y)$ was once computed by Ramberg-Osgood model and the other by the API hyperbolic tangent model. The difference in the pile displacement was around $14 \%$ between both cases. As anticipated, the numerical model in which the pile soil force-displacement curve was modeled by the Ramberg-Osgood model showed more pile displacement than the API model. This is attributed to the difference in stiffness of the two relationships as mentioned above.

was once computed by Ramberg-Osgood model and the other by the API hyperbolic tangent model. The difference in the pile displacement was around $14 \%$ between both cases. As anticipated, the numerical model in which the pile soil force-displacement was modeled by the Ramberg-Osgood model showed more pile displacement than the API model. This is attributed to difference in stiffness of the two relationships as mentioned above.

Therefore, the adopted simulation of foundation soil has appreciable impact on the substructure performance. Unfortunately, most soil models related to soil-structure interaction are of empirical nature and inherent uncertainties. Therefore, these models have to be used with care. In the current study, Ramberg-Osgood model was implemented in the numerical method. 


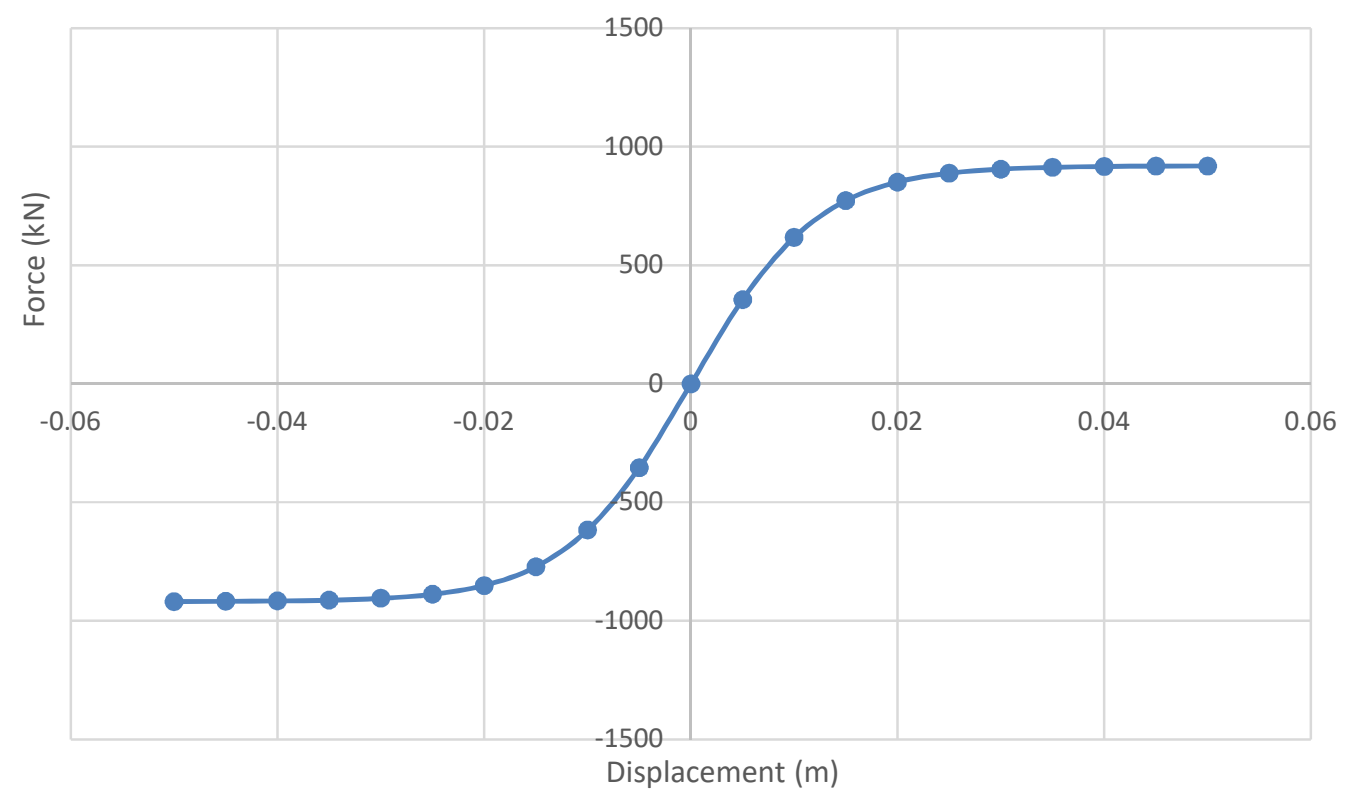

Figure 4.1 Pile Soil Force-Displacement Relationship at depth of $10.2 \mathrm{~m}$ Calculated Using the API Hyperbolic Tangent Equation

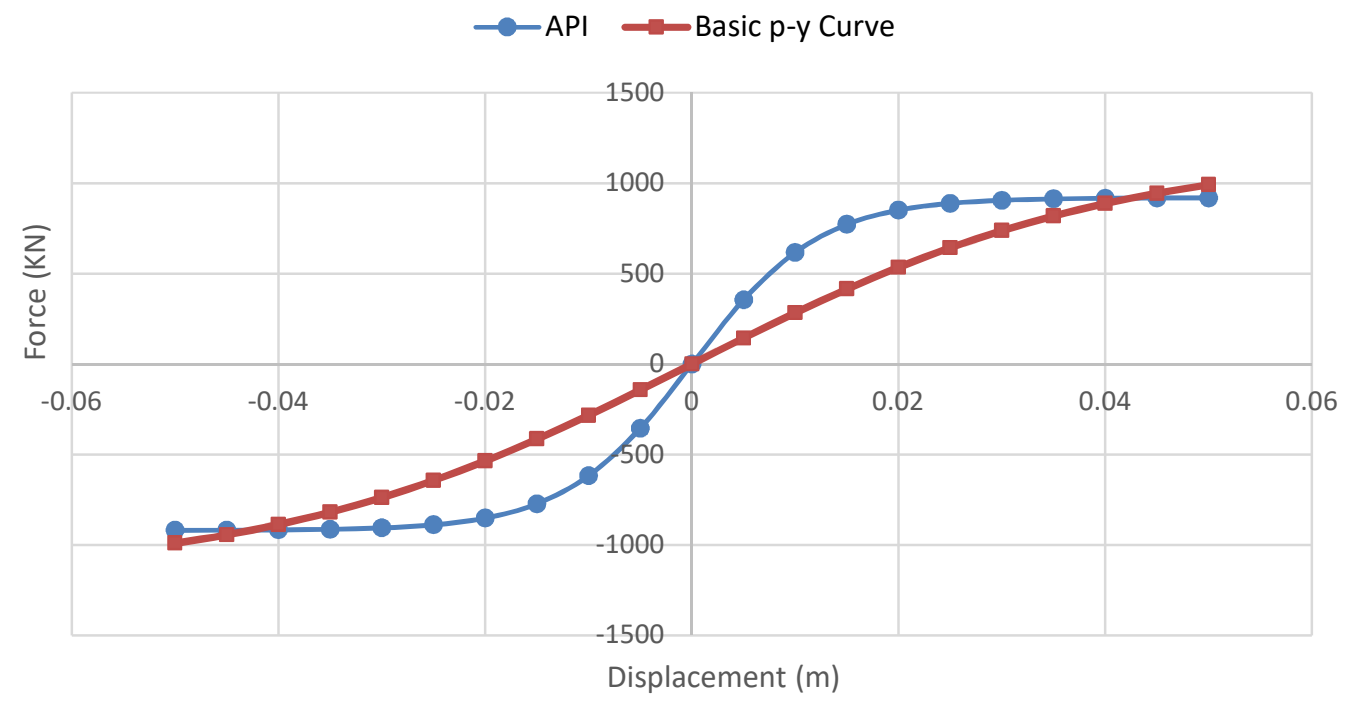

Figure 4.2 Comparison between Pile Soil Force-Displacement Relationship at depth of $10.20 \mathrm{~m}$ Calculated by the API Relationship and Basic $p$-y Curve Model 


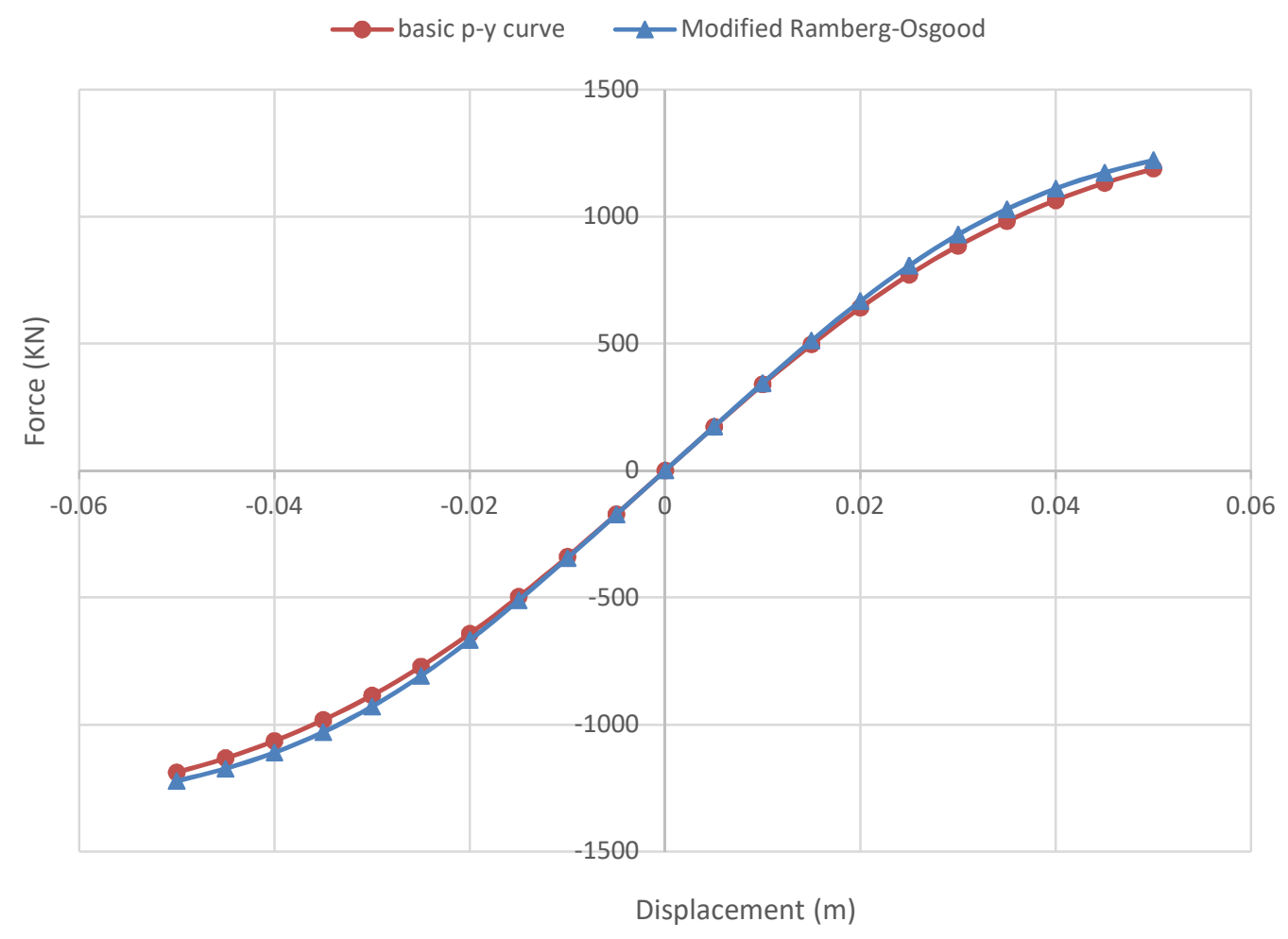

Figure 4.3 Comparison between Pile Soil Force-Displacement Relationships at Depth of $11.17 \mathrm{~m}$ Computed by the Basic $p$ - $y$ Curve Curve and the Modified Ramberg-Osgood Model

\subsection{Effect of Varying Pile Size on P-Y Curve}

$(p-y)$ Relationships were established from field tests on $0.3 \mathrm{~m}$ diameter steel piles Matlock (1970). Later, O'Neill and Gazioglu (1984) tried to include the pile diameter effect in alternative clay $(p-y)$ procedure. But API did not adopt the proposed changes and Matlock clay criterion remained the API recommended clay $(p-y)$ procedure.

The effect of varying the pile size on the soil load-displacement relationship ( $p-y)$ was examined. Two piles were chosen, namely: HP 310X125 and HP 457X460. The Dimensions of both piles are shown in Figure 4.4. In the soil load-displacement relationship, the pile size manifested by the pile width $B$ is a first degree variable in the $p$-y equations used to calculate the ultimate lateral bearing capacity. However, the question is to what extent varying the pile size will affect the load-displacement relationship was not clear, so a set of $p$-y curves for the two piles having identical soil conditions (dense sand for the abutment and piles imbedded in medium dense sand) were established, the differences between both $p$-y curves were extremely minimum as shown in Figure 4.5. 


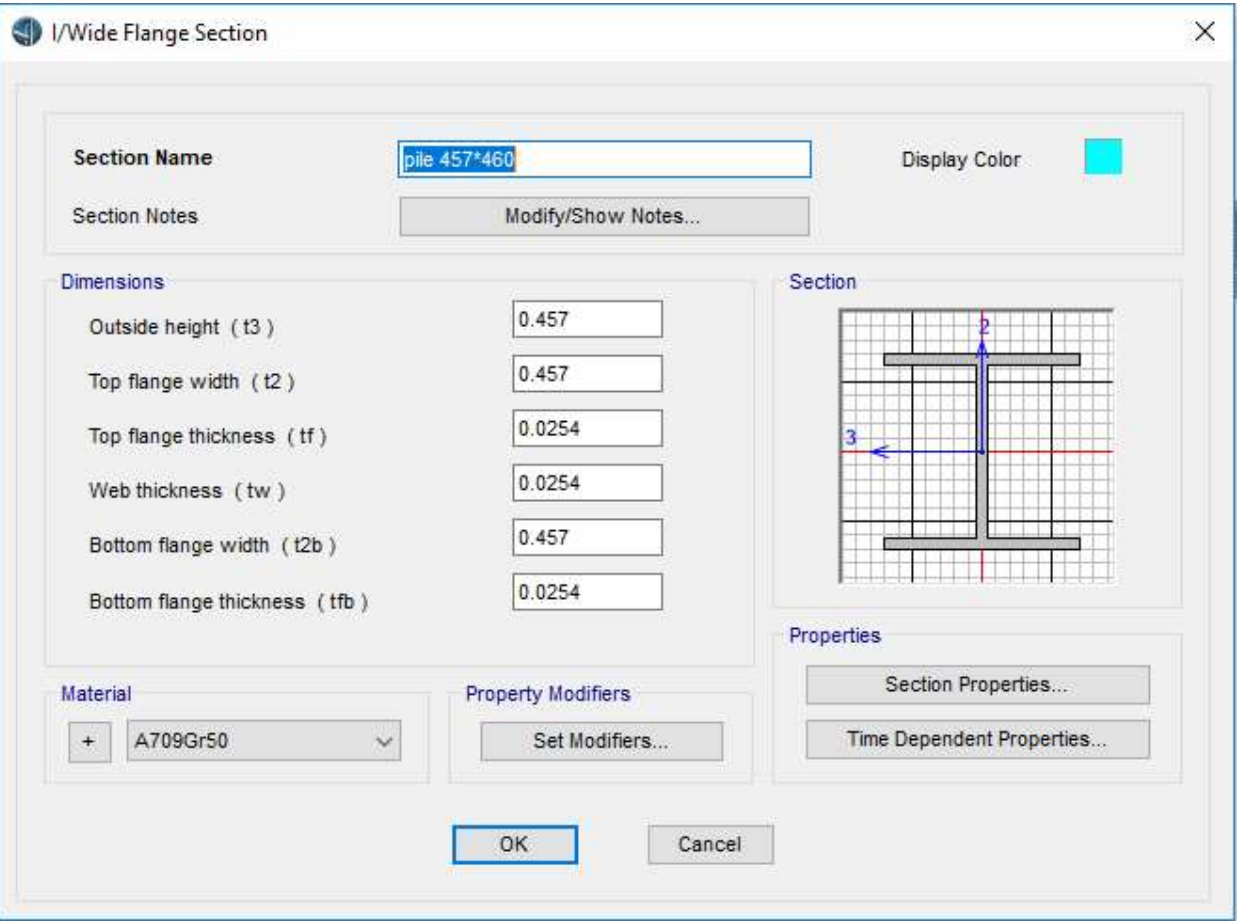

a) Properties of HP $457 \times 460 \mathrm{H}-$ Pile

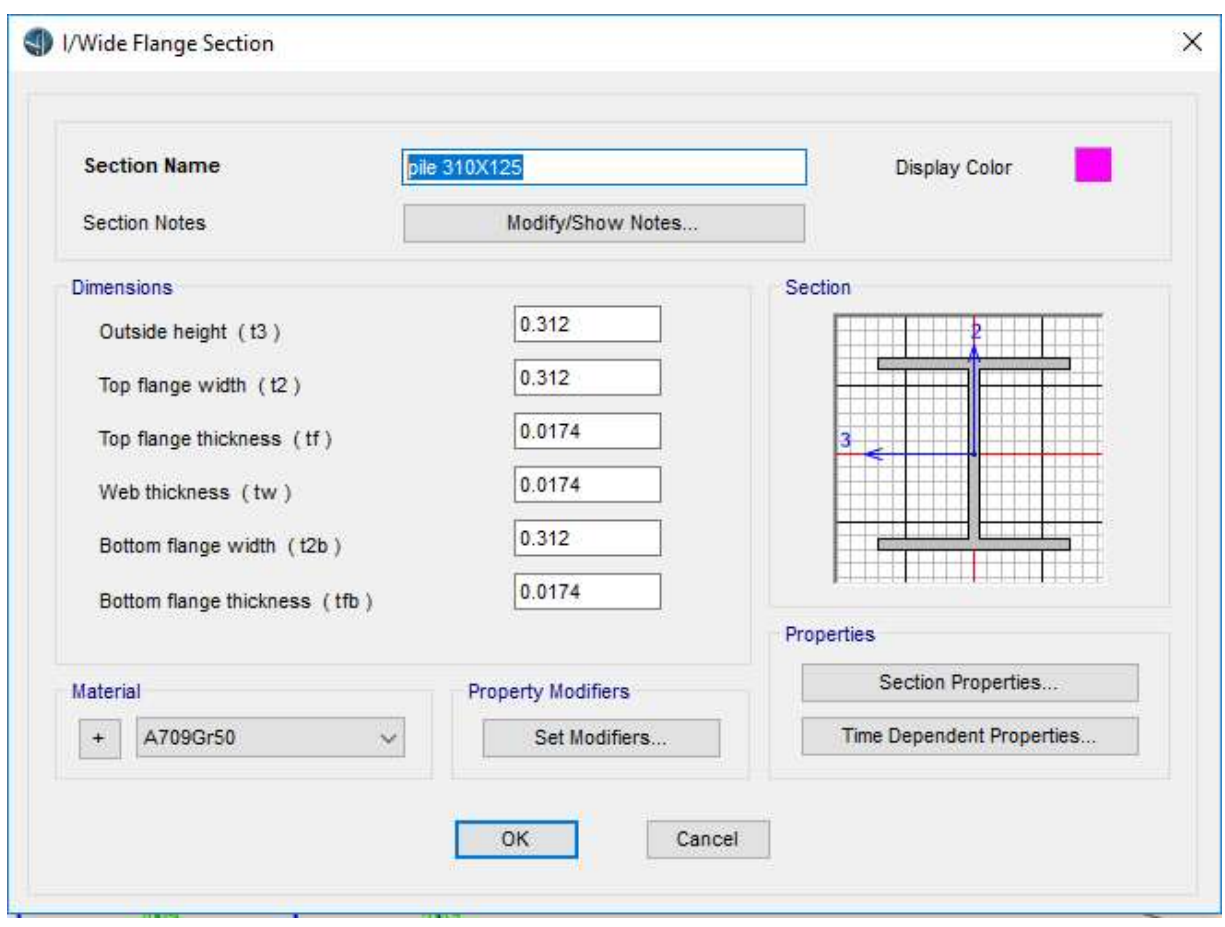

b) Properties of HP $310 \times 125$ H-Pile

Figure 4.4 Comparison between Properties of Two Steel H-Pile Dimensions 


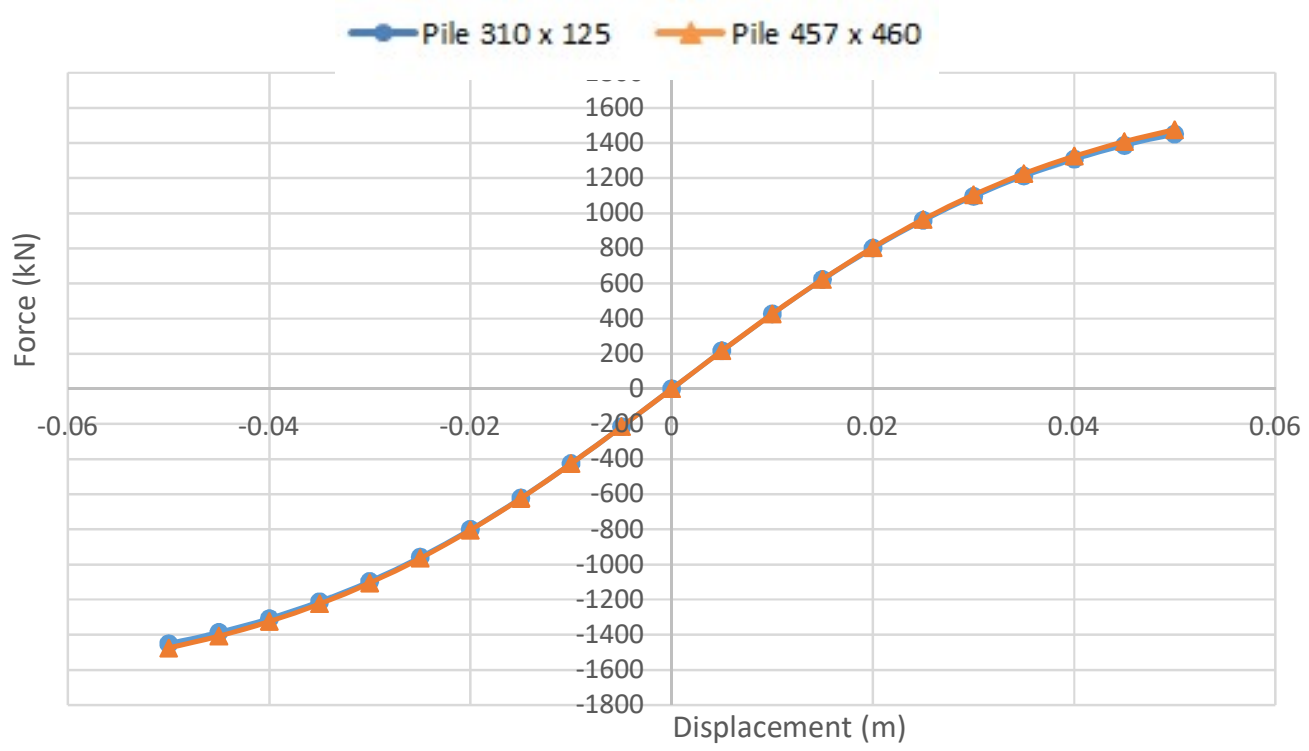

Figure 4.5 Comparison between P-Y Curves for HP 457X460 and HP 310X125 Piles

\subsection{Effect of Bridge Span Under Positive Thermal Loading Condition}

The effect of bridge span length was investigated using several finite element models. It is well known that span length influences the size of the steel l-girder and the reinforcement of deck slab from structural, serviceability, and aesthetical points of view. It was noticed from the performance of models under the effect of self-weight of deck that the longer the bridge span length, the more the deflection in the girders and the bridge slab. Meanwhile, the more girder and deck slab deflection, the less thermally induced displacement at the pile head. This observation was reinforced with the results of the finite element models. A horizontally curved bridge of $200 \mathrm{~m}$ radius and $418 \mathrm{~m}$ length was analyzed under expansion (temperature increase) for pile maximum resultant displacement when the span length was taken as 17.4, $34.8 \mathrm{~m}$ and $104.7 \mathrm{~m}$ for the same bridge cross-section geometry. Abutment height was 6.64 $m$ and was supported by dense sand, while piles were Imbedded in medium dense sand. The $34.8 \mathrm{~m}$ span length resulted in pile maximum resultant displacement of $6.05 \mathrm{~mm}$. When the span length was reduced to $17.4 \mathrm{~m}$, the maximum pile resultant displacement increased to $9.5 \mathrm{~mm}$, around 57\% difference as shown in Table 4.5. But when the span length was taken unrealistically as $104.7 \mathrm{~m}$, the pile maximum resultant displacement increased to $14.10 \mathrm{~mm}$, this can be attributed to the large radial displacement in the bridge deck due to the elimination of the piers. 
The Second model examined for such effect was of $200 \mathrm{~m}$ radius and a total length of $279 \mathrm{~m}$. Abutment height was $6.64 \mathrm{~m}$ and was supported by dense sand, while piles were Imbedded in medium dense sand. The pile maximum resultant displacements were examined when bridge spans were $17.4 \mathrm{~m}$ and $34.8 \mathrm{~m}$. The shorter span gave maximum pile resultant displacement of $7.4 \mathrm{~mm}$, while the $34.8 \mathrm{~m}$ span gave maximum pile resultant displacement of $4.6 \mathrm{~mm}$, a difference of $60 \%$ as shown in Table 4.5 .

The third model analysed was of a $200 \mathrm{~m}$ bridge radius and of $139.6 \mathrm{~m}$ total length. Abutment height was $6.64 \mathrm{~m}$ and was supported by Dense Sand, while piles were Imbedded in medium dense sand. The maximum pile resultant displacement was $3.58 \mathrm{~mm}$ when the span was 34.8 $\mathrm{m}$. When the span was reduced to $17.4 \mathrm{~m}$, the displacement at the pile head increased to 4.4 $\mathrm{mm}$, a difference of $23 \%$ as shown in Table 4.5 .

In conclusion, it may be concluded that the pile maximum resultant displacement is inversely proportional with the bridge span length. Noteworthy, large spans can be translated to smaller spans to get more economical girder sections as well as smaller slab thickness. On the other hand, smaller spans means more piers needed, less available free space under the bridge. This result concurs with the assumption that the span length has an appreciable effect on the pile maximum resultant displacement.

Table 4.5 Effect of Bridge Span Length on Pile Maximum Resultant Displacement Under Positive Thermal Loading

\begin{tabular}{|c|c|c|c|c|c|c|}
\hline $\begin{array}{c}\text { Backfill } \\
\text { Soil }\end{array}$ & $\begin{array}{l}\text { Foundation } \\
\text { Soil }\end{array}$ & $\begin{array}{c}\text { Abutment } \\
\text { Height (H) } \\
\text { (m) }\end{array}$ & $\begin{array}{c}\text { Radius of } \\
\text { Curvature } \\
\text { (R) } \\
\text { (m) }\end{array}$ & $\begin{array}{c}\text { Bridge } \\
\text { Total } \\
\text { Length (L) } \\
\text { (m) }\end{array}$ & $\begin{array}{l}\text { Bridge } \\
\text { Span } \\
\text { Length } \\
\text { (m) }\end{array}$ & $\begin{array}{c}\text { Pile Maximum } \\
\text { Resultant } \\
\text { Displacement }(\Delta) \\
(\mathrm{mm})\end{array}$ \\
\hline \multirow{2}{*}{$\begin{array}{l}\text { Dense } \\
\text { Sand }\end{array}$} & \multirow{2}{*}{$\begin{array}{l}\text { Medium } \\
\text { Dense Sand }\end{array}$} & \multirow{2}{*}{6.64} & \multirow{2}{*}{200} & \multirow{2}{*}{418} & 17.40 & 9.50 \\
\hline & & & & & 34.80 & 6.05 \\
\hline \multirow{2}{*}{$\begin{array}{l}\text { Dense } \\
\text { Sand }\end{array}$} & \multirow{2}{*}{$\begin{array}{l}\text { Medium } \\
\text { Dense Sand }\end{array}$} & \multirow{2}{*}{6.64} & \multirow{2}{*}{200} & \multirow{2}{*}{279} & 17.40 & 7.40 \\
\hline & & & & & 34.80 & 4.60 \\
\hline \multirow{2}{*}{$\begin{array}{l}\text { Dense } \\
\text { Sand }\end{array}$} & \multirow{2}{*}{$\begin{array}{l}\text { Medium } \\
\text { Dense Sand }\end{array}$} & \multirow{2}{*}{6.64} & \multirow{2}{*}{200} & \multirow{2}{*}{139.6} & 17.40 & 4.40 \\
\hline & & & & & 34.80 & 3.58 \\
\hline
\end{tabular}




\subsection{Effect of Bridge Span at Different Abutment Heights Under the Effect of Positive and Negative Thermal Loading Conditions}

To investigate the effect of bridge span on pile maximum resultant displacement, a bridge of radius $200 \mathrm{~m}$ was analyzed. The bridge was subjected to positive and negative loading conditions. Table 4.6 presents a summary of the studied cases, where the backfill supporting the abutment was either loose sand or dense sand, while the foundation soil was either medium dense sand or stiff clay. The aim of study presented in this section is to emphasize the effect of bridge span, under the effect of positive and negative thermal loading conditions, on pile maximum resultant displacement. The achieved results are presented in Figures 4.6 to 4.13 . From these figures, the following observations were noted:

a) The pile maximum resultant displacement increased linearly as bridge length increased, either the bridge superstructure is subjected to positive thermal loading or negative thermal loading condition. Therefore, the end movements of the bridge are function of effective expansion length and temperature change. This finding agrees with that by Frosch and lovell (2011), Nikarvan (2013) and LaFave et al. (2016), for straight integral abutment bridge. Noteworthy, the pile which exhibits the maximum resultant displacement is at the outermost radius of the abutment. This agrees with similar conclusions by Greimann et al. (2014).

b) As pointed out above, with the increase of bridge span, the pile maximum resultant displacement decreased, due to decrease of girders rotation stiffness and increase in internal girders displacements. Decrease in girder stiffness exerted less restraint on the abutment rotation and thus, the pile maximum resultant displacement decreased, which caused less movement and stress in the pile. This finding agrees with that by Olson et al. (2009).

c) The pile maximum resultant displacements under thermal loading conditions, positive and negative, are consistent, when loose sand backfill is present and the supporting soil is stiff clay as shown in Figures 4.8 and 4.9. This agrees with the results reported by LaFave et al. (2016). But the pile maximum resultant displacement, in case of positive thermal load, is between $40 \%$ to $60 \%$ of that in case of negative thermal load 
for the of case of loose sand backfill and medium dense sand foundation soil as shown in Figures 4.12 and 4.13.

d) With the increase of bridge abutment height, the equivalent rotation stiffness of the abutment and pile increases, therefore, the pile maximum resultant displacement decreased. Also, with the increase of abutment height, the passive earth pressure imposed on the abutment increased, reducing the shearing force transferred to the abutment pile, and in turn reduces the pile maximum resultant displacement. Furthermore, increasing the height of backfill increases the stiffness of soil spring and increase the spring resistance to pile deflection during thermal expansion. These findings agree with those reached by Nikarvan (2013) and LaFave et al. (2016).

e) During thermal expansion, the pile maximum resultant displacement in case of loose sand backfill and foundation soil of medium dense sand is between 1.6 to 5.0 times of that exhibited by the pile in case of dense sand backfill in the same foundation soil. In case of foundation soil of stiff clay, the above ratio varies between 1.80 to 10 . Therefore, the stiffness of backfill soil has significant effect on both superstructure and substructure of the bridge. Stiffer soil will provide increased relief on pile head demand (displacement, bending moment, shearing force and lateral displacement). This agrees with the conclusion reached by LaFave et al. (2016) and Kalayci et al. (2012).

f) The type of foundation soil affects the magnitude of pile maximum resultant displacement during bridge expansion as shown in Figures 4.6, 4.8, 4.10, and 4.12.

g) During bridge contraction, the foundation soil has slight effect on pile maximum resultant displacement as shown in Figures 4.7 and 4.9 as well as Figures 4.11 and 4.13. The above findings agree with those presented by Olson et al. (2009), with respect to the effect of foundation soil in case of bridge contraction. 
Table 4.6 Studied Cases in the Current Research

\begin{tabular}{|c|c|c|c|}
\hline Bridge Radius & Backfill Supporting & Foundation Soil & Thermal Loading \\
\hline 200 & Dense Sand & Medium Dense Sand & Positive \\
\hline 200 & Dense Sand & Medium Dense Sand & Negative \\
\hline 200 & Loose Sand & Stiff Clay & Positive \\
\hline 200 & Loose Sand & Stiff Clay & Negative \\
\hline 200 & Dense Sand & Stiff Clay & Positive \\
\hline 200 & Dense Sand & Stiff Clay & Negative \\
\hline 200 & Loose Sand & Medium Dense Sand & Positive \\
\hline 200 & Loose sand & Medium Dense Sand & Negative \\
\hline
\end{tabular}

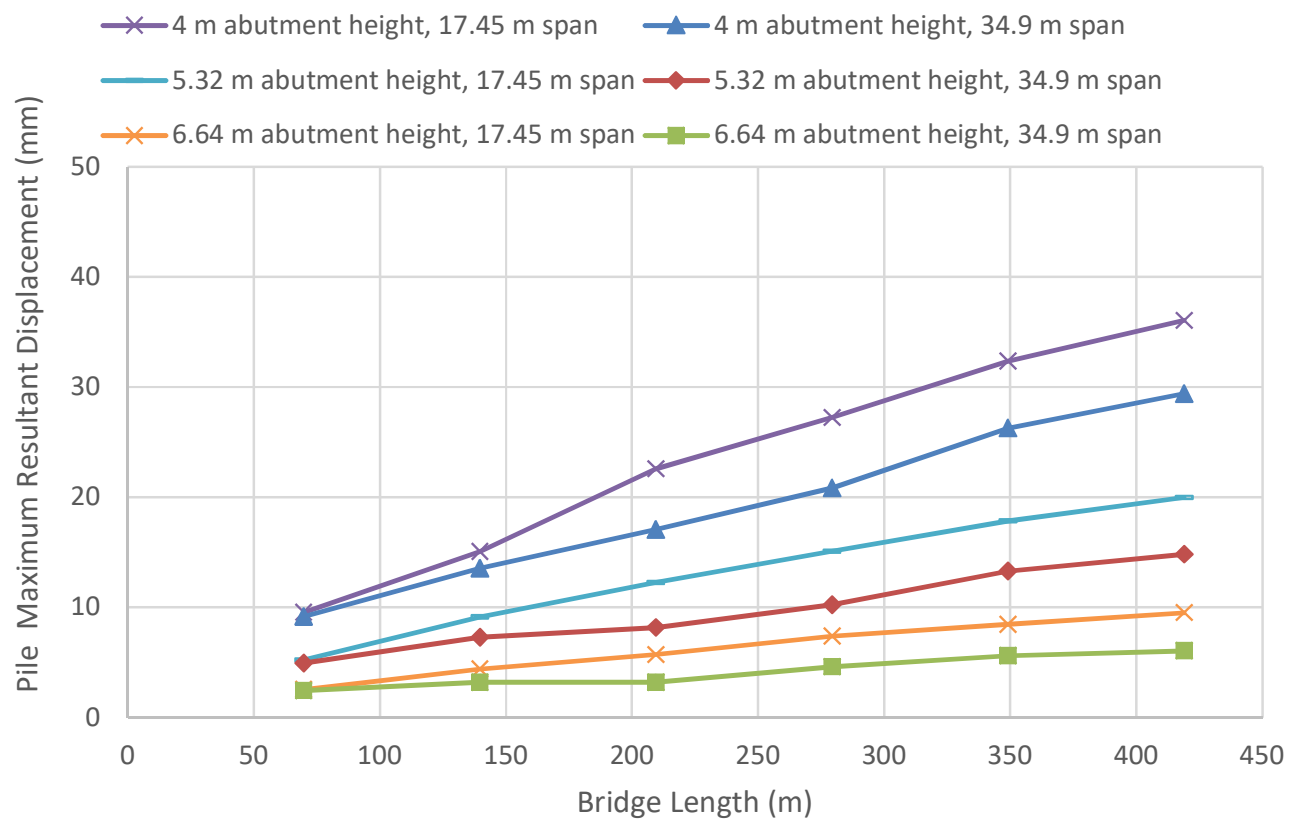

Figure 4.6 Pile Maximum Resultant Displacement for $\mathbf{2 0 0}$ m Radius Integral Bridge Under Expansion in Case of Dense Sand Supporting the Abutment and pile Embedded in Medium Dense

Sand 
$\leftarrow 4 \mathrm{~m}$ abutment height, $17.45 \mathrm{~m}$ span $\rightarrow-4 \mathrm{~m}$ abutment height, $34.9 \mathrm{~m}$ span

- $5.32 \mathrm{~m}$ abutment height, $17.45 \mathrm{~m}$ span $\longrightarrow-5.32 \mathrm{~m}$ abutment height, $34.9 \mathrm{~m}$ span

-6.64 m abutment height, $17.45 \mathrm{~m}$ span —-6.64 m abutment height, $34.9 \mathrm{~m}$ span

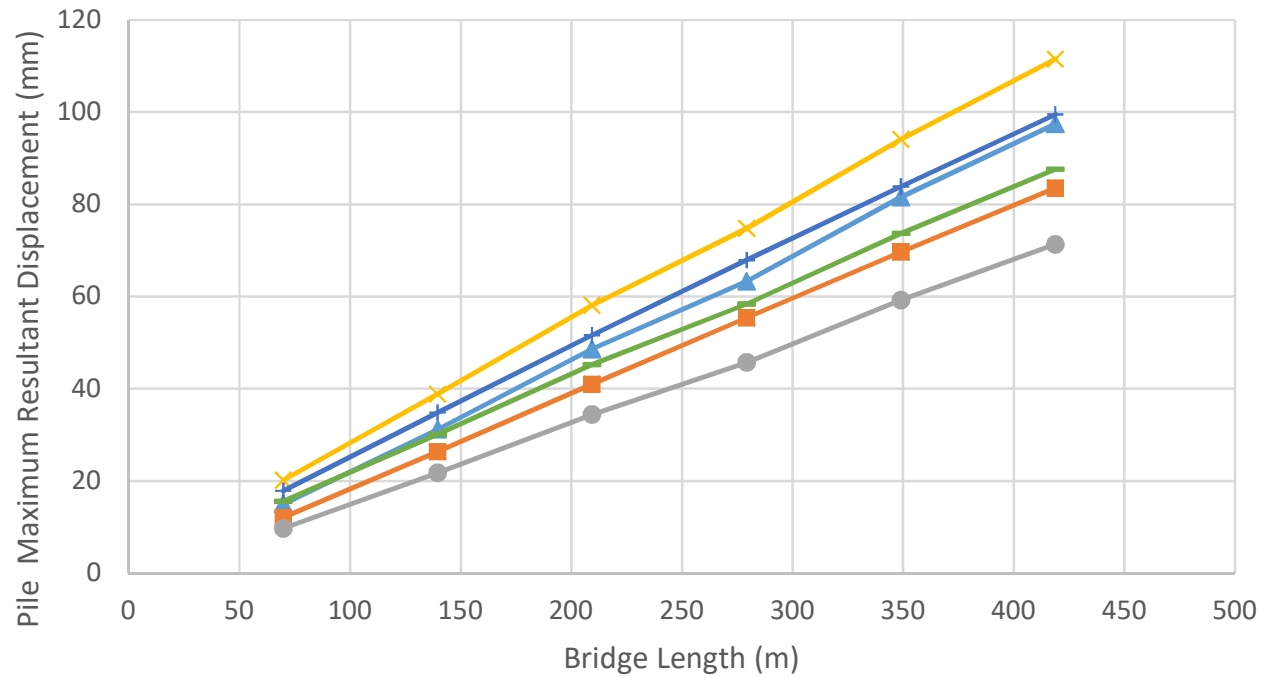

Figure 4.7 Pile Maximum Resultant Displacement for $\mathbf{2 0 0} \mathrm{m}$ Radius Integral Bridge Under Contraction in Case of Dense Sand Supporting the Abutment and Pile Embedded in Medium Dense Sand

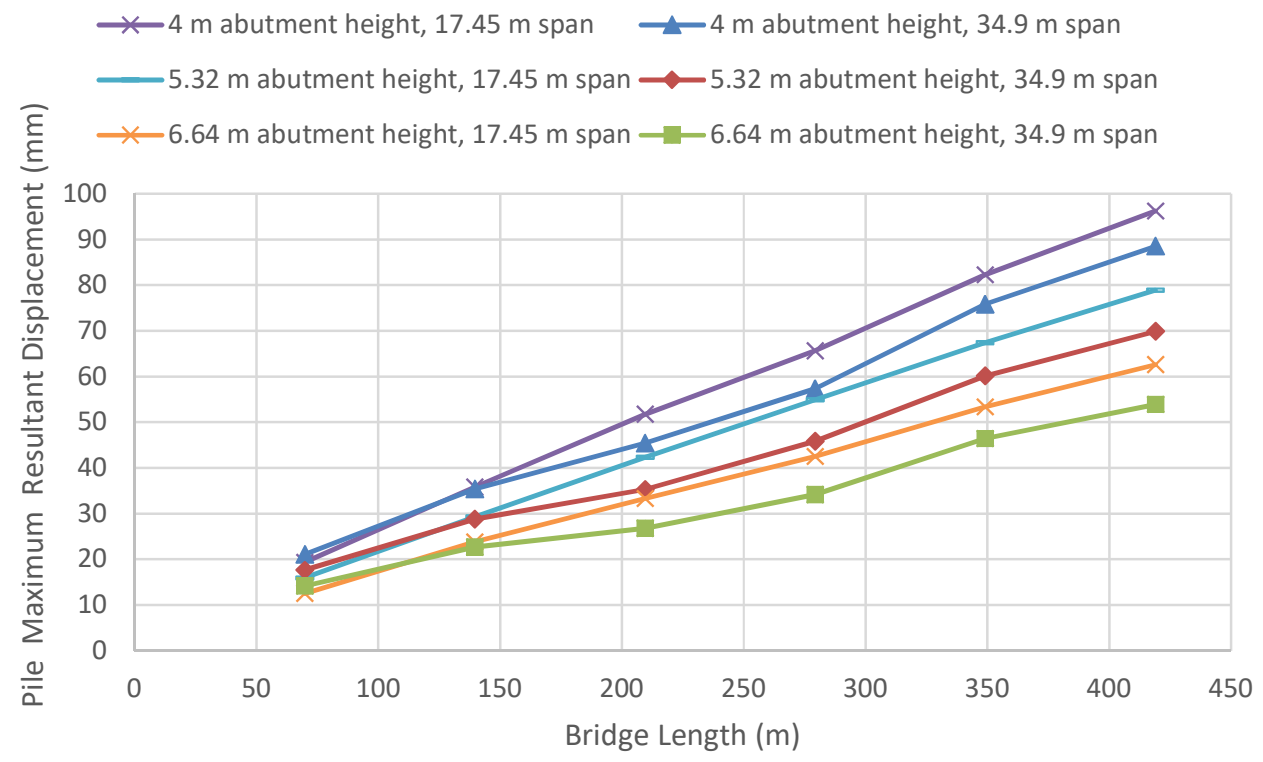

Figure 4.8 Pile Maximum Resultant Displacement for $\mathbf{2 0 0}$ m Radius Integral Bridge Under Expansion in Case of Loose Sand Supporting the Abutment and Pile Embedded in Stiff Clay 
$\leftarrow 4 \mathrm{~m}$ abutment height, $17.45 \mathrm{~m}$ span $\longrightarrow 4 \mathrm{~m}$ abutment height, $34.9 \mathrm{~m}$ span

$-5.32 \mathrm{~m}$ abutment height, $17.45 \mathrm{~m}$ span $\longrightarrow 5.32 \mathrm{~m}$ abutment height, $34.9 \mathrm{~m}$ span

-6.64 m abutment height, $17.45 \mathrm{~m}$ span $-6.64 \mathrm{~m}$ abutment height, $34.9 \mathrm{~m}$ span

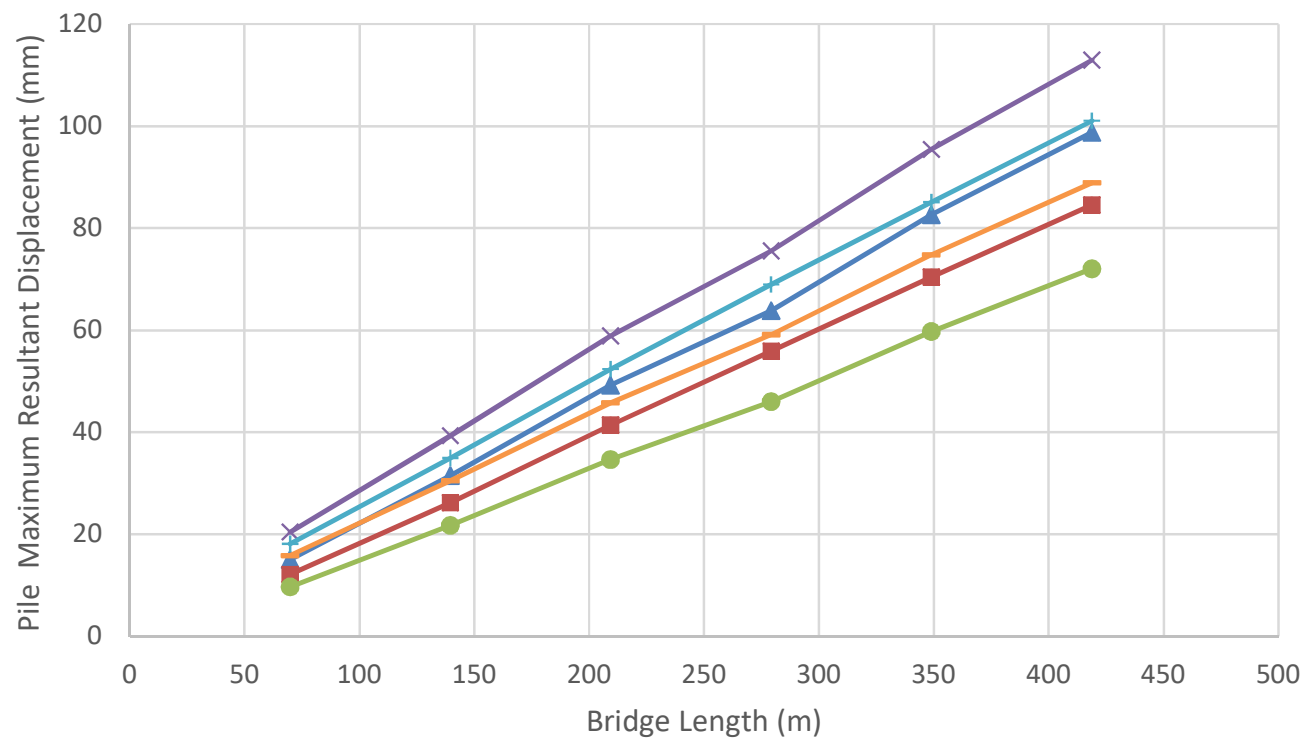

Figure 4.9 Pile Maximum Resultant Displacement for $\mathbf{2 0 0}$ m Radius Integral Bridge Under Contraction in Case of Loose Sand Supporting the Abutment and Pile Embedded in Stiff Clay

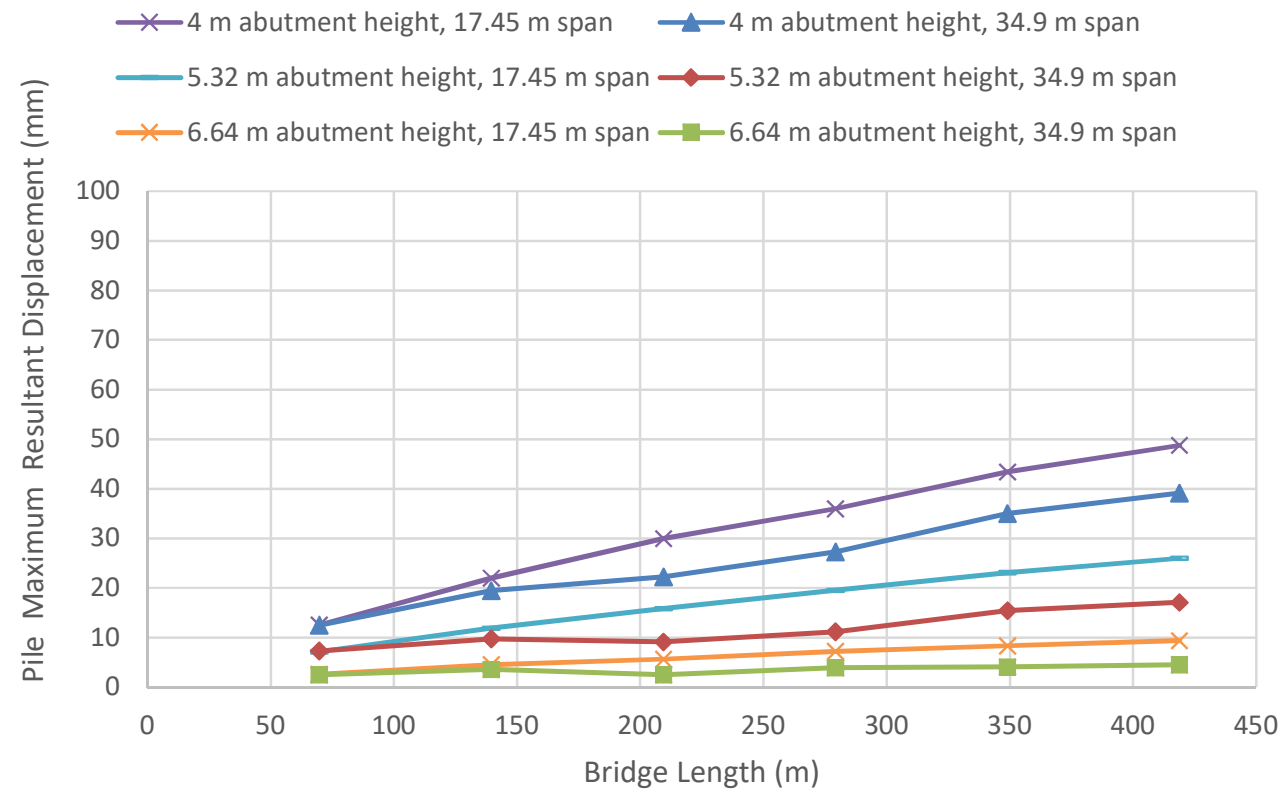

Figure 4.10 Pile Maximum Resultant Displacement for 200 m Radius Integral Bridge Under Expansion in Case of Dense Sand Supporting the Abutment and Pile Embedded in Stiff Clay 
$\leftarrow 4 \mathrm{~m}$ abutment height, $17.45 \mathrm{~m}$ span $\quad-4 \mathrm{~m}$ abutment height, $34.9 \mathrm{~m}$ span

- $5.32 \mathrm{~m}$ abutment height, $17.45 \mathrm{~m}$ span $\longrightarrow 5.32 \mathrm{~m}$ abutment height, $34.9 \mathrm{~m}$ span

-6.64 m abutment height, $17.45 \mathrm{~m}$ span $-6.64 \mathrm{~m}$ abutment height, $34.9 \mathrm{~m}$ span

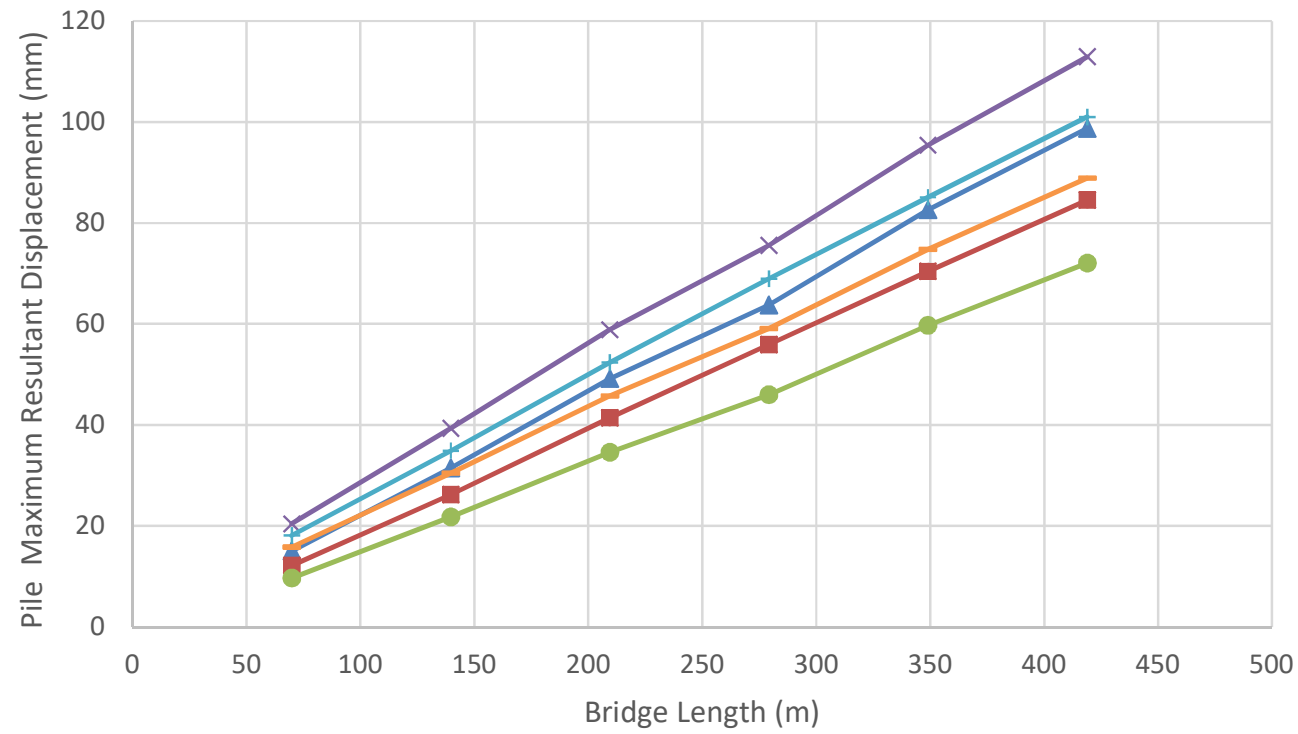

Figure 4.11 Pile Maximum Resultant Displacement for $\mathbf{2 0 0}$ m Radius Integral Bridge Under Contraction in Case of Dense Sand Supporting the Abutment and Pile Embedded in Stiff Clay

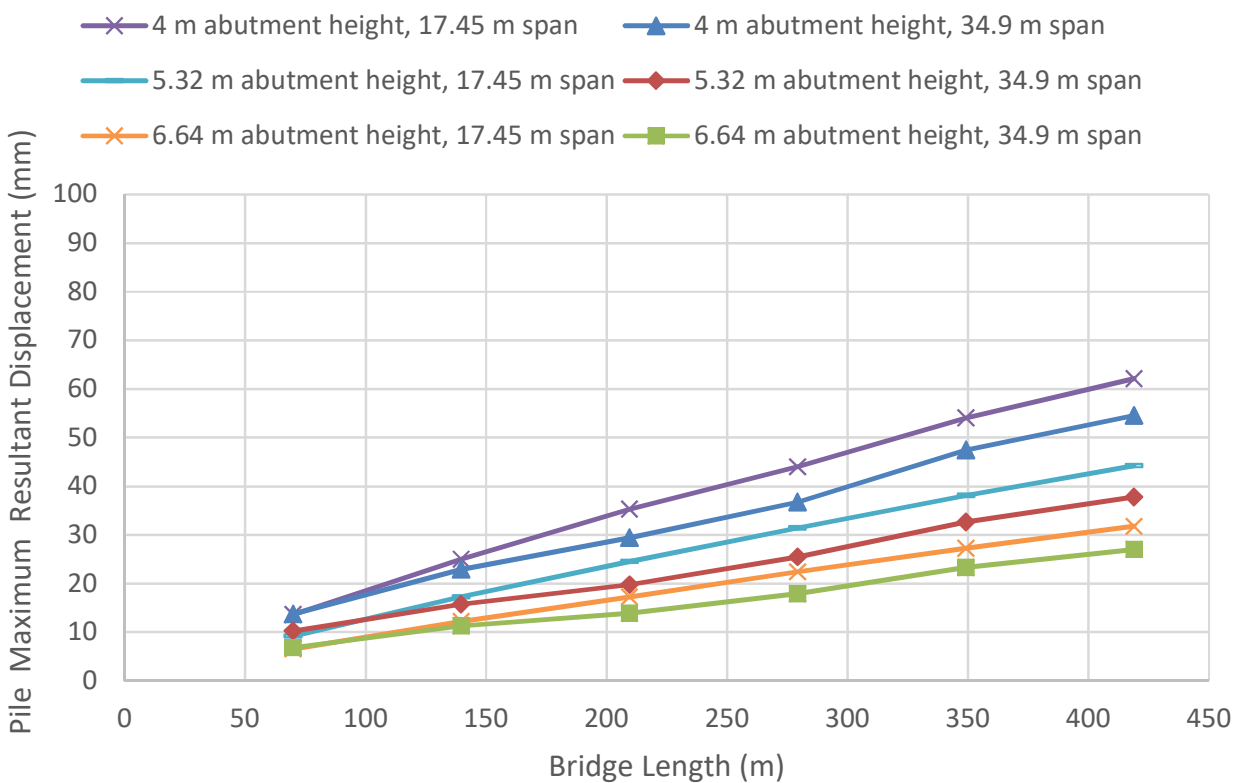

Figure 4.12 Pile Maximum Resultant Displacement for 200 m Radius Integral Bridge Under Expansion in Case of Loose Sand Supporting the Abutment and Pile Embedded in Medium Dense Sand 


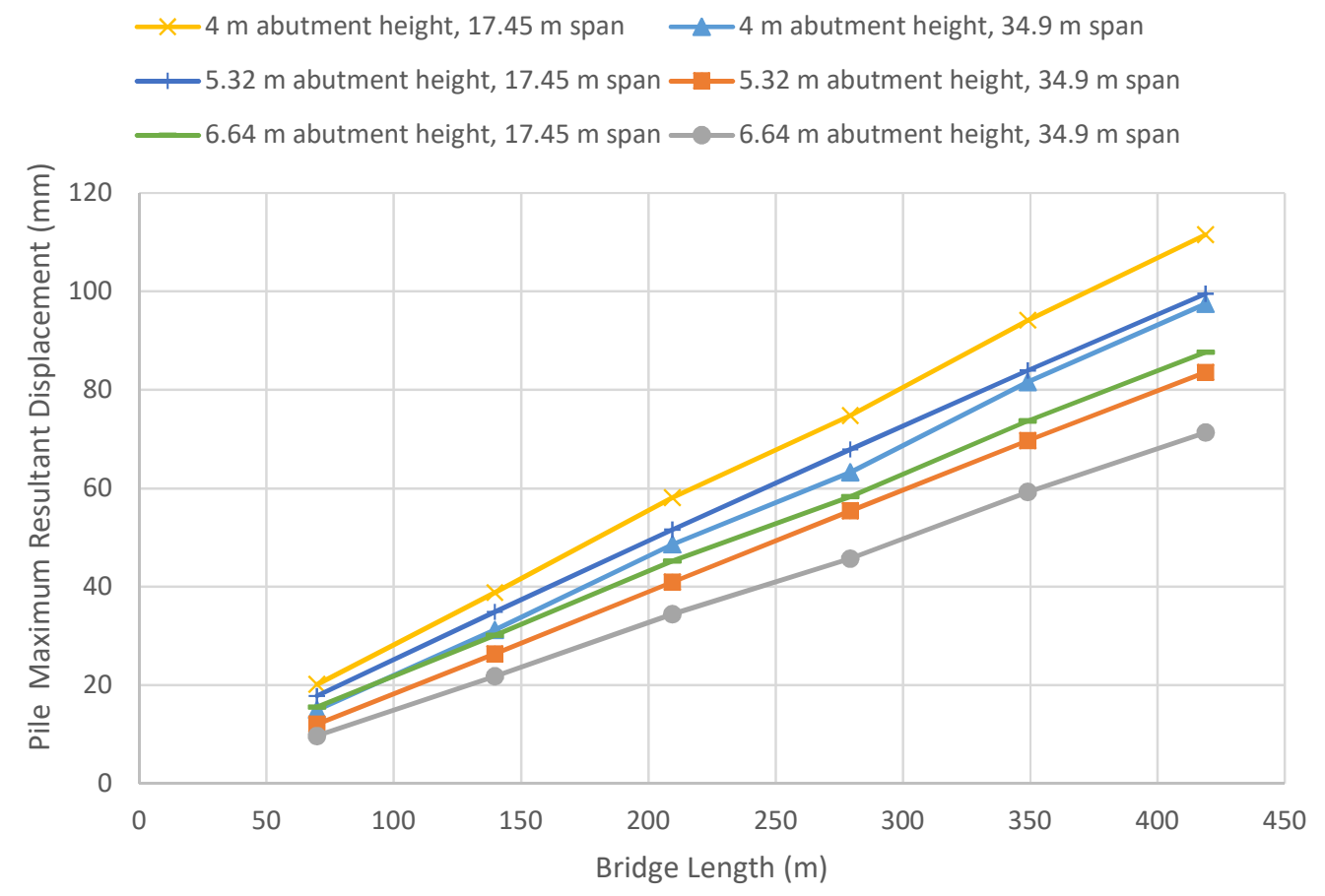

Figure 4.13 Pile Maximum Resultant Displacement for 200 m Radius Integral Bridge Under Contraction in Case of Loose Sand Supporting the Abutment and Pile Embedded in Medium Dense Sand

\subsection{Effect of Bridge Abutment}

The superstructure of horizontally curved integral abutment bridge is integrated with abutments/stubs, which in turn, most likely, supported on abutment piles. This section discusses the behavior of abutment piles where the bridge superstructure is under thermal loading and self-weight causing expansion in bridge length.

\subsubsection{Substructure Piles Embedded in Stiff Clay}

Based on bridge data in Table 3.1, Figures 4.14 through 4.25 describe the behavior of abutment piles of integral abutment bridges having different Radii. The bridge superstructure is under thermal expansion loading in addition to its own weight. The piles are embedded in stiff clay, while the granular backfill soil behind the abutment is either loose or dense sand. It is clear from the figures that the pile maximum resultant displacement is directly proportional to the bridge length. As the bridge length increased, the pile maximum resultant displacement increased as well. Also, the figures show the effect of increasing abutment height on reducing 
pile maximum resultant displacement. For instance, when the abutment height increased from 4 to $6.64 \mathrm{~m}$, the pile maximum resultant displacement reduced from $18.63 \mathrm{~mm}$ to 4.76 $\mathrm{mm}$. this is attributed to the increase of the equivalent rotation stiffness of bridge abutment and piles with the increase of abutment height. For each bridge radius, two soil conditions behind the bridge abutment were considered, namely: dense and loose sand. It is obvious that dense sand behind the abutment has greater effect on the reduction of pile maximum displacement in comparison with loose sand for the same bridge configuration. For instance, when the state of sand behind the abutment was dense, pile maximum displacement was $18.63 \mathrm{~mm}$ in comparison with $30.90 \mathrm{~mm}$ when the sand behind the abutment was in the loose state. Dense sand restraints the rotation of bridge abutment, and increases the head pile bending moment.

The pile maximum resultant displacement (PMRD) is a measure of bridge deck expansion, $\Delta \mathrm{L}$, inherent in the effect of restraint from passive earth pressure behind abutment wall, rotation stiffness of bridge abutment, stiffness of foundation soil and longitudinal and rotation stiffness of bridge superstructure. Therefore, the displacement at any point on end boundaries of the bridge, $\Delta \mathrm{L}$, may be expressed as;

$\Delta L=\beta \alpha l_{i} \Delta T$

Where;

$\alpha$ : Coefficient of thermal expansion,

$\Delta T$ : Thermal loading,

$l_{i}$ : The distance between fixity point and the end boundary point of the bridge, the effective expansion length,

$\beta$ : Factor to account for the influence of restrained conditions and bridge curvature.

The top of abutment-displacement of the bridge varies from one point to another, depending upon the location of the point with respect to fixity point. It is anticipated that the pile at the outermost corner of the bridge exhibit the maximum resultant displacement. This observation was prevailed from results of the numerical model. The pile maximum resultant displacement (PMRD) increased linearly with the increasing of bridge length. This is in 
agreement with the results prepared by Griton et al. (1991), Jorgensen (1983), Lawver et al. (2000) and Razmi et al. (2014).

To simplify presenting results, data is introduced through a parameter $\varepsilon$ which is defined as unit change in bridge total length in $\mathrm{mm} / \mathrm{m}$ units. In other words, $\varepsilon$ values represent the slope of each of the curves in Figure 4.14 as an example. $\varepsilon$ values for pile maximum resultant displacement-bridge length relationships for each abutment height were calculated. The magnitudes of the inclinations $(\varepsilon)$ were drawn versus the radius of curvature $(R)$ as shown in Figures 4.26 and 4.27. The figures show scatter in results probably due to the effect of span length. But generally, the $\varepsilon$ values decreased as the radius of curvature (R) increased. For loose sand backfill, the relationship between the $\varepsilon$ values and the radius of curvature of the bridge $(R)$ is presented in Figure 4.26. The relationship can be expressed using empirical equations for best fit as shown in Table 4.7. To obtain pile maximum resultant displacement in $\mathrm{mm}, \mathrm{PMRD}$, the $\varepsilon$ values should be multiplied by the bridge total length, $\mathrm{L}$, in meters (i.e. $\operatorname{PMRD}=\varepsilon L)$.

The derived equations in case of loose sand backfill are consistent. Equation 4.5 has the biggest absolute term, decreasing with increase of abutment height. Also, the derived equations in case of dense sand are consistent. Equation 4.8 has the biggest absolute term, decreasing with the increase of abutment height. The two sets of equations emphasize the effect of abutment height and the stiffness of backfill on pile maximum resultant displacement. 


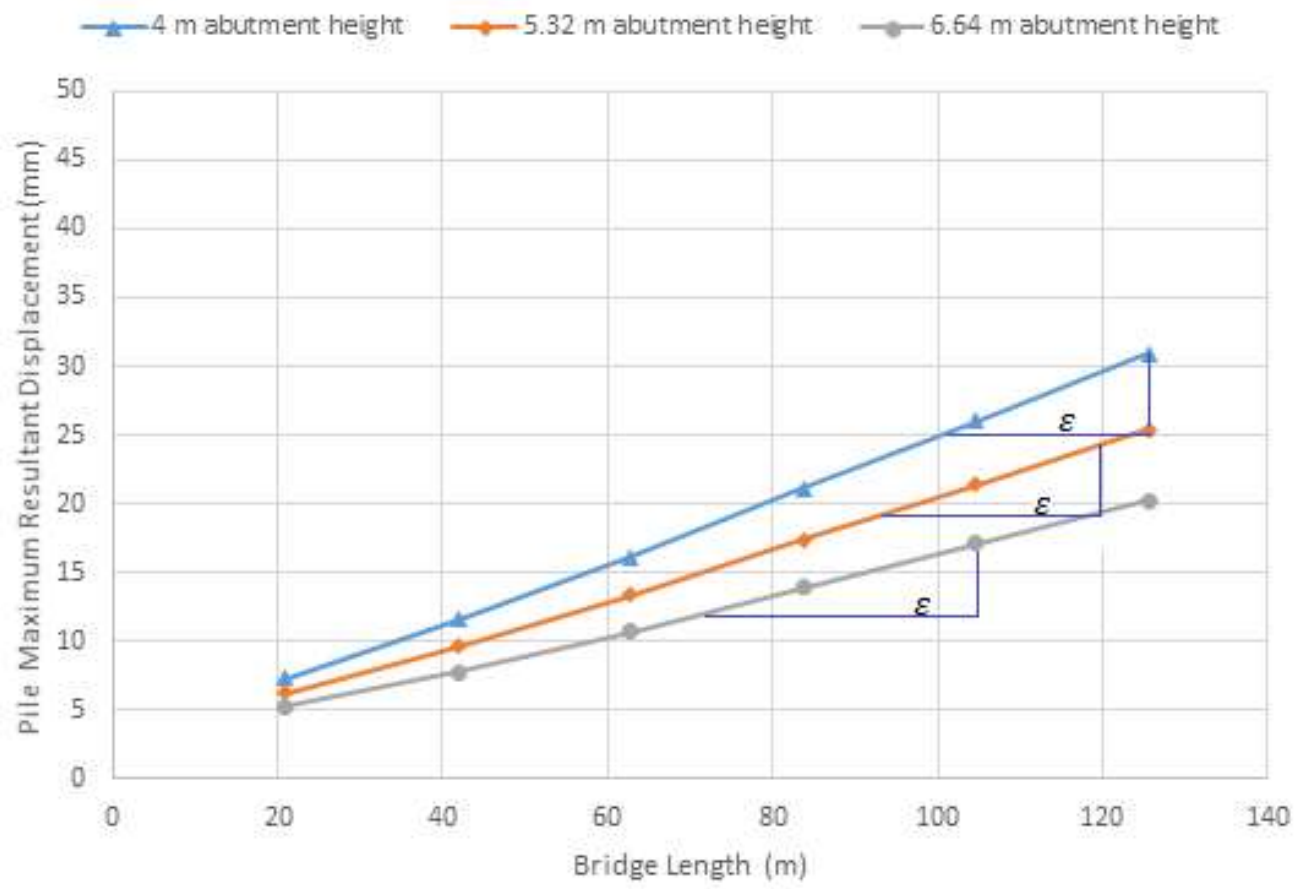

Figure 4.14 Pile Maximum Resultant Displacement Under Thermal Expansion for $\mathbf{6 0} \mathrm{m}$ Radius Integral Bridge in Case of Loose Sand Behind the Abutment and Piles Embedded in Stiff Clay

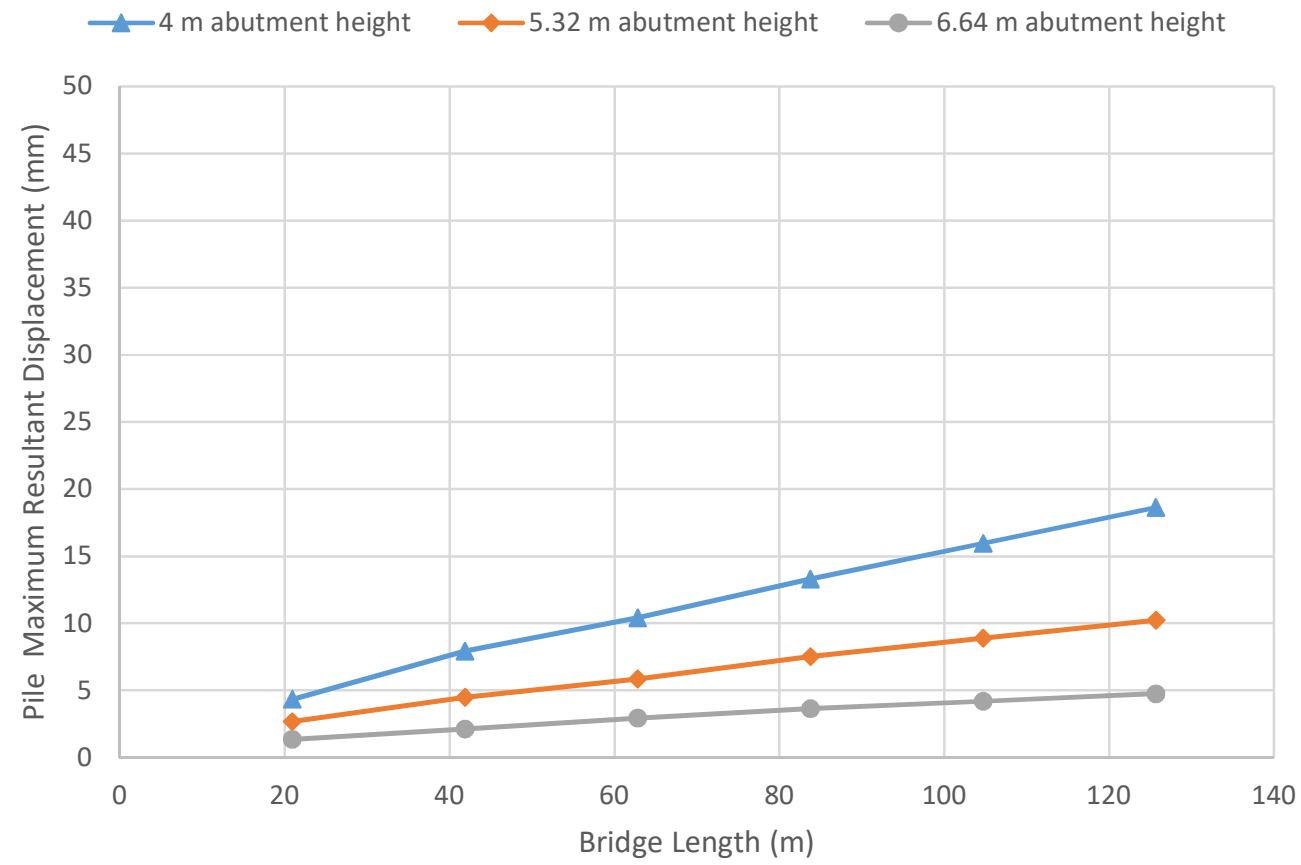

Figure 4.15 Pile Maximum Resultant Displacement Under Thermal Expansion for $60 \mathrm{~m}$ Radius Integral Bridge in Case of Dense Sand Behind the Abutment and Piles Embedded in Stiff Clay 

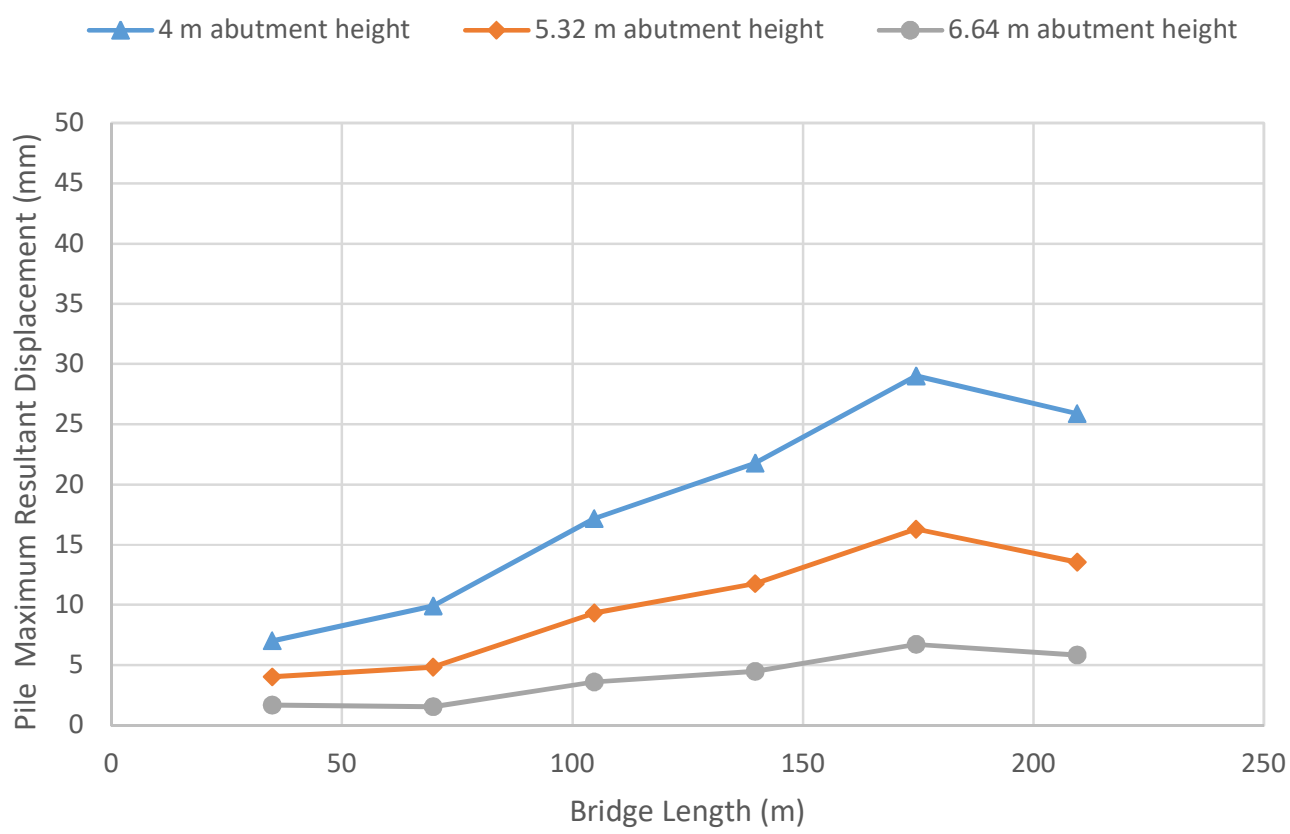

Figure 4.16 Pile Maximum Resultant Displacement Under Thermal Expansion for $100 \mathrm{~m}$ Radius Integral Bridge in Case of Dense Sand Behind the Abutment and Piles Embedded in Stiff Clay

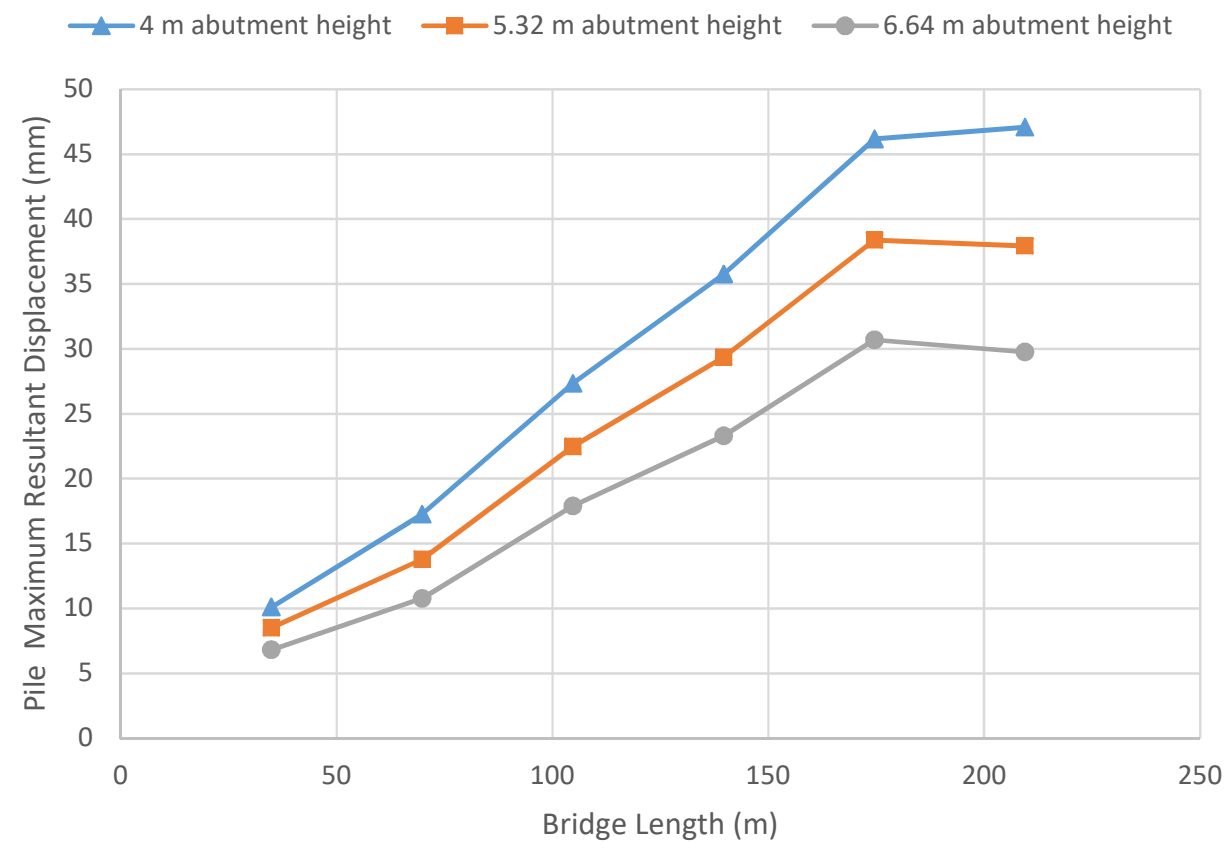

Figure 4.17 Pile Maximum Resultant Displacement Under Thermal Expansion for $100 \mathrm{~m}$ Radius Integral Bridge in Case of Loose Sand Behind the Abutment and Piles Embedded in Stiff Clay 


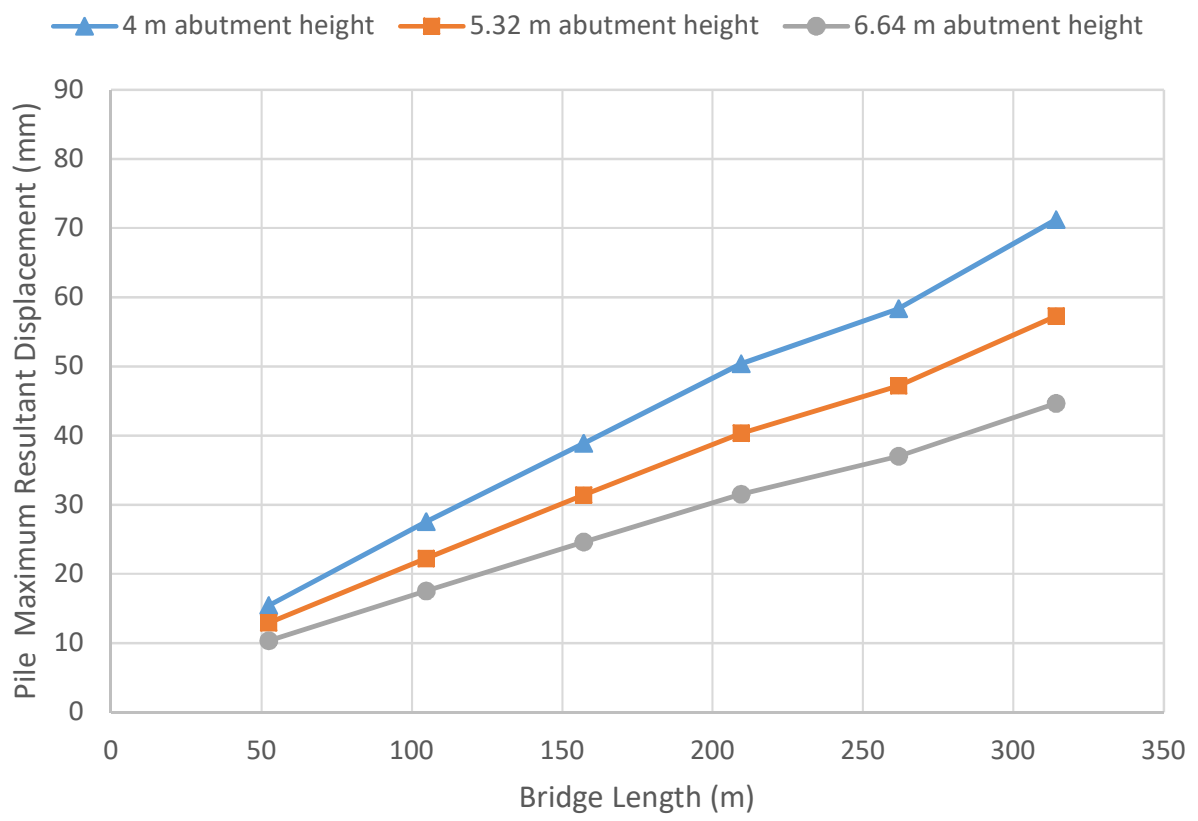

Figure 4.18 Pile Maximum Resultant Displacement Under Thermal Expansion for $150 \mathrm{~m}$ Radius Integral Bridge in Case of Loose Sand Behind the Abutment and Piles Embedded in Stiff Clay

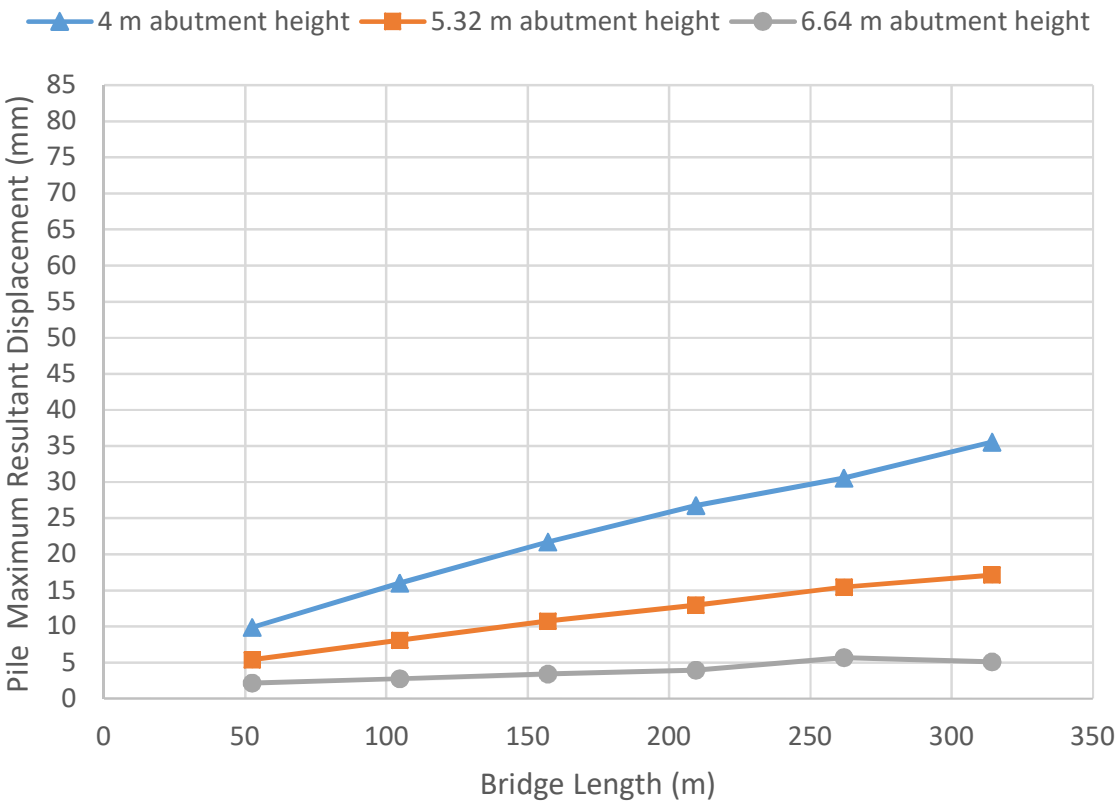

Figure 4.19 Pile Maximum Resultant Displacement Under Thermal Expansion for $150 \mathrm{~m}$ Radius Integral Bridge in Case of Dense Sand Behind the Abutment and Piles Embedded in Stiff Clay 


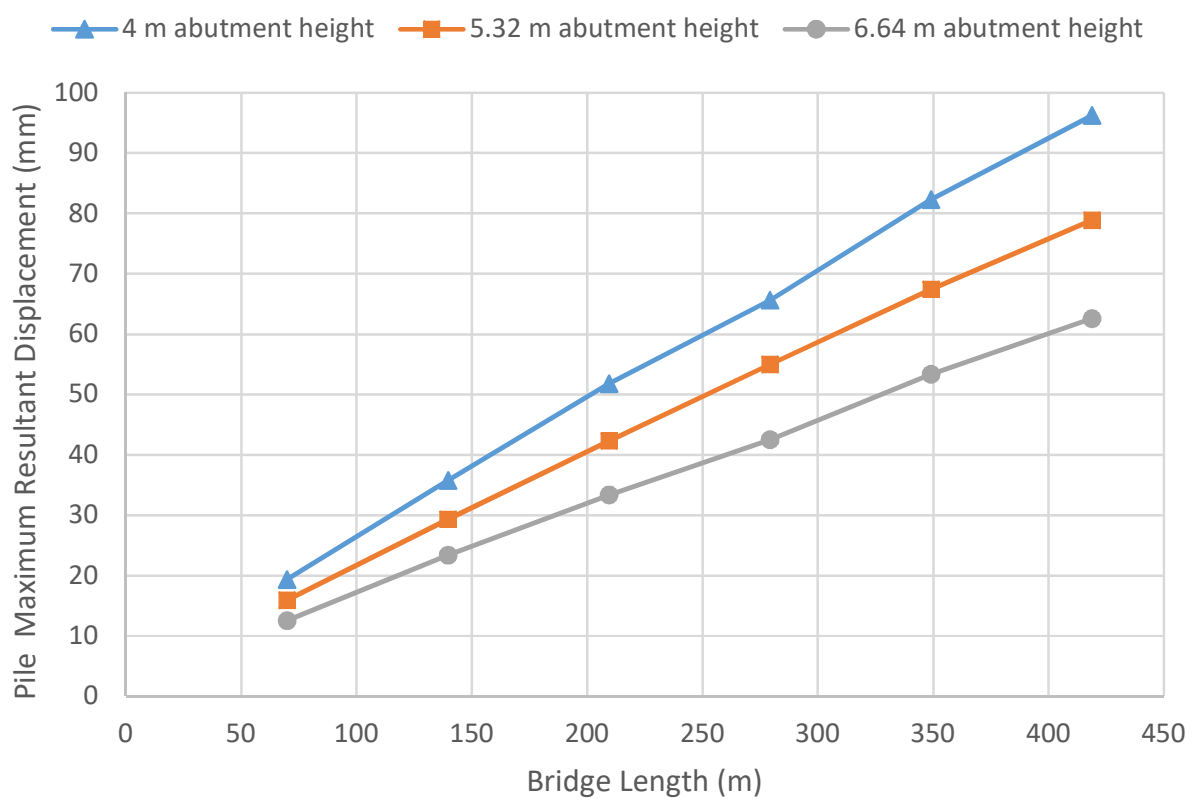

Figure 4.20 Pile Maximum Resultant Displacement Under Thermal Expansion for $\mathbf{2 0 0} \mathrm{m}$ Radius Integral Bridge in Case of Loose Sand Behind the Abutment and Piles Embedded in Stiff Clay

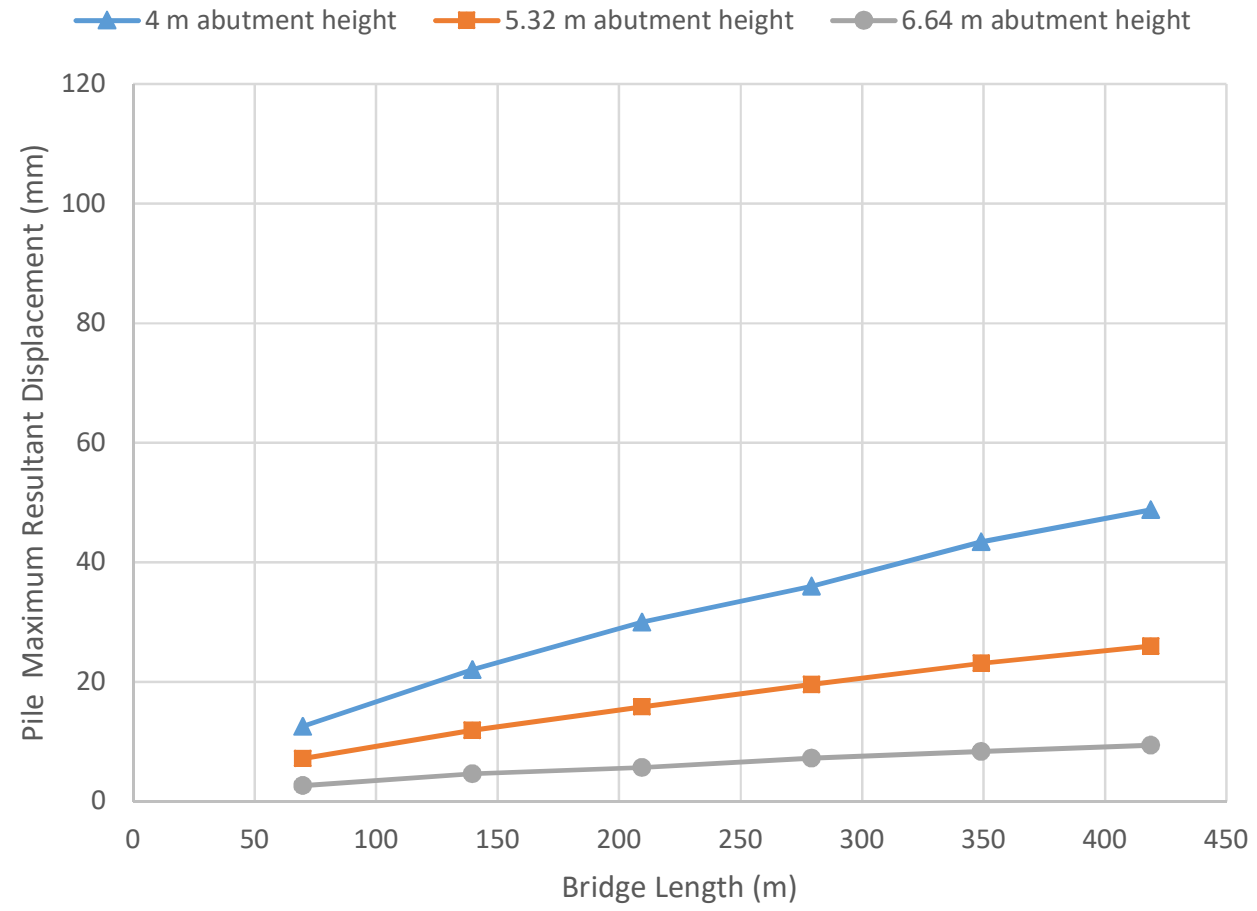

Figure 4.21 Pile Maximum Resultant Displacement Under Thermal Expansion for $200 \mathrm{~m}$ Radius Integral Bridge in Case of Dense Sand Behind the Abutment and Piles Embedded in Stiff Clay 


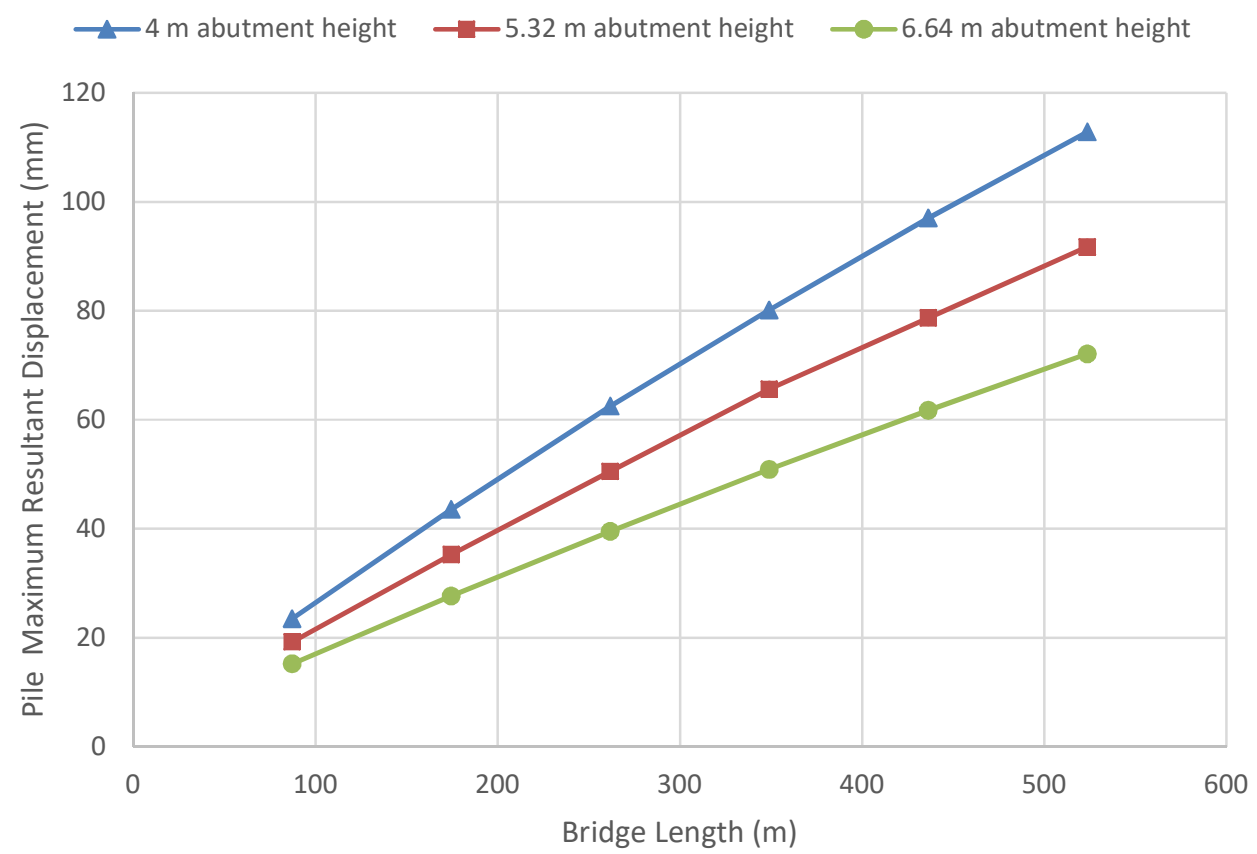

Figure 4.22 Pile Maximum Resultant Displacement Under Thermal Expansion for $\mathbf{2 5 0} \mathrm{m}$ Radius Integral Bridge in Case of Loose Sand Behind the Abutment and Piles Embedded in Stiff Clay

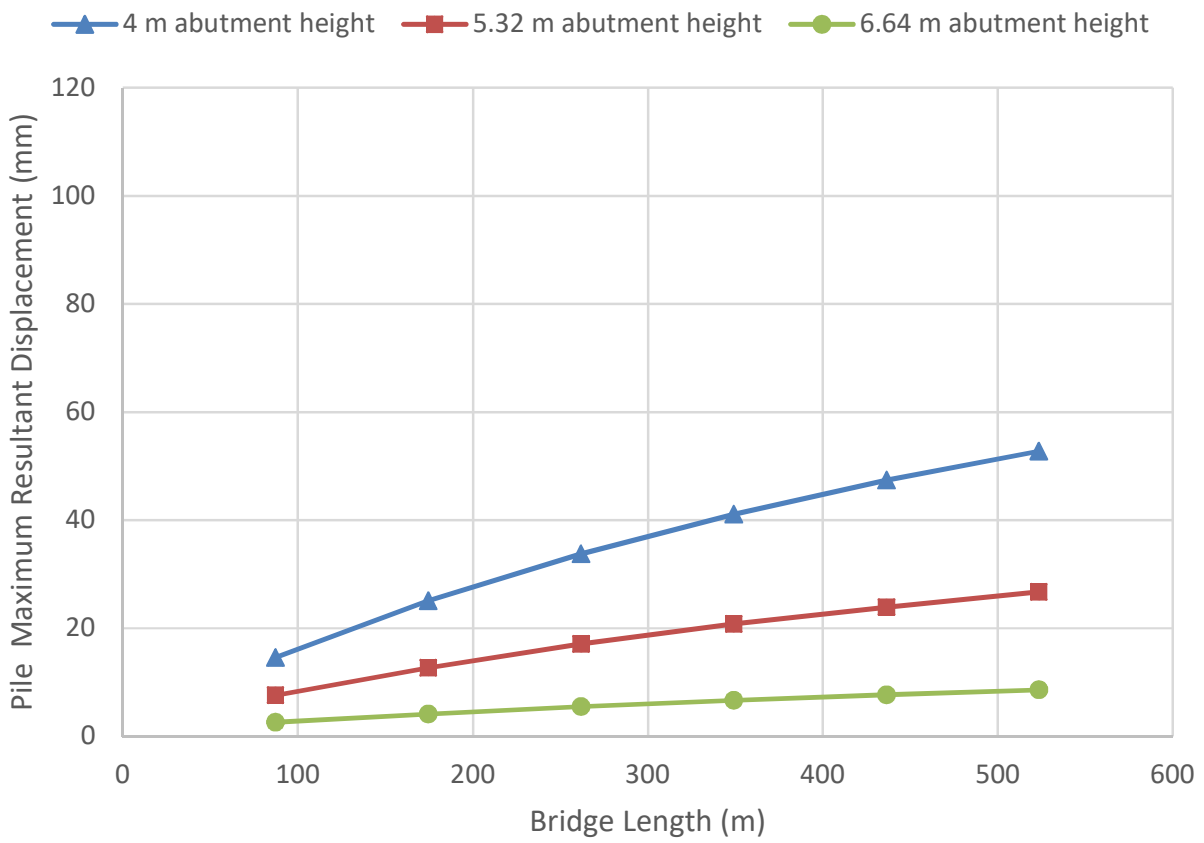

Figure 4.23 Pile Maximum Resultant Displacement Under Thermal Expansion for $\mathbf{2 5 0} \mathrm{m}$ Radius Integral Bridge in Case of Dense Sand Behind the Abutment and Piles Embedded in Stiff Clay 


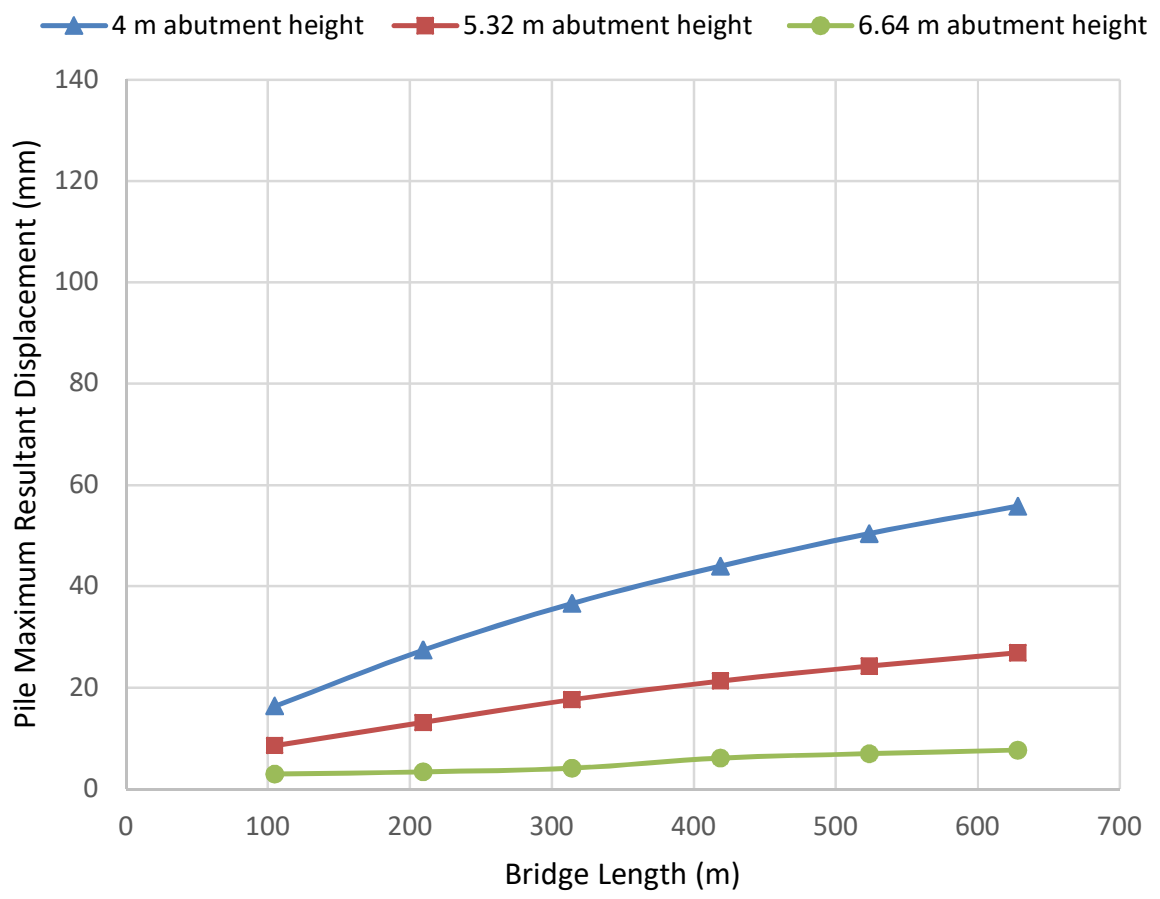

Figure 4.24 Pile Maximum Resultant Displacement Under Thermal Expansion for $\mathbf{3 0 0} \mathrm{m}$ Radius Integral Bridge in Case of Dense Sand Behind the Abutment and Piles Embedded in Stiff Clay

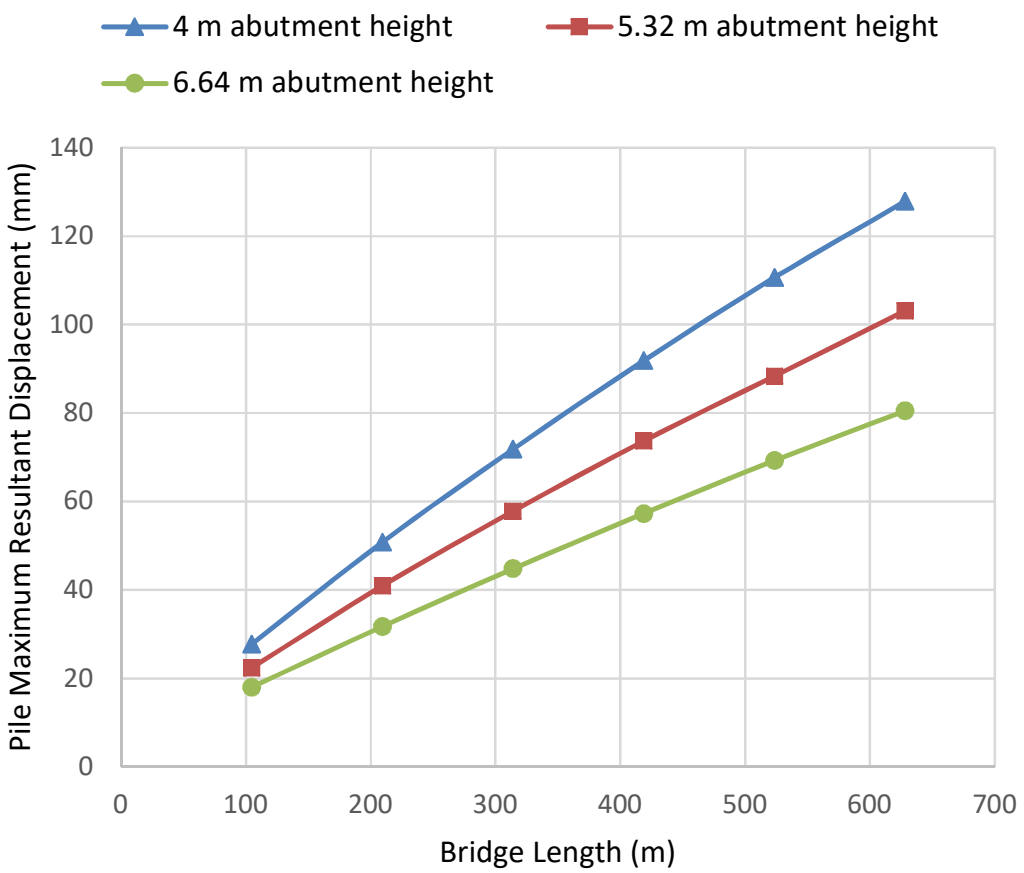

Figure 4.25 Pile Maximum Resultant Displacement Under Thermal Expansion for $\mathbf{3 0 0} \mathrm{m}$ Radius Integral Bridge in Case of Loose Sand Behind the Abutment and Piles Embedded in Stiff Clay 


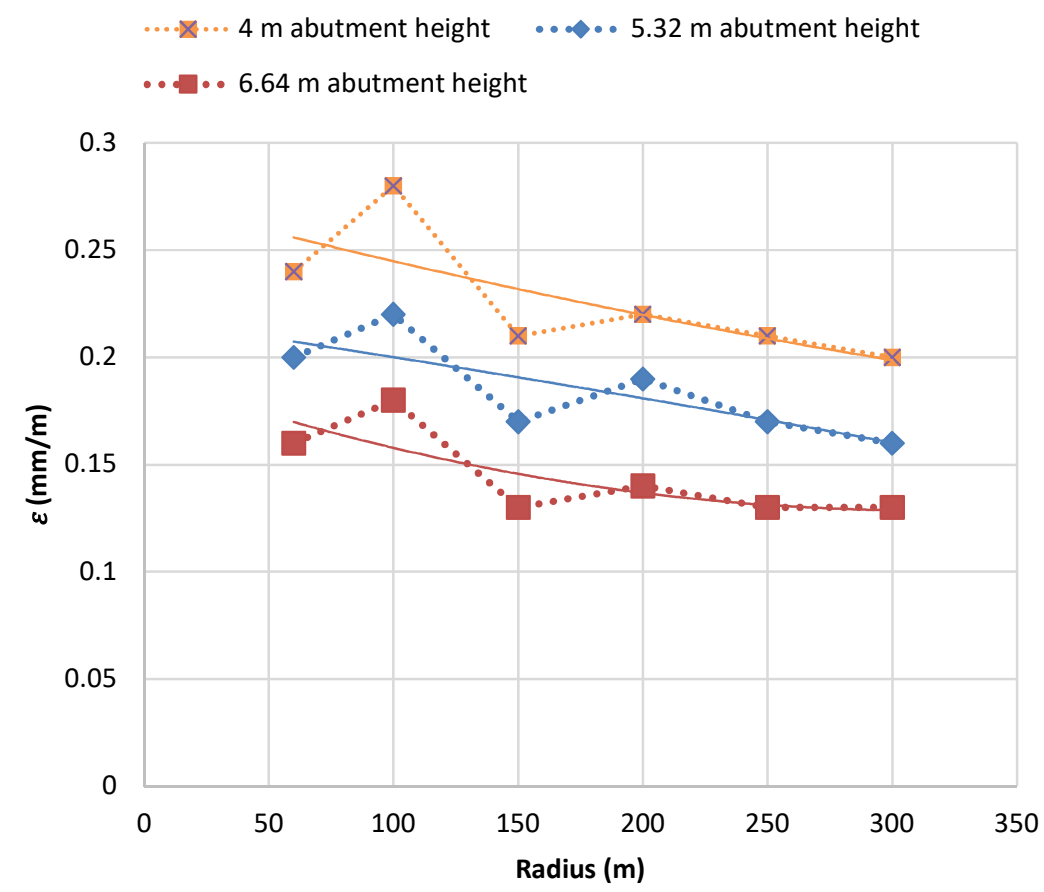

Figure 4.26 Unit Change in Bridge Total Length, $\varepsilon$, Versus Radius of Curvature Under Thermal Expansion in Case of Loose Sand Behind the Abutment and Piles Embedded in Stiff Clay

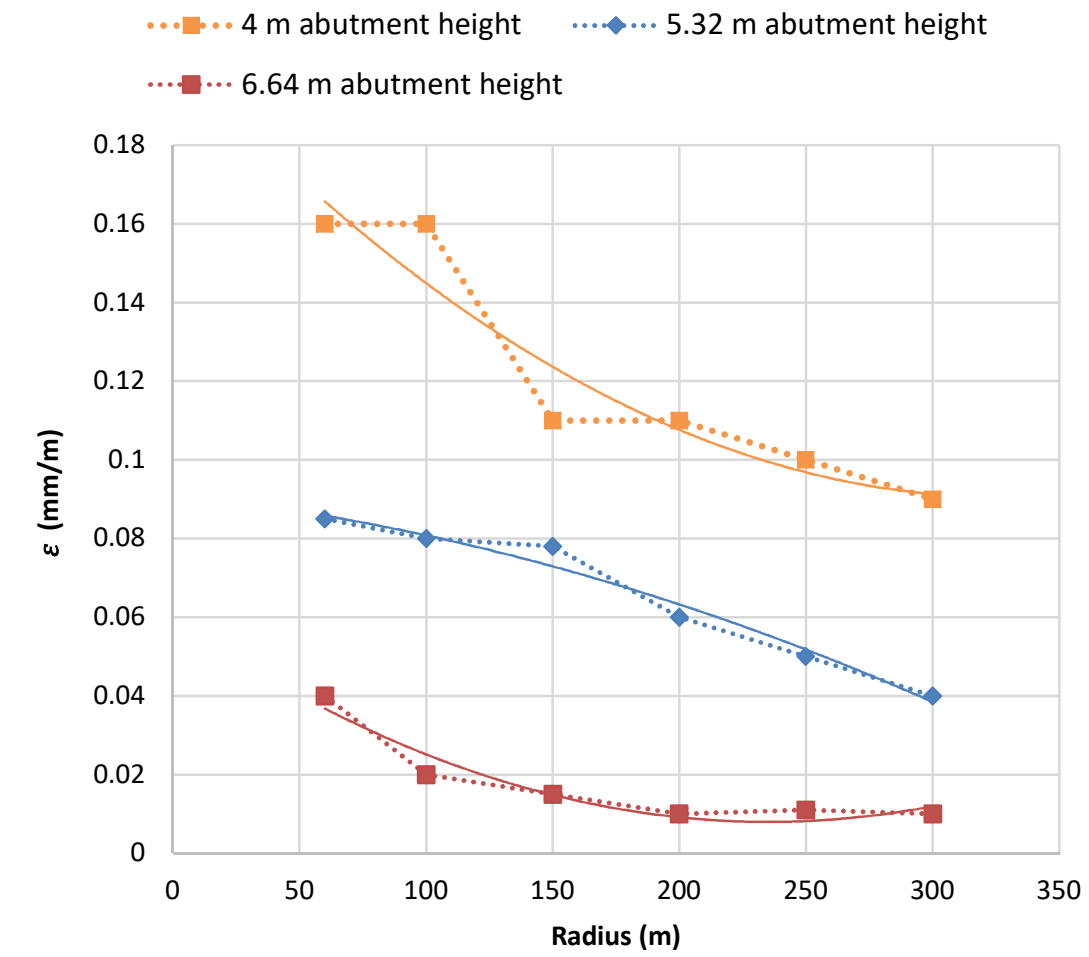

Figure 4.27 Unit Change in Bridge Total Length, $\varepsilon$, Versus Radius of Curvature Under Thermal Expansion in Case of Dense Sand Behind the Abutment and Piles Embedded in Stiff Clay 
Table 4.7 Equations of $\varepsilon(\mathrm{mm} / \mathrm{m})$ - Stiff Clay Foundation Soil

\begin{tabular}{|c|c|lc|}
\hline $\begin{array}{c}\text { Condition of } \\
\text { Granular Backfill }\end{array}$ & $\begin{array}{c}\text { Height of Bridge } \\
\text { Abutment }(\mathrm{H}) \\
(\mathrm{m})\end{array}$ & & \multicolumn{2}{|c|}{ Equation Form } \\
\hline \multirow{3}{*}{ Loose Sand } & $4.0 \mathrm{~m}$ & $\varepsilon=0.0003 R+0.2738$ & $(4.5)$ \\
\cline { 2 - 5 } & $5.32 \mathrm{~m}$ & $\varepsilon=0.0002 R+0.2177$ & $(4.6)$ \\
\cline { 2 - 5 } & $6.64 \mathrm{~m}$ & $\varepsilon=0.0004 R+0.1917$ & $(4.8)$ \\
\hline \multirow{3}{*}{ Dense Sand } & $4.0 \mathrm{~m}$ & $\varepsilon=0.0007 R+0.2032$ & $(4.9)$ \\
\cline { 2 - 5 } & $5.32 \mathrm{~m}$ & $\varepsilon=0.00007 R+0.0911$ & $(4.10)$ \\
\cline { 2 - 5 }
\end{tabular}

\subsubsection{Substructure Piles Embedded in Medium Dense Sand}

Based on bridge data in Table 3.1, Figures 4.28 through 4.39 describe the behavior of abutment piles of an integral abutment bridges having different Radii in which the piles are imbedded in medium dense sand and the bridge superstructure is under thermal expansion loading in addition to its own weight. It is clear from the graphs that the pile maximum resultant displacement is directly proportional to the bridge length. As the bridge length increases, the pile maximum displacement increases, which agrees with results reported by Razmi et al. (2014). Also, the figures show the effect of increasing abutment height on reducing pile maximum resultant displacement. For instance, when the abutment height increased from 4 to $6.64 \mathrm{~m}$, the pile maximum resultant displacement decreased from 14.02 $\mathrm{mm}$ to $4 \mathrm{~mm}$ for the same bridge configuration and soil condition. For each bridge radius, two backfill soil conditions behind the abutment were considered, namely: dense and loose sand. It is obvious that dense sand behind the abutment has greater effect on the reduction of pile maximum displacement in comparison with loose sand for the same bridge configuration. The dense sand provides more restraints to bridge deck against expansion, thus, decreasing bridge abutment rotation. For instance, when the state of sand behind the abutment was dense, pile maximum resultant displacement was $14.02 \mathrm{~mm}$ in comparison with $21.20 \mathrm{~mm}$ when the sand behind the abutment was in the loose state.

To explore the effects of foundation soil on the bridge substructure performance, comparison between results shown in Figure 4.22 and those shown in Figure 4.36 where the radius of curvature was $250 \mathrm{~m}$. The backfill soil for the two cases was loose sand, while the foundation soil in former was stiff clay, and the later was medium dense sand. At bridge length $520 \mathrm{~m}$, 
the magnitudes of PMRDs in case of stiff clay were 114, 91.9 and $71.4 \mathrm{~mm}$, while in case of medium dense sand, the magnitudes of PMRDs were 70, 50 and $37 \mathrm{~mm}$, for abutment heights of 4, 5.32 and $6.64 \mathrm{~m}$, respectively. The comparison revealed that the foundation soil has appreciable influence on the substructure bridge performance. To support this finding, another comparison was carried out. Considering a radius of curvature of $60 \mathrm{~m}$, the PMRDs at bridge length of $125 \mathrm{~m}$ in case of stiff clay foundation soil are 30, 25 and $20 \mathrm{~mm}$ as shown in Figure 4.14. The corresponding values in case of medium dense sand foundation soil were 21, 15 and $11 \mathrm{~mm}$ as shown in Figure 4.29 for abutment heights of 4, 5.32 and $6.64 \mathrm{~m}$, respectively.

The above comparisons were carried out in case of loose sand backfill. To get a firm conclusion, the comparisons were extended to dense sand backfill. At radius of curvature of $250 \mathrm{~m}$, the PMRDs at bridge length of $537 \mathrm{~m}$, were 40, 20 and $10 \mathrm{~mm}$ in case of mediumdense sand foundation soil as shown in Figure 4.37, while the corresponding values in case of stiff clay foundation soil were 55, 27 and $9.6 \mathrm{~mm}$ as shown in Figure 4.23 corresponding to abutment heights of 4.0, 5.32 and $6.64 \mathrm{~m}$, respectively. At radius of curvature of $60 \mathrm{~m}$, the values of PMRDs in case of medium dense sand foundation soil and at bridge length of $123 \mathrm{~m}$, were 14, 7.8 and $4 \mathrm{~mm}$ as shown in Figure 4.28, while in case of stiff clay, the magnitudes were 20, 10 and $5 \mathrm{~mm}$ as shown in Figure 4.15, corresponding to abutment heights of 4.0, 5.32 and $6.64 \mathrm{~m}$, respectively.

The above study revealed that the foundation soil has great influence on the response of substructure of the bridge when the bridge is subjected to thermal positive loading, since medium dense sand foundation soil contributes in decreasing the PMRD, and consequently, in all straining induced in the abutment piles, compared with the case of stiff clay. The decrease in PMRD values was observed to be between $40 \%$ to $60 \%$ in the studied cases. These findings are in agreement with those presented by LaFave et al. (2016).

Figures 4.28 through 4.39 depict that the PMRD increased linearly with the increase in bridge length. The PMRD-bridge length ratios, represented by $\varepsilon$ were assessed at different abutment heights $(H)$ and drawn against radii of curvature (R) as shown in Figures 4.40 and 4.41. Polynomial equations were developed to express $\varepsilon_{i}$ - radius of curvature relationships as depicted in Table 4.8. The scatter of the points around the mathematical relationship may be attributed to the effect of bridge span length. 


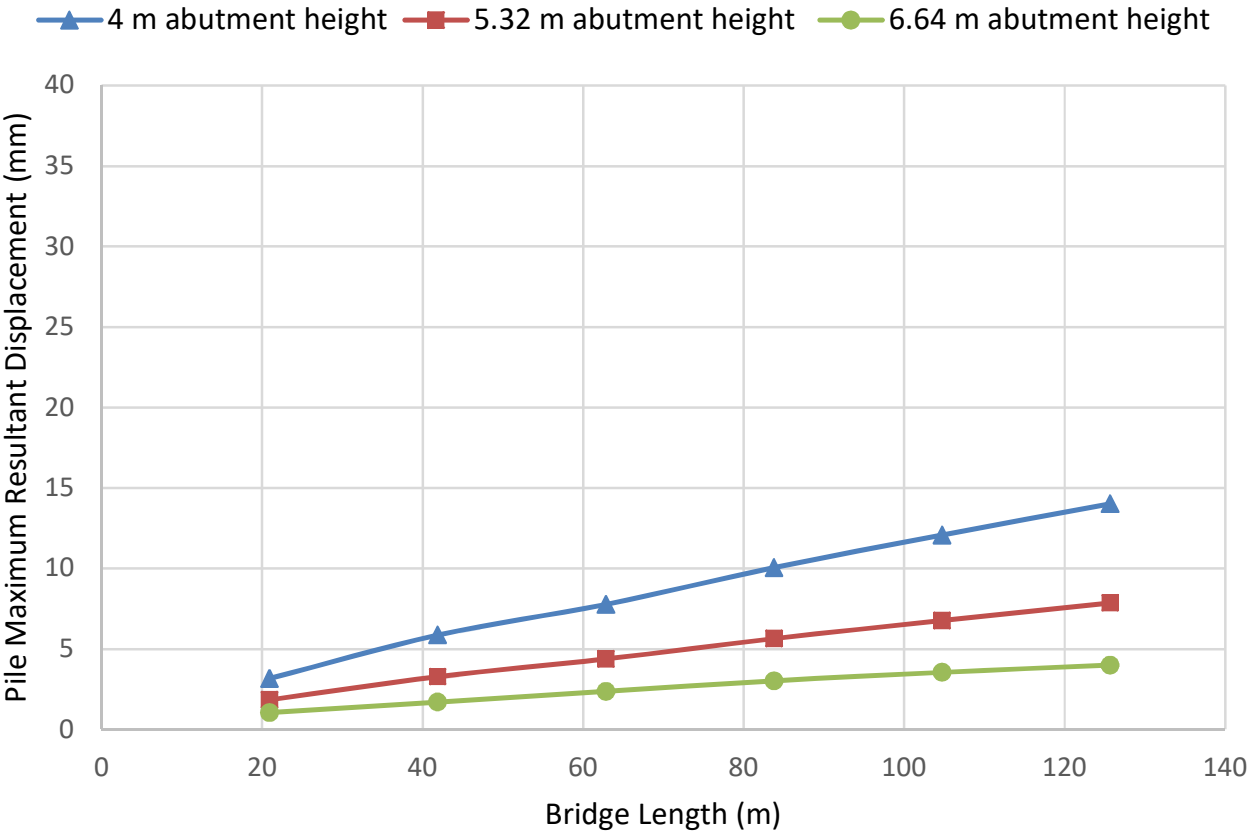

Figure 4.28 Pile Maximum Resultant Displacement Under Thermal Expansion for $\mathbf{6 0} \mathrm{m}$ Radius Integral Bridge in Case of Dense Sand Behind the Abutment and Piles Embedded in Medium Dense Sand

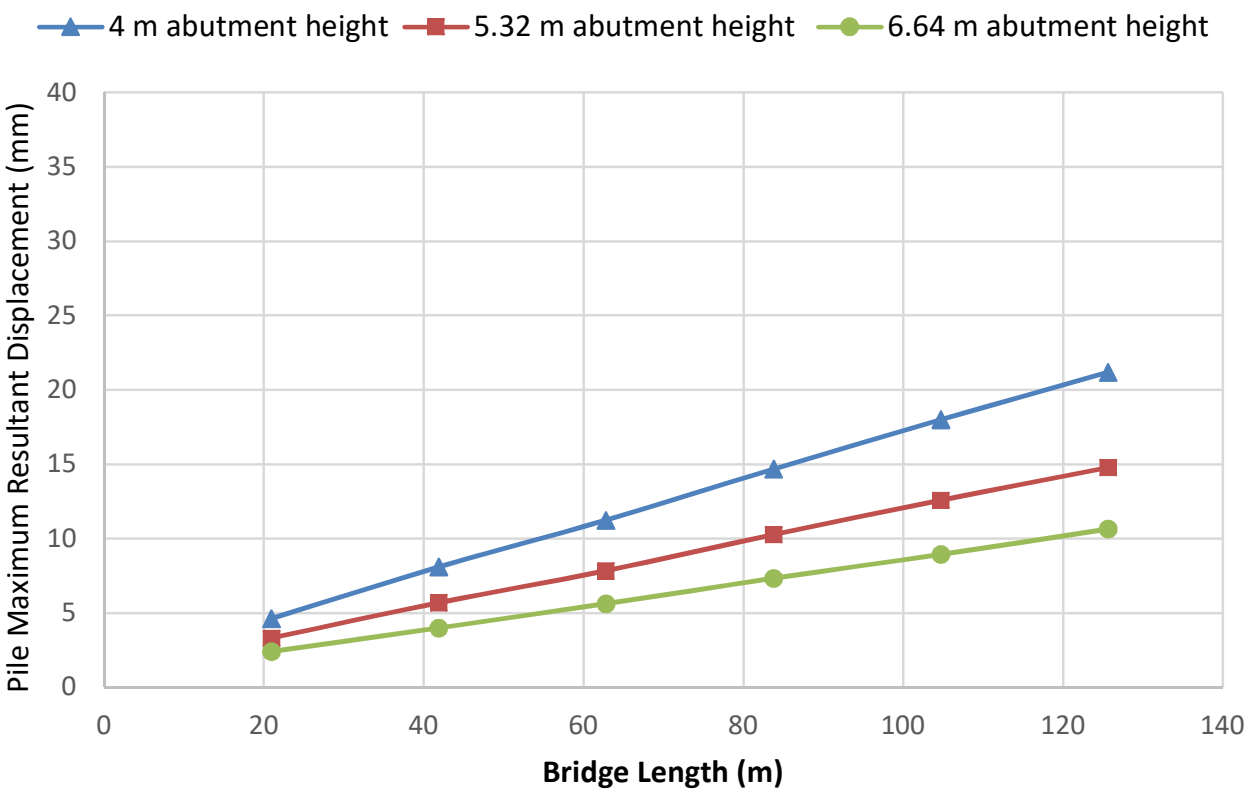

Figure 4.29 Pile Maximum Resultant Displacement Under Thermal Expansion for $60 \mathrm{~m}$ Radius Integral Bridge in Case of Loose Sand Behind the Abutment and Piles Embedded in Medium Dense Sand 


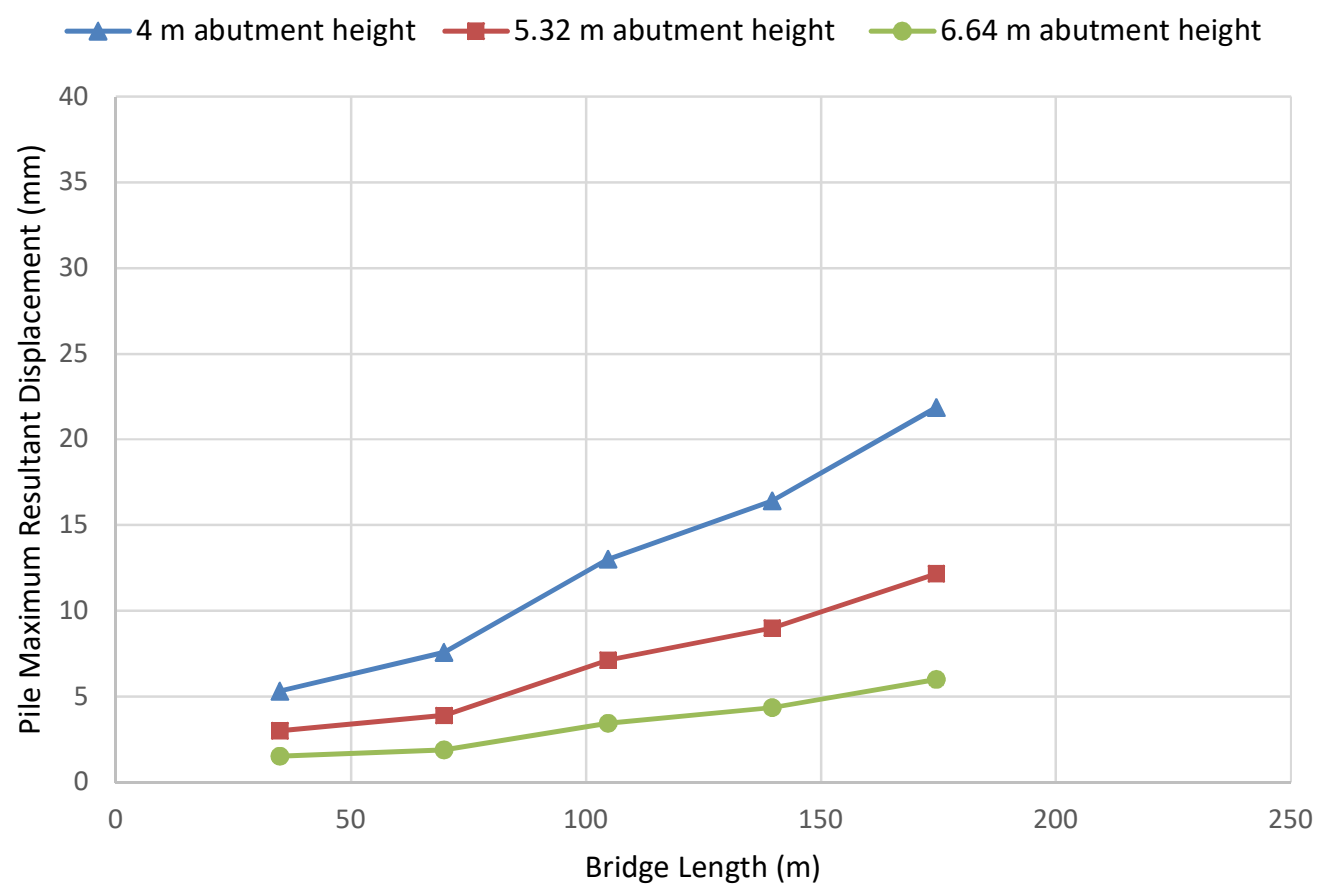

Figure 4.30 Pile Maximum Resultant Displacement Under Thermal Expansion for $100 \mathrm{~m}$ Radius Integral Bridge in Case of Dense Sand Behind the Abutment and Piles Embedded in Medium Dense Sand

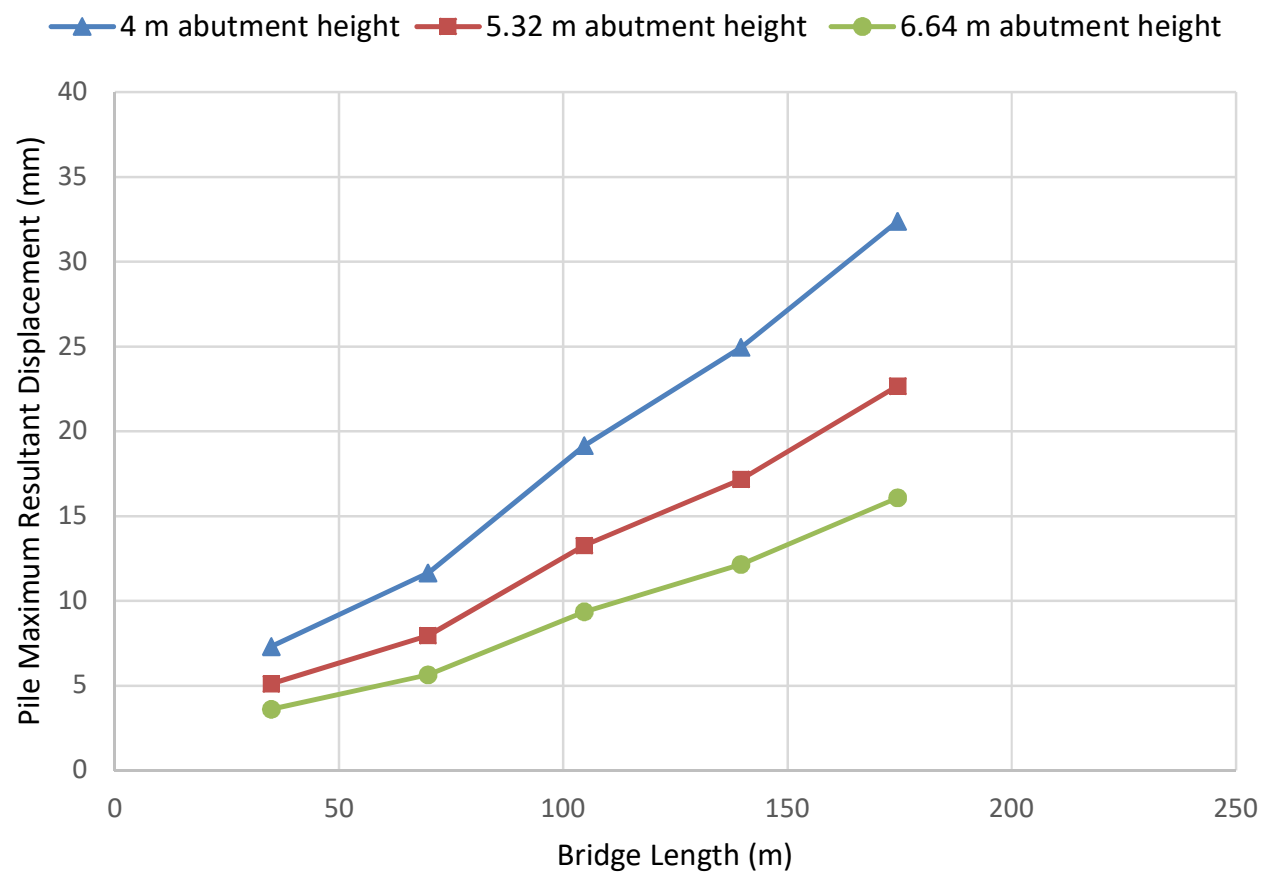


Figure 4.31 Pile Maximum Resultant Displacement Under Thermal Expansion for $100 \mathrm{~m}$ Radius Integral Bridge in Case of Loose Sand Behind the Abutment and Piles Embedded in Medium Dense Sand

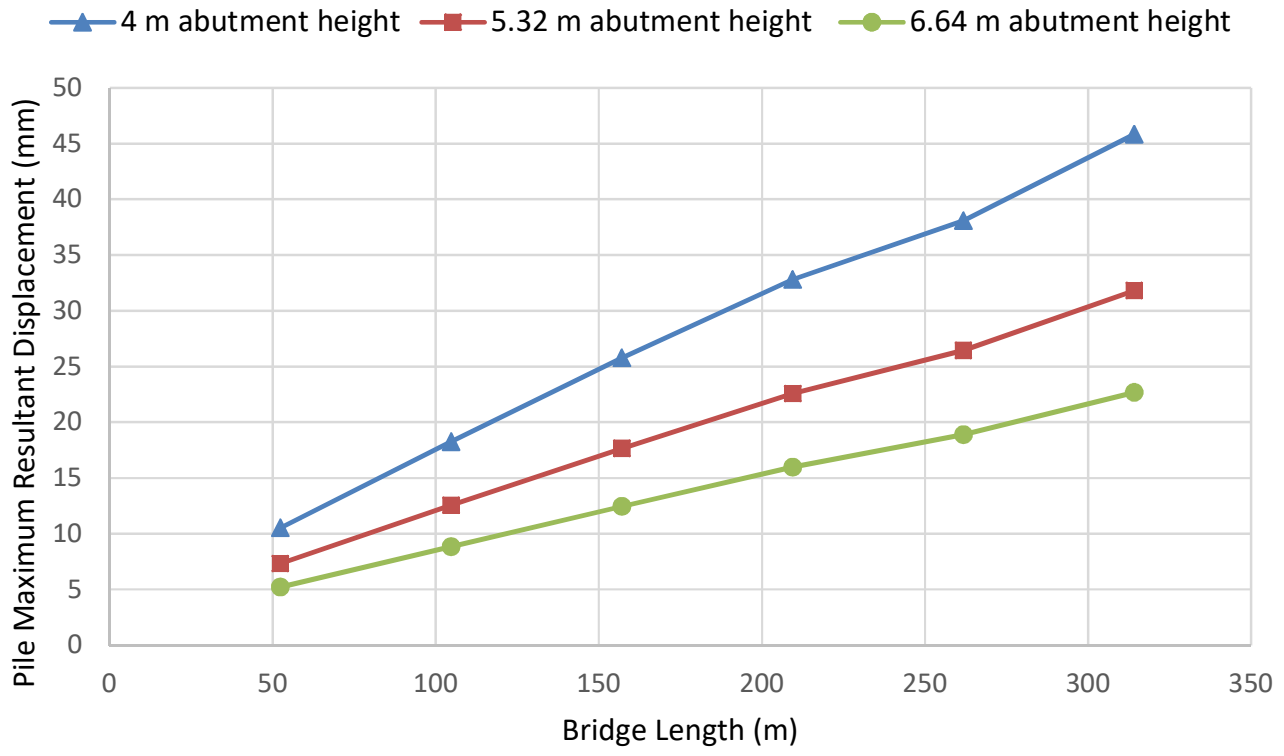

Figure 4.32 Pile Maximum Resultant Displacement Under Thermal Expansion for $150 \mathrm{~m}$ Radius Integral Bridge in Case of Loose Sand Behind the Abutment and Piles Embedded in Medium Dense Sand

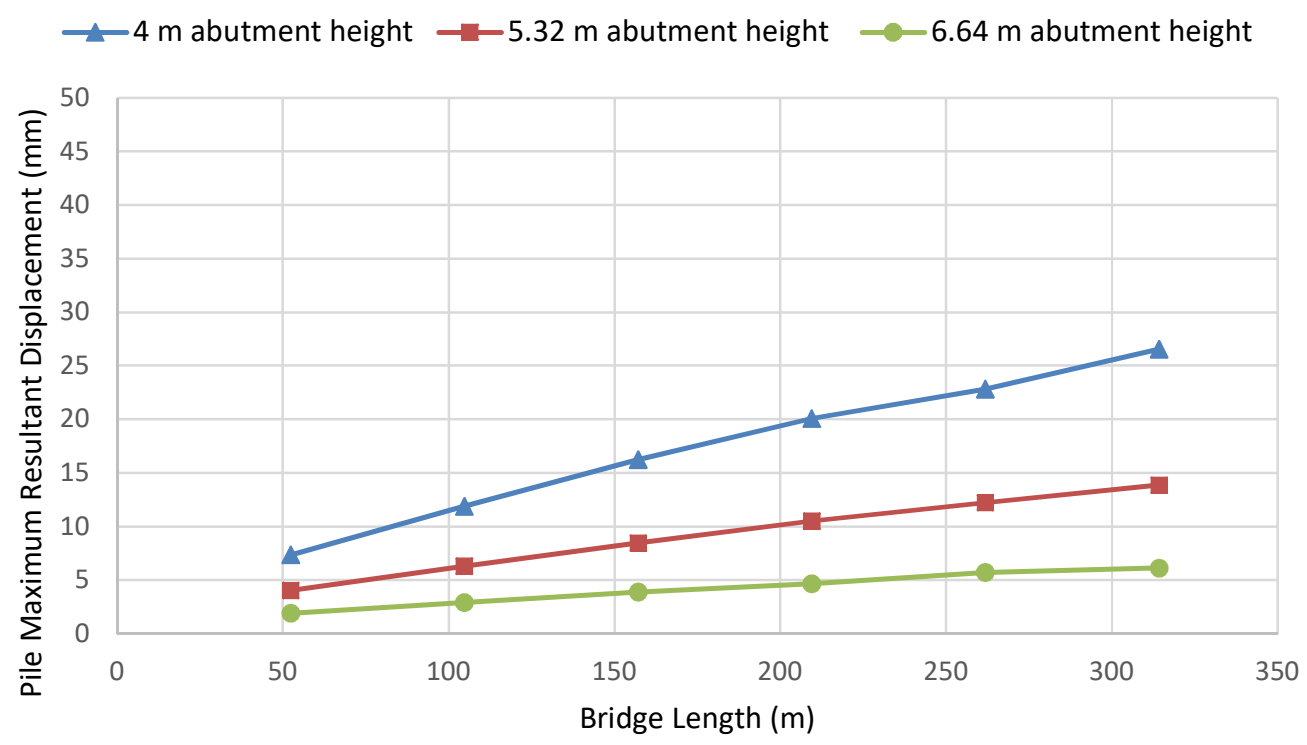

Figure 4.33 Pile Maximum Resultant Displacement Under Thermal Expansion for $150 \mathrm{~m}$ Radius Integral Bridge in Case of Dense Sand Behind the Abutment and Piles Embedded in Medium Dense Sand 


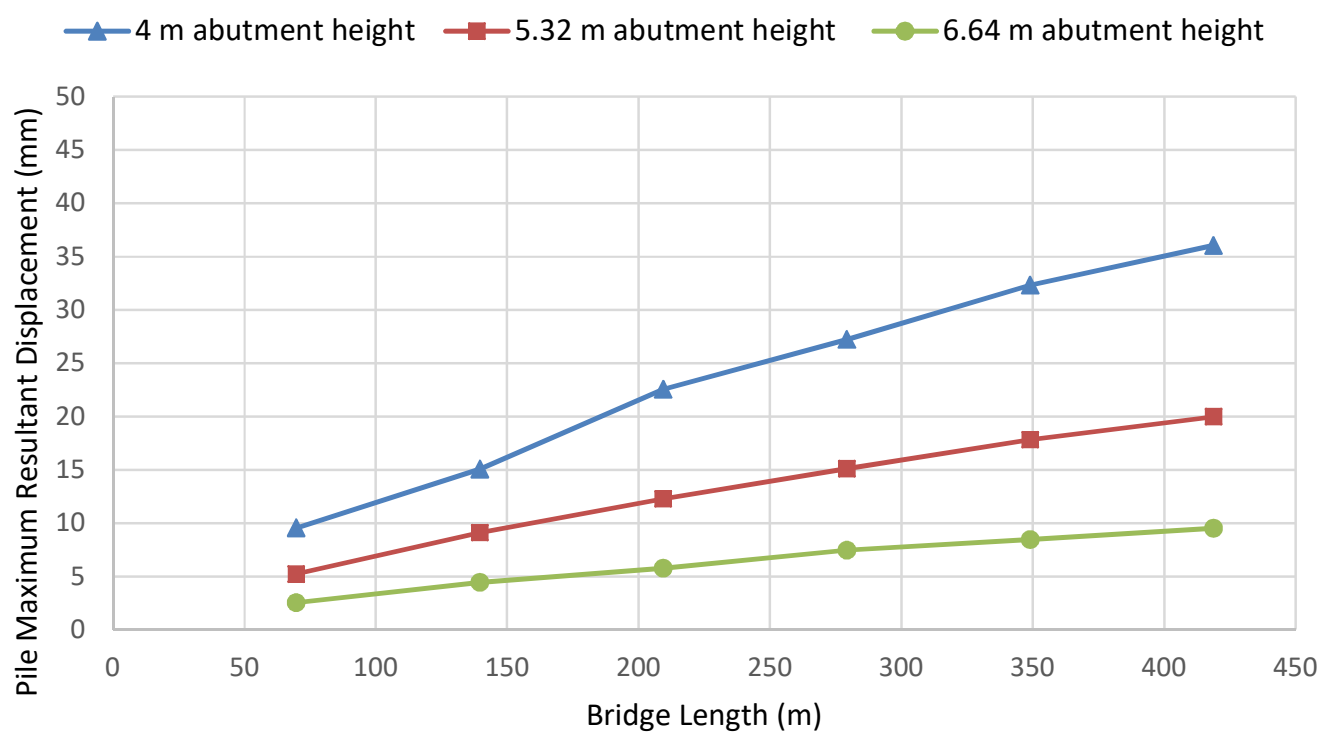

Figure 4.34 Pile Maximum Resultant Displacement Under Thermal Expansion for $\mathbf{2 0 0} \mathrm{m}$ Radius Integral Bridge in Case of Dense Sand Behind the Abutment and Piles Embedded in Medium Dense Sand

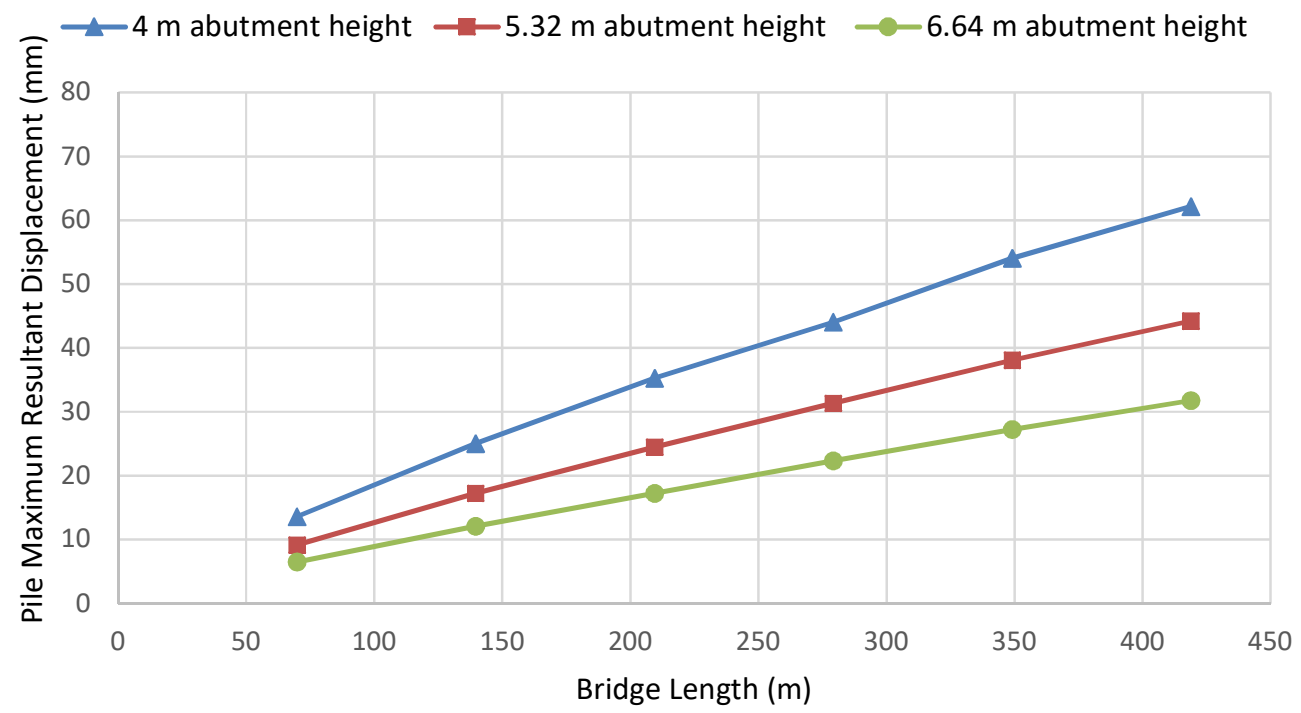

Figure 4.35 Pile Maximum Resultant Displacement Under Thermal Expansion for $\mathbf{2 0 0} \mathbf{m}$ Radius Integral Bridge in Case of Loose Sand Behind the Abutment and Piles Embedded in Medium Dense Sand 


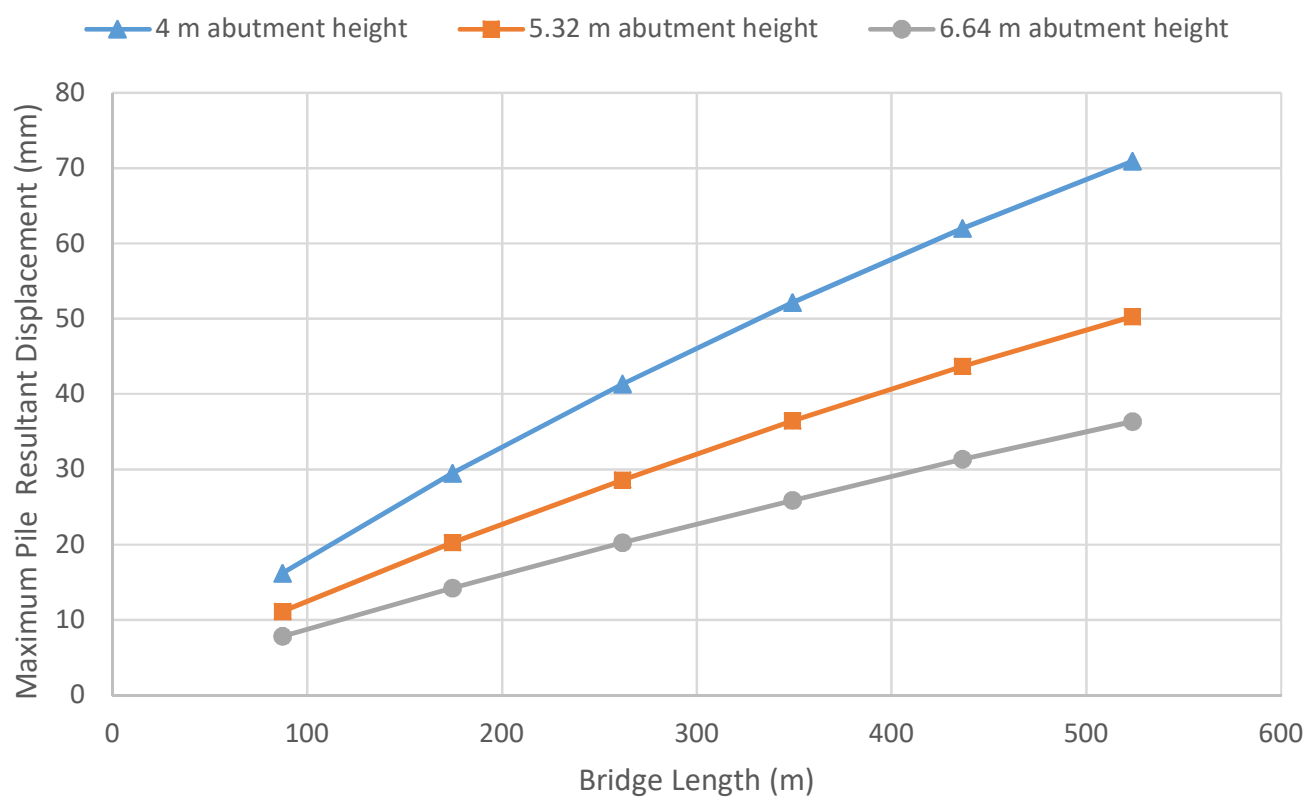

Figure 4.36 Pile Maximum Resultant Displacement Under Thermal Expansion for $\mathbf{2 5 0} \mathrm{m}$ Radius Integral Bridge in Case of Loose Sand Behind the Abutment and Piles Embedded in Medium Dense Sand

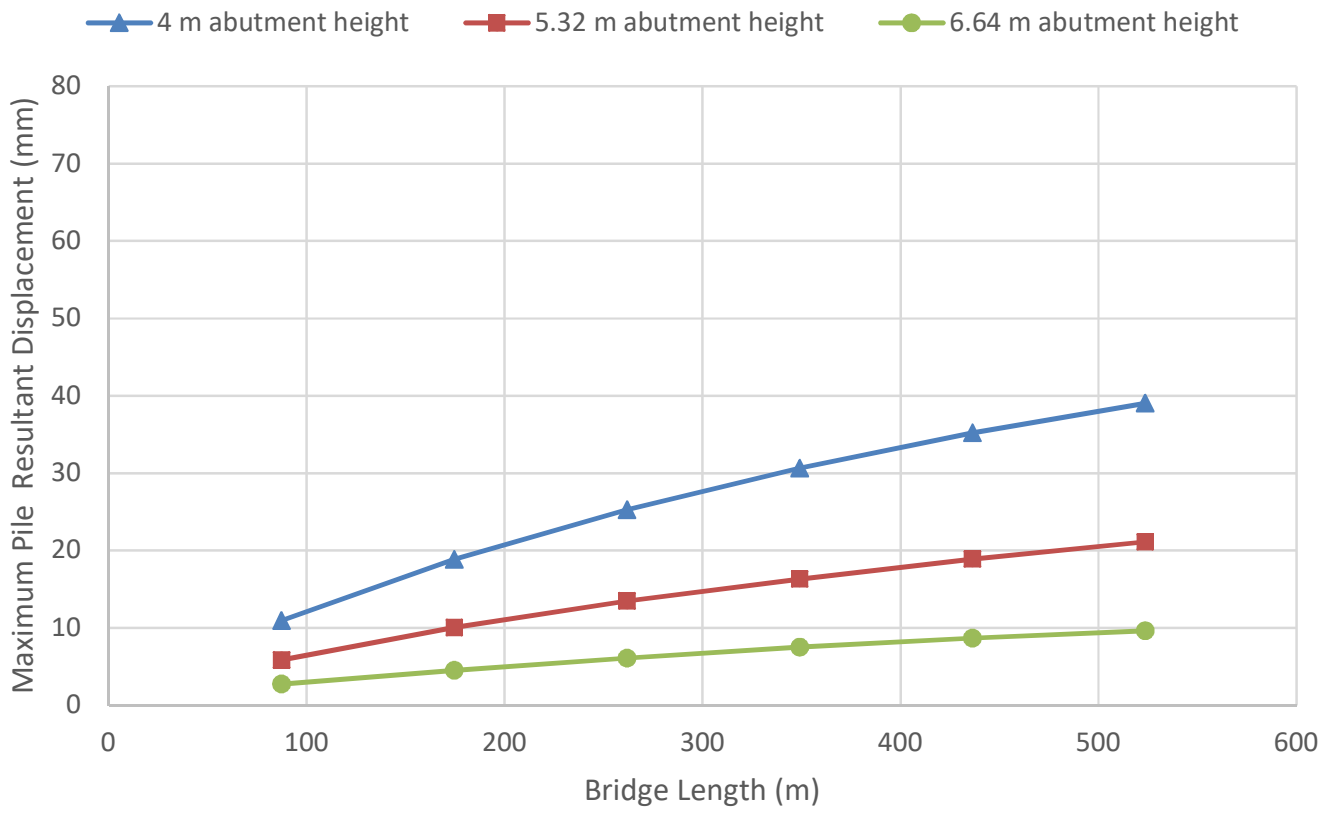

Figure 4.37 Pile Maximum Resultant Displacement Under Thermal Expansion for $250 \mathrm{~m}$ Radius Integral Bridge in Case of Dense Sand Behind the Abutment and Piles Embedded in Medium Dense Sand 


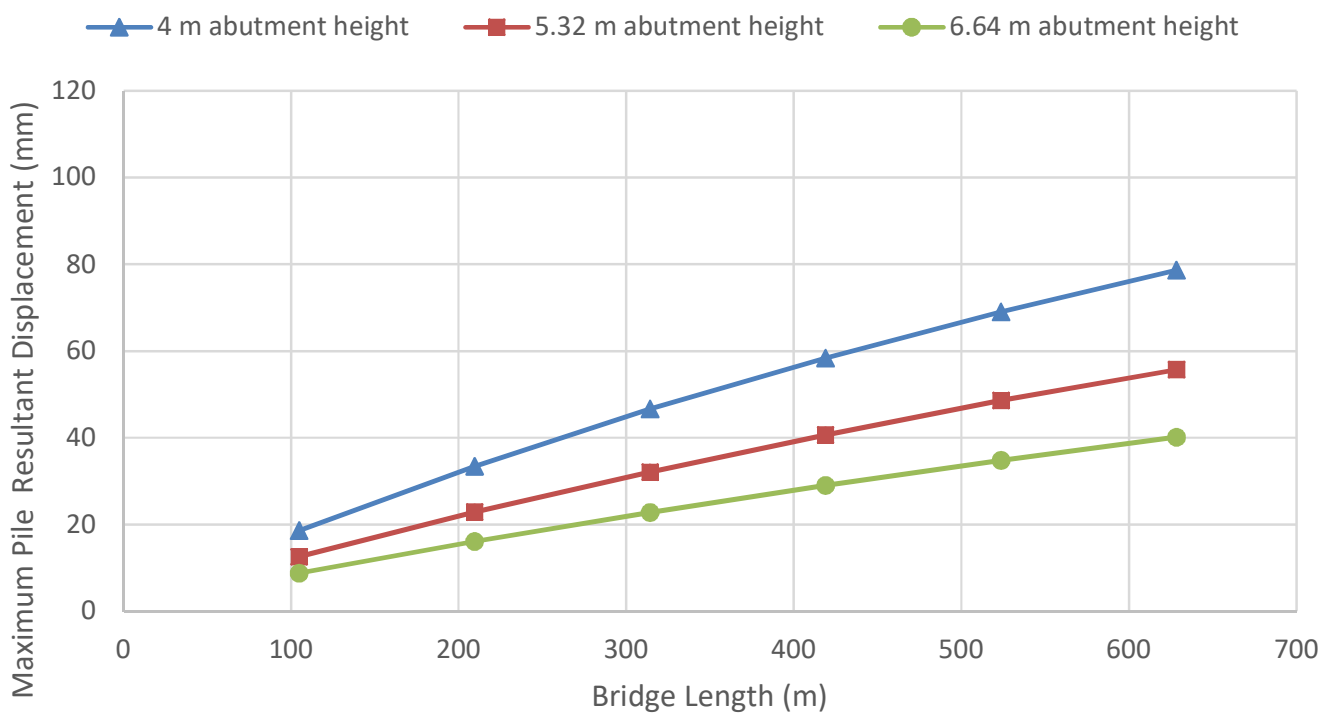

Figure 4.38 Pile Maximum Resultant Displacement Under Thermal Expansion for $\mathbf{3 0 0} \mathrm{m}$ Radius Integral Bridge in Case of Loose Sand Behind the Abutment and Piles Embedded in Medium Dense Sand

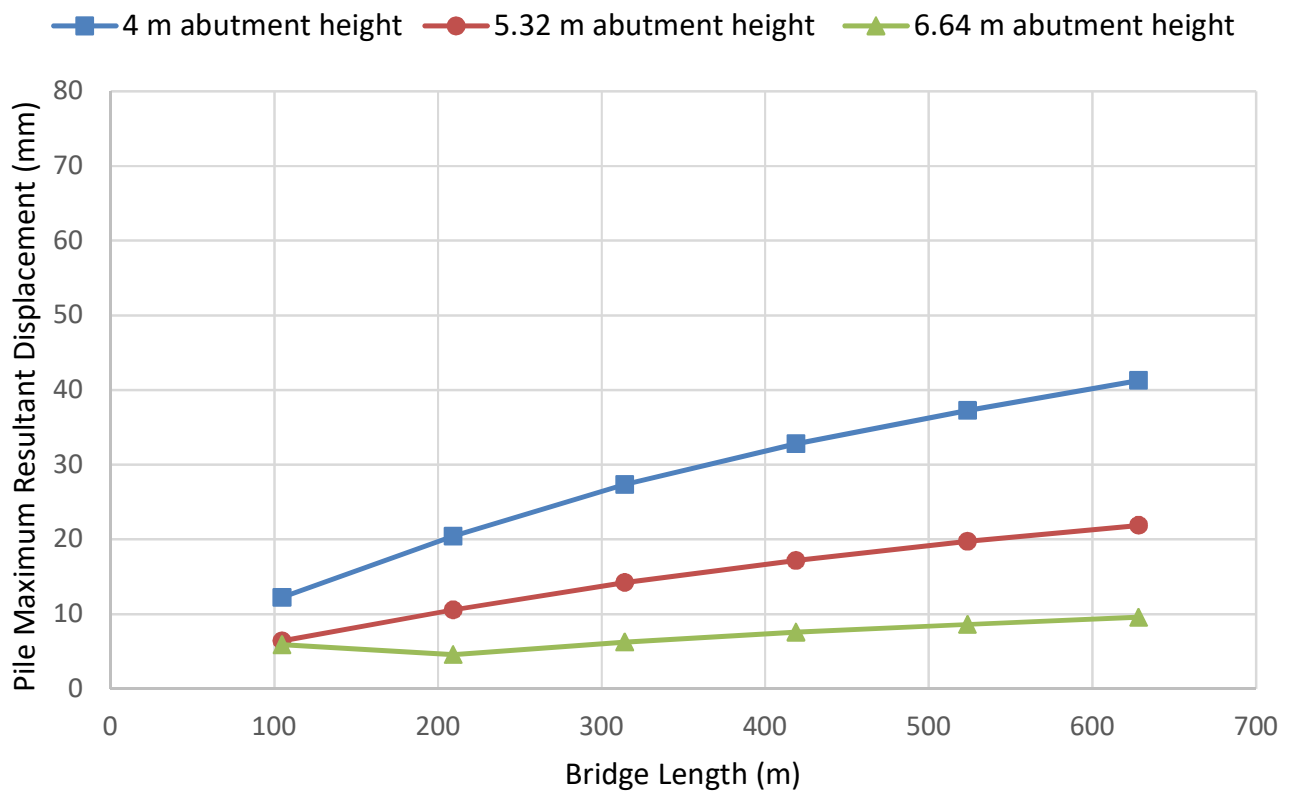

Figure 4.39 Pile Maximum Resultant Displacement Under Thermal Expansion for $\mathbf{3 0 0} \mathrm{m}$ Radius Integral Bridge in Case of Dense Sand Behind the Abutment and Piles Embedded in Medium Dense Sand 


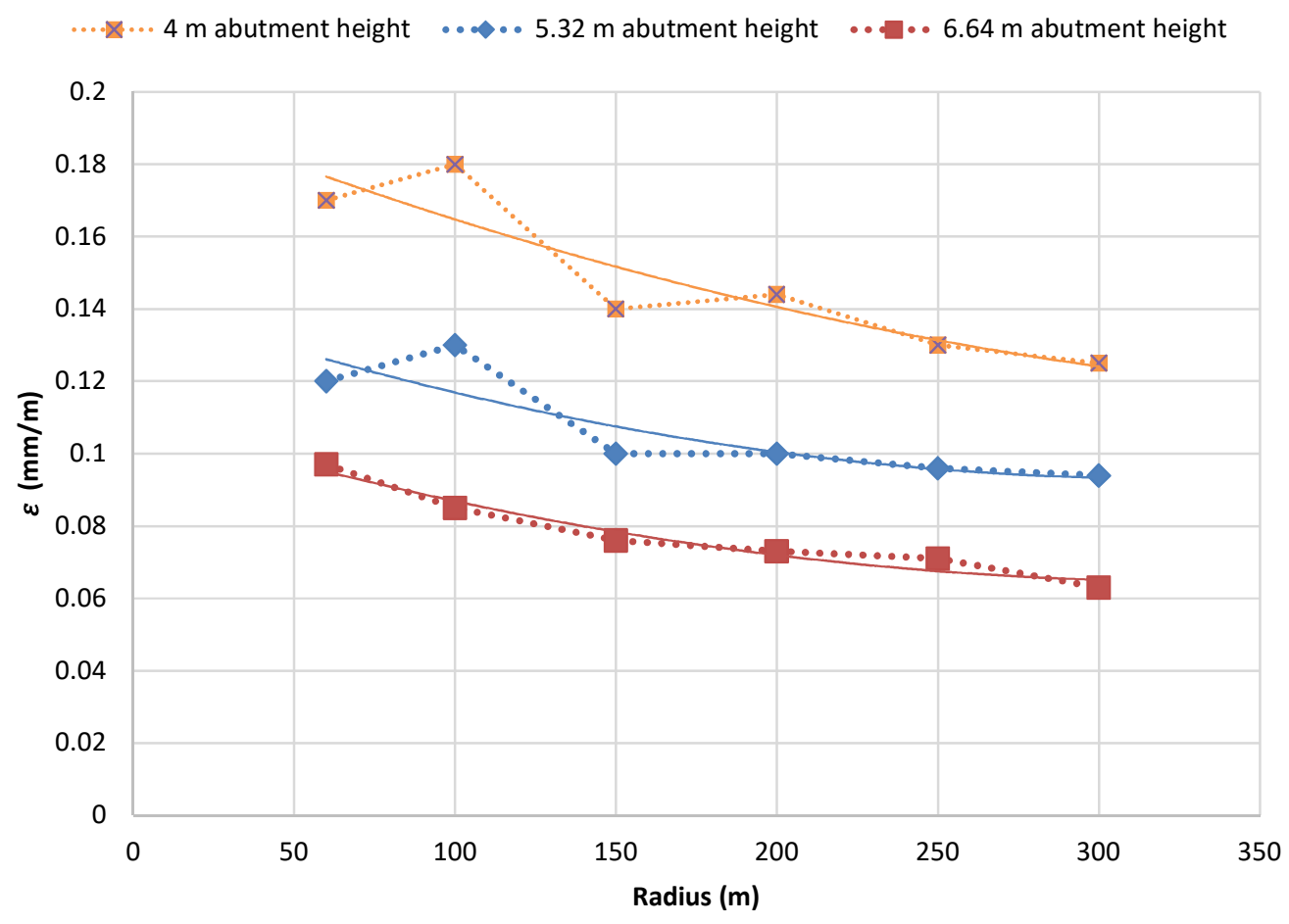

Figure 4.40 Unit Change in Bridge Length, $\varepsilon$, Versus Radius of Curvature Under Thermal Expansion in Case of Loose Sand Behind the Abutment and Piles Embedded in Medium Dense Sand

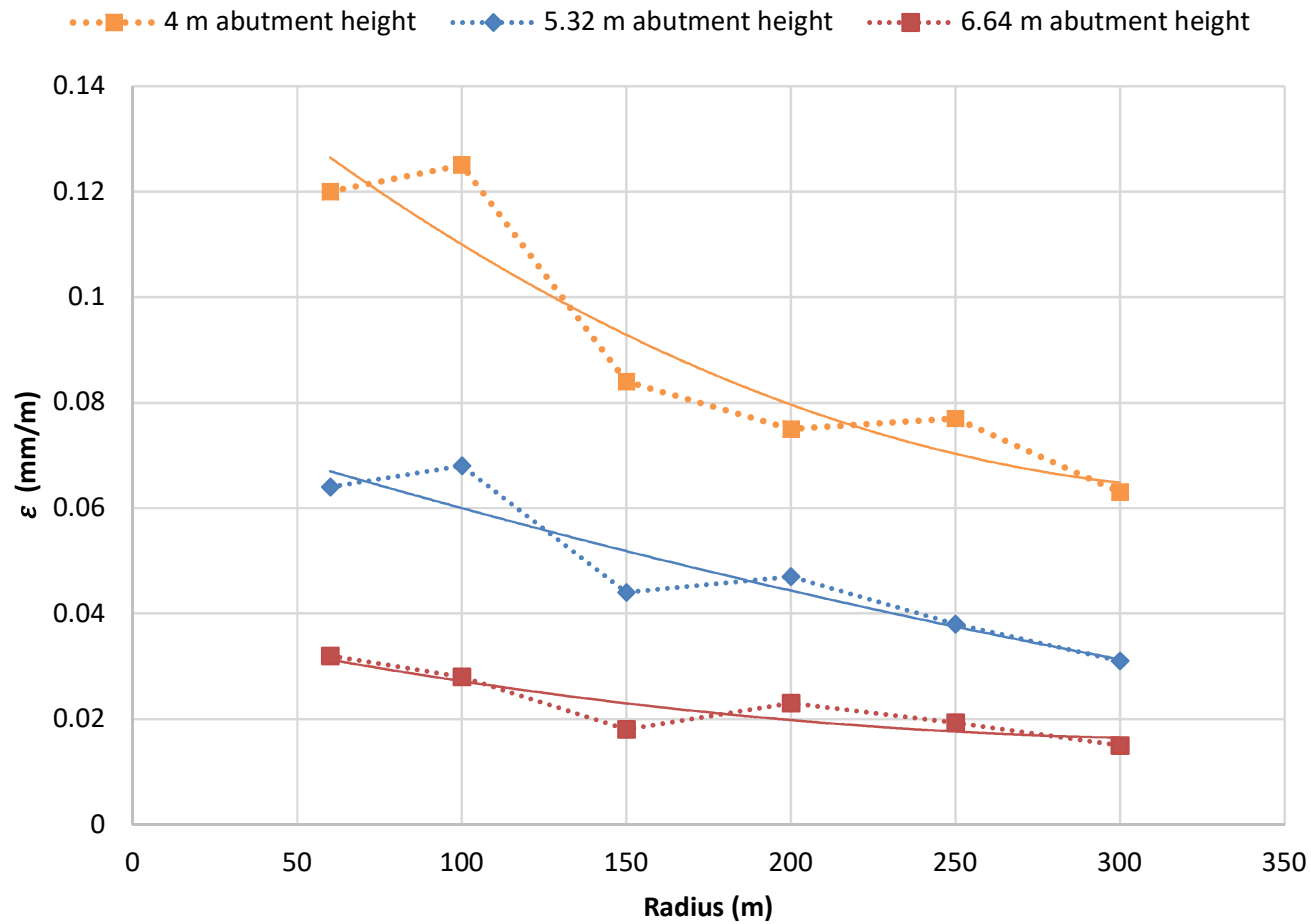

Figure 4.41 Unit Change in Bridge Length, $\varepsilon$, Versus Radius of Curvature Under Thermal Expansion in Case of Dense Sand Behind the Abutment and Piles Embedded in Medium Dense Sand 
Table 4.8 Equations of $\varepsilon(\mathrm{mm} / \mathrm{m})$ - Medium Dense Sand Foundation Soil

\begin{tabular}{|c|c|lc|}
\hline $\begin{array}{c}\text { Condition of } \\
\text { Granular Backfill }\end{array}$ & $\begin{array}{c}\text { Height of Bridge } \\
\text { Abutment }(\mathrm{H}) \\
(\mathrm{m})\end{array}$ & & \\
\hline \multirow{3}{*}{ Loose Sand } & $4.0 \mathrm{~m}$ & $\varepsilon=0.0004 R+0.1967$ & $(4.11)$ \\
\cline { 2 - 5 } & $5.32 \mathrm{~m}$ & $\varepsilon=0.0003 R+0.1427$ & $(4.12)$ \\
\cline { 2 - 5 } & $6.64 \mathrm{~m}$ & $\varepsilon=0.0003 R+0.1099$ & $(4.13)$ \\
\hline \multirow{3}{*}{ Dense Sand } & $4.0 \mathrm{~m}$ & $\varepsilon=0.0005 R+0.1559$ & $(4.14)$ \\
\cline { 2 - 4 } & $5.32 \mathrm{~m}$ & $\varepsilon=0.0002 R+0.0783$ & $(4.16)$ \\
\cline { 2 - 4 } & $6.64 \mathrm{~m}$ & $\varepsilon=0.0001 R+0.0386$ & \\
\hline
\end{tabular}

Comparison between sets of equation in Table 4.7 and 4.8 revealed the effect of foundation soil in cases of loose and dense sand backfill. Stiff clay foundation soil shows greater pile maximum resultant displacement compared with dense sand. Also, dense sand backfill in both cases exerts more restraint on bridge abutment which reduces the pile maximum resultant displacement.

\subsection{Integral Abutment Bridges Under Thermal Contraction}

From the Lateral Earth Pressure Coefficient Versus Relative Wall Movement graph proposed by Husain \& Bagnariol (1996), it was found that in the case of dense sand behind the retaining wall, the lateral active earth pressure coefficient, $K$, at limit state is 0.17 , while it is 0.33 in case of loose sand. The unit weight of loose sand, $\gamma$, was taken $15 \mathrm{kN} / \mathrm{m}^{3}$ while that of dense sand $20 \mathrm{kN} / \mathrm{m}^{3}$. That gives a value of $k \gamma$ of $3.4 \mathrm{kN} / \mathrm{m}^{3}$ in case of dense sand, and a value of $k \gamma$ of $4.95 \mathrm{kN} / \mathrm{m}^{3}$ in case of loose sand. By delving into the literature, it was found that some researchers adopted the same concept of discarding the active earth pressure behind the abutment in case of contraction as shown in Figure 4.42 (Frosch \& Lovell, 2011). However, $p$ $\Delta$ relationship documented in Canadian Foundation Engineering Manual (1992) depicted that the coefficient of active earth pressure $\left(K_{\mathrm{a}}\right)$ of dense sand equals to 0.1 at wall movement $Y / H$ of 0.001 , where $Y$ is the abutment displacement and $H$ is the abutment height, it increases to a stabilized value at active limit state of about 0.2 at wall movement $Y / H$ of 0.004. For loose compacted sand, this value equals to 0.2 at very small wall movement (not defined in CFEM). The active limit state earth pressures, at $Y / H$ of 0.001 as reported by Husain \& Bagnariol (1996) are 0.17 and 0.33 for dense and loose sand respectively. Frosch 
and Lovell (2011) stated that lateral earth pressure is reduced to approximately zero during bridge contraction and the maximum lateral pile demand occurs during bridge contraction.

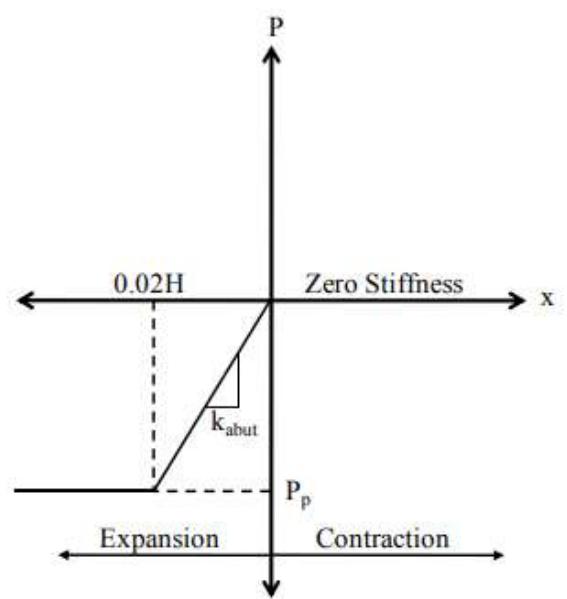

Figure 4.42 Abutment-Soil Force-Displacement Relationship Using Rankine Theory (Frosch \& Lovell, 2011)

\subsubsection{Substructure Piles Embedded in Stiff Clay}

Based on bridge data in Table 3.1, Figures 4.43 through 4.54 describe the behavior of abutment piles of integral abutment bridges having different Radii in which the piles are embedded in stiff clay and the bridge superstructure is under thermal contraction loading in addition to its own weight. It is clear from the figures that the pile maximum resultant displacement is directly proportional to the bridge length. As the bridge length increased, the pile maximum displacement increased, due to the increase of the contraction of bridge superstructure. Also, the graphs show the effect of increasing abutment height on reducing pile maximum resultant displacement, due to the increase of equivalent abutment and piles stiffness. For instance, when the abutment height increased from 4 to $6.64 \mathrm{~m}$, the pile maximum resultant displacement under construction phase of the bridge decreased from $33.09 \mathrm{~mm}$ to $25.54 \mathrm{~mm}$ for the same bridge configuration and soil conditions. For each bridge radius, two soil conditions behind the bridge abutment were considered, namely: dense and loose sand backfill. In the case of contraction, the state of sand behind the abutment has no effect on the pile maximum resultant displacement, since the active earth pressure is too small in magnitude to be considered. 
Figures 4.43 through 4.54 present the PMRD versus the bridge length (L), for different abutment heights $(H)$. For the sake of comparison, the figures included the same relationships, but, in case of the expansion phase of the bridge superstructure. The average ratio of PMRDs in case of contraction to that takes place in case of expansion, $n$, were obtained as reported in Table 4.9. The mean values and standard deviation of ( $n$ ) was calculated as reported in Table 4.10.

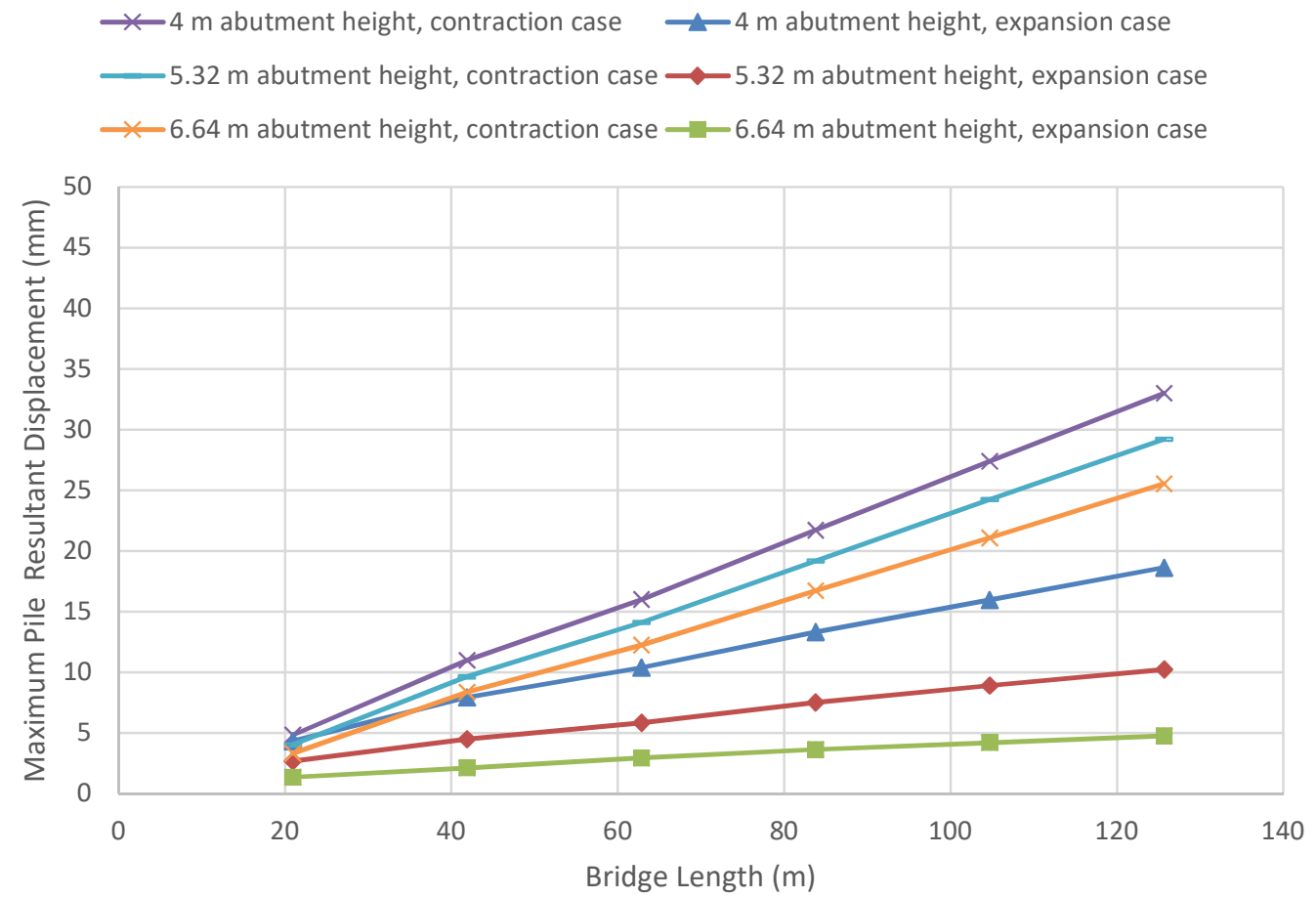

Figure 4.43 Pile Maximum Resultant Displacement for $60 \mathrm{~m}$ Radius Integral Bridge in Case of Dense Sand Behind the Abutment and Piles Embedded in Stiff Clay 


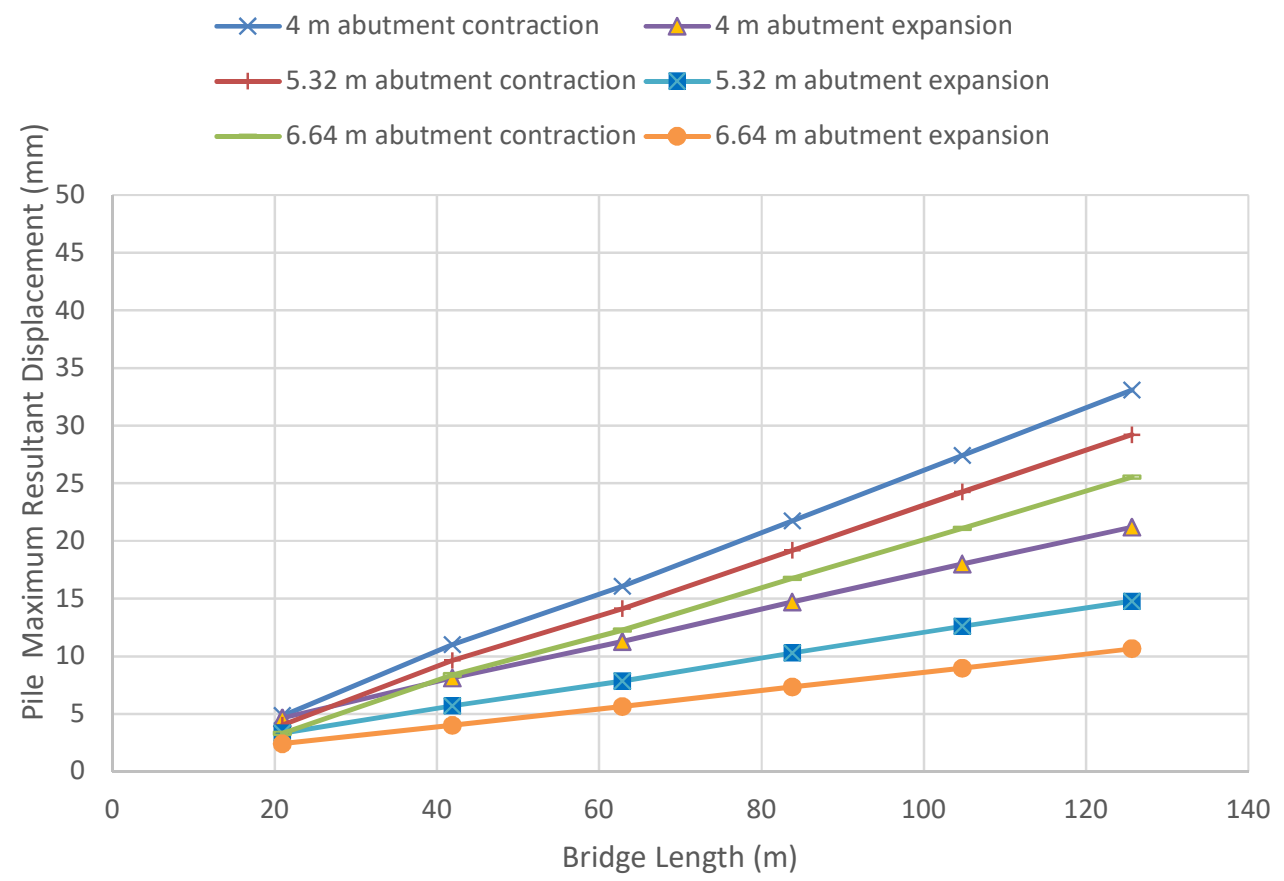

Figure 4.44 Pile Maximum Resultant Displacement for $60 \mathrm{~m}$ Radius Integral Bridge in Case of Loose Sand Behind the Abutment and Piles Embedded in Stiff Clay

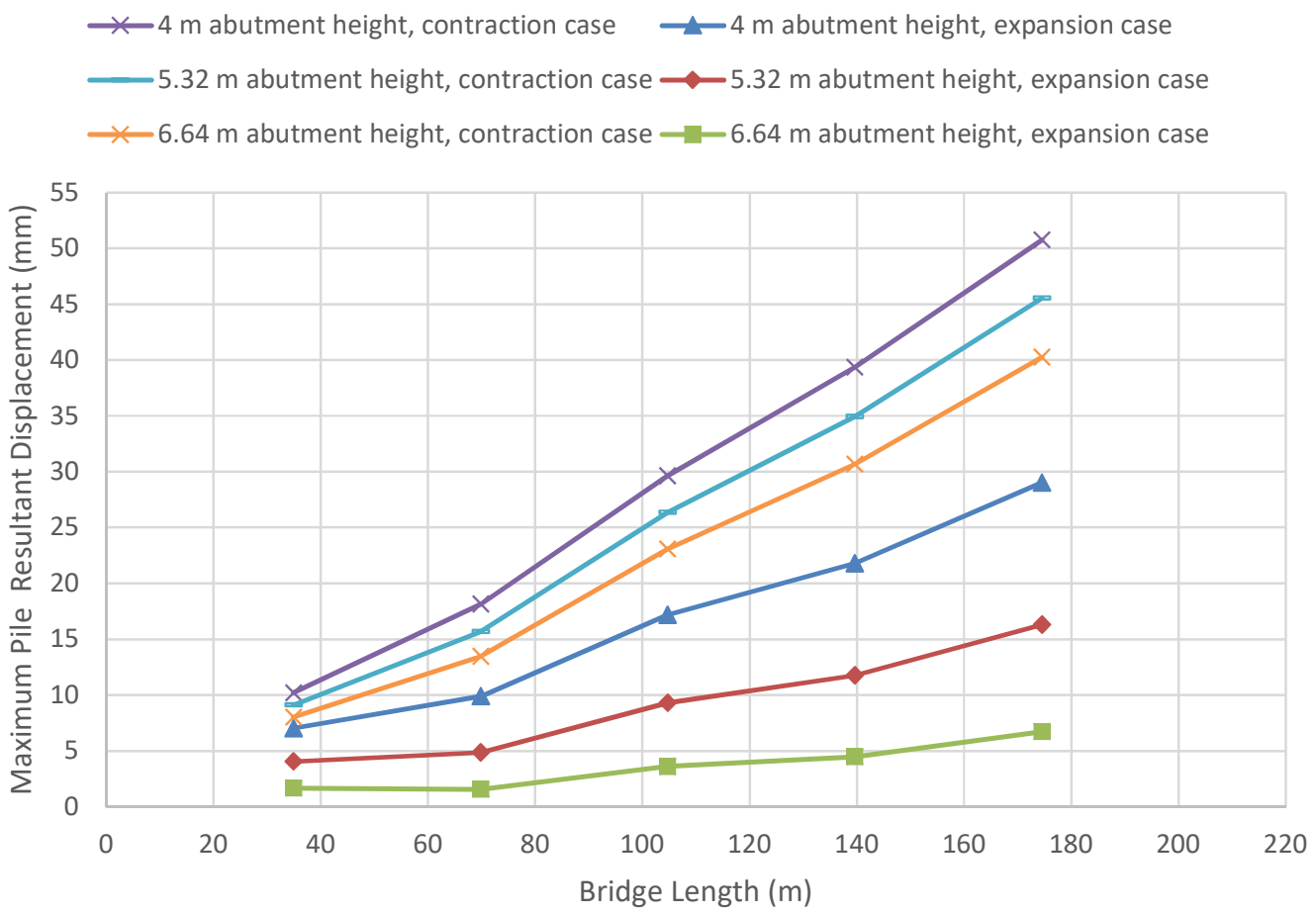

Figure 4.45 Pile Maximum Resultant Displacement for $100 \mathrm{~m}$ Radius Integral Bridge in Case of Dense Sand Behind the Abutment and Piles Embedded in Stiff Clay 
$\leftarrow 4 \mathrm{~m}$ abutment height, contraction case $\longrightarrow-4 \mathrm{~m}$ abutment height, expansion case

$5.32 \mathrm{~m}$ abutment height, contraction case $\_-5.32 \mathrm{~m}$ abutment height, expansion case

$\times 6.64 \mathrm{~m}$ abutment height, contraction case $-6.64 \mathrm{~m}$ abutment height, expansion case

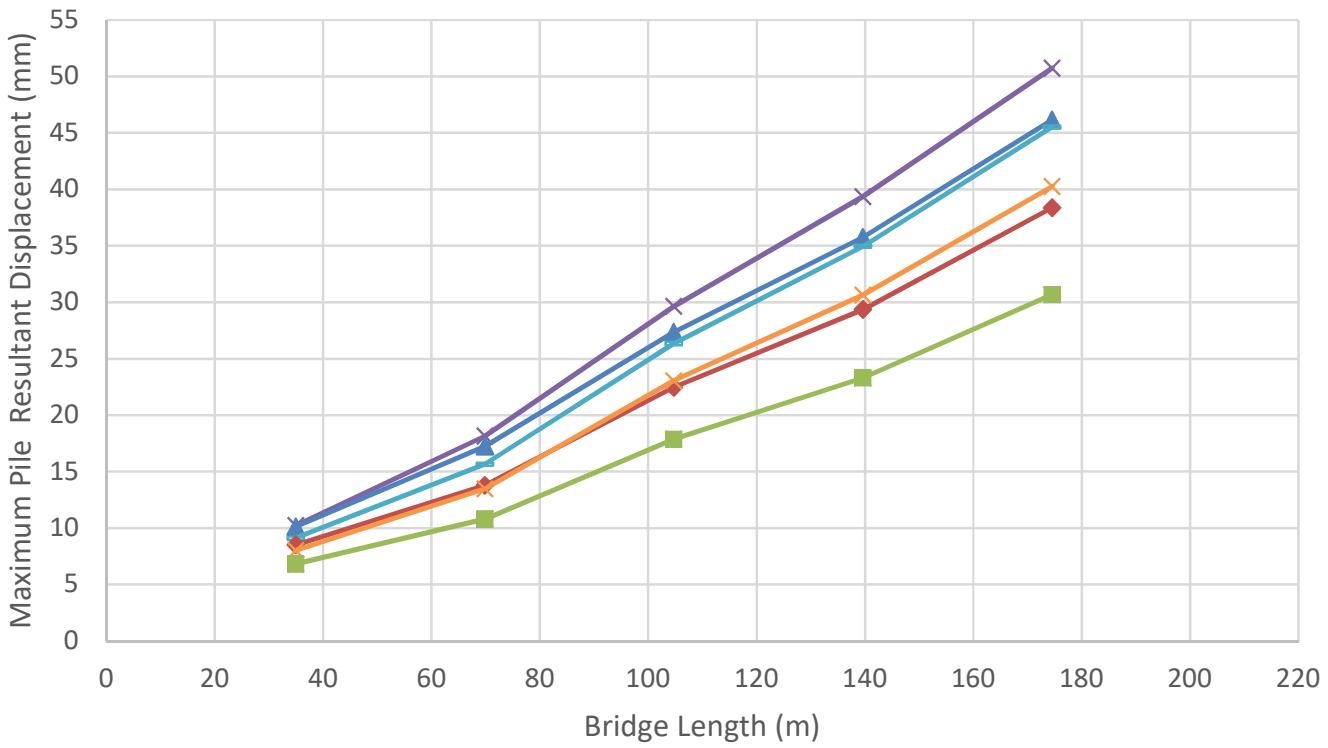

Figure 4.46 Pile Maximum Resultant Displacement for $100 \mathrm{~m}$ Radius Integral Bridge in Case of Loose Sand Behind the Abutment and Piles Embedded in Stiff Clay

$\leftarrow 4 \mathrm{~m}$ abutment height, contraction case $\quad \longrightarrow-4 \mathrm{~m}$ abutment height, expansion case

$-5.32 \mathrm{~m}$ abutment height, contraction case $\_-5.32 \mathrm{~m}$ abutment height, expansion case

$\times 6.64 \mathrm{~m}$ abutment height, contraction case $-6.64 \mathrm{~m}$ abutment height, expansion case

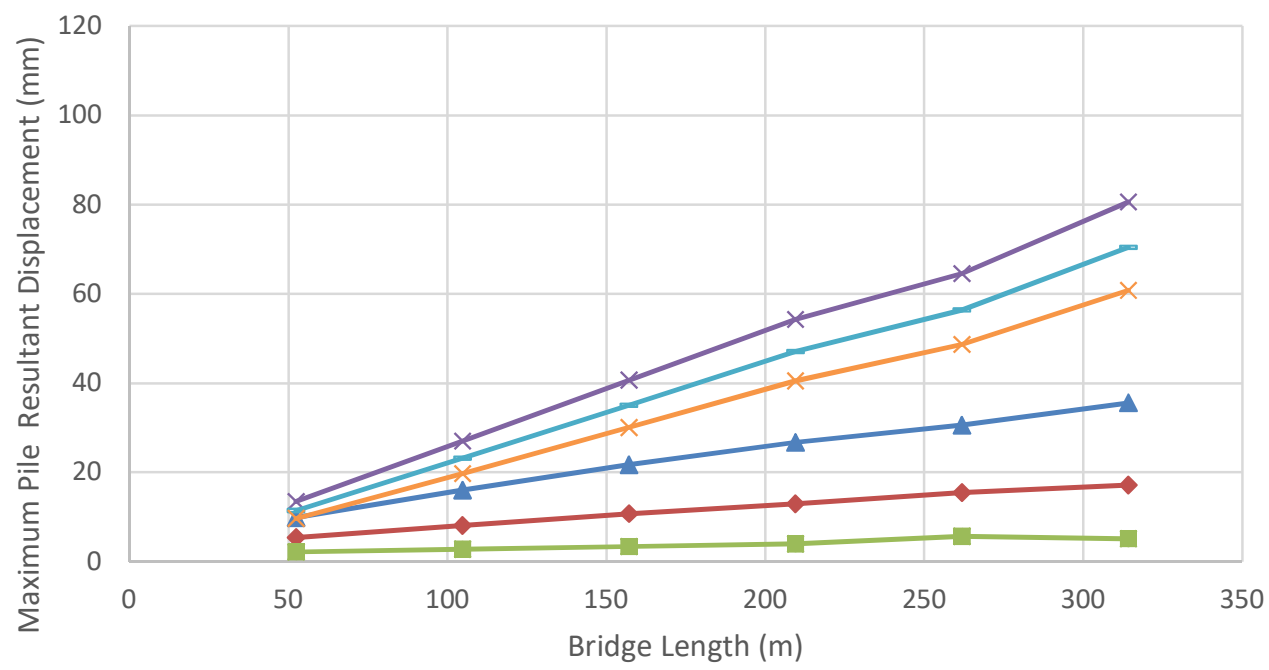

Figure 4.47 Pile Maximum Resultant Displacement for $150 \mathrm{~m}$ Radius Integral Bridge in Case of Dense Sand Behind the Abutment and Piles Embedded in Stiff Clay 
$\leftarrow 4 \mathrm{~m}$ abutment height, contraction case $\rightarrow-4 \mathrm{~m}$ abutment height, expansion case

$5.32 \mathrm{~m}$ abutment height, contraction case $\_5.32 \mathrm{~m}$ abutment height, expansion case

$\leftarrow 6.64 \mathrm{~m}$ abutment height, contraction case $-6.64 \mathrm{~m}$ abutment height, expansion case

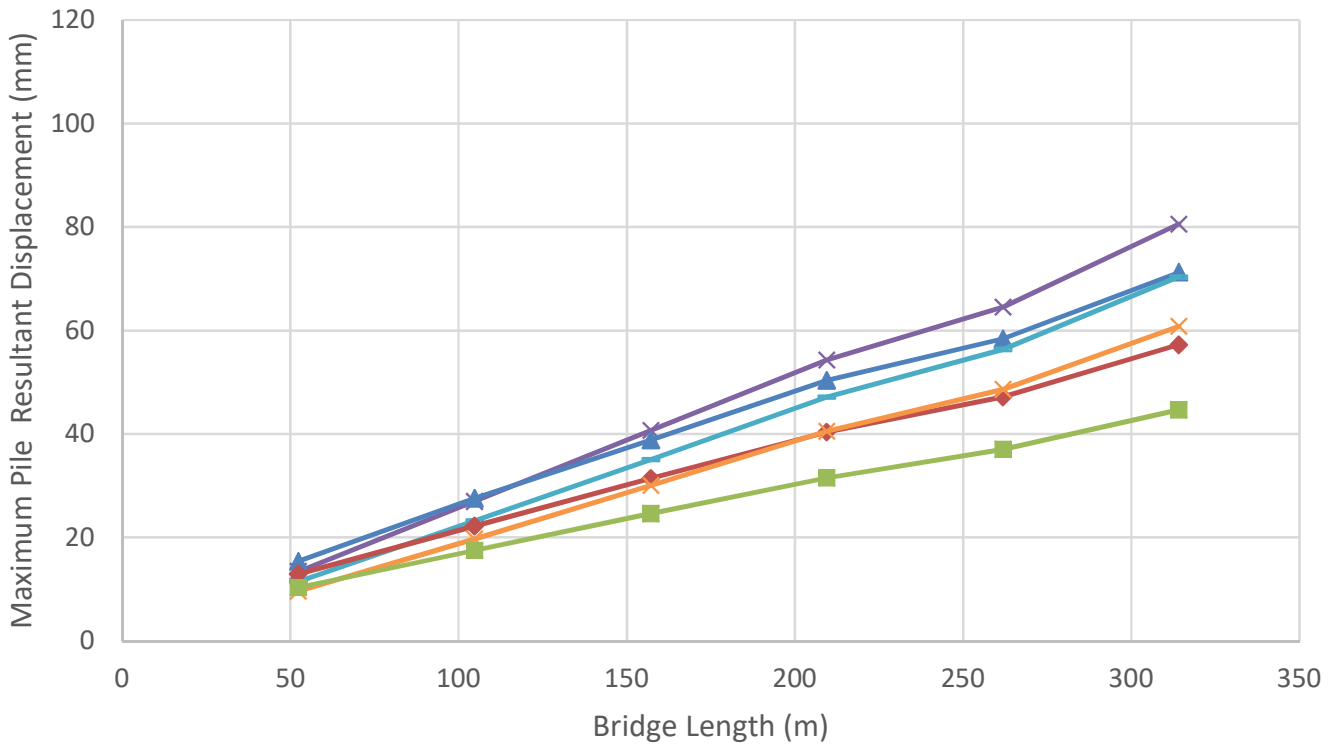

Figure 4.48 Pile Maximum Resultant Displacement for $\mathbf{1 5 0} \mathrm{m}$ Radius Integral Bridge in Case of Loose Sand Behind the Abutment and Piles Embedded in Stiff Clay

$\leftarrow 4 \mathrm{~m}$ abutment height, contraction case $\quad-4 \mathrm{~m}$ abutment height, expansion case

$5.32 \mathrm{~m}$ abutment height, contraction case $\longleftarrow 5.32 \mathrm{~m}$ abutment height, expansion case

$\leftarrow 6.64 \mathrm{~m}$ abutment height, contraction case $-6.64 \mathrm{~m}$ abutment height, expansion case

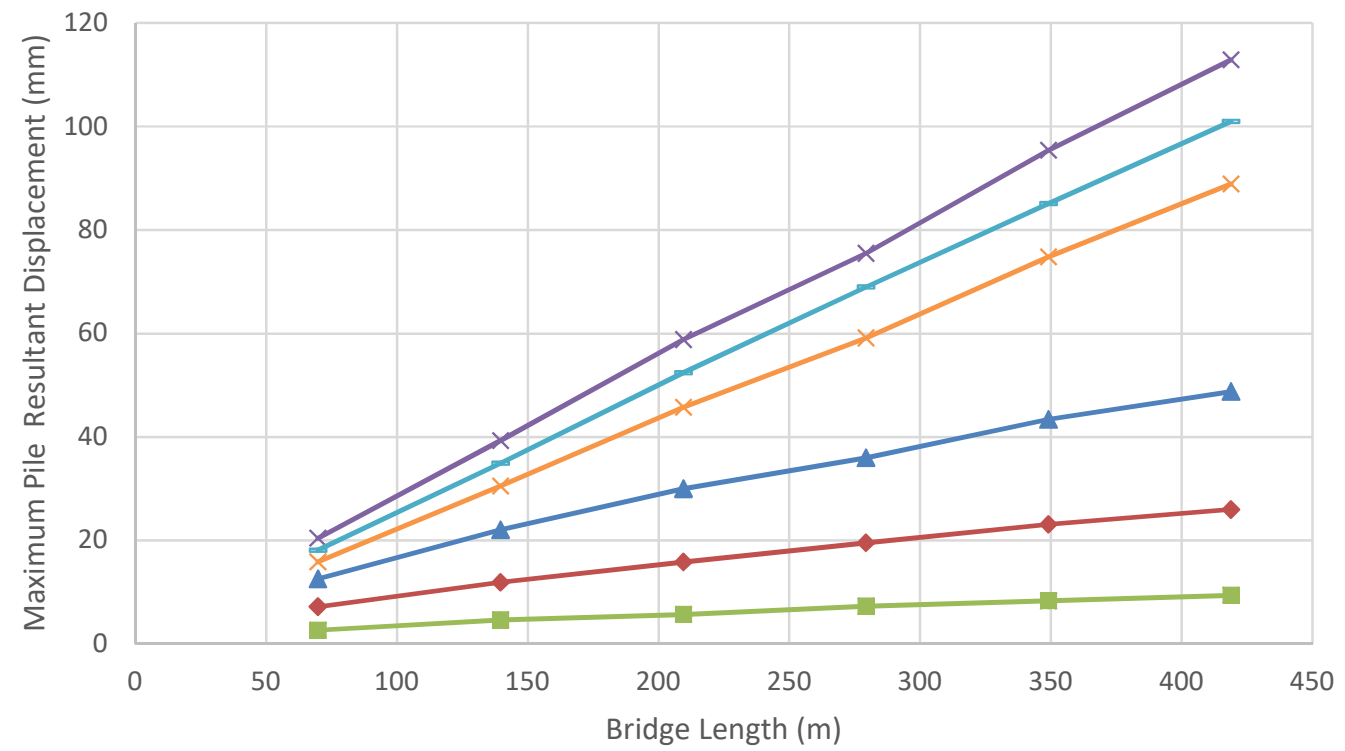

Figure 4.49 Pile Maximum Resultant Displacement for 200 m Radius Integral Bridge in Case of Dense Sand Behind the Abutment and Piles Embedded in Stiff Clay 
$\leftarrow 4 \mathrm{~m}$ abutment height, contraction case $\longrightarrow 4 \mathrm{~m}$ abutment height, expansion case

$5.32 \mathrm{~m}$ abutment height, contraction case $\_-5.32 \mathrm{~m}$ abutment height, expansion case

$\star 6.64 \mathrm{~m}$ abutment height, contraction case $\rightarrow-6.64 \mathrm{~m}$ abutment height, expansion case

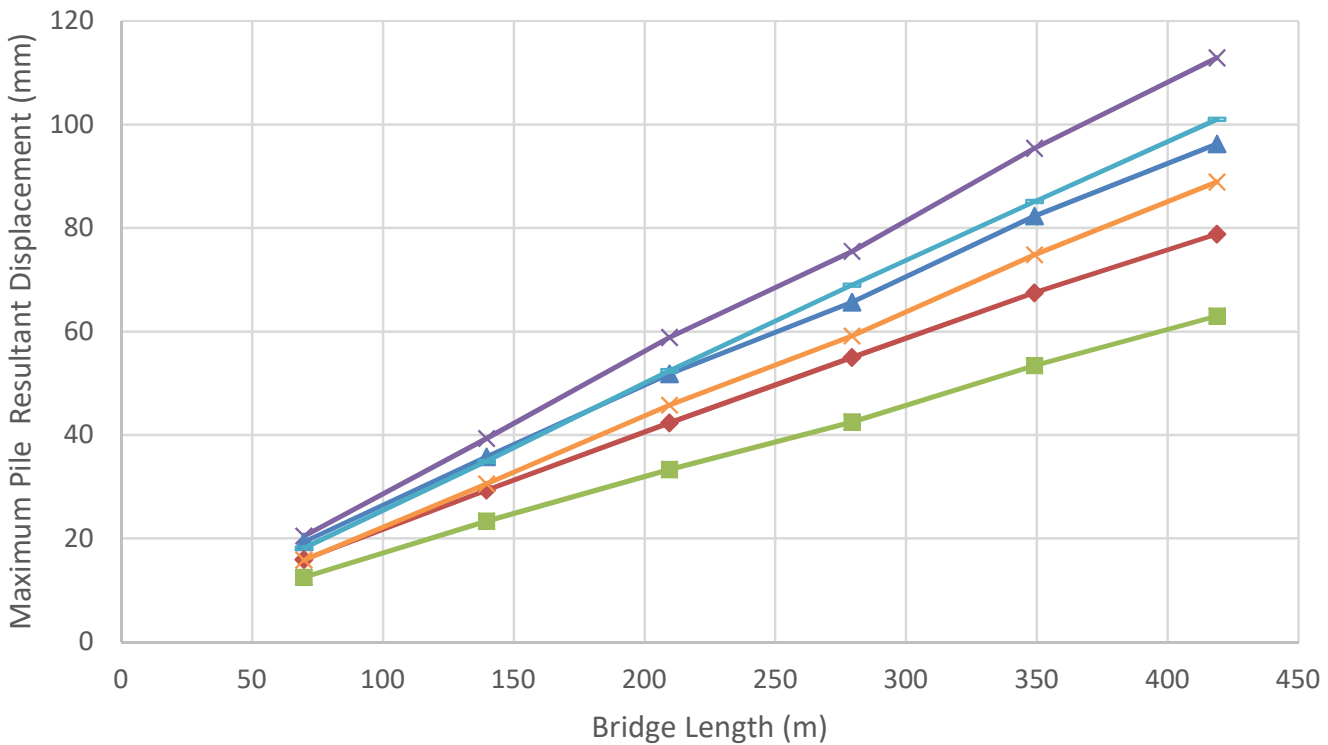

Figure 4.50 Pile Maximum Resultant Displacement for $\mathbf{2 0 0} \mathrm{m}$ Radius Integral Bridge in Case of Loose Sand Behind the Abutment and Piles Embedded in Stiff Clay

$* 4 \mathrm{~m}$ abutment height, contraction case $\rightarrow-4 \mathrm{~m}$ abutment height, expansion case

$5.32 \mathrm{~m}$ abutment height, contraction case $\_5.32 \mathrm{~m}$ abutment height, expansion case

$\rightarrow 66.64 \mathrm{~m}$ abutment height, contraction case $-6.64 \mathrm{~m}$ abutment height, expansion case

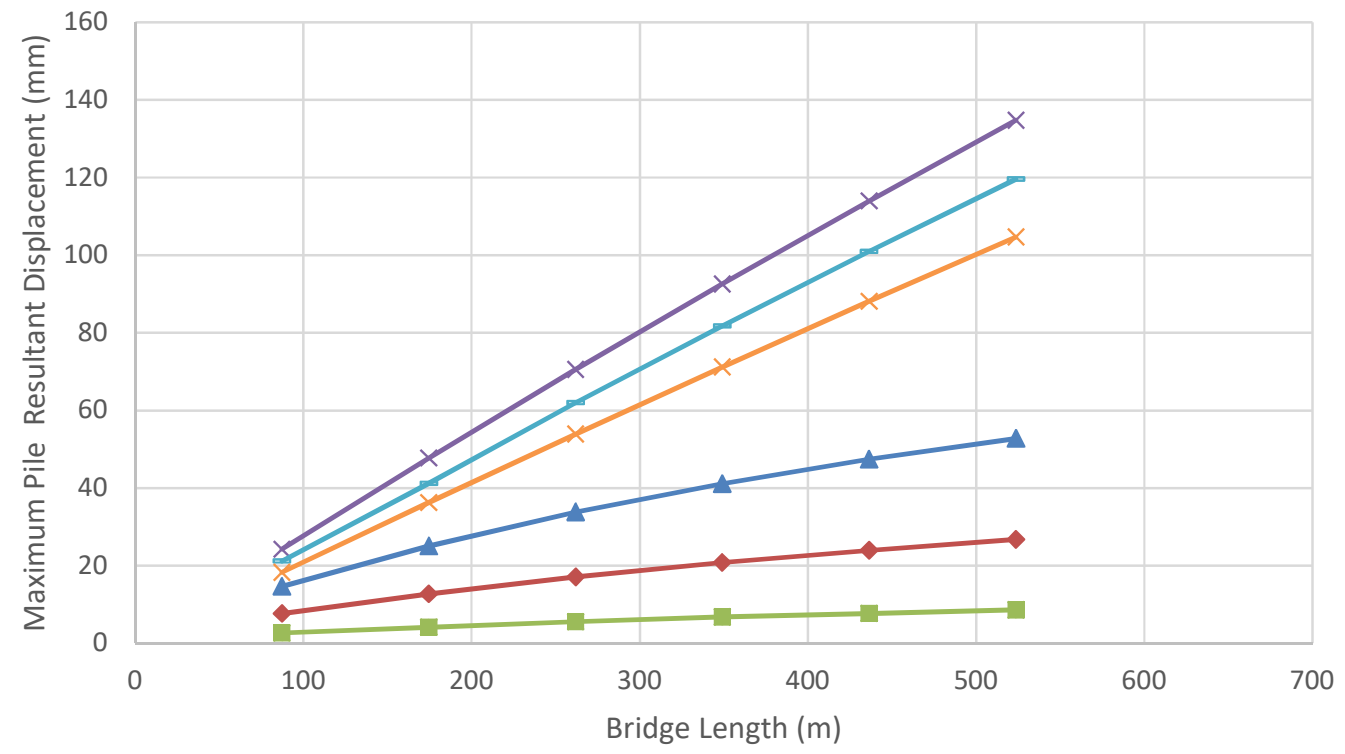

Figure 4.51 Pile Maximum Resultant Displacement for $\mathbf{2 5 0} \mathrm{m}$ Radius Integral Bridge in Case of Dense Sand Behind the Abutment and Piles Embedded in Stiff Clay 
$\leftarrow 4 \mathrm{~m}$ abutment height, contraction case $\quad-4 \mathrm{~m}$ abutment height, expansion case

$5.32 \mathrm{~m}$ abutment height, contraction case $\_-5.32 \mathrm{~m}$ abutment height, expansion case

$\leftarrow 6.64 \mathrm{~m}$ abutment height, contraction case $\rightarrow-6.64 \mathrm{~m}$ abutment height, expansion case

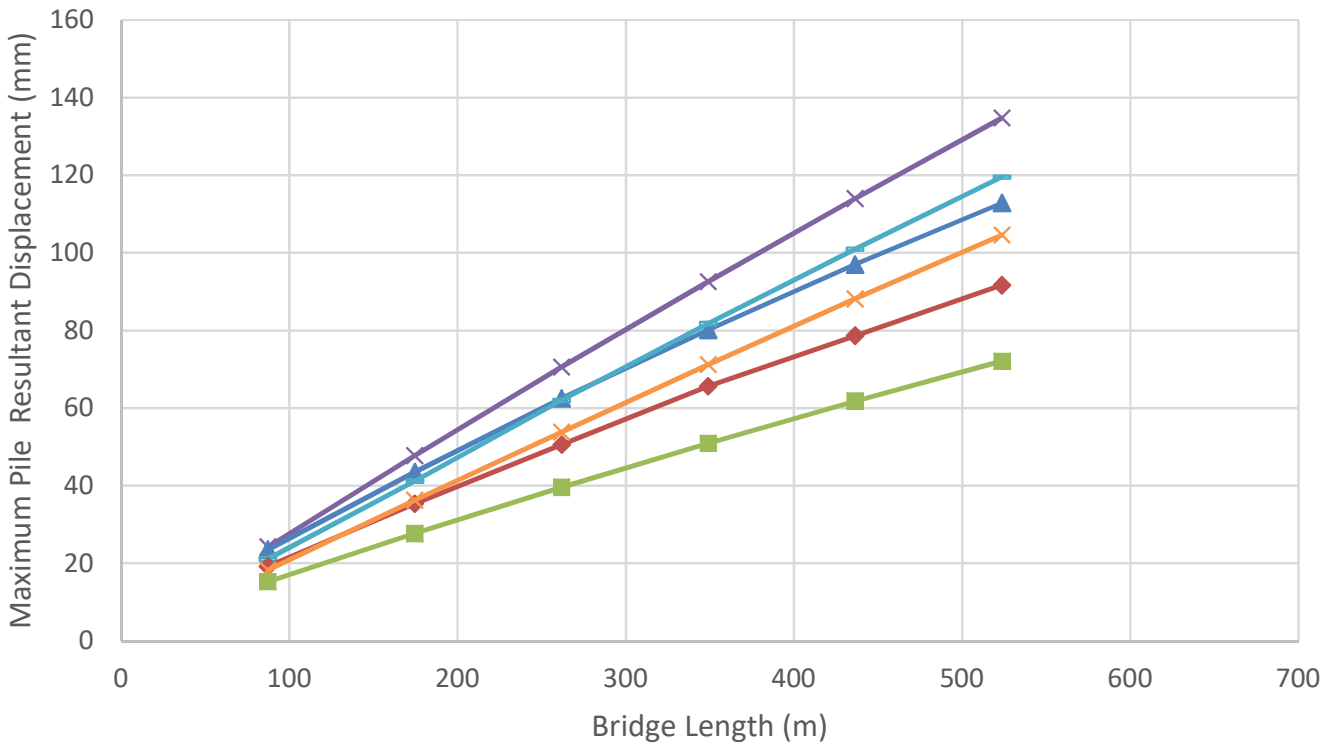

Figure 4.52 Pile Maximum Resultant Displacement for $\mathbf{2 5 0} \mathrm{m}$ Radius Integral Bridge in Case of Loose Sand Behind the Abutment and Piles Embedded in Stiff Clay

$* 4 \mathrm{~m}$ abutment height, contraction case $\rightarrow-4 \mathrm{~m}$ abutment height, expansion case

$5.32 \mathrm{~m}$ abutment height, contraction case $\_5.32 \mathrm{~m}$ abutment height, expansion case

$\rightarrow 66.64 \mathrm{~m}$ abutment height, contraction case $-6.64 \mathrm{~m}$ abutment height, expansion case

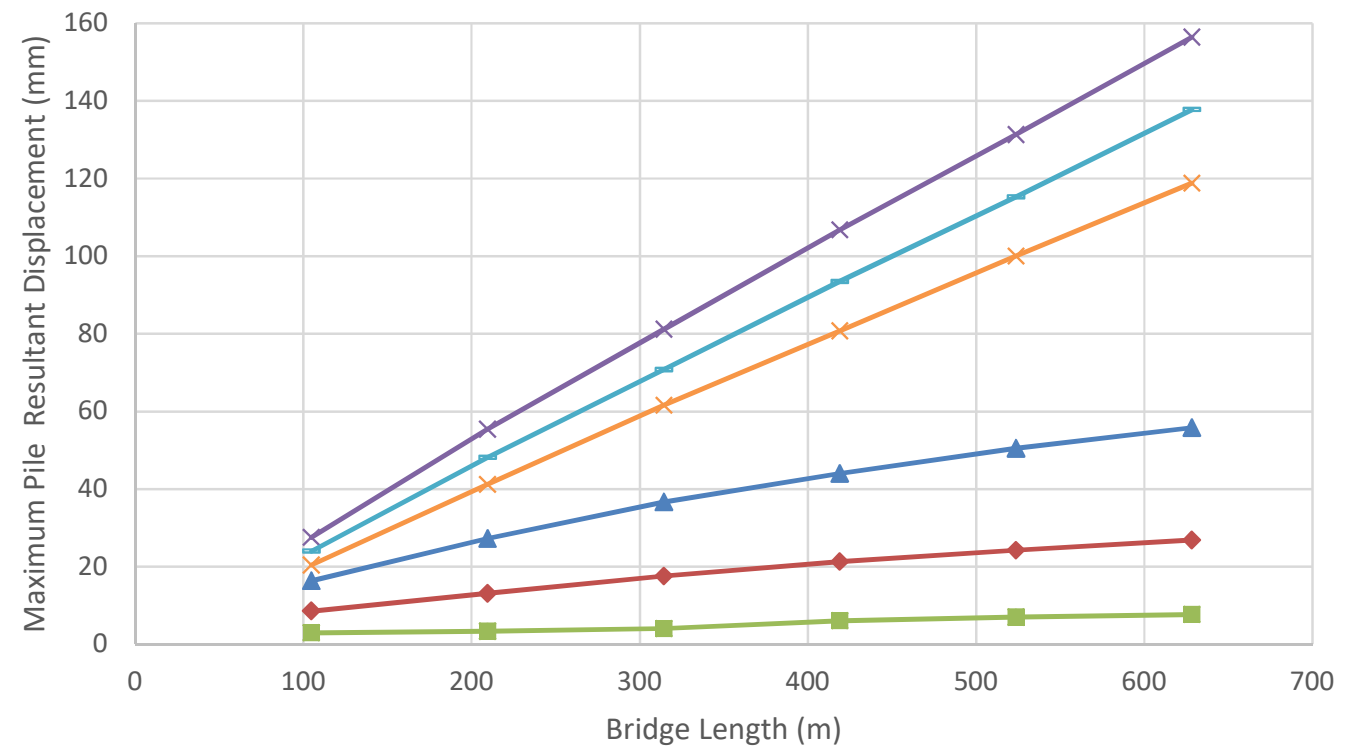

Figure 4.53 Pile Maximum Resultant Displacement for $\mathbf{3 0 0} \mathrm{m}$ Radius Integral Bridge in Case of Dense Sand Behind the Abutment and Piles Embedded in Stiff Clay 
$\leftarrow 4 \mathrm{~m}$ abutment height, contraction case $\longrightarrow-4 \mathrm{~m}$ abutment height, expansion case

$5.32 \mathrm{~m}$ abutment height, contraction case $\_5.32 \mathrm{~m}$ abutment height, expansion case

$\leftarrow 6.64 \mathrm{~m}$ abutment height, contraction case $\longrightarrow-6.64 \mathrm{~m}$ abutment height, expansion case

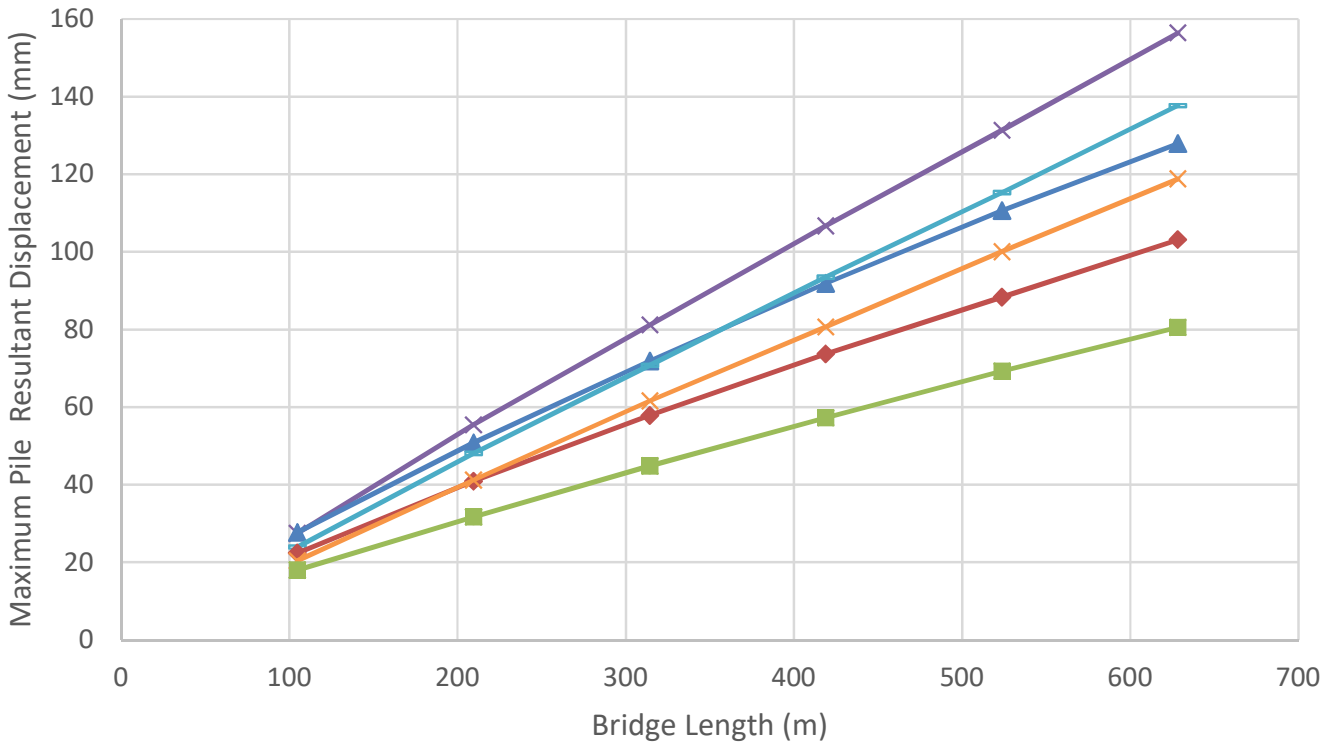

Figure 4.54 Pile Maximum Resultant Displacement for $\mathbf{3 0 0} \mathrm{m}$ Radius Integral Bridge in case of Loose Sand Behind the Abutment and Piles Embedded in Stiff Clay 
Table 4.9 (PMRD) contraction / (PMRD) expansion Ratios

\begin{tabular}{|c|c|c|c|c|}
\hline \multirow{2}{*}{$\begin{array}{l}\text { Radius of } \\
\text { Curvature }\end{array}$} & \multirow{2}{*}{$\begin{array}{l}\text { Condition of } \\
\text { Backfill Soil }\end{array}$} & \multirow{2}{*}{$\begin{array}{c}\text { Condition of } \\
\text { Foundation Soil }\end{array}$} & \multicolumn{2}{|c|}{$\mathbf{n}=(\mathbf{P M R D})_{\text {contraction }} /(\mathbf{P M R D})_{\text {expansion }}$} \\
\hline & & & $\mathrm{H}=\mathbf{4 . 0 \mathrm { m }}$ & $H=6.64 \mathrm{~m}$ \\
\hline 60 & Dense Sand & Stiff Clay & 1.60 & 4.25 \\
\hline 60 & Loose Sand & Stiff Clay & 1.37 & 2.11 \\
\hline 100 & Dense Sand & Stiff Clay & 1.70 & 6.54 \\
\hline 100 & Loose Sand & Stiff Clay & 1.06 & 1.26 \\
\hline 150 & Dense Sand & Stiff Clay & 1.88 & 8.52 \\
\hline 150 & Loose Sand & Stiff Clay & 1.03 & 1.20 \\
\hline 200 & Dense Sand & Stiff Clay & 2.00 & 7.87 \\
\hline 200 & Loose Sand & Stiff Clay & 1.12 & 1.35 \\
\hline 250 & Dense Sand & Stiff Clay & 2.14 & 9.93 \\
\hline 250 & Loose Sand & Stiff Clay & 1.13 & 1.35 \\
\hline 300 & Dense Sand & Stiff Clay & 2.29 & 12.93 \\
\hline 300 & Loose Sand & Stiff Clay & 1.13 & 1.35 \\
\hline
\end{tabular}

Table 4.10 Mean Values of $n$

\begin{tabular}{|c|c|c|c|}
\hline $\begin{array}{c}\text { Condition of } \\
\text { Backfill Soil }\end{array}$ & $\begin{array}{c}\text { Abutment Height (H) } \\
(\mathbf{m})\end{array}$ & Mean n-Value & Standard Deviation \\
\hline \multirow{2}{*}{ Loose Sand } & 4.00 & 1.14 & \pm 0.12 \\
\cline { 2 - 4 } & 6.64 & 1.43 & \pm 0.33 \\
\hline \multirow{2}{*}{ Dense Sand } & 4.00 & 1.94 & \pm 0.26 \\
\cline { 2 - 4 } & \multirow{2}{*}{6.64} & 8.34 & \pm 2.96 \\
\hline
\end{tabular}

As it can be shown from Tables 4.9 and 4.10, loose sand backfill supporting the bridge abutment provides less restraint of bridge superstructure during expansion compared by 
dense sand. Thus, there is no much difference between PMRD in case of contraction and expansion phase. Therefore, the value of $\mathrm{n}$ shall be smaller than in case of dense sand.

Since the ratio $\mathrm{n}$ is always more than 1 , the rotation stiffness of bridge abutment in case of bridge expansions is bigger than that in case of bridge contraction, the magnitude of $n$ increased with the increase of abutment height. For instance, in case of bridge abutment height of $4.0 \mathrm{~m}$, and loose sand backfill, the value of $\mathrm{n}$ equals to 1.375 , while $\mathrm{n}$ equals to 2.11 when the abutment height increased to $6.64 \mathrm{~m}$ as shown in Table 4.9 for a bridge of $60 \mathrm{~m}$ radius and stiff clay as foundation soil.

In case of dense sand backfill supporting the bridge abutment, the PMRD due to bridge expansion decreased compared with that in case of loose sand backfill. So, it is expected that $\mathrm{n}$ to increase as shown in Table 4.10. The scatter in magnitudes of $\mathrm{n}$ in case of bridge abutment of $6.64 \mathrm{~m}$ height can be attributed to the influence of bridge span. Furthermore, during bridge contraction phase, the direction of displacement due to self-weight of the bridge and the displacement of thermal contraction are the same. Therefore, these horizontal displacements are added together to create the total displacement of the abutment piles. During thermal expansion, the direction of displacement due to thermal expansion is opposite to the direction of displacement due to self-weight of the bridge. Therefore, these horizontal displacements are subtracted to create the total displacement of the abutment piles. Therefore, bridge span length has influence on the magnitude of $n$.

\subsubsection{Substructure Piles Embedded in Medium Dense Sand}

Based on bridge data in Table 3.1, Figures 4.55 through 4.66 describe the behavior of abutment piles of integral abutment bridges having different Radii while the piles are imbedded in medium dense sand. The bridge superstructure is under the effect of thermal contraction loading in addition to its own weight. It is clear from the figures that the pile maximum resultant displacement (PMRD) is directly proportional to the bridge length (L). As the bridge length increases, the pile maximum resultant displacement increases. Also, the figures show the effect of increasing abutment height on reducing pile maximum resultant displacement. For instance, when the abutment height increased from 4 to $6.64 \mathrm{~m}$, the pile maximum resultant displacement decreased from $32 \mathrm{~mm}$ to $25 \mathrm{~mm}$ for the same bridge configuration and soil condition. For each bridge radius, two soil conditions behind the 
abutment were considered, namely: dense and loose sand backfill. In the case of contraction, the state of sand behind the abutment has no effect on the pile maximum resultant displacement.

As described above, the average ratio of PMRD in the condition of the contraction of the bridge deck to that in case of bridge deck expansion was calculated at different bridge abutment height $(H)$ and different radii of curvature $(R)$ as shown in Table 4.11 in terms of $n$ values. The contraction of the bridge deck is independent of soil conditions supporting the bridge abutment, since the active earth pressure was neglected in finite element model. Therefore, the magnitudes of (PMRD) contraction are the same in case of dense and loose sand. On the other hand, the magnitudes of (PMRD) expansion in case of dense sand are less than that in case of loose sand. As a result of this finding, the values of the ratio $(n)$ increased with the increase of the backfill soil stiffness as shown in Table 4.11.

The average value of ( $n$ ) in case of dense sand is 2.54 , while it is 1.58 in case of loose sand, for bridge abutment of height of $4.0 \mathrm{~m}$. In case of abutment height of $6.64 \mathrm{~m}$, the $\mathrm{n}$ values are 2.45 and 7.59 in case of loose and dense sand, respectively, for abutment height of $6.64 \mathrm{~m}$.

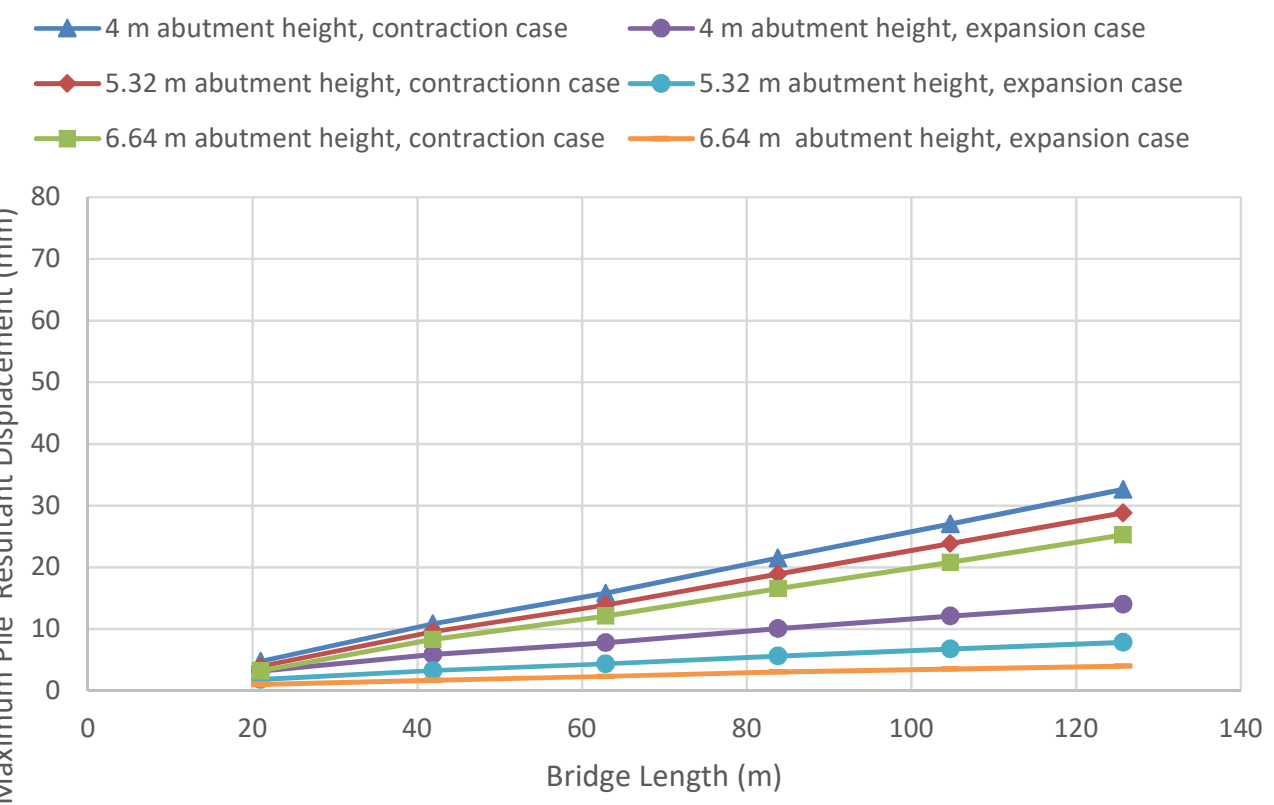

Figure 4.55 Pile Maximum Resultant Displacement for $60 \mathrm{~m}$ Radius Integral Bridge in Case of Dense Sand behind the Abutment and Piles Embedded in Medium Dense Sand 


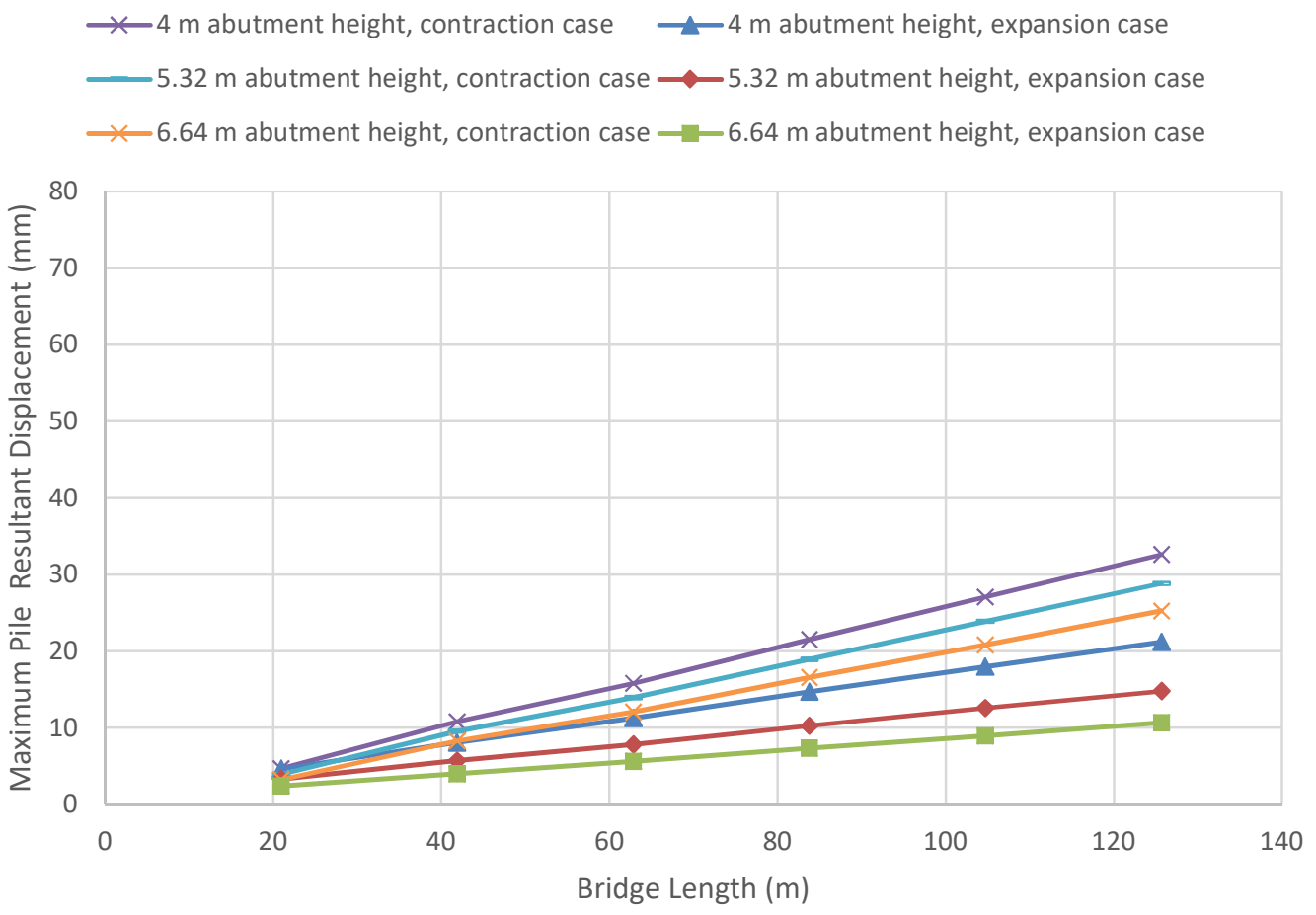

Figure 4.56 Pile Maximum Resultant Displacement for $60 \mathrm{~m}$ Radius Integral Bridge in Case of Loose Sand Behind the Abutment and Piles Embedded in Medium Dense Sand

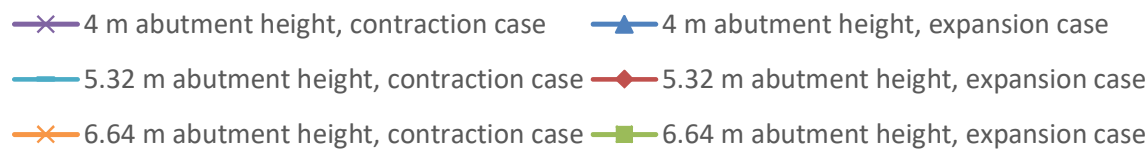

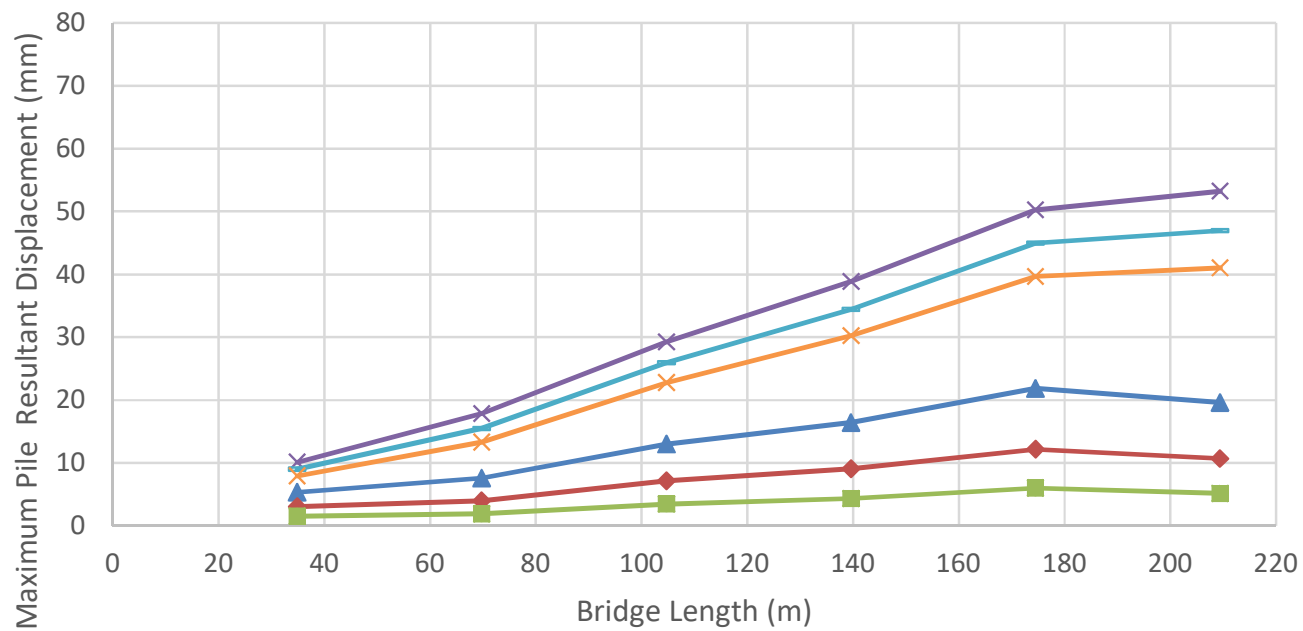

Figure 4.57 Pile Maximum Resultant Displacement for 100 m Radius Integral Bridge in Case of Dense Sand Behind the Abutment and Piles Embedded in Medium Dense Sand 
$\leftarrow 4 \mathrm{~m}$ abutment height, contraction case $\longrightarrow-4 \mathrm{~m}$ abutment height, expansion case

$5.32 \mathrm{~m}$ abutment height, contraction case $\_-5.32 \mathrm{~m}$ abutment height, expansion case

$\leftarrow 6.64 \mathrm{~m}$ abutment height, contraction case $\rightarrow-6.64 \mathrm{~m}$ abutment height, expansion case

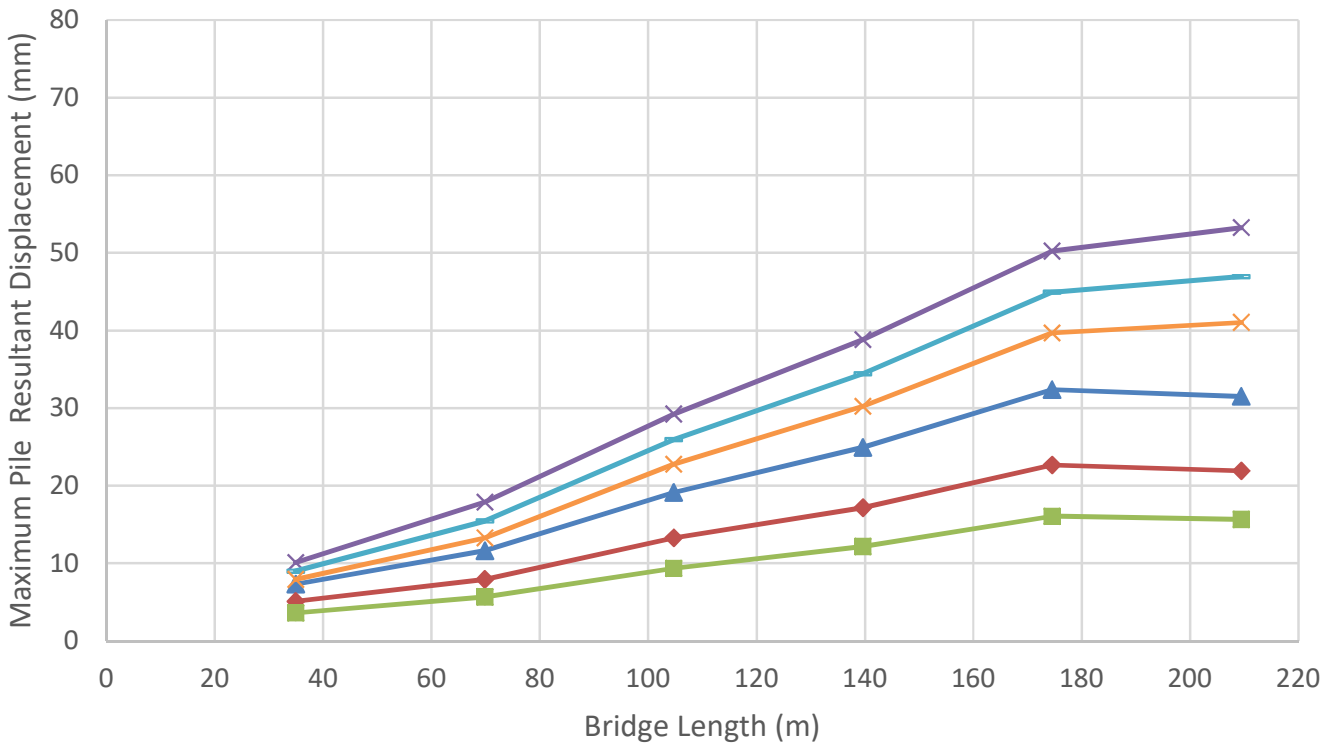

Figure 4.58 Pile Maximum Resultant Displacement for $\mathbf{1 0 0} \mathrm{m}$ Radius Integral Bridge in Case of Loose Sand Behind the Abutment and Piles Embedded in Medium Dense Sand

* $4 \mathrm{~m}$ abutment height, contraction case $\quad-4 \mathrm{~m}$ abutment height, expansion case

$\longrightarrow 5.32 \mathrm{~m}$ abutment height, contraction case - -5.32 $\mathrm{m}$ abutment height, expansion case

-6.64 m abutment height, contraction case $-6.64 \mathrm{~m}$ abutment height, expansion case

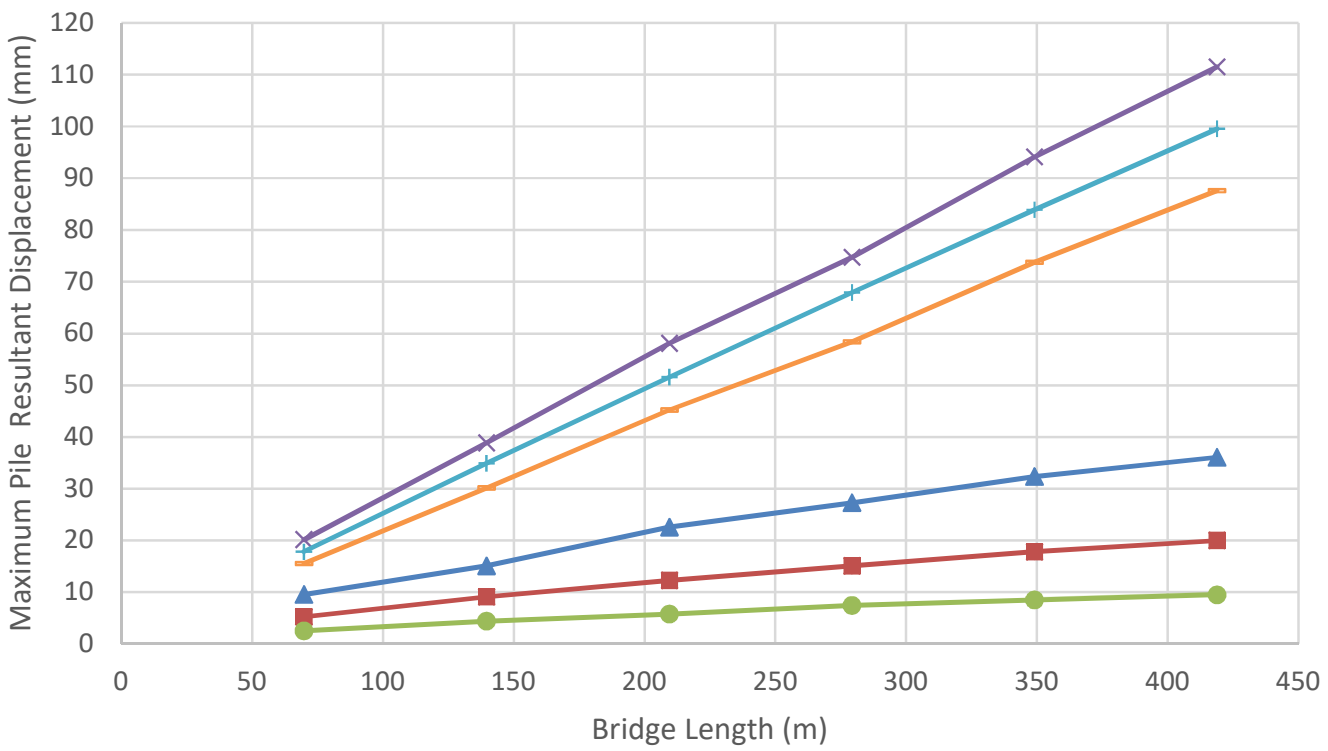

Figure 4.59 Pile Maximum Resultant Displacement for $\mathbf{2 0 0}$ m Radius Integral Bridge in Case of Dense Sand Behind the Abutment and Piles Embedded in Medium Dense Sand 
$\leftarrow 4 \mathrm{~m}$ abutment height, contraction case $\longrightarrow 4 \mathrm{~m}$ abutment height, expansion case

$5.32 \mathrm{~m}$ abutment height, contraction case $\_5.32 \mathrm{~m}$ abutment height, expansion case

$\leftarrow 6.64 \mathrm{~m}$ abutment height, contraction case $\rightarrow-6.64 \mathrm{~m}$ abutment height, expansion case

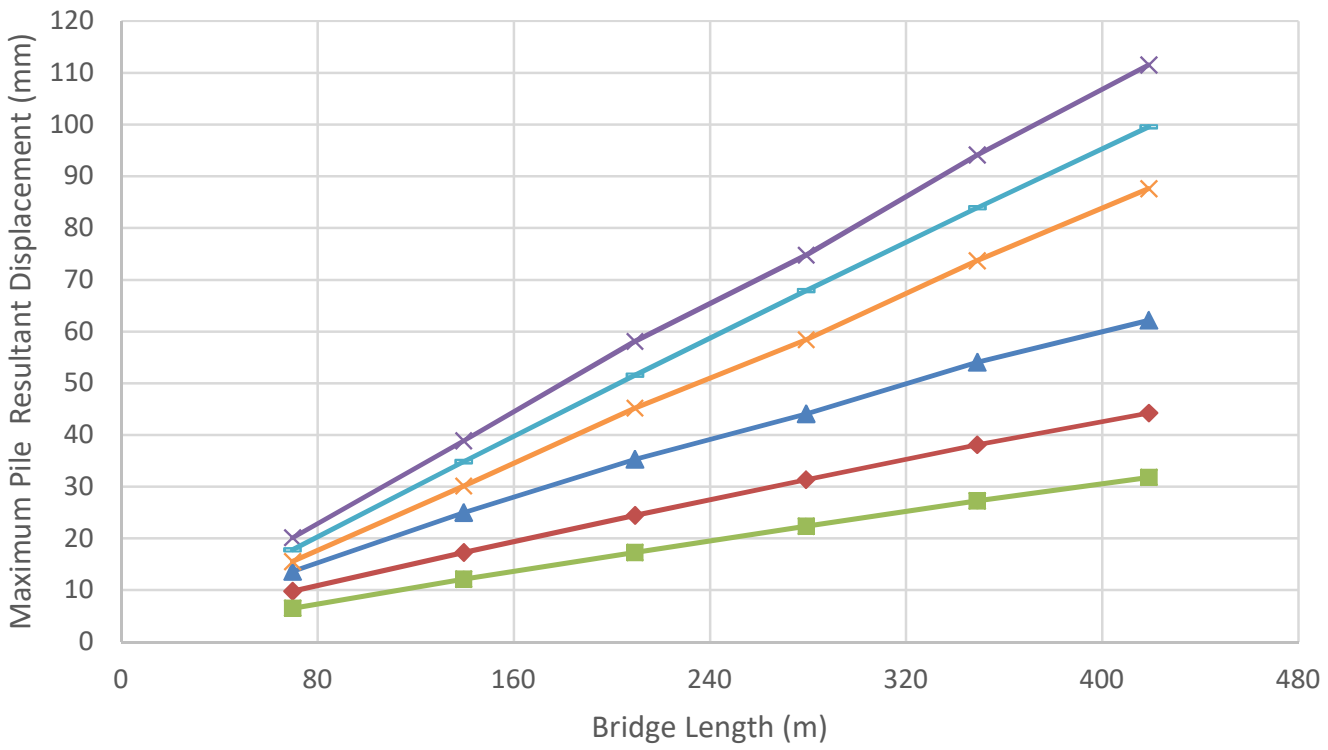

Figure 4.60 Pile Maximum Resultant Displacement for $\mathbf{2 0 0} \mathrm{m}$ Radius Integral Bridge in Case of Loose Sand Behind the Abutment and Piles Embedded in Medium Dense Sand

$\leftarrow 4 \mathrm{~m}$ abutment height, contraction case $\_4 \mathrm{~m}$ abutment height, expansion case

$-5.32 \mathrm{~m}$ abutment height, contraction case $\multimap 5.32 \mathrm{~m}$ abutment height, expansion case

$\leftarrow 6.64 \mathrm{~m}$ abutment height, contraction case $-6.64 \mathrm{~m}$ abutment height, expansion case

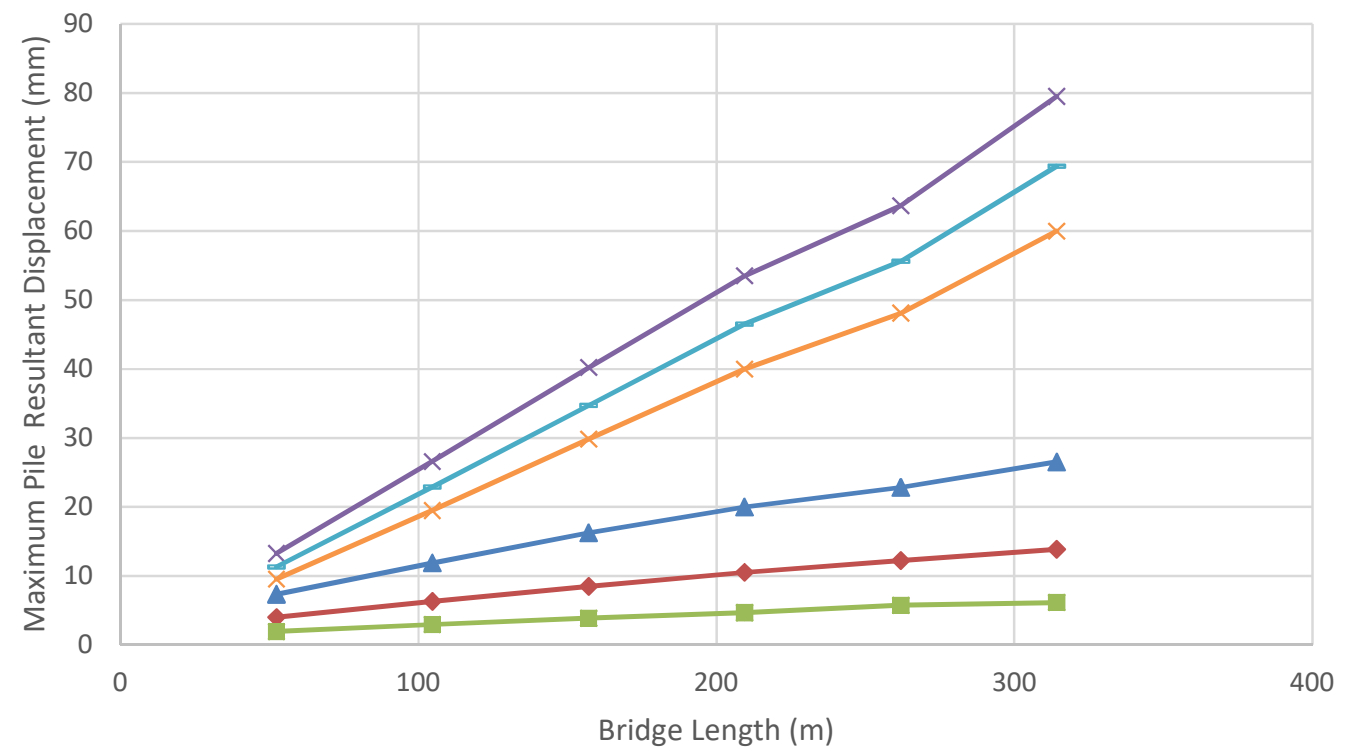

Figure 4.61 Pile Maximum Resultant Displacement for $150 \mathrm{~m}$ Radius Integral Bridge in case of Dense Sand Behind the Abutment and Piles Embedded in Medium Dense Sand 
$\leftarrow 4 \mathrm{~m}$ abutment height, contraction case $\longrightarrow 4 \mathrm{~m}$ abutment height, expansion case

$5.32 \mathrm{~m}$ abutment height, contraction case $\_5.32 \mathrm{~m}$ abutment height, expansion case

$\leftarrow 6.64 \mathrm{~m}$ abutment height, contraction case $\rightarrow-6.64 \mathrm{~m}$ abutment height, expansion case

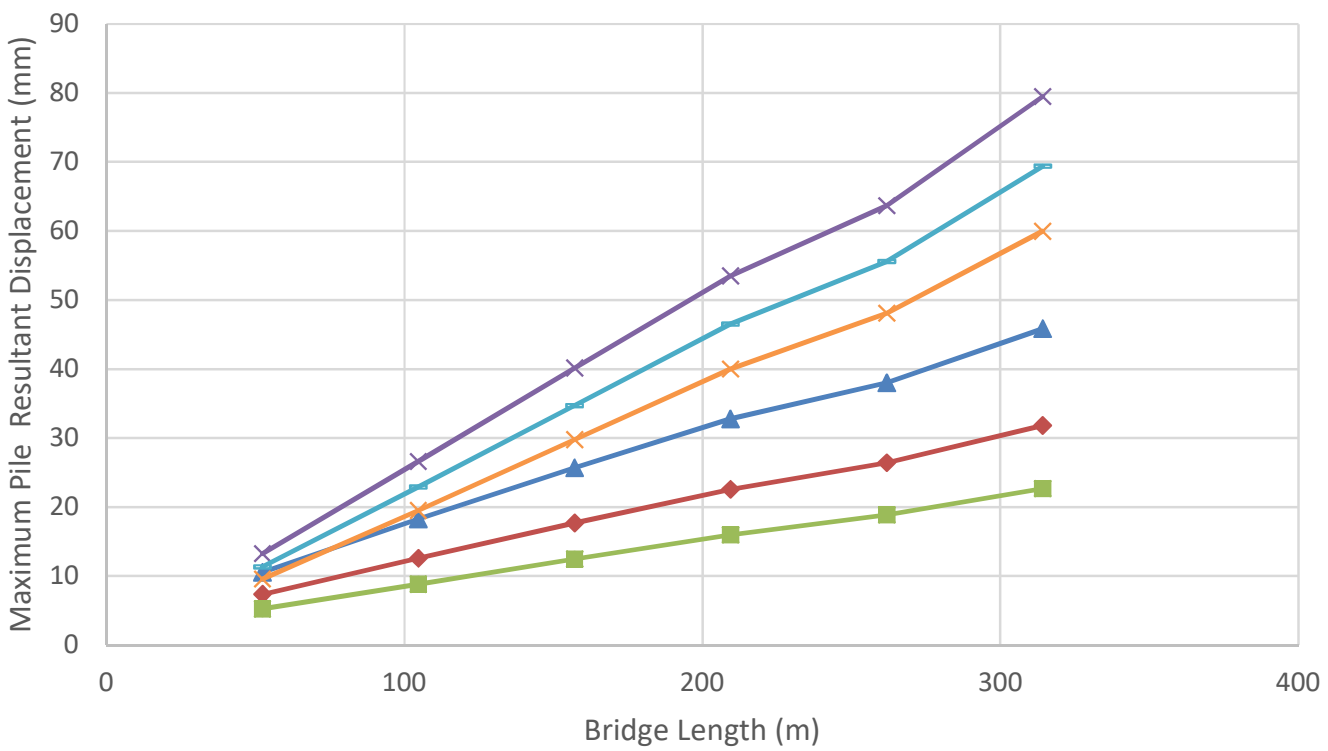

Figure 4.62 Pile Maximum Resultant Displacement for $\mathbf{1 5 0} \mathrm{m}$ Radius Integral Bridge in Case of Loose Sand Behind the Abutment and Piles Embedded in Medium Dense Sand

$\leftarrow 4 \mathrm{~m}$ abutment height, contraction case $\quad-4 \mathrm{~m}$ abutment height, expansion case

$\longrightarrow 5.32 \mathrm{~m}$ abutment height, contraction case $\longleftarrow-5.32 \mathrm{~m}$ abutment height, expansion case

$6.64 \mathrm{~m}$ abutment height, contraction case $-6.64 \mathrm{~m}$ abutment height, expansion case

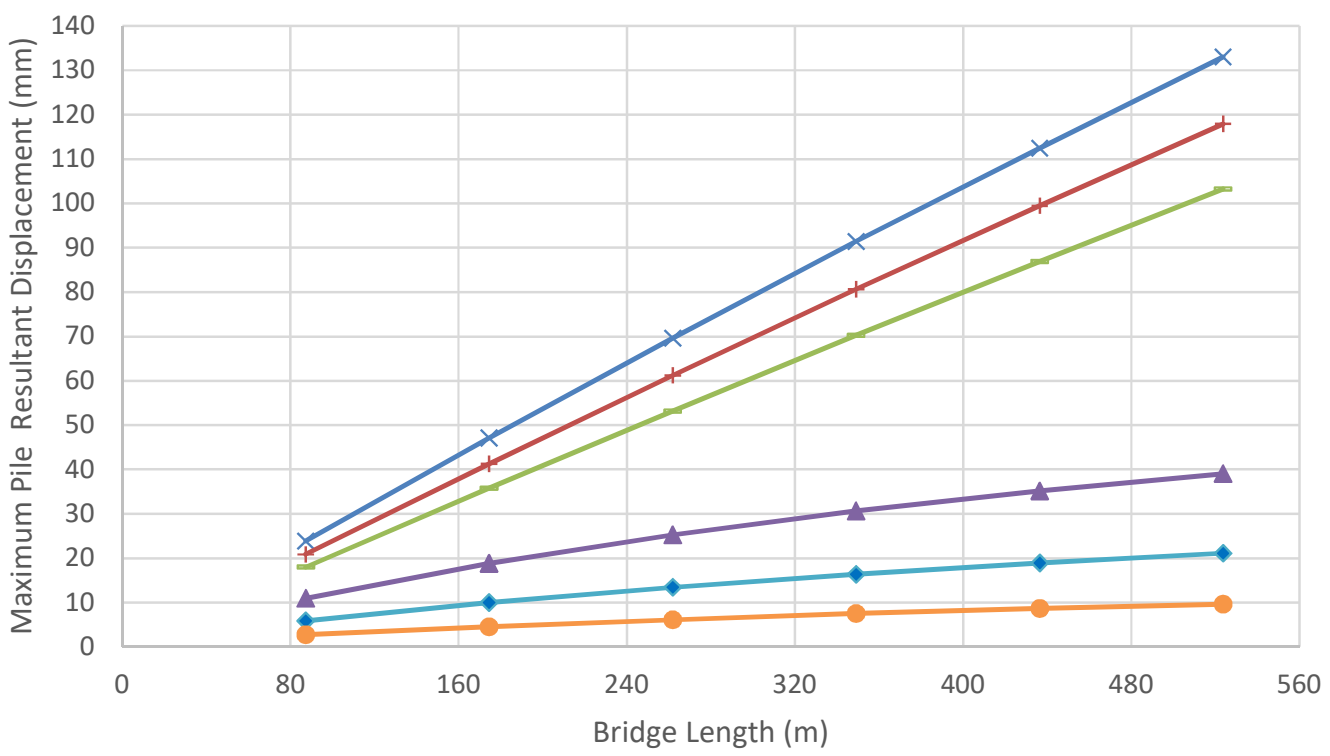

Figure 4.63 Pile Maximum Resultant Displacement for $250 \mathrm{~m}$ Radius Integral Bridge in Case of Dense Sand Behind the Abutment and Piles Embedded in Medium Dense Sand 
$\leftarrow 4 \mathrm{~m}$ abutment height, contraction case $\longrightarrow-4 \mathrm{~m}$ abutment height, expansion case

$5.32 \mathrm{~m}$ abutment height, contraction case $\_5.32 \mathrm{~m}$ abutment height, expansion case

$\times 6.64 \mathrm{~m}$ abutment height, contraction case $-6.64 \mathrm{~m}$ abutment height, expansion case

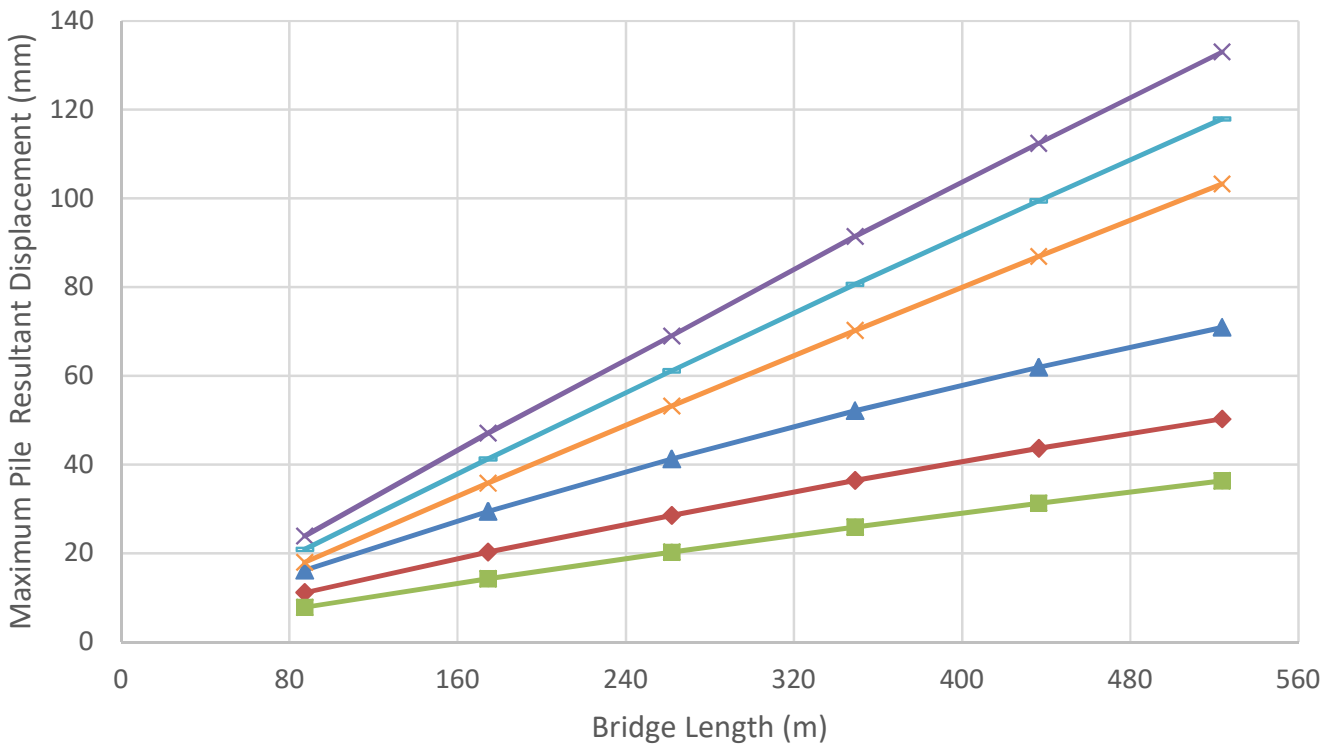

Figure 4.64 Pile Maximum Resultant Displacement for $\mathbf{2 5 0} \mathrm{m}$ Radius Integral Bridge in Case of Loose Sand Behind the Abutment and Piles Embedded in Medium Dense Sand
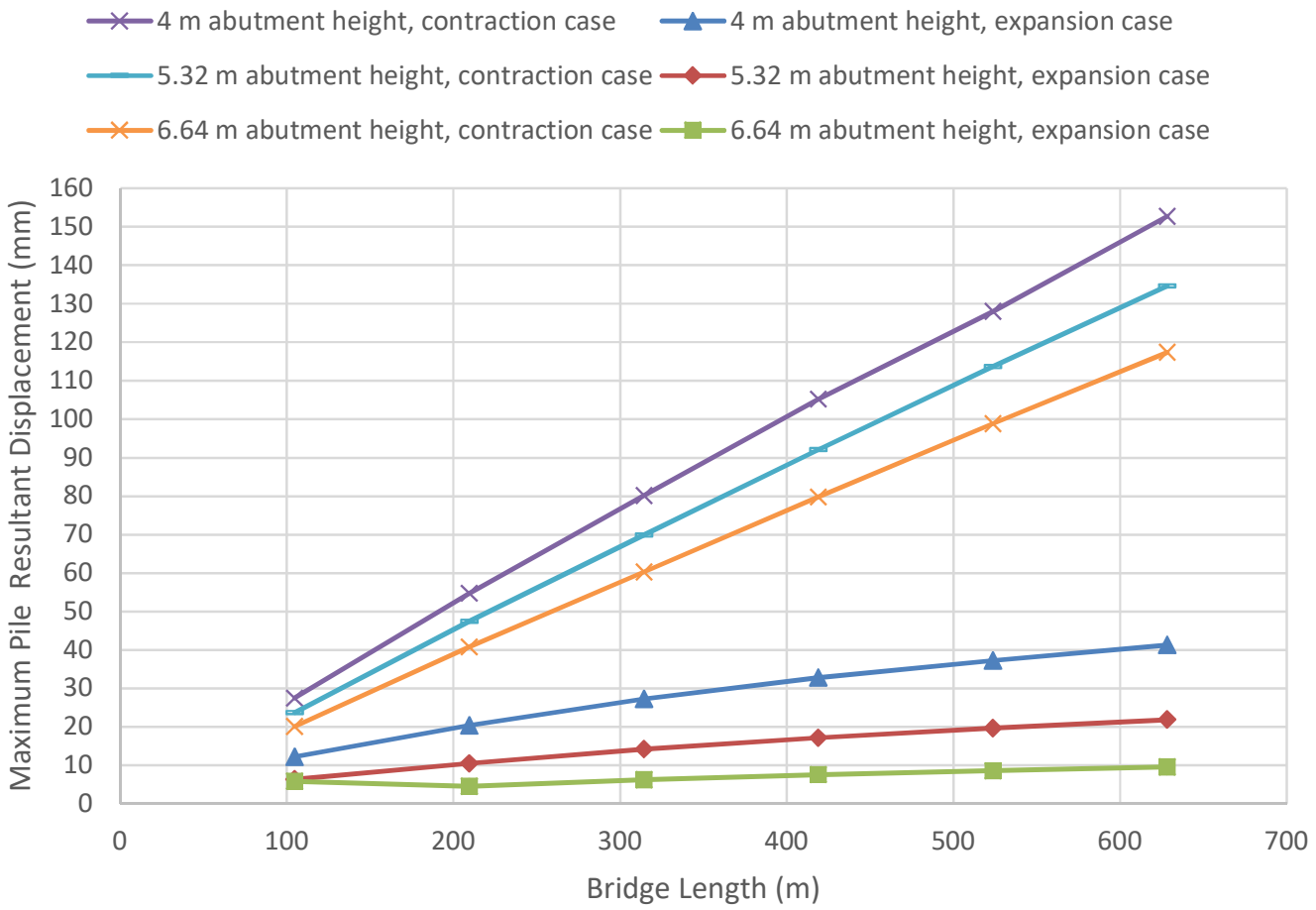

Figure 4.65 Pile Maximum Resultant Displacement for $\mathbf{3 0 0}$ m Radius Integral Bridge in case of dense sand Behind the abutment and Piles Embedded in Medium Dense Sand 
$\leftarrow 4 \mathrm{~m}$ abutment height, contraction case $\quad-4 \mathrm{~m}$ abutment height, expansion case

-5.32 m abutment height, contraction case $\_5.32 \mathrm{~m}$ abutment height, expansion case

$\star 6.64 \mathrm{~m}$ abutment height, contraction case $-6.64 \mathrm{~m}$ abutment height, expansion case

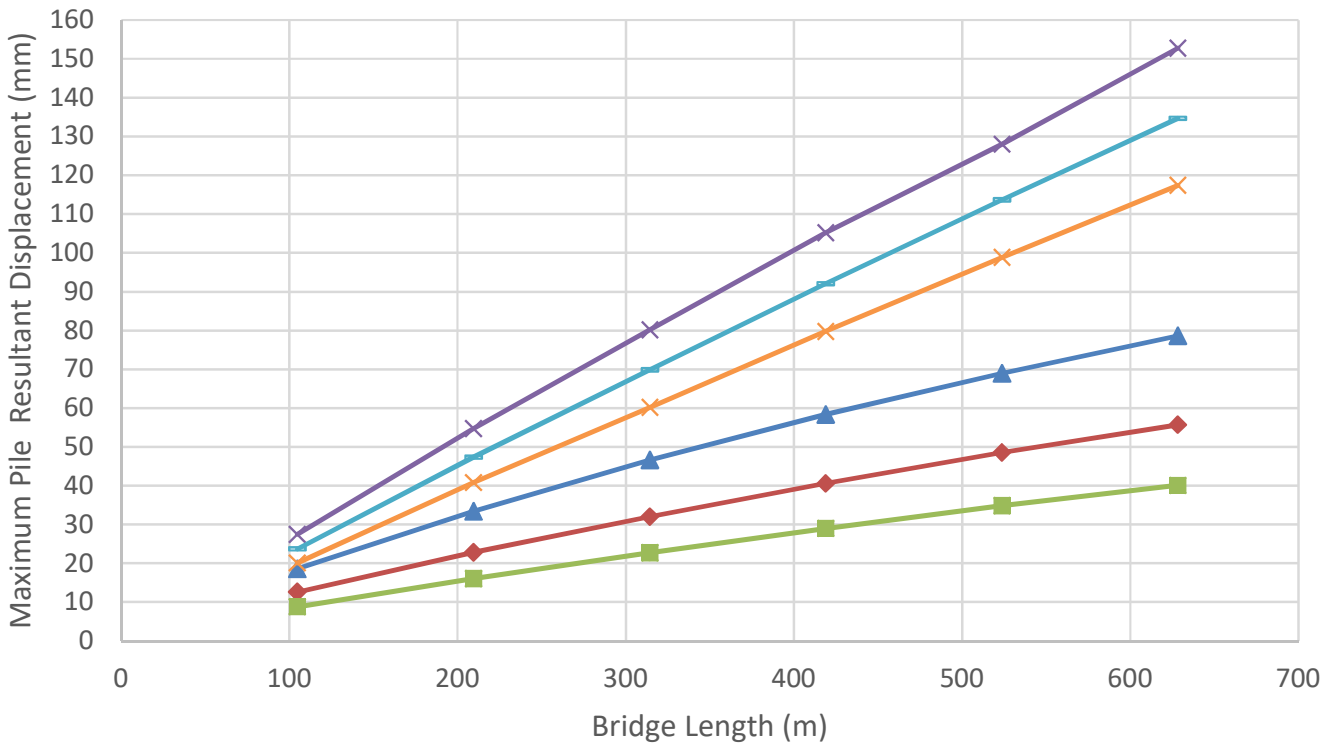

Figure 4.66 Pile Maximum Resultant Displacement for $\mathbf{3 0 0} \mathrm{m}$ Radius Integral Bridge in Case of Loose Sand Behind the Abutment and Piles Embedded in Medium Dense Sand 
Table 4.11 (PMRD) contraction / (PMRD) expansion Ratio

\begin{tabular}{|c|c|c|c|c|}
\hline \multirow[t]{2}{*}{$\begin{array}{l}\text { Radius of } \\
\text { Curvature }\end{array}$} & \multirow{2}{*}{$\begin{array}{l}\text { Condition of } \\
\text { Backfill Soil }\end{array}$} & \multirow{2}{*}{$\begin{array}{l}\text { Condition of } \\
\text { Foundation Soil }\end{array}$} & \multicolumn{2}{|c|}{$\mathbf{n}=(\mathbf{P M R D})_{\substack{\text { contraction } \\
\text { expansion }}}$} \\
\hline & & & $\mathrm{H}=4.0 \mathrm{~m}$ & $\mathrm{H}=6.64 \mathrm{~m}$ \\
\hline 60 & Dense Sand & Medium Dense Sand & 2.00 & 5.07 \\
\hline 60 & Loose Sand & Medium Dense Sand & 1.37 & 2.08 \\
\hline 100 & Dense Sand & Medium Dense Sand & 2.31 & 6.72 \\
\hline 100 & Loose Sand & Medium Dense Sand & 1.54 & 2.42 \\
\hline 150 & Dense Sand & Medium Dense Sand & 2.49 & 7.74 \\
\hline 150 & Loose Sand & Medium Dense Sand & 1.55 & 2.35 \\
\hline 200 & Dense Sand & Medium Dense Sand & 2.66 & 7.75 \\
\hline 200 & Loose Sand & Medium Dense Sand & 1.65 & 2.59 \\
\hline 250 & Dense Sand & Medium Dense Sand & 2.83 & 8.89 \\
\hline 250 & Loose Sand & Medium Dense Sand & 1.69 & 2.62 \\
\hline 300 & Dense Sand & Medium Dense Sand & 3.00 & 9.37 \\
\hline 300 & Loose Sand & Medium Dense Sand & 1.73 & 2.66 \\
\hline
\end{tabular}

Table 4.12 Mean Values of $n$

\begin{tabular}{|c|c|c|c|}
\hline $\begin{array}{l}\text { Condition of } \\
\text { Backfill Soil }\end{array}$ & $\begin{array}{l}\text { Height of Abutment (H) } \\
\text { (m) }\end{array}$ & Mean n-Value & Standard Deviation \\
\hline \multirow{2}{*}{ Loose Sand } & 4.00 & 1.58 & \pm 0.13 \\
\hline & 6.64 & 2.45 & \pm 0.21 \\
\hline \multirow{2}{*}{ Dense Sand } & 4.00 & 2.54 & \pm 0.36 \\
\hline & 6.64 & 7.59 & \pm 1.55 \\
\hline
\end{tabular}

\subsection{Ratio of Pile Tangential Displacement to Pile Resultant Displacement}

The abutment supporting piles are subject to displacements due to bridge expansion or contraction, in different directions depending upon the locations of the piles with respect to centerline of bridge deck. The pile on the outermost radius exhibits horizontal displacement, 
which can be resolved into two perpendicular components, one in the direction of the tangent to the bridge deck and the other in the radial direction.

The ratio of abutment pile tangential displacement to pile resultant displacement is a function of the support conditions at the piers and the number of piers along the bridge length. Additionally, the location of the pile with respect to bridge abutment either at innermost radius or at the outermost radius, radius of curvature (R), and span length affect the components of piles resultant displacements. If the support conditions at the pier inhibit radial displacement which is the case implemented in the developed numerical models in this study, it would be logical that the radial displacement at the pile head will be small. If the piers allow the radial displacement, the radial displacement at the pile head will be much bigger, as it can be seen from Figure 4.67. The figure presents the horizontal displacement of the outermost pile supporting the bridge abutment. The displacement of the pile is not due to thermal load only, but also due to deformation and rotation of superstructure boundaries due to self-weight of the bridge. Accordingly, the bending moment induced in the pile acts in the strong axis direction of abutment pile, with very little of the resulted moment acting in the pile weak axis direction. The radial displacement is indeed small compared to the tangential displacement. This can be attributed to the fact that the piers supports inhibit radial displacement of the bridge deck at their location. 


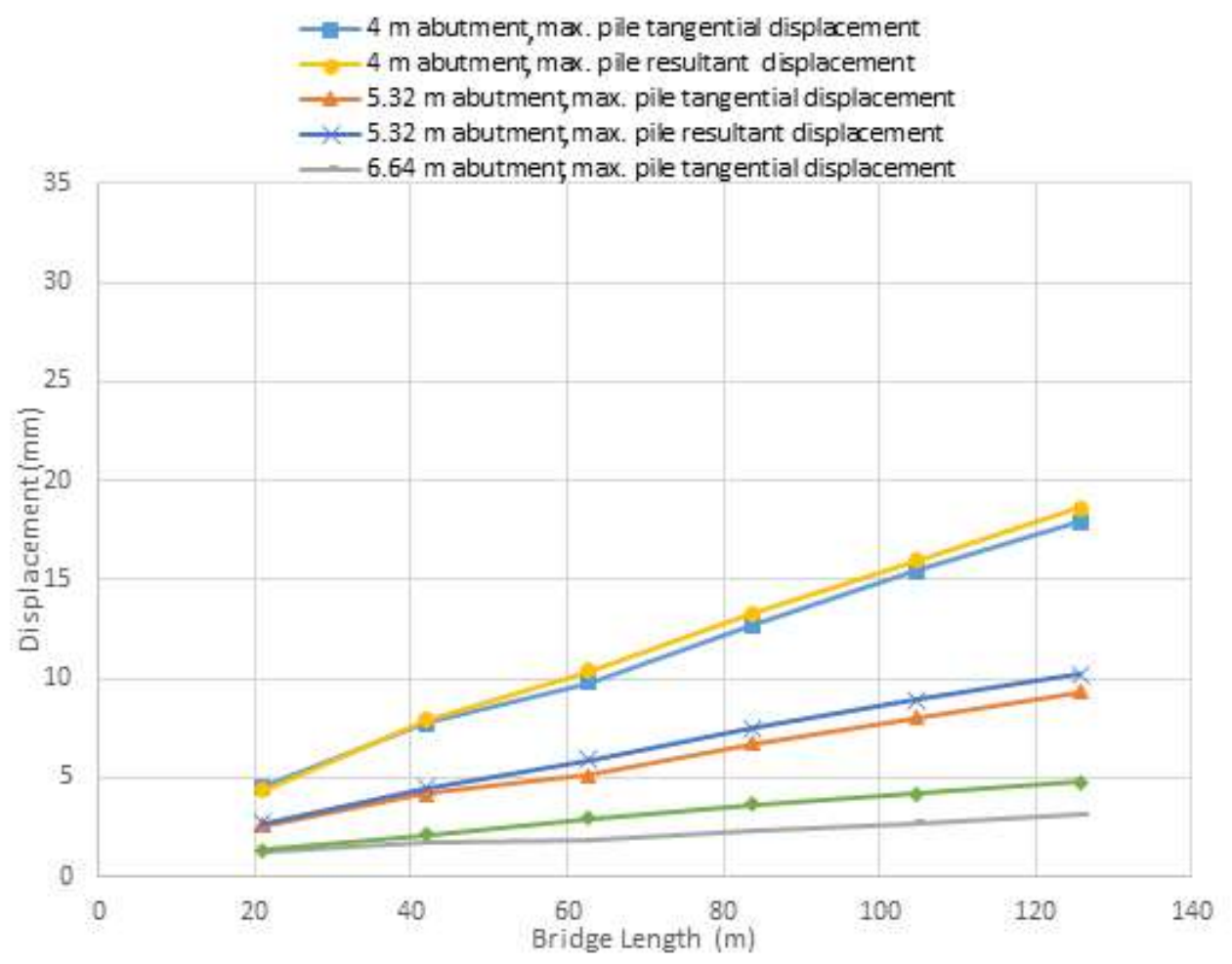

Figure 4.67 Comparison between Pile Maximum Tangential and Pile Maximum Resultant Displacement in the Case of Thermal Expansion for $60 \mathrm{~m}$ Radius Integral Bridge with Dense Sand Supporting the Abutment and Piles Embedded in Stiff Clay

\subsection{Pile Average Maximum Resultant Displacement Relative to Top Abutment Maximum Displacement}

In the numerical models, different bridge lengths were analyzed for each bridge radius. For each bridge length, the pile maximum resultant displacement was assessed. The mean value of these maximum pile resultant displacements was obtained and named "Pile average maximum resultant displacement" corresponding to a specified bridge radius (R). The pile average maximum resultant displacement was compared to the maximum top of abutment displacement for the two backfill soil conditions and the two types of foundation soil as shown in Tables 4.13 to 4.16 . This ratio is named $(B / T)$. Tables 4.13 and 4.14 present results for abutment piles embedded in medium dense sand and stiff clay foundation soil, respectively. The bridge is subjected to negative thermal loading conditions. These figures revealed that the radius of curvature has slight effect on the ratio $(B / T)$, while the ratio $(B / T)$ decreased with the increase of bridge abutment height. In contraction phase of the bridge, there is no effect of the stiffness of backfill soil in the ratio $(B / T)$, since the active earth pressure of 
backfill soil was too small to be discarded. Table 4.13 and 4.14 revealed that there is slight effect of foundation soil on $(B / T)$ ratio. During expansion phase of the bridge, the ratio $(B / T)$ decreased due to the effect of backfill stiffness. Still, the radius of curvature of the bridge has slight effect on the ratio $(B / T)$. But this ratio decreased, appreciably, by the increase of the height of bridge abutment. The stiffness of backfill soil affects the ratio $(B / T)$ in a way that $(B / T)$ increased with the decrease of backfill soil stiffness, due to the decrease in backfill soil restraint. The foundation soil has appreciable effect on $(B / T)$ values as depicted in Tables 4.15 and 4.16 , in case of bridge expansion.

The top of abutment displacement is affected by effective expansion length and temperature change (LaFave et al., 2016), while the pile maximum resultant displacement is affected by bridge abutment height, backfill soil stiffness and slightly by foundation soil.

During contraction of the bridges, the values of $(B / T)$ varies between 0.76 and 0.58 , whether the foundation soil is stiff clay or medium dense sand, while $(B / T)$ during expansion of the bridge varies from 0.32 to 0.09 in case of dense sand backfill and medium dense sand foundation soil. In case of loose sand backfill, with the same foundation soil, $(B / T)$ varies from 0.48 to 0.24 . When the foundation soil is stiff clay, the ratio of $(B / T)$ varies from 0.43 to 0.09 in case of dense sand backfill, and from 0.7 to 0.48 in case of loose sand backfill. Civjan et al. (2013) reported from monitoring two integral abutment bridges in Vermont, USA, that the maximum displacement at the top of the piles is $1 / 3$ to $1 / 2$ of the values of top of abutment displacement. Off course, the values reported by Civjan et al. (2013) are not comparable with the achieved $(B / T)$ results in the current study. This is because the values reported by Civjan et al. (2013) were obtained from monitoring a straight single span bridge of $40.0 \mathrm{~m}$ length, and another $15^{\circ}$ skewed bridge with the piles oriented such that their weak axis resisting longitudinal bridge movement. In any case, the measured upper limit value of 0.50 agrees reasonably with the predicted upper limit value of 0.48 in case of loose sand backfill and medium dense sand foundation soil.

When the bridge is subjected to negative thermal loading conditions, the bridge contracts and the abutments rotate inward (away from the backfill). Tables 4.13 and 4.14 revealed that the rotation of the abutment is independent of the height of the abutment, the backfill soil type, the foundation soil type and the bridge curvature (1/R). 
When the bridge is subjected to positive thermal loading conditions, the bridge expands and the abutments rotate outward (towards the backfill soil). In case of medium dense sand foundation soil, the rotation of the abutment-backfill soil system slightly decreased with the increase of the abutment height and with the decrease of the unit weight of sand backfill (decrease of stiffness). The rotation of the abutment-backfill soil system is independent of bridge curvature (1/R), while it is depended on foundation soil type as shown in Tables 4.15 and 4.16.

Table 4.16 presents the case of stiff clay foundation soil. The rotation of the abutment- backfill soil system seems to be independent of abutment height and bridge curvature (1/R). However it decreased with the decrease of the stiffness backfill soil system. It can be concluded that for abutment piles embedded in medium dense sand, and the bridge is subjected to positive thermal loading conditions, the abutment bottom displacement (pile maximum resultant displacement) decreased with the increase of unit weight of backfill soil, while the rotation of the abutment increased. This finding agrees well with that reported by Greimann et al. (2014).

The pile maximum resultant displacements in case of dense sand backfill are smaller than those in case of loose sand backfill, for a bridge having pile installed in either medium dense sand or stiff clay and subjected to positive thermal loading. This is attributed to the fact that the rotation of abutment in case of dense sand backfill is bigger than that in case of loose sand backfill. Therefore, abutment rotations reduce the deformation demand on the pile. This agrees with the conclusion reached by Civjan et al. (2014).

Table 4.13 Pile Average Maximum Displacement to Maximum top Abutment Displacement Ratio for Piles Embedded in Medium Dense Sand - Contraction Case

\begin{tabular}{|c|c|c|c|c|c|c|c|c|c|c|c|c|}
\hline Radius & \multicolumn{2}{|c|}{$300 \mathrm{~m}$} & \multicolumn{2}{|c|}{$250 \mathrm{~m}$} & \multicolumn{2}{|c|}{$200 \mathrm{~m}$} & \multicolumn{2}{|c|}{$150 \mathrm{~m}$} & \multicolumn{2}{|c|}{$100 \mathrm{~m}$} & \multicolumn{2}{|c|}{$60 \mathrm{~m}$} \\
\hline Abutm- & \multicolumn{12}{|c|}{ Soil Type Behind The Abutment } \\
\hline $\begin{array}{c}\text { Height } \\
\text { (m) }\end{array}$ & $\begin{array}{l}\text { Loose } \\
\text { Sand }\end{array}$ & $\begin{array}{l}\text { Dense } \\
\text { Sand }\end{array}$ & $\begin{array}{l}\text { Loose } \\
\text { Sand }\end{array}$ & $\begin{array}{l}\text { Dense } \\
\text { Sand }\end{array}$ & $\begin{array}{l}\text { Loose } \\
\text { Sand }\end{array}$ & $\begin{array}{l}\text { Dense } \\
\text { Sand }\end{array}$ & $\begin{array}{l}\text { Loose } \\
\text { Sand }\end{array}$ & $\begin{array}{l}\text { Dense } \\
\text { Sand }\end{array}$ & $\begin{array}{l}\text { Loose } \\
\text { Sand }\end{array}$ & $\begin{array}{l}\text { Dense } \\
\text { Sand }\end{array}$ & $\begin{array}{l}\text { Loose } \\
\text { Sand }\end{array}$ & $\begin{array}{l}\text { Dense } \\
\text { Sand }\end{array}$ \\
\hline 4 & 0.74 & 0.74 & 0.77 & 0.77 & 0.80 & 0.80 & 0.74 & 0.74 & 0.81 & 0.81 & 0.73 & 0.73 \\
\hline 5.32 & 0.64 & 0.64 & 0.67 & 0.67 & 0.70 & 0.70 & 0.63 & 0.63 & 0.71 & 0.71 & 0.66 & 0.66 \\
\hline 6.64 & 0.54 & 0.54 & 0.58 & 0.58 & 0.61 & 0.61 & 0.54 & 0.54 & 0.60 & 0.60 & 0.58 & 0.58 \\
\hline
\end{tabular}


Table 4.14 Pile Average Maximum Displacement to Maximum top Abutment Displacement Ratio for Piles Embedded in Stiff Clay - Contraction Case

\begin{tabular}{|c|c|c|c|c|c|c|c|c|c|c|c|c|}
\hline Radius & \multicolumn{2}{|c|}{$300 \mathrm{~m}$} & \multicolumn{2}{|c|}{$250 \mathrm{~m}$} & \multicolumn{2}{|c|}{$200 \mathrm{~m}$} & \multicolumn{2}{|c|}{$150 \mathrm{~m}$} & \multicolumn{2}{|c|}{$100 \mathrm{~m}$} & \multicolumn{2}{|c|}{$60 \mathrm{~m}$} \\
\hline \multirow{2}{*}{$\begin{array}{c}\text { Abutm } \\
\text {-ent } \\
\text { Height } \\
\text { (m) }\end{array}$} & \multicolumn{12}{|c|}{ Soil Type Behind The Abutment } \\
\hline & $\begin{array}{l}\text { Loose } \\
\text { Sand }\end{array}$ & $\begin{array}{c}\text { Dense } \\
\text { Sand }\end{array}$ & $\begin{array}{l}\text { Loose } \\
\text { Sand }\end{array}$ & $\begin{array}{c}\text { Dense } \\
\text { Sand }\end{array}$ & $\begin{array}{l}\text { Loose } \\
\text { Sand }\end{array}$ & $\begin{array}{l}\text { Dense } \\
\text { Sand }\end{array}$ & $\begin{array}{l}\text { Loose } \\
\text { Sand }\end{array}$ & $\begin{array}{l}\text { Dense } \\
\text { Sand }\end{array}$ & $\begin{array}{l}\text { Loose } \\
\text { Sand }\end{array}$ & $\begin{array}{l}\text { Dense } \\
\text { Sand }\end{array}$ & $\begin{array}{l}\text { Loose } \\
\text { Sand }\end{array}$ & $\begin{array}{c}\text { Dense } \\
\text { Sand }\end{array}$ \\
\hline 4 & 0.76 & 0.76 & 0.78 & 0.78 & 0.81 & 0.81 & 0.75 & 0.75 & 0.81 & 0.81 & 0.75 & 0.75 \\
\hline 5.32 & 0.65 & 0.65 & 0.68 & 0.68 & 0.71 & 0.71 & 0.64 & 0.64 & 0.73 & 0.73 & 0.65 & 0.65 \\
\hline 6.64 & 0.56 & 0.56 & 0.59 & 0.59 & 0.62 & 0.62 & 0.55 & 0.55 & 0.63 & 0.63 & 0.58 & 0.58 \\
\hline
\end{tabular}

Table 4.15 Pile Average Maximum Displacement to Maximum top Abutment Displacement Ratio for Piles Embedded in Medium Dense Sand - Expansion Case

\begin{tabular}{|c|c|c|c|c|c|c|c|c|c|c|c|c|}
\hline Radius & \multicolumn{2}{|c|}{$300 \mathrm{~m}$} & \multicolumn{2}{|c|}{$250 \mathrm{~m}$} & \multicolumn{2}{|c|}{$200 \mathrm{~m}$} & \multicolumn{2}{|c|}{$150 \mathrm{~m}$} & \multicolumn{2}{|c|}{$100 \mathrm{~m}$} & \multicolumn{2}{|c|}{$60 \mathrm{~m}$} \\
\hline \multirow{2}{*}{$\begin{array}{c}\text { Abutm } \\
\text {-ent } \\
\text { Height } \\
\text { (m) }\end{array}$} & \multicolumn{12}{|c|}{ Soil Type Behind The Abutment } \\
\hline & $\begin{array}{l}\text { Loose } \\
\text { Sand }\end{array}$ & $\begin{array}{l}\text { Dense } \\
\text { Sand }\end{array}$ & $\begin{array}{l}\text { Loose } \\
\text { Sand }\end{array}$ & $\begin{array}{l}\text { Dense } \\
\text { Sand }\end{array}$ & $\begin{array}{l}\text { Loose } \\
\text { Sand }\end{array}$ & $\begin{array}{l}\text { Dense } \\
\text { Sand }\end{array}$ & $\begin{array}{l}\text { Loose } \\
\text { Sand }\end{array}$ & $\begin{array}{l}\text { Dense } \\
\text { Sand }\end{array}$ & $\begin{array}{l}\text { Loose } \\
\text { Sand }\end{array}$ & $\begin{array}{l}\text { Dense } \\
\text { Sand }\end{array}$ & $\begin{array}{l}\text { Loose } \\
\text { Sand }\end{array}$ & $\begin{array}{l}\text { Dense } \\
\text { Sand }\end{array}$ \\
\hline 4 & 0.48 & 0.32 & 0.49 & 0.35 & 0.52 & 0.38 & 0.48 & 0.34 & 0.54 & 0.40 & 0.53 & 0.36 \\
\hline 5.32 & 0.32 & 0.16 & 0.33 & 0.175 & 0.35 & 0.20 & 0.33 & 0.17 & 0.37 & 0.20 & 0.35 & 0.20 \\
\hline 6.64 & 0.21 & 0.065 & 0.22 & 0.078 & 0.24 & 0.09 & 0.22 & 0.07 & 0.25 & 0.10 & 0.24 & 0.09 \\
\hline
\end{tabular}

Table 4.16 Pile Average Maximum Displacement to Maximum top Abutment Displacement Ratio for Piles Embedded in Stiff Clay - Expansion Case

\begin{tabular}{|c|c|c|c|c|c|c|c|c|c|c|c|c|c|c|}
\hline Radius & \multicolumn{2}{|c|}{$300 \mathrm{~m}$} & $250 \mathrm{~m}$ & \multicolumn{2}{c|}{$200 \mathrm{~m}$} & \multicolumn{2}{c|}{$150 \mathrm{~m}$} & \multicolumn{2}{|c|}{$100 \mathrm{~m}$} & \multicolumn{2}{c|}{$60 \mathrm{~m}$} \\
\hline $\begin{array}{c}\text { Abutm } \\
\text {-ent } \\
\text { Height } \\
(\mathrm{m})\end{array}$ & \multicolumn{9}{|c|}{ Soil Type Behind The Abutment } \\
\cline { 2 - 14 } & $\begin{array}{c}\text { Loose } \\
\text { Sand }\end{array}$ & $\begin{array}{c}\text { Dense } \\
\text { Sand }\end{array}$ & $\begin{array}{c}\text { Loose } \\
\text { Sand }\end{array}$ & $\begin{array}{c}\text { Dense } \\
\text { Sand }\end{array}$ & $\begin{array}{c}\text { Loose } \\
\text { Sand }\end{array}$ & $\begin{array}{c}\text { Dense } \\
\text { Sand }\end{array}$ & $\begin{array}{c}\text { Loose } \\
\text { Sand }\end{array}$ & $\begin{array}{c}\text { Dense } \\
\text { Sand }\end{array}$ & $\begin{array}{c}\text { Loose } \\
\text { Sand }\end{array}$ & $\begin{array}{c}\text { Dense } \\
\text { Sand }\end{array}$ & $\begin{array}{c}\text { Loose } \\
\text { Sand }\end{array}$ & $\begin{array}{c}\text { Dense } \\
\text { Sand }\end{array}$ \\
\hline 4 & 0.70 & 0.43 & 0.71 & 0.46 & 0.74 & 0.50 & 0.73 & 0.43 & 0.78 & 0.55 & 0.75 & 0.48 \\
\hline 5.32 & 0.55 & 0.19 & 0.57 & 0.22 & 0.60 & 0.25 & 0.59 & 0.21 & 0.58 & 0.26 & 0.60 & 0.24 \\
\hline 6.64 & 0.41 & 0.035 & 0.44 & 0.06 & 0.47 & 0.08 & 0.45 & 0.045 & 0.50 & 0.09 & 0.48 & 0.09 \\
\hline
\end{tabular}




\subsection{Effect of Abutment Height on the Reduction of the Pile Maximum Bending Moment}

Figures 4.69 through 4.84 show the effect of abutment height on the maximum bending moment at pile head considering different soil conditions of backfill soil and different types of foundation soil. The bridge thermal contraction condition was adopted, since it produces the maximum pile displacement and bending moment. Results show that increasing the bridge abutment height is associated with a decrease in pile maximum resultant displacement and consequently a decrease in pile maximum moment. Notably, the rotation of the abutment is independent of abutment height. This trend is similar to that for the reduction of the pile resultant displacement with increasing abutment height. This is attributed to the fact that, the abutment piles are fixed into the abutment and the moment developed at the abutment head is dependent on the magnitude of pile lateral displacement. The relieving of the bending moments developed at pile heads are the same for all piles-abutment heights. Since the pile satisfies stability Equations 3.1 and 3.2, the pile bending capacity is the pile material yield stress multiplied by the pile plastic section modulus $\left(379,211 \mathrm{kN} / \mathrm{m}^{2} \times 0.001934\right.$ $\mathrm{m}^{3}=733 \mathrm{kN} . \mathrm{m}$ for the current studied pile size). Figure 4.68 shows the bending moment diagram for the 9 pile arranged in a single row and supporting the abutment for one of the modeled integral abutment bridges.

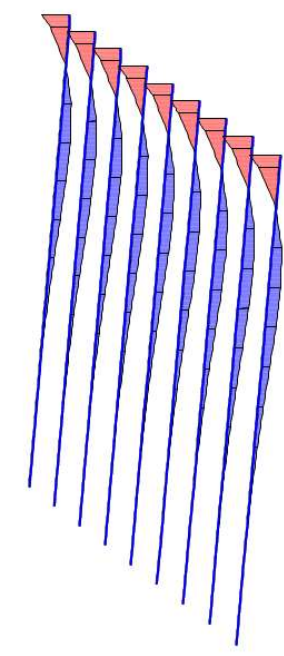

Figure 4.68 View of a Numerical Model for Abutment pile Bending Moment Under Thermal Contraction and Own Weight Loading 
The piles exhibit maximum bending moment at the pile head. Figures 4.69 through 4.84 revealed that the maximum bending moment induced in bridge abutment piles varies linearly with the bridge length (L). This agrees with results reported by Olson (2013). To explore the effect of the radius of curvature on the induced bending moment in abutment piles, the ratio of maximum pile bending moment and bridge length $(\mathrm{M} / \mathrm{L})$ was obtained at different bridge abutment heights, as shown in Table 4.17.

The table indicates that, in case of stiff clay foundation soil, the average values of $(M / L)$ are 2.36, 1.96 and 1.46 for bridge abutment heights of $4.0 \mathrm{~m}, 5.32 \mathrm{~m}$ and $6.64 \mathrm{~m}$, respectively. The average values revealed that there is no appreciable effect of bridge curvature on maximum moment induced in the piles. Furthermore, the average values reflect the effect of bridge abutment height on the induced bending moment. With the increase of bridge abutment height, the ratio of $(\mathrm{M} / \mathrm{L})$ relationship decreased. Additionally, the table reflects the effect of foundation soil on the induced bending moment in abutment piles. Piles in medium dense sand exhibit $5 \%$ to $10 \%$ increase in bending moment induced in piles embedded in stiff clay. The stiffness of sand increases with depth and provides more restraint to the pile. The maximum bending moments induced in piles were calculated based on bridge deck displacement under the effect of negative thermal load conditions. Therefore, there is no effect of backfill soil conditions on the value of maximum bending moment, due to neglecting the active earth pressure during contraction of bridge deck. 
Table 4.17 (M/L) at Different Abutment Height

\begin{tabular}{|c|c|c|c|c|c|}
\hline \multirow{2}{*}{$\begin{array}{c}\text { Radius of } \\
\text { curvature } \\
\text { (R) }\end{array}$} & \multirow{2}{*}{$\begin{array}{l}\text { Condition of } \\
\text { Backfill Soil }\end{array}$} & \multirow{2}{*}{$\begin{array}{l}\text { Condition of } \\
\text { Foundation Soil }\end{array}$} & \multicolumn{3}{|c|}{$\mathrm{M} / \mathrm{L}(\mathrm{kN})$} \\
\hline & & & $4.00 \mathrm{~m}$ & $5.32 \mathrm{~m}$ & $6.64 \mathrm{~m}$ \\
\hline 300 & $\begin{array}{l}\text { Dense Sand/ } \\
\text { Loose Sand }\end{array}$ & Stiff Clay & 2.32 & 1.84 & 1.44 \\
\hline 250 & $\begin{array}{l}\text { Dense Sand/ } \\
\text { Loose Sand }\end{array}$ & Stiff Clay & 2.40 & 2.00 & 1.50 \\
\hline 200 & $\begin{array}{l}\text { Dense Sand/ } \\
\text { Loose Sand }\end{array}$ & Stiff Clay & 2.50 & 2.13 & 1.65 \\
\hline 150 & $\begin{array}{l}\text { Dense Sand/ } \\
\text { Loose Sand }\end{array}$ & Stiff Clay & 2.25 & 1.87 & 1.26 \\
\hline \multicolumn{3}{|c|}{ Average } & 2.36 & 1.96 & 1.46 \\
\hline \multicolumn{3}{|c|}{ Standard Deviation } & 0.11 & 0.13 & 0.16 \\
\hline 300 & $\begin{array}{l}\text { Dense Sand/ } \\
\text { Loose Sand }\end{array}$ & $\begin{array}{l}\text { Medium Dense } \\
\text { Sand }\end{array}$ & 2.16 & 2.09 & 1.60 \\
\hline 250 & $\begin{array}{l}\text { Dense Sand/ } \\
\text { Loose Sand }\end{array}$ & $\begin{array}{l}\text { Medium Dense } \\
\text { Sand }\end{array}$ & 2.80 & 2.30 & 1.80 \\
\hline 200 & $\begin{array}{l}\text { Dense Sand/ } \\
\text { Loose Sand }\end{array}$ & $\begin{array}{c}\text { Medium Dense } \\
\text { Sand }\end{array}$ & 2.30 & 1.80 & 1.25 \\
\hline 150 & $\begin{array}{l}\text { Dense Sand/ } \\
\text { Loose Sand }\end{array}$ & $\begin{array}{l}\text { Medium Dense } \\
\text { Sand }\end{array}$ & 2.80 & 2.25 & 1.67 \\
\hline \multicolumn{3}{|c|}{ Average } & 2.51 & 2.11 & 1.58 \\
\hline \multicolumn{3}{|c|}{ Standard Deviation } & 0.30 & 0.22 & 0.23 \\
\hline
\end{tabular}




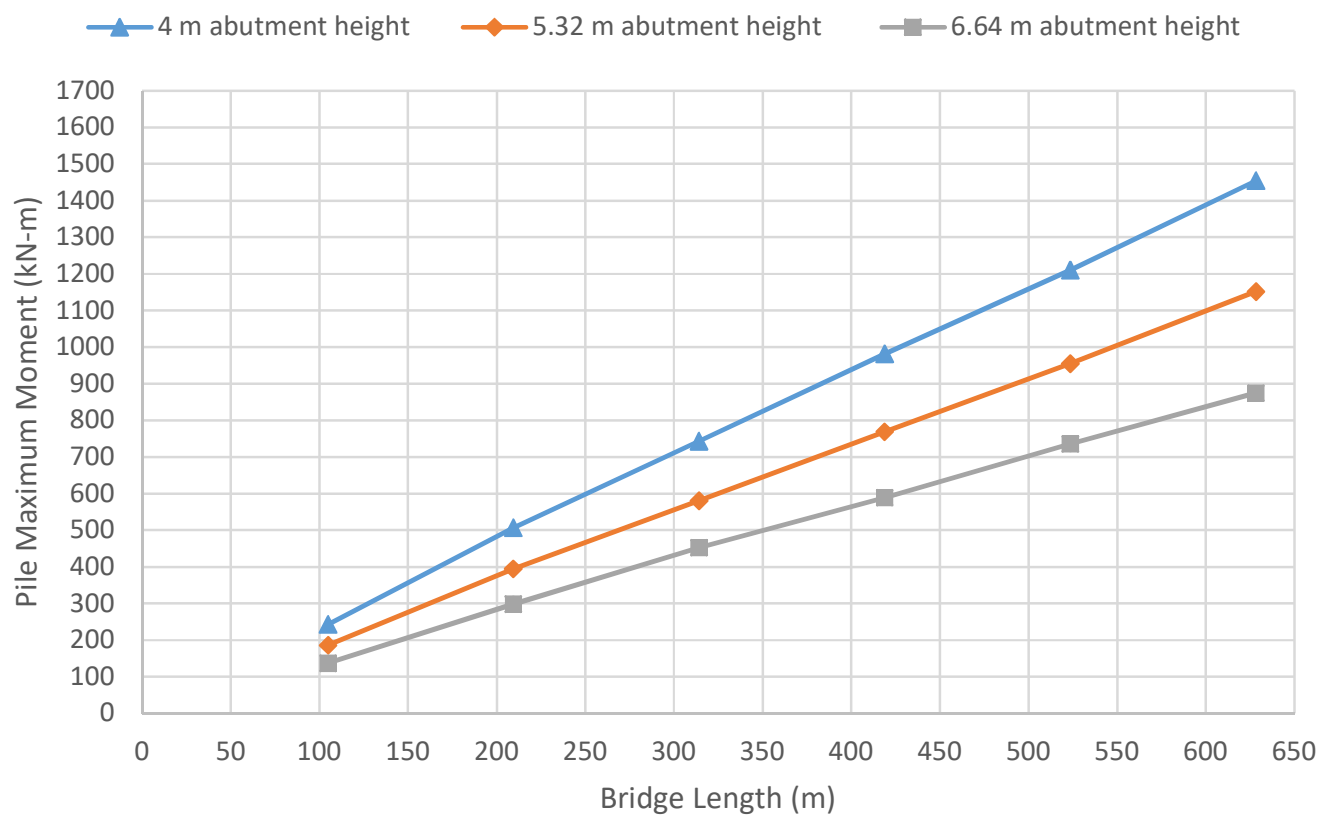

Figure 4.69 Pile Maximum Moment in Case of Dense Sand Supporting the Abutment and Piles Embedded in Stiff Clay for Bridge at Radius of $300 \mathrm{~m}$

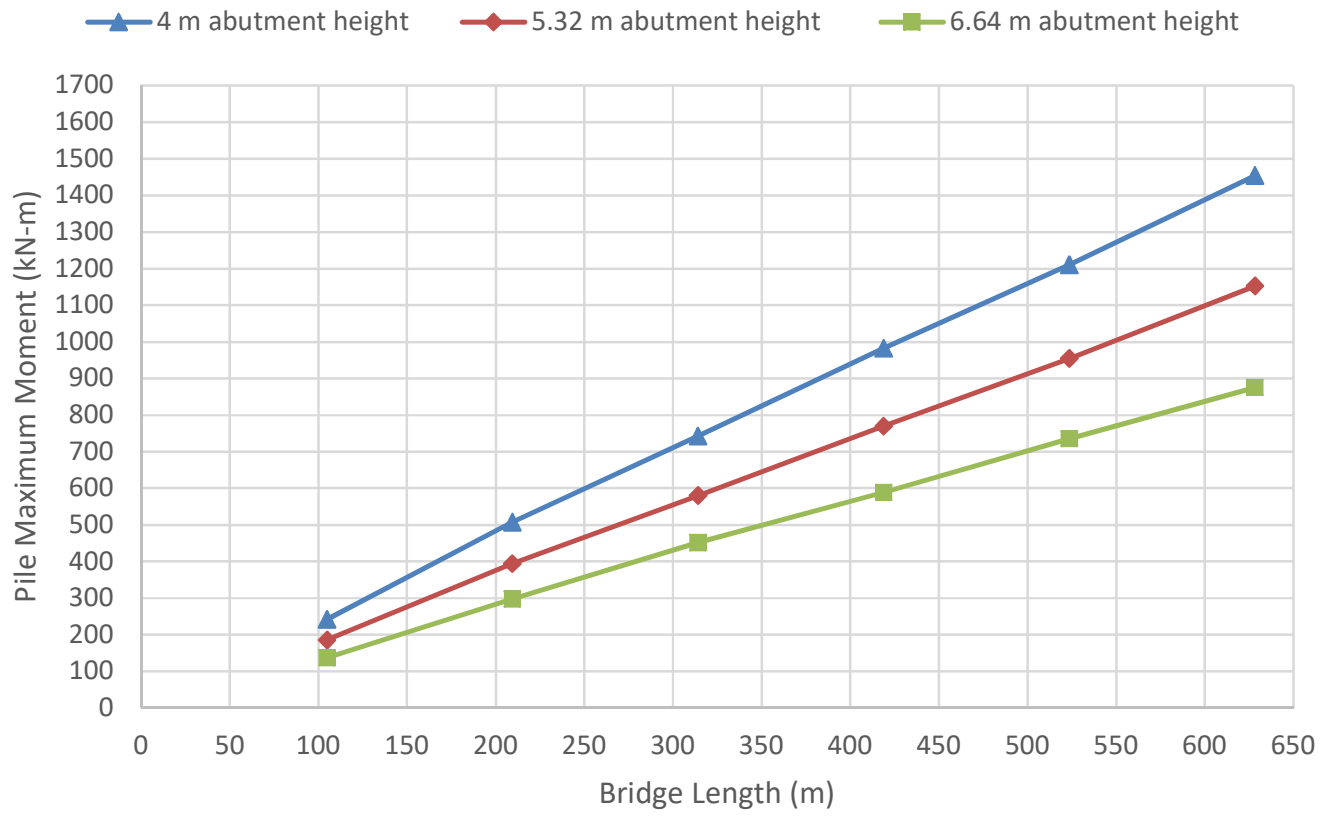

Figure 4.70 Pile Maximum Moment in Case of Loose Sand Supporting the Abutment and Piles Embedded in Stiff Clay for Bridge at Radius of $300 \mathrm{~m}$ 


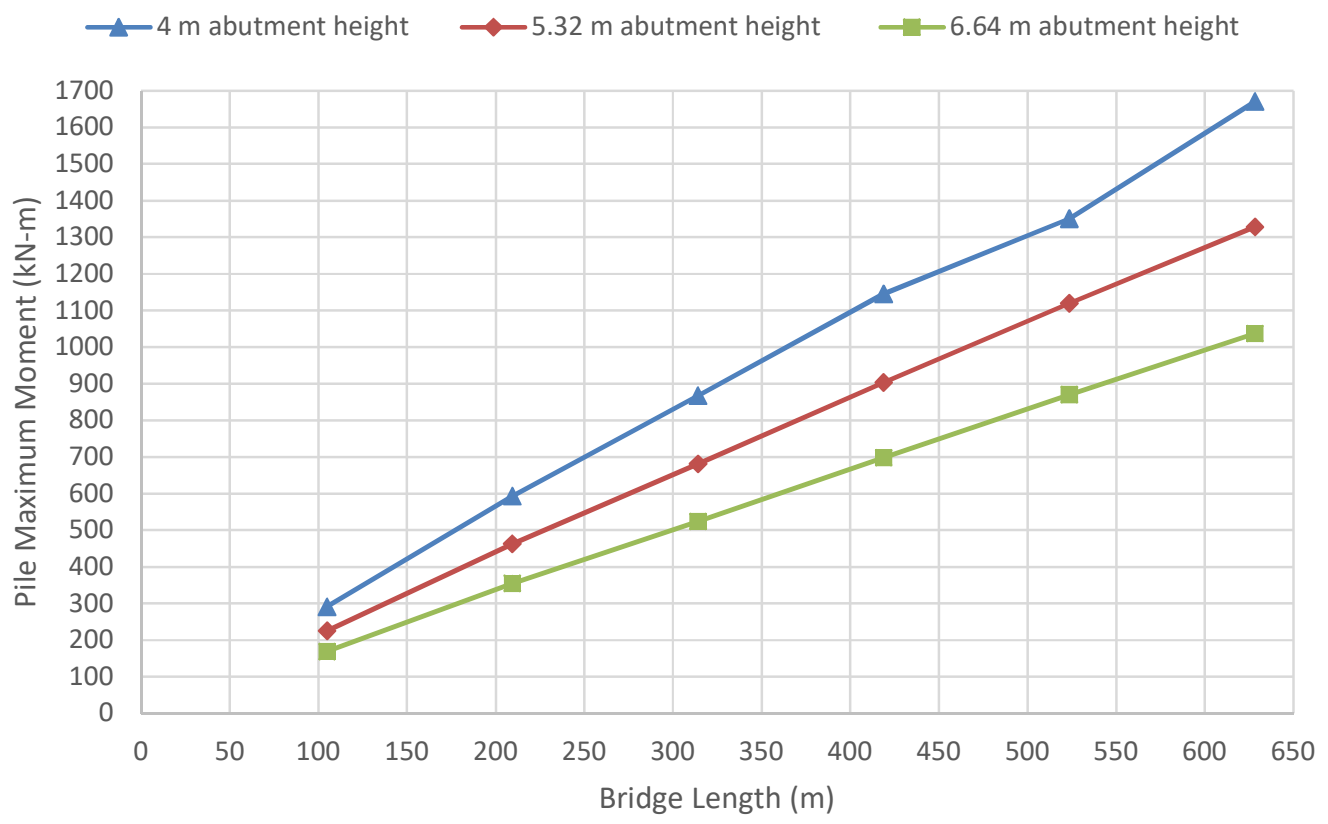

Figure 4.71 Pile Maximum Moment in Case of Dense Sand Supporting the Abutment and Piles Embedded in Dense Sand for Bridge at Radius of $300 \mathrm{~m}$

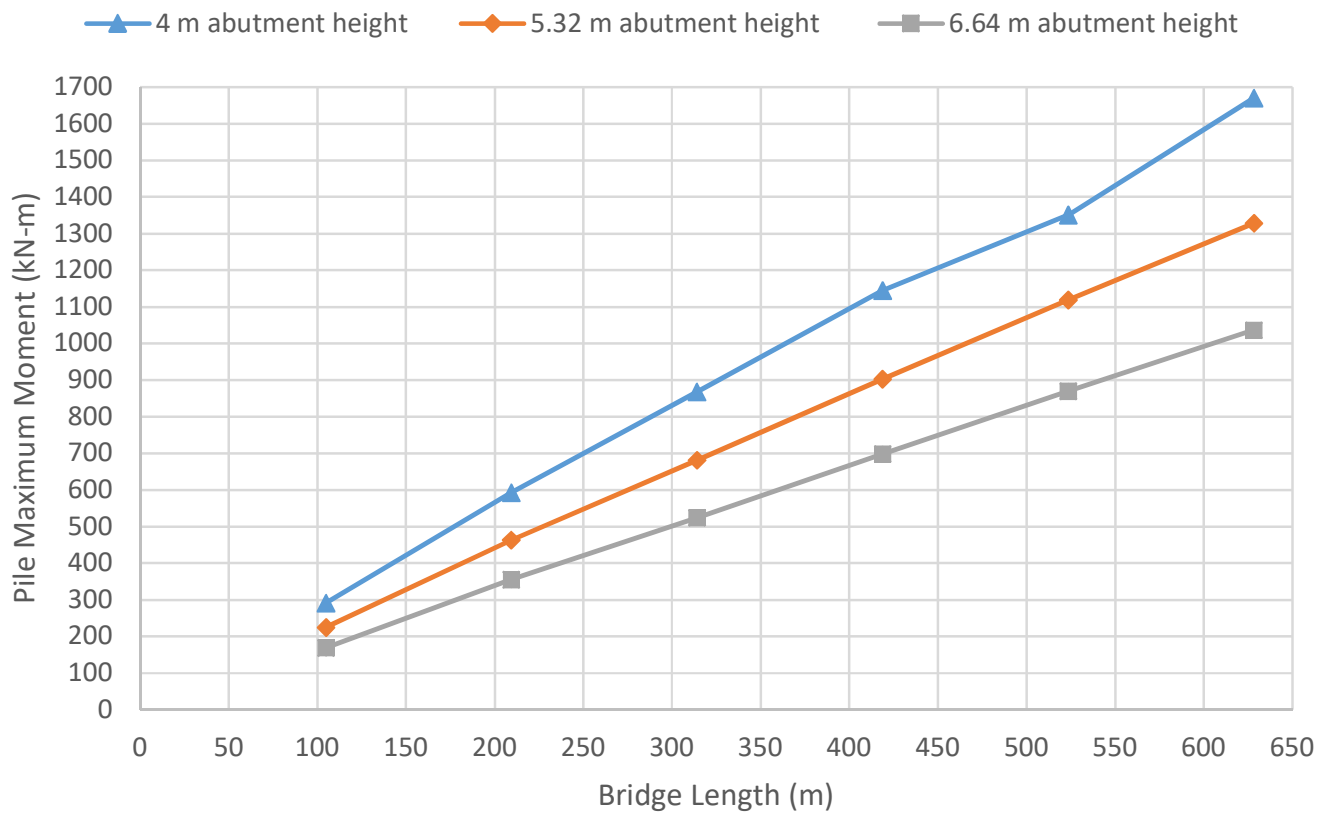

Figure 4.72 Pile Maximum Moment in Case of Loose Sand Supporting the Abutment and Piles Embedded in Dense Sand for Bridge at Radius of $300 \mathrm{~m}$ 


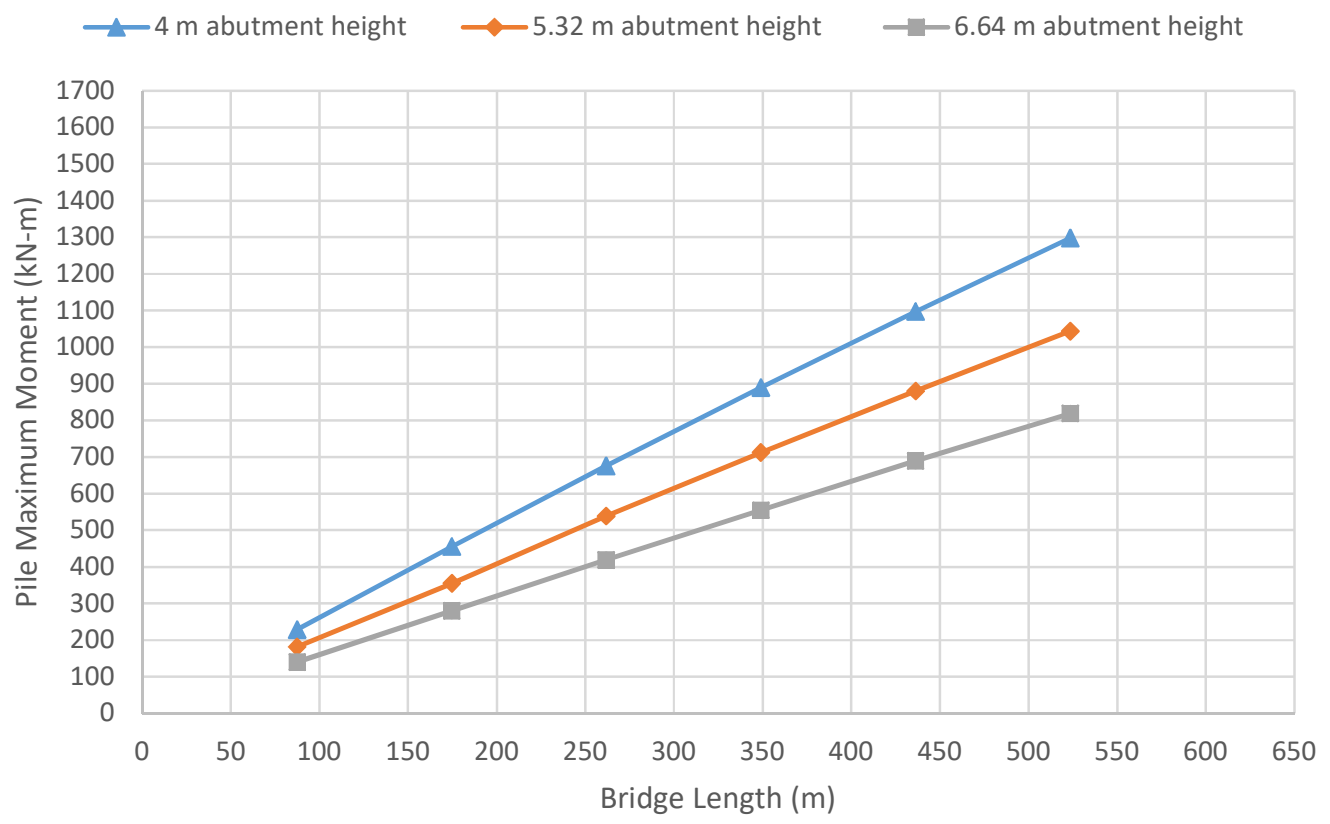

Figure 4.73 Pile Maximum Moment in Case of Dense Sand Supporting the Abutment and Piles Embedded in Stiff Clay for Bridge at Radius of $250 \mathrm{~m}$

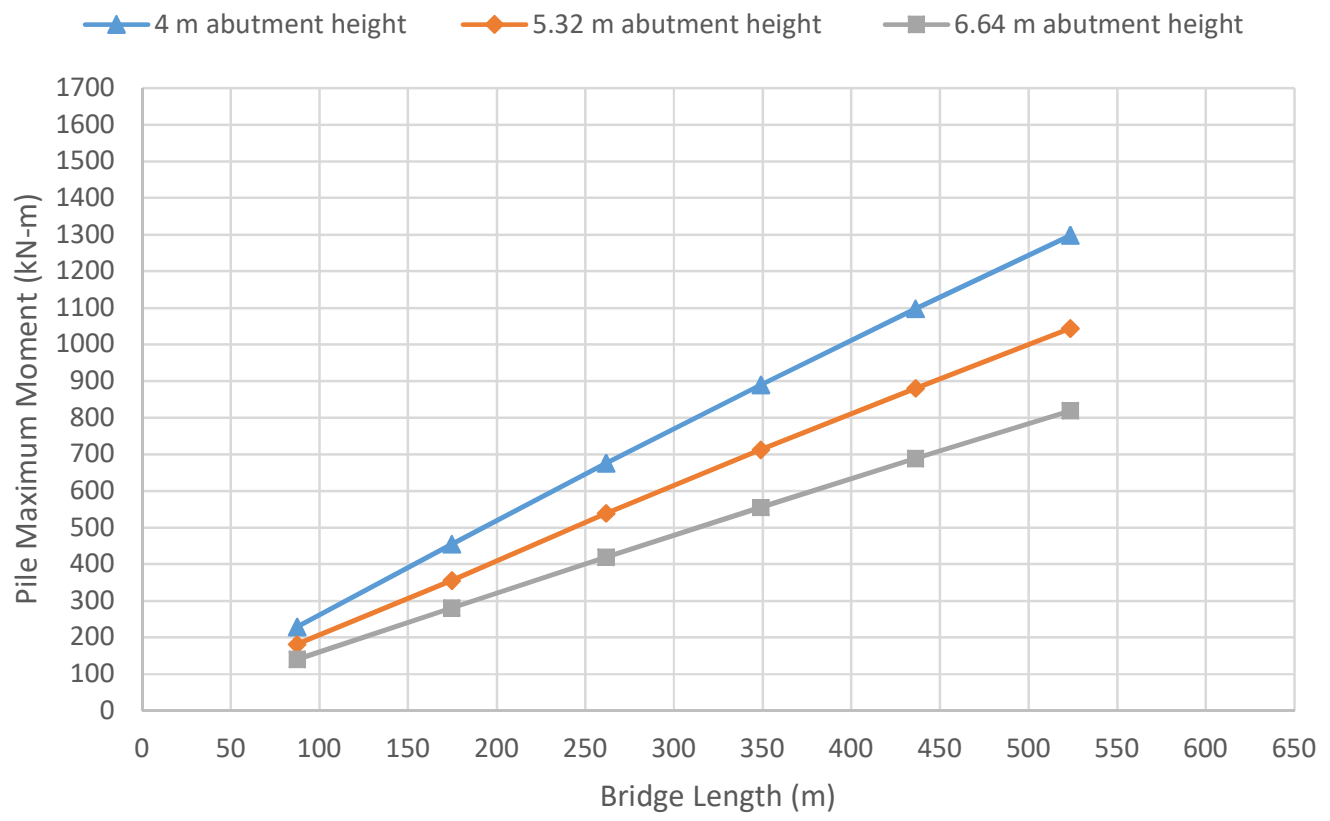

Figure 4.74 Pile Maximum Moment in Case of Loose Sand Supporting the Abutment and Piles Embedded in Stiff Clay for Bridge at Radius of $250 \mathrm{~m}$ 


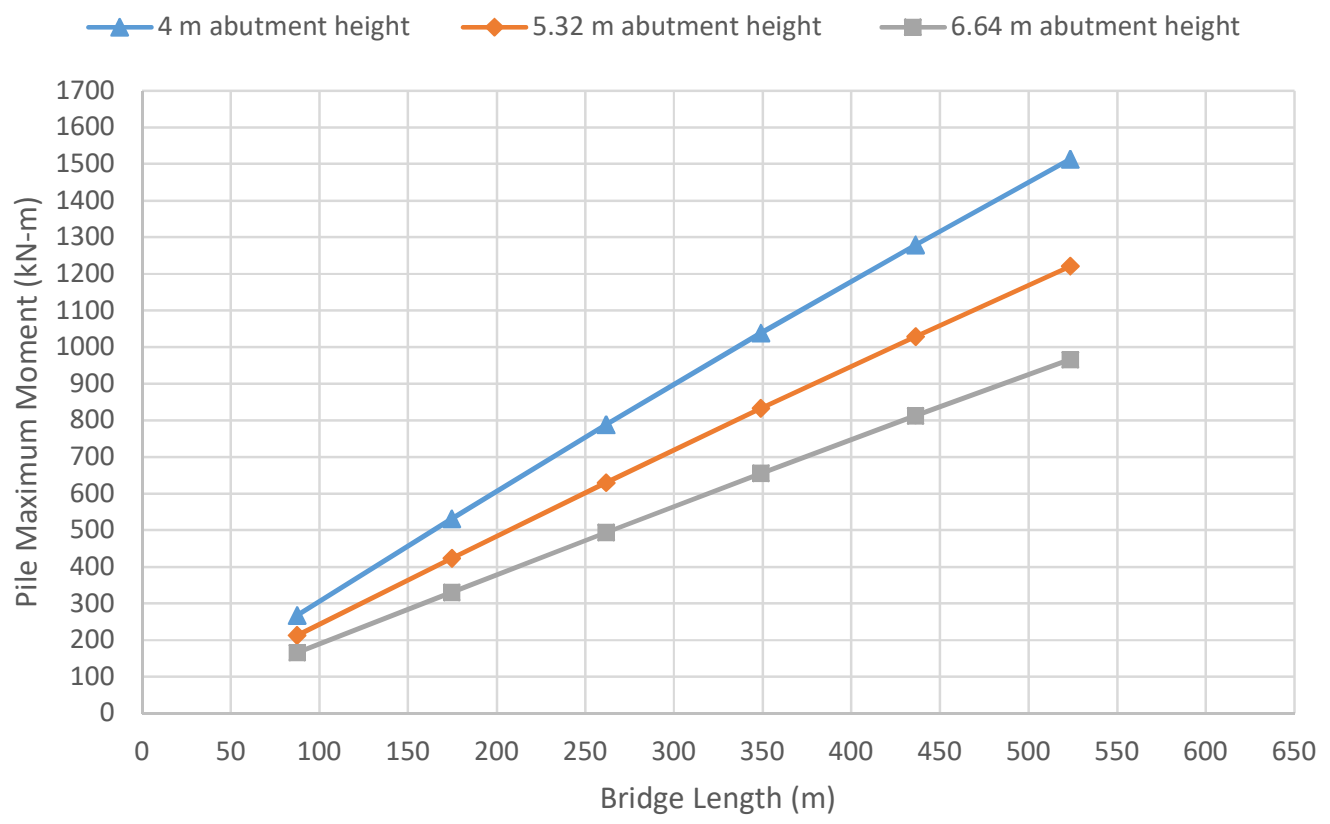

Figure 4.75 Pile Maximum Moment in Case of Dense Sand Supporting the Abutment and Piles Embedded in Medium Dense Sand for Bridge at Radius of $250 \mathrm{~m}$

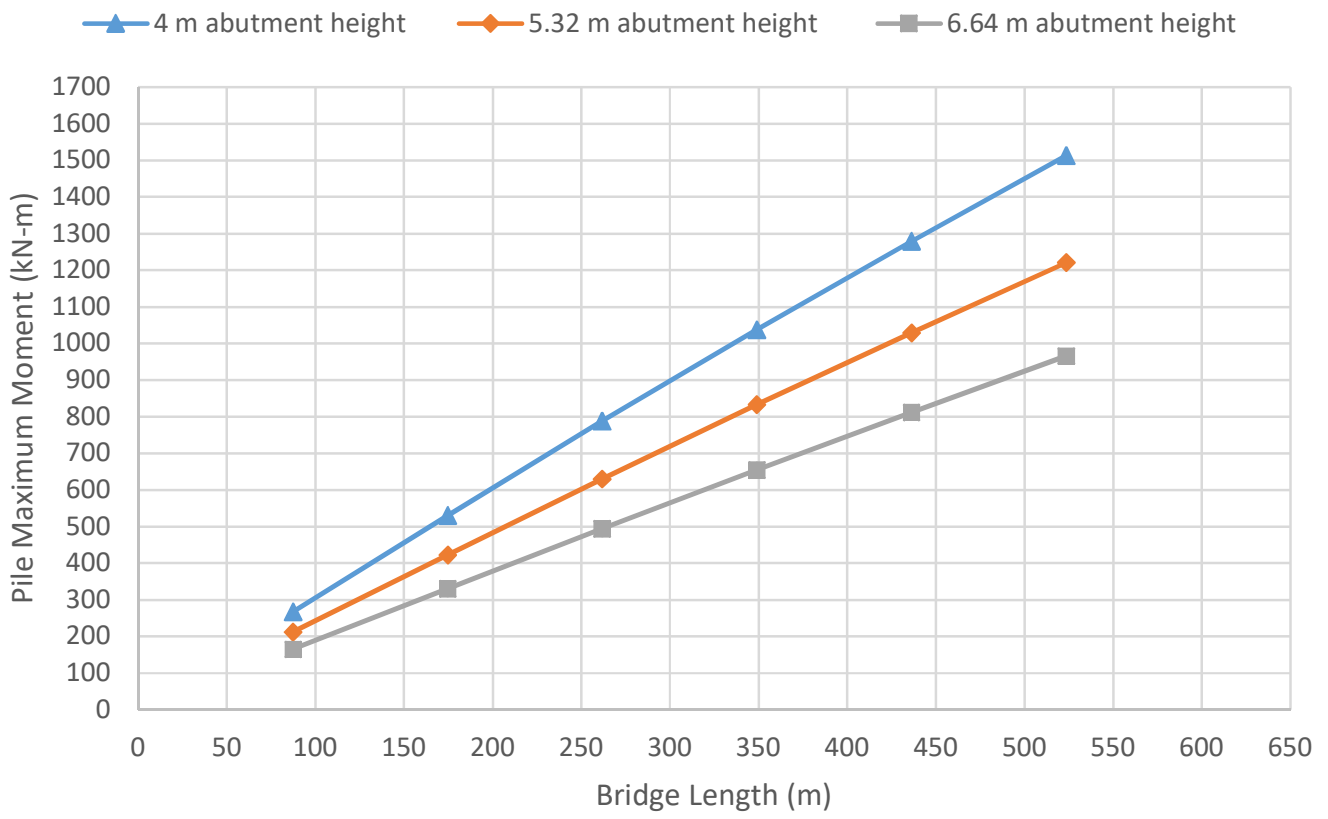

Figure 4.76 Pile Maximum Moment in Case of Loose Sand Supporting the Abutment and Piles Embedded in Medium Dense Sand for Bridge at Radius of $250 \mathrm{~m}$ 


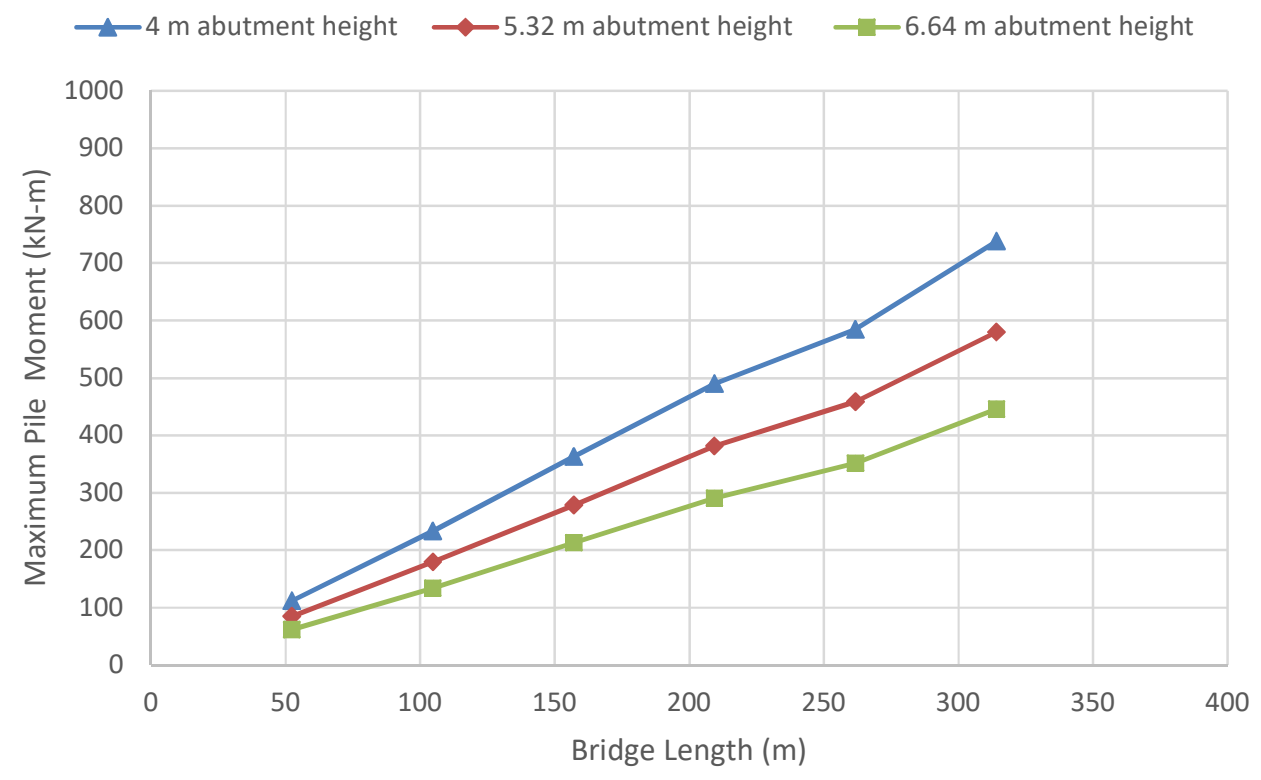

Figure 4.77 Pile Maximum Moment in Case of Dense Sand Supporting the Abutment and Piles Embedded in Stiff Clay for Bridge at Radius of $150 \mathrm{~m}$

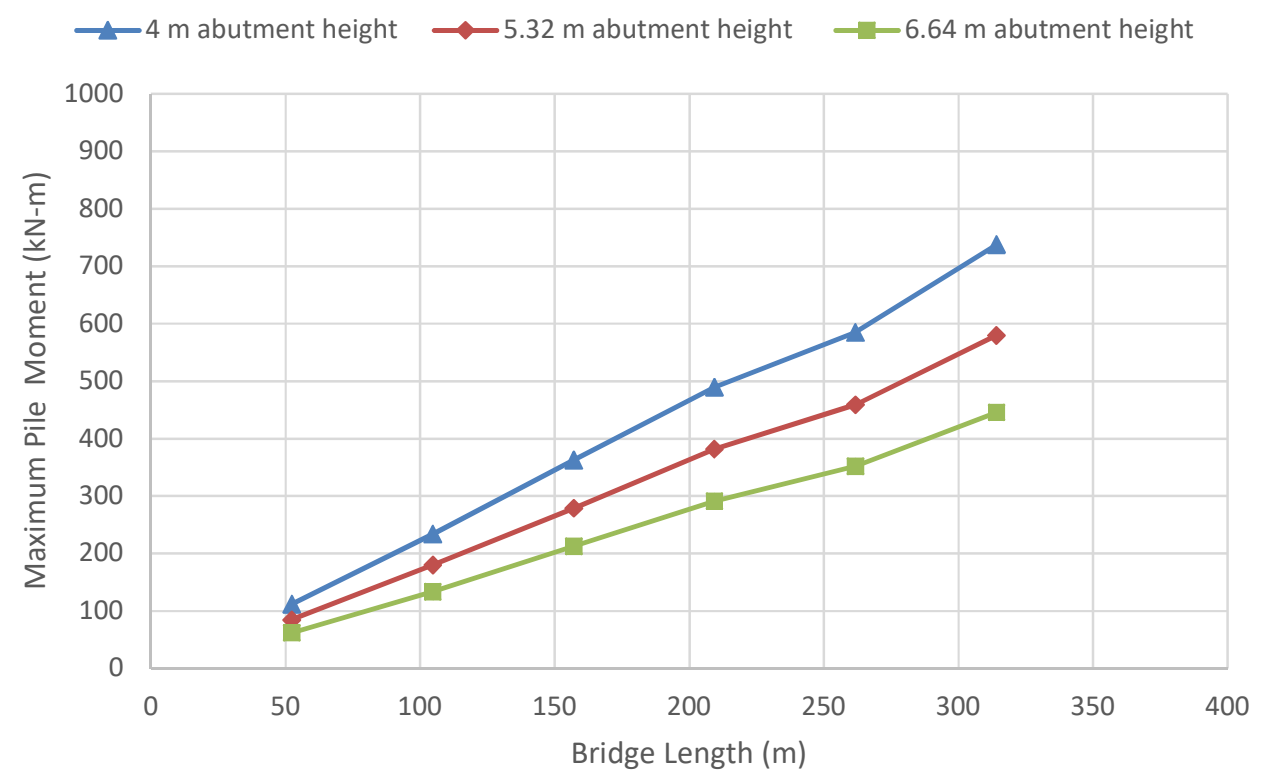

Figure 4.78 Pile Maximum Moment in Case of Loose Sand Supporting the Abutment and Piles Embedded in Stiff Clay for Bridge at Radius of $150 \mathrm{~m}$ 


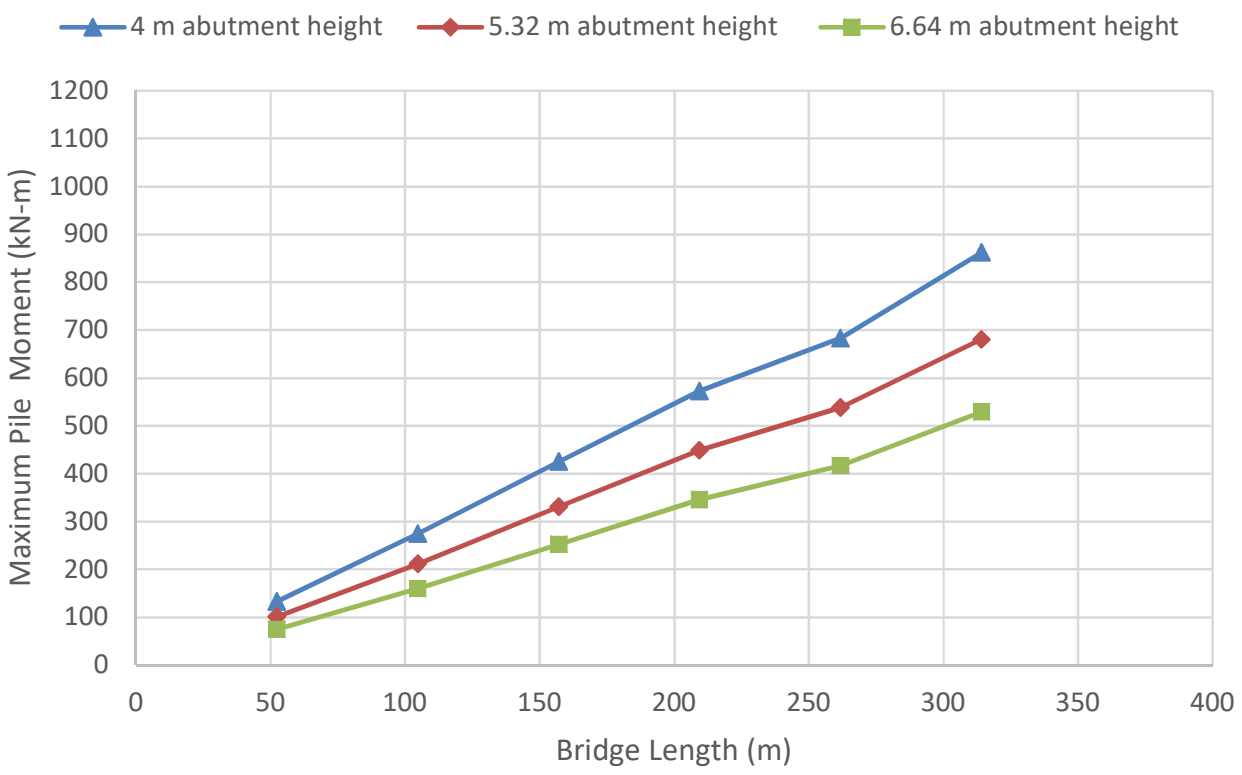

Figure 4.79 Pile Maximum Moment in Case of Loose Sand Supporting the Abutment and Piles Embedded in Medium Dense for Bridge at Radius of $150 \mathrm{~m}$

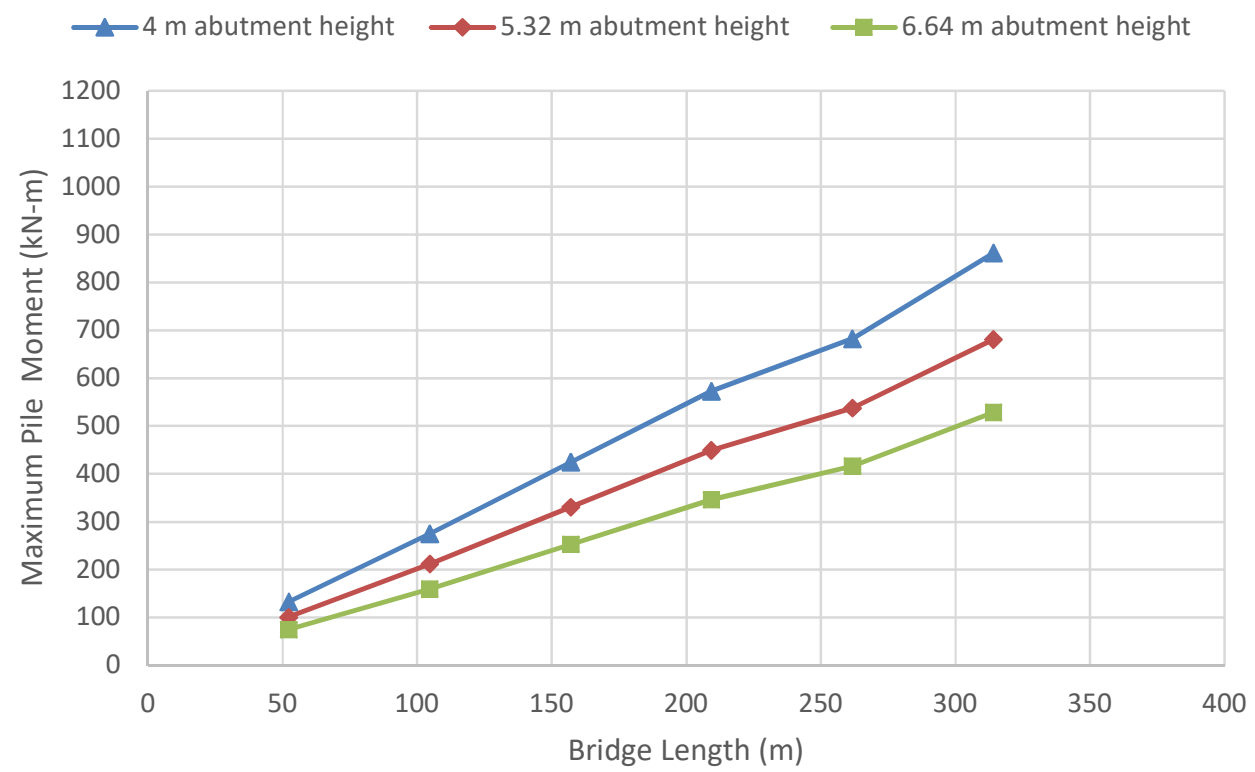

Figure 4.80 Pile Maximum Moment in Case of Dense Sand Supporting the Abutment and Piles Embedded in Medium Dense for Bridge at Radius of $150 \mathrm{~m}$ 


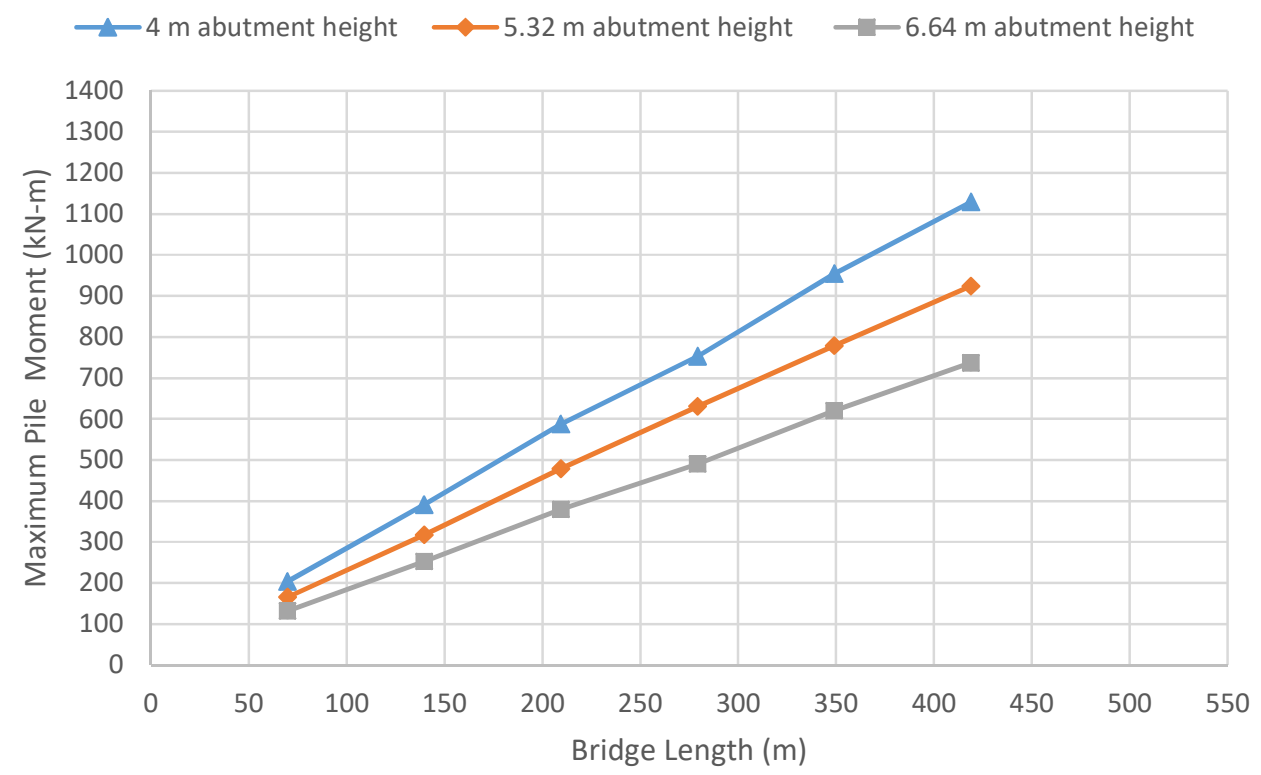

Figure 4.81 Pile Maximum Moment in Case of Dense Sand Supporting the Abutment and Piles Embedded in Stiff Clay for Bridge at Radius of $200 \mathrm{~m}$

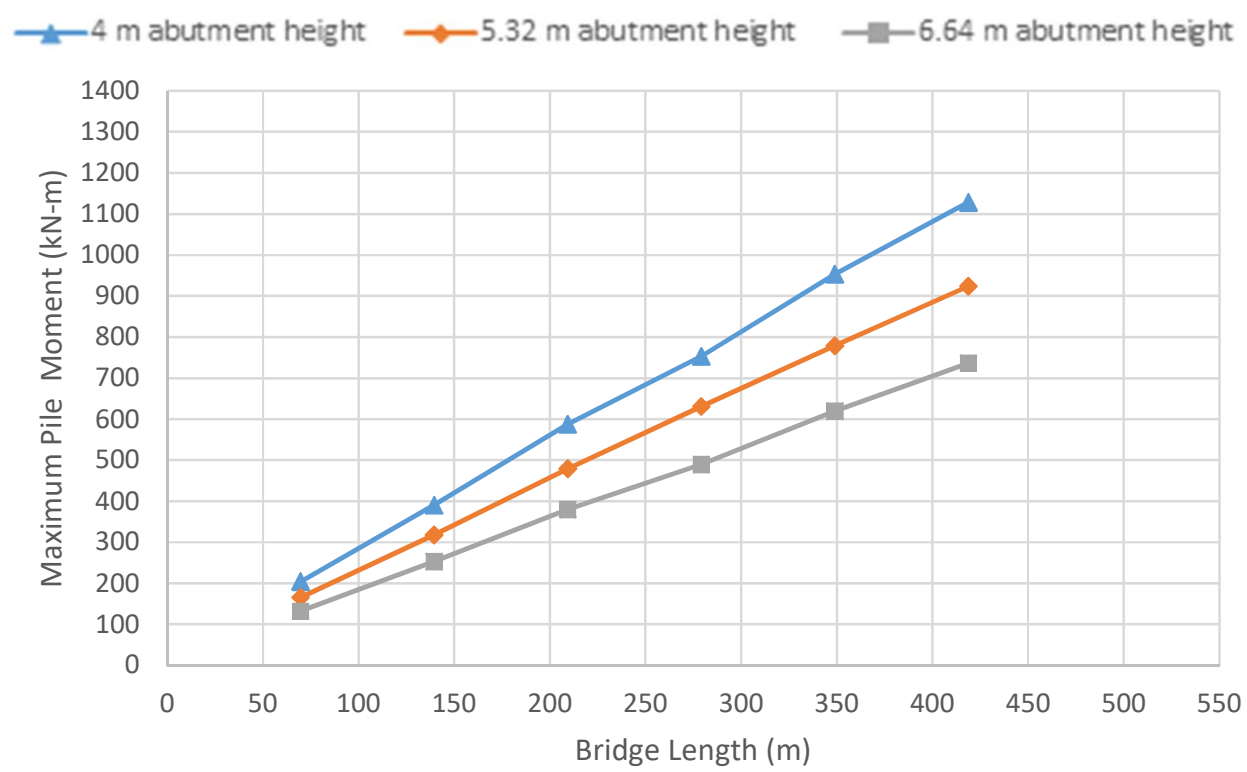

Figure 4.82 Pile Maximum Moment in Case of Loose Sand Supporting the Abutment and Piles Embedded in Stiff Clay for Bridge at Radius of $200 \mathrm{~m}$ 


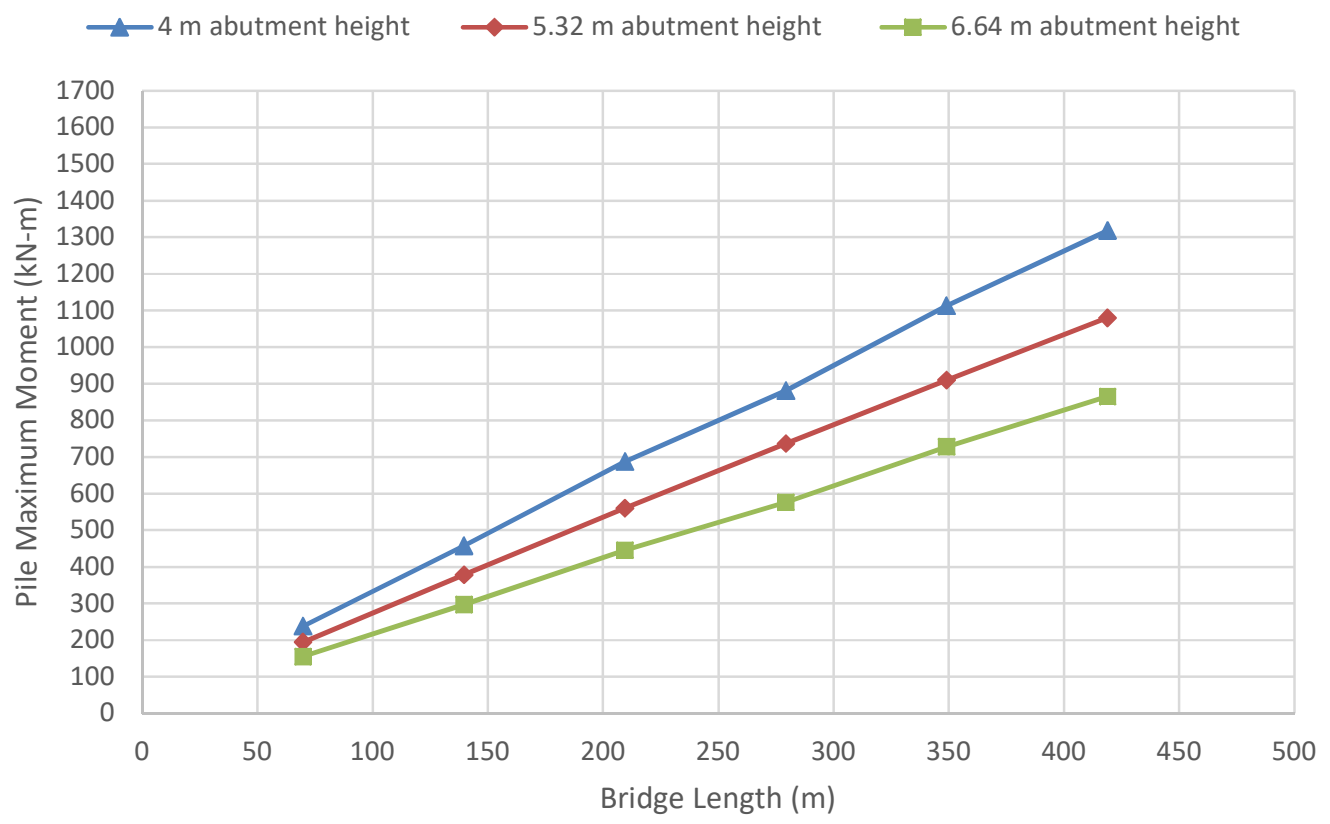

Figure 4.83 Pile Maximum Moment in Case of Loose Sand Supporting the Abutment and piles Embedded in Medium Dense Sand for Bridge at Radius of $200 \mathrm{~m}$

$\longrightarrow 4 \mathrm{~m}$ abutment height $\because 5.32 \mathrm{~m}$ abutment height $\rightarrow-6.64 \mathrm{~m}$ abutment height

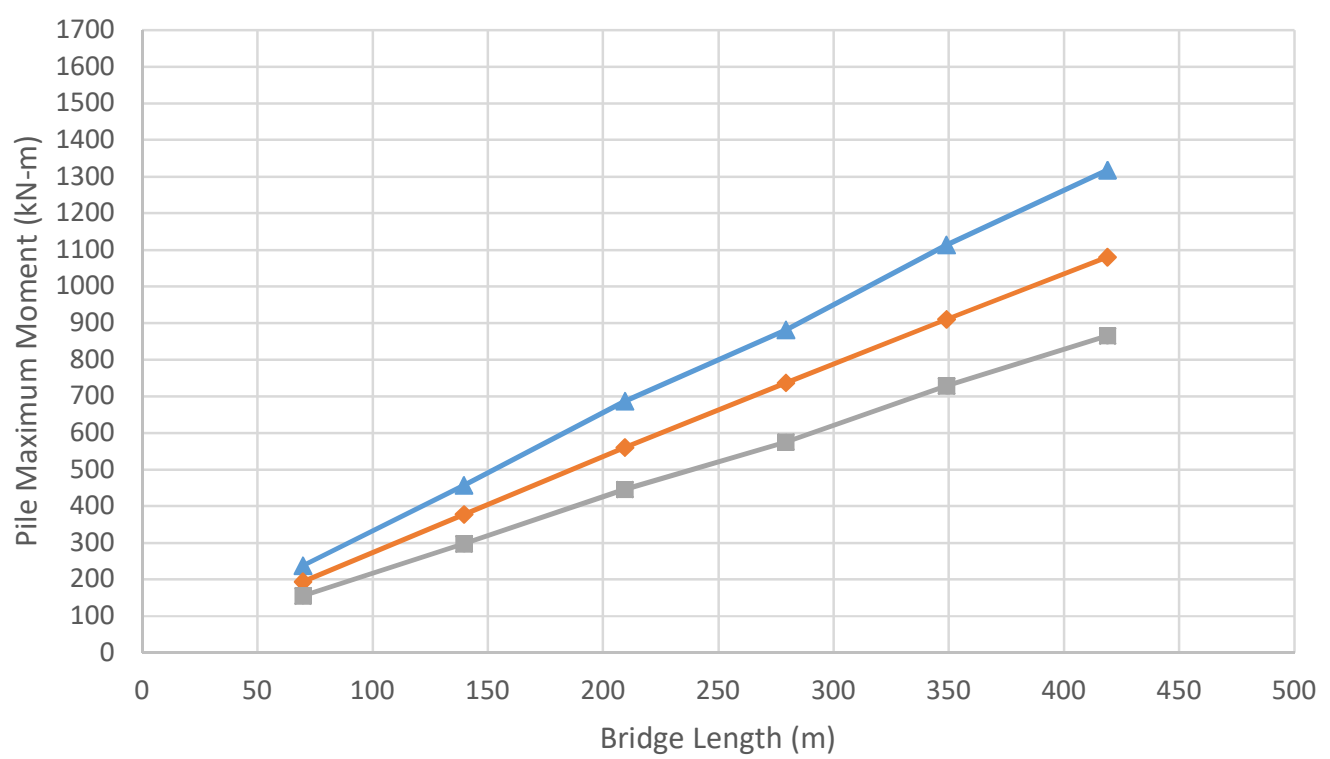

Figure 4.84 Pile Maximum Moment in Case of Dense Sand Supporting the Abutment and Piles Embedded in Medium Dense Sand for Bridge at Radius of $\mathbf{2 0 0 ~ m ~}$ 


\subsection{Maximum Length Limit of Integral Abutment Bridge}

The estimation of maximum length limit of integral abutment bridge (named sometimes critical length) is based on the displacement capacity of the abutment piles. The displacement capacity of the pile depends upon the size and material of the pile. Therefore, the maximum length limit is affected by abutment-pile connection, girders material either concrete or steel, height of bridge abutment, foundation soil, stiffness of backfill material, orientation of the steel $\mathrm{H}$-pile and geographic location of the bridge. Accordingly, the maximum length limits of integral abutment bridges are not rational, but are limited to specified bridge conditions and regions with specified temperature.

Knoxville University in USA conducted a series of field tests on integral abutments supported on both five $250 \times 63 \mathrm{HP}$ piles and four $356 \mathrm{~mm}$ square prestressed concrete piles. Piles were embedded into clay soils. The abutments were displaced laterally under horizontal loading. Results concluded that with steel HP piles, the pile displacement capacity was governed by the cracking of the abutment. No specific recommendation was formulated by the researchers but a value of as much as $38 \mathrm{~mm}$ seemed reasonable for concrete piles and more for steel piles as reported elsewhere (Pétursson, 2015). Arsoy et al. (2002) reported from a literature survey that bridge abutment piles can tolerate 0.65 inches to 2.0 inches of bridge contraction, while the induced stresses in the pile reached $100 \%$ of nominal yield stress. In other bridges, they can tolerate 1.2 inches to 1.7 inches from bridge contraction, while the induced stresses in the pile were bigger than $60 \%$ to $75 \%$ of nominal yield stress. This literature review emphasized that the displacement capacity of the pile can be considered as the maximum pile lateral displacement to ensure its elastic response under service loading.

Assuming pile displacement capacity to be $40 \mathrm{~mm}$ in the current study, the maximum length limit was calculated as the bridge length that satisfies that displacement limit under specific conditions of span length, soil strata and bridge configuration listed in Table 3.1. The following section summarizes the findings of this approach considering the temperature loading along with self-weight of the structure. 


\subsubsection{Equations Relating Bridge Maximum Length Limit to Abutment Height where Piles are Embedded in Clay}

The bridge maximum length limits were obtained from pile maximum resultant displacementbridge length relationships during contraction phases of the bridge. Therefore, the influence of backfill soil type supporting the bridge abutment on the maximum length limit is discarded. Frosch and Lovell (2011) reported that the maximum lateral pile demand occurs due to contraction. Also, Doust (2011) reported that contraction loading of an integral abutment bridge is the most critical loading for bridge design. This explains the dependency on pile maximum resultant displacement during bridge contraction for assessing the maximum limit length.

Figures 4.85 through 4.93 show the change in bridge maximum length limit as a function of abutment height in case of either dense or loose sand behind the abutment with piles embedded in stiff clay foundation soil. Such bridge maximum length limits produce displacement under thermal contraction phase and self-weight in which the piles can tolerate $40 \mathrm{~mm}$ maximum resultant displacement at pile head. The change of the backfill type from loose to dense sand behind the abutment has no effect on the maximum length limit, since backfill active pressure was discarded in case of thermal contraction. Table 4.18 summarizes the developed equations for the bridge maximum length limit as a function of abutment height for each radius of curvature considered in this study. The figures and the table indicated that the bridge maximum length limit is highly dependent on the bridge abutment height. This agrees with results reported by Nikravan (2013). The figures depicted that the radius of curvature of the bridge has no appreciable effect on the critical length within the range of radius of curvature considered in this study. The critical length increased with the increase of abutment height. The mean value of the absolute term in equations presented in Table 4.18 is (114) for all values of $R$. 
Table 4.18 Equations Correlating Abutment Height with Bridge Maximum Length Limit Where Piles Embedded in Clay

\begin{tabular}{|c|cc|}
\hline Radius $(\mathbf{m})$ & \multicolumn{3}{|c|}{ Equation } \\
\hline 60 & $L=1.37 H^{2}+1.66 H+123.03$ & $(4.17)$ \\
\hline 100 & $L=0.82 H^{2}+3.45 H+114.74$ & $(4.18)$ \\
\hline 150 & $L=1.46 H^{2}+4.64 H+114.58$ & $(4.19)$ \\
\hline 200 & $L=1.96 H^{2}-4.72 H+129.71$ & $(4.20)$ \\
\hline 250 & $L=0.94 H^{2}+8.61 H+95.374$ & $(4.21)$ \\
\hline 300 & $L=1.39 H^{2}+5.80 H+104.29$
\end{tabular}

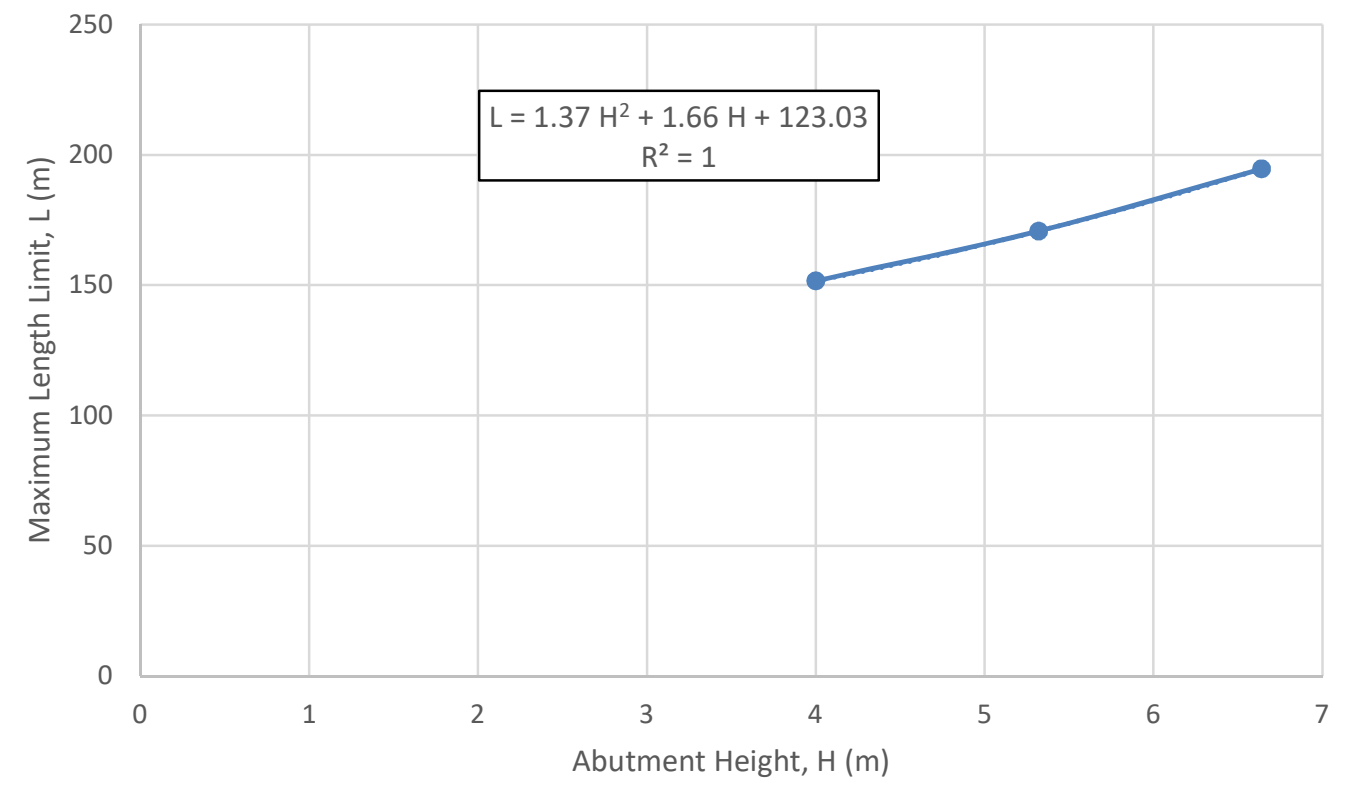

Figure 4.85 Equation Correlating Abutment Height and Bridge Maximum Length Limit Derived for $60 \mathrm{~m}$ Radius Integral Bridge in Case of Dense Sand Behind the Abutment and Piles Embedded in Clay 


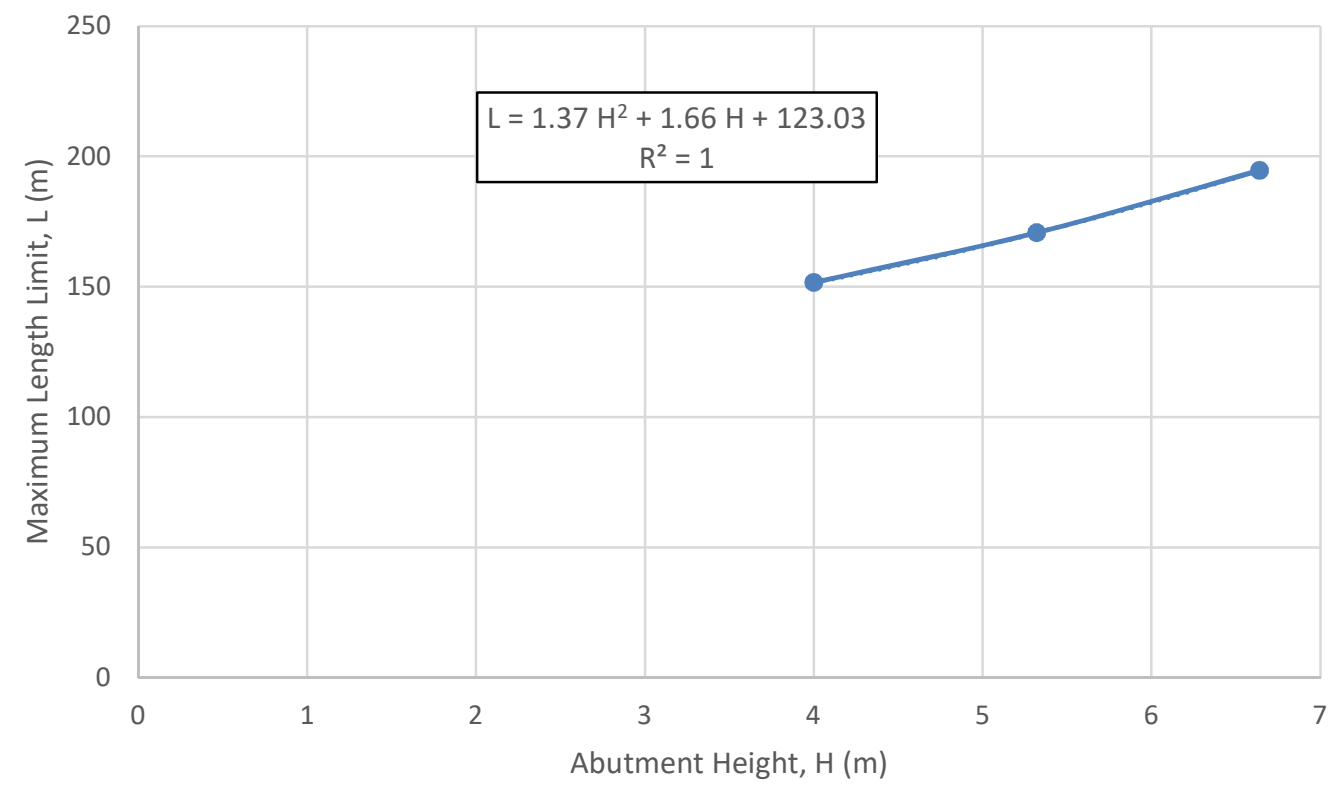

Figure 4.86 Equation Correlating Abutment Height and Bridge Maximum Length Limit Derived for $60 \mathrm{~m}$ Radius Integral Bridge in Case of Loose Sand Behind the Abutment and Piles Embedded in Clay

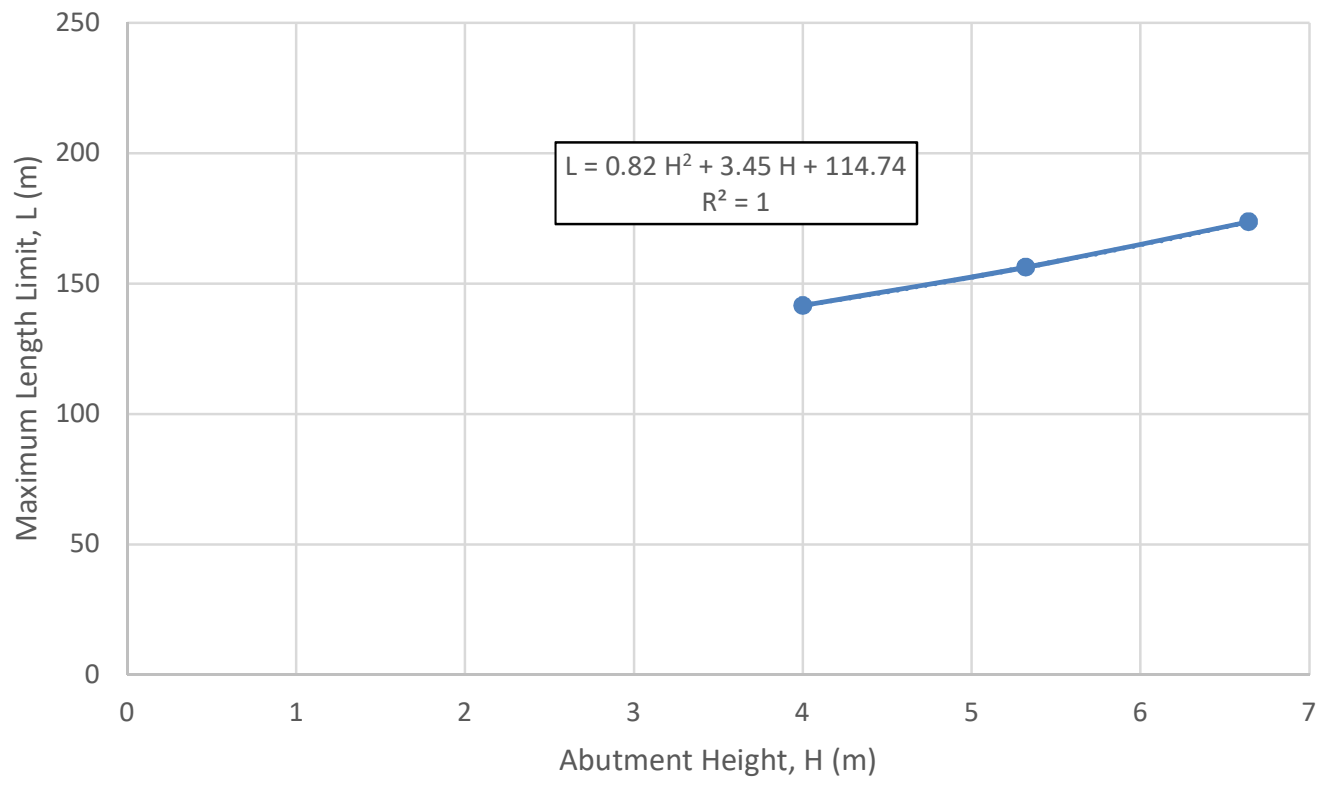

Figure 4.87 Equation Correlating Abutment Height and Bridge Maximum Length Limit Derived for $100 \mathrm{~m}$ Radius Integral Bridge in Case of Dense Sand Behind the Abutment and Piles Embedded in Clay 


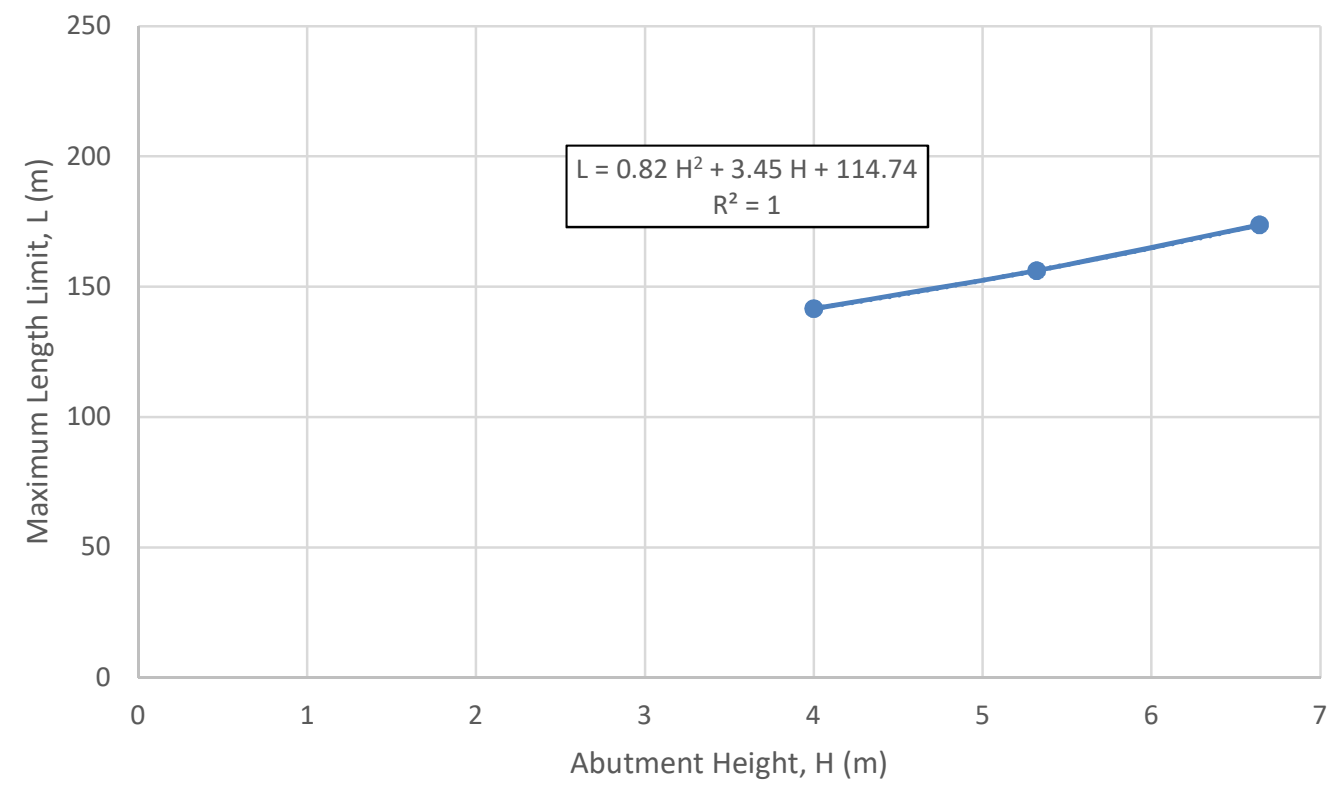

Figure 4.88 Equation Correlating Abutment Height and Bridge Maximum Length Limit Derived for $100 \mathrm{~m}$ Radius Integral Bridge in Case of Loose Sand Behind the Abutment and Piles Embedded in Clay

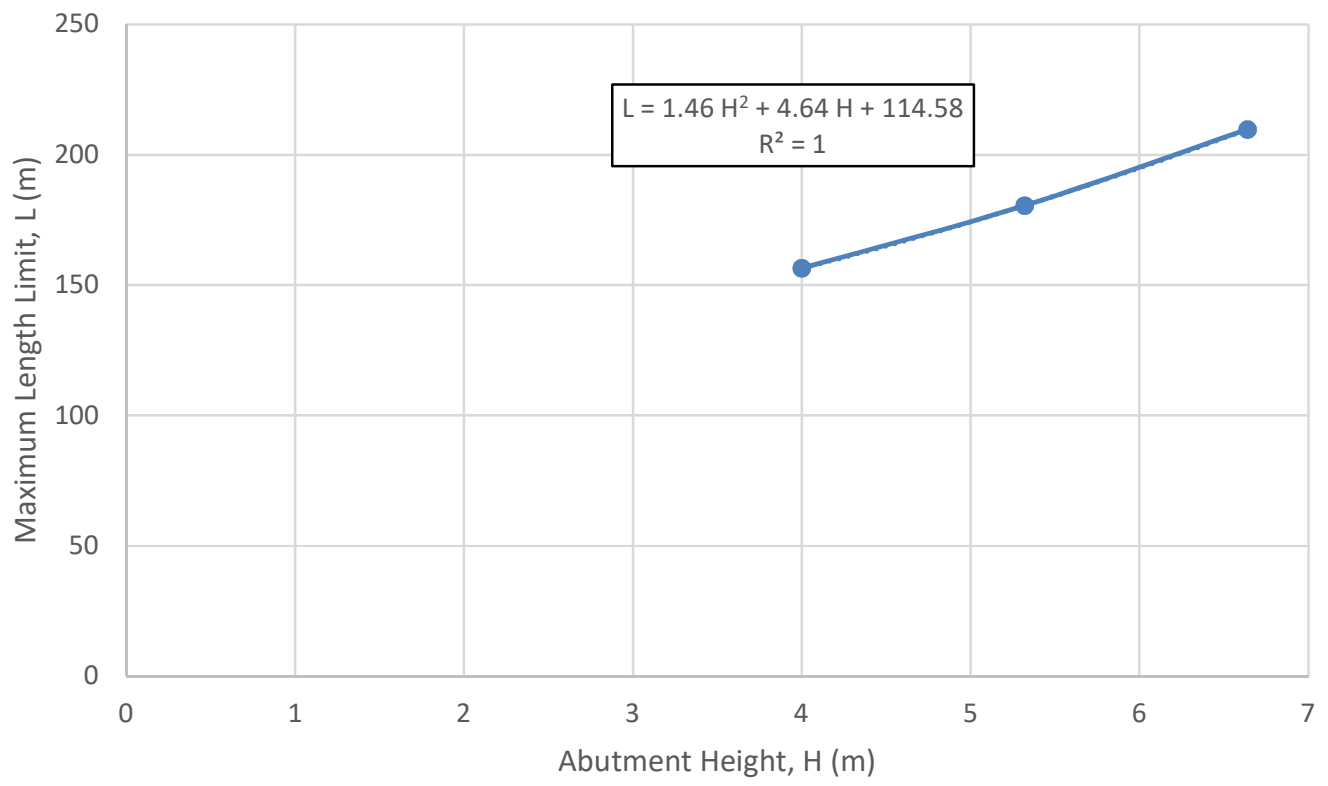

Figure 4.89 Equation Correlating Abutment Height and Bridge Maximum Length Limit Derived for $150 \mathrm{~m}$ Radius Integral Bridge in Case of Dense Sand Behind the Abutment and Piles Embedded in Clay 


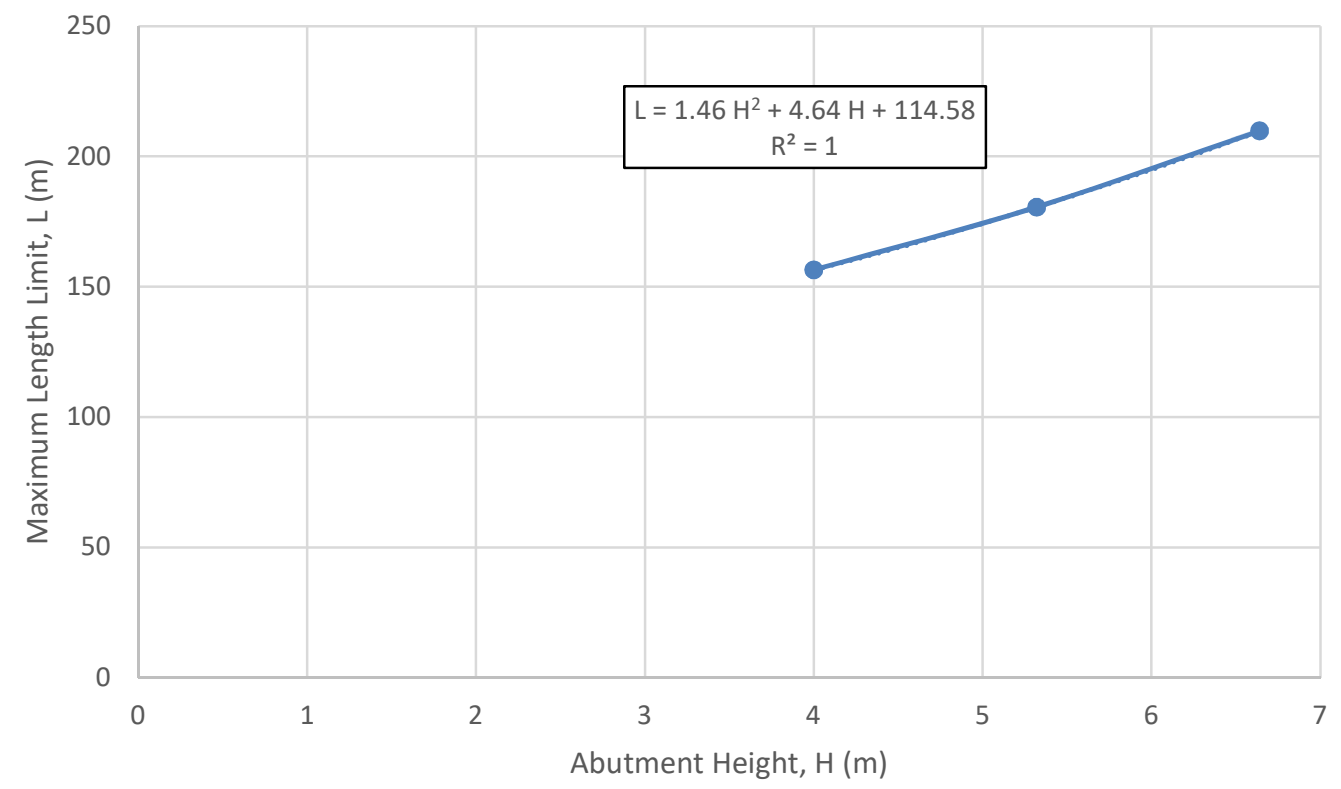

Figure 4.90 Equation Correlating Abutment Height and Bridge Maximum Length Limit Derived for $150 \mathrm{~m}$ Radius Integral Bridge in Case of Loose Sand Behind the Abutment and Piles Embedded in Clay

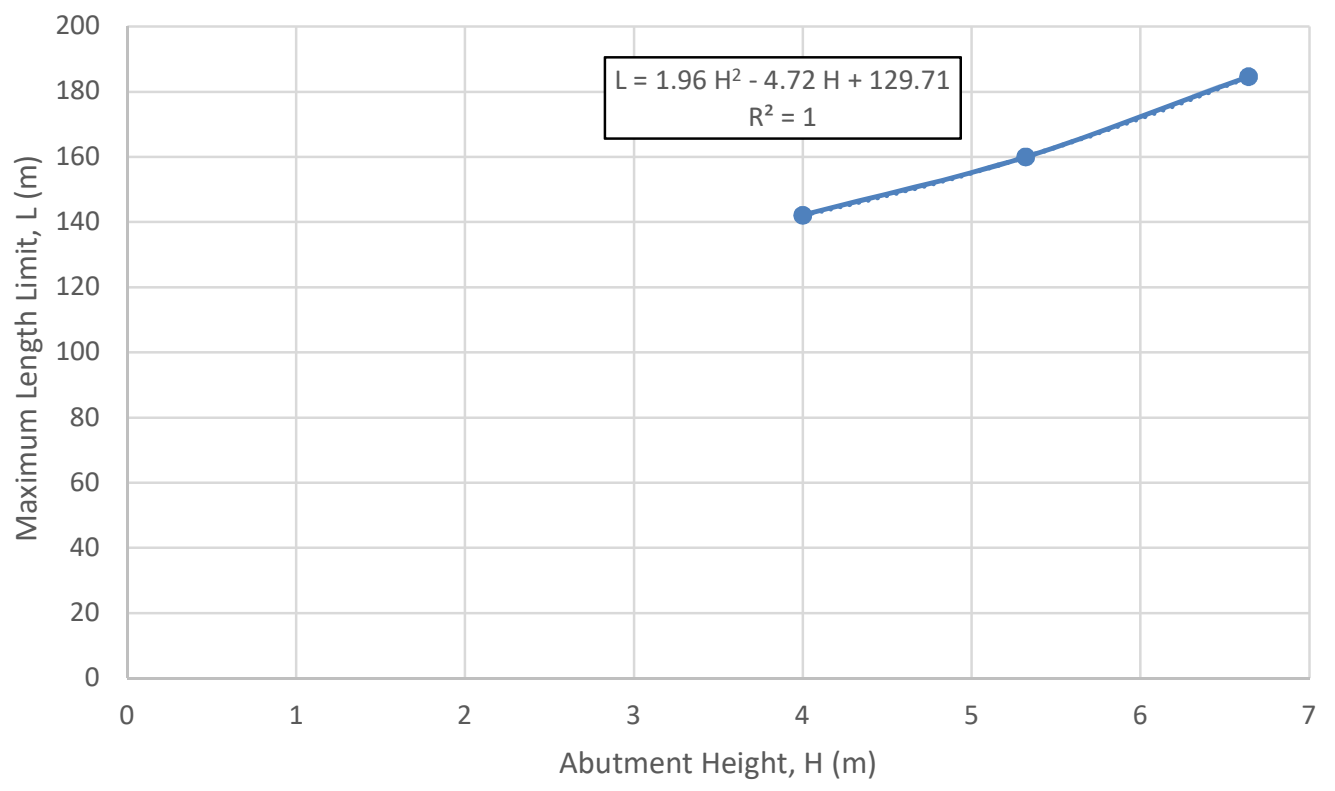

Figure 4.91 Equation Correlating Abutment Height and Bridge Maximum Length Limit Derived for $200 \mathrm{~m}$ Radius Integral Bridge in Case of Dense Sand Behind the Abutment and Piles Embedded in Clay 


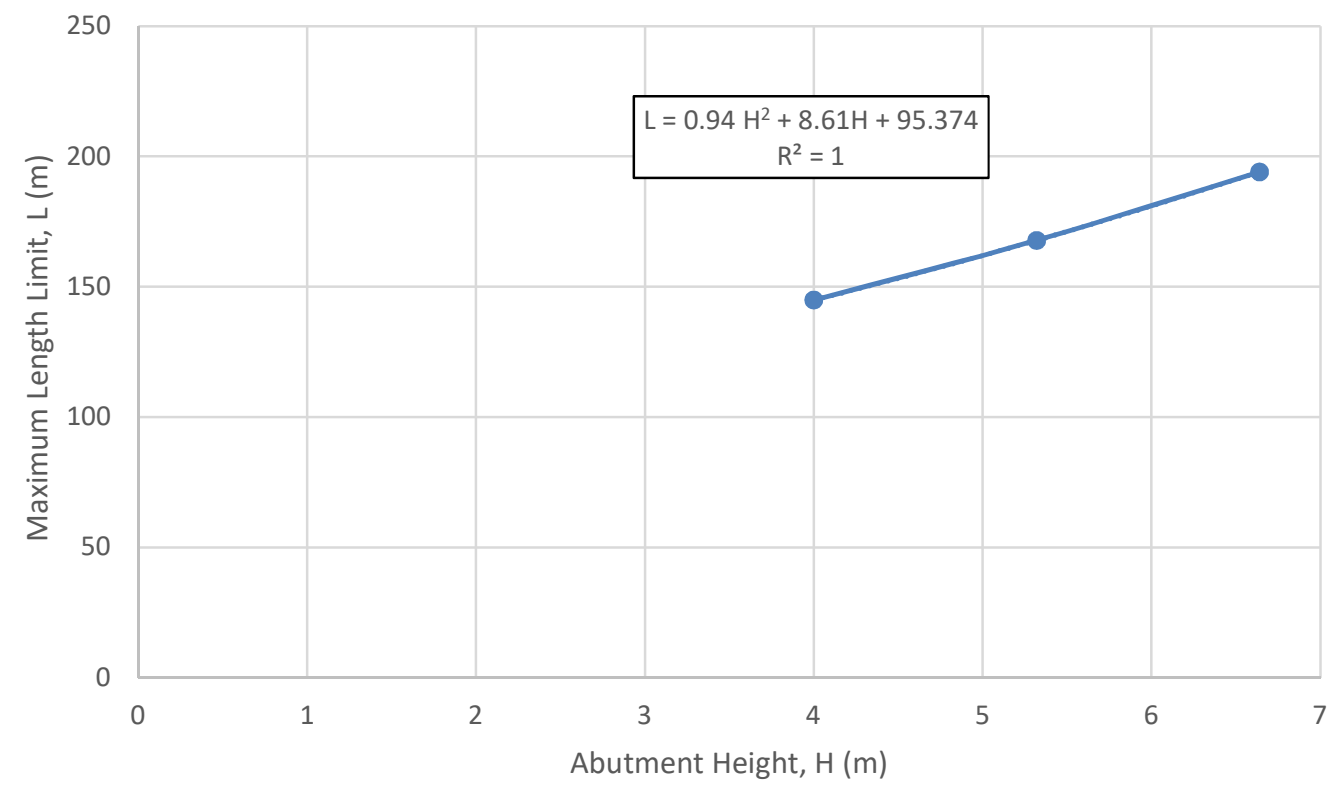

Figure 4.92 Equation Correlating Abutment Height and Bridge Maximum Length Limit Derived for $\mathbf{2 5 0} \mathbf{m}$ Radius Integral Bridge in Case of Loose Sand Behind the Abutment and Piles Embedded in Clay

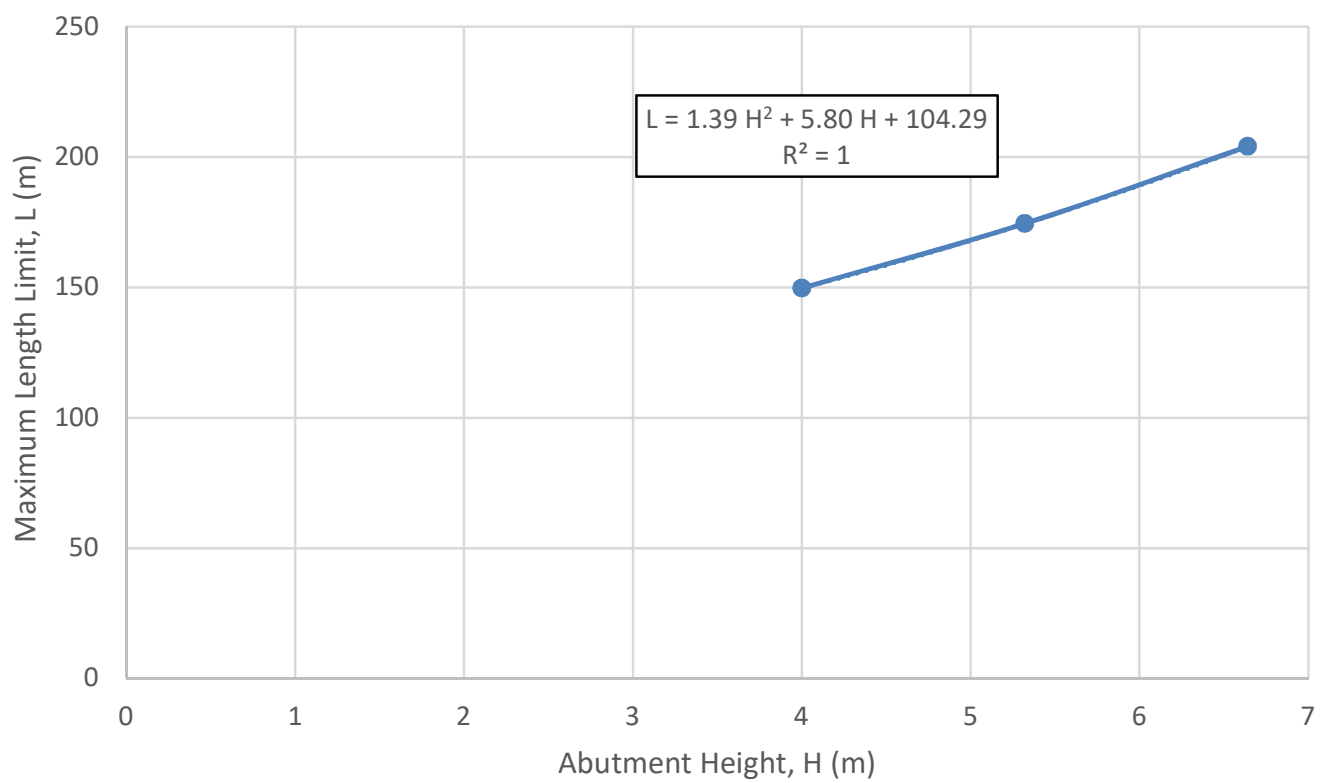

Figure 4.93 Equation Correlating Abutment Height and Bridge Maximum Length Limit Derived for $300 \mathrm{~m}$ Radius Integral Bridge in Case of Dense Sand Behind the Abutment and Piles Embedded in Clay 


\subsubsection{Equations Relating Bridge Maximum Length Limit to Abutment Height where Piles are Embedded in Medium Dense Sand}

Figures 4.94 through 4.99 show the change in bridge maximum length limit as a function of abutment height in case of either dense or loose sand behind the abutment with piles embedded in medium dense sand foundation soil. Such bridge maximum length limits produce displacement under thermal contraction phase and self-weight in which the piles can tolerate $40 \mathrm{~mm}$ maximum resultant displacement at pile head. The change of the backfill type from loose to dense sand behind the abutment has no effect on the maximum length limit, since backfill active earth pressure of sand was discarded in case of thermal contraction. Table 4.19 summarizes the developed equations for the bridge maximum length limit as a function of abutment height for each radius of curvature considered in this study. The figures and the table indicated that the bridge maximum length limit is highly affected by bridge abutment height. The same conclusion was reported by Nikravan (2013).

The mean value of the absolute term in equations presented in Table 4.19 is (116 m) for all values of R. By comparing the mean of absolute value of the two sets of equations presented in Tables 4.18 and 4.19 revealed that there is no appreciable effect of foundation soil type on bridge maximum length limit sine the difference is within $3 \%$.

Table 4.19 Equations Correlating Abutment Height with Bridge Maximum Length Limit Where Piles Embedded in Medium Dense Sand

\begin{tabular}{|c|c|c|}
\hline Radius (m) & Equation & \\
\hline 60 & $L=1.14 H^{2}+4.08 H+119.13$ & (4.23) \\
\hline 100 & $L=0.87 H^{2}+3.23 H+116.38$ & (4.24) \\
\hline 150 & $L=1.47 H^{2}+4.68 H+116.45$ & $(4.25)$ \\
\hline 200 & $L=2.15 H^{2}-6.49 H+135.60$ & (4.26) \\
\hline 250 & $L=1.43 H^{2}+3.63 H+109.77$ & (4.27) \\
\hline 300 & $L=1.38 H^{2}+6.99 H+100.31$ & (4.28) \\
\hline
\end{tabular}




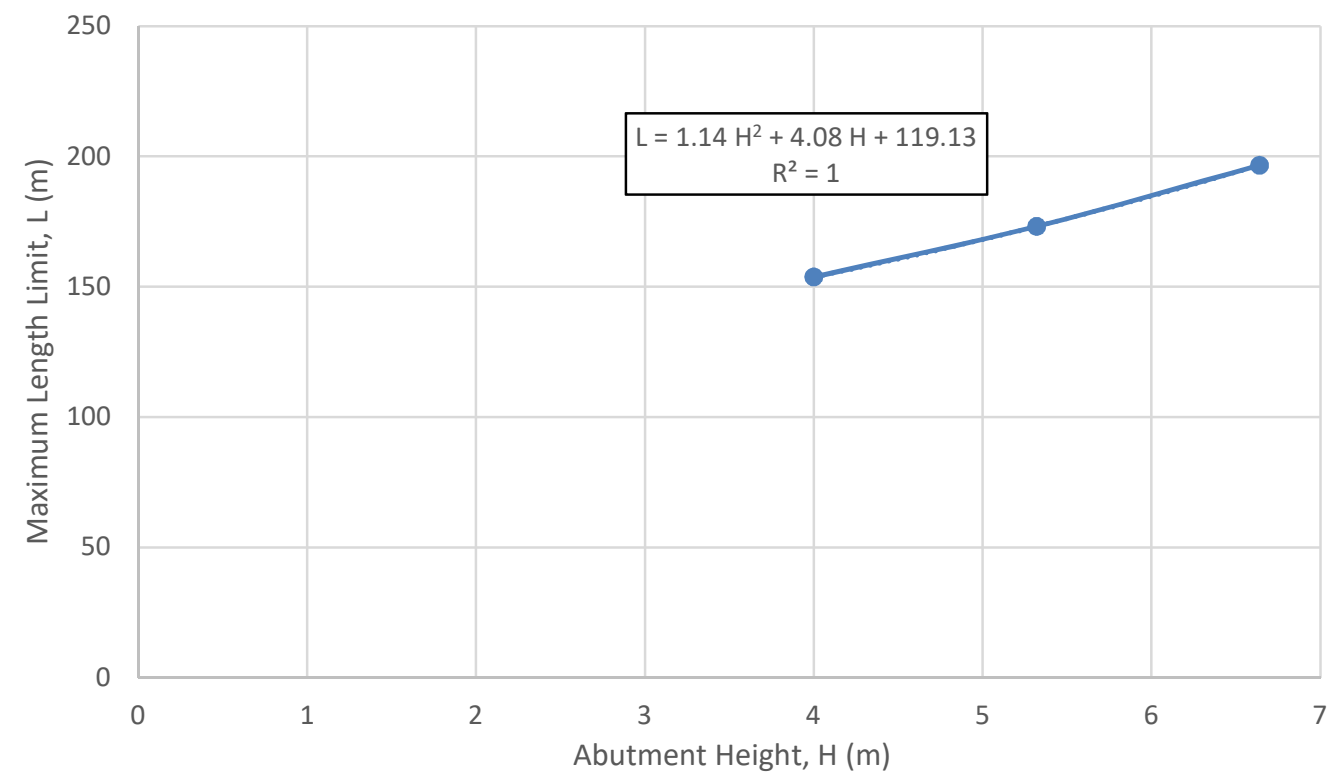

Figure 4.94 Equation Correlating Abutment Height and Bridge Maximum Length Limit Derived for $60 \mathrm{~m}$ Radius Integral Bridge in Case of Dense Sand Behind the Abutment and Piles Embedded in Medium Dense Sand

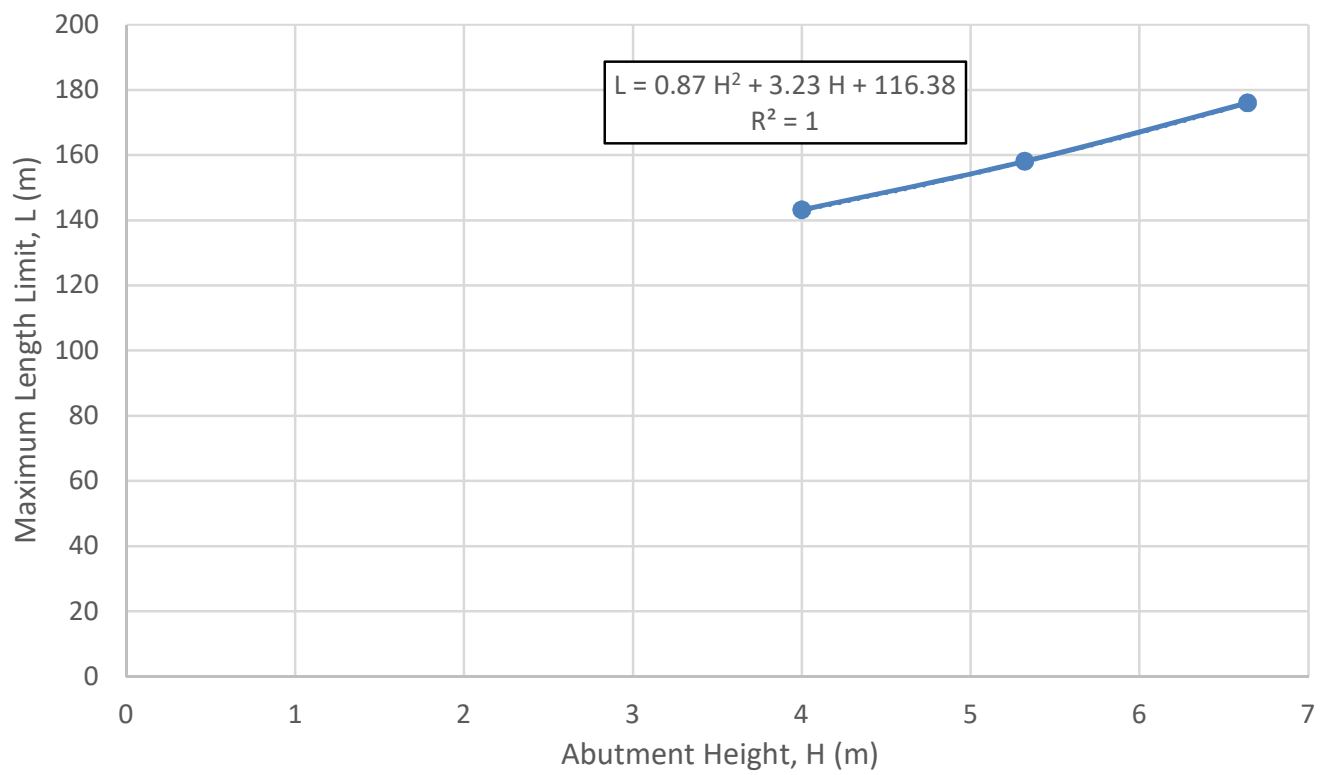

Figure 4.95 Equation Correlating Abutment Height and Bridge Maximum Length Limit Derived for $100 \mathrm{~m}$ Radius Integral Bridge in Case of Dense Sand Behind the Abutment and Piles Embedded in Medium Dense Sand 


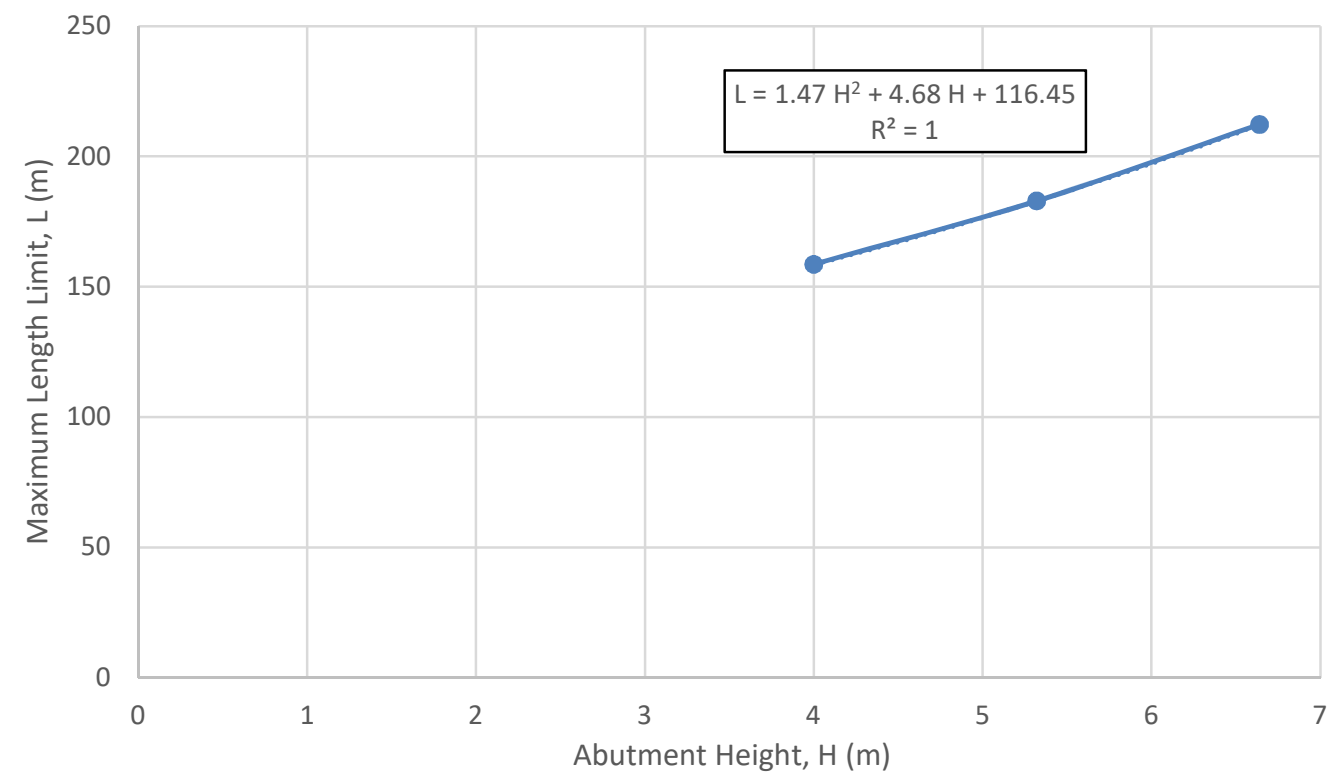

Figure 4.96 Equation Correlating Abutment Height and Bridge Maximum Length Limit Derived for $150 \mathrm{~m}$ Radius Integral Bridge in Case of Dense Sand Behind the Abutment and Piles Embedded in Medium Dense Sand

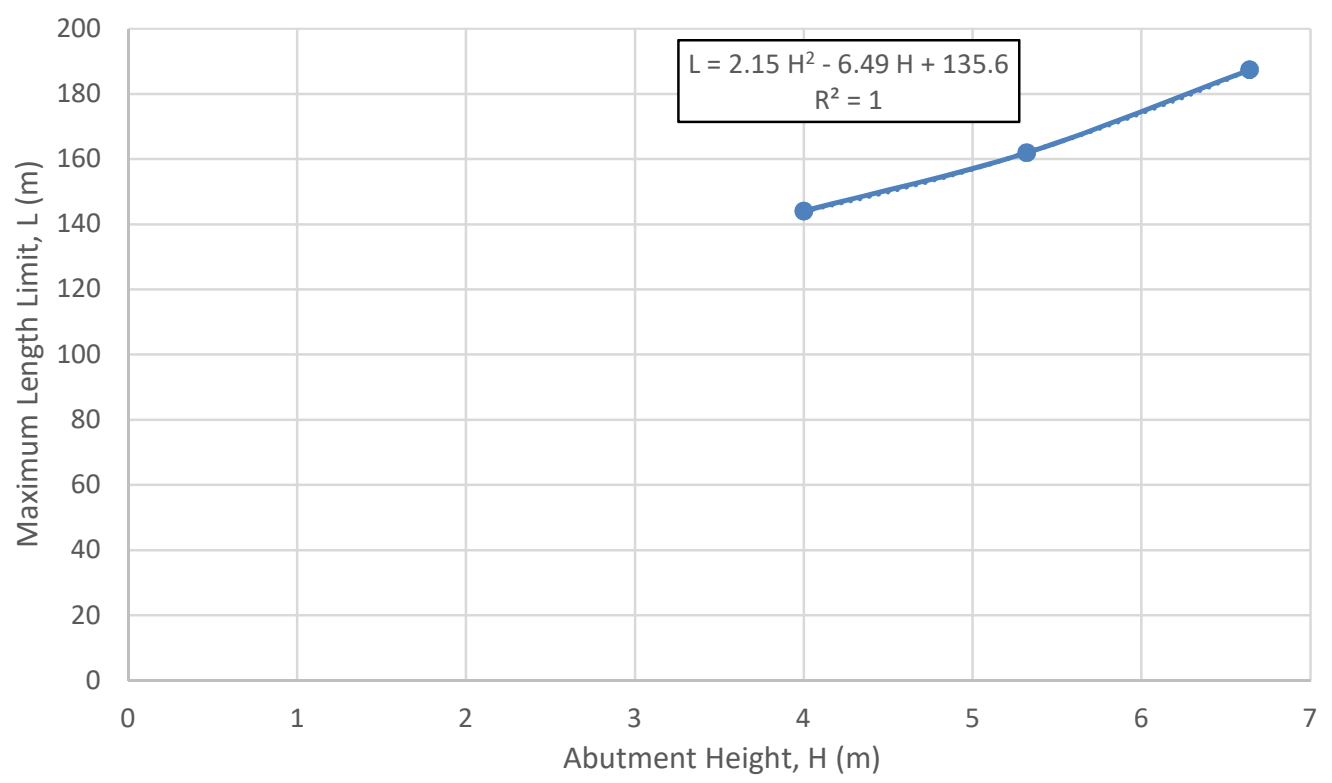

Figure 4.97 Equation Correlating Abutment Height and Bridge Maximum Length Limit Derived for $200 \mathrm{~m}$ Radius Integral Bridge in Case of Dense Sand Behind the Abutment and Piles Embedded in Medium Dense Sand 


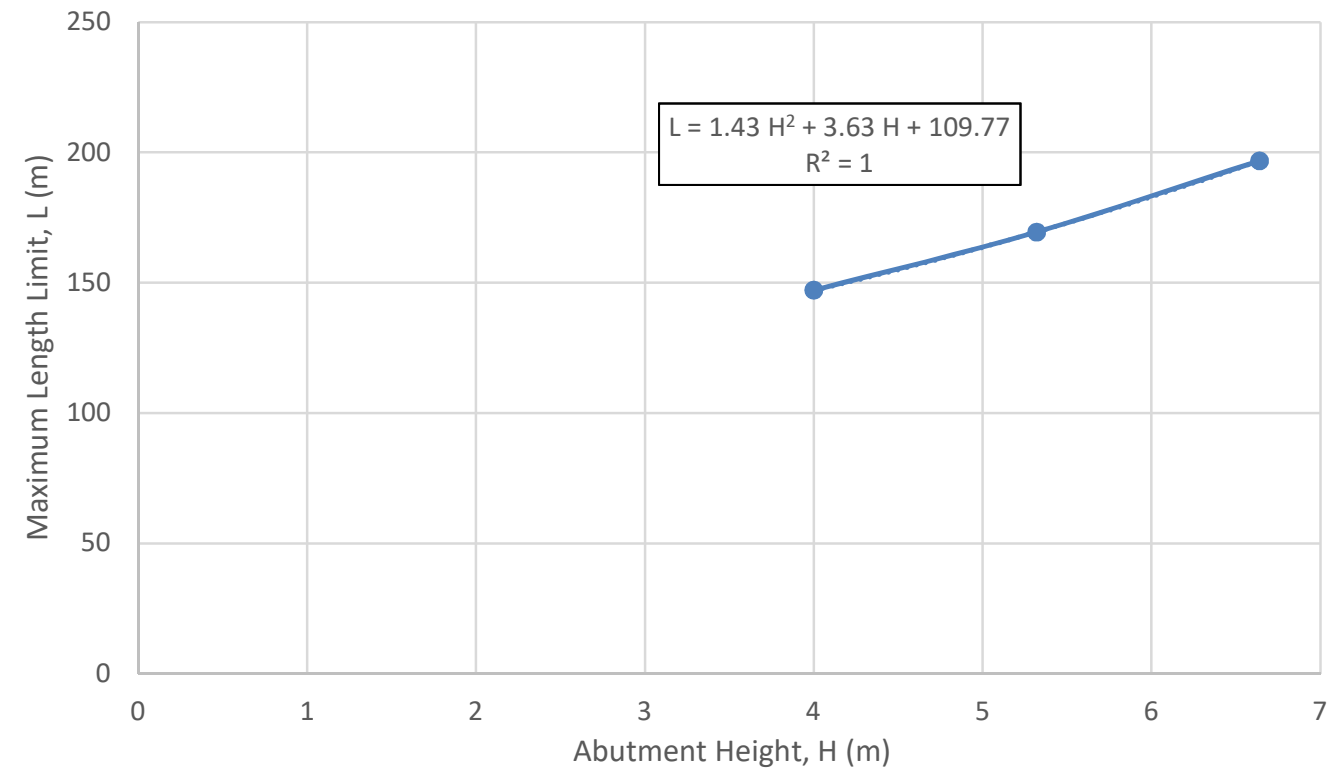

Figure 4.98 Equation Correlating Abutment Height and Bridge Maximum Length Limit Derived for $250 \mathrm{~m}$ Radius Integral Bridge in Case of Dense Sand Behind the Abutment and Piles Embedded in Medium Dense Sand

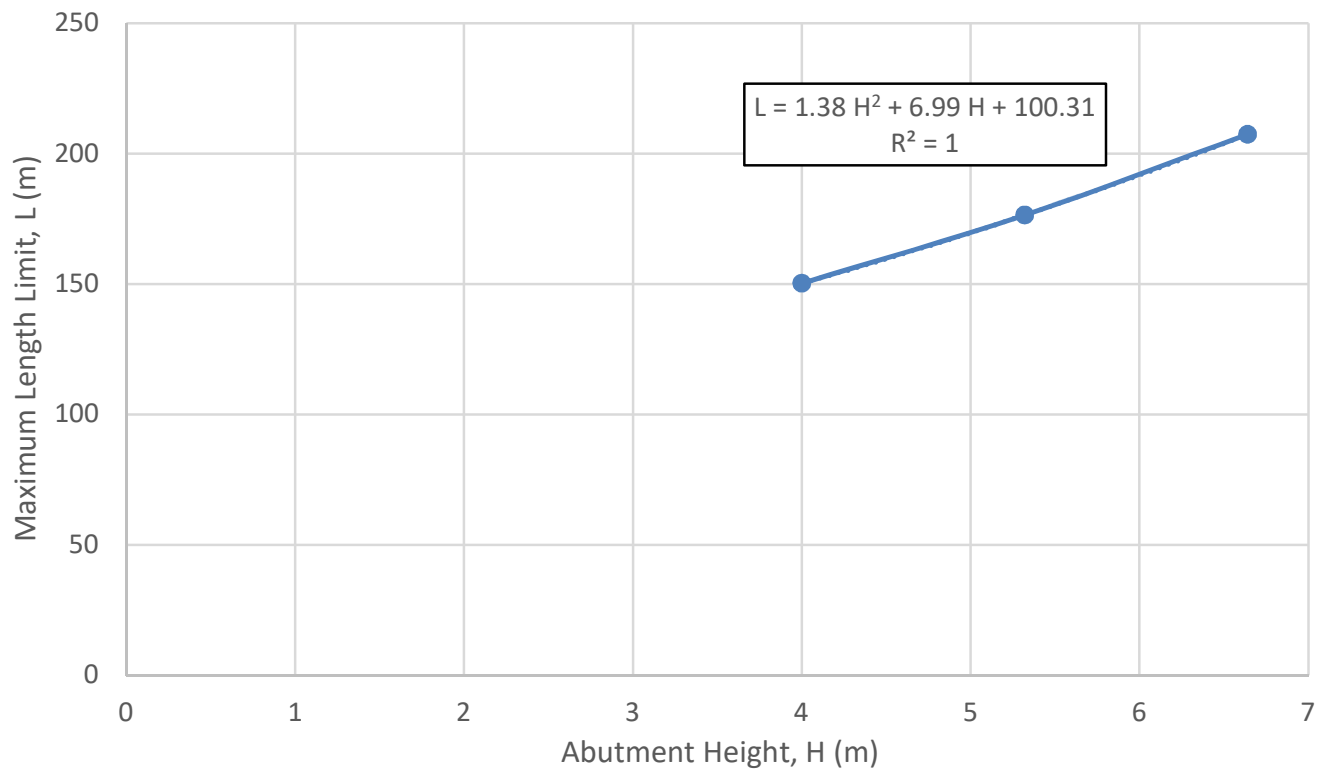

Figure 4.99 Equation Correlating Abutment Height and Bridge Maximum Length Limit Derived for $300 \mathrm{~m}$ Radius Integral Bridge in Case of Dense Sand Behind the Abutment and Piles Embedded in Medium Dense Sand 


\subsection{Effect of Radius of Curvature on Bridge Maximum Length Limit Abutment Piles in Stiff clay}

The bridge maximum length limits were drawn against abutment height for two integral abutment bridges having radius of curvature of $300 \mathrm{~m}$ and $150 \mathrm{~m}$ as shown in Figure 4.100. The two bridges had the same bridge spans length of $26.17 \mathrm{~m}$, and piles embedded in stiff clay. Figure 4.100 depicted that the radius of curvature slightly affect the bridge maximum length limit. This can be attributed to the steel I-girders of the bridge are restrained against lateral displacement in radial directions at piers support. Similar comparison was conducted on other two bridges having radius of curvature of $100 \mathrm{~m}$ and $200 \mathrm{~m}$, respectively. The two bridges had bridge span length of $17.45 \mathrm{~m}$ as shown in Figure 4.101 . The abutment piles were embedded in stiff clay. The figure depicted that the effect of bridge curvature on bridge maximum length limit is minimal. The results of a third case study are presented in Figure 4.102. In this case, the two bridges had radius of curvature of $60 \mathrm{~m}$ and $250 \mathrm{~m}$, with span lengths 20.94 and $21.80 \mathrm{~m}$, respectively. The abutment piles were embedded in stiff clay. The figure depicted that the radius of curvature of the bridge had small effect on bridge maximum length limit. Two horizontally curved integral bridges having radius of curvature of $100 \mathrm{~m}$ and $200 \mathrm{~m}$, respectively, and span length of $17.45 \mathrm{~m}$ were analyzed, and the bridge maximum length limits were obtained. Figure 4.103 presents the variation of bridge maximum length limit against abutment height, where the piles were embedded in medium dense sand. The figure revealed that the curvature of the bridge $(1 / R)$ has no effect on the bridge maximum length limit. Similar analysis was carried out on other two bridges of radius $250 \mathrm{~m}$ and $60 \mathrm{~m}$. The two bridges had spans of $21.8 \mathrm{~m}$ and $20.0 \mathrm{~m}$ respectively. Figure 4.104 revealed that the curvature of the bridge $(1 / R)$ doesn't have an effect on bridge maximum length limit. Last analysis was carried out on two different bridges with radius of curvature of $150 \mathrm{~m}$ and 300 $m$. The two bridges were of equal spans. Figure 4.105 revealed that the bridge curvature $(1 / R)$ doesn't have any appreciable effect on bridge maximum length limit. 


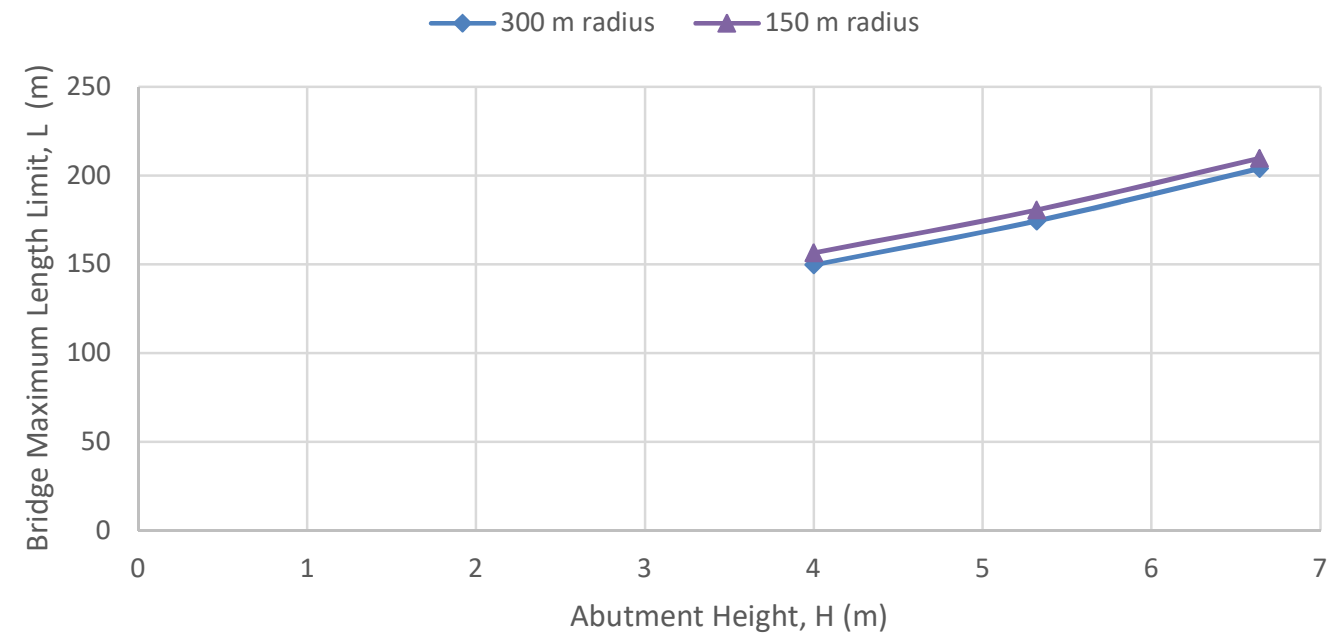

Figure 4.100 Bridge Maximum Length Limit Versus Bridge Abutment Height in Case of Piles Embedded in Stiff Clay and Bridge Span Length of $26.17 \mathrm{~m}$

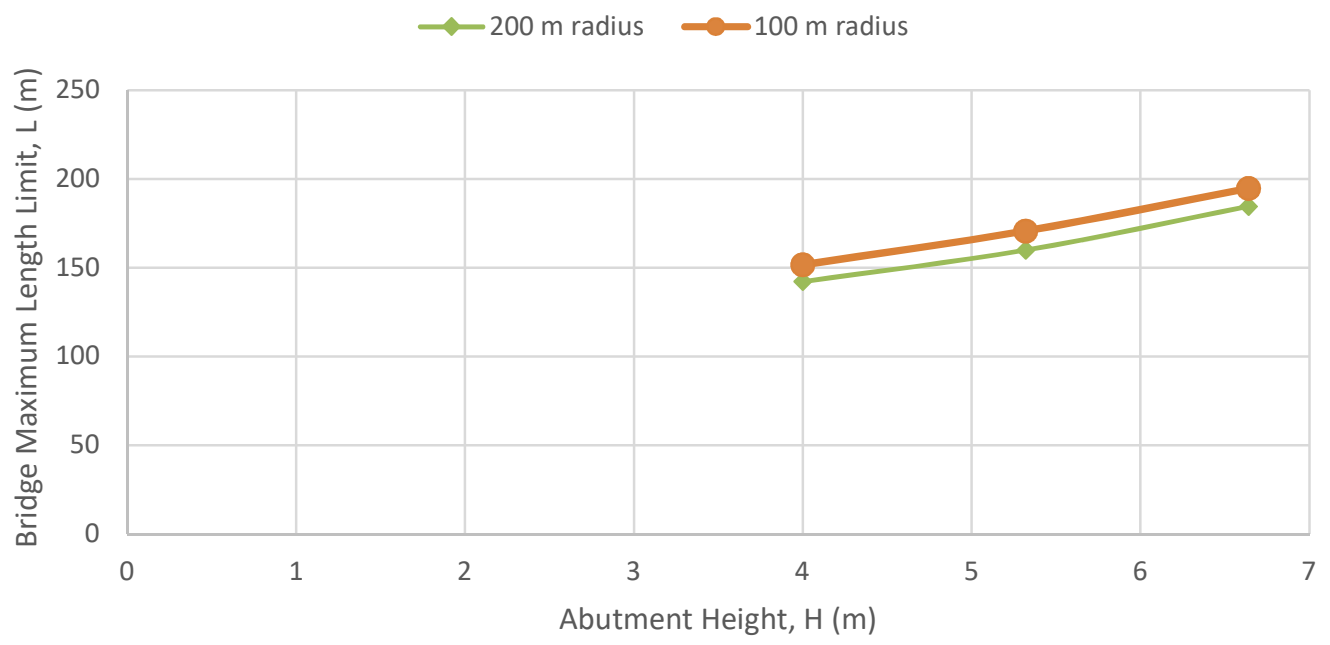

Figure 4.101 Bridge Maximum Length Limit Versus Bridge Abutment Height in Case of Piles Embedded in Stiff Clay and Bridge Span Length of $17.45 \mathrm{~m}$ 


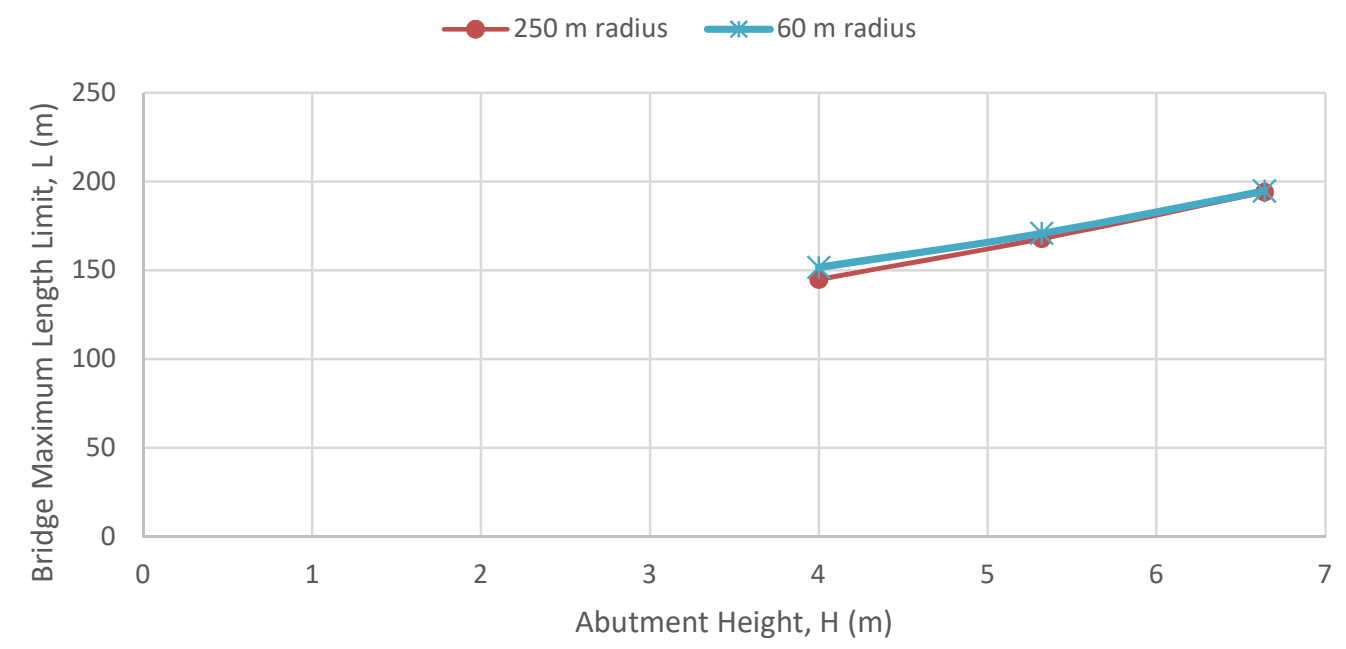

Figure 4.102 Bridge Maximum Length Limit Versus Bridge Abutment Height in Case of Piles Embedded in Stiff Clay and Bridge Span Length of $21.80 \mathrm{~m}$ and $20.94 \mathrm{~m}$

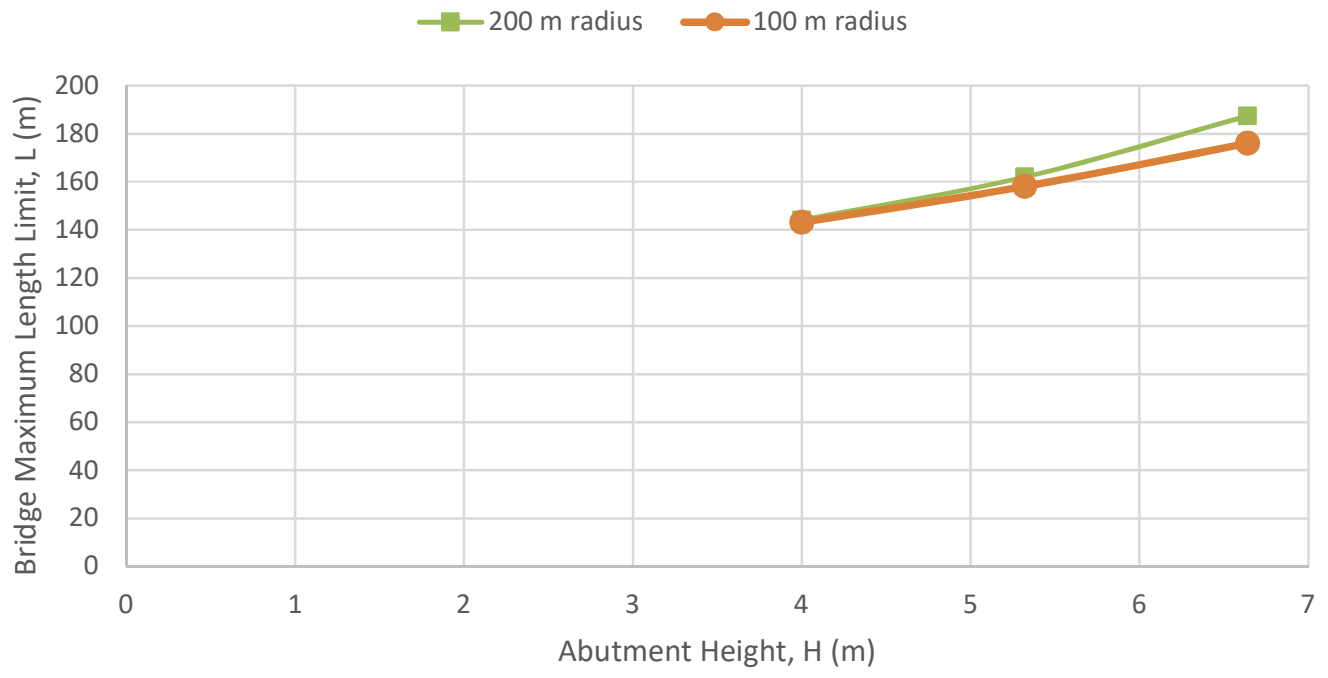

Figure 4.103 Bridge Maximum Length Limit Versus Bridge Abutment Height in Case of Piles Embedded in Medium Dense Sand and Bridge Span Length of $17.40 \mathrm{~m}$ 


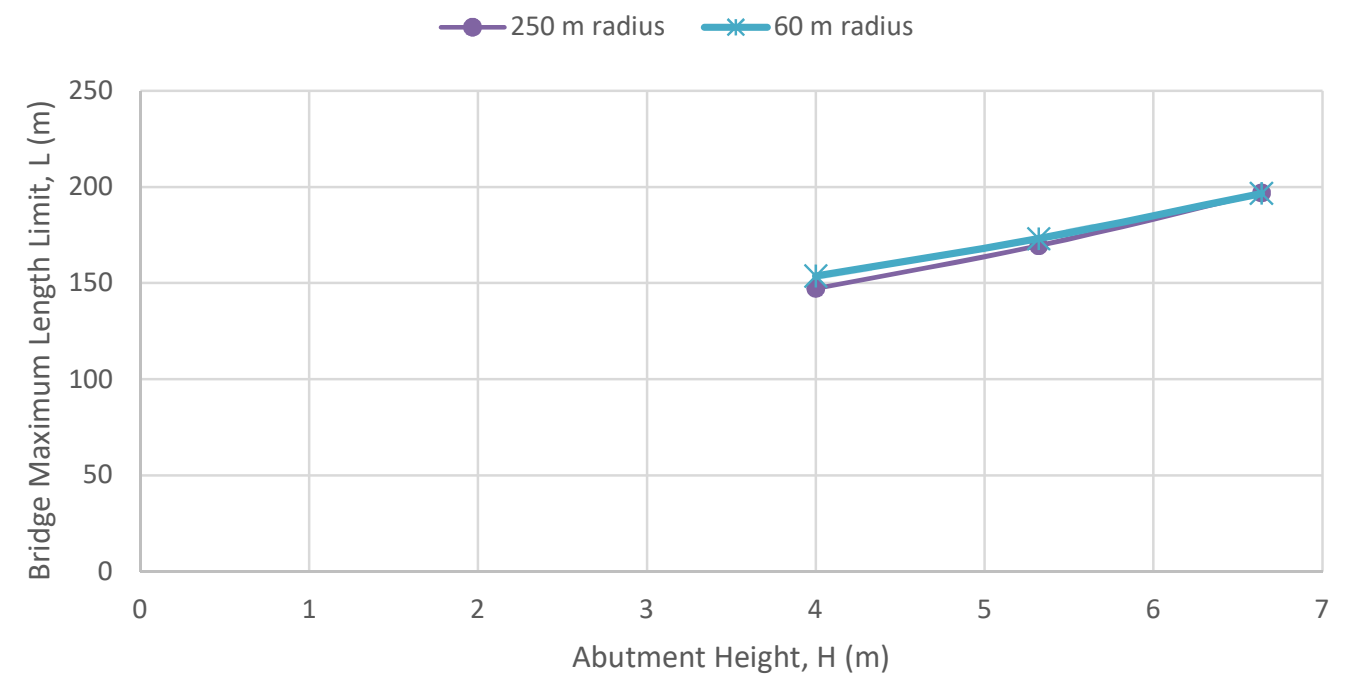

Figure 4.104 Bridge Maximum Length Limit Versus Bridge Abutment Height in Case of Piles Embedded in Medium Dense Sand and Bridge Span Length of $21.80 \mathrm{~m}$ and $20.94 \mathrm{~m}$

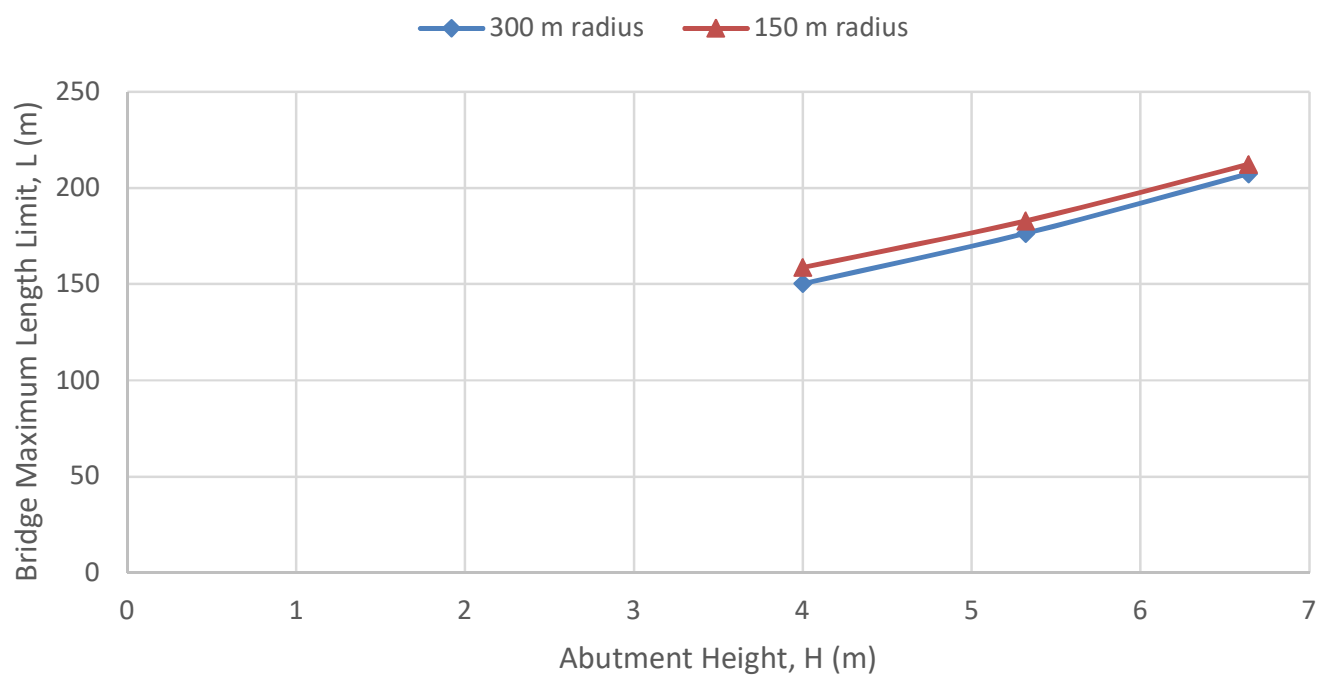

Figure 4.105 Bridge Maximum Length Limit Versus Bridge Abutment Height in Case of Piles Embedded in Medium Dense Sand and Bridge Span Length of $26.17 \mathrm{~m}$

\subsection{Effect of Bridge Span Length on Bridge Maximum Length Limit}

As depicted in table 3.1, the span lengths of the modeled bridges were doubled to be 41.88 $\mathrm{m}, 34.9 \mathrm{~m}, 52.34 \mathrm{~m}$ and $43.6 \mathrm{~m}$ to study the effect of span length on maximum bridge length limit due to seasonal temperature variation. These bridges were analyzed except bridges 
having spans of length $52.34 \mathrm{~m}$ because it is anticipated that steel l-girders of bridges with spans of length $52.34 \mathrm{~m}$ are not common. Also, same of bridges having spans length of 41.8 $\mathrm{m}$, were not analyzed. The pile maximum resultant displacements were presented in Table 4.20. Doubling the span length in a bridge, with a specified length, reduces the number of intermediate piers and a horizontally curved bridge becomes less laterally restrained. McBride (2013) reported that movements in horizontally curved steel I-girder bridges are sensitive to bridge bearings. The piers hinder the lateral deformation of the bridge and increase the lateral bending moment in the bottom flanges of the steel I-girders (Greimann et al., 2014). Greimann et al. (2014) raised special attention to the effect of restraining the lateral deformation of horizontally curved bridge on the induced lateral bottom flange bending moment resulting from thermal loading. However, increasing span length produces a bridge with greater steel I-girder dimensions. Meanwhile, the pile maximum resultant displacement decreases with the increase of span length due to the increase in lateral displacement of bridge superstructure. Also, as concluded above, the pile maximum resultant displacement decreased with the increase of bridge abutment height. Nikravan (2013) reached to the same conclusion, but in another way. The author reported that as the bridge abutment height increases, the bridge length limit increases. Nikravan's conclusion agrees well with Figures 4.85 through 4.99 and Table 4.18. It is interesting to note that as the length of bridge increases, the demand of pile maximum resultant displacement linearly increases, Figures 4.106 through 4.111. The lines representing the relationship are offset from zero due to lateral deflection caused by self-weight of bridge deck. Frosch and Lovell (2011) reported the same finding from a numerical analysis model for a straight integral abutment bridge. The offset from zero increases with the increase of bridge span, due to the increase of bridge own weight. The figures also revealed that there is no appreciable effect of foundation soil on the pile maximum resultant displacement. This agrees with results reported by Olson et al. (2009) The bridge maximum length limits of bridges with doubled span length were obtained and related to bridge maximum length limit of undoubled span as shown in Table 4.21. The table revealed that with doubling span lengths for bridges having radius of curvature of $100 \mathrm{~m}$, the limiting bridge length ratio for doubled spans versus the undoubled spans is between 1.23 to 1.33 in case of medium dense sand foundation soil, and between 1.22 to 1.33 in case of stiff clay foundation soil. With the increase of the radius of curvature to $200 \mathrm{~m}$, the above ratios decrease to be between 1.22 to 1.28 in case of medium dense sand foundation soil, and to 
be between 1.22 to 1.33 in case of stiff clay foundation soil. Therefore, doubling the bridge span does increase the bridge maximum length limit by about $23 \%$ to $33 \%$ according to bridge abutment height. The table revealed that the radius of curvature has no appreciable effect on the ratio of the bridge maximum length limit. At radius of $250 \mathrm{~m}$, the increase in maximum length limit due to doubling of bridge span is between $34 \%$ and $44 \%$. The values in Table 4.20 were checked using the developed Equation 4.5 too.

Table 4.20 Pile Maximum Resultant Displacement for Different Bridge Spans

\begin{tabular}{|c|c|c|c|c|c|c|c|c|c|}
\hline $\begin{array}{l}\text { Radius } \\
(\mathrm{m})\end{array}$ & Displacement (mm) & $\mathrm{L} 1(\mathrm{~m})$ & $\mathrm{L} 2(\mathrm{~m})$ & L3 (m) & L4 (m) & $\mathrm{L} 5$ (m) & L6 (m) & $\begin{array}{c}\text { Pier } \\
\text { Spacing } \\
\text { (m) }\end{array}$ & $\begin{array}{l}\text { Diaphragm } \\
\text { Spacing }(m)\end{array}$ \\
\hline \multicolumn{10}{|c|}{ Abutment Height $=4.00 \mathrm{~m}$} \\
\hline \multirow{5}{*}{60} & $\begin{array}{l}\text { Length L1 Through } \\
\text { L6 }\end{array}$ & 20.94 & 41.88 & 62.83 & 83.77 & 104.71 & 125.66 & & \multirow{5}{*}{4.69} \\
\hline & $\begin{array}{l}\text { Foundation Soil: } \\
\text { Medium Dense Sand }\end{array}$ & 4.76 & 10.81 & 15.79 & 21.49 & 27.00 & 32.61 & \multirow{2}{*}{20.94} & \\
\hline & $\begin{array}{l}\text { Foundation Soil: Stiff } \\
\text { Clay }\end{array}$ & 4.80 & 11.01 & 16.06 & 21.75 & 27.40 & 33.00 & & \\
\hline & $\begin{array}{c}\text { Foundation Soil: } \\
\text { Medium Dense Sand }\end{array}$ & NA & 4.90 & NA & 12.67 & NA & 19.89 & \multirow{2}{*}{41.88} & \\
\hline & $\begin{array}{c}\text { Foundation Soil:Stiff } \\
\text { Clay }\end{array}$ & NA & 4.00 & NA & 12.66 & NA & 19.75 & & \\
\hline \multirow{5}{*}{100} & $\begin{array}{l}\text { Length L1 Through } \\
\text { L6 }\end{array}$ & 34.90 & 69.81 & 104.70 & 139.62 & 174.52 & 209.43 & & \multirow{5}{*}{3.27} \\
\hline & $\begin{array}{c}\text { Foundation Soil: } \\
\text { Medium Dense Sand }\end{array}$ & 10.10 & 17.86 & 29.24 & 38.84 & 50.24 & 53.25 & \multirow{2}{*}{17.45} & \\
\hline & $\begin{array}{l}\text { Foundation Soil: Stiff } \\
\text { Clay }\end{array}$ & 10.20 & 18.15 & 29.64 & 39.34 & 50.74 & 53.99 & & \\
\hline & $\begin{array}{l}\text { Foundation Soil: } \\
\text { Medium Dense Sand }\end{array}$ & 2.62 & 12.10 & 21.29 & 30.18 & 40.29 & 42.82 & \multirow{2}{*}{34.9} & \\
\hline & $\begin{array}{c}\text { Foundation Soil: Stiff } \\
\text { Clay }\end{array}$ & 2.30 & 12.08 & 21.41 & 30.51 & 40.82 & 43.27 & & \\
\hline \multirow{5}{*}{150} & $\begin{array}{l}\text { Length L1 Through } \\
\text { L6 }\end{array}$ & 52.35 & 104.71 & 157.10 & 209.43 & 261.79 & 314.15 & & \multirow{5}{*}{5.02} \\
\hline & $\begin{array}{c}\text { Foundation Soil: } \\
\text { Medium Dense Sand }\end{array}$ & 13.23 & 26.59 & 40.18 & 53.48 & 63.67 & 79.50 & \multirow{2}{*}{26.17} & \\
\hline & $\begin{array}{c}\text { Foundation Soil: Stiff } \\
\text { Clay }\end{array}$ & 13.42 & 26.98 & 40.67 & 52.47 & 64.52 & 80.58 & & \\
\hline & $\begin{array}{c}\text { Foundation Soil: } \\
\text { Medium Dense Sand }\end{array}$ & NA & NA & NA & NA & NA & NA & \multirow{2}{*}{52.34} & \\
\hline & $\begin{array}{c}\text { Foundation Soil: Stiff } \\
\text { Clay }\end{array}$ & NA & NA & NA & NA & NA & NA & & \\
\hline
\end{tabular}


Table 4.20 Pile Maximum Resultant Displacement for Different Bridge Spans - Continued

\begin{tabular}{|c|c|c|c|c|c|c|c|c|c|}
\hline \multirow{5}{*}{200} & $\begin{array}{l}\text { Length L1 Through } \\
\text { L6 }\end{array}$ & 69.81 & 139.62 & 209.4 & 279.24 & 349.05 & 418.86 & & \multirow{5}{*}{6.76} \\
\hline & $\begin{array}{c}\text { Foundation Soil: } \\
\text { Medium Dense Sand }\end{array}$ & 20.13 & 38.82 & 58.08 & 74.74 & 94.12 & 111.15 & \multirow{2}{*}{17.45} & \\
\hline & $\begin{array}{c}\text { Foundation Soil: Stiff } \\
\text { Clay }\end{array}$ & 20.42 & 39.30 & 58.87 & 75.52 & 95.40 & 112.91 & & \\
\hline & $\begin{array}{c}\text { Foundation Soil: } \\
\text { Medium Dense Sand }\end{array}$ & 14.94 & 31.16 & 48.62 & 63.28 & 81.55 & 97.47 & \multirow{2}{*}{34.9} & \\
\hline & $\begin{array}{c}\text { Foundation Soil: Stiff } \\
\text { Clay }\end{array}$ & 15.04 & 31.48 & 49.21 & 63.79 & 82.63 & 98.75 & & \\
\hline \multirow{5}{*}{250} & $\begin{array}{l}\text { Length L1 Through } \\
\text { L6 }\end{array}$ & 87.26 & 174.52 & 261.80 & 349.05 & 436.31 & 523.58 & & \multirow{5}{*}{8.51} \\
\hline & $\begin{array}{c}\text { Foundation Soil: } \\
\text { Medium Dense Sand }\end{array}$ & 23.87 & 47.05 & 69.59 & 91.43 & 112.47 & 133.01 & \multirow{2}{*}{21.8} & \\
\hline & $\begin{array}{c}\text { Foundation Soil: Stiff } \\
\text { Clay }\end{array}$ & 24.25 & 47.72 & 70.56 & 95.59 & 114.00 & 134.76 & & \\
\hline & $\begin{array}{c}\text { Foundation Soil: } \\
\text { Medium Dense Sand }\end{array}$ & 15.00 & 34.72 & 54.76 & 74.39 & 93.6 & 112.26 & \multirow{2}{*}{43.6} & \\
\hline & $\begin{array}{c}\text { Foundation Soil: Stiff } \\
\text { Clay }\end{array}$ & 15.00 & 34.90 & 55.20 & 75.16 & 94.60 & 113.50 & & \\
\hline \multirow{5}{*}{300} & $\begin{array}{c}\text { Length L1 Through } \\
\text { L6 }\end{array}$ & 104.70 & 209.40 & 314.10 & 418.80 & 523.50 & 628.30 & & \multirow{5}{*}{10.25} \\
\hline & $\begin{array}{c}\text { Foundation Soil: } \\
\text { Medium Dense Sand }\end{array}$ & 27.50 & 54.70 & 80.18 & 105.22 & 127.99 & 152.76 & \multirow{2}{*}{26.17} & \\
\hline & $\begin{array}{c}\text { Foundation Soil: Stiff } \\
\text { Clay }\end{array}$ & 27.52 & 55.41 & 81.19 & 106.74 & 131.31 & 156.43 & & \\
\hline & $\begin{array}{c}\text { Foundation Soil: } \\
\text { Medium Dense Sand }\end{array}$ & NA & NA & NA & NA & NA & NA & \multirow{2}{*}{52.34} & \\
\hline & $\begin{array}{c}\text { Foundation Soil: Stiff } \\
\text { Clay }\end{array}$ & NA & NA & NA & NA & NA & NA & & \\
\hline
\end{tabular}


Table 4.20 Pile Maximum Resultant Displacement for Different Bridge Spans - Continued

\begin{tabular}{|c|c|c|c|c|c|c|c|c|c|}
\hline \multicolumn{10}{|c|}{ Abutment Height $=5.32 \mathrm{~m}$} \\
\hline \multirow{5}{*}{60} & $\begin{array}{l}\text { Length L1 Through } \\
\text { L6 }\end{array}$ & 20.94 & 41.88 & 62.83 & 83.77 & 104.71 & 125.66 & & \multirow{5}{*}{4.69} \\
\hline & $\begin{array}{c}\text { Foundation Soil: } \\
\text { Medium Dense Sand }\end{array}$ & 3.94 & 9.55 & 13.92 & 18.92 & 23.87 & 28.83 & \multirow{2}{*}{20.94} & \\
\hline & $\begin{array}{c}\text { Foundation Soil: Stiff } \\
\text { Clay }\end{array}$ & 4.03 & 9.63 & 14.11 & 19.12 & 24.24 & 29.21 & & \\
\hline & $\begin{array}{l}\text { Foundation Soil: } \\
\text { Medium Dense Sand }\end{array}$ & NA & 5.80 & NA & 10.00 & NA & 16.00 & \multirow{2}{*}{41.88} & \\
\hline & $\begin{array}{c}\text { Foundation Soil: Stiff } \\
\text { Clay }\end{array}$ & NA & 5.54 & NA & 9.88 & NA & 15.78 & & \\
\hline \multirow{5}{*}{100} & $\begin{array}{l}\text { Length L1 Through } \\
\text { L6 }\end{array}$ & 34.9 & 69.81 & 104.70 & 139.62 & 174.52 & 209.43 & & \multirow{5}{*}{3.27} \\
\hline & $\begin{array}{c}\text { Foundation Soil: } \\
\text { Medium Dense Sand }\end{array}$ & 9.01 & 15.47 & 25.95 & 34.52 & 44.95 & 46.95 & \multirow{2}{*}{17.45} & \\
\hline & $\begin{array}{c}\text { Foundation Soil: Stiff } \\
\text { Clay }\end{array}$ & 9.11 & 15.66 & 26.35 & 34.95 & 45.54 & 47.68 & & \\
\hline & $\begin{array}{c}\text { Foundation Soil: } \\
\text { Medium Dense Sand }\end{array}$ & 1.48 & 9.36 & 17.46 & 25.18 & 34.20 & 35.60 & \multirow{2}{*}{34.9} & \\
\hline & $\begin{array}{l}\text { Foundation Soil: Stiff } \\
\text { Clay }\end{array}$ & 0.70 & 9.34 & 17.47 & 25.33 & 34.54 & 35.85 & & \\
\hline \multirow{5}{*}{150} & $\begin{array}{l}\text { Length L1 Through } \\
\text { L6 }\end{array}$ & 52.35 & 104.71 & 157.10 & 209.43 & 261.79 & 314.15 & & \multirow{5}{*}{5.02} \\
\hline & $\begin{array}{c}\text { Foundation Soil: } \\
\text { Medium Dense Sand }\end{array}$ & 11.33 & 22.89 & 34.69 & 46.49 & 55.58 & 69.39 & \multirow{2}{*}{26.17} & \\
\hline & $\begin{array}{c}\text { Foundation Soil: Stiff } \\
\text { Clay }\end{array}$ & 11.45 & 23.18 & 35.07 & 47.08 & 56.33 & 70.38 & & \\
\hline & $\begin{array}{c}\text { Foundation Soil: } \\
\text { Medium Dense Sand }\end{array}$ & NA & NA & NA & NA & NA & NA & \multirow{2}{*}{52.34} & \\
\hline & $\begin{array}{c}\text { Foundation Soil: Stiff } \\
\text { Clay }\end{array}$ & NA & NA & NA & NA & NA & NA & & \\
\hline \multirow{5}{*}{200} & $\begin{array}{l}\text { Length L1 Through } \\
\text { L6 }\end{array}$ & 69.81 & 139.62 & 209.40 & 279.24 & 349.05 & 418.86 & & \multirow{5}{*}{6.76} \\
\hline & $\begin{array}{c}\text { Foundation Soil: } \\
\text { Medium Dense Sand }\end{array}$ & 17.83 & 34.87 & 51.59 & 67.9 & 83.92 & 99.53 & \multirow{2}{*}{17.45} & \\
\hline & $\begin{array}{c}\text { Foundation Soil: Stiff } \\
\text { Clay }\end{array}$ & 18.13 & 34.91 & 52.38 & 68.98 & 85.10 & 101.00 & & \\
\hline & $\begin{array}{c}\text { Foundation Soil: } \\
\text { Medium Dense Sand }\end{array}$ & 12.05 & 26.31 & 40.92 & 55.43 & 69.64 & 83.56 & \multirow{2}{*}{34.9} & \\
\hline & $\begin{array}{c}\text { Foundation Soil:Stiff } \\
\text { Clay }\end{array}$ & 12.14 & 26.22 & 41.40 & 55.90 & 70.43 & 84.54 & & \\
\hline
\end{tabular}


Table 4.20 Pile Maximum Resultant Displacement for Different Bridge Spans - Continued

\begin{tabular}{|c|c|c|c|c|c|c|c|c|c|}
\hline \multirow{5}{*}{250} & $\begin{array}{l}\text { Length L1 Through } \\
\text { L6 }\end{array}$ & 87.26 & 174.52 & 261.8 & 349.05 & 436.31 & 523.58 & & \multirow{5}{*}{8.51} \\
\hline & $\begin{array}{c}\text { Foundation Soil: } \\
\text { Medium Dense Sand }\end{array}$ & 20.87 & 41.25 & 61.18 & 80.63 & 99.46 & 117.89 & \multirow{2}{*}{21.8} & \\
\hline & $\begin{array}{c}\text { Foundation Soil: Stiff } \\
\text { Clay }\end{array}$ & 21.16 & 41.23 & 62.06 & 81.79 & 100.92 & 119.65 & & \\
\hline & $\begin{array}{l}\text { Foundation Soil: } \\
\text { Medium Dense Sand }\end{array}$ & 11.16 & 27.70 & 44.93 & 61.86 & 78.49 & 94.72 & \multirow{2}{*}{43.6} & \\
\hline & $\begin{array}{c}\text { Foundation Soil: Stiff } \\
\text { Clay }\end{array}$ & 11.00 & 27.19 & 45.12 & 62.24 & 79.00 & 95.48 & & \\
\hline \multirow{5}{*}{300} & $\begin{array}{l}\text { Length L1 Through } \\
\text { L6 }\end{array}$ & 104.70 & 209.40 & 314.10 & 418.80 & 523.50 & 628.30 & & \multirow{5}{*}{10.25} \\
\hline & $\begin{array}{c}\text { Foundation Soil: } \\
\text { Medium Dense Sand }\end{array}$ & 23.70 & 47.41 & 69.80 & 92.10 & 113.60 & 134.63 & \multirow{2}{*}{26.17} & \\
\hline & $\begin{array}{c}\text { Foundation Soil:Stiff } \\
\text { Clay }\end{array}$ & 23.98 & 48.11 & 70.78 & 93.44 & 115.29 & 137.73 & & \\
\hline & $\begin{array}{c}\text { Foundation Soil: } \\
\text { Medium Dense Sand }\end{array}$ & NA & NA & NA & NA & NA & NA & \multirow{2}{*}{52.34} & \\
\hline & $\begin{array}{c}\text { Foundation Soil: Stiff } \\
\text { Clay }\end{array}$ & NA & NA & NA & NA & NA & NA & & \\
\hline \multicolumn{10}{|c|}{ Abutment Height $=6.64 \mathrm{~m}$} \\
\hline \multirow{5}{*}{60} & $\begin{array}{l}\text { Length L1 Through } \\
\text { L6 }\end{array}$ & 20.94 & 41.88 & 62.83 & 83.77 & 104.71 & 125.66 & & \multirow{5}{*}{4.69} \\
\hline & $\begin{array}{c}\text { Foundation Soil: } \\
\text { Medium Dense Sand }\end{array}$ & 3.20 & 8.20 & 12.00 & 16.50 & 20.80 & 25.20 & \multirow{2}{*}{20.94} & \\
\hline & $\begin{array}{c}\text { Foundation Soil: Stiff } \\
\text { Clay }\end{array}$ & 3.30 & 8.30 & 12.25 & 16.73 & 21.08 & 25.54 & & \\
\hline & $\begin{array}{c}\text { Foundation Soil: } \\
\text { Medium Dense Sand }\end{array}$ & NA & 6.36 & NA & 8.13 & NA & 13.37 & \multirow{2}{*}{41.88} & \\
\hline & $\begin{array}{c}\text { Foundation Soil: Stiff } \\
\text { Clay }\end{array}$ & NA & 6.29 & NA & 7.84 & NA & 12.89 & & \\
\hline \multirow{5}{*}{100} & $\begin{array}{l}\text { Length L1 Through } \\
\text { L6 }\end{array}$ & 34.9 & 69.81 & 104.70 & 139.62 & 174.52 & 209.43 & & \multirow{5}{*}{3.27} \\
\hline & $\begin{array}{c}\text { Foundation Soil: } \\
\text { Medium Dense Sand }\end{array}$ & 7.92 & 13.28 & 22.76 & 30.25 & 39.66 & 41.03 & \multirow{2}{*}{17.45} & \\
\hline & $\begin{array}{c}\text { Foundation Soil: Stiff } \\
\text { Clay }\end{array}$ & 8.01 & 13.47 & 23.06 & 30.65 & 40.25 & 41.56 & & \\
\hline & $\begin{array}{c}\text { Foundation Soil: } \\
\text { Medium Dense Sand }\end{array}$ & 1.20 & 7.30 & 14.32 & 21.02 & 28.81 & 29.81 & \multirow{2}{*}{34.9} & \\
\hline & $\begin{array}{c}\text { Foundation Soil: Stiff } \\
\text { Clay }\end{array}$ & 0.40 & 7.21 & 14.32 & 21.00 & 29.04 & 29.85 & & \\
\hline
\end{tabular}


Table 4.20 Pile Maximum Resultant Displacement for Different Bridge Spans - Continued

\begin{tabular}{|c|c|c|c|c|c|c|c|c|c|}
\hline \multirow{5}{*}{150} & $\begin{array}{l}\text { Length L1 Through } \\
\text { L6 }\end{array}$ & 52.35 & 104.71 & 157.10 & 209.43 & 261.79 & 314.15 & & \multirow{5}{*}{5.02} \\
\hline & $\begin{array}{c}\text { Foundation Soil: } \\
\text { Medium Dense Sand }\end{array}$ & 9.54 & 19.50 & 29.79 & 39.99 & 48.09 & 59.99 & \multirow[b]{2}{*}{26.17} & \\
\hline & $\begin{array}{c}\text { Foundation Soil:Stiff } \\
\text { Clay }\end{array}$ & 9.64 & 19.70 & 30.08 & 40.48 & 48.64 & 60.78 & & \\
\hline & $\begin{array}{l}\text { Foundation Soil: } \\
\text { Medium Dense Sand }\end{array}$ & NA & NA & NA & NA & NA & NA & \multirow{2}{*}{52.34} & \\
\hline & $\begin{array}{c}\text { Foundation Soil: Stiff } \\
\text { Clay }\end{array}$ & NA & NA & NA & NA & NA & NA & & \\
\hline \multirow{5}{*}{200} & $\begin{array}{l}\text { Length L1 Through } \\
\text { L6 }\end{array}$ & 69.81 & 139.62 & 209.40 & 279.24 & 349.05 & 418.86 & & \multirow{5}{*}{6.76} \\
\hline & $\begin{array}{c}\text { Foundation Soil: } \\
\text { Medium Dense Sand }\end{array}$ & 15.53 & 30.13 & 45.19 & 58.35 & 73.71 & 87.63 & \multirow{2}{*}{17.45} & \\
\hline & $\begin{array}{c}\text { Foundation Soil: Stiff } \\
\text { Clay }\end{array}$ & 15.83 & 30.51 & 45.77 & 59.13 & 74.80 & 88.9 & & \\
\hline & $\begin{array}{c}\text { Foundation Soil: } \\
\text { Medium Dense Sand }\end{array}$ & 9.66 & 21.75 & 34.42 & 45.67 & 59.23 & 71.34 & \multirow{2}{*}{34.9} & \\
\hline & $\begin{array}{c}\text { Foundation Soil: Stiff } \\
\text { Clay }\end{array}$ & 9.66 & 21.75 & 34.60 & 46.00 & 59.72 & 72.00 & & \\
\hline \multirow{5}{*}{250} & $\begin{array}{l}\text { Length L1 Through } \\
\text { L6 }\end{array}$ & 87.26 & 174.52 & 261.80 & 349.05 & 436.31 & 523.58 & & \multirow{5}{*}{8.51} \\
\hline & $\begin{array}{c}\text { Foundation Soil: } \\
\text { Medium Dense Sand }\end{array}$ & 17.99 & 35.72 & 53.18 & 70.21 & 86.95 & 103.28 & \multirow{2}{*}{21.8} & \\
\hline & $\begin{array}{c}\text { Foundation Soil: Stiff } \\
\text { Clay }\end{array}$ & 18.27 & 36.23 & 53.85 & 71.19 & 88.11 & 104.64 & & \\
\hline & $\begin{array}{c}\text { Foundation Soil: } \\
\text { Medium Dense Sand }\end{array}$ & 8.28 & 22.20 & 36.93 & 51.44 & 65.76 & 79.88 & \multirow{2}{*}{43.6} & \\
\hline & $\begin{array}{c}\text { Foundation Soil: Stiff } \\
\text { Clay }\end{array}$ & 8.00 & 22.00 & 36.80 & 51.50 & 65.94 & 80.00 & & \\
\hline \multirow{5}{*}{300} & $\begin{array}{l}\text { Length L1 Through } \\
\text { L6 }\end{array}$ & 104.70 & 209.40 & 314.10 & 418.80 & 523.50 & 628.30 & & \multirow{5}{*}{10.25} \\
\hline & $\begin{array}{c}\text { Foundation Soil: } \\
\text { Medium Dense Sand }\end{array}$ & 20.10 & 40.80 & 60.23 & 79.79 & 98.83 & 117.38 & \multirow{2}{*}{26.17} & \\
\hline & $\begin{array}{c}\text { Foundation Soil: Stiff } \\
\text { Clay }\end{array}$ & 20.43 & 41.21 & 61.61 & 80.72 & 100.00 & 118.00 & & \\
\hline & $\begin{array}{c}\text { Foundation Soil: } \\
\text { Medium Dense Sand }\end{array}$ & NA & NA & NA & NA & NA & NA & \multirow{2}{*}{52.34} & \\
\hline & $\begin{array}{c}\text { Foundation Soil: Stiff } \\
\text { Clay }\end{array}$ & NA & NA & NA & NA & NA & NA & & \\
\hline
\end{tabular}


Table 4.21 Bridge Maximum Length Limit of Span $S_{2}$ / Bridge Maximum Length Limit of Span $S_{1}$, at Different Abutment Heights

\begin{tabular}{|c|c|c|c|c|c|}
\hline \multirow{3}{*}{$\begin{array}{l}\text { Bridge } \\
\text { Radius } \\
\text { (m) }\end{array}$} & \multirow{3}{*}{ Foundation Soil } & \multicolumn{3}{|c|}{$\begin{array}{l}\text { Bridge Maximum Length Limit of Span } S_{2} / \\
\text { Bridge Maximum Length Limit of Span } S_{1}\end{array}$} & \multirow{3}{*}{$\begin{array}{c}S_{2}, S_{1} \\
(m)\end{array}$} \\
\hline & & \multicolumn{3}{|c|}{ Bridge Abutment Height (m) } & \\
\hline & & 4.00 & 5.32 & 6.64 & \\
\hline \multirow{2}{*}{100} & Medium Dense Sand & 1.23 & 1.29 & 1.33 & $34.90,17.45$ \\
\hline & Stiff Clay & 1.22 & 1.24 & 1.33 & $34.90,17.45$ \\
\hline \multirow{2}{*}{200} & Medium Dense Sand & 1.22 & 1.29 & 1.28 & $34.90,17.45$ \\
\hline & Stiff Clay & 1.22 & 1.28 & 1.33 & $34.90,17.45$ \\
\hline \multirow{2}{*}{250} & Medium Dense Sand & 1.34 & 1.39 & 1.43 & $43.60,21.80$ \\
\hline & Stiff Clay & 1.36 & 1.40 & 1.44 & $43.60,21.80$ \\
\hline
\end{tabular}

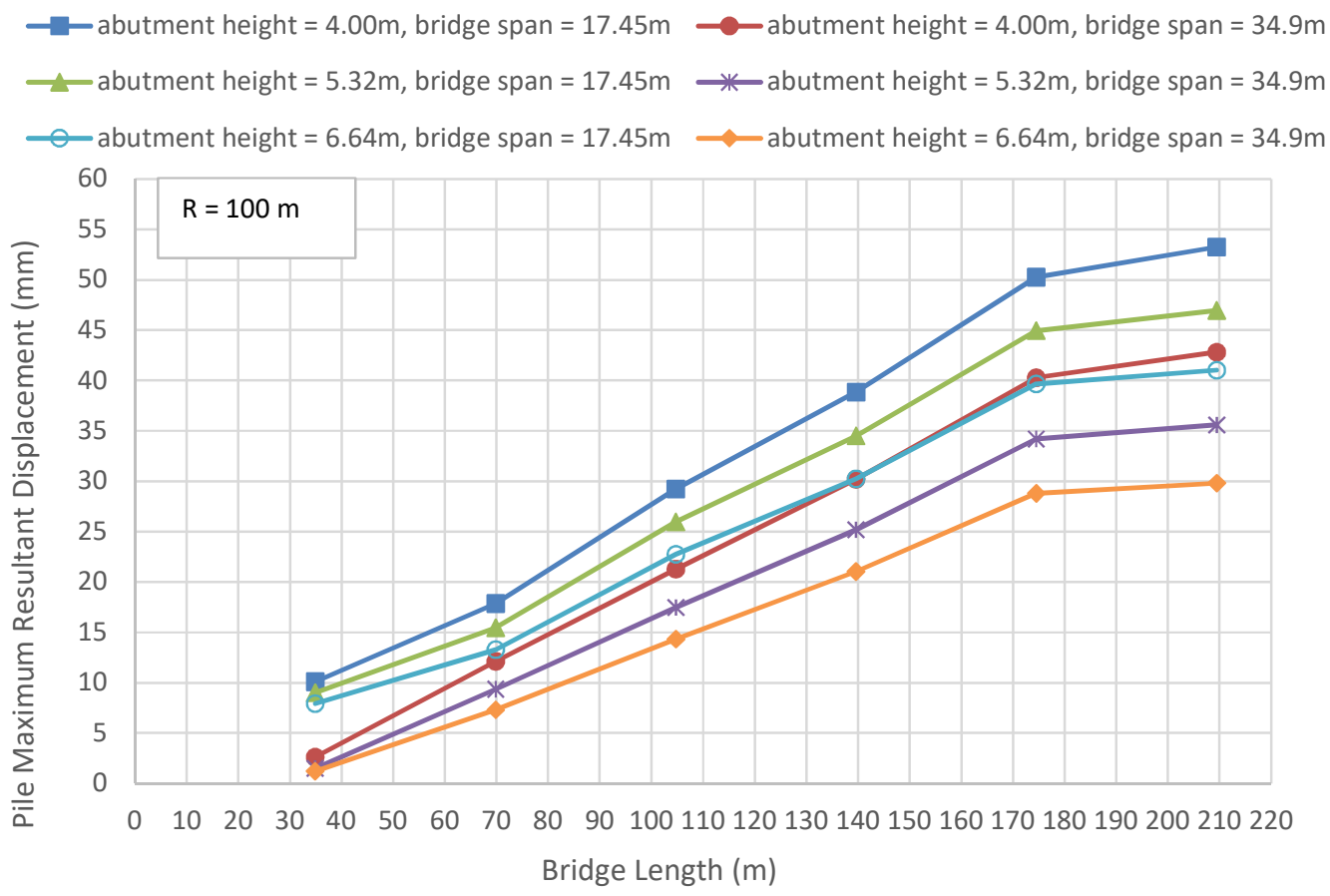

Figure 4.106 Pile Maximum Resultant Displacement Versus Bridge Length

(Foundation Soil: Medium Dense Sand) 

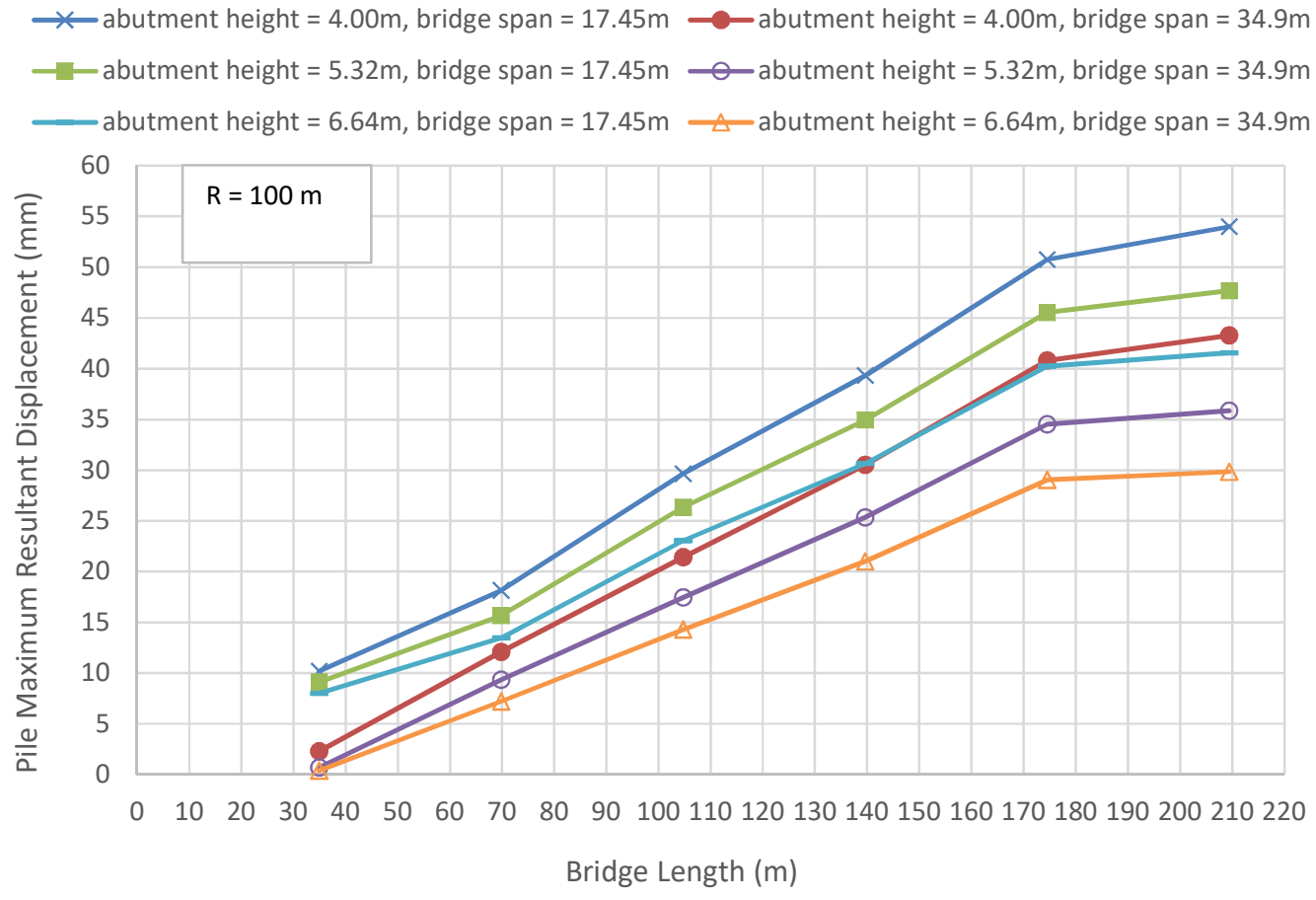

Figure 4.107 Pile Maximum Resultant Displacement Versus Bridge Length

(Foundation Soil: Stiff Clay)

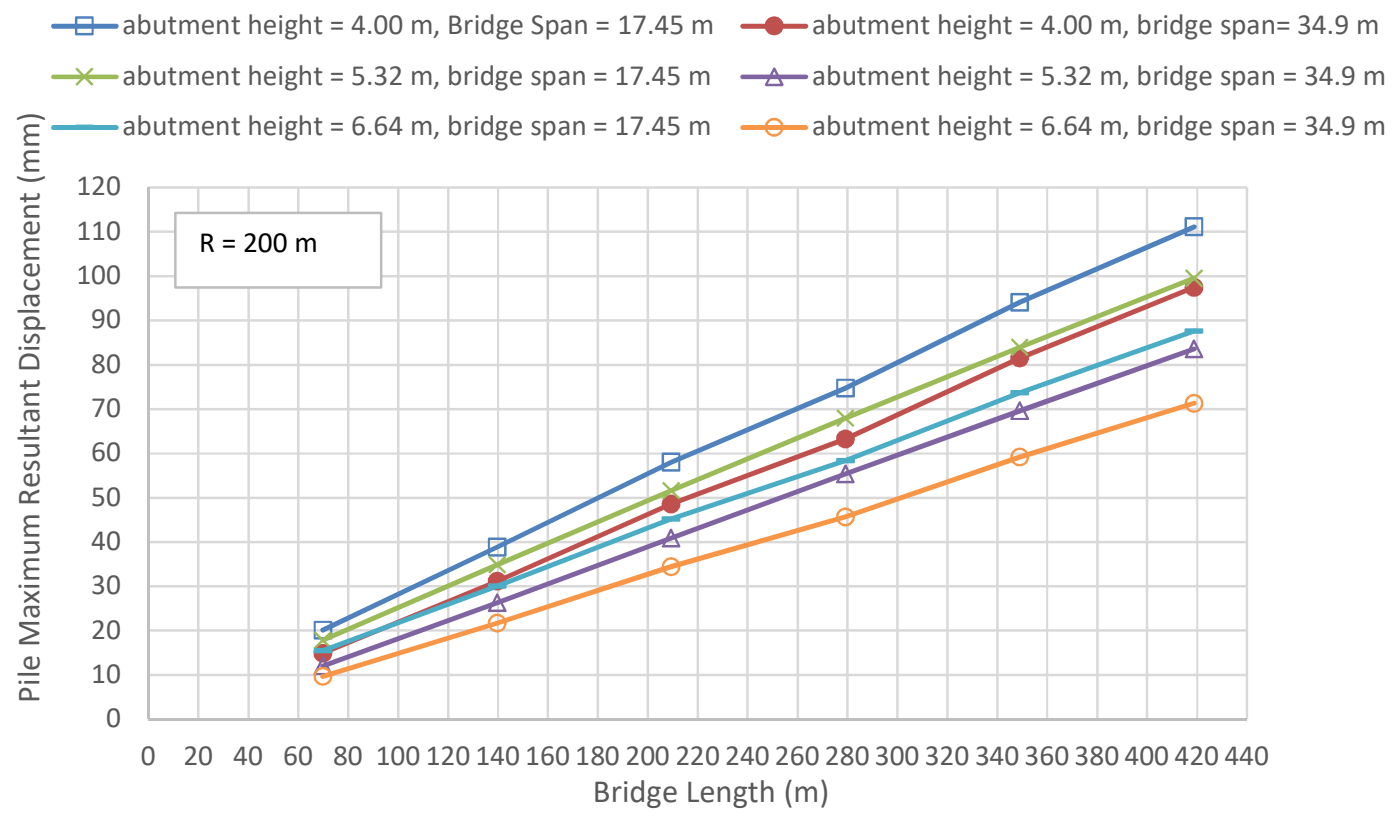

Figure 4.108 Pile Maximum Resultant Displacement Versus Bridge Length

(Foundation Soil: Medium Dense Sand) 


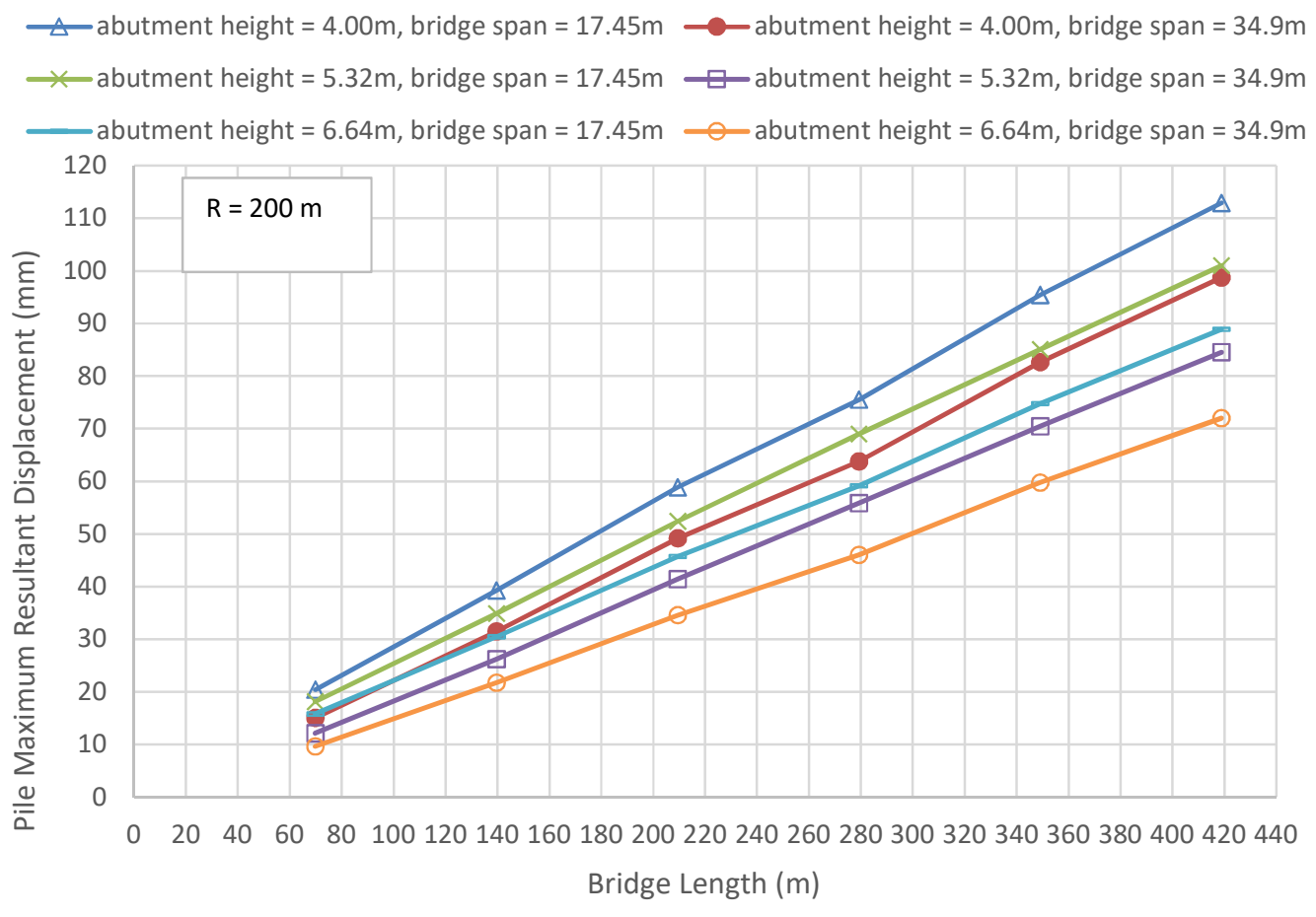

Figure 4.109 Pile Maximum Resultant Displacement Versus Bridge Length (Foundation Soil: Stiff Clay)

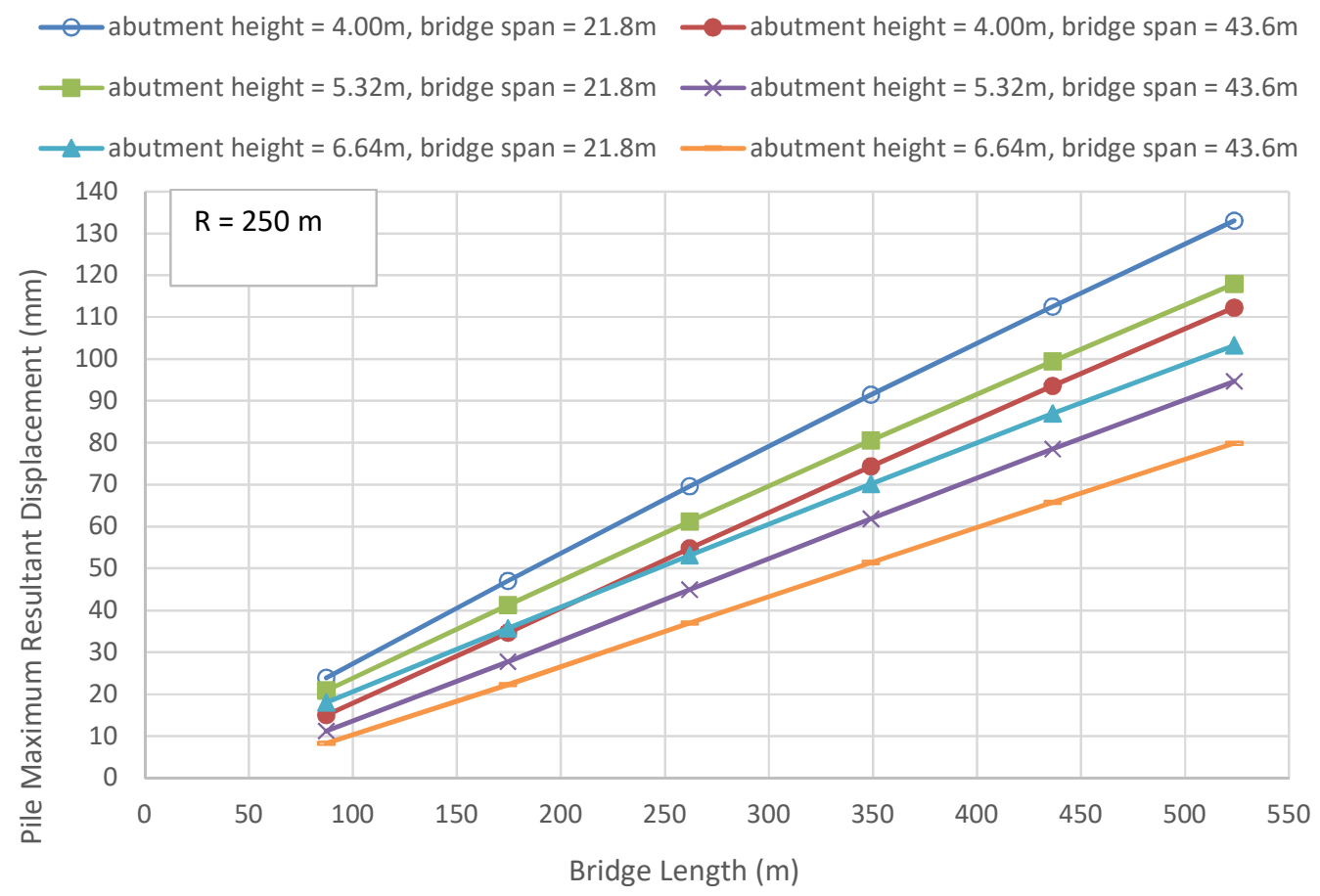

Figure 4.110 Pile Maximum Resultant Displacement Versus Bridge Length

(Foundation Soil: Medium Dense Sand) 


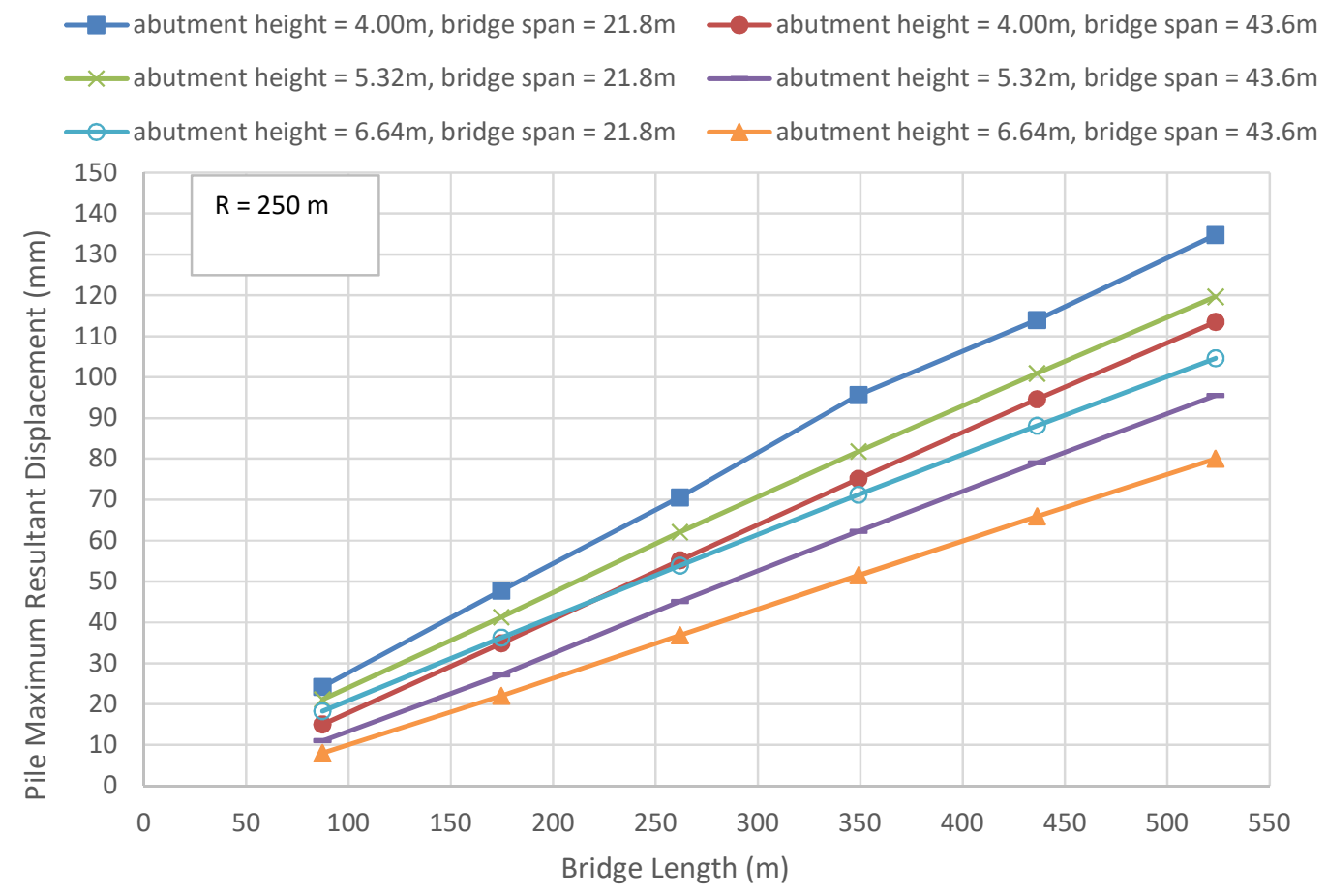

Figure 4.111 Pile Maximum Resultant Displacement Versus Bridge Length

(Foundation Soil: Stiff Clay) 


\subsection{General Closed Form Solution of Bridge Maximum Length Limit}

From the above study, the bridge maximum length limit depends upon the height of the bridge abutment $(\mathrm{H})$ and the bridge span between piers $(\mathrm{S})$. The equations presented in Tables 4.18 and 4.19 were manipulated and a generalized empirical solution of bridge length limit as function of $(\mathrm{H})$ and $(\mathrm{S})$ was derived as;

$L_{S}=\left[3 \times 10^{-5} H^{2}+0.0002 H+0.1335\right] x\left[S^{2}\right]+[0.4953 H-7.0936] x[S]+7.7235 H+$ 159.33

Where;

$L_{s}:$ Bridge maximum length limit, $\mathrm{m}$,

$H$ : Bridge Abutment Height, $\mathrm{H}$,

$S$ : Bridge span, $\mathrm{m}$.

This equation is limited for $4 \mathrm{~m} \leq H \geq 6.64 \mathrm{~m}$ and $17.45 \mathrm{~m} \leq S \leq 34.9 \mathrm{~m}$

Table 4.22 show the accuracy of the developed equation (4.29) compared to the FEA by substituting for actual bridge length limits obtained from FEA in column (1) in the table to obtain the estimated abutment height in column (4) and then obtaining the percentage difference between the actual and the estimated abutment height. Good accuracy was observed as depicted in the right column of the table. 
Table 4.22 Actual vs Estimated Abutment Height from Developed Equation (4.29)

\begin{tabular}{|c|c|c|c|c|}
\hline $\begin{array}{l}\text { Maximum } \\
\text { Bridge } \\
\text { Length } \\
\text { Limit }(m)\end{array}$ & $\begin{array}{l}\text { Span } \\
\text { Length } \\
\text { (m) }\end{array}$ & $\begin{array}{c}\text { Actual } \\
\text { Abutment } \\
\text { Height (m) }\end{array}$ & $\begin{array}{l}\text { Abutment Height } \\
\text { Estimated from } \\
\text { Equation }(4.29)(\mathrm{m})\end{array}$ & $\begin{array}{c}\text { Percentage Difference } \\
\text { Between the Actual and } \\
\text { the Estimated Values } \\
(\%)\end{array}$ \\
\hline 140.00 & 17.45 & 4.00 & 3.88 & -2.84 \\
\hline 142.12 & 17.45 & 4.00 & 4.01 & 0.36 \\
\hline 144.06 & 17.45 & 4.00 & 4.13 & 3.30 \\
\hline 159.96 & 17.45 & 5.32 & 5.09 & -4.26 \\
\hline 161.97 & 17.45 & 5.32 & 5.21 & -1.97 \\
\hline 184.62 & 17.45 & 6.64 & 6.58 & -0.83 \\
\hline 185.00 & 17.45 & 6.64 & 6.60 & -0.48 \\
\hline 187.37 & 17.45 & 6.64 & 6.75 & 1.67 \\
\hline 144.89 & 21.8 & 4.00 & 4.09 & 2.37 \\
\hline 167.84 & 21.8 & 5.32 & 5.32 & 0.01 \\
\hline 170.00 & 21.8 & 5.32 & 5.43 & 2.18 \\
\hline 194.07 & 21.8 & 6.64 & 6.72 & 1.23 \\
\hline 200.00 & 21.8 & 6.64 & 7.03 & 6.00 \\
\hline 149.70 & 26.17 & 4.00 & 4.06 & 1.55 \\
\hline 155.00 & 26.17 & 4.00 & 4.31 & 7.84 \\
\hline 156.50 & 26.17 & 4.00 & 4.38 & 9.62 \\
\hline 174.44 & 26.17 & 5.32 & 5.23 & -1.56 \\
\hline 180.59 & 26.17 & 5.32 & 5.52 & 3.92 \\
\hline 204.02 & 26.17 & 6.64 & 6.64 & 0.01 \\
\hline 209.00 & 26.17 & 6.64 & 6.87 & 3.57 \\
\hline 210.00 & 26.17 & 6.64 & 6.92 & 4.28 \\
\hline 218.00 & 26.17 & 6.64 & 7.30 & 10.00 \\
\hline 175.98 & 34.9 & 4.00 & 4.00 & 0.12 \\
\hline 205.39 & 34.9 & 5.32 & 5.15 & -3.14 \\
\hline 242.41 & 34.9 & 6.64 & 6.59 & -0.64 \\
\hline
\end{tabular}




\subsection{Effect of Predrilled Holes on Bridge Performance}

\subsubsection{Pile Maximum Resultant Displacement}

In normal practice, the depth of predrilled holes varies from $1.8 \mathrm{~m}$ to $6.0 \mathrm{~m}$ (Crovo, 1998; Wasserman, 2001; Haj-Najib, 2002; Mistry, 2005; Amde et al, 2014). The holes are filled with loose sand (Arockiasamy et al., 2004) or bentonite slurry (Olson et al., 2013). lowa integral abutment bridge piles are installed in predrilled holes to a minimum depth of $3.0 \mathrm{~m}$. The effect

of predrilled hole is to increase the flexibility of the pile (Dunker and Liu, 2007), reduce the developed pile moment (Yang et al., 1985; Greimann et al, 1986; Faraji, 1997; Khodair and Hassiotis, 2003), reduce shearing forces along the pile and reduce stresses in bridge superstructure. Hence, the bridge maximum length limit increases (Olson et al., 2013).

In the current study, the lengths of predrilled holes are $2.75 \mathrm{~m}$ as considered by Paraschos (2016) filled with bentonite slurry filling (Deng et al., 2015). The stiffness of bentonite slurry was considered to be too small to be discarded. Therefore, pile springs along the top $2.75 \mathrm{~m}$ were removed from finite element model. This exactly simulates the condition of a pile inserted inside a sleeve with a length of $2.75 \mathrm{~m}$ below bottom-of-the abutment. Deng et al. (2015) stated that springs within the predrilled holes would have zero stiffness.

The diameter of predrilled holes is taken equal to the diagonal diameter of the H-Pile plus $0.15 \mathrm{~m}$ minimum per State of Vermont Specification. While Massachusetts and lowa Department of Transportation make the diameter $0.75 \mathrm{~m}$ and equal to twice the equivalent diameter of H-Pile (Paraschos, 2016). The bridges with characteristics shown in Table 3.1 were modeled and analyzed, where the foundation soil were stiff clay. The bridges were subjected to thermal-contraction phase.

The abutment piles maximum resultant displacements were obtained as shown in Table 4.23 and compared with the displacements of piles in case of stiff clay foundation soil, without predrilled holes as;

$n_{\Delta}=\frac{\Delta_{p}-\Delta}{\Delta}$

Where; 
$n_{\Delta}$ : Percentage increase in pile maximum resultant displacement,

$\Delta_{p}$ : Pile maximum resultant displacement of pile in predrilled hole,

$\Delta$ : Pile maximum resultant displacement of pile in stiff clay.

The magnitudes of $\mathrm{n}_{\Delta}$ are presented in Table 4.24. The magnitudes of the percentage increase $\left(\mathrm{n}_{\Delta}\right)$ were drawn versus the bridge length, at different radii as shown in Figures 4.112 through 4.117. these figures revealed that there is no appreciable effect of bridge length on $\left(n_{\Delta}\right)$ magnitudes. The scatter in results is due to the effect of bridge span length which is difficult to isolate. The values of $\left(\mathrm{n}_{\Delta}\right)$ increased with the increase of bridge abutment height. Table 4.24 presents the mean values of $\mathrm{n}_{\Delta}$ corresponding to abutment height at different bridge radius of curvature. The table indicates that the radius of curvature has slight effect on the values of $n_{\Delta}$. The table indicates that the percentage increases in pile maximum resultant displacements are $13.06 \%, 19.36 \%$ and $26.3 \%$ for abutment heights of $4.0 \mathrm{~m}, 5.32 \mathrm{~m}$ and 6.64 m, respectively. Furthermore, Figures 4.118 through 4.126 present pile maximum resultant displacement versus bridge length at different bridge spans and bridge radius curvature. Figures 4.118 through 4.120 are devoted for bridge span 20.94/21.8 m and radius of bridge curvatures of $60.0 \mathrm{~m}$ and $250.0 \mathrm{~m}$. The figures revealed that there is no effect of bridge curvature on pile maximum resultant displacement. Figures 4.121 through 4.126 revealed the same conclusion.

Noteworthy, that the pile maximum resultant displacements decreased as the height of the bridge abutment increased, for bridges with piles either embedded in stiff clay foundation soil, or installed in predrilled holes as shown in Table 4.23. However the magnitudes of $n_{\Delta}$ increased with the bridge abutment height. This can be attributed to the fact that the increase of maximum resultant displacements of piles driven in predrilled holes are associated with a decrease in the angle of rotation of bridge abutment, compared by the rotation of piles embedded in stiff clay. 
Table 4.23 (a) Pile Maximum Resultant Displacement in Predrilled Holes for Abutment of Height $4.00 \mathrm{~m}$

\begin{tabular}{|c|c|c|c|c|c|c|c|c|c|}
\hline $\begin{array}{l}\text { Radius } \\
\text { (m) }\end{array}$ & $\begin{array}{c}\text { Pile } \\
\text { Resultant } \\
\text { Displacement } \\
\text { (mm) }\end{array}$ & L1 (m) & $\mathrm{L} 2(\mathrm{~m})$ & L3 (m) & L4 (m) & L5 (m) & L6 (m) & $\begin{array}{c}\text { Pier } \\
\text { Spacing } \\
\text { (m) }\end{array}$ & $\begin{array}{l}\text { Diaphragm } \\
\text { Spacing } \\
\text { (m) }\end{array}$ \\
\hline \multirow{2}{*}{60} & $\begin{array}{l}\text { Length L1 } \\
\text { Through L6 }\end{array}$ & 20.94 & 41.88 & 62.83 & 83.77 & 104.71 & 125.66 & - & \multirow{2}{*}{4.69} \\
\hline & $\begin{array}{l}\text { Pile Resultant } \\
\text { Displacement }\end{array}$ & 5.90 & 12.20 & 17.74 & 24.15 & 30.49 & 36.95 & 20.94 & \\
\hline \multirow{2}{*}{100} & $\begin{array}{l}\text { Length L1 } \\
\text { Through L6 }\end{array}$ & 34.90 & 69.81 & 104.71 & 139.62 & 174.52 & 209.43 & - & \multirow{2}{*}{3.27} \\
\hline & $\begin{array}{l}\text { Pile Resultant } \\
\text { Displacement }\end{array}$ & 11.20 & 20.50 & 32.70 & 43.60 & 55.90 & 61.20 & 17.45 & \\
\hline \multirow{2}{*}{150} & $\begin{array}{l}\text { Length L1 } \\
\text { Through L6 }\end{array}$ & 52.35 & 104.71 & 157.07 & 209.43 & 261.79 & 314.15 & - & \multirow{2}{*}{5.02} \\
\hline & $\begin{array}{l}\text { Pile Resultant } \\
\text { Displacement }\end{array}$ & 14.90 & 30.30 & 46.10 & 61.70 & 73.70 & 92.70 & 26.17 & \\
\hline \multirow{2}{*}{200} & $\begin{array}{l}\text { Length L1 } \\
\text { Through L6 }\end{array}$ & 69.81 & 139.62 & 209.43 & 279.24 & 349.05 & 418.86 & - & \multirow{2}{*}{6.76} \\
\hline & $\begin{array}{l}\text { Pile Resultant } \\
\text { Displacement }\end{array}$ & 22.40 & 43.40 & 65.70 & 84.90 & 108.10 & 128.90 & 17.45 & \\
\hline \multirow{2}{*}{250} & $\begin{array}{l}\text { Length L1 } \\
\text { Through L6 }\end{array}$ & 87.26 & 174.52 & 261.79 & 349.05 & 436.31 & 523.58 & - & \multirow{2}{*}{8.51} \\
\hline & $\begin{array}{l}\text { Pile Resultant } \\
\text { Displacement }\end{array}$ & 26.90 & 53.60 & 79.90 & 105.80 & 131.40 & 156.60 & 21.8 & \\
\hline \multirow{2}{*}{300} & $\begin{array}{l}\text { Length L1 } \\
\text { Through L6 }\end{array}$ & 104.70 & 209.40 & 314.10 & 418.80 & 523.50 & 628.30 & - & \multirow{2}{*}{10.25} \\
\hline & $\begin{array}{l}\text { Pile Resultant } \\
\text { Displacement }\end{array}$ & 30.80 & 63.10 & 93.00 & 123.30 & 153.50 & 184.90 & 26.17 & \\
\hline
\end{tabular}


Table 4.23 (b) Continue Pile Maximum Resultant Displacement in Predrilled Holes for Abutment of Height $5.32 \mathrm{~m}$

\begin{tabular}{|c|c|c|c|c|c|c|c|c|c|}
\hline $\begin{array}{l}\text { Radius } \\
\text { (m) }\end{array}$ & $\begin{array}{c}\text { Pile Resultant } \\
\text { Displacement } \\
\text { (mm) }\end{array}$ & L1 (m) & L2 (m) & L3 (m) & L4 (m) & L5 (m) & L6 (m) & $\begin{array}{c}\text { Pier } \\
\text { Spacing } \\
\text { (m) }\end{array}$ & $\begin{array}{l}\text { Diaphragm } \\
\text { Spacing } \\
\text { (m) }\end{array}$ \\
\hline \multirow{2}{*}{60} & $\begin{array}{l}\text { Length L1 } \\
\text { Through L6 }\end{array}$ & 20.94 & 41.88 & 62.83 & 83.77 & 104.71 & 125.66 & - & \multirow{2}{*}{4.69} \\
\hline & $\begin{array}{l}\text { Pile Resultant } \\
\text { Displacement }\end{array}$ & 5.20 & 11.40 & 16.63 & 22.40 & 28.40 & 34.48 & 20.94 & \\
\hline \multirow{2}{*}{100} & $\begin{array}{l}\text { Length L1 } \\
\text { Through L6 }\end{array}$ & 34.90 & 69.81 & 104.71 & 139.62 & 174.52 & 209.43 & - & \multirow{2}{*}{3.27} \\
\hline & $\begin{array}{l}\text { Pile Resultant } \\
\text { Displacement }\end{array}$ & 10.60 & 18.80 & 30.70 & 40.90 & 52.70 & 57.00 & 17.45 & \\
\hline \multirow{2}{*}{150} & $\begin{array}{l}\text { Length L1 } \\
\text { Through L6 }\end{array}$ & 52.35 & 104.71 & 157.07 & 209.43 & 261.79 & 314.15 & - & \multirow{2}{*}{5.02} \\
\hline & $\begin{array}{l}\text { Pile Resultant } \\
\text { Displacement }\end{array}$ & 13.50 & 27.60 & 42.10 & 56.70 & 67.90 & 85.50 & 26.17 & \\
\hline \multirow{2}{*}{200} & $\begin{array}{l}\text { Length L1 } \\
\text { Through L6 }\end{array}$ & 69.81 & 139.62 & 209.43 & 279.24 & 349.05 & 418.86 & - & \multirow{2}{*}{6.76} \\
\hline & $\begin{array}{l}\text { Pile Resultant } \\
\text { Displacement }\end{array}$ & 21.10 & 40.80 & 61.60 & 81.60 & 101.40 & 121.00 & 17.45 & \\
\hline \multirow{2}{*}{250} & $\begin{array}{l}\text { Length L1 } \\
\text { Through L6 }\end{array}$ & 87.26 & 174.52 & 261.79 & 349.05 & 436.31 & 523.58 & - & \multirow{2}{*}{8.51} \\
\hline & $\begin{array}{l}\text { Pile Resultant } \\
\text { Displacement }\end{array}$ & 24.90 & 48.90 & 74.23 & 98.50 & 122.45 & 146.00 & 21.8 & \\
\hline \multirow{2}{*}{300} & $\begin{array}{l}\text { Length L1 } \\
\text { Through L6 }\end{array}$ & 104.70 & 209.40 & 314.10 & 418.80 & 523.50 & 628.30 & - & \multirow{2}{*}{10.25} \\
\hline & $\begin{array}{l}\text { Pile Resultant } \\
\text { Displacement }\end{array}$ & 27.94 & 58.00 & 85.70 & 114.12 & 141.90 & 171.10 & 26.17 & \\
\hline
\end{tabular}


Table 4.23 (c) Continue Pile Maximum Resultant Displacement in Predrilled Holes for Abutment of Height $6.64 \mathrm{~m}$

\begin{tabular}{|c|c|c|c|c|c|c|c|c|c|}
\hline $\begin{array}{l}\text { Radius } \\
\text { (m) }\end{array}$ & $\begin{array}{l}\text { Pile Resultant } \\
\text { Displacement } \\
\quad(\mathrm{mm})\end{array}$ & L1 (m) & $\mathrm{L} 2$ (m) & L3 (m) & L4 (m) & L5 (m) & L6 (m) & $\begin{array}{c}\text { Pier } \\
\text { Spacing } \\
\text { (m) }\end{array}$ & $\begin{array}{l}\text { Diaphragm } \\
\text { Spacing } \\
\text { (m) }\end{array}$ \\
\hline \multirow{2}{*}{60} & $\begin{array}{l}\text { Length L1 } \\
\text { Through L6 }\end{array}$ & 20.94 & 41.88 & 62.83 & 83.77 & 104.71 & 125.66 & - & \multirow{2}{*}{4.69} \\
\hline & $\begin{array}{l}\text { Pile Resultant } \\
\text { Displacement }\end{array}$ & 4.50 & 10.60 & 15.35 & 20.70 & 26.25 & 31.80 & 20.94 & \\
\hline \multirow{2}{*}{100} & $\begin{array}{l}\text { Length L1 } \\
\text { Through L6 }\end{array}$ & 34.90 & 69.81 & 104.71 & 139.62 & 174.52 & 209.43 & - & \multirow{2}{*}{3.27} \\
\hline & $\begin{array}{l}\text { Pile Resultant } \\
\text { Displacement }\end{array}$ & 9.70 & 17.17 & 28.40 & 37.90 & 49.14 & 52.50 & 17.45 & \\
\hline \multirow{2}{*}{150} & $\begin{array}{l}\text { Length L1 } \\
\text { Through L6 }\end{array}$ & 52.35 & 104.71 & 157.07 & 209.43 & 261.79 & 314.15 & - & \multirow{2}{*}{5.02} \\
\hline & $\begin{array}{l}\text { Pile Resultant } \\
\text { Displacement }\end{array}$ & 12.10 & 24.90 & 38.20 & 51.67 & 61.90 & 77.90 & 26.17 & \\
\hline \multirow{2}{*}{200} & $\begin{array}{l}\text { Length L1 } \\
\text { Through L6 }\end{array}$ & 69.81 & 139.62 & 209.43 & 279.24 & 349.05 & 418.86 & - & \multirow{2}{*}{6.76} \\
\hline & $\begin{array}{l}\text { Pile Resultant } \\
\text { Displacement }\end{array}$ & 19.50 & 37.71 & 57.00 & 73.90 & 93.90 & 112.00 & 17.45 & \\
\hline \multirow{2}{*}{250} & $\begin{array}{l}\text { Length L1 } \\
\text { Through L6 }\end{array}$ & 87.26 & 174.52 & 261.79 & 349.05 & 436.31 & 523.58 & - & \multirow{2}{*}{8.51} \\
\hline & $\begin{array}{l}\text { Pile Resultant } \\
\text { Displacement }\end{array}$ & 22.80 & 45.50 & 68.10 & 90.50 & 112.50 & 134.30 & 21.80 & \\
\hline \multirow{2}{*}{300} & $\begin{array}{l}\text { Length L1 } \\
\text { Through L6 }\end{array}$ & 104.70 & 209.40 & 314.10 & 418.80 & 523.50 & 628.30 & - & \multirow{2}{*}{10.25} \\
\hline & $\begin{array}{l}\text { Pile Resultant } \\
\text { Displacement }\end{array}$ & 25.60 & 52.60 & 79.10 & 104.10 & 129.70 & 154.90 & 26.17 & \\
\hline
\end{tabular}


Table 4.24 Mean Values of $\mathbf{n}_{\Delta}$

\begin{tabular}{|c|c|c|c|}
\hline Radius (m) & $\begin{array}{l}\text { Abutment Height } \\
\text { (m) }\end{array}$ & Mean $\left(\mathbf{n}_{\Delta}\right) \%$ & Standard Deviation \\
\hline \multirow{3}{*}{60} & 4.00 & 13.08 & 4.85 \\
\hline & 5.32 & 19.60 & 4.64 \\
\hline & 6.64 & 27.02 & 4.78 \\
\hline \multirow{3}{*}{100} & 4.00 & 11.24 & 1.52 \\
\hline & 5.32 & 17.53 & 1.81 \\
\hline & 6.64 & 23.96 & 2.46 \\
\hline \multirow{3}{*}{150} & 4.00 & 13.92 & 2.29 \\
\hline & 5.32 & 19.91 & 1.26 \\
\hline & 6.64 & 26.99 & 0.94 \\
\hline \multirow{3}{*}{200} & 4.00 & 11.94 & 1.70 \\
\hline & 5.32 & 18.02 & 1.32 \\
\hline & 6.64 & 24.64 & 1.10 \\
\hline \multirow{3}{*}{250} & 4.00 & 13.11 & 2.26 \\
\hline & 5.32 & 19.95 & 1.65 \\
\hline & 6.64 & 26.66 & 1.32 \\
\hline \multirow{3}{*}{300} & 4.00 & 15.16 & 2.23 \\
\hline & 5.32 & 21.26 & 2.68 \\
\hline & 6.64 & 28.54 & 2.01 \\
\hline
\end{tabular}




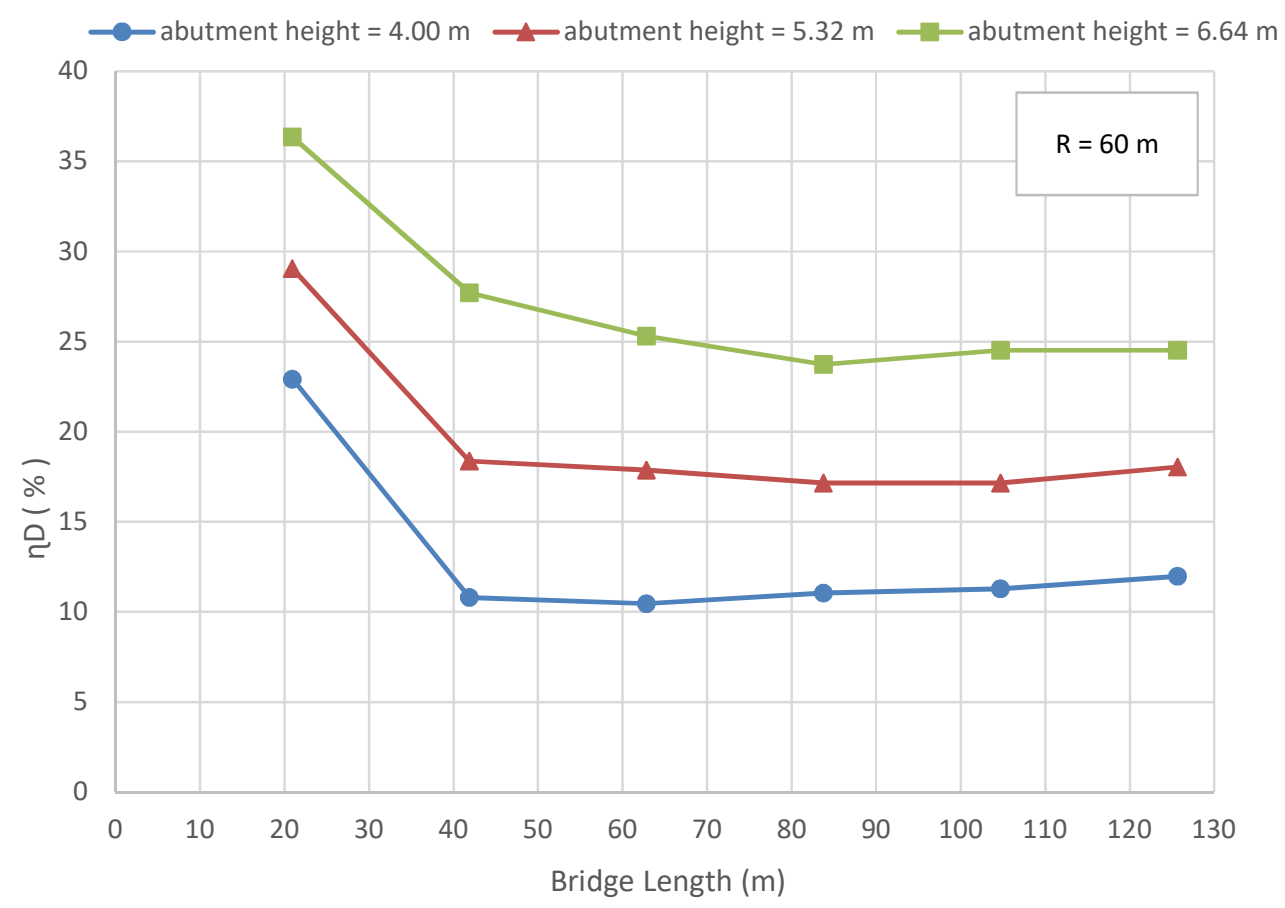

Figure 4.112 $n_{\Delta}$ Versus Bridge Length at Different Abutment Heights

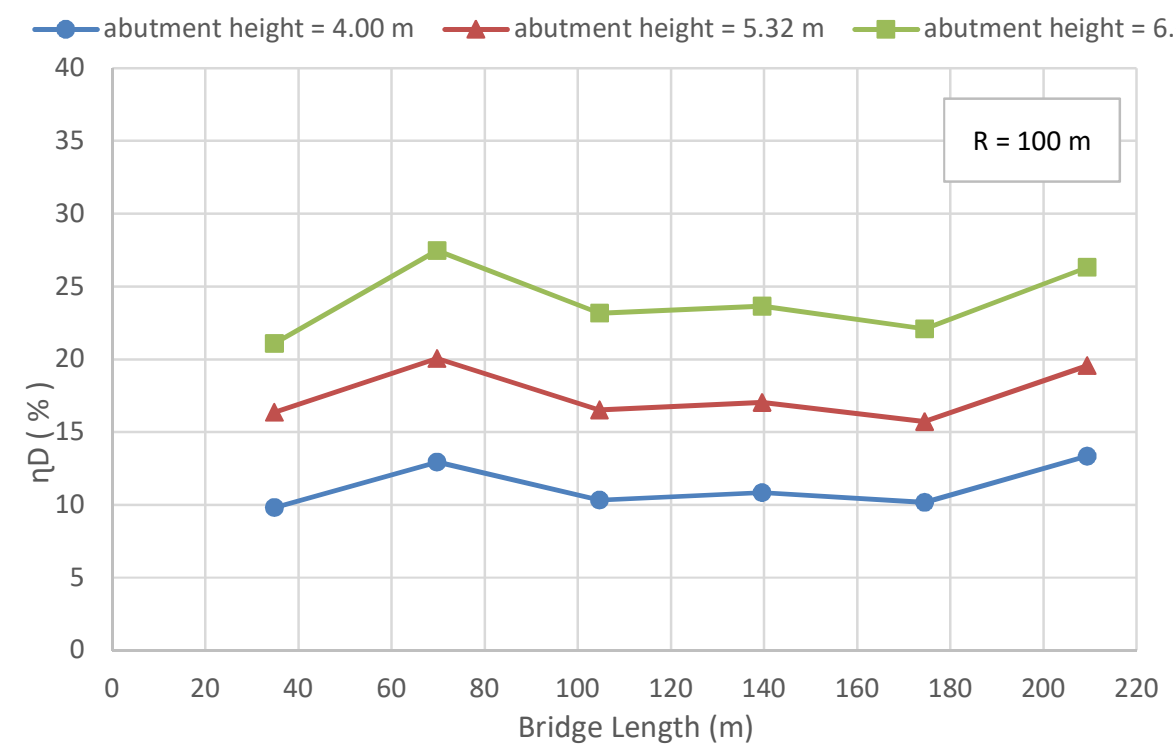

Figure 4.113 $n_{\Delta}$ Versus Bridge Length at Different Abutment Heights 


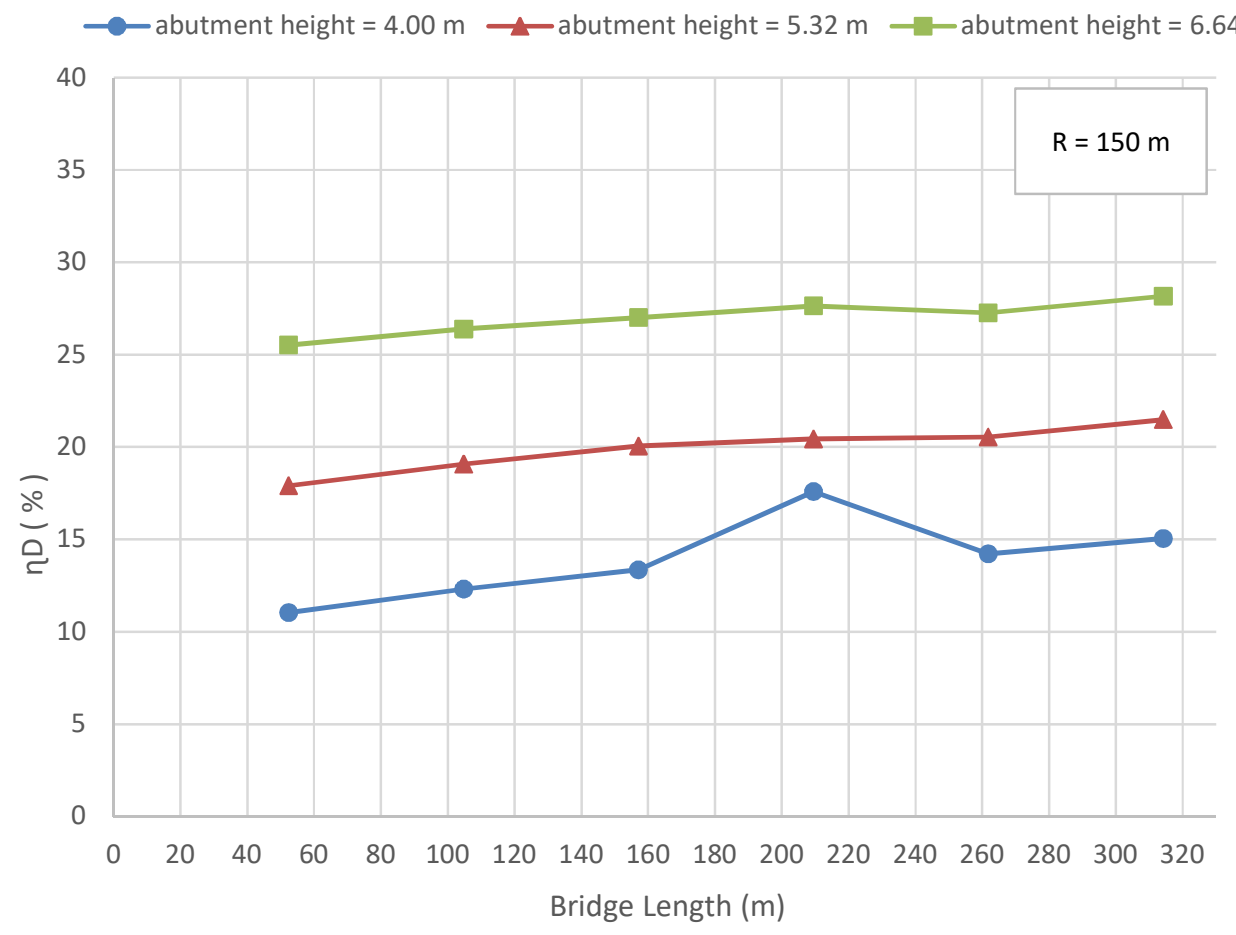

Figure 4.114 $n_{\Delta}$ Versus Bridge Length at Different Abutment Heights

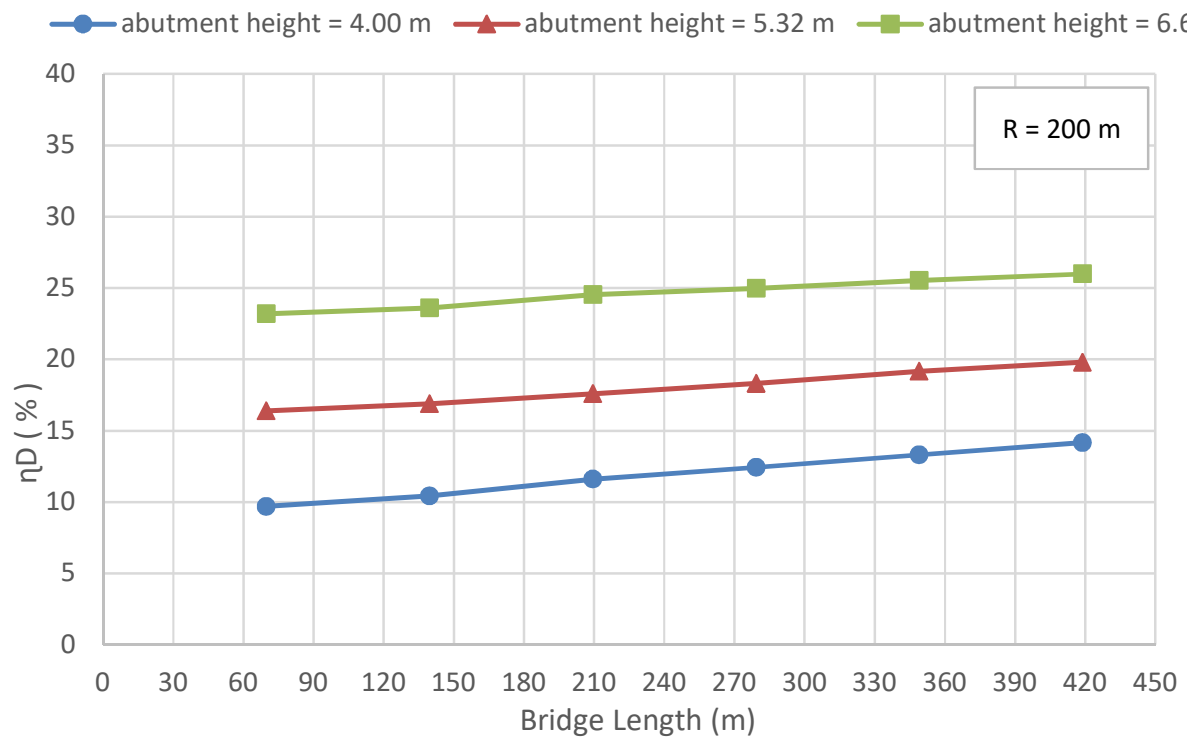

Figure 4.115 $n_{\Delta}$ Versus Bridge Length at Different Abutment Heights 


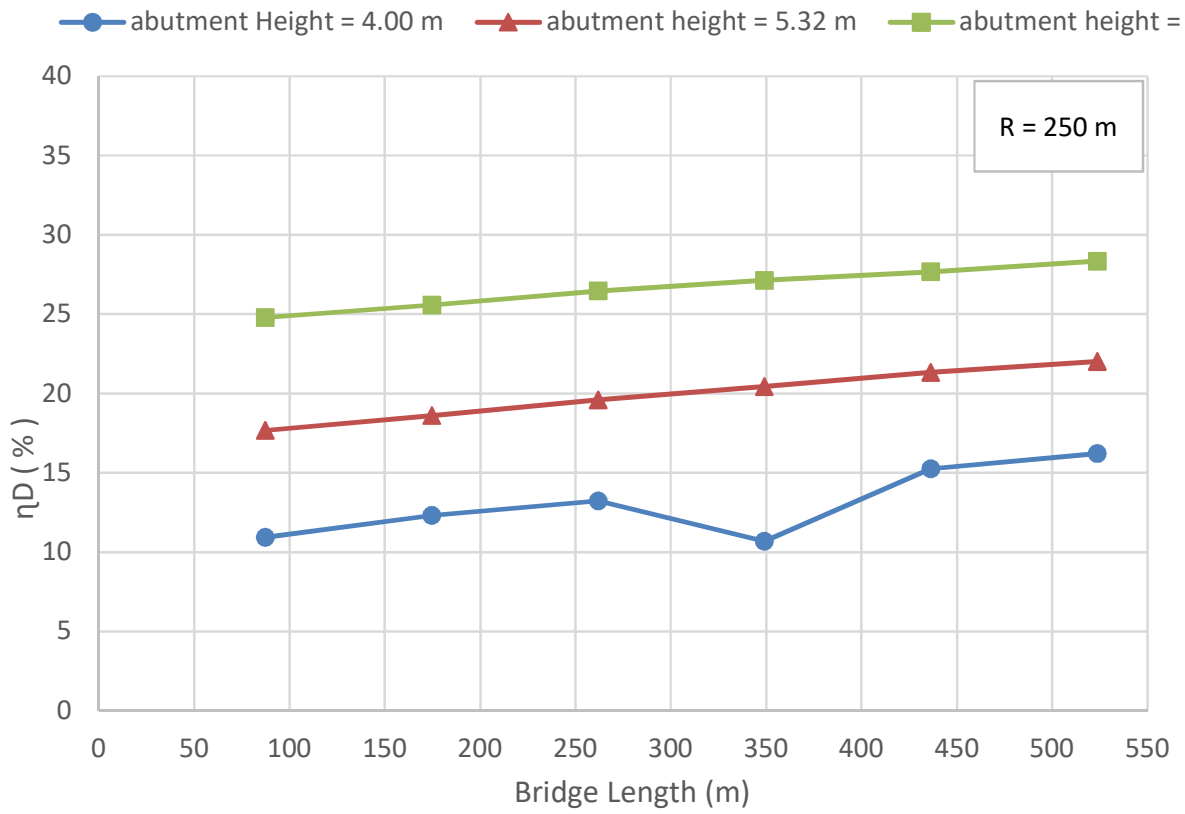

Figure 4.116 $n_{\Delta}$ Versus Bridge Length at Different Abutment Heights

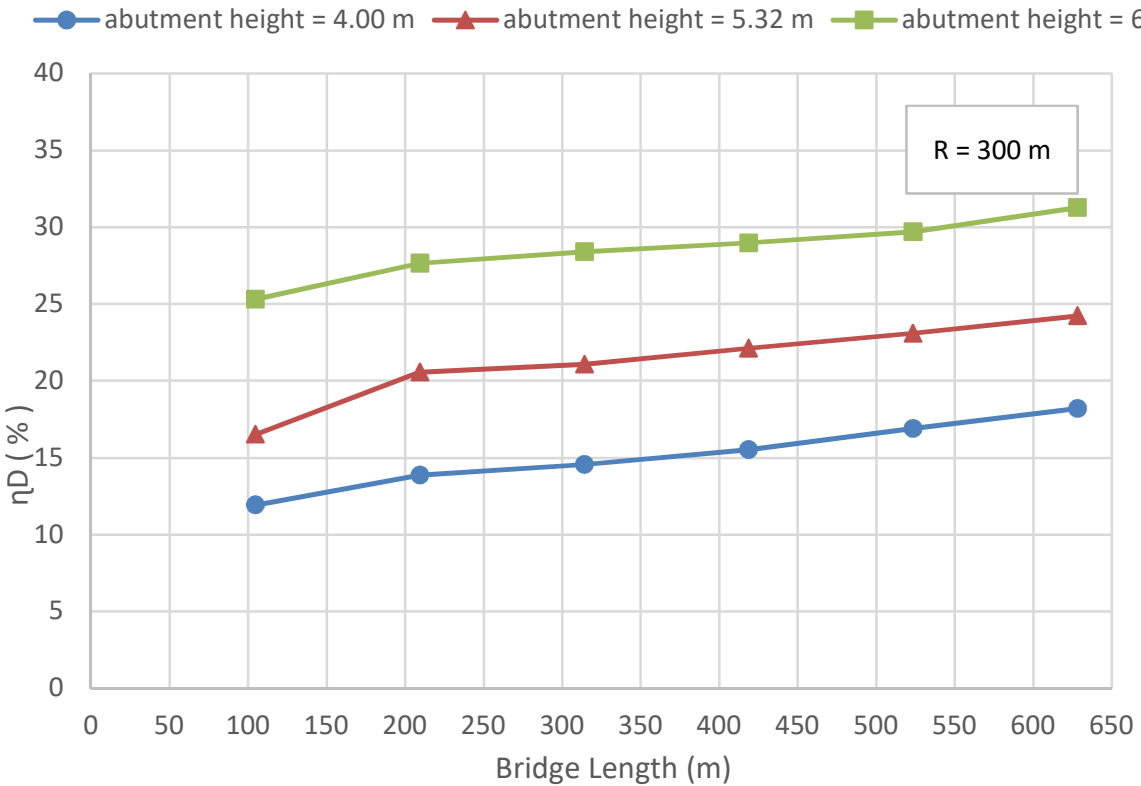

Figure 4.117 $n_{\Delta}$ Versus Bridge Length at Different Abutment Heights 


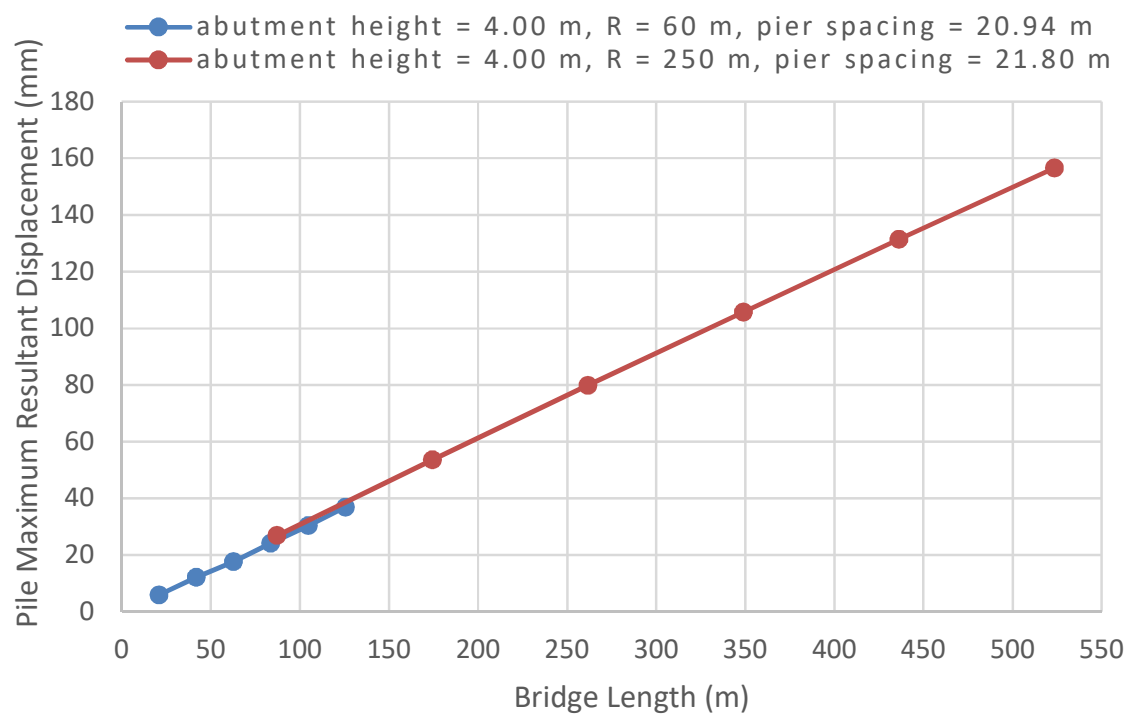

Figure 4.118 Pile Maximum Resultant Displacement Versus Bridge Length

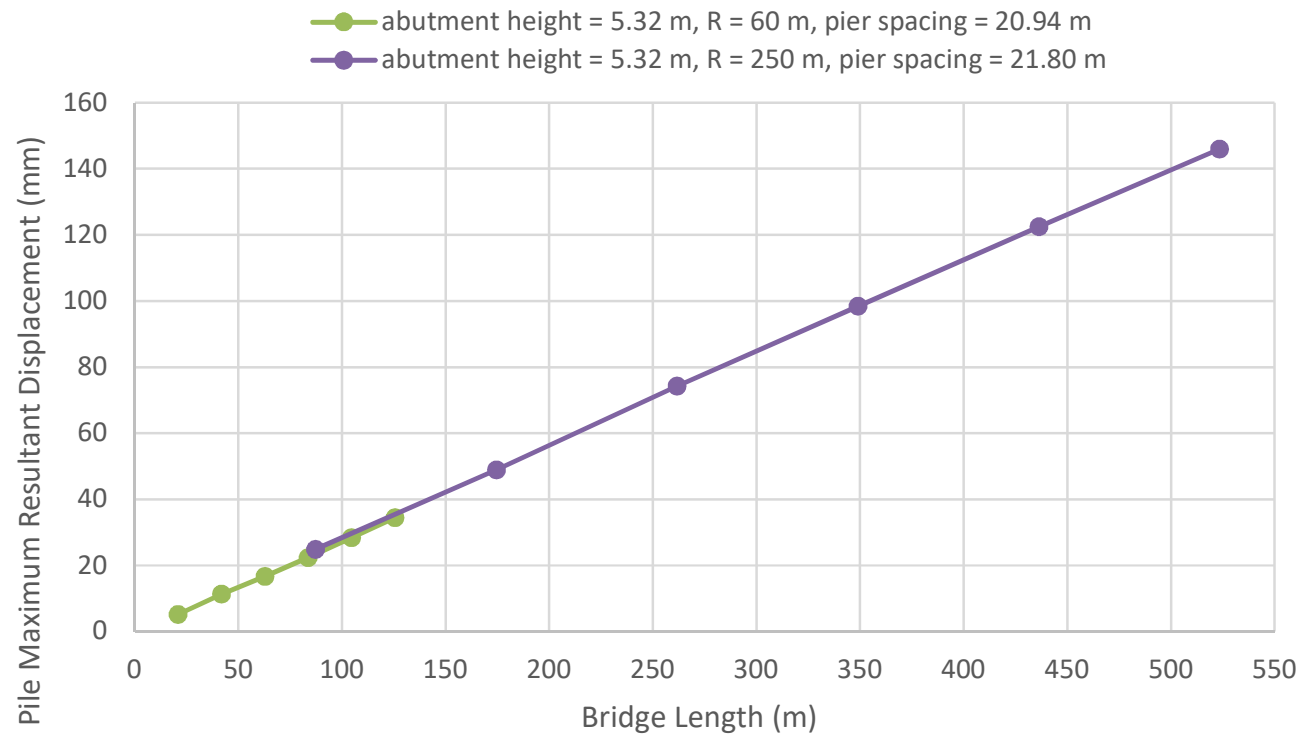

Figure 4.119 Pile Maximum Resultant Displacement Versus Bridge Length 


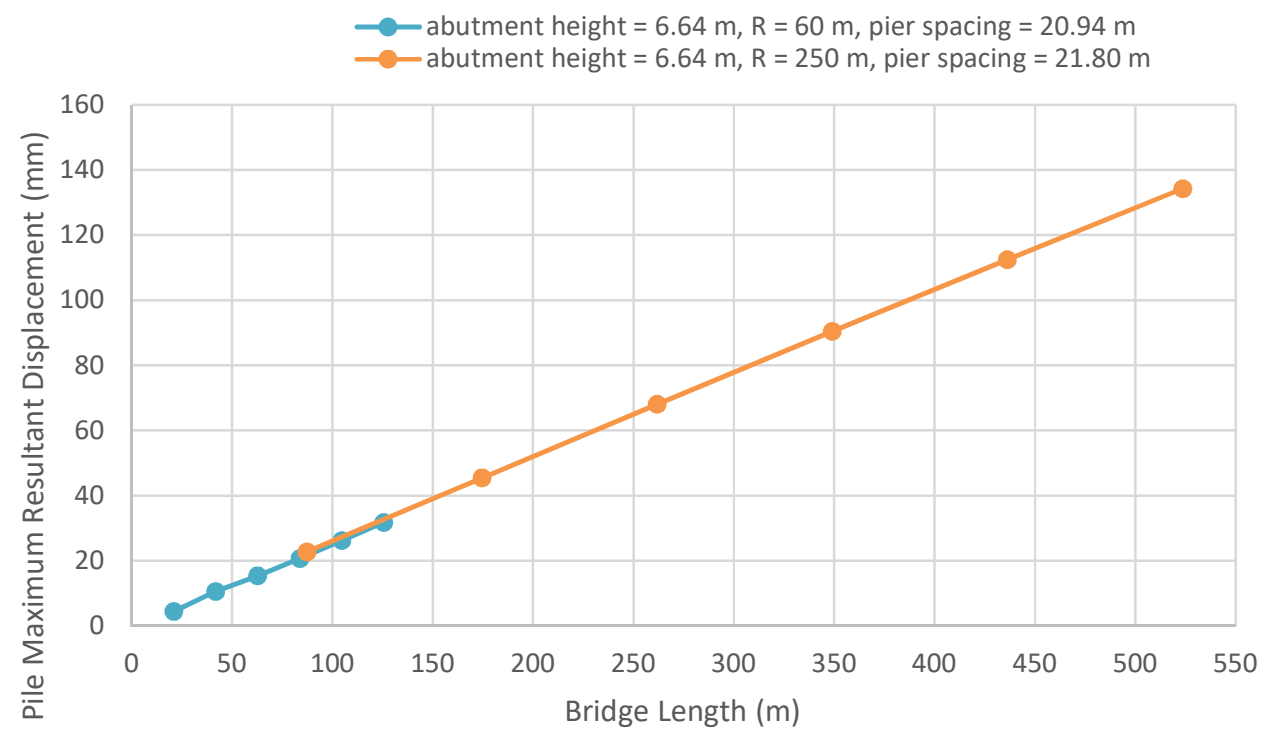

Figure 4.120 Pile Maximum Resultant Displacement Versus Bridge Length

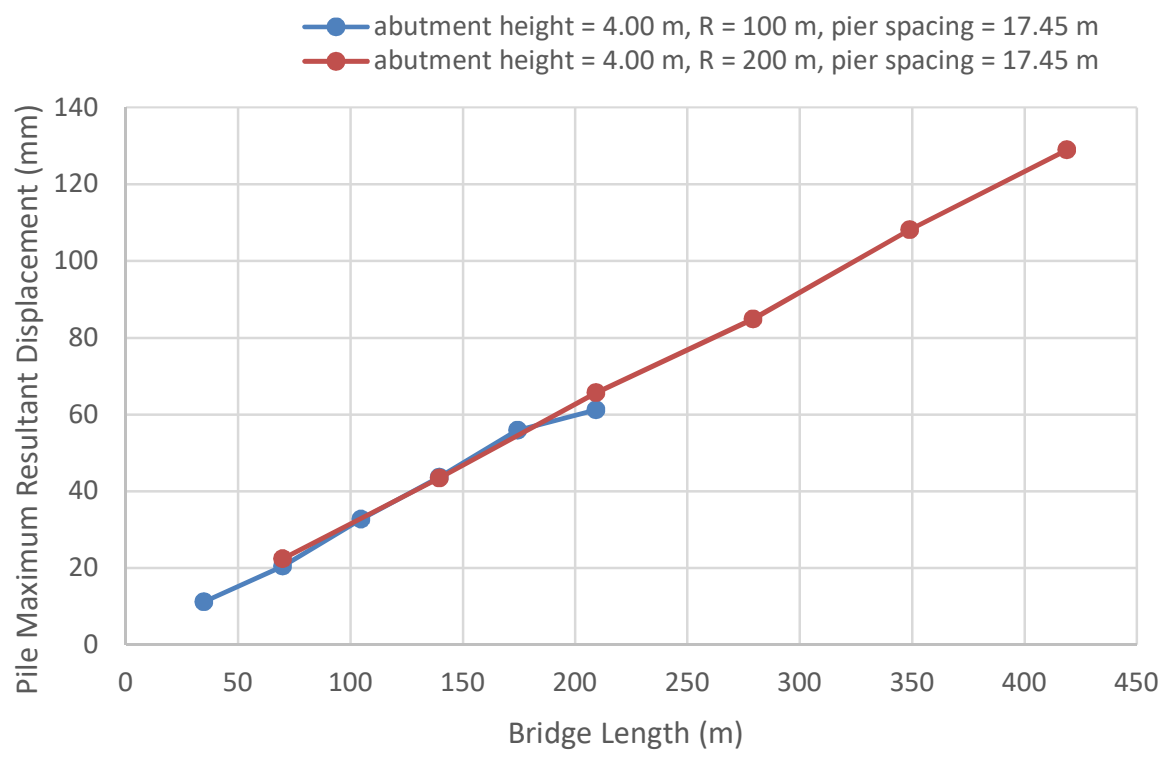

Figure 4.121 Pile Maximum Resultant Displacement Versus Bridge Length 


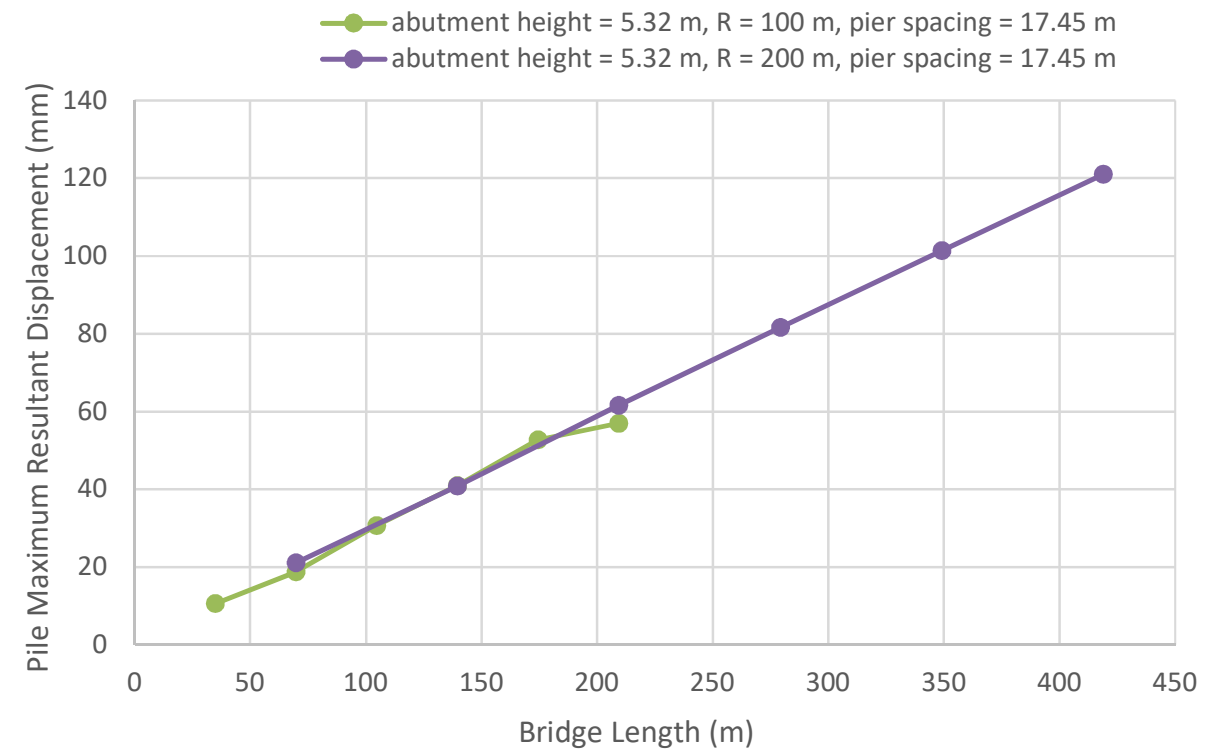

Figure 4.122 Pile Maximum Resultant Displacement Versus Bridge Length

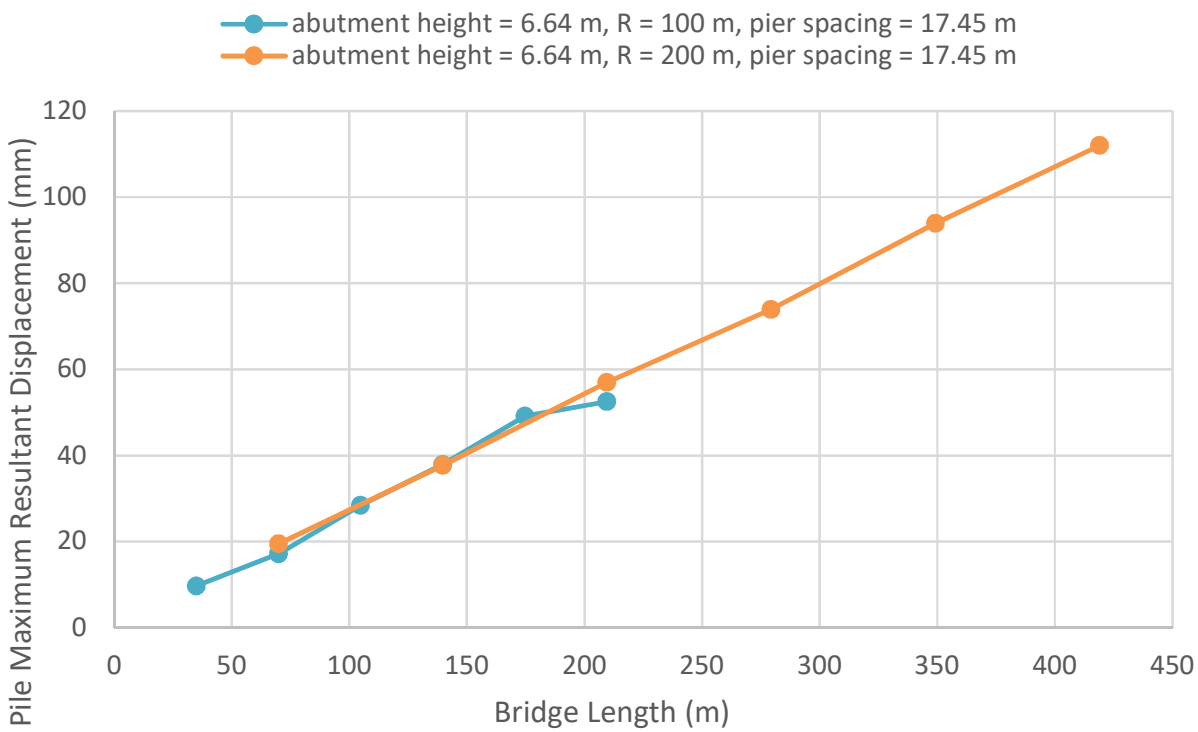

Figure 4.123 Pile Maximum Resultant Displacement Versus Bridge Length 


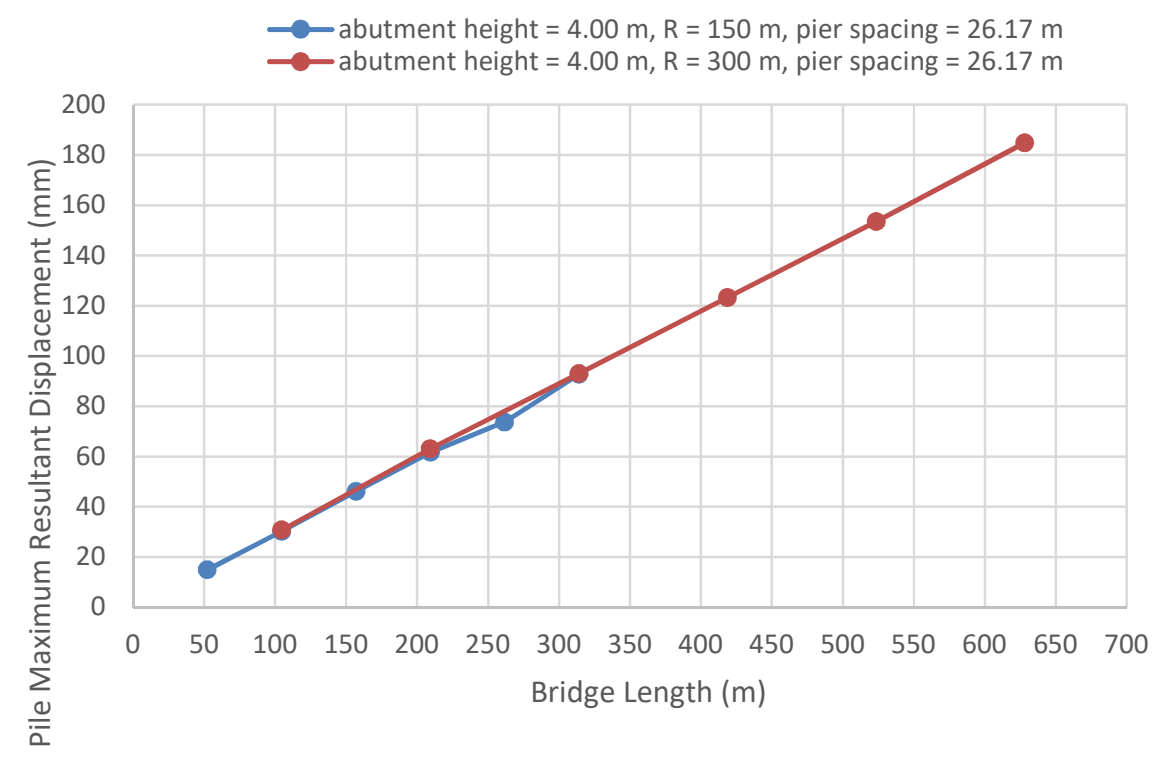

Figure 4.124 Pile Maximum Resultant Displacement Versus Bridge Length

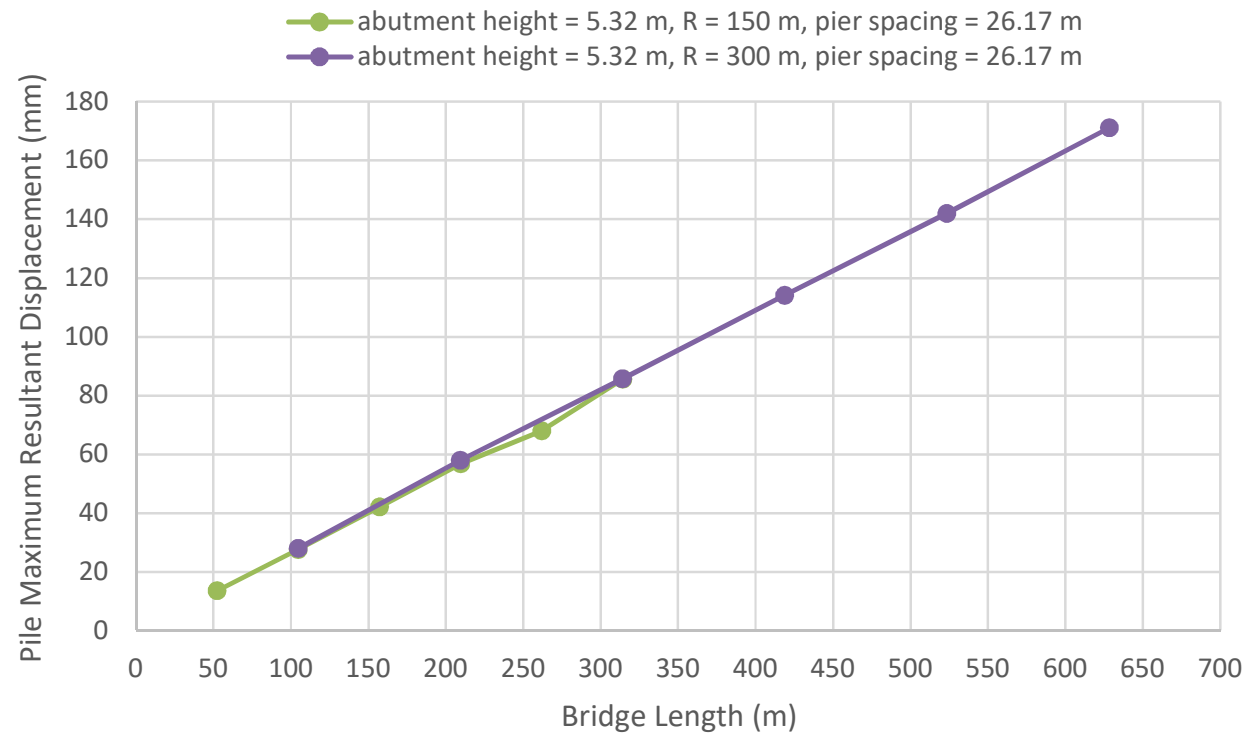

Figure 4.125 Pile Maximum Resultant Displacement Versus Bridge Length 


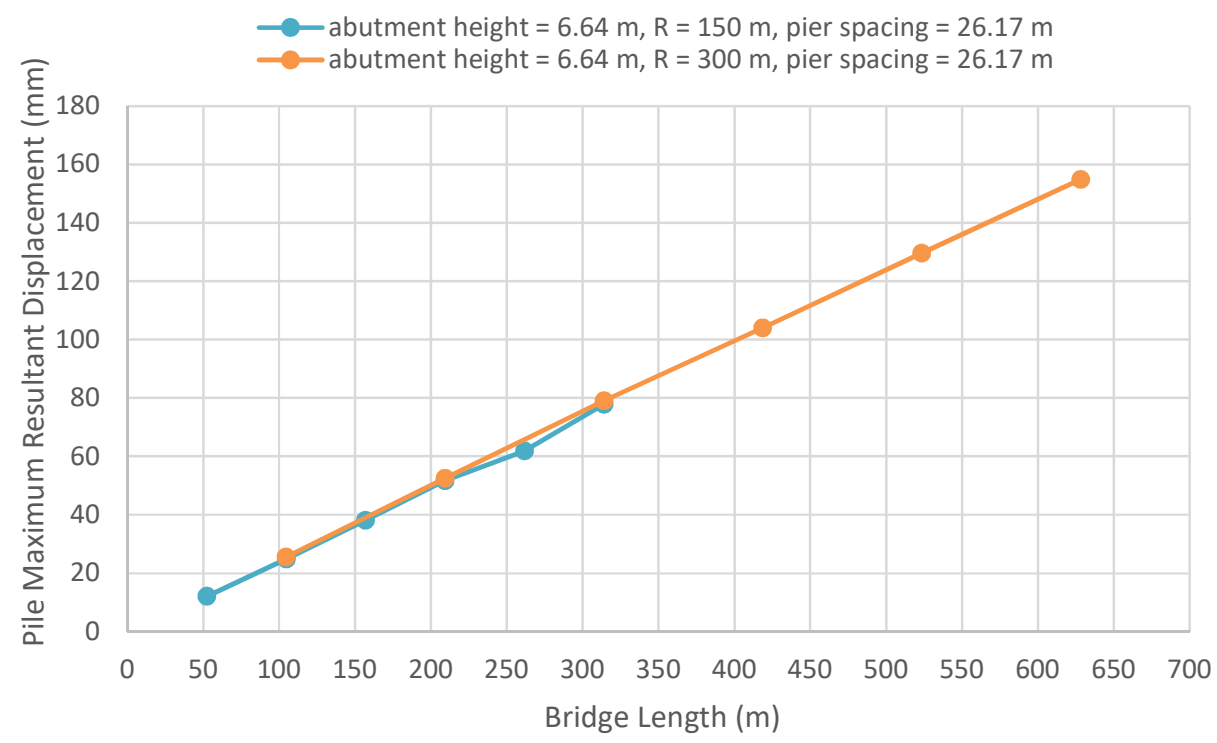

Figure 4.126 Pile Maximum Resultant Displacement Versus Bridge Length

\subsubsection{Bending Moment}

The bending moment imposed on piles heads embedded in stiff clay and fixed in bridge abutment is dependent on pile head displacement, abutment rotation and pile flexibility. The abutment rotation relieves the moment resulting from pile displacement. The pile maximum resultant moment decreases with the increase of abutment height. Either the piles are driven in predrilled holes or in stiff clay without predrilled holes. The moments shown in Table 4.25 are assessed at piles heads. The moments imposed on piles installed in stiff clay without predrilled holes are denoted $M_{2}$, while the moments imposed on piles heads installed in predrilled holes are denoted $\mathrm{M}_{1}$.

The predrilled holes introduce great deal of flexibility into abutment piles. Therefore, the pile maximum resultant bending moment imposed on the pile head decreased (Yang et al., 1985; Greimann et al., 1986; Faraji, 1997; Crovo, 1998; Haj-Najib, 2002).

The percentage change in pile maximum resultant bending moment, $\mathrm{n}_{\mathrm{m}}$, in case of piles with predrilled holes over $2.75 \mathrm{~m}$ depth compared to that for piles embedded in clay without drilled holes is expressed as; 
$n_{\mathrm{m}}=\frac{M_{1}-M_{2}}{M_{2}}$

Where;

$n_{m}$ : Percentage change in pile maximum resultant moment driven in stiff clay with $2.75 \mathrm{~m}$ deep predrilled holes compared to that for piles embedded in stiff clay without drilled holes.

$M_{1}$ : Pile maximum resultant bending moment of piles with $2.75 \mathrm{~m}$ deep predrilled holes at its top portion,

$M_{2}$ : Pile maximum resultant bending moment of piles embedded in stiff clay.

To investigate the effect of bridge curvature on the maximum resultant moment imposed on pile head, Figures 4.127 through 4.135 were developed. Figures 4.127 and 4.129 present maximum resultant moment $\left(\mathrm{M}_{2}\right)$ on piles embedded in stiff clay and similar piles embedded in $2.75 \mathrm{~m}$-deep predrilled holes $\left(\mathrm{M}_{1}\right)$. The bridges have a span length of $20.94 / 21.8 \mathrm{~m}$, while the radii of curvature are $60 \mathrm{~m}$ and $250 \mathrm{~m}$. The figures revealed that the bridge curvature has insignificant effect on the imposed moment on piles heads. Figures 4.130 through 4.132 provide similar results but for bridge span length of $17.45 \mathrm{~m}$ radius of curvature of $100 \mathrm{~m}$ and 200 m, while Figures 4.133 through 4.135 provide similar results for bridges of span length $26.17 \mathrm{~m}$ and radius of curvature of $150 \mathrm{~m}$ and $300 \mathrm{~m}$. The figures revealed that there is insignificant effect of bridge curvature on pile maximum resultant moments. Figures 4.136 through 4.141 present the variation of pile moment percentage change, $n_{\mathrm{m}}$, against bridge length. In summary, pile moment with the use of drilled hole decrease with increase of abutment height.

The figures show reduction in pile moment with the use of drilled holes for abutment heights of 4 and $5.32 \mathrm{~m}$. on the other hand, pile moment increases with the use of drilled holes for abutment height of $6.64 \mathrm{~m}$. 
Table 4.25 Pile Maximum Resultant Moment

A) Abutment Height $4.00 \mathrm{~m}$

\begin{tabular}{|c|c|c|c|c|c|c|c|}
\hline $\begin{array}{l}\text { Radius } \\
\text { (m) }\end{array}$ & $\begin{array}{l}\text { Pile Resultant Moment } \\
\text { (kN.m) }\end{array}$ & $\begin{array}{l}\text { L1 } \\
\text { (m) }\end{array}$ & $\begin{array}{l}\text { L2 } \\
\text { (m) }\end{array}$ & $\begin{array}{l}\text { L3 } \\
\text { (m) }\end{array}$ & $\begin{array}{l}\text { L4 } \\
\text { (m) }\end{array}$ & $\begin{array}{l}\text { L5 } \\
\text { (m) }\end{array}$ & $\begin{array}{l}\text { L6 } \\
\text { (m) }\end{array}$ \\
\hline \multirow{4}{*}{60} & Length L1 Through L6 & 20.4 & 41.8 & 62.8 & 83.7 & 104.7 & 125.66 \\
\hline & $M_{1}(k N . m)$ & 35 & 87 & 125 & 168 & 215 & 263 \\
\hline & $\mathrm{M}_{2}(\mathrm{kN} . \mathrm{m})$ & 43 & 108 & 152 & 203 & 258 & 315 \\
\hline & Percentage of Reduction (\%) & -18.6 & -19.4 & -17.7 & -17.2 & -16.6 & -16.5 \\
\hline \multirow{4}{*}{100} & Length L1 Through L6 & 34.9 & 69.81 & 104.71 & 139.62 & 174.52 & 209.43 \\
\hline & $\mathrm{M}_{1}(\mathrm{kN} . \mathrm{m})$ & 83 & 141 & 242 & 323 & 421 & 437 \\
\hline & $\mathrm{M}_{2}$ (kN.m) & 102 & 162 & 295 & 393 & 521 & 511 \\
\hline & Percentage of Reduction (\%) & -18.6 & -12.9 & -17.9 & -17.8 & -19.1 & -14.4 \\
\hline \multirow{4}{*}{150} & Length L1 Through L6 & 52.35 & 104.71 & 157.07 & 209.43 & 261.79 & 314.15 \\
\hline & $M_{1}(k N . m)$ & 93 & 200 & 312 & 423 & 507 & 644 \\
\hline & $\mathrm{M}_{2}$ (kN.m) & 112 & 234 & 363 & 490 & 585 & 738 \\
\hline & Percentage of Reduction (\%) & -16.9 & -14.5 & -14 & -13.6 & -13.3 & -12.7 \\
\hline \multirow{4}{*}{200} & Length L1 Through L6 & 69.81 & 139.62 & 209.43 & 279.24 & 349.05 & 418.86 \\
\hline & $\mathrm{M}_{1}(\mathrm{kN} . \mathrm{m})$ & 166 & 321 & 488 & 628 & 803 & 958 \\
\hline & $\mathrm{M}_{2}$ (kN.m) & 204 & 391 & 588 & 753 & 954 & 1129 \\
\hline & Percentage of Reduction (\%) & -18.6 & -17.9 & -17 & -16.6 & -15.8 & -15 \\
\hline \multirow{4}{*}{250} & Length L1 Through L6 & 87.26 & 174.52 & 261.79 & 349.05 & 436.31 & 523.58 \\
\hline & $\mathrm{M}_{1}$ (kN.m) & 191 & 384 & 276 & 766 & 952 & 1136 \\
\hline & $\mathrm{M}_{2}$ (kN.m) & 229 & 455 & 676 & 890 & 1097 & 1298 \\
\hline & Percentage of Reduction (\%) & -16.5 & -15 & -14.7 & -13.9 & -13.2 & -12.4 \\
\hline \multirow{4}{*}{300} & Length L1 Through L6 & 104.7 & 209.4 & 314.1 & 418.8 & 523.5 & 628.3 \\
\hline & $\mathrm{M}_{1}$ (kN.m) & 206 & 437 & 648 & 867 & 1080 & 1309 \\
\hline & $\mathrm{M}_{2}$ (kN.m) & 242 & 507 & 743 & 982 & 1210 & 1454 \\
\hline & Percentage of Reduction (\%) & -14.8 & -13.8 & -12.6 & -11.7 & -10.7 & -9.9 \\
\hline
\end{tabular}


Table 4.25 Continue - Pile Maximum Resultant Moment

B) Abutment Height $5.32 \mathrm{~m}$

\begin{tabular}{|c|c|c|c|c|c|c|c|}
\hline $\begin{array}{l}\text { Radius } \\
(\mathrm{m})\end{array}$ & $\begin{array}{l}\text { Pile Resultant Moment } \\
\text { (kN.m) }\end{array}$ & $\begin{array}{l}\text { L1 } \\
(\mathrm{m})\end{array}$ & $\begin{array}{l}\text { L2 } \\
(\mathrm{m})\end{array}$ & $\begin{array}{l}\text { L3 } \\
\text { (m) }\end{array}$ & $\begin{array}{l}\mathrm{L4} \\
(\mathrm{m})\end{array}$ & $\begin{array}{l}\text { L5 } \\
(\mathrm{m})\end{array}$ & $\begin{array}{l}\mathrm{L6} \\
(\mathrm{m})\end{array}$ \\
\hline \multirow{4}{*}{60} & Length L1 Through L6 & 20.94 & 41.88 & 62.83 & 83.77 & 104.71 & 125.66 \\
\hline & $\mathrm{M}_{1}$ (kN.m) & 29 & 78 & 110 & 150 & 191 & 234 \\
\hline & $\mathrm{M}_{2}$ (kN.m) & 31 & 87 & 121 & 163 & 208 & 255 \\
\hline & Percentage of Reduction (\%) & -6.45 & -10.34 & -9.09 & -7.97 & -8.17 & -8.23 \\
\hline \multirow{4}{*}{100} & Length L1 Through L6 & 34.9 & 69.81 & 104.71 & 139.62 & 174.52 & 209.43 \\
\hline & $\mathrm{M}_{1}(\mathrm{kN} . \mathrm{m})$ & 76 & 123 & 217 & 290 & 380 & 386 \\
\hline & $\mathrm{M}_{2}$ (kN.m) & 85 & 126 & 241 & 322 & 433 & 410 \\
\hline & Percentage of Reduction (\%) & -10.5 & -2.3 & -9.9 & -9.9 & -12 & -5.8 \\
\hline \multirow{4}{*}{150} & Length L1 Through L6 & 52.35 & 104.71 & 157.07 & 209.43 & 261.79 & 314.15 \\
\hline & $\mathrm{M}_{1}$ (kN.m) & 82 & 171 & 267 & 367 & 441 & 561 \\
\hline & $\mathrm{M}_{2}$ (kN.m) & 85 & 180 & 279 & 382 & 459 & 580 \\
\hline & Percentage of Reduction (\%) & -3.5 & -5 & -4.3 & -3.9 & -3.9 & -3.2 \\
\hline \multirow{4}{*}{200} & Length L1 Through L6 & 69.81 & 139.62 & 209.43 & 279.24 & 349.05 & 418.86 \\
\hline & $M_{1}(k N . m)$ & 150 & 287 & 435 & 576 & 715 & 853 \\
\hline & $\mathrm{M}_{2}$ (kN.m) & 166 & 318 & 479 & 631 & 779 & 924 \\
\hline & Percentage of Reduction (\%) & -9.6 & -9.7 & -9.1 & -8.7 & -8.2 & -7.6 \\
\hline \multirow{4}{*}{250} & Length L1 Through L6 & 87.26 & 174.52 & 261.79 & 349.05 & 436.31 & 523.58 \\
\hline & $\mathrm{M}_{1}(\mathrm{kN} . \mathrm{m})$ & 168 & 331 & 506 & 673 & 888 & 1000 \\
\hline & $\mathrm{M}_{2}$ (kN.m) & 181 & 355 & 539 & 712 & 880 & 1044 \\
\hline & Percentage of Reduction (\%) & -7.1 & -6.7 & -6.1 & -5.4 & -4.7 & -4.2 \\
\hline \multirow{4}{*}{300} & Length L1 Through L6 & 104.7 & 209.4 & 314.1 & 418.8 & 523.5 & 628.3 \\
\hline & $\mathrm{M}_{1}$ (kN.m) & 169 & 379 & 563 & 751 & 940 & 1142 \\
\hline & $\mathrm{M}_{2}$ (kN.m) & 186 & 394 & 580 & 769 & 955 & 1152 \\
\hline & Percentage of Reduction (\%) & -9.1 & -3.8 & -2.9 & -2.3 & -1.5 & -0.8 \\
\hline
\end{tabular}


Table 4.25 Continue - Pile Maximum Resultant Moment

C) Abutment Height $6.64 \mathrm{~m}$

\begin{tabular}{|c|c|c|c|c|c|c|c|}
\hline $\begin{array}{l}\text { Radius } \\
(\mathrm{m})\end{array}$ & $\begin{array}{l}\text { Pile Resultant Moment } \\
\text { (kN.m) }\end{array}$ & L1 (m) & L2 (m) & L3 (m) & L4 (m) & L5 (m) & L6 (m) \\
\hline \multirow{4}{*}{60} & Length L1 Through L6 & 20.94 & 41.88 & 62.83 & 83.77 & 104.71 & 125.66 \\
\hline & $\mathrm{M}_{1}(\mathrm{kN} . \mathrm{m})$ & 23 & 69 & 95 & 131 & 167 & 205 \\
\hline & $\mathrm{M}_{2}$ (kN.m) & 22 & 68 & 93 & 128 & 164 & 202 \\
\hline & Percentage of Reduction (\%) & 4.5 & 1.4 & -2.15 & 2.34 & 1.82 & 1.4 \\
\hline \multirow{4}{*}{100} & Length L1 Through L6 & 34.9 & 69.81 & 104.71 & 139.62 & 174.52 & 209.43 \\
\hline & $\mathrm{M}_{1}$ (kN.m) & 69 & 105 & 191 & 255 & 336 & 338 \\
\hline & $\mathrm{M}_{2}$ (kN.m) & 68 & 96 & 192 & 257 & 349 & 322 \\
\hline & Percentage of Reduction (\%) & 1.4 & 9.3 & 0 & -0.7 & -3.7 & 4.9 \\
\hline \multirow{4}{*}{150} & Length L1 Through L6 & 52.35 & 104.71 & 157.07 & 209.43 & 261.79 & 314.15 \\
\hline & $M_{1}(k N . m)$ & 68 & 144 & 229 & 314 & 377 & 481 \\
\hline & $\mathrm{M}_{2}$ (kN.m) & 62 & 134 & 213 & 291 & 352 & 446 \\
\hline & Percentage of Reduction (\%) & 9.6 & 7.4 & 7.5 & 7.9 & 7.1 & 7.8 \\
\hline \multirow{4}{*}{200} & Length L1 Through L6 & 69.81 & 139.62 & 209.43 & 279.24 & 349.05 & 418.86 \\
\hline & $M_{1}(k N . m)$ & 132 & 252 & 381 & 491 & 626 & 748 \\
\hline & $\mathrm{M}_{2}(\mathrm{kN} . \mathrm{m})$ & 132 & 253 & 380 & 490 & 620 & 737 \\
\hline & Percentage of Reduction (\%) & 0 & -0.39 & 0.26 & 0.2 & 0.96 & 1.4 \\
\hline \multirow{4}{*}{250} & Length L1 Through L6 & 87.26 & 174.52 & 261.79 & 349.05 & 436.31 & 523.58 \\
\hline & $\mathrm{M}_{1}(\mathrm{kN} . \mathrm{m})$ & 145 & 291 & 437 & 582 & 725 & 867 \\
\hline & $\mathrm{M}_{2}$ (kN.m) & 140 & 280 & 419 & 555 & 689 & 819 \\
\hline & Percentage of Reduction (\%) & 3.5 & 3.9 & 4.2 & 4.8 & 5.2 & 5.8 \\
\hline \multirow{4}{*}{300} & Length L1 Through L6 & 104.7 & 209.4 & 314.1 & 418.8 & 523.5 & 628.3 \\
\hline & $M_{1}(k N . m)$ & 143 & 321 & 489 & 642 & 805 & 964 \\
\hline & $\mathrm{M}_{2}$ (kN.m) & 137 & 298 & 452 & 589 & 735 & 875 \\
\hline & Percentage of Reduction (\%) & 4.3 & 7.7 & 8.1 & 8.9 & 9.5 & 10 \\
\hline
\end{tabular}




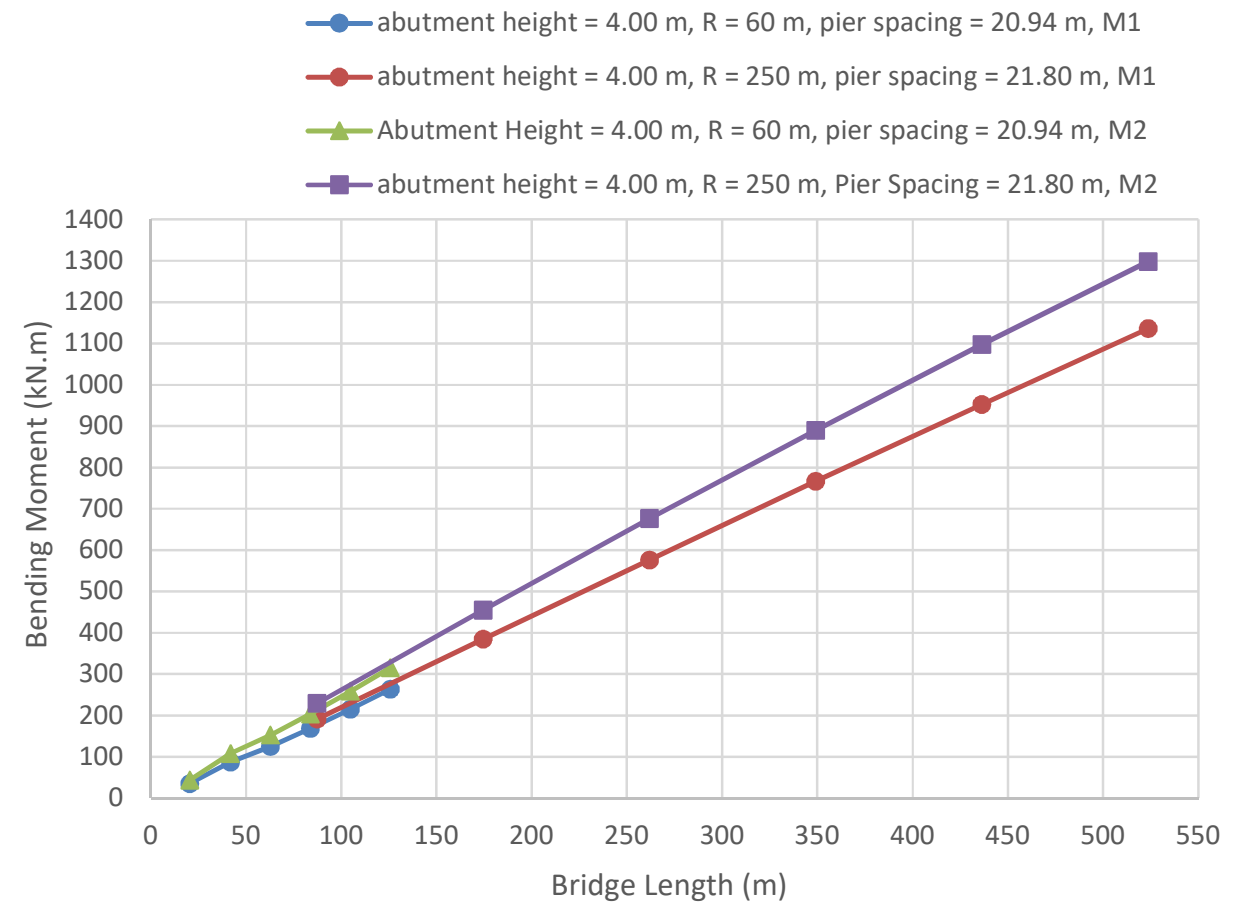

Figure 4.127 Pile Bending Moments Versus Bridge Length

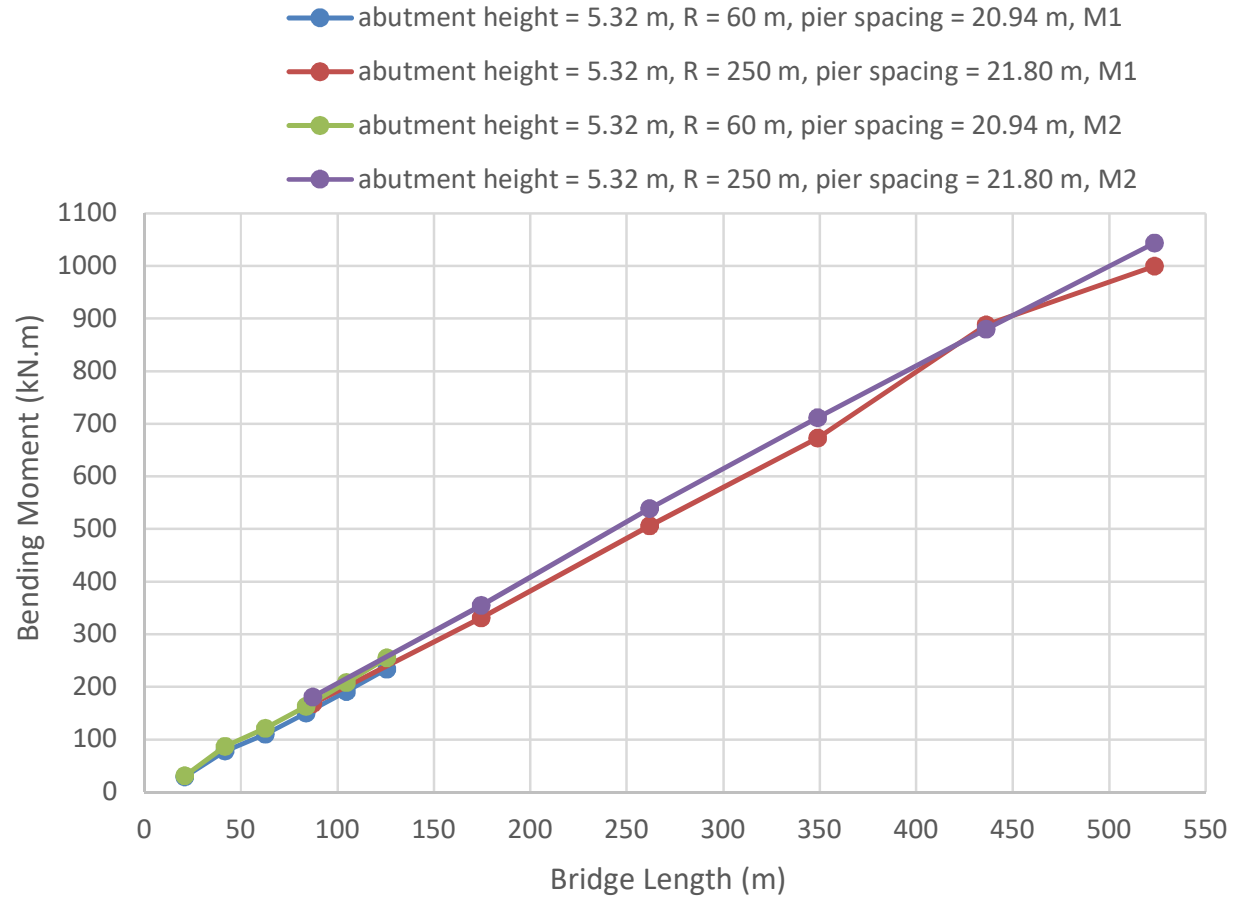

Figure 4.128 Pile Bending Moments Versus Bridge Length 


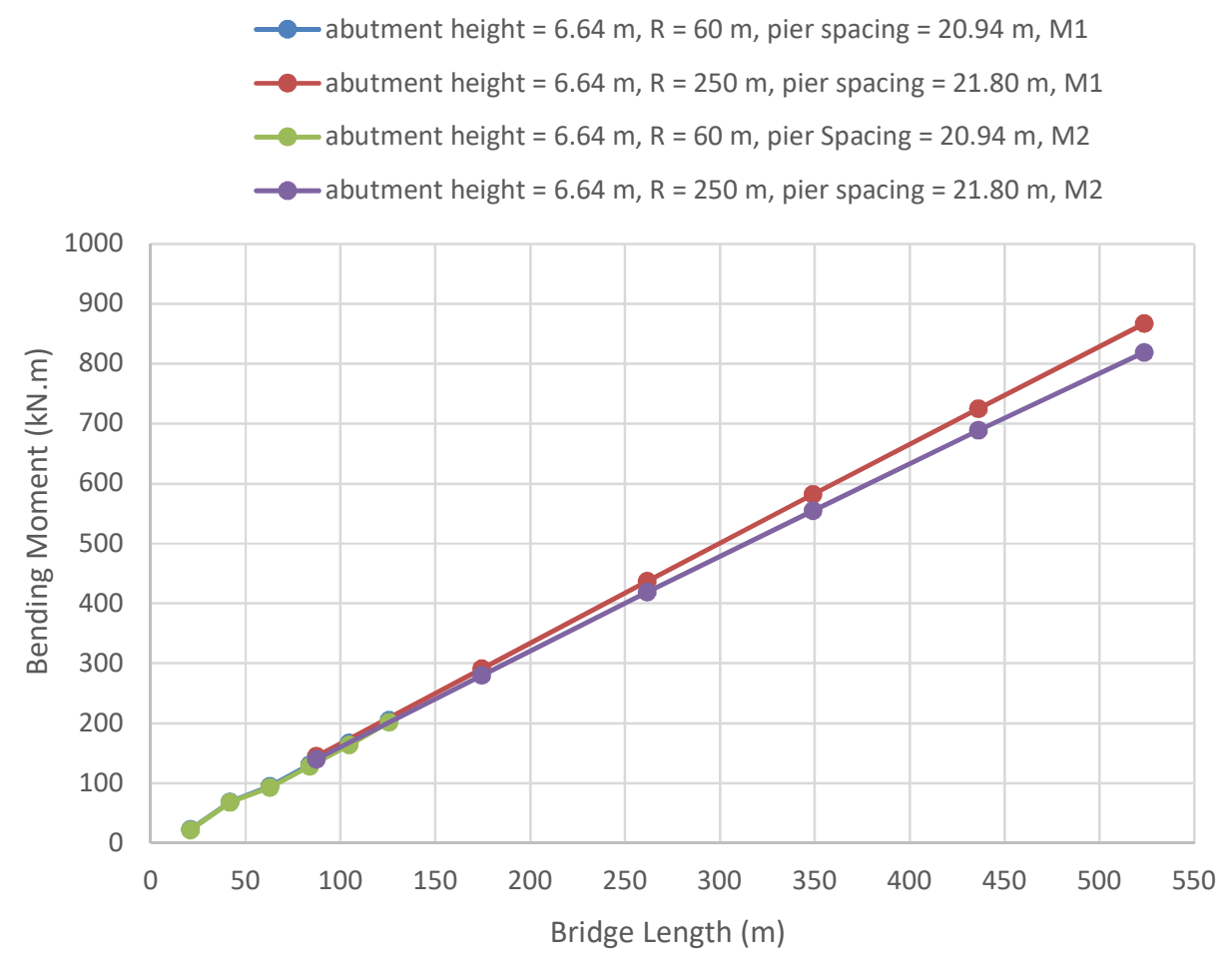

Figure 4.129 Pile Bending Moments Versus Bridge Length

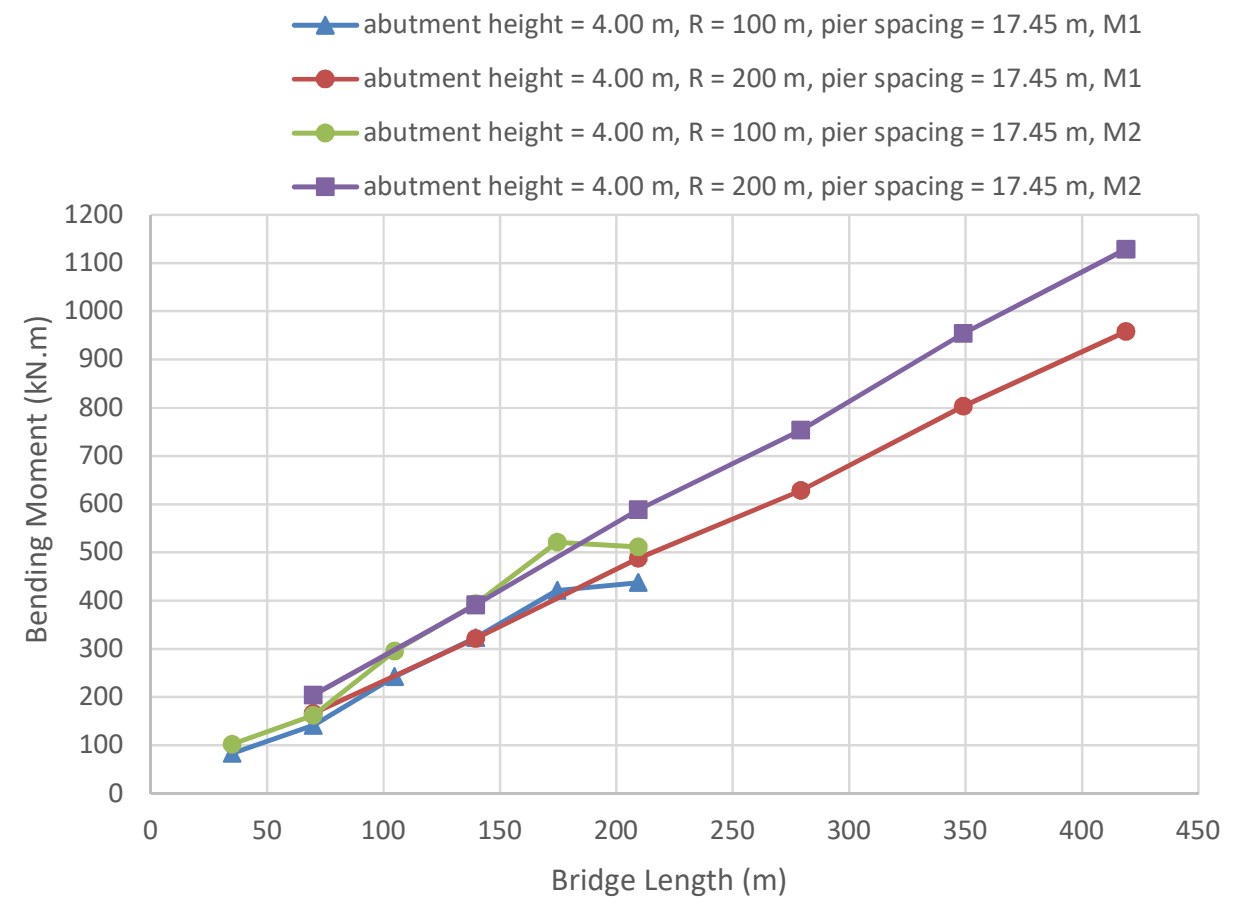

Figure 4.130 Pile Bending Moments Versus Bridge Length 


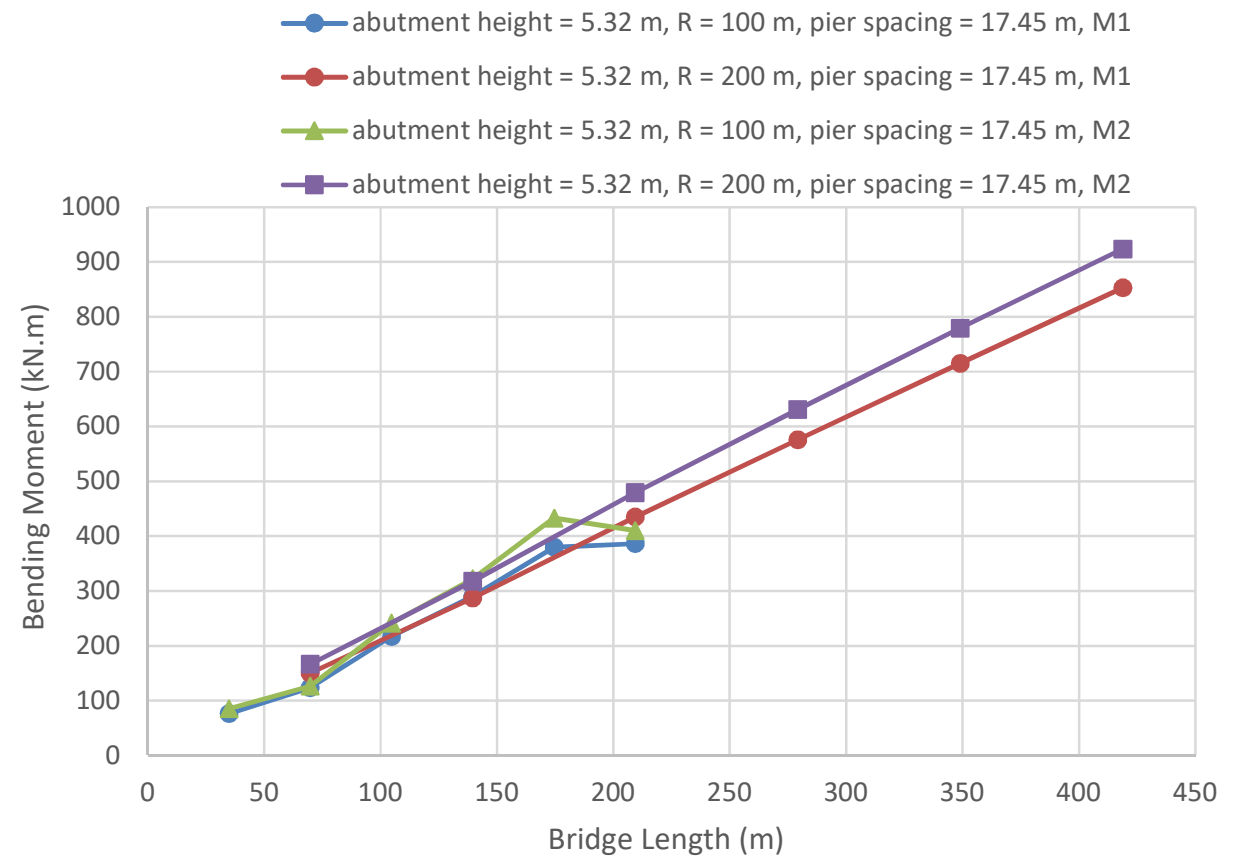

Figure 4.131 Pile Bending Moments Versus Bridge Length
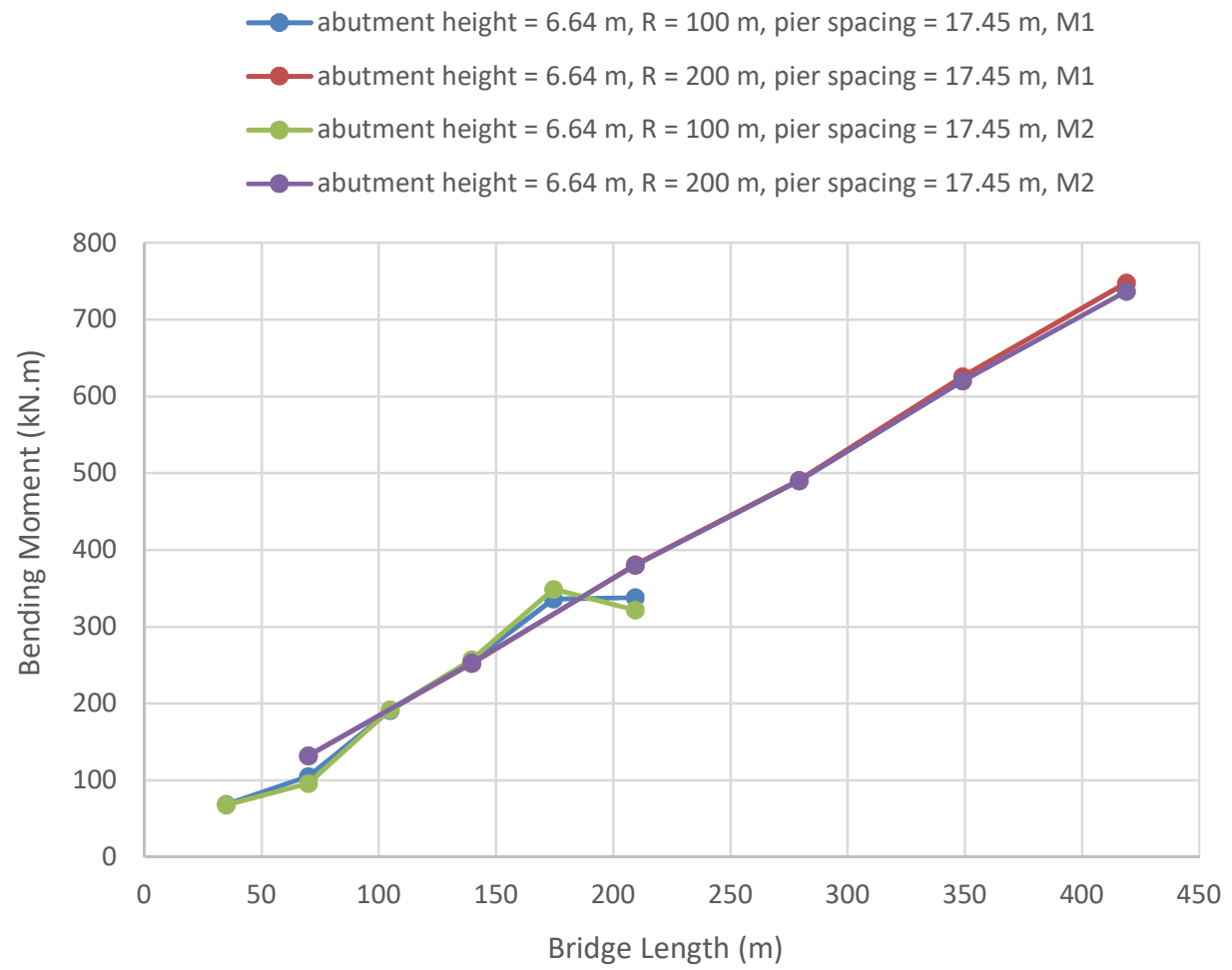

Figure 4.132 Pile Bending Moments Versus Bridge Length 


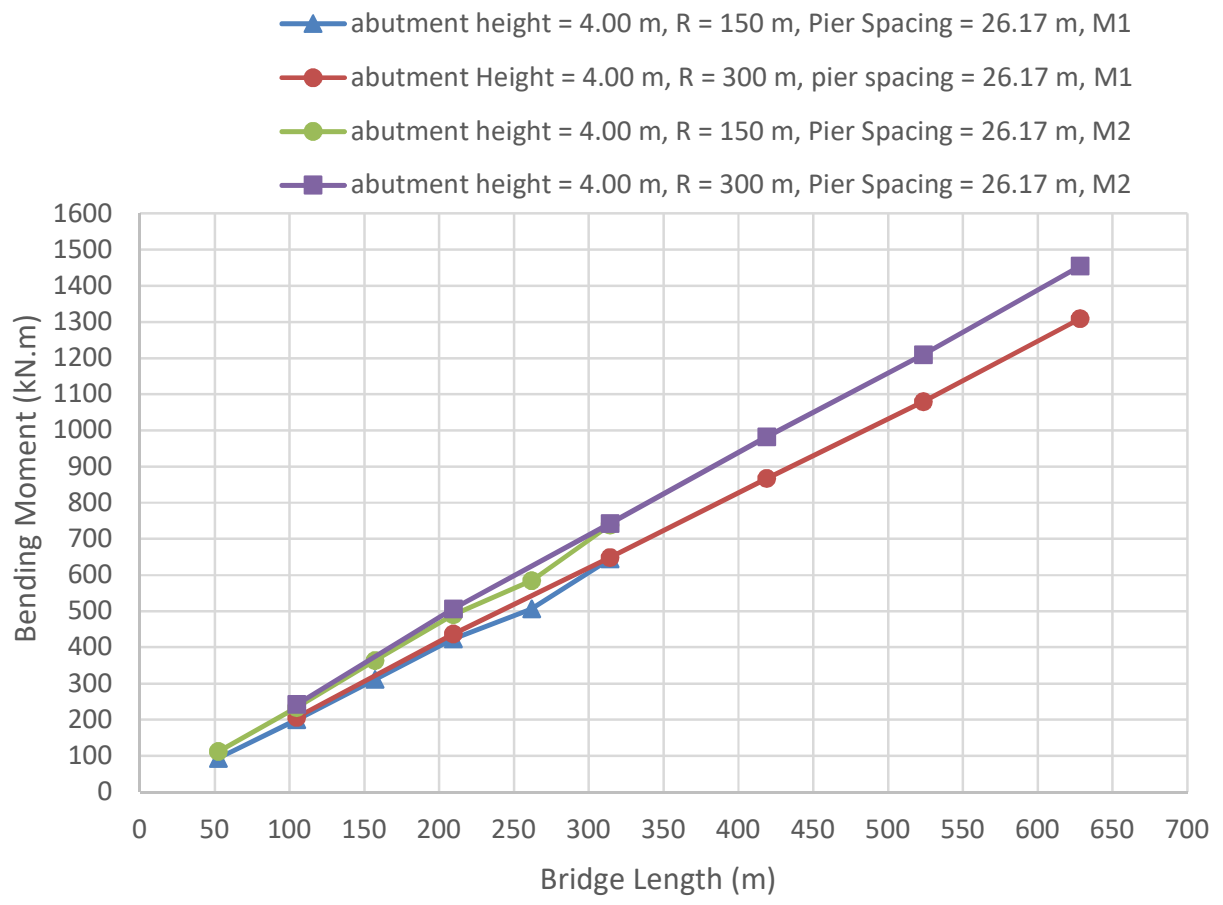

Figure 4.133 Pile Bending Moments Versus Bridge Length

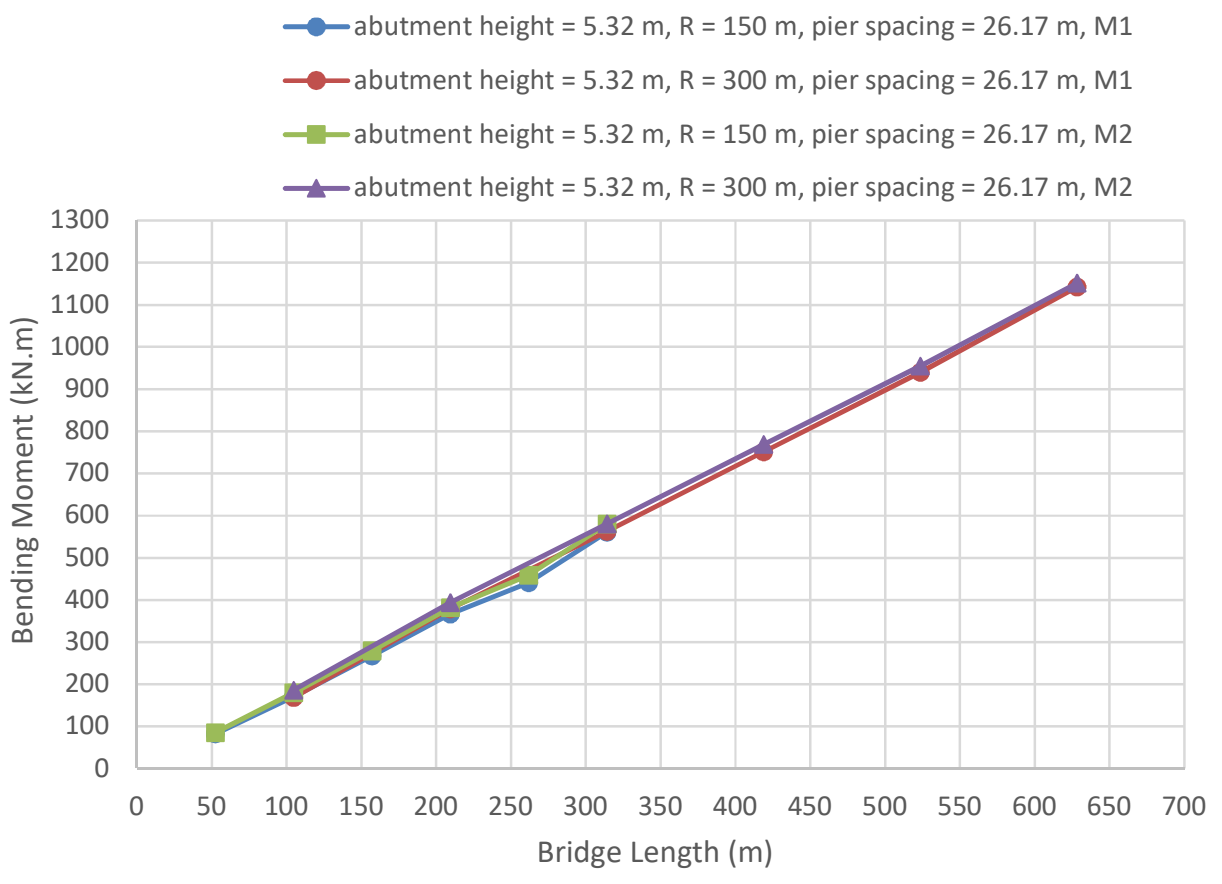

Figure 4.134 Pile Bending Moments Versus Bridge Length 


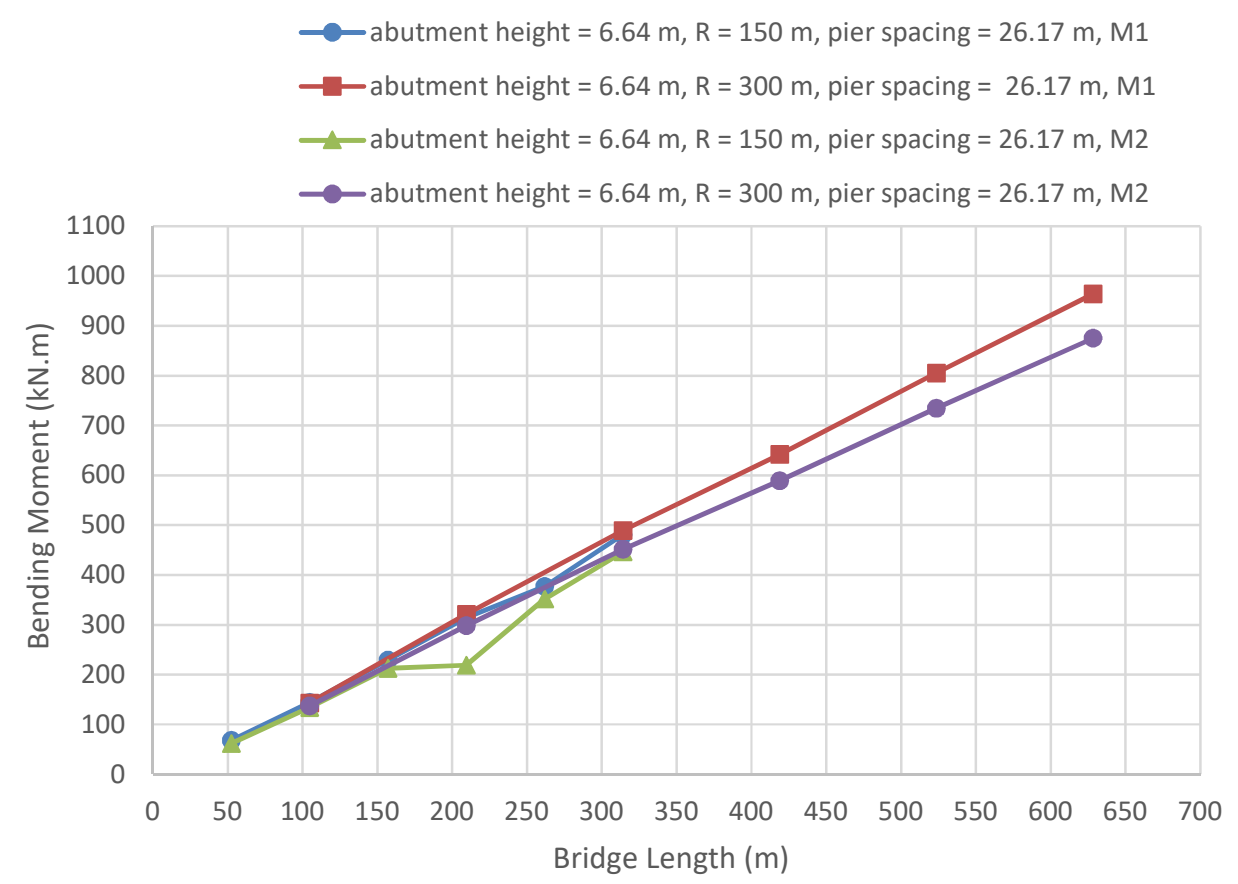

Figure 4.135 Pile Bending Moments Versus Bridge Length

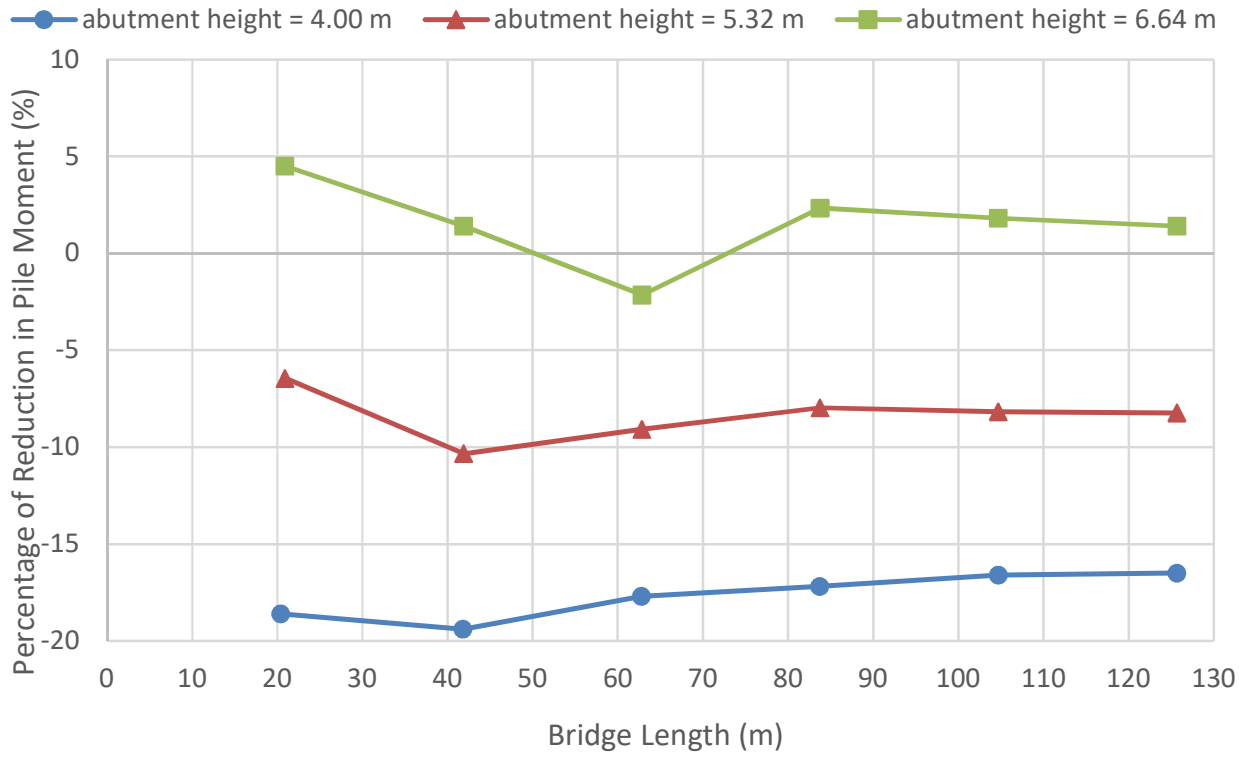

Figure 4.136 Percentage of Reduction in Pile Moment Versus Bridge Length $(R=60 \mathrm{~m})$ 


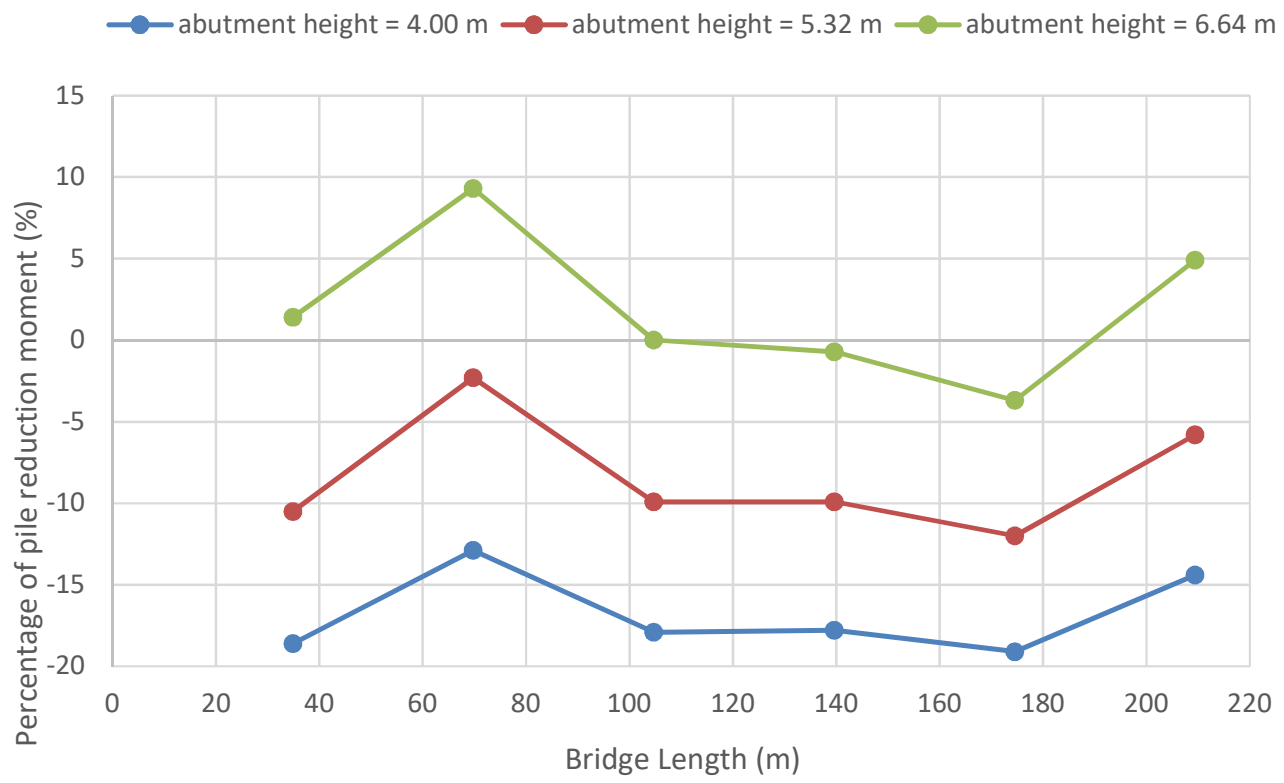

Figure 4.137 Percentage of Reduction in Pile Moment Versus Bridge Length $(R=100 \mathrm{~m})$

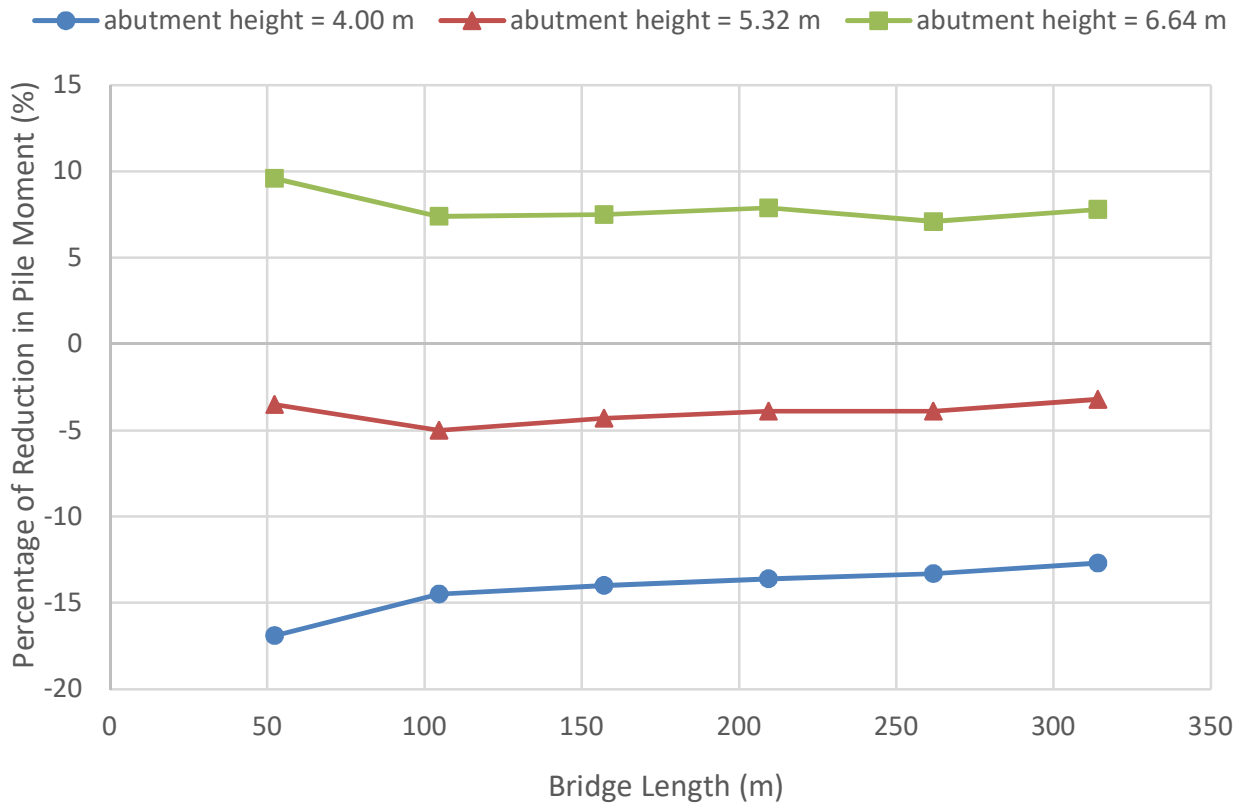

Figure 4.138 Percentage of Reduction in Pile Moment Versus Bridge Length $(R=150 \mathrm{~m})$ 


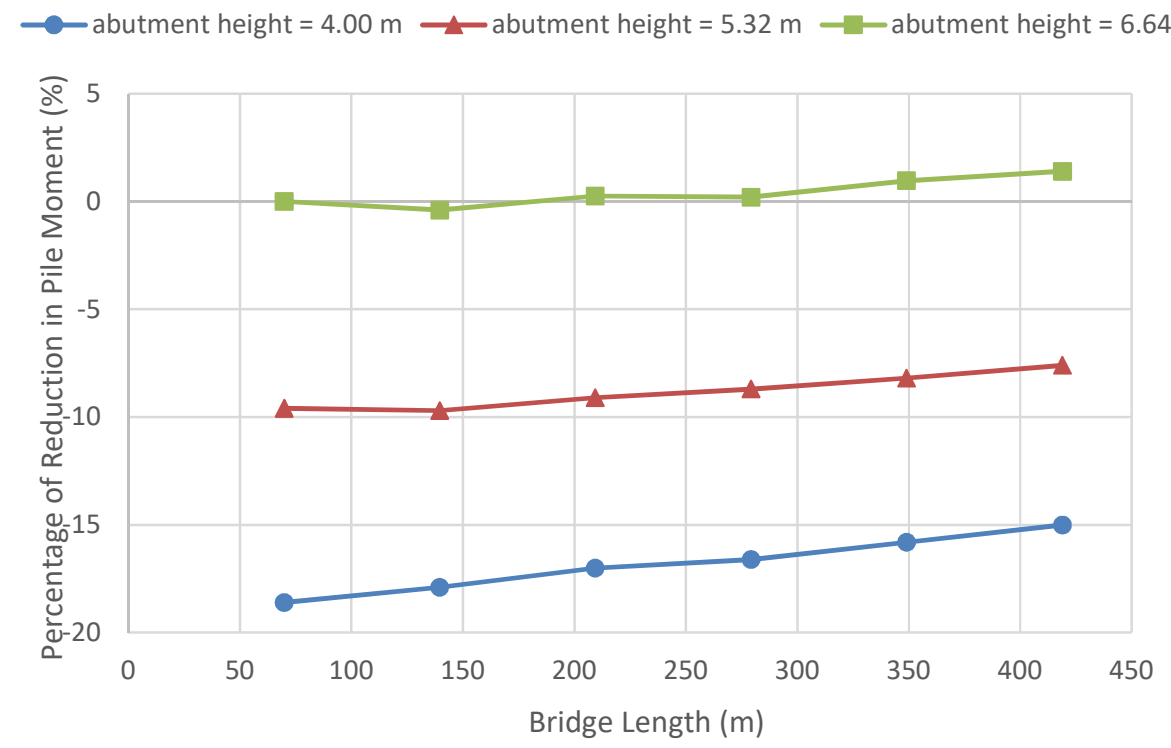

Figure 4.139 Percentage of Reduction in Pile Moment Versus Bridge Length $(R=200 \mathrm{~m})$

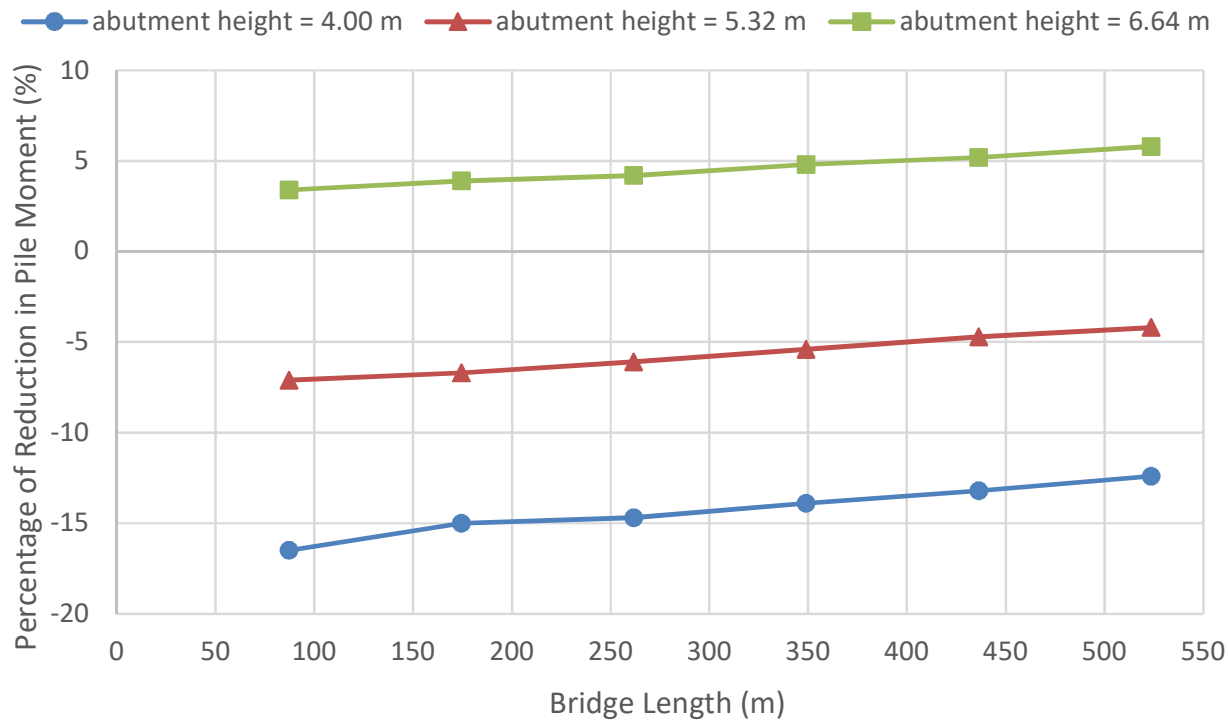

Figure 4.140 Percentage of Reduction in Pile Moment Versus Bridge Length $(R=\mathbf{2 5 0} \mathrm{m})$ 


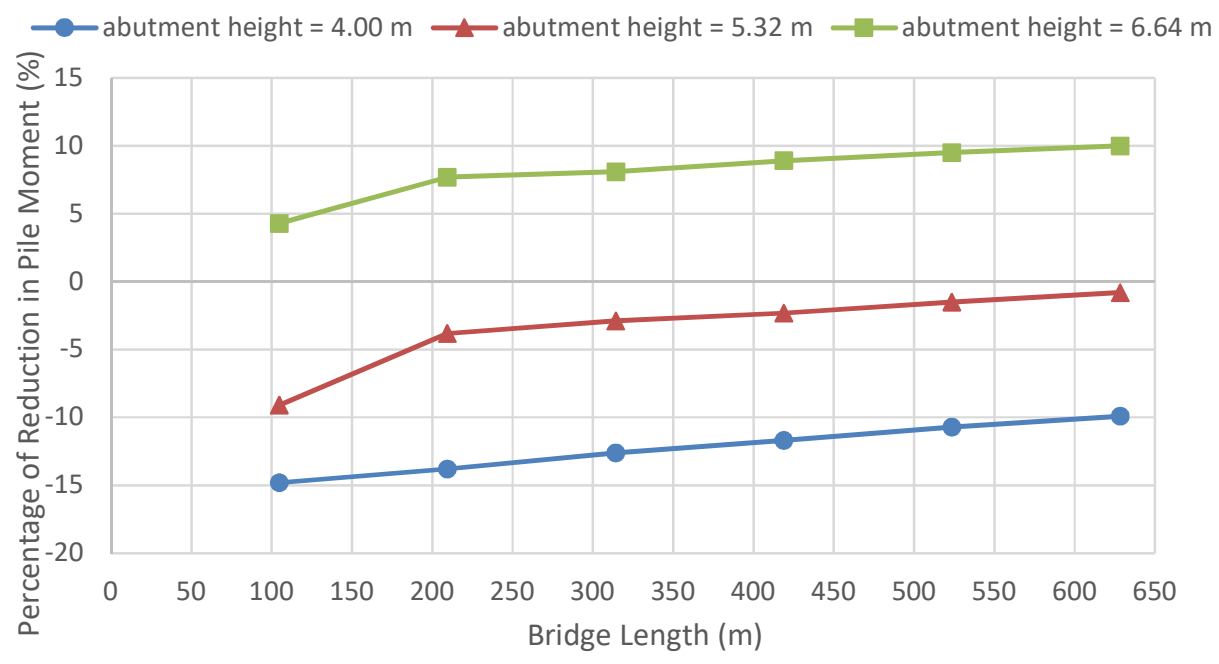

Figure 4.141 Percentage of Reduction in Pile Moment Versus Bridge Length $(R=300 \mathrm{~m})$

\subsection{Proposed Procedure for Assessing Bridge Maximum Length Limit for Piles without Drilled Hole}

The procedure is based on discarding the effect of bridge span length, using the $(B / T)$ displacement ratio of bridge abutment and $n_{\Delta}$. The bridge maximum length limit $\left(L_{s}\right)$ can, approximately, be assessed as in the following section.

Equation 4.32 yields the average bridge contraction displacement, $\Delta L$, as;

$\Delta L=\beta \alpha l_{i} \Delta T$

Where;

$\alpha$ : Coefficient of thermal expansion,

$\Delta T:$ Thermal loading,

$l_{i}$ : The distance between fixity point and the end boundary point of the bridge, the effective expansion length,

$\beta$ : Factor to account for the influence of restrained conditions and the bridge curvature.

The weighted average value of $\alpha$ is equal to $1 \times 10^{-5} \mathrm{~m} / \mathrm{m} /{ }^{\circ} \mathrm{C}$ per equation (1.5) in chapter 1 . Therefore, $\alpha \Delta T$ is equal to $65 \times 10^{-5} \mathrm{~m} / \mathrm{m}$. The pile maximum resultant displacement (PMRD) of abutment piles embedded in stiff clay is related to average top-of-bridge abutment displacement as; 
$P M R D=0.5 \beta\left(\frac{B}{T}\right) \times 65 \times 10^{-5} L$

Where, the average values were obtained from Tables 4.13 and 4.14;

$\frac{B}{T}=0.776$ for abutment height $=4.00 \mathrm{~m}$,

$\frac{B}{T}=0.676$ for abutment height $=5.32 \mathrm{~m}$,

$\frac{B}{T}=0.583$ for abutment height $=6.64 \mathrm{~m}$.

Pile maximum resultant displacement of abutment piles driven in predrilled holes $(P M R D)_{H}$ is related to pile maximum resultant displacement driven in stiff clay as;

$(P M R D)_{H}=0.5 \beta\left(\frac{B}{T}\right)\left(1+n_{\Delta}\right) \times 65 \times 10^{-5} \mathrm{~L}$

Where $n_{\Delta}$ is the percentage increase of pile maximum resultant displacement with the use of predrilled holes and obtained from Table 4.24;

$n_{\Delta}=0.13$ for abutment height $=4.00 \mathrm{~m}$,

$n_{\Delta}=0.1937$ for abutment height $=5.32 \mathrm{~m}$,

$n_{\Delta}=0.2630$ for abutment height $=6.64 \mathrm{~m}$.

Therefore;

$\beta=\frac{(\mathrm{PMRD})_{\mathrm{H}}}{0.5\left(\frac{B}{T}\right)\left(1+n_{\Delta}\right) \times 65 \times 10^{-5} \mathrm{~L}}$

The values of $\frac{(\mathrm{PMRD})_{\mathrm{H}}}{\mathrm{L}}$, which were previously called $\varepsilon$, as they represent the slope of curves 4.142 for example were obtained from Figure 4.142 through 4.147, and Table 4.27, and by substitution in Equation 4.35, $\beta$ values can be obtained from Table 4.28. 
Table $4.26 \varepsilon$ Values for Piles with Predrilled Holes

A) Abutment Height $=4.00 \mathrm{~m}$

\begin{tabular}{|c|c|}
\hline Radius & $\begin{array}{c}\text { Slope }(\boldsymbol{\varepsilon}) \\
\mathbf{m m} / \mathbf{m}\end{array}$ \\
\hline 60 & 0.30 \\
\hline 100 & 0.32 \\
\hline 150 & 0.29 \\
\hline 200 & 0.31 \\
\hline 250 & 0.30 \\
\hline 300 & 0.30 \\
\hline mean & 0.30 \\
\hline
\end{tabular}

B) Abutment Height $=5.32 \mathrm{~m}$

\begin{tabular}{|c|c|}
\hline Radius & Slope $(\boldsymbol{\varepsilon}) \mathbf{m m} / \mathbf{m}$ \\
\hline 60 & 0.29 \\
\hline 100 & 0.31 \\
\hline 150 & 0.27 \\
\hline 200 & 0.29 \\
\hline 250 & 0.28 \\
\hline 300 & 0.28 \\
\hline mean & 0.28 \\
\hline
\end{tabular}

c) Abutment Height $=6.64 \mathrm{~m}$

\begin{tabular}{|c|c|}
\hline Radius & Slope $(\varepsilon) \mathrm{mm} / \mathrm{m}$ \\
\hline 60 & 0.26 \\
\hline 100 & 0.28 \\
\hline 150 & 0.23 \\
\hline 200 & 0.26 \\
\hline 250 & 0.26 \\
\hline 300 & 0.25 \\
\hline mean & 0.26 \\
\hline
\end{tabular}


Table 4.27 Values of $\beta$ for Piles

\begin{tabular}{|c|c|c|c|c|}
\hline $\begin{array}{c}\text { Abutment } \\
\text { Height } \\
(\mathbf{m})\end{array}$ & $\begin{array}{c}\left(\frac{\boldsymbol{B}}{\boldsymbol{T}}\right) \\
\text { From Table 4.13 } \\
\text { and 4.14 }\end{array}$ & $\begin{array}{c}\boldsymbol{n}_{\Delta} \\
\text { From Table 4.24 }\end{array}$ & $\begin{array}{c}\frac{(\text { PMRD })}{\mathbf{L}} \\
(\mathbf{m m} / \mathrm{m})\end{array}$ & $\boldsymbol{\beta}$ \\
\hline 4.00 & 0.77 & 0.13 & 0.30 & 1.07 \\
\hline 5.32 & 0.68 & 0.19 & 0.28 & 1.09 \\
\hline 6.64 & 0.58 & 0.26 & 0.26 & 1.08 \\
\hline
\end{tabular}

The values of $\beta$ are independent of abutment height, bridge radius of curvature and type of foundation soil, with a mean value of 1.08 . Substituting values of $\beta$ into Equation 4.33 , and considering PMRD equals to $40 \mathrm{~mm}$, the approximate bridge maximum length limit $\left(\mathrm{L}_{\mathrm{s}}\right)$ was obtained as shown in Table 4.29.

Table 4.28 Bridge Maximum Length Limits for Piles Without Predrilled Hole

\begin{tabular}{|c|c|c|}
\hline $\begin{array}{c}\text { Height of Abutment } \\
(\mathbf{m})\end{array}$ & $\begin{array}{c}\text { Bridge Maximum Length Limit } \\
(\mathbf{m})\end{array}$ & $\begin{array}{c}\text { Equation (4.29) } \\
(\mathbf{m})\end{array}$ \\
\hline 4.00 & 148.68 & $142-175$ \\
\hline 5.32 & 167.64 & $159-205$ \\
\hline 6.64 & 195.16 & $184-242$ \\
\hline
\end{tabular}

The above procedure for assessing bridge maximum length limit is limited to the conditions presented in thesis. Decleli and Albhaisi (2004) reported that the maximum length limit for steel integral abutment bridges ranges between $80 \mathrm{~m}$ and $145 \mathrm{~m}$ in cold climate and from 125 $\mathrm{m}$ to $230 \mathrm{~m}$ in moderate climates. Decleli and Albhaisi (2004) stated that the recommended bridge maximum length limit used by different agencies in USA and Canada ranges from $95 \mathrm{~m}$ to $195 \mathrm{~m}$. While, Nikravan stated that the recommended bridge maximum length limit of bridge with small skew angles used by different agencies in USA and Canada ranges from 90 $\mathrm{m}$ to $200 \mathrm{~m}$. Therefore, the obtained bridge maximums limit length, shown in Table 4.29 are within the limit stated by Decleli and Albhaisi (2004) and Nikravan (2013). 


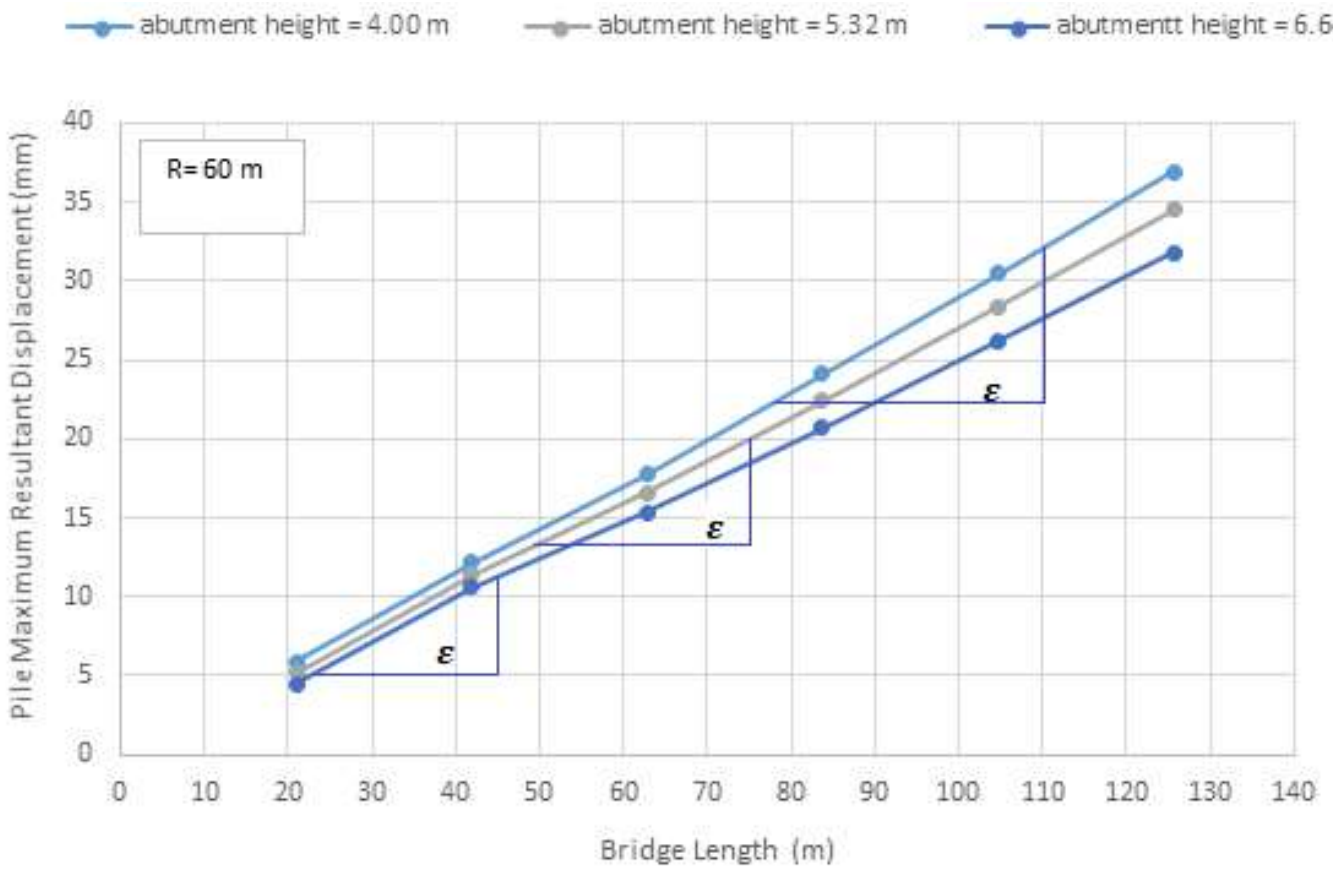

Figure 4.142 Pile Maximum Resultant Displacement Versus Bridge Length for Piles with Predrilled Holes
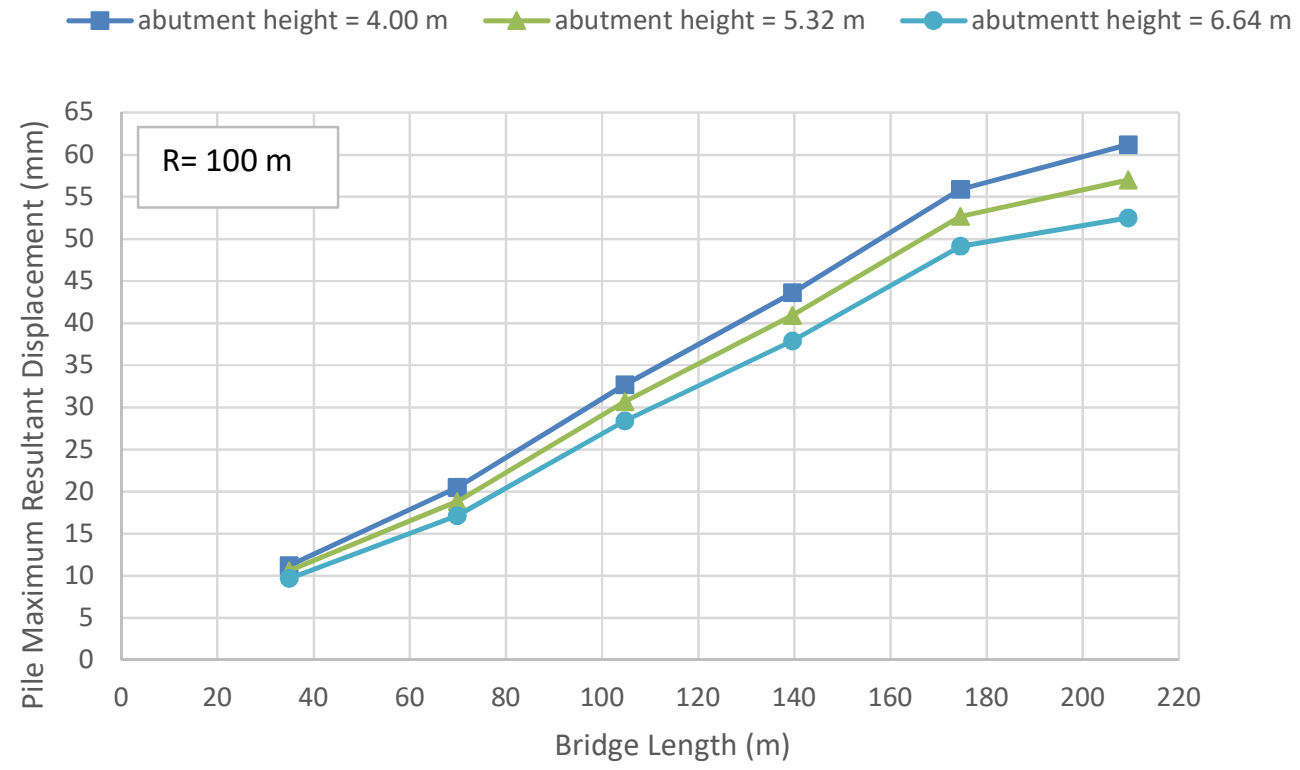

Figure 4.143 Pile Maximum Resultant Displacement Versus Bridge Length for Piles with Predrilled Holes 


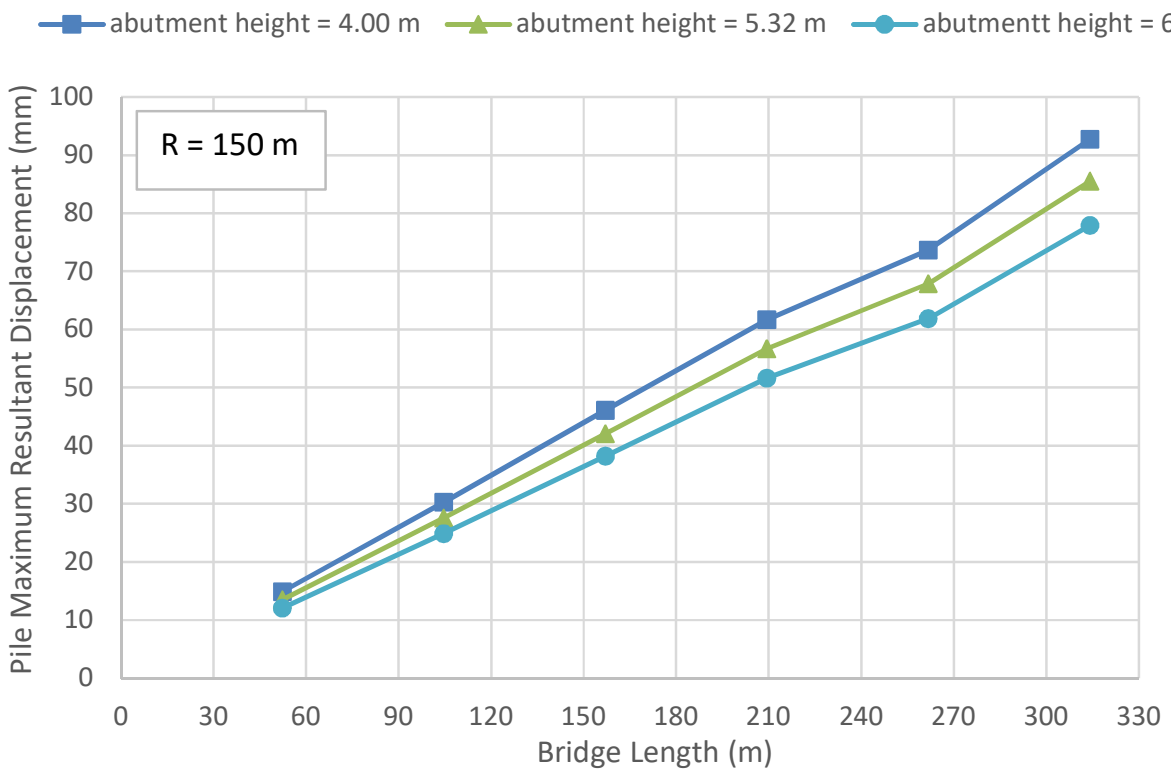

Figure 4.144 Pile Maximum Resultant Displacement Versus Bridge Length for Piles with Predrilled Holes

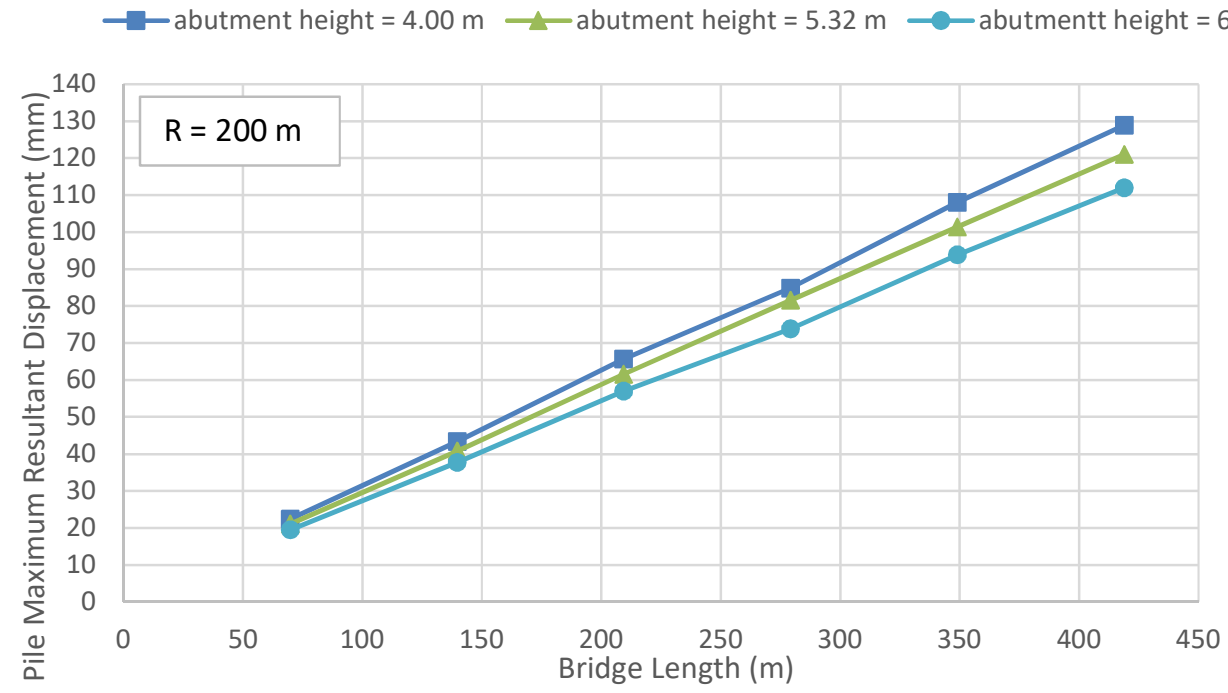

Figure 4.145 Pile Maximum Resultant Displacement Versus Bridge Length for Piles with Predrilled Holes 


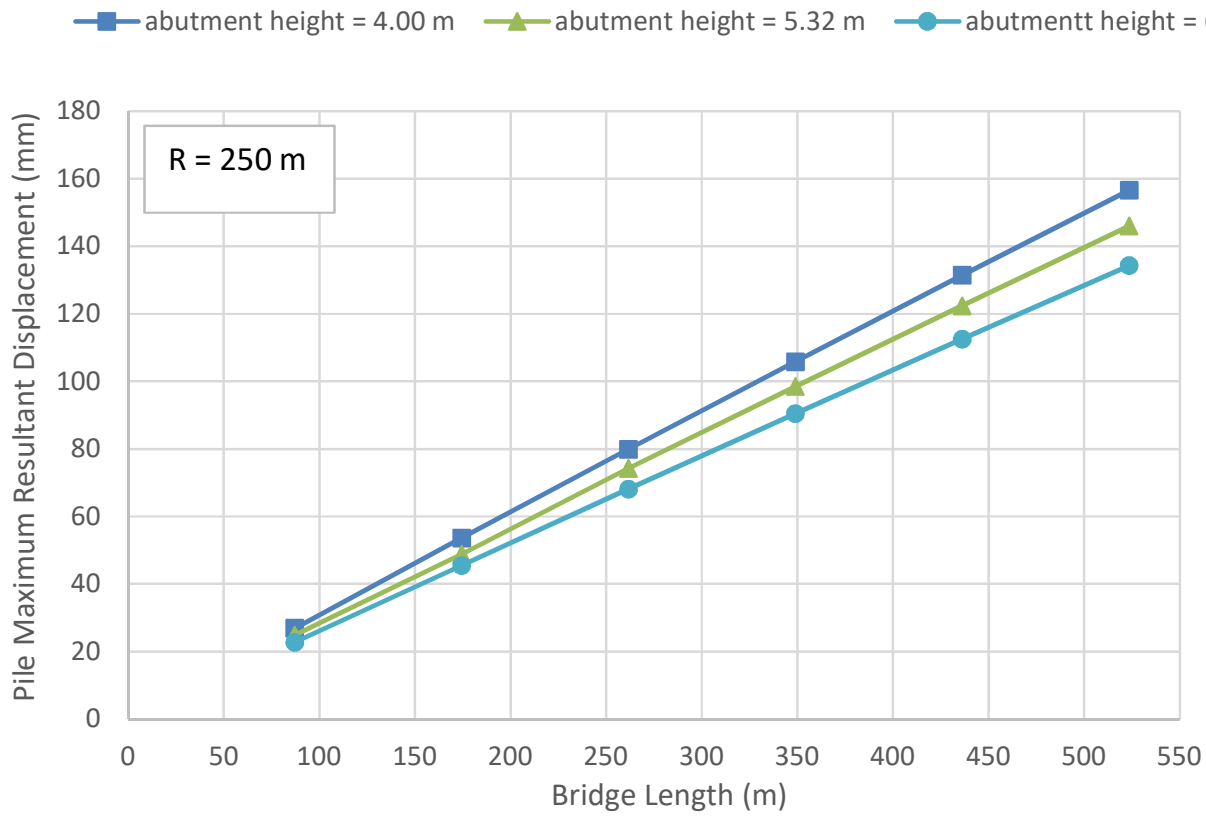

Figure 4.146 Pile Maximum Resultant Displacement Versus Bridge Length for Piles with Predrilled Holes

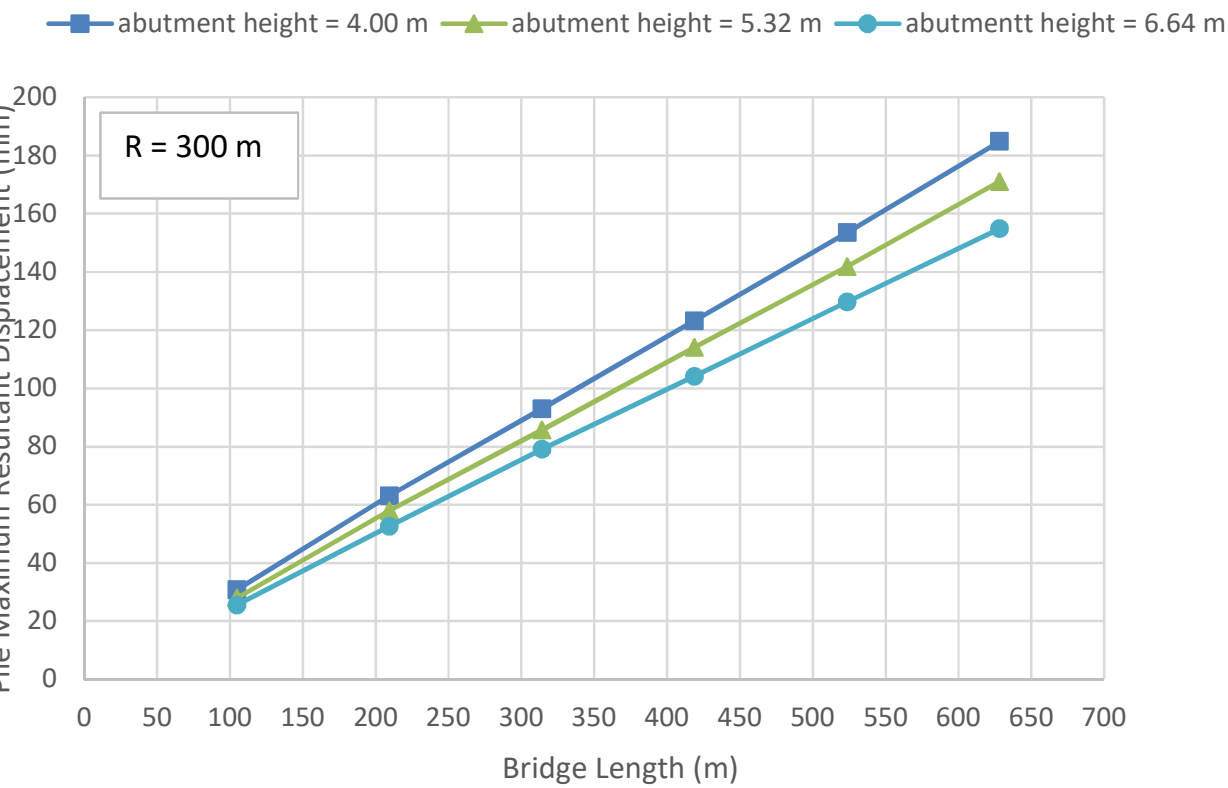

Figure 4.147 Pile Maximum Resultant Displacement Versus Bridge Length for Piles with Predrilled Holes 


\section{CHAPTER 5}

\section{SUMMARY, CONCLUSIONS AND RECOMMENDATIONS FOR FURTHER STUDY}

The aim of this research was to investigate bridge maximum length limit for curved integral abutment bridge under both dead and thermal loading conditions which satisfy pile horizontal displacement capacity limit of no more than $40 \mathrm{~mm}$. This displacement limit was established through a series of field tests conducted by Knoxville University in the USA, assuming the maximum horizontal displacement at the pile top to maintain its behavior in the elastic range.

The spatial variables considered in the current research are: abutment height, radius of curvature, radial steel diaphragm spacing, and pier spacing (i.e. bridge span length). The backfill soil conditions are loose sand and dense sand, while foundation soil is stiff clay and medium dense sand. Horizontal curved composite steel girder bridges with integral abutment bridges were modelling using 3D finite element method. The bridge was analyzed under thermal load conditions of $\pm 65^{\circ} \mathrm{C}$, in addition to bridge self-weight. The results presented in the current research yielded the following conclusions.

\subsection{Summary and Conclusions}

a) In modeling the soil continuum by series of unconnected nonlinear springs, the ground water has no appreciable effect on the performance of a bridge substructure subjected to thermal-induced loading.

b) The radial steel diaphragm spacing between $3.27 \mathrm{~m}$ and $10.25 \mathrm{~m}$ has insignificant effect (within $4.2 \%$ ) on pile resultant displacement at abutment location, when subjected to thermal-induced loading.

c) The characteristics of $(p-y)$ relationships have appreciable effects on the performance of bridge substructure due to thermal-induced loading. Care must be taken to adopt the proper $(p-y)$ relationship.

d) The effect of HP-Pile width on ( $p-y)$ relationship is minimal, for HP-Piles having width less than $457 \mathrm{~mm}$. 
e) The abutment pile maximum resultant displacement is affected by bridge span length and restraint conditions of steel I-girders on intermediate piers. The pile maximum resultant displacement decreases with increase in bridge span length between piers.

f) When the bridge is subjected to negative thermal loading conditions (i.e. contraction), the bridge abutments rotate away from the backfill. Thus, the pile maximum resultant displacement is independent of the backfill soil type.

g) When the bridge is subjected to positive thermal loading conditions and the foundation soil is either medium dense sand or stiff clay, the bridge abutments rotate towards backfill soil. The rotation of abutment-backfill soil system is dependent on the abutment height, stiffness of backfill soil and foundation soil type.

h) The pile foundation soil has no appreciable effect on the performance of a bridge substructure, when the bridge is subjected to negative thermal load condition (i.e. contraction), while the foundation soil has pronounced effect on bridge substructure performance during positive thermal load condition (i.e. expansion).

i) The pile average maximum resultant displacement during bridge expansion, in case of medium dense sand foundation and dense sand backfill, varies between 0.07 and 0.36 of maximum top-of-abutment displacement, according to abutment height. While in case of loose sand backfill, the ratio varies between 0.24 and 0.50 . In stiff clay foundation soil, the above ratios vary from 0.09 to 0.43 in case of dense sand backfill and from 0.48 to 0.70 in case of loose sand backfill. During bridge contraction, the ratio varies from 0.58 to 0.80 irrespective of foundation soil and backfill soil. The bridge abutment height affects the ratio of pile average maximum resultant displacement to top abutment maximum displacement, in a way that with the increase of abutment height, the ratio decreased in case of bridge expansion or contraction.

j) The pile maximum resultant displacement resulted from either positive or negative thermal loading condition decreases with the increase of bridge span length between piers, and with the increase of bridge abutment height.

k) Radius of curvature of horizontally curved integral abutment bridges when restraint against radial displacement at piers support is applied has insignificant effect on the pile maximum resultant displacement.

I) The pile maximum resultant displacement increases linearly with bridge length. 
m) During bridge expansion, dense sand backfill produces greater restraint against movement of bridge deck than loose sand backfill due to positive thermal load, resulting in a decrease in pile maximum resultant displacement compared with loose sand backfill.

n) The ratio between pile resultant displacement due to contraction and expansion depends upon the bridge abutment height and foundation soil. In case of stiff clay foundation soil, these ratios in case of loose sand backfill are 1.14 and 1.43 for bridge abutment heights of $4 \mathrm{~m}$ and $6.64 \mathrm{~m}$, respectively. In case of dense sand backfill, these ratios are 1.94 and 8.34, respectively. In case of medium dense sand foundation soil, these ratios are 1.58 and 2.45 for bridge abutment heights of $4 \mathrm{~m}$ and $6.64 \mathrm{~m}$, respectively, in case of loose sand backfill. In case of dense sand supporting the bridge abutment, the above ratios become 2.54 and 7.59.

o) Foundation soil has little effect, about 3\%, on the magnitude of bridge maximum length limit for thermal loading.

p) The component of pile maximum resultant displacement in the direction of bridge abutment is of small value and most of pile resultant displacement in the tangential direction of the bridge. Therefore, most of moment induced in the pile head acts around the strong axis of the piles and very little acting around its weak axis.

q) The maximum bending moment induced in the piles increases linearly with the increase of bridge length. Radius of curvature of the bridge has insignificant effect on the bending moment induced in abutment piles. The maximum bending moment induced in pile abutment increases with the decrease of bridge abutment height.

r) Foundation soil affects the maximum bending moment induced in abutment piles. Piles embedded in dense sand exhibited $5 \%$ to $10 \%$ more than that maximum bending moment induced in a similar abutment pile embedded in stiff clay.

s) Radius of curvature of the bridge has small effect on the bridge maximum length limit. Bridge maximum length limit increases with the increase of abutment height.

t) An equation relating the bridge maximum length limit, the bridge span length between piers, and abutment height was developed.

u) The presence of predrilled holes of $2.75 \mathrm{~m}$ depth under the abutment to host the piles results in increase of pile maximum resultant displacement by $13.06 \%, 19.36 \%$ and $26.3 \%$ corresponding to bridge abutment heights of $4.0 \mathrm{~m}, 5.32 \mathrm{~m}$ and $6.64 \mathrm{~m}$. 
v) For abutment piles driven in predrilled holes, the abutment height has crucial effects on the percentage reduction in pile maximum resultant bending moment. The percentage reduction in bending moment varies from $18 \%$ to $5 \%$ as the abutment height increases from $4 \mathrm{~m}$ to $5.32 \mathrm{~m}$. For abutment height of $6.64 \mathrm{~m}$, the piles exhibited increase in bending moment in the order of $2.5 \%$.

w) Doubling of bridge span between piers from $17.45 \mathrm{~m}$ and $21.80 \mathrm{~m}$ to $34.90 \mathrm{~m}$ and 43.60 $m$, respectively (i.e. while reducing number of piers) increases the bridge maximum length limit by $1.26,1.31$ and 1.35 for abutment heights of $4.0 \mathrm{~m}, 5.32 \mathrm{~m}$ and $6.64 \mathrm{~m}$, respectively.

x) Based on the developed empirical equations for bridge total length limit in case of bridges with pier spacing between $17.45 \mathrm{~m}$ and $34.90 \mathrm{~m}$, the maximum length limit of a two-lane steel I-girder bridge ranges from $142 \mathrm{~m}$ to $242 \mathrm{~m}$ depending upon abutment height and span length between piers in case of piles without predrilled holes.

y) The results from this research are limited to two-lane composite-slab-over steel I-girder bridges made of 5 girders with abutment height between 4.00 and $6.64 \mathrm{~m}$, radius of curvature between $60 \mathrm{~m}$ and $300 \mathrm{~m}$, radial diaphragm spacing between $3.27 \mathrm{~m}$ and 10.25 $\mathrm{m}$, and pier spacing along the outer girder of the bridge, away from the center of curvature, between 17.45 and $43.6 \mathrm{~m}$. Also, the backfill soil conditions are either loose or dense sand, while foundation soil is either stiff clay or medium dense sand. Moreover, the bridge was analyzed under thermal load conditions $\pm 65^{\circ} \mathrm{C}$, in addition to bridge self-weight. Wing walls at abutments were not considered in this study.

\subsection{Recommendations for Further Study}

a) The current research was done assuming symmetrical soil conditions at the two abutments. In field, it is not a necessity that both abutments have the same number of piles and same soil conditions. A future research topic may include the effect of asymmetric abutment soil conditions on pile deformation for integral abutment bridges under thermal loading.

b) The current research ignored soil layering effect on pile deformation and considered piles embedded in either pure sand or pure clay formation. In actual field conditions, piles could be embedded in stratification of soils. A future research topic can include the effect of pile embedded in stratified soil. 
c) The current research ignored group effect of piles since all the piles supporting the abutment are in a single row. A future research can assess the pile deformation including the pile group action.

d) Several types of jointless bridges exist in the field. The type that was tackled in the current research was an integral abutment bridge with rigid piers. Future research topic can include comparison between the displacement of the abutment piles in thermally loaded jointless bridges in case of flexible and rigid integral abutment bridge piers.

e) Long-term performance of integral abutment bridge subjected to cyclic induced-thermal abutment displacement can be investigated.

f) The performance of internal abutment bridges provided with pinned abutment-pile connection can be investigated.

g) The effects of different geometrical parameters and orientation of bearings on piers on the performance of integral abutment bridge under different thermal loading conditions can be studied. 


\section{References}

Amde A. M., Haj-Najib, R., \& Paraschos, A. (2014). Oversized Predrilled Holes in Skewed Integral Abutment Bridges. Proceedings $3^{\text {rd }}$ World Conference on Applied Science Engineering and Technology, Kathmandu, Nepal, PP. 18-24.

American Association of State Highway and Transportation Officials (AASHTO). (2002). Standard Specifications for Highway Bridge, $17^{\text {th }}$ Edition, 2002, Washington, D.C.

American Association of State Highway and Transportation Officials (AASHTO). Subcommittee on Bridges and Structures. (2003). AASHTO Guide Specifications for Horizontally Curved Steel Girder Highway Bridges, 2003. Washington, D.C.

American Association of State Highway and Transportation Officials (AASHTO). (2010). LRFD Bridge Design Specifications, $5^{\text {th }}$ Edition, 2010, Washington, D.C.

American Association of State Highway and Transportation Officials (AASHTO). (2012). LRFD Bridge Design Specifications, $6^{\text {th }}$ ed., Washington, D.C.

AASHTO LRFD Bridge Design Specifications. (2017). Association of State Highway and Transportation Officials. Washington, D.C.

Albhaisi, S., Nassif, H., \& Hwang, E. S. (2012). Effect of Substructure Stiffness on Performance of Steel Integral Abutment Bridges under Thermal Loads. Transportation Research Record: Journal of the Transportation Research Board, (2313), 22-32.

American Petroleum Institute (API). (2002). Recommended Practice for Planning, Designing and Constructing Fixed Offshore Platforms - Working Stress Design, Washington, D.C.

American Petroleum Institute (API). (2003). Recommended Practice for Planning, Designing and Constructing Fixed Offshore Platforms - Working Stress Design, Washington, D.C.

Arenas, A., Filz, G., and Cousins, T. (2013). Thermal Response of Integral Abutment Bridges with Mechanically Stabilized Earth Walls, Report No. VCTIR 13-R7, Virginia Center for Transportation Innovation and Research, Virginia Polytechnic Institute \& State University, Virginia.

Arockiasamy, M., Butrieng, N., and Sivakumar, M. (2004). State-of-the-Art of Integral Abutment Bridges: Design and Practice. Journal of Bridge Engineering, 9(5), 497-506.

Arockiasamy, M., \& Sivakumar, M. (2005). Time-Dependent Behavior of Continuous Composite Integral Abutment Bridges. Practice Periodical on Structural Design and Construction ASCE, PP. 161170.

Arsoy, S., Barker, R.M., and Duncan, J.M. (1999). The Behavior of Integral Abutment Bridges. Report No. VTRC 00-CR3, Virginia Transportation Research Council, Charlottesville, VA.

Arsoy, S., Barker, R.M., and Duncan, J.M. (2002). Experimental and Analytical Investigation of Piles and Abutments of Integral Bridges. Report No. VTRC 02-CR6, Virginia Transportation Research Council, Charlottesville, VA.

BA 42/96. (2003). The Highways Agency, The Design of Integral Bridges, Amendment No. 1. Design Manual for Roads and Bridges (DMRB). UK: Department for Transport. 
Barker, R. M., Duncan, J. M., Rojiani, K. B., Ooi, P. S., \& Tan, C. K. (1991). Manuals for the Design of Bridge Foundations. National Cooperative Highway Research Program (NCHRP), Washington, D.C.

BD 57/01. (2001). The Highways Agency, Design for Durability. Design Manual for Roads and Bridges (DMRB). UK: Department for Transport, Vol. 1, Section. 3.

Bloodworth, A. G., Xu, M., Banks, J. R., \& Clayton, C. R. I. (2012). Predicting the Earth Pressure on Integral Bridge Abutments. Journal of Bridge Engineering, 10.1061/(ASCE)BE. 1943-5592.0000263, 17 (2), 371-381.

Bowles, JE. (1996). Foundation Analysis and Design. 5th ed. New York, NY: McGraw-Hill.

Breña, S. F., Bonczar, C. H., Civjan, S. A., DeJong, J. T., \& Crovo, D. S. (2007). Evaluation of Seasonal and Yearly Behavior of an Integral Abutment Bridge. Journal of Bridge Engineering, 12 (3), 296-305.

British Colmbia, Ministry of Transportation and Infrastructure. (2016). Bridge Standards and Procedure Manual Vol. 1, Supplement to CHBDC 56-14.

Burke, M.P. Jr. (1990). Integral Bridges. Transp. Res. Rec. 1275, TRB 1990. Washington, D.C., 53-61.

Burke, M.P. Jr. (1993). The Design of Integral Concrete Bridges. Concrete international, Vol. 15, No. 6, pp. 37-42.

Burke, M.P. Jr. (2009). Integral and Semi-Integral Bridges, Wiley-Blackwell, Hoboken, NJ.

Canadian Foundation Engineering Manual. (1992). Canadian Foundation Engineering Manual. Third ed., Canadian Geotechnical Society, Richmond, BC, Canada, 512 pp.

Canadian Standard Association, CSA. (2006). Canadian Highway Bridge Design Code, CHBDC. Etobicoke, ON.

Caquot, A., and Kérisel, J. (1948). Tables de Poussée et de Butée. Gauthier-Villars, Paris.

Carder, D. R., and Hayes, J. p. (2000). Performance under Cyclic Loading of the Foundation of Integral Bridges. Crowthorne: Transport Research Laboratory.

Chen, W. F., \& Mizuno, E. (1990). Nonlinear Analysis in Soil Mechanics: Theory and Implementation. Developments in Geotechnical Engineering, No. (53). Elsevier.

Civjan, S. A., Bonczar, C., Brena, S. F., DeJong, J., \& Crovo, D. (2007). Integral Bridge Behavior: Parametric Analysis of a Massachusetts Bridge. Journal of Bridge Engineering, 12(1), 64-71.

Chovinchien, V. (2004). The Behavior and Design of Piles for Integral Abutment Bridges. West Lafayette: Purdue University.

Civjan, S. A., Brena, S. F., Kalayci, E., \& Quinn, B. H. (2014). Performance Monitoring of Jointless Bridges-Phase III. Final Rep. 2014-07, Vermont Agency of Transportation, Montpelier, VT.

Civjan, S. A., Kalayci, E., Quinn B.H., Brena S.F., \& Allen C.A. (2013). Observed Integral Abutment Bridge Substructure Response. Engineering Structures, 56, 1177-1191.

Clough, G. W., \& Duncan, J. M. (1971). Finite Element Analyses of Retaining Wall Behavior. Journal of Soil Mechanics \& Foundations Div.

Clough, G. W., and Duncan, J. M. (1991). Earth pressures. In Foundation Engineering Handbook, ed. H-Y. Fang, pp. 224-235. Van Nostrand Reinhold, New York. 
Comisu, C. C., \& Gheorghita, B. (2010). Integral Bridges and Environmental Conditions. In Proc., Int. Conf. on Risk Management, Assessment and Mitigation (pp. 164-169). Bucharest, Romania: World Scientific and Engineering Academy and Society (WSEAS).

Conboy D, Stoothoff E. (2005). Integral Abutment Design and Construction: the New England Experience. In: Proceedings of the 2005 FHWA Conference: Integral Abutment and Jointless Bridges, Baltimore, Maryland.

Crovo, D. S. (1998). The Massachusetts Experience with Jointless Abutment Bridges. $15^{\text {th }}$ Annual International Bridge Conference, Pittsbutgh, PA.

Darley, P., Carder, D. R., \& Alderman, G. H. (1996). Seasonal Thermal Effects on the Shallow Abutment of an Integral Bridge in Glasgow. TRL Rep. 178, Transport Research Laboratory, Crowthorne, Berks, U.K.

Das, B. M. (2007). Principles of Foundation Engineering 6th Edition. Thomson.

Davids, W. G., Sandford, T., Ashley, S., Delano, J. \& Lyons, C. 2010. Field-Measured Response of an Integral Abutment Bridge with Short Steel H-Piles. Journal of Bridge Engineering, 15, 32-43.

Davidson, J. S., Keller, M. A., \& Yoo, C. H. (1996). Cross-Frame Spacing and Parametric Effects in Horizontally Curved I-Girder Bridges. Journal of Structural Engineering, New York, N.Y., 122(9), 10891096.

Deng, Y., Phares, B. M., Greimann, L., and Hoffman, J. J. (2015). Behavior of Curved and Skewed Bridges with Integral Abutments. Journal of Construction Steel Research, 109, 115-136.

Dicleli, M. (2000). Simplified Model for Computer-Aided Analysis of Integral Bridges. Journal of Bridge engineering, 5(3), 240-248.

Dicleli, M. (2000). A Rational Design Approach for Prestressed-Concrete-Girder Integral bridges. Engineering Structures. 22: 230-245.

Dicleli, M., \& Albhaisi, S. M. (2004). Performance of Abutment-Backfill System Under Thermal Variations in Integral Bridges Built on Clay. Engineering Structures, 26(7), 949-962.

Dicleli, M., \& Albhaisi, S. (2004a). Effect of Cyclic Thermal Loading on the Performance of Steel HPiles in Integral Bridges with Stub-Abutments. Journal of Construction Steel Research, 60, 161-182.

Dicleli, M., \& Albhaisi, S. (2004b). Estimation of Length Limits for Integral Bridges Built on Clay. Journal of Bridges Engineering, 572-581.

Dicleli, M., \& Albhaisi, S. (2004c). Performance of Abutment-Backfill System Under Thermal Variations in Integral Bridges Built on Clay. Engineering Structures, 949-962.

Dicleli, M., \& Albhaisi, S. M. (2003). Effect of Cyclic Thermal Loading on the Performance of Steel HPiles in Integral Bridges with Stub-Abutments. Journal of Constructional Steel Research, 60(2), 161182.

Dicleli, M., \& Albhaisi, S. M. (2005). Analytical Formulation of Maximum Length Limits of Integral Bridges on Cohesive soils. Canadian Journal of Civil Engineering, 32(4), 726-738.

Dicleli, M., \& Erhan, S. (2010). Effect of Soil-Bridge Interaction on the Magnitude of Internal Forces in Integral Abutment Bridge Components due to Live Loads Effects. Engineering Structures, 32, 129145. 
Doust, S. E. (2011). Extending Integral Concepts to Curved Bridge Systems. Doctoral Dissertation, University of Nebraska, Retrieved from

https://digitalcommons.unl.edu/cgi/viewcontent.cgi?article=1041\&context=civilengdiss.

Duncan, J. M., \& Mokwa, R. L. (2001). Passive Earth Pressures: Theories and Tests. Journal of Geotechnical and Geoenvironmental Engineering, 127(3), 248-257.

Dunker, K., and Liu, D. (2007). Foundations for Integral Abutment Bridges. ASCE Practice Periodical on Structural Design and Construction, Vol. 12, No. 1, pp. 22-30.

Durbin, K.O. (2001). Investigation of the Behavior of an Integral Abutment Bridge, M.S. Thesis, Purdue University, West Lafayette.

Efretuei, E. O. (2013). Thermal Impact on Soil-Structure Interaction for Integral Bridges. Ph.D. Thesis, School of Civil Engineering, University of Leeds.

EN 1991-1-5. (2003). (English): Eurocode 1: Actions on structures - Part 1-5: General actions Thermal actions.

Faraji, S. (1997). Behavior of Integral Abutment Bridges in Massachusetts. Project UMTC-96-5, Massachusetts Highway Department, Boston, MA.

Faraji, S., Ting J. M., Crovo, D., and Ernest, H. (2001). Nonlinear Analysis of Integral Abutment Bridges. Journal of Geotechnical and Geoenvironmental Engineering, Vol. 127, No. 5, pp. 454-461.

Fayyazi, M. S., Taiebat, M., Finn, W. L., \& Ventura, C. E. (2012). Evaluation of P-Multiplier Method for Performance Based. Second International Conference on Performance-Based, Taormina, Italy.

Federal Highway Administration (FHWA). Integral, NO-Joint Structures and Required Provisions of Movement, Technical Advisory T5140.13, 1980, Washington, D.C.

Fennema, J. L., Laman, J. A., \& Linzell, D. G. (2005). Predicted and Measured Response of an Integral Abutment Bridge. Journal of Bridge Engineering, 10(6), 666-677.

French, J. W., \& McKeel, W. T. (2003). An Evaluation of Bridge Deck Joint Sealing Systems in Virginia (No. FHWA/VTRC 03-TAR7). Virginia Transportation Research Council.

Frosch, R. J., \& Lovell, M. D. (2011). Long-Term Behavior of Integral Abutment Bridges. Publication FHWA/IN/JTRP-2011/16. Joint Transportation Research Program, Indiana Department of Transportation and Purdue University, West Lafayette, IN.

Frosch, R. J., Chovichien, V., Durbin, K., and Fedroff, D. (2006). Jointless and Smoother Bridges: Behavior and Design of Piles. Final Report FHWA/IN/JTRP-2004/24. Joint Transportation Research Program. SPR-2393, West Lafayette: Purdue University.

Gorst, N. J., Williamson, S. J., Pallett, P. F., \& Clark, L. A. (2003). Friction in Temporary Works. Birmingham.

Greimann, L., \& Wolde-Tinsae, A. M. (1988). Design Model for Piles in Jointless Bridges. Journal of Structural Engineering, 114(6), 1354-1371.

Greimann, L., Phares, B. M., Deng, Y. J., Shryack, G., \& Hoffman, J. (2014). Field Monitoring of Curved Girder Bridges with Integral Abutments. Bridge Engineering Center, lowa State University. 
Greimann, L. F., Wolde-Tinsae, A. M. (Amde, A. M.), and Yang, P. S. (1986). Nonlinear Analysis of Integral Abutment Bridges. Journal of Structural Engineering, ASCE, Vol. 112, No. 10, pp. 2263-2280.

Greimann, L. F., Wolde-Tinsae, A. M. (Amde, A. M.), and Yang, P. S. (1988). End-Bearing Pile in Jointless Bridges. Journal of Structural Engineering, ASCE, Vol. 114, No. 8, pp. 1870-1884.

Greimann, L. F., Yang, P. S., Edmunds, S.K., and Wolde-Tinsae, A.M. (Amde M. Amde). (1984). Design of Piles for Integral Abutment Bridges. Final Report, lowa DOT Project HR-252, ISU-ERI-Ames 80026, lowa State University of Maryland, College Park.

Griton, D. D., Hawkinson, T. R., and Greimann, L. F. (1991). Validation of Design Recommendations for Integral -Abutment Piles. Journal of Structural Engineering, Vol. 117, No. 7, pp. 2117-2134.

Haj-Najib, R. (2002). Integral Abutment Bridges with Skew Angles. PhD thesis, University of Maryland, College Park.

Hannigan, P. J., Rausche, F., Likins, G. E., Robinson, B. R., and Becker, M. L. (2016). Design and Construction of Driven Pile Foundations. Volume I (No. FHWA-NHI-16-009).

Hassiotis, S., \& Xiong, K. (2007). Field Measurements of Passive Pressures Behind an Integral Abutment Bridge, Proc., Seventh International Symposium on Field Measurements in Geomechanics. American Society of Civil Engineers.

Hassiotis, S., Khodair, Y., Roman, E. K., and Dehne, Y. (2006). Evaluation of Integral Abutments. Report No. FHWA-NJ-2005-025, New Jersey Department of Transportation, Trenton, NJ.

Hoppe, E. J., and Gomez, J. P. (1996). Field Study of an Integral Backwall Bridge. Report VTRC 97-R7, Virginia Transportation Research Council, Charlottesville, VA.

Horvath, J. S. (2000). Integral Abutment Bridges: Problems and Innovative Solutions Using EPS Geofoam and Other Geosynthetics. Manhattan College Research Report No. CE/GE-00-2, Manhattan College, Bronx, NY.

Hoffman, J., \& Phares, B. (2014). Thermal Load Design Philosophies for Horizontally Curved Girder Bridges with Integral Abutments. Journal of Bridge Engineering, 19(5), 4014008.

Doi:10.1061/(ASCE)BE.1943-5592.0000573.

Huang, J., French, C. and Shield, C. (2004). Behavior of Concrete Integral Abutment Bridges, University of Minnesota, Minnesota Department of Transportation Research Services Section.

Husain, I., and Bagnariol, D. (1996). Integral-Abutment Bridges. Ontario Ministry of Transportation, St. Catharines, Ontario. Canada. Report SO-96-01.

Iles, D. C. (2006). Integral Bridges in United Kingdom. International Workshop on Bridges with Integral Abutments. Lulea University of Technology. Lulea, Swedan. pp. 13-24.

Illinois Department of Transportation Memorandum. (2012). Integral Abutment Bridge Policies and Details. Illinois Department of Transportation Bureau of Bridges and Structures. Illinois.

Jaafar, M. S., Noorzaei, J., \& Thanoon, W. (2003). Integral and Jointless Bridges - Consideration for Secondary Effects. Seminar on Design and Construction of Integral Bridges. Kuala Lumpor, Malysia: Jabatan Kerji Raya. 
Jorgenson, J. L. (1983). Behavior of Abutment Piles in an Integral Abutment in Response to Bridge Movements. Transportation Research Board, National Research Council, Washington, D.C. Transportation Research Record, No. 903, pp. 72-79.

Juhl, H. G. (1970). Horizontal Thermal Movement of Curved Bridge Decks. Journal of the Structural Division, ASCE, Vol. 96, No. 10, pp. 2037-2044.

Kalayci, E., Civjan, S. A., \& Breña, S. F. (2012). Parametric Study on the Thermal Response of Curved Integral Abutment Bridges. Engineering Structures, 43, 129-138.

Kerokoski, O. (2006). Soil-Structure Interaction of Long Jointless Bridges with Integral Abutments. PhD Thesis. Tampere, Finland: Tampere University of Technology. Publication 605.

Khodair, Y., and Hassiotis, S. (2003). Analysis of Pile Soil Interaction. ASCE 16th Engineering Mechanics Conference, University of Washington, Seattle, WA.

Kim, W., and Laman, J. A. (2010). Integral Abutment Bridge Response under Thermal Loading. Engineering Structures, Vol. 32, Issue 6, pp. 1495-1508.

Knickerbocker, D.J., Basu, P.K., Holloran, M. A. \& Wasserman, E. P. (2003). Recent Experience with High-Performance Concrete Jointless Bridges in Tennessee. Design of Structures, 104 -114.

Kunin, J., and Alampalli, S. (2000). Integral Abutment Bridges: Current Practice in United States and Canada. Journal of Performance of Constructed Facilities, Vol. 14, No. 3, pp. 104-111.

LaFave, J. M., Fahnestock, L. A., Brambila, G., Ridelle J. K., Jarrett M. W., Svatura J. S., Wright B. A. and An. H. (2017). Integral Abutment Bridges Under Thermal Loading Field Monitoring and Analysis. A Report of the Findings of ICT Project R27-115. Illinois Center For Transportation, Rantol IL No. 0197-9191, Research No. FHWA-ICT-17-017. Illinois.

LaFave, J. M., Fahnestock, L. A., Wright, B. A., Riddle, J. K., Jarrett, M. W., Svatora, J. S., An, H. \& Brambila, G. (2016). Integral Abutment Bridges Under Thermal Loading: Numerical Simulations and Parametric Study. A report of the Findings of ICT-R27-115. Illinois Center for Transportation Series No. 16-015. Research Report No. FHWA-ICT-16-014. Illinois Center for Transportation, Rantoul, IL. Lawver, A., French, C., and Shield, C.K. (2000). Field Performance of Integral Abutment Bridge. Transportation Research Record 1740, Transportation Research Board, National Research Council, Washington, D.C., pp. 108-117.

Lydzinski, J. and T. Baber. (2008). Finite Element Analysis of the Wolf Creek Multi-Span Curved Girder Bridge. Virginia Transportation Research Council, FHWA/VTRC 08-CR8.

Maruri, R., and Petro, S. (2005). Integral Abutments and Jointless Bridges (IAJB) 2004 Survey Summary. Proc., 2005 FHWA Conf., Federal Highway Administration, Washington D.C.

Massachusetts Highway Department (MHD). (1999). Design Guidelines and Standard Details for Integral Abutment Bridges. MHD Bridge Manual, Boston.

Matlock, H. (1970). Correlations for Design of Laterally Loaded Piles in Soft Clay. Proceedings of the 2nd Offshore Technology Conference, Houston, 577-594.

Mcbride, K. (2013). Effect of Thermal Loading on the Performance of Horizontally Curved I-Girder Bridges, Ph.D. Thesis, Mechanical Engineering, Morgantown, West Virginia.

Ministry of Transportation Ontario. (1996). Integral Abutment Bridge Manual. Ontario. 
Mistry, V. (2005). Integral Abutment and Jointless Bridges. FHWA Integral Abutment Jointless Bridges Conference, Baltimore, MD.

Mokwa, R. L. (1999). Investigation of the Resistance of Pile Caps to Lateral Loading. Doctoral Dissertation, Virginia Polytechnic Institute and State University. Retrieved from https://vulcanhammerinfo.files.wordpress.com/2017/08/mokwa.pdf.

New York State Department of Transportation (NYSDOT), Bridge Manual, (2007), Albany, NY.

Nikravan, N. (2013). Structural Design Issues for Integral Abutment Bridges. Ph.D. Dissertation, Department of Civil Engineering, Ryerson University.

Nordland, R.L. (1963). Bearing Capacity of Piles in Cohesion Soils, JSMFE, ASCE, Vol. 89, SM3.

Oesterle, R.G., Tabatabai, H., and Lawson, T.J. (2002). Jointless and Integral Abutment Bridges: Experimental Research and Field Studies. Final Report to FHWA, Washington D.C.

Olson, S. M., Holloway, K. P., Buenker, J. M., Long, J. H., \& LaFave, J. M. (2013). Thermal Behavior of IDOT Integral Abutment Bridges and Proposed Design Modifications. ICT-12-022, Illinois Center for Transportation Research Report, Univ. of Illinois, Urbana, IL.

Olson, S. M., Long, J. H., Hansen, J. R., Renekis, D., and LaFave, J. M. (2009). Modification of IDOT Integral Abutment Design Limitations and Details. Illinois Center for Transportation, Research Report, ICT-09-054. Illinois Center for Transportation, Rantoul, IL.

O'Neill, M. W., \& Murchison, J. M. (1983). An Evaluation of p-y Relationships in Sands. University of Houston.

O'Neill, M. W., and Gazioglu, S. M. (1984). An Evaluation of p-y Relationships in Clays. Report to the American Petroleum Institute. Report PRAC 82-41-2, University of Houston, Texas.

Paraschos, A. (2016). Effects of Wingwall Configurations on the Behavior of Integral Abutment Bridges, Ph.D. Dissertation, Department of Civil Engineering, University of Maryland.

Paraschos, A., and Amde, M. (2011). A survey on the Status of Use, Problems and Costs Associated with Integral Abutment Bridges. Better Roads Magazine. Illinois: Randall Reilly Publishing.

Paul, M., Laman, J. A., and Linzell, D. G. (2005). Thermally Induced Superstructure Stresses in Prestressed Girder Integral Abutment Bridges. Proc., $6^{\text {th }}$ Int. Bridge Engineering Conf.: Reliability, Security, and Sustainability in Bridge Engineering, Transportation Research Board, Washington, D.C, 287-297.

Pétursson, H. (2015). Design of Steel Piles for Integral Abutment Bridges. Doctoral Dissertation, Luleå University of Technology.

Poulos, H. G., \& Davis, E. H. (1980). Pile Foundation Analysis and Design. John Wiley, New York.

Quinn, B. H. and Civjan, S. A. (2017). Parametric Study on Effects of Pile Orientation in Integral Abutment Bridges. Journal of Bridge Engineering, ASCE, 22(4), 04016132.

Razmi, J., Ladani, L., and Aggour, S. M. (2014). Finite Element Simulation of Pile Behaviour under Thermo-Mechanical Loading in Integral Abutment Bridges. Structure and Infrastructure Engineering, Vol. 10, No. 5, 643-653. 
Reese, L. C., Cox, W.R., \& Koop, F. D. (1975). Field Testing and Analysis of Laterally Loaded Piles on Stiff Clay. Offshore Technology Conference. Houston, Texas.

Reese, L. C. (1984). Handbook on Design of Piles and Drilled Shafts Under Lateral Load. (No. FHWAIP-84-11).

Roeder, C. W., and Moorty, S. (1990). Thermal Movements in Bridges. Transportation Research Record 1290, Transportation Research Board, National Research Council, Washington, D.C., pp. 135143.

Rollins, K. M., \& Stenlund, T. E. (2010). Laterally Loaded Pile Cap Connections, Utah Department of Transportation Research Division Report No. UT-10.16. Brigham Young University.

SAP2000. Integrated Finite Element Analysis and Design of Structures. Berkeley, California: computers and structures Inc, 2019.

Sherafati, A. (2013). Expanding the Length of Jointless Bridges by Providing Rotational Capacity over the Pile Head. Ph.D. thesis, Univ. of Nebraska-Lincoln, Lincoln, NE.

Soltani, A. A., and Kukreti, A. R. (1992). Performance Evaluation of Integral Abutment Bridges. Transportation Research Report 1371, Transportation Research Board, National Research Council, Washington, D.C. pp. 17-25.

Stewart, J. P., Taciroglu, E., Ahlberg, E. R., Lemnitzer, A., Rha, C., \& Tehrani, P. K. (2007). Full Scale Cyclic Testing of Foundation Support Systems for Highway Bridges Part II: Abutment Backwalls. University of California, Los Angeles.

Talbott, A. (2008). Earthquake Resistance of Integral Abutment Bridges. West Lafayette: Purdue University.

Thanasattayawibul, N. (2006). Curved Integral Abutment Bridges. Doctoral Dissertation, University of Maryland. Retrieved from https://drum.lib.umd.edu/bitstream/handle/1903/4119/umi-umd3909.pdf.

Thaanasarttayawibul, J., Amde, A. M., and Paraschos, A. (2014). Effects of Bridge Length and Span Variations in Curved Integral Abutment Bridges. Journal of Civil Engineering and Construction Technology. Vol. 5, No. 1, pp. 1-10.

U.S. Department of the Navy. (1982). Foundations and Earth Structures, Design Manual 7.2, Naval Facilities Engineering Command, Alexandria, VA.

Vermont Agency of Transportation (VTrans), Integral Abutment Bridge Design Guidelines, Second edition, October 2008, Montpelier, VT.

Wasserman, E. P. (2001). Design of Integral Abutments for Jointless Bridges. Structure Magazine, pp. 24-33.

White, H. (2007). Integral Abutment Bridges: Comparison of Current Practice Between European Countries and the United States of America. Special Report 152, Transportation Research and Development Bureau, New York State Department of Transportation.

White, H., Ptursson, H., and Collin, P. (2010). Integral Abutment Bridges: The European Way. Practice Periodical on Structural Design and Construction, 15, 201-208. 
Winkler, E. (1867). Die Lehre von der Elasticitaet und Festigkeit, Teil 1, 2. H. Dominicus, Prague, 712.

Xu, M. (2006). The Soil Pressure behind Integral Bridge Abutments. 7th International Conference on Short and Medium Span Bridges, Montreal, Canada, pp. 1-7.

Xu, M., and Clayton, C. R. I., Bloodworth, A. G. (2007). The Earth Pressure Behind Full-Height Frame Integral Abutments Supporting Granular Fill. Canadian Geotechnical Journal, Vol. 44, No. 3, pp. 284298.

Yang, P.S., Amde, A.M., and Greimann, L.F. (1985). Effects of Predrilling and Layered Soil on Piles. ASCE Journal of Geotechnical Engineering, No. 111, pp. 18-31.

Yang, Z., and Jeremic, B. (2005). Study of soil layering effects on lateral loading behaviour of Piles. J. Geotech. Geoenviron. Eng., 1316, 762-770.

Zhu, Z., Davidson, M. T., Harik, I. E., Sun, L., \& Sandefur, K. (2015). Effect of Superstructure Temperature Changes on Intermediate Pier Foundation Stresses in Integral Abutment Bridges. Journal of Bridge Engineering, 20(1), 04014058.

Zordan, T., Briseghella, B., \& Lan, C. (2011). Parametric and Pushover Analysis on Integral Abutment Bridge. Engineering Structures, 33, 502-515. 